\title{
Influence of live -load deflections on superstructure performance of slab on steel stringer bridges
}

Haiyong Wu

West Virginia University

Follow this and additional works at: https://researchrepository.wvu.edu/etd

\section{Recommended Citation}

Wu, Haiyong, "Influence of live -load deflections on superstructure performance of slab on steel stringer bridges" (2003). Graduate Theses, Dissertations, and Problem Reports. 2542.

https://researchrepository.wvu.edu/etd/2542

This Dissertation is protected by copyright and/or related rights. It has been brought to you by the The Research Repository @ WVU with permission from the rights-holder(s). You are free to use this Dissertation in any way that is permitted by the copyright and related rights legislation that applies to your use. For other uses you must obtain permission from the rights-holder(s) directly, unless additional rights are indicated by a Creative Commons license in the record and/ or on the work itself. This Dissertation has been accepted for inclusion in WVU Graduate Theses, Dissertations, and Problem Reports collection by an authorized administrator of The Research Repository @ WVU.

For more information, please contact researchrepository@mail.wvu.edu. 


\title{
Influence of Live-Load Deflections on Superstructure Performance of Slab on Steel Stringer Bridges
}

\author{
Haiyong Wu \\ Dissertation submitted to the \\ College of Engineering and Mineral Resources \\ at West Virginia University \\ in partial fulfillment of the requirements \\ for the degree of
Doctor of Philosophy
in
Civil Engineering \\ Karl E. Barth, Ph.D., Chair \\ Julio F. Davalos, Ph.D. \\ Udaya B. Halabe, Ph.D. \\ Bruce Kang, Ph.D. \\ Thomas M. Damiani, Ph.D. \\ Department of Civil and Environmental Engineering
}

\author{
Morgantown, West Virginia \\ 2003
}

Keywords: Live-Load Deflections, High Performance Steel Bridges, Natural Frequency, Finite Element Analysis 


\section{ABSTRACT \\ Influence of Live-Load Deflections on Superstructure Performance of Slab on Steel Stringer Bridges}

\section{Haiyong Wu}

High performance steel (HPS), specifically HPS 70W, was introduced to the bridge market in the United States in the late 1990s. With its added strength, greater durability, and improved weldability, HPS allows engineers to design longer and shallower spans, which may increase the live-load deflections. The AASHTO Standard Specification limits live-load deflections to L/800 for ordinary bridges and L/1000 for bridges in urban areas subjected to pedestrian use. Bridges designed by the AASHTO LRFD Specification have an optional deflection limit. Previous research focused on evaluating AASHTO live-load deflection limits showed that the justification for existing deflection limits was not clearly defined and the best available information indicated that they were initiated to control undesirable bridge vibrations and assure user comfort. Significant design costs may be saved if more rational live-load serviceability criteria can be adopted. Bridge design specifications from other countries do not commonly employ direct live-load deflection limits. Vibration control is often achieved through a relationship between the first flexural natural frequency of the bridge and live-load deflection. However no direction is provided to how to calculate the flexural natural frequency.

This research establishes the rationale behind existing design provisions and compares AASHTO provisions to design methods used in other countries. The effect of AASHTO and other existing live-load deflection limits on steel bridge design and performance are evaluated through a parametric design study and analysis of existing typical highway bridges. In this work, 3D FEA tools have been developed to investigate the natural frequency of continuous span bridges and have been employed in a comprehensive parametric study. From these results, practical and simplified equations are proposed to predict the natural frequencies of continuous span bridges to be used in conjunction with frequency based serviceability limit states. 


\section{ACKNOWLEDGMENTS}

Funding for this research was provided by the American Iron and Steel Institute, the Federal Highway Administration, and the West Virginia DOT Division of Highways.

Special thanks are given to Professor Karl E. Barth, my academic and thesis advisor, for his kindness, encouragement and guidance during this research. I wish to extend my thanks to Professors Julio F. Davalos, Udaya B. Halabe, Bruce Kang, and Thomas M. Damiani, members of the committee for their time and effort to review this dissertation.

I also thank previous Master students of Professor Karl E. Barth, Rachel Christopher and Beth F. Clingenpeel, for their efforts in the parametric design study. I would also like to thank Professor Michael G. Barker at the University of Missouri Columbia for the field testing results of the 2-span continuous high performance steel bridge.

Finally, I must give my thinks to my wife, Limin Li, for her love, support and help during these years. I also need to thank my daughter, Jessica $\mathrm{H}$. Wu, who has sacrificed so much time to stay together with her dad. 


\section{DEDICATIONS}

This dissertation is dedicated to my family in China: my grandmother, Amei Wu; my father, Yuqing $\mathrm{Wu}$; my mother, Shujin $\mathrm{Wu}$; my sister, Haihua, Wu; and my brother, Haipu, Wu. 


\section{TABLE OF CONTENTS}

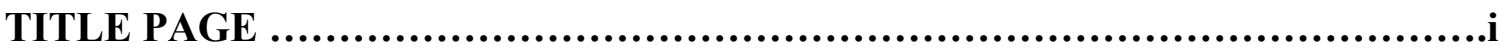

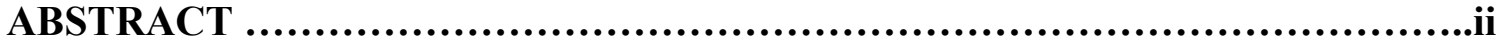

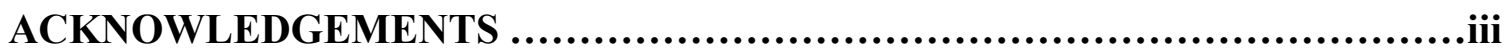

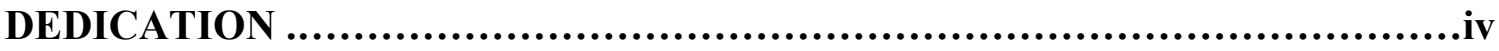

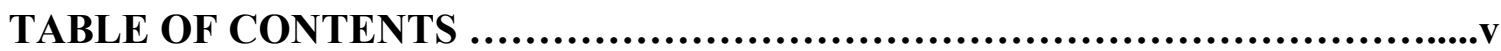

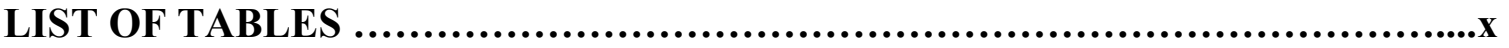

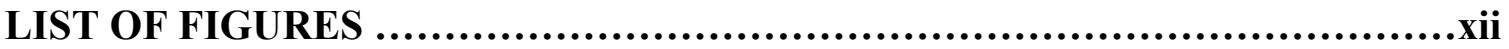

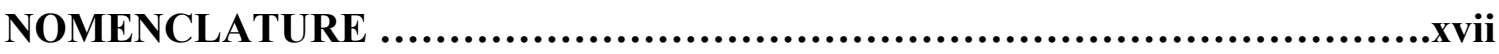

CHAPTER 1 INTRODUCTION .....................................................1

1.1. Problem Statement and Research Significant ............................

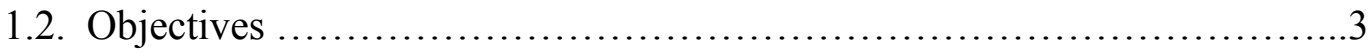

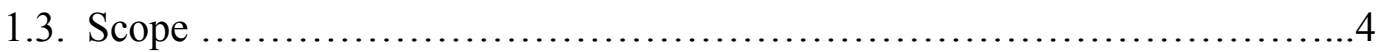

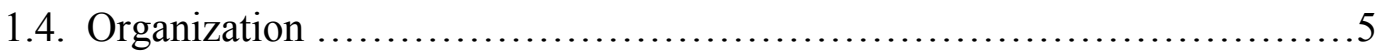

CHAPTER 2 BACKGROUND AND OVERVIEW OF THE PROBLEM ............9

2.1. Overview and Historical Perspectives .................................. 9

2.2. Effect of Bridge Deflections on Structural Performance ....................13

2.3. Effect of Bridge Deflection on Superstructure Bridge Vibration ............19

2.3.1. Human Response to Vibration .............................21

2.3.2. Field Studies ............................................25

2.3.3. Analytical Studies ........................................28

2.4. Alternate Live-Load Deflection Serviceability Criteria ......................30 
2.4.1. Canadian Standards and Ontario Highway Bridge Code .30

2.4.2. Australian Codes ................................................31

2.4.3. Codes and Specifications of Other Countries .....................33

2.4.4. Wright and Walker Study ....................................34

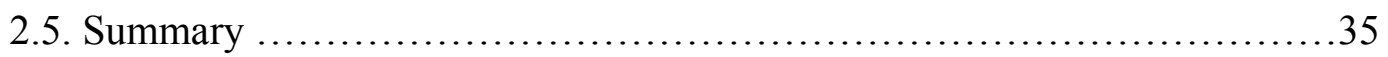

\section{CHAPTER 3 ON THE ESTIMATION OF NATURAL FREQUENCIES IN} CONTIUNOUS SPANS: A LITERATURE REVIEW ............................53

3.1. Introduction ........................................................ 53

3.2. Dynamic Load Testing of Highway Bridges .............................54

3.3. Formulation of Natural Frequency Equations for Highway Bridges Based on Load Testing ..................................................... 61

3.4. Formulation of Natural Frequency Equations for Highway Bridges Based on

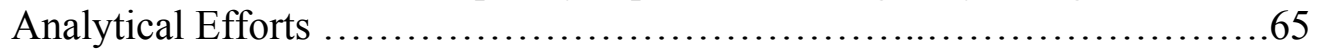

3.5. Summary of Previous Works ........................................ 73

CHAPTER 4 ON THE ACCURATE FINITE ELEMENT MODEIING OF LIVELOAD EFFECTS IN COMPOSITE STEEL BRIDGES ..........................80

4.1. Acceptable Refined Methods ........................................ 80

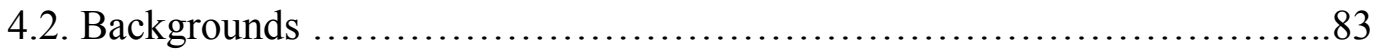

4.3. Proposed Finite Element Analysis Model ................................. 90

4.4. Experimental Verification ..........................................99

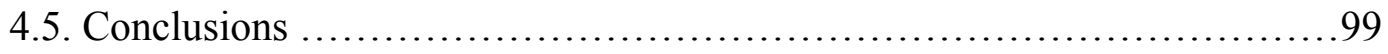

CHAPTER 5 EVALUATION OF AASHTO DEFLECTION LIMITS ON PARAMETRIC DESIGN STUDY BRIDGES AND EXISTING PLATE GIRGER

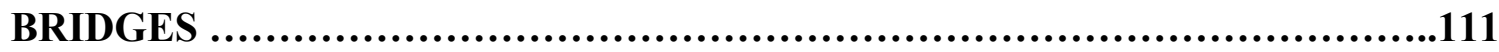

5.1. Parametric Design Study ...........................................111

5.1.1. Introduction ..............................................111 
5.1.2. Methodology 112

5.1.3. Design Parameters 115

5.1.4. Results ..............................................116

5.2. Evaluation of Existing Plate Girder Bridges ........................... 124

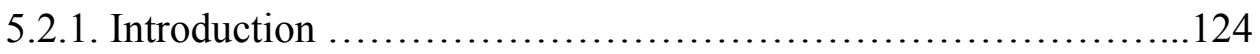

5.2.2. Analysis Methods ........................................125

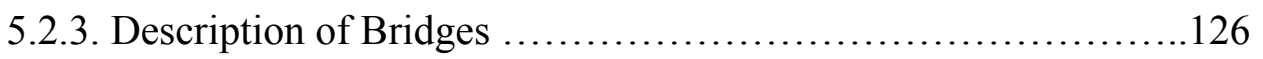

5.2.4. Analysis Results ....................................131

5.2.5. Concluding Remarks ....................................135

CHAPTER 6 DEVELOPMENT OF NATURAL FREQUENCY EQUATIONS FOR COMPOSITE STEEL I-GIRGER BRIDGES $\ldots \ldots \ldots \ldots \ldots \ldots \ldots \ldots \ldots \ldots \ldots \ldots \ldots \ldots \ldots . \ldots \ldots 2$

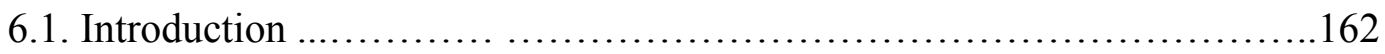

6.1. Parametric Study ............................................. 163

6.2.1. Variables ................................................164

6.2.2. Results .............................................. 164

6.2.3. Comparisons with Existing Methods .........................169

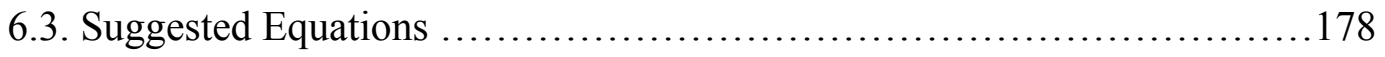

6.4. Extended Application of the Suggested Equations ..................... 180

6.5. Conclusions ................................................. 183

CHAPTER 7 FIELD PERFORMANCE EVALUATION OF A CONTINUOUS SPAN HPS STEEL I-GIRGER BRIDGE $\ldots \ldots \ldots \ldots \ldots \ldots \ldots \ldots \ldots \ldots \ldots \ldots \ldots \ldots \ldots \ldots \ldots . \ldots \ldots 7$

7.1. Introduction .................................................207

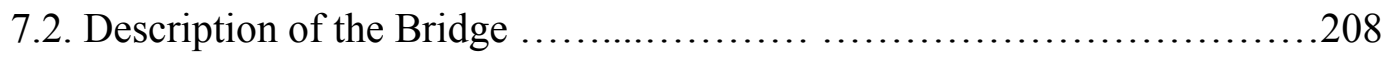

7.3. Description of Test Program ......................................209 
7.3.1. Testing System .209

7.3.2. Instrumentation ............................................211

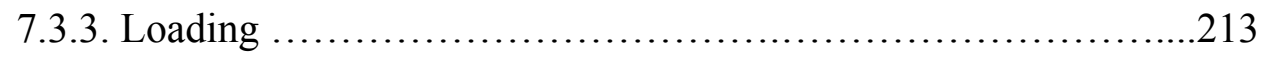

7.4. Testing Results and Comparisons ........................................214

7.4.1. Data Reduction Process.........................................215

7.4.2. Deflection Results and Comparisons ............................215

7.4.3. Stress Results and Comparisons ............................216

7.4.4. Natural Frequencies and Comparisons ........................217

7.5. Evaluations of AASHTO L/800 limit and Alternative Criteria .............218

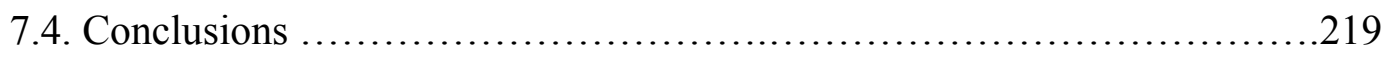

CHAPTER 8 CONCLUSIONS AND RECOMMENDATIONS ....................247

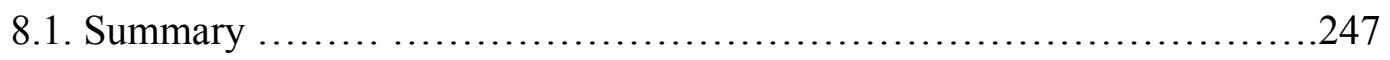

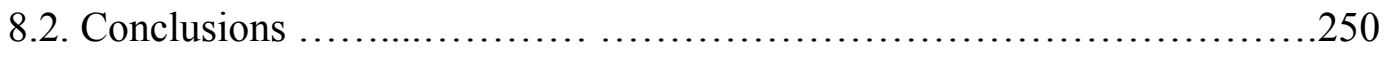

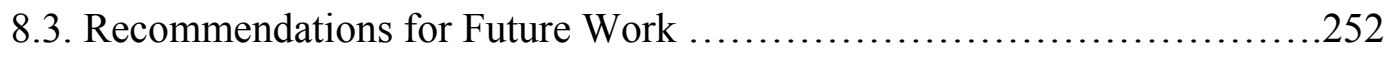

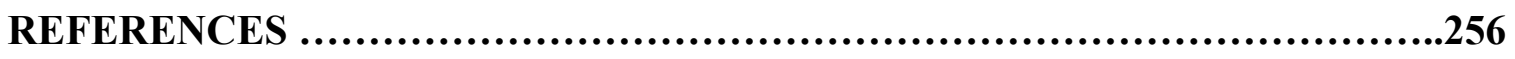

APPENDIX A Survey of Professional Practice ....................................265

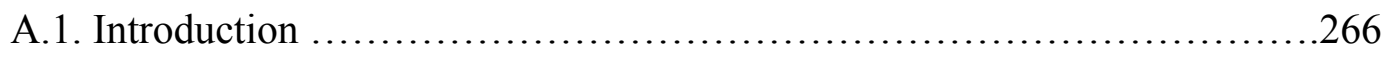

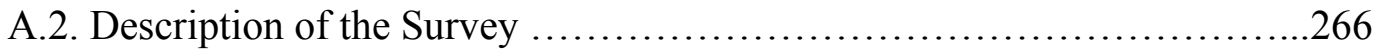

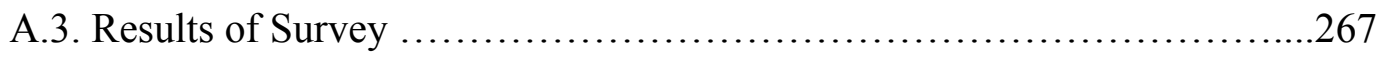

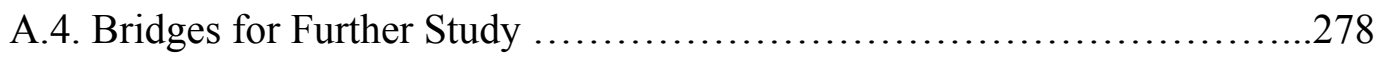

Appendix B Detailed Girder Elevations .......................................282

Appendix C Design Summary ...............................................298

Appendix D Girder Elevations and Design Summary of Redesigned Bridges ......312 
Appendix E Wright and Walker Procedure and OHBDC Results 


\section{LIST OF TABLES}

\section{Table}

Table 2.1. Depth-to-span, D/L, ratios in A.R.E.A. and A.A.S.H.O ..................... 38

Table 2.2. Peak acceleration criterion for human response to harmonic vertical vibration

Table 4.1. Comparisons of natural frequencies for Colquitz Rive Bridge

Table 4.2. Comparisons of natural frequencies for Tennessee Rt. 13 Elk River Bridge

Table 5.1. Matrix of initial parameters

Table 5.2. Comparison of initial girder designs with girders not meeting the deflection criteria for cross section 1

Table 5.3. Comparison of initial girder designs with girders not meeting the deflection criteria for cross section 2 ....

Table 5.4. Comparison of initial girder designs with girders not meeting the deflection criteria for cross section 3

Table 5.5. Comparison of initial girder designs with girders not meeting the deflection criteria for cross section 4

Table 5.6. Summary of typical plate girder bridges analyzed in this study

Table 5.7. Comparisons with AASHTO Standard Specifications .145

Table 5.8. Comparisons with Wright and Walker alternative serviceability criteria ......146

Table 5.9. Comparisons with Ontario Highway Bridge Design Code

Table 6.1. Coefficients $\mathrm{a}, \mathrm{b}$ and $\mathrm{c}$ for use in multi-variable regression equation $6.24 \ldots 187$

Table 6.2. Comparisons of the proposed equations, FEA, testing and existing methods

Table A.1. Summary of general survey results

Table B5.1. Detailed girder elevation for cross section $1(\mathrm{~S}=9 \mathrm{ft}) \ldots \ldots \ldots \ldots \ldots \ldots . .283$

Table B5.2. Detailed girder elevation for cross section $2(\mathrm{~S}=11$ ' -6 ') .286 
Table B5.3. Detailed girder elevation for cross section $3\left(\mathrm{~S}=10^{\prime}-4^{\prime \prime}\right)$.................289

Table B5.4. Detailed girder elevation for cross section $4\left(\mathrm{~S}=8^{\prime}-6^{\prime \prime}\right) \ldots \ldots \ldots \ldots \ldots \ldots . . .295$

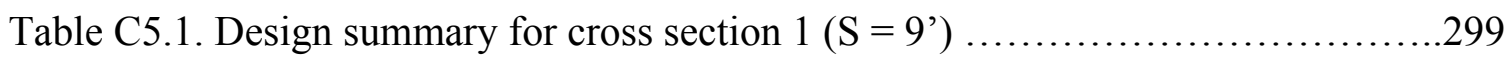

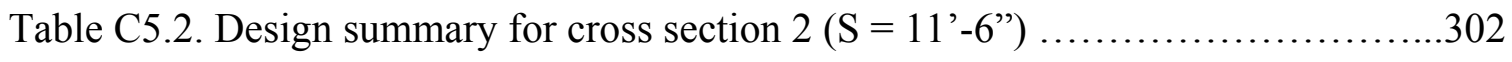

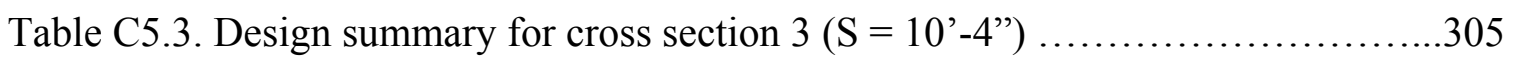

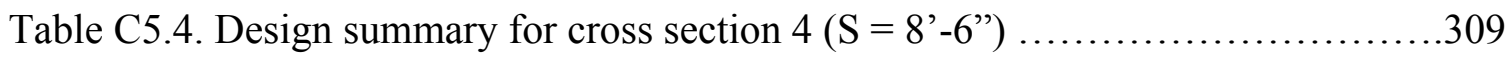

Table D5.1. Detailed redesign girder elevations for original design bridges failing L/800 ...................................................... 313

Table D5.2. Design summary for redesign bridges ................................. 317

Table E5.1. Wright and Walker procedure and OHBDC results for cross section 1 $\left(\mathrm{S}=9^{\prime}\right)$

Table E5.2. Wright and Walker procedure and OHBDC results for cross section 2

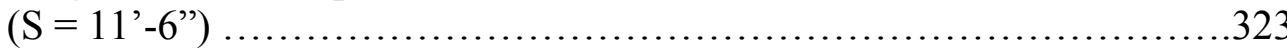

Table E5.3. Wright and Walker procedure and OHBDC results for cross section 3 ( $\mathrm{S}=10^{\prime}-4$ ')

Table E5.4. Wright and Walker procedure and OHBDC results for cross section 4 ( $\mathrm{S}=8$ '-6") 330 


\section{LIST OF FIGURES}

\section{Figure}

Figure 1.1. The status of HPS bridge building and design in the United States ..........8

Figure 2.1. Effect of stringer flexibility on transverse moment in deck ................40

Figure 2.2. Six human tolerance levels for vertical vibration $\ldots \ldots \ldots \ldots \ldots \ldots \ldots \ldots \ldots . . . \ldots 1$

Figure 2.3. Average amplitude of vibration at various frequencies ...................42

Figure 2.4. Average peak accelerations at various frequencies $\ldots \ldots \ldots \ldots \ldots \ldots \ldots \ldots . \ldots 43$

Figure 2.5. Observed amplitude and frequency of bridge vibrations compared with recommended safe limits by Janeway .................................44

Figure 2.6. Contours of equal sensitivity to vibration - "isosensors" $\ldots \ldots \ldots \ldots \ldots \ldots . . \ldots 45$

Figure 2.7. Measured acceleration compared to human tolerance limits by Bolt, Baranek and Newman ...........................................46

Figure 2.8. Effect of flexibility on acceleration ................................ 47

Figure 2.9. Effect of surface roughness on acceleration $\ldots \ldots \ldots \ldots \ldots \ldots \ldots \ldots \ldots \ldots \ldots \ldots$

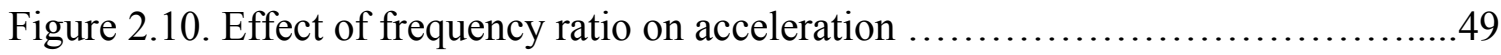

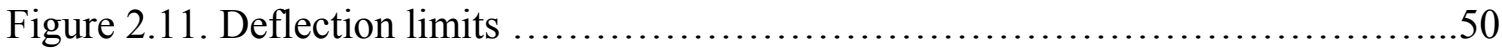

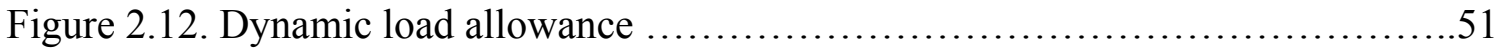

Figure 2.13. Deflection limits for vibration controls of Australian Codes ..............52

Figure 3.1. Measured bridge natural frequency versus calculated natural

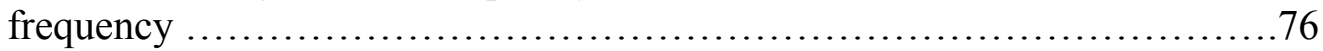

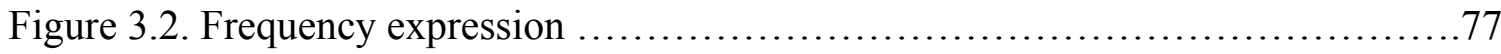

Figure 3.3. Fundamental frequencies as a function of maximum span length ...........78

Figure 3.4. First bending frequencies for 871 highway bridges ..................... 79

Figure 4.1. Typical FEA mesh of elastic modeling for bridge evaluation ...............104

Figure 4.2. Sections of University of Illinois Model Bridge C15 .................... 105 
Figure 4.3. Deflection distribution at mid-span cross section 106

Figure 4.4. Cross section and layout of wheel load positions for University of Nebraska Bridge

Figure 4.5. Deflection distributions at mid-span cross section for 2 HS20 trucks ......108

Figure 4.6. Cross section of Colquitz River Bridge in Canada 109

Figure 4.7. Cross section Tennessee 4-Span Continuous Bridge 110

Figure 5.1. Cross-sectional geometry for 4 bridge arrangements 148

Figure 5.2. Girder elevations of parametric design study bridges 149

Figure 5.3. The influence of $\mathrm{L} / \mathrm{D}$ on live-load deflection 150

Figure 5.4. The influence of span length on live-load deflection

Figure 5.5. The influence of steel strength on live-load deflections

Figure 5.6. Comparison of LFD with LRFD on live-load deflection for cross section\#3

Figure 5.7. Comparison with OHBDC for the initial bridge designs 154

Figure 5.8. Comparison with OHBDC for simple span girders failing the AASHTO L/800 deflection limit 155

Figure 5.9. Comparison with OHBDC for 2-span continuous girders failing the AASHTO L/800 deflection limit .156

Figure 5.10. Deflection versus L/D for $150 \mathrm{ft}$. simple span bridge, cross section 3 .....157

Figure 5.11. Weight versus L/D for $150 \mathrm{ft}$. simple span bridge, cross section 3 ..........158

Figure 5.12. Deflection limits of bridges comparing to OHBDC 159

Figure 5.13. L/ $\delta$ versus L/D for typical highway bridges 160

Figure 5.14. Comparisons to Wright and Walker recommendations for typical highway bridges 161

Figure 6.1. AISI parapet 189

Figure 6.2. Natural frequency of simple span bridges 190 
Figure 6.3. Natural frequencies of 2 -span bridges 191

Figure 6.4. Natural frequencies of 3-span bridges 192

Figure 6.5. Natural frequencies of all bridges included in the parametric study .193

Figure 6.6. Effect of parapets versus span length for simple span bridges 194

Figure 6.7. Comparisons between FEA and simple beam equation for simple span bridges

Figure 6.8. Comparisons between FEA and simple beam equation (or Billing's method and Gorman's method) for 2-span bridges

Figure 6.9. Comparisons between FEA and pinned-clamped beam equation for 2-span bridges

Figure 6.10. Comparisons between FEA and simple beam equation for 3-span bridges

Figure 6.11. Comparisons between FEA and Billing's method for 3-span bridges

Figure 6.12. Comparisons between FEA and clamped-clamped beam equation for 3 -span bridges

Figure 6.13. Effect of end restraint on the nature frequencies for 2-span bridges .201

Figure 6.14. Effect of end restraints on the nature frequencies for 3-span bridges .202

Figure 6.15. Comparisons between proposed equation and FEA results for 2-span bridge .203

Figure 6.16. Histogram between proposed equation and FEA results for 2-span bridges .204

Figure 6.17. Comparisons between proposed equation and FEA results for 3-span bridge .205

Figure 6.18. Histogram between proposed equation and FEA results for 3-span bridges .206

Figure 7.1. Elevation of field-tested/Missouri Bridge A6101 .221

Figure 7.2. Underside of Missouri Bridge A6101 .222

Figure 7.3. Typical field splice .223 


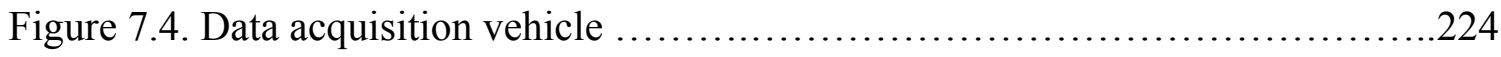

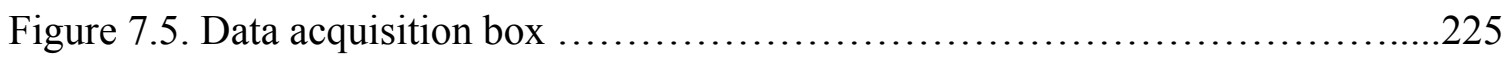

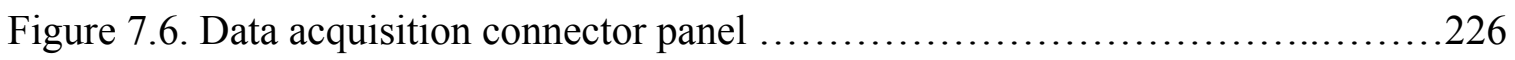

Figure 7.7. Manlift .....................................................22

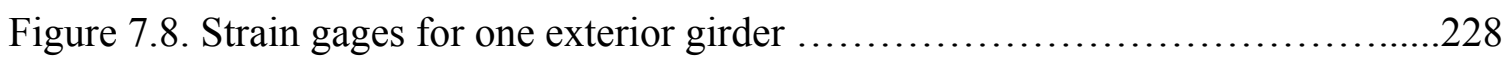

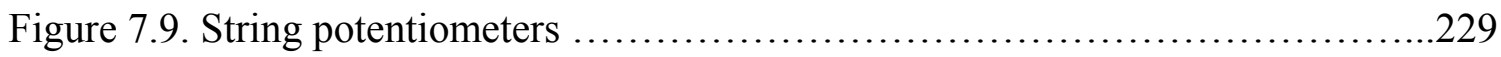

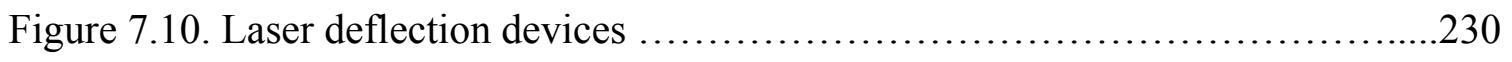

Figure 7.11. Missouri test vehicle and its weight distributions ....................231

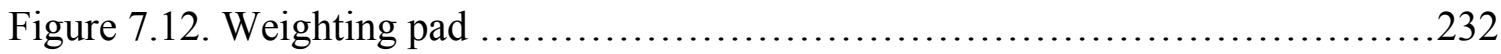

Figure 7.13. Maximum load positions for girder 1 (load case 1$) \ldots \ldots \ldots \ldots \ldots \ldots \ldots . . .233$

Figure 7.14. Maximum load positions for girder 2

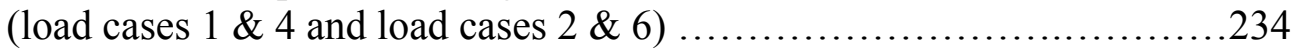

Figure 7.15. Maximum load positions for girder 3

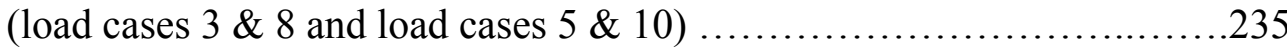

Figure 7.16. Maximum load positions for girder 4

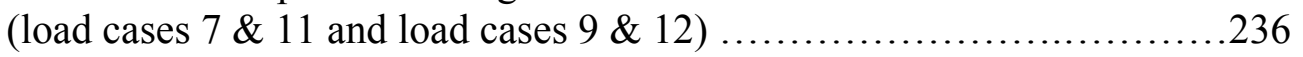

Figure 7.17. Maximum load positions for girder 5 (load case 12) .................237

Figure 7.18. Construction vehicle used for dynamic testing .......................238

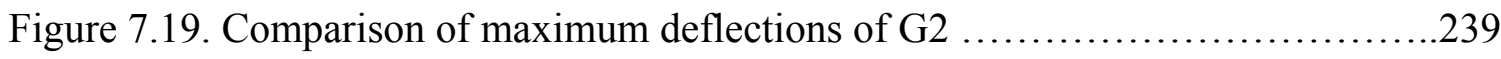

Figure 7.20. FEA maximum deflections - load cases 1 through $6 \ldots \ldots \ldots \ldots \ldots \ldots \ldots . \ldots 240$

Figure 7.21. FEA maximum deflections - load cases 7 through $12 \ldots \ldots \ldots \ldots \ldots \ldots . . .241$

Figure 7.22. Maximum stress in bottom flange at $0.4 \mathrm{~L}$ section ......................242

Figure 7.23. Maximum stress in bottom flange of pier section ......................243

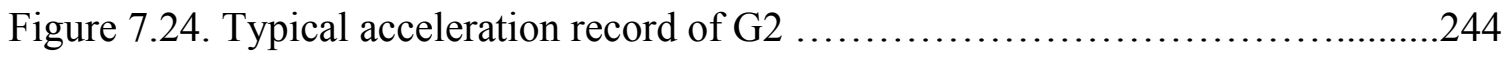

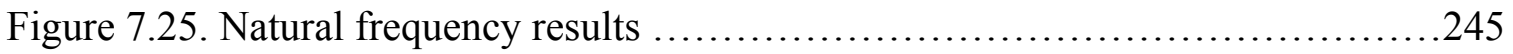


Figure 7.26. OHBDC evaluation of Missouri Bridge .246 


\section{NOMENCLATURE}

The following symbols are used in this dissertation:

$a=$ dynamic peak acceleration,

$a_{n}=$ eigenvalue appearing in beam vibration problem,

$b_{\text {effective }}=$ effective slab width,

$C=$ frequency coefficient depending upon the ratio of middle span length and end span length of 3-span continuous beams,

$D=$ bridge girder depth,

$D_{s}=$ steel girder depth,

$D_{w} / b_{f}=$ ratio between web depth and flange width,

$e_{1}=1^{\text {st }}$ mode eigenvalue,

$E_{c}=$ modulus of elasticity for the concrete deck,

$E I=$ bending stiffness of the beam,

$E_{b} I_{b}=$ bending stiffness of the composite steel girder,

$E_{s} I_{s}=$ bending stiffness of the steel beam,

$f=1^{\text {st }}$ flexural natural frequency of bridges,

$f_{c}^{\prime}=28$-day concrete compressive strength,

$f_{k}=k$ th mode of natural frequency of bridges,

$f_{\text {obs }}=$ measured natural frequency,

$f_{s b}$ and $f_{c a l}=1^{\text {st }}$ natural frequency of a simply supported uniform beam or continuous beams with equal span lengths,

$f_{s s}=f_{s b}$ multiplying by a factor $r$ to consider the effect of width on the natural frequency, 
$f_{2 c s}=$ natural frequency of a 2 -span continuous beam by multiplying $f_{s s}$ with a factor $r^{\prime}$,

$f_{3 c s}=$ natural frequency of a 3 -span continuous beam by multiplying $f_{2 c s}$ with factors $r_{2}$ and $r_{3}$,

$f_{\text {Billing }}=1^{\text {st }}$ flexural natural frequency based on Billing's method,

$f_{n}=$ natural frequency of a prismatic simply-supported beam,

$f_{n s c}=$ natural frequency of a pinned-clamped beam,

$f_{\text {ncc }}=$ natural frequencies of a clamped-clamped beam,

$f_{n_{-} \text {analysis }}=$ FEA $1^{\text {st }}$ flexural frequency of composite steel bridge,

$f_{n \_ \text {w/ parapets }}=$ FEA $1^{\text {st }}$ flexural frequency of composite steel bridge with parapets,

$f_{n \_ \text {w/o parapets }}=$ FEA $1^{\text {st }}$ flexural frequency of composite steel bridge without parapets,

$f_{n}(t)=$ time function in the solution of a beam vibration equation,

$f_{c c}=1^{\text {st }}$ flexural frequency of a clamped-clamped beam,

$f_{s c}=1^{\text {st }}$ flexural frequency of a pinned-clamped beam,

$f_{\text {eqn }}=1^{\text {st }}$ flexural frequency from the proposed equation,

$g=$ acceleration due to the gravity,

$h=$ thickness of the concrete deck,

$H=$ ratio of steel beam stiffness and slab stiffness,

$I=$ moment of inertia of the composite girder,

$K, K_{1}$ and $K_{2}=$ rotational stiffness of pinned rotational spring,

$K^{*}, K_{1}{ }^{*}$ and $K_{2}{ }^{*}=$ normalized rotational stiffness of pinned rotational spring, 
$L=$ bridge span length,

$L_{1}=$ length of the end span of a 3-span continuous beam,

$L_{2}=$ length of the middle span of a 3 -span continuous beam,

$L_{\max }=$ maximum bridge span length,

$m=$ mass per unit length of a beam,

$n=$ ratio between elastic modulus of steel and elastic modulus of concrete,

$v=$ vehicle speed

$t=$ time,

$t_{w}=$ web thickness,

$w=$ weight per unit length of the composite steel girder,

$w_{c}=$ density of normal concrete,

$w_{L}=$ total weight of truck loading on the bridge,

$\alpha=K_{2}{ }^{*} / K_{1}^{*}=K_{2} / K_{1}$ in beam vibration with nonclassical boundary conditions,

$\alpha_{v}=$ vehicle speed parameter,

$\beta=$ eigenvalue appearing in beam vibration problem,

$\delta=$ live-load deflection,

$\delta_{s}=$ static deflection,

$\phi_{k}=$ frequency factor obtained from Billing's table,

$\phi_{n}(t)=$ characteristics shape of a beam vibration,

$\eta=$ coefficient of vibration,

$v=$ poisson's ratio of the concrete deck, 
$\sigma_{f}=$ standard deviation,

$\lambda^{2}=$ frequency coefficient,

$\omega_{n}=$ circular natural frequency of a prismatic simply-supported beam, and

$\zeta=$ factor to consider the effect of parapets on the natural frequency 


\section{CHAPTER 1}

\section{INTRODUCTION}

\subsection{Problem Statement and Research Significance}

High performance steel (HPS), specifically HPS 70W, was recently introduced as the result of a collaborative effort by the American Iron and Steel Institute (AISI), the US Navy, and the Federal Highway Administration (FHWA) to produce more economical and durable steel that was suitable for bridge applications. Consequently, HPS offers added strength, greater durability, and improved weldability, which allows engineers to design longer, shallower spans. The Nebraska Department of Roads completed the first HPS bridge in the United States in 1997 and currently there are more than 150 HPS bridges nationwide, with even more currently in the construction or design phases. Figure 1.1 illustrates the use of HPS bridges across the United States by reporting the number of in-service bridges and bridges currently in the fabrication or design stages in each state (FHWA, 2002).

The cost savings provided by the use of HPS $70 \mathrm{~W}$ compared to that of conventional Grade 50W steel are well documented (Horton et al., 2000; Barker and Schrage, 2000; and Clingenpeal, 2001). The Tennessee Department of Transportation reports construction cost savings of nearly $10 \%$ by using HPS. Also, the state of Missouri built its first HPS bridge in 2002 with a weight savings of nearly $17 \%$ and a cost savings of approximately $11 \%$ compared to a conventional Gr. $50 \mathrm{~W}$ bridge. However, one of the critical issues facing the economical use of HPS are the current AASHTO liveload deflection requirements (Mertz, 1999). 
The AASHTO Standard Specification (AASHTO,1996) limits live-load deflections to $\mathrm{L} / 800$ for ordinary bridges and $\mathrm{L} / 1000$ for bridges in urban areas that are subjected to pedestrian use, where L is the span length. These limits are required for steel, prestressed and reinforced concrete, and other bridge superstructure types. The limits were initially established in early 1930's as the result of a study from the Bureau of Public Roads and were intended to control vibrations found to be unacceptable based on subjective human response. However, it is widely believed by engineers that these limits are required for long-term superstructure durability.

The above deflection limits are optional in the AASHTO LRFD Specification (AASHTO, 1998) and serviceability is the responsibility of the engineer. However, most engineers using the LRFD Specifications revert back to the deflection criteria in the Standard Specifications because they believe that the use of these limits assures superstructure serviceability. As a result, antiquated deflection limits are imposed on HPS bridges. Although present deflection limits are ineffective in controlling the deformations that cause structural damage, bridge engineers oppose elimination of the existing deflection limits until rationally-developed improved guidelines are available.

Historically, the deflection limit has not affected a significant range of bridge designs. However, this has changed since the introduction of HPS to the bridge market in 1996. HPS $70 \mathrm{~W}$ has a $40 \%$ higher yield stress than conventional Grade 50 and the larger yield stress permits smaller cross sections and moments of inertia for bridge members. As a result, deflections may be larger for HPS bridges, and deflection limits are increasingly 
likely to control the design of bridges built from these new materials. It is therefore necessary to investigate:

- How the deflection limit affects steel bridge performance?

- Whether the deflection limit is justified or needed?

- Whether it achieves its intended purpose?

- Whether it benefits the performance of steel bridges?

- Whether it affects the economy of steel bridges?

- If current deflection limits are unreasonable, should a modified simple and effective serviceability requirements for bridges be developed?

One of the major impedances to the economical implementation for HPS in bridges is the current AASHTO live-load deflection limits. Because of these antiquated limits, the economical benefit of HPS may not be fully realized in today's modern bridge inventory. Therefore, there is a need for improved and more effective serviceability design specifications to insure user comfort and to reduce the potential for structural damage. Developing such specifications will enable HPS bridges to become more economical. This research will have a broad impact on the bridge engineering community and society by leading to reduced bridge design and construction costs and better long term performance.

\subsection{Objectives}

This research was initiated to determine whether the current live-load deflection limits for steel bridges are needed or warranted. The research focuses on composite steel 
bridges, which are the most common type of bridges in the federal highway system, and the particular objectives are to:

- Determine how the deflection limits are employed in steel bridge design in the United States,

- Establish the rationale behind existing design provisions and to compare AASHTO provisions to design methods used in other countries,

- Evaluate the effect of AASHTO and other existing live-load deflection limits on steel bridge design and performance, and evaluate where existing deflection limits prevent damage and reduced service life,

- Develop three-dimensional (3D) efficient finite element analysis (FEA) tools to investigate the live-load effects in composite steel bridges,

- Propose more rational serviceability criteria to assure long-term performance of composite steel bridges, and

- Conduct field performance evaluation for a two-span continuous HPS I-girder bridge.

\subsection{Scope}

This research reviews the background of live-load deflection limits and vibration characteristics of composite steel bridges. Evaluation of the influence of current AASHTO live-load deflections on bridge performance and economics is conducted for parametric design study bridges and existing plate girder bridges. In the parametric design studies, bridges are designed using commercially available bridge design packages that provide optimum designs based on the AASHTO LFD (1996) and LRFD (1998) specifications. The parametric study consists of four bridge cross sections, five span lengths ranging from $100 \mathrm{ft}$. to $300 \mathrm{ft}$, , four span length to depth (L/D) ratios and two steel grades (HPS 70W and Grade 50). Thirteen representative existing plate girder bridges from across the country are also considered. Comparisons are also made to 
previous research procedures and specifications from other countries that are aimed at controlling superstructure live-load deflection serviceability.

Three-dimensional FEA models that have been verified with the experimental results of two laboratory tests and two field tests of composite steel bridges are proposed to investigate live-load deflection relationships and vibration characteristics of composite steel bridges. The effects of parapets on the natural frequencies are also considered. The FEA natural frequency results are also compared with existing natural frequency prediction methods, which illustrates the need for a refined analysis. Based on the results of this FEA parametric study, practical natural frequency equations are developed by using a nonlinear multiple variable regression based on sensitivity studies of significant variables. Experimental results on natural frequencies for composite steel bridges from other studies are used to evaluate and verify the proposed natural frequency equations.

The field-testing of a 2-span skewed HPS bridges was conducted with the University of Missouri - Columbia to evaluate stresses, live-load deflections and vibration characteristics. The previously developed 3D FEA method is also used to study the live-load deflections and natural frequencies of this bridge and the analytical results are compared with the field-testing results, which further illustrates the accuracy of the proposed FEA model and the natural frequency equation.

\subsection{Organization}

This thesis consists of eight chapters. Chapter 1 introduces the problem statement, research significance, objectives, scope of the research and the organization of the thesis. 
The background and overview of the problem, summarizing the previous efforts and studies focused on the general topic issue of superstructure behavior under live-load deflections, are presented in Chapter 2. This discussion, together with the information contained in Appendix A (a survey of professional practice related to AASHTO deflection limits) demonstrates the rationale of deflection criteria based on a natural frequency approach.

In Chapter 3, an extensive literature review on the estimation of the natural frequencies of continuous span beams (bridges) is presented. This includes dynamic load testing, empirical existing natural frequency equations and other analytical efforts. The scope of work, results and limits of these previous efforts are discussed.

The development of efficient finite element modeling tools to investigate the liveload behavior and vibration characteristics in composite steel girder bridges using the commercial finite element software ABAQUS is presented in Chapter 4. This chapter also includes experimental testing data for four composite steel bridges conducted elsewhere, which are presented to verify the modeling techniques. These FEA tools are used in subsequent chapters discussing parametric studies focused on determination of the natural frequency of composite steel bridges.

Chapter 5 discusses a parametric design study and the analysis of thirteen existing typical highway bridges, to assess existing AASHTO L/800 deflection limit on the economy of steel bridge designs. The evaluations of the alternative live-load deflection serviceability criteria are also presented. In the parametric design study, a series of key design variable (including span length, girder spacing, cross-section geometry, span configuration, and girder material configuration) are selected to develop a matrix of 
bridges representing a wide range of steel bridge designs. Bridges are then designed for combinations of these variables based on the least weight approach using various commercial bridge design software programs.

Based on nonlinear multiple variable regression analysis of the FEA natural frequency results for the parametric design study bridges, natural frequency equations are proposed in Chapter 6 for composite steel girder bridges. The FEA natural frequency results are also compared with existing prediction methods. The experimental natural frequencies of two continuous span composite steel bridges available in the literature are used to further verify the proposed prediction equation.

Chapter 7 presents comparisons of live-load deflections, stresses and natural frequencies between the FEA and field testing results for a 2-span continuous HPS Igirder bridge. Comparisons between the experimental natural frequency and that from the proposed prediction equation are also presented.

Finally, Chapter 8 provides a summary of the research and presents the conclusions drawn from the research findings with suggested changes to be implemented in AASHTO Specifications. Suggestions for future investigation are also discussed. 


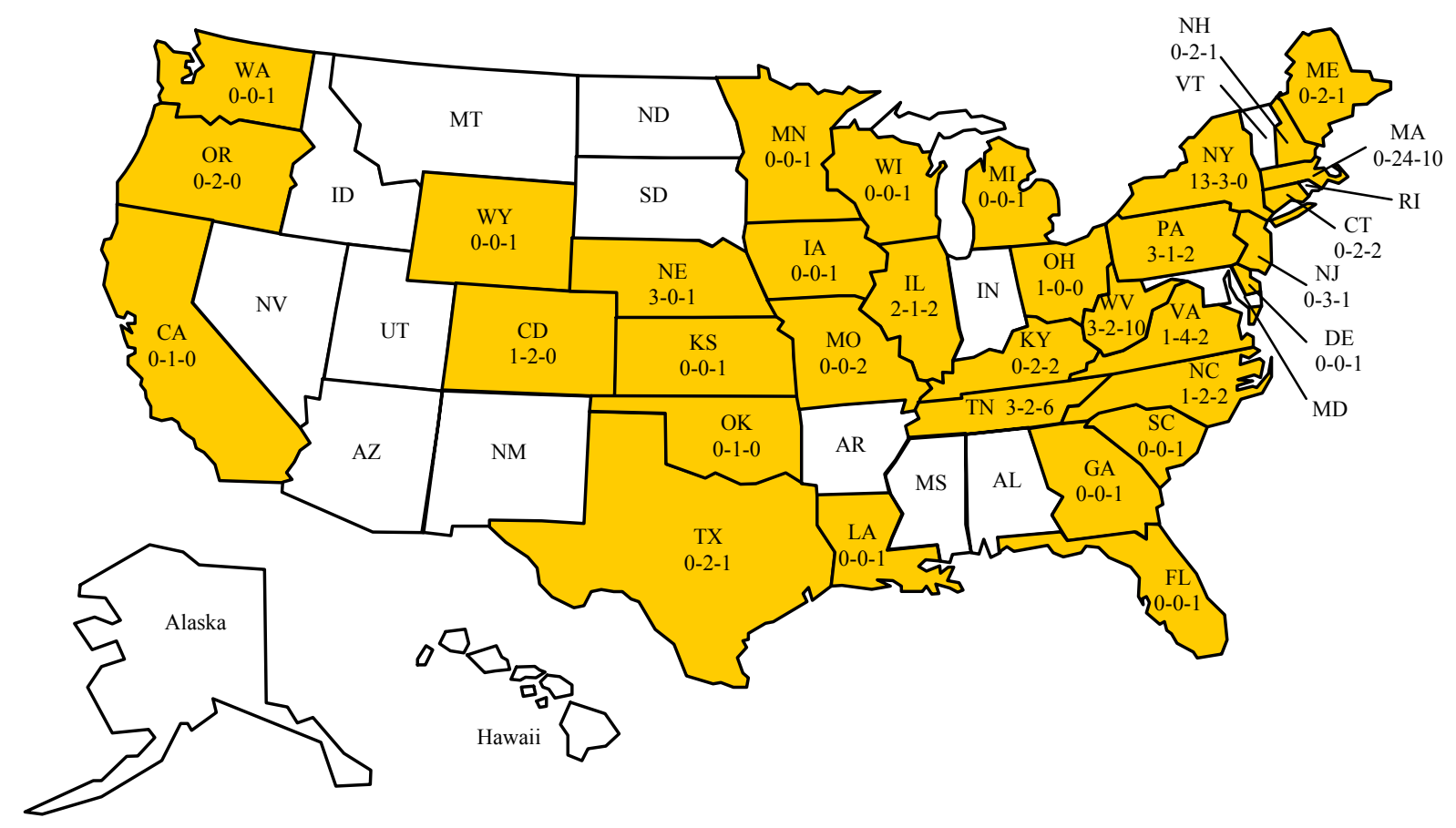

States with HPS bridges.

The first number indicates bridges that are in service, the second lists those in fabrication or construction, and the third number indicates bridges in planning or design.

Figure 1.1. The status of HPS bridge building and design in the United States (FHWA, 2002) 


\section{CHAPTER 2}

\section{BACKGROUND AND OVERVIEW OF THE PROBLEM}

\subsection{Overview and Historical Perspective}

The original source of the present AASHTO deflection limits is of interest to this study, because the possible existence of a rational basis for the original deflection limits is an important consideration. The source of the present limitations is traceable to the 1905 American Railway Engineering Association (AREA) specification, where limits on the span-to-depth (L/D) ratio of railroad bridges were initially established. L/D limits indirectly control the maximum live-load deflection by controlling the bending stiffness of the bridge. For a given span length, L/D or bridge depth is closely related to the bridge bending stiffness. Table 2.1 shows these limiting minimum $\mathrm{D} / \mathrm{L}$ ratios that have been incorporated in previous AREA and AASHTO specifications (ASCE, 1958). While initially live-load deflections were not directly controlled, the 1935 AASHO specification includes the following stipulation:

If depths less than these are used, the sections shall be so increased that the maximum deflection will be not greater than if these ratios had not been exceeded.

It is valuable to note that while L/D limits have been employed for many years, the definitions of the span length and depth have changed over time. Commonly, engineers have used either the center-to-center bearing distance or the distance between points of contraflexure to define span length. The depth has varied between the steel section depth and the total superstructure depth (steel section plus haunch plus concrete deck in the case of a plate or rolled girder). While these differences may appear to be 
small, they have a significant influence on the final geometry of the section, and they significantly affect the application of the $\mathrm{L} / \mathrm{D}$ and deflection limits.

Actual limits on allowable live-load deflection appeared in the early 1930's when the Bureau of Public Roads conducted a study that attempted to link the objectionable vibrations on a sample of bridges with bridge properties (ASCE, 1958; Oehler, 1970; Wright and Walker, 1971; and Fountain and Thunman, 1987). This study concluded that structures having unacceptable vibrations, determined by subjective human response, had deflections that exceeded $\frac{\mathrm{L}}{800}$, and this conclusion resulted in the $\frac{\mathrm{L}}{800}$ deflection criterion. Some information regarding the specifics of these studies is lost in history; however, the bridges included in this early study had wood plank decks, and the superstructure samples were either pony trusses, simple beams, or pin-connected throughtrusses.

The $\frac{\mathrm{L}}{1000}$ deflection limit for pedestrian bridges was set in 1960 . The limit was established after a baby was awakened on a bridge. The prominent mother's complaint attributed the baby's response to the bridge vibration, and the more severe deflection limit was established for bridges open to pedestrian traffic (Fountain and Thunman, 1987).

A 1958 American Society of Civil Engineers (ASCE) committee (ASCE, 1958) reviewed the history of bridge deflection criteria, completed a survey to obtain data on bridge vibrations, reviewed the field measurements of bridges subjected to moving loads, and gathered information on human perception to vibrations. The committee examined the effect of the deflection limit on undesirable structural effects including: 
- Excessive deformation stresses resulting directly from the deflection or from rotations at the joints or supports induced by deflections,

- Excessive stresses or impact factors due to dynamic loads, and

- Fatigue effects resulting from excessive vibration.

The committee also considered the measures needed to avoid undesirable psychological reactions of pedestrians, whose reactions are clearly consequences of the bridge motion, and vehicle occupants, whose reactions may be caused by bridge motion or a combination of vehicle suspension/bridge interaction.

The committee noted that the original deflection limit was intended for different bridges than those presently constructed. Design changes such as increased highway live-loads and different superstructure designs such as composite design, pre-stressed concrete, and welded construction were not envisioned when the limit was imposed. The limited survey conducted by the committee showed no evidence of serious structural damage attributable to excessive live-load deflection. The study concluded that human psychological reaction to vibration and deflection was a more significant issue than that of structural durability and that no clear structural basis for the deflection limits were found.

A subsequent study (Wright and Walker, 1971) also investigated the rationality of the deflection limits and the effects of slenderness and flexibility on serviceability. They reviewed literature on human response to vibration and on the effect of deflection and vibration on deck deterioration. This study suggested that bridge deflections did not have a significant influence on bridge structural performance, and that deflection limits alone were not a good method of controlling bridge vibrations or assuring human comfort. 
Oehler (Oehler, 1970) surveyed state bridge engineers to investigate the reactions of vehicle passengers and pedestrians to bridge vibrations. Of forty-one replies, only 14 states reported vibration problems. These were primarily in continuous, composite structures due to a single truck either in the span or in an adjacent span. In no instance was structural safety perceived as a concern. The survey showed that only pedestrians or occupants of stationary vehicles had objections to bridge vibration. The study noted that objectionable vibration could not be consistently prevented by a simple deflection limit alone. It was suggested that deflection limits and span-to-depth limits in the specifications be altered to classify bridges in three categories with the following restrictions:

- Bridges carrying vehicular traffic alone should have only stress restrictions,

- Bridges in urban areas with moving pedestrians and parking should have a minimum stiffness of 200 kips per inch deflection to minimize vibrations, and

- Bridges with fishing benches, etc. should have a minimum stiffness of 200 kips per inch of deflection and $7.5 \%$ critical damping of the bridge to practically eliminate vibrations.

Others (Fountain and Thunman, 1987) also suggested the AASHTO live-load deflection limits show no positive effect on bridge strength, durability, safety, maintenance, or economy. They also noted that subjective human response to objectionable vibrations determined the $\frac{\mathrm{L}}{800}$ deflection criterion, but deflection limits do not limit the vibration and acceleration that induces the human reaction.

This chapter presents a comprehensive literature review summarizing efforts and studies focused on the general issue of superstructure behavior under live-load 
deflections. More detailed discussion is provided on three factors that influence, or are influenced by, live-load deflection. These include:

- Structural performance, mainly reinforced deck deterioration,

- Bridge vibration characteristics, and

- Human response to bridge vibration.

\subsection{Effect of Bridge Deflections on Structural Performance}

Deterioration of reinforced concrete bridge decks is an increasing problem in all types of bridge superstructures, and it is caused by various internal and external factors. Bridge deck deterioration reduces service life by reducing load capacity of the structure and the quality of the riding surface. It is logical to ask whether bridge deterioration is attributable to excessive bridge flexibility and deflection.

There are four main types of deck deterioration: spalling, surface scaling, transverse cracking, and longitudinal cracking. Spalling is normally caused by corrosion of reinforcement and freeze/thaw cycles of the concrete. Scaling is caused by improper finishing and curing of the concrete and the simultaneous effects of freeze-thaw cycles and de-icing salts.

Transverse cracking is the most common form of bridge deck deterioration. Plastic shrinkage of the concrete, drying shrinkage of the hardened concrete combined with deck restraint, settlement of the finished plastic concrete around top mat of reinforcement, long term flexure of continuous spans under service loads, and traffic induced repeated vibrations due to fatigue all contribute to this damage. 
Longitudinal cracks occur as a result of poor mix design, temperature changes, live-load effects, or a reflection of shrinkage cracking. Multiple cracks appear on bridge decks that are fatigued or "worn out" from heavy traffic due to pounding caused from the wheel impact on the expansion joints and surface irregularities.

Research has shown that the width and intensity of these cracks tend to be uniformly distributed throughout the entire length of a bridge deck, rather than being concentrated in negative bending regions (State Highway Commission of Kansas, 1965; Fountain and Thunman, 1987; Krauss and Rogalla, 1996). One study (Fountain and Thunman, 1987) questioned the beneficial influence of the AASHTO deflection criteria, because flexural stresses in the deck of composite bridges are small. Bridge dynamic response changes very little as flexibility increases, because the lateral distribution of loads to adjacent girders increases with flexibility. In the negative moment regions of composite spans, the design flexural stresses in the deck are predictable and reinforcing steel can be provided for crack width control. They also argue that increased stiffness may increase deck deterioration, because the effects of volume change on the tensile stresses due to deck/beam interaction increase as the beam stiffness increases.

Deck deterioration noted in field survey data accumulated by the Portland Cement Association (PCA) (PCA, 1970) in cooperation with FHWA from 20 states representative of various climates was examined. The bridges included simple and continuous span concrete T-beams, slabs, box girders, and pre-stressed beams, as well as steel rolled beams, plate girders, decks and through trusses. These bridges were systematically and consistently inspected, and the damage characteristics were noted in detail. Laboratory studies of core samples of deteriorated and non-deteriorated areas were examined. From 
detailed investigations and random survey, no correlation was found between the degree of deck deterioration and bridge factors having a significant influence on the vibration characteristics of a bridge such as materials (steel or concrete), span length and span configuration. Also by analyzing the natural frequencies by using simple beam equation (Eqn. 2.2) for 12 simple-span bridges ( 8 steel and 4 concrete bridges) and 34 continuous span bridges (18 steel and 16 concrete bridges), no consistent relationship was found between high or low frequency of vibration and the deck determination. Scaling was the progressive deterioration and was related to the adequacy of the deck drainage and to some localized characteristics of the deck concrete such as freezing of water or de-icer solution in the concrete. Transverse cracking was caused by restraints imposed by the steel girders on the shrinkage of the slab and the influence of the top slab reinforcement as a source of tensile stress and shrinkage stresses induced by differential rate of drying. Live-load stresses played relatively minor roles in transverse cracking on steel bridges. The longitudinal cracks were formed primarily by resistance to subsidence of the plastic concrete imposed by top longitudinal reinforcement.

Others (Krauss and Rogalla, 1996) reviewed literature, surveyed 52 transportation agencies throughout the U.S. and Canada and conducted analytical, field, and laboratory research. The survey was sent to develop an understanding of the magnitude and mechanistic basis of transverse cracking in recently constructed bridge decks. The analytical parametric study examined stresses in more than 18,000 bridge scenarios caused by uniform and nonuniform shrinkage and temperature in bridges, and determined how bridge geometry and material properties affect these stresses. The longitudinal tensile stresses in the concrete deck causing transverse cracking were largely caused by 
concrete shrinkage and changing bridge temperature and, to lesser extent, traffic. Further, one deck replacement was monitored in the field, and laboratory experiments examined the effect of concrete mix and environmental parameters on cracking potential. It was concluded that multi-span continuous large steel girder structures were most susceptible to cracking because additional restraint from the steel girders, which were the least likely to have deck cracking for concrete girder bridges where deck and the girders shrink together. Longer spans were more susceptible than shorter spans. It was felt that reducing deck flexibility may potentially reduce early cracking.

Three studies (Goodpasture and Goodwin, 1971; Wright and Walker, 1971; and Nevels and Dixon, 1973) focus on the relationship between deck deterioration and liveload deflection. Goodpasture and Goodwin studied 27 bridges in Phase I of their research to determine which type of bridges exhibited the most cracking. The bridges were then divided into five major categories: plate girders, rolled beams, concrete girders, prestressed girders, and trusses. Emphasis was placed on the behavior of continuous span steel bridges, a type which had exhibited relatively more cracking than other types. The effect of stiffness on transverse cracking was evaluated for 10 of the continuous steel bridges in Phase II. There was a significant difference in the cracking intensities between positive and negative moment regions after the bridges had been opened. No correlation between girder flexibility and transverse cracking intensity could be established.

Wright and Walker show no evidence to associate spalling, scaling or longitudinal cracking with girder flexibility (Wright and Walker, 1971). Transverse deck moments lead to tension at the top of the deck and possible deck cracking, and were of interest to this research; the longitudinal deck moments are small. Figure 2.1 showed the influence 
of stringer flexibility and span length on transverse moments. The curves give moment per unit width produced by a dimensionless unit force, $\mathrm{M} / \mathrm{P}$. The stiffness parameter, $H$, was the ratio of stiffness $E_{s} I_{s}$ of the beam and slab stiffness for the span length, $L$.

$$
H=\frac{E_{s} I_{s}}{\frac{E_{c} L h^{3}}{12(1-v)^{2}}}
$$

In equation $2.1, E_{c}, h$, and $v$ were the modulus of elasticity, thickness, and Poisson's ratio for the deck slab, respectively, and $h$ and $L$ were in like units. The stiffness parameter $H$ was varied between 2, 5, 10, 20 and infinity $(\infty)$ in the figure, because this range included practical extremes of flexibility and stiffness. Span lengths of 40,80 , and $160 \mathrm{ft}$. for both simple and continuous span bridges were used. The more flexible the structure was the lower the stiffness parameter. Figure $2.1 \mathrm{~b}$ showed that low values of $H$ (increased girder flexibility) increase the peak positive transverse moment in the deck. In turn, the peak negative live-load moments were decreased with increased flexibility, and this subsequently reduces deck cracking.

Nevels and Hixon (Nevels and Hixon, 1973) completed field measurements on 25 I-girder bridges to determine the causes of bridge deck deterioration. The total sample of 195 bridges (666 spans) consisted of simple and continuous span plate girder and I-beam structures as well as prestressed concrete beams with span lengths ranging from 40 to 115 ft. The work showed no relationship between flexibility and deck deterioration.

The preponderance of the evidence indicates no association between bridge girder flexibility and poor bridge deck performance (ASCE, 1958; Wright and Walker, 1971; and Goodpasture and Goodwin, 1971). While the literature showed no evidence that bridge deck deterioration was caused by excessive bridge live-load deflections, other 
factors are known to influence bridge deck deterioration. High temperature, wind velocity, and low humidity during placement and curing accelerate cracking (Krauss and Rogalla, 1996). Further, the deck casting sequence has been found to have a significant effect on the deterioration of concrete at early ages (Issa 1999; Issa et. al., 2000). Concrete material factors important in reducing early cracking include low shrinkage, low modulus of elasticity, high creep, low heat of hydration, and the use of shrinkage compensating cement. Variables in the design process that affected cracking include the size, placement and protective coating of reinforcement bars. Smaller diameter reinforcement, more closely spaced, was recommended to reduce cracking (Krauss and Rogalla, 1996; French et. al., 1999). Increased deck reinforcement helps reduce cracking, but the reinforcement must have a sufficient cover, between 1 and 3 inches. However, a CALTRANS study reported placement as having no effect on transverse cracking (Poppe, 1981). In general, existing research provided little support for deflection limits as a method of controlling damage in bridges.

An early PCA (PCA, 1970) study provided substantial evidence that steel bridges and bridge flexibility had no greater tendency toward deck cracking damage than other bridge systems. However, recent study (Dunker and Rabbat, 1990 and 1995) funded by PCA contradicted earlier PCA results (PCA, 1970). This more recent study examined bridge performance on a purely statistical basis; no bridges were inspected. The condition assessment and the statistical evaluation were based entirely upon the National Bridge Inventory data. They showed that steel bridges had greater damage levels than concrete bridges, and implied that this was caused by greater flexibility and deflection. There were several reasons for questioning this inference. First, the damage scale in the 
inventory data was very approximate, and the scale was not necessarily related to structural performance. Second, the age and bridge construction methods were not considered in the statistical evaluation. It was likely that the average age of the steel bridges was significantly older than the prestressed concrete bridges used for comparison. Therefore, any increased damage noted with steel bridges may be caused by greater wear and age and factors such as corrosion and deterioration. Finally, there were numerous other factors that affect the bridge inventory condition assessment. As a consequence, the results of this study must be viewed with caution.

In addition to deck cracking or deterioration, the ASCE committee examined other structural performance issues related to live-load deflections, such as excessive deformation stresses resulting from the deflection, excessive stresses due to dynamic load, and fatigue effects from excessive vibration (ASCE, 1958). Previous research (Roeder et al., 2002) showed damaged web at diaphragm connections for plate girder bridges due to differential girder deflections.

\subsection{Effect of Bridge Deflection on Superstructure Bridge Vibration}

There is considerable evidence that the existing deflection limits are motivated by vibration control, so research into bridge vibrations is relevant to this study.

The dynamic responses of highway bridges (Huang et. al., 1960; Oran et. al., 1961; Eberhardt, 1962; Linger et. al., 1962; Kawatani et. al., 1992; Chatterjee et. al., 1994; Wang et. al., 1993 and 1996; Senthilvasan et al., 2002; and Nassif et. al., 2003) subjected to moving trucks have been observed to be complex function of the following factors affecting the bridge-road-vehicle dynamic interaction systems: 
- The type of the bridge and its natural frequency of vibrations,

- Vehicle properties such as truck mass, truck configuration, weight, speeds and lane positions,

- Ratio of the vehicle and bridge masses,

- The damping characteristics of the bridge and vehicle, and

- Road riding surface roughness profiles of the bridge and its approaches.

A review of dynamic amplification factors (DAF) showed a general lack of consistency exists in calculating DAF by using the test data (Bakht and Pinjarkar, 1989). A preferred method of calculating DAF was proposed.

Analytical and standard experimental procedures were presented for bridge dynamic characteristics from acceleration data and the DAF from typical deformation and displacement data (Paultre et. al., 1992). DAF was closely related to the first natural frequency, however DAF can be interpreted in many ways when using testing data to compute this value.

A procedure with the grillage beam systems, nonlinear vehicle model, and road surface roughness generated from power spectral density functions were proposed to study the DAF for multi-girder steel bridges (Wang et al., 1993 and 1996). The bridges have girder numbers from 4 to 8 and span length changing from 40 to $120 \mathrm{ft}$. The DAF of each steel girder was closely related to the lateral loading position of vehicles. The DAF decreased with increasing vehicle weight. The total number of longitudinal girders had little influence on the maximum DAF of each girder, provided that bridges had good road surface. However, the maximum DAF increased significantly with increasing number of girders for average or poor road surfaces. The difference of maximum DAFs will become smaller as the span length increases. 
Recent work (Nassif et. al., 2003) presents a 3D grillage model to study the dynamic bridge-road-vehicle interaction for composite steel bridges. The study leaded to the following conclusions about DAF. The DAF decreased with the static stress increases. The representation of the DAF as a function of span length (AASHTO, 1996) or the first natural frequency (Ministry of Transportation, 1991) did not fully address the complexity of bridge-road-vehicle interactions. Values of DAF for design purpose should be based on those obtained from the most loaded interior girders.

No attempt is made here to review all of these factors affecting the dynamic response of highway bridges in detail. Only those works which are closely related to this research are reviewed.

\subsubsection{Human Response to Vibration}

Research (Nowak and Grouni, 1988) has shown that deflection and vibration criteria should be derived by considering human reaction to vibration rather than structural performance. The important parameters that effect human perception to vibration were the acceleration, deflection, and period (or frequency) of the response. Human reactions to vibrations were classified as either physiological or psychological. Psychological discomfort results from unexpected motion, but physiological discomfort results from a low frequency, high amplitude vibration, such as seasickness. Vertical bridge acceleration was of primary concern, since it was associated with human comfort (Shahabadi, 1977).

The most frequently cited reference on the human evaluation of steady-state vibration was the study (Reiher and Meister, 1931), which produced 6 tolerance ranges 
based on the reactions of 10 adult subjects of different backgrounds between the ages of 20 to 37 years, in standing and reclining positions. In a laboratory setting, subjects were exposed to sinusoidal movements in the vertical or horizontal directions for 10-minute periods. The tolerance ranges were classified as imperceptible, slightly perceptible, distinctly perceptible, strongly perceptible or annoying, unpleasant or disturbing, and very disturbing or injurious as shown in Fig. 2.2 for a person standing and subjected to steady-state vertical motion. For the human response to the vibration in the frequency range 1 to 70 cycles per second, Goldman (Goldman, 1948) reviewed the problem and produced from several different sources, including Reiher and Meister, a set of revised averaged curves corresponding to three tolerance levels: I. the threshold of perception, II. The threshold of discomfort, and III. the threshold of tolerance. These three levels are shown in Fig. 2.3 with the vertical lines about the means representing one standard deviation about and below them. As shown in Fig. 2.4, another plot gave three similar levels in terms of peak acceleration.

A 1957 study (Oehler, 1957) cited empirical amplitude limits developed by Janeway (Janeway, 1950) that were developed to control intolerable levels of vibration amplitude at various frequencies of vibration. These limits were based on data from subjects standing, or sitting on hard seats. For frequency from 1 to 6 cycles per second, the recommended safety limits are based on the equation $a f^{3}=2$, where $a$ was the amplitude and $f$ was the frequency of vibration. For frequency from 6 to 20 cycles per second, the recommended amplitude limits were based on the equation $a f^{2}=1 / 3$. Bridge deflection, vibration amplitude, and frequency of vibration were measured for 34 spans of 15 bridges to determine which bridge types were more susceptible to excessive 
vibrations. Simple-spans, continuous spans, and cantilever spans of reinforced concrete, steel plate girders, and rolled beam superstructures were investigated. The observed amplitude and frequency data was compared to Janeway's recommended limits. The amplitude of vibration is shown with the test truck on the span and off the bridge in Fig. 2.5. The test vehicle produced vibration amplitudes that exceeded Janeway's human comfort limits in 7 cantilever-span and 7 simple-span bridges, but this amplitude of vibration never lasted more than one or two cycles. Reactions from personnel performing the tests disagreed with the limits set by Janeway. They perceived the vibration on the simple and continuous spans but noted that it was not disturbing. Additionally, they felt discomfort at high amplitude, low frequency vibration. It was concluded that the cantilever spans were more prone to longer periods of vibration and larger amplitudes than the simple or continuous spans. Further, increasing bridge stiffness did not decrease the vibration amplitude sufficiently to change the "perceptible" classification as prescribed by Reiher and Meister and Goldman (Oehler, 1970).

Wright and Green (Wright and Green, 1964) compared the peak levels of vibration from 52 bridges to levels based on Reiher and Meister's scale and Goldman's work. They showed that $25 \%$ of the bridges reached the level indicated as intolerable by subjects in the Reiher and Meister's and Goldman's work. They concluded that low natural frequencies, up to $3 \mathrm{~Hz}$, were not the only parameter that will reduce vibrations. Smoothness of a bridge deck and the bridge approaches and expansion joints can contribute significantly to reduced vibration, although tendencies for vehicles to brake on or before entering a span can more than offset benefits obtained through improving deck smoothness. As shown in Fig. 2.6, a new proposed quantitative and qualitative scale of 
"isosensors" has been developed, which reflects more carefully human reactions at different frequencies and the nature of the variation from person to person. However, most of the existing scales were for steady vibrations maintained for a considerable period of time, there was no known scale of vibration intensity that may be directly related to the kind of vibrations experienced in highway bridges in which intensities vary with peak levels sustained only for a few second. A summary of their results concerning highway bridge vibrations was presented.

- Simple geometrical or static considerations such as $\mathrm{L} / \mathrm{D}$ ratio or deflections due to static "live" loads did not provide adequate means of controlling or estimating undue vibration,

- Theoretical studies for dynamic behavior were available and valuable for individual instances, but they were of little use for design, and

- Human reaction to motion was very complex and cannot be consistently described in terms of any single parameter or function. No simple correlation between measures of human reaction to vibration and the principle theoretical and design parameters describing bridge motion was apparent from existing data.

There are no live-load deflection limits in AASHTO specifications for bridges constructed with advanced composite materials such as E-glass/vinylester composite sandwich) (Demitz et al., 2003). This study focused on the establishment of live-load deflection limitations for the new material, based on limiting response accelerations. A transient dynamic FEA using ANSYS was carried out to assess the dynamic response of three composite bridge designs, based on AASHTO L/800, L/600 and L/400 live-load deflection limits, subjected to the passage of a design truck, for a variety of vehicle speeds. These designs were compared against the response of three traditional bridges designed on the basis of strengths for a concrete slab on steel stinger bridge, a concrete slab on prestressed concrete stringer bridge, and a concrete slab on glulam stringer 
bridge. The bridges had span lengths of $60 \mathrm{ft}$. and widths of $30 \mathrm{ft}$. The limiting design acceleration for each bridge design was taken as $0.5 f^{1 / 2}$ in $\mathrm{m} / \mathrm{s}$, which was one of the limiting criteria for human response to steady vibration (Ministry of Transportation, 1991). Compared to the 3 traditional bridges with the first mode frequencies in the range of 4.25 to $5.11 \mathrm{~Hz}$, the 3 new material bridges had much higher first mode frequencies in the range of 8.74 to $12.05 \mathrm{~Hz}$ and limiting design accelerations. However, different design methodologies, strength basis for traditional bridges and the stiffness basis for new material bridges, should partly contribute to these differences. Based on the accelerations with respect to vehicle speed, all 3 composite designs would be acceptable up to a design speed of $60 \mathrm{mph}$. Beyond the $60 \mathrm{mph}$ design speed, the $\mathrm{L} / 800$ and $\mathrm{L} / 600$ design are acceptable. The response of the L/400 design significantly increased as truck speed increased to beyond $60 \mathrm{mph}$. When considering the fatigue truck for the assessment of accelerations, the $\mathrm{L} / 400$ design was acceptable at high vehicle speed.

\subsubsection{Field Studies}

Many early dynamic studies (Biggs et al., 1959; Cantieni, 1983) were directed primarily toward development of impact factors and understanding bridge dynamic response. The dynamic response of the Jackson and the Fennville Bridges (Foster and Oehler, 1954) were monitored under normal commercial traffic, a controlled two-axle truck, and a special three-axle truck. The Jackson Bridge was an eight-span composite plate girder bridge with 5-simple and 3-continuous spans. The Fennville Bridge consisted of 6-simple spans of rolled beam construction of which only one span exhibits composite action. Measured deflections were compared to theoretical predictions, and 
the effect of vehicle weight, vehicle type, axle arrangement, speed, and surface roughness on vibration was studied. Deck surface irregularities were simulated by boards placed on the bridge deck in the path of the test vehicle, which caused increased bridge vibration amplitude. Increasing span flexibility increased the observed amplitude and duration of vibration. Computed deflections were consistently larger than the measured deflections. Vibrations increased when the natural period of vibration of the span nearly coincided with the time interval between axles passing a reference point on the span.

Midspan deflections due to a 3-axle truck with axle loads of 5.6, 18.1, and 15.5 kips were measured (Oehler, 1957) for all spans of 15 bridges built between 1947 and 1957. Several spans showed appreciable vibration although live-load plus impact deflections were less than $\frac{\mathrm{L}}{1000}$.

The dynamic behavior of 52 representative Ontario highway bridges that vibrate under normal traffic were measured (Wright and Green, 1964). Each bridge was inspected to determine traffic conditions, road surface condition and bridge details. A wide variety of differing types, spans and cross-sectional geometries were chosen, including beam, plate girder and truss systems, as well as simple and continuous spans. Span lengths ranged from 50 to $320 \mathrm{ft}$. and widths from 15 to $68 \mathrm{ft}$. One bridge was selected for further evaluation of the influence of surface roughness on the dynamic response. A test was performed on that bridge before the final asphalt pavement was laid and after the pavement was laid while normal traffic operated on the bridge under both cases. The deck was not considered especially rough or smooth before the pavement was placed but was smooth immediately after the pavement was placed. Comparison of the results of the two tests showed great improvement in the dynamic performance with the 
smooth deck. Values of stiffness and natural frequency were almost identical for the two tests. Median values of vibration intensity were also significant reduced with the fresh paving, though it was interesting to note that the maximum level of vibration intensity for the paved bridge was as high as the maximum recorded for the unpaved bridge.

Live-load deflections were measured (Nevels and Hixon, 1973) on 25 bridges due to an HS20 vehicle, with wheel loadings of 7.29 and 32.36 kips and an axle spacing of $13.25 \mathrm{ft}$., and compared to calculated deflections. The calculated deflection was approximately 50 percent larger than the actual values.

Haslebacher (1980) measured deflections on steel superstructures, and suggested that intolerable dynamic conditions may result if the ratio of forcing frequency to bridge natural frequency is in the range of 0.5 to 1.5 . He defined intolerable movements as those adversely affecting structural integrity or human perception. He noted that by choosing a critical value of forcing frequency and comparing this value to the natural frequency of the structure, the designer could determine if the structure had enough mass and stiffness to prevent excessive dynamic deflections.

DeWolf et al. (1986) conducted a field study on a four-span noncomposite continuous bridge with two nonprismatic steel plate girders. When one direction of traffic was stopped on the bridge while the other lane was moving, this 30-year old structure had been reported to have objectionable vibrations which are noticeable to someone standing on it or sitting in a stopped vehicle. Accelerations were determined and compared to human tolerance limits developed by Bolt, Beranek and Newman, Inc. (Bolt et al., 1966). The maximum acceleration values, seen in Fig. 2.7, exceeded those accelerations tolerable by most people. However, the structural performance of the bridge and the 
resulting stresses, based on the initial analysis of the data, were acceptable. The torsional aspects, due to the cantilevered portions, create most of the lively behavior.

DeWolf and Kou (1987) estimated static deflections using present AASHTO Load Factor Specifications, natural frequencies, and mode shapes and compared this data to field measurements. Twenty-three test runs were completed with 2-axle dump trucks that weighed 30.52 and 36.4 kips. The maximum determined deflection of 0.64 in was approximately 25 percent of the AASHTO limit, but the bridge had unacceptable vibrations at that load level.

\subsubsection{Analytical Studies}

Finite element studies of representative noncomposite simple span and continuous multi-girder bridges investigated the effects of bridge span length and stiffness, deck surface roughness, axle spacing and number of axles on bridge acceleration (Amaraks, 1975). Surface roughness produced the most significant effect on acceleration for both the simple and continuous span bridges; the maximum accelerations with a rough roadway surface were found to be as much as five times those for the same bridge with a smooth deck. Furthermore, maximum accelerations increased as the span length decreased. Maximum acceleration also increased when the stiffness was reduced, but this increase was significantly less severe than noted for the surface roughness variations as may be seen in Fig. 2.8 and 2.9, respectively. Aramraks observed that vehicle speed greatly influences peak acceleration. The maximum accelerations were approximately the same for two and three axle vehicle models, but were about two thirds of the magnitudes produced by the single axle vehicle model. An investigation of the influence 
of initial oscillation of the vehicle suspension on bridge acceleration was also conducted. Initial oscillation causes a 30 to 50 percent increase in maximum accelerations for a bridge assumed to have a smooth deck surface.

Aramraks (1975) evaluated maximum accelerations for varied ratios of bridge natural frequency to vehicle frequency, in the range of 0.5 to 2.0, as can be seen in Fig. 2.10. The vehicle frequency, using an HS20-44 loading, is the tire frequency of the rear axles. For the two-span bridges and three-span bridges, the fundamental natural frequency is 3.53 and $3.0 \mathrm{~Hz}$, respectively. Commonly, the acceleration magnitudes were approximately the same but increased slightly in the midspan when the vehicle and bridge had the same natural frequency.

Another study (Kou and DeWolf, 1997) demonstrated the influence of the vehicle speed, vehicle weight, bridge surface roughness, initial vehicle oscillation, deck thickness and girder flexibility using a three-dimensional finite element model. The bridge was previously monitored in the field (DeWolf et al., 1986), and was a composite continuous four-span bridge with nonprismatic steel plate girders. They found that the maximum displacement in different spans changed by only 5 to 12 percent but the maximum acceleration increased by 50 to 75 percent when road surface roughness changed from smooth to one inch surface roughness amplitude. Furthermore, only minor influence of girder flexibility on overall dynamic bridge behavior was found. Also, the maximum displacement increased with increased vehicle speed. This increase was up to 40 percent in extreme cases. However, vehicle speed was found to have the greatest effect on the maximum girder acceleration. Additionally, they showed that initial vehicle oscillation 
had the greatest effect on maximum deflections, increasing 2.5 times, while the maximum girder acceleration showed a minimal increase with an increase in oscillations.

\subsection{Alternate Live-Load Deflection Serviceability Criteria}

Four alternative methods of providing for the serviceability limit state are found and discussed here. These are: (1) the requirements specified by the Canadian Standards and the Ontario Highway Bridge Design Code, (2) the Australian Specifications, (3) the codes of practice used by New Zealand and European countries, and (4) the suggestions resulting from a 1971 AISI study conducted by Wright and Walker.

\subsubsection{Canadian Standards and Ontario Highway Bridge Code}

Both the Canadian Standards and the Ontario Highway Bridge Design Code (OHBDC) use a relationship between natural frequency and maximum superstructure static deflection to evaluate the acceptability of a bridge design for the anticipated degree of pedestrian use (Ministry of Transportation, 1991; CSA International, 2000). Figure 2.11 shows the plot of the first flexural frequency $(\mathrm{Hz})$ versus static deflection $(\mathrm{mm})$ at the edge of the bridge. The superstructure deflection limitations are based on human perception to vibration.

Three types of pedestrian use of highway bridges are considered for serviceability:

- Very occasional use by pedestrians or maintenance personnel of bridges without sidewalks,

- Infrequent pedestrian use (generally do not stop) of bridges with sidewalks, and 
- Frequent use by pedestrians who may be walking or standing on bridges with sidewalks.

This relationship was developed from extensive field data collection and analytical models conducted by Wright and Green in 1964. For highway bridges, acceleration limits were converted to equivalent static deflection limits to simplify the design process. For pedestrian traffic, the deflection limit applies at the center of the sidewalk or at the inside face of the barrier wall or railing for bridges with no sidewalk.

More recent studies by Billings conducted over a wide range of bridge types and vehicle loads, loads ranging from 22.5 kip to 135 kips, confirm the results of the initial study (Ministry of Transportation, 1991).

For both the Canadian Standards and the Ontario Code, only one truck is placed at the center of a single traveled lane and the lane load is not considered. The maximum deflection is computed due to factored highway live-load including the dynamic load allowance, which is also a function of the first natural frequency (shown in Fig. 2.12), and the gross moment of inertia of the cross-sectional area is used (i.e. for composite members, use the actual slab width). For slab-and-girder construction, deflection due to flexure is computed at the closest girder to the specified location if the girder is within $1.5 \mathrm{~m}$ of that location.

\subsubsection{Australian Codes}

Australian Codes (AUSTROADS, 1992; AUSTRALIAN, 1996) require a similar curve, shown in Fig. 2.13, to limit the static deflection as a function of the first mode flexural frequency for road bridges with footways. The serviceability design load of a single T44 Truck, including the same dynamic load allowance as that of OHBDC shown 
in Fig. 2.12, should be positioned along the spans and within a lane to produce the maximum static deflection at a footway.

Where the deflection of a road bridge without a public footway complies with the other limits specified in the codes, the vibration behavior of the bridge need not be specifically investigated. Where these deflection limits are exceeded, the vibration behavior of the bridge shall be assessed by a rational method, using acceptance criteria appropriate to the structure and its intended use.

Meanwhile, the deflection of highway bridge girders under live-load plus dynamic load allowance shall not exceed 1/800 of the span length (AUSTRALIAN, 1996). However, the work (Sergeev and Pressley, 1999) showed that the origin of this live-load deflection limit is uncertain. It was originally adopted in earlier versions of the Code, apparently taken from contemporary AASHTO Specifications. In this study, the live-load deflection limits for three exiting bridges were investigated and alternative serviceability criteria were proposed. As a result of the combination of both the proposed design live loadings (A160, S1600 and M1600), which are heavier than the original design T44 truck, and the utilization of higher strength steels $50 \mathrm{ksi}$ (350 Mpa and higher), concrete/steel composite bridges were found to be particularly vulnerable to the deflection limits. So, the validity of a live-load deflection control criterion was questioned. The Lotus Street Duplication Bridge is a slab on steel I-girder bridge with spans of $153+117 \mathrm{ft}$. and the actual $\mathrm{L} / \mathrm{D}$ equals 23.7 , less than the recommended value of 25 for composite girders. However, the live-load deflection limit was exceeded by $12 \%$ for $101 \mathrm{t}$ Double Bottom Road Train (DBRT) loading and by $45 \%$ for M1600 loading. The Mortlock River Bridge is a 6-span continuous composite steel bridge. The 
deflection under 101T DBRT loading controlled the design and resulted in low $\mathrm{L} / \mathrm{D}$ ratio of 13.7. The deflection limit L/800 is exceeded under M1600 by 7\%. Bridge 1470 is a simply supported composite steel bridge with a span length of $87.4 \mathrm{ft}$., the deflection under 101T DBRT loading also controlled this design and the M1600 live-load deflection is $44 \%$ greater than the $\mathrm{L} / 800$ limit. Thus, it is recommended that the Serviceability Limit State Criteria in the Australian Design Code should be optimized by eliminating the artificial live load and placing more emphasis on the elastic response of structures to serviceability loads, namely preventing rapid structure deterioration by controlling crack widths under short term loads and controlling vibration as appropriate to the situation.

\subsubsection{Codes and Specifications of Other Countries}

A brief review of the codes and specifications used in other countries was also conducted. Most European Common Market countries base their design specifications upon the Eurocodes (Dorka, 2001), which are only a framework for national standards. Each country must issue a "national application document (NAD)" which specifies the details of their procedures. A Eurocode becomes a design standard only in connection with the respective NAD. Thus, there is considerable variation in the design specifics from country to country in Europe. If an NAD exists for a specific Eurocode, then this design standard is enforced when it is applied to a building or bridge. Often, the old national standards are also still valid and are applied. There is the rule though, that the designer cannot mix specifications. The designer must make an initial choice and then

consistently use that specification in all aspects of the design for a given structure. However, in general, the full live-loads are factored with a "vibration factor" to account 
for extra stresses due to vibrations. No additional checks (frequency, displacements etc.) are then required. For long span or slender pedestrian bridges, a frequency and mode shape analysis is also usually performed. Special attention is always paid to cables, since vibrations are common, and some European bridges have problems with wind induced cable vibration. Deflection limits are not normally applied in European bridge design.

In New Zealand, the 1994 Transit NZ Bridge Manual limits the maximum vertical velocity to $2.2 \mathrm{in} / \mathrm{sec}$ under two $27 \mathrm{kip}$ axles of one $\mathrm{HN}$ unit if the bridge carries significant pedestrian traffic or where cars are likely to be stationary (Walpole, 2001). Older versions of this Bridge Manual also employed limits on L/D and deflection, but these are no longer used in design.

\subsubsection{Wright and Walker Study}

A 1971 study conducted by AISI reviewed AASHTO criteria and recommended relaxed design limits based on vertical acceleration to control bridge vibrations (Wright and Walker, 1971). The proposed criteria require that:

1. Static deflection, $\delta_{\mathrm{s}}$, is the deflection as a result of live-loads, with a wheel load distribution factor of 0.7 , on one stringer acting with its share of the deck

2. Natural frequency, $f_{s b}(\mathrm{cps})$, is computed for simple span bridges or continuous bridges with approximately equal spans

$f_{s b}=\frac{\pi}{2 L^{2}} \sqrt{\frac{E_{b} I_{b} g}{w}}$

where

$\mathrm{L}=$ the span length

$E_{b} I_{b}=$ the flexural rigidity of the composite steel girder

$g=$ the acceleration due to gravity

$w=$ the weight per unit length of the composite steel girder 
3. The speed parameter, $\alpha_{v}$, is determined by

$$
\alpha_{v}=\frac{v}{2 f_{s b} L}
$$

where

$$
v=\text { vehicle speed, fps. }
$$

4. The Impact Factor, DI, is determined as

$$
D I=\alpha+0.15
$$

5. Dynamic Component of Acceleration, $a\left(\mathrm{in} / \mathrm{sec}^{2}\right)$

$$
a=D I \delta_{s}\left(2 \pi f_{s b}\right)^{2}
$$

6. Acceleration limit must not exceed the limit

$$
a=100 \mathrm{in} . / \mathrm{sec}^{2}
$$

7. If the Dynamic Component of Acceleration exceeds the acceleration limit, a redesign is needed

8. Table 2.2 shows the peak acceleration criterion for human response to harmonic vertical vibration. For bridge vibrations, the peak acceleration values for transient motions in Table 2.2 should be used.

\subsection{Summary}

AASHTO specifications require that deflections be controlled by limiting span-todepth ratio preferably great than $1 / 25$ for composite steel bridges and by limiting the maximum unfactored deflection to:

- $\frac{\mathrm{L}}{800}$ for most design situations, and

- $\frac{\mathrm{L}}{1000}$ for urban areas where the structure may be used in part by pedestrian traffic where $L$ is the span length of the girder. 
The justification for the existing AASHTO deflection limits are not clearly defined in the literature, but the best available information indicates that they were initiated as a method of controlling undesirable bridge vibration. The limits are based on undetermined loads, and the bridges used to initially develop this limit state requirement are very different from those used today. The research has shown that reduced bridge deflections and increased bridge stiffness will reduce bridge vibrations, but this is clearly not the best way to control bridge vibration. Bridge vibration concerns are largely based upon human perception, which depends upon a combination of maximum deflection, maximum acceleration and frequency of response. Several models have been proposed to classify limits for perception of vibration, but there does not appear to be a consensus regarding acceptable limits at this point. Bridge surface roughness and vehicle speed interact with the dynamic characteristics of the vehicle and the bridge (such as natural frequency) to influence the magnitude of bridge response. Field measurements of bridges show that the actual bridge live-load deflections are often smaller than computed values for a given truck weight.

Initial vehicle suspension oscillation tends to significantly increase bridge accelerations and displacements. As the ratio of natural frequency of the bridge to the natural frequency of the vehicle suspension approach unity (i.e. a resonant condition), the bridge response increases. Various estimates on the fundamental frequency for slab on girder bridges range from 1 to $10 \mathrm{~Hz}$, but vehicle natural frequency has been estimated between 2 to $5 \mathrm{~Hz}$ (typically closer to the lower value).

Past research shows no evidence that bridge live-load deflections cause significant damage to bridge decks. In general, the strain in bridge decks due to normal bridge 
flexure is quite small, and damage is unlikely to occur under these conditions. On the contrary, other attributes such as quality and material characteristics of concrete clearly do influence deck deterioration and reduced deck life. Past research has given relatively little consideration to the possibility that large bridge deflections cause other types of bridge structural damage. Furthermore, local deformations may well cause structural damage, but the $\frac{\mathrm{L}}{800}$ deflection limit is not typically applied in such a way to control this damage.

Within this framework, it is not surprising that the bridge design specifications of other countries do not commonly employ live-load deflection limits. Instead vibration control is often achieved through a relationship between bridge natural frequency, acceleration, and live-load deflection. 
Table 2.1. Depth-to-span, D/L, ratios in A.R.E.A. and A.A.S.H.O. (ASCE, 1958)

\begin{tabular}{|l|l|l|l|}
\hline Year (s) & Trusses & Plate Girders & Rolled Beams \\
\hline A.R.E.A. & & & \\
\hline 1905 & $1 / 10$ & $1 / 10$ & $1 / 12$ \\
\hline $1907,1911,1915$ & $1 / 10$ & $1 / 12$ & $1 / 12$ \\
\hline $1919,1921,1950,1953$ & $1 / 10$ & $1 / 12$ & $1 / 15$ \\
\hline A.A.S.H.O. & & & \\
\hline 1913,1924 & $1 / 10$ & $1 / 12$ & $1 / 20$ \\
\hline 1931 & $1 / 10$ & $1 / 15$ & $1 / 20$ \\
\hline $1935,1941,1949,1953$ & $1 / 10$ & $1 / 25$ & $1 / 25$ \\
\hline
\end{tabular}


Table 2.2. Peak acceleration criterion for human response to harmonic vertical vibration (Wright and Walker, 1971)

\begin{tabular}{|c|c|c|}
\hline \multirow{2}{*}{ Human Responses } & \multicolumn{2}{|c|}{ Peak Acceleration, in./sec } \\
\cline { 2 - 3 } & Transient & Sustained \\
\hline Imperceptible & 5 & 0.5 \\
\hline Perceptible to Some & 10 & 1 \\
Perceptible to Most & 20 & 2 \\
Perceptible & 50 & 5 \\
\hline Unpleasant to Few & 100 & 10 \\
Unpleasant to Some & 200 & 20 \\
Unpleasant to Most & 500 & 50 \\
\hline Intolerable to Some & 1000 & 100 \\
Intolerable to Most & 2000 & 200 \\
Intolerable & & \\
\hline
\end{tabular}




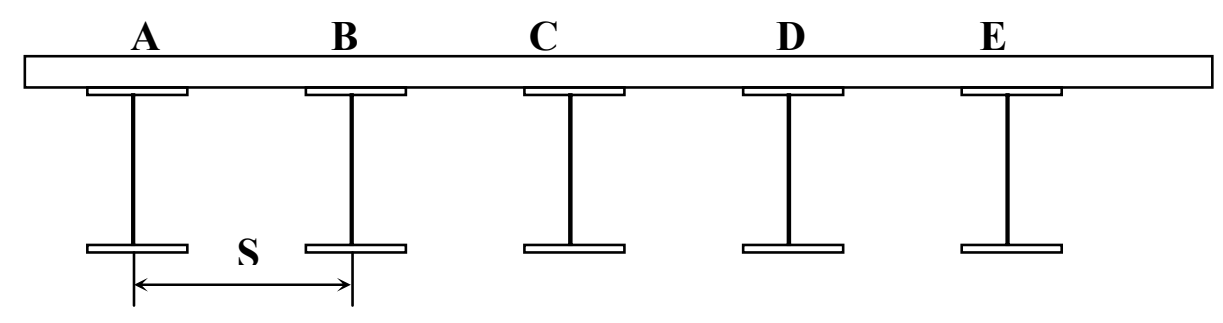

(a) Cross - section
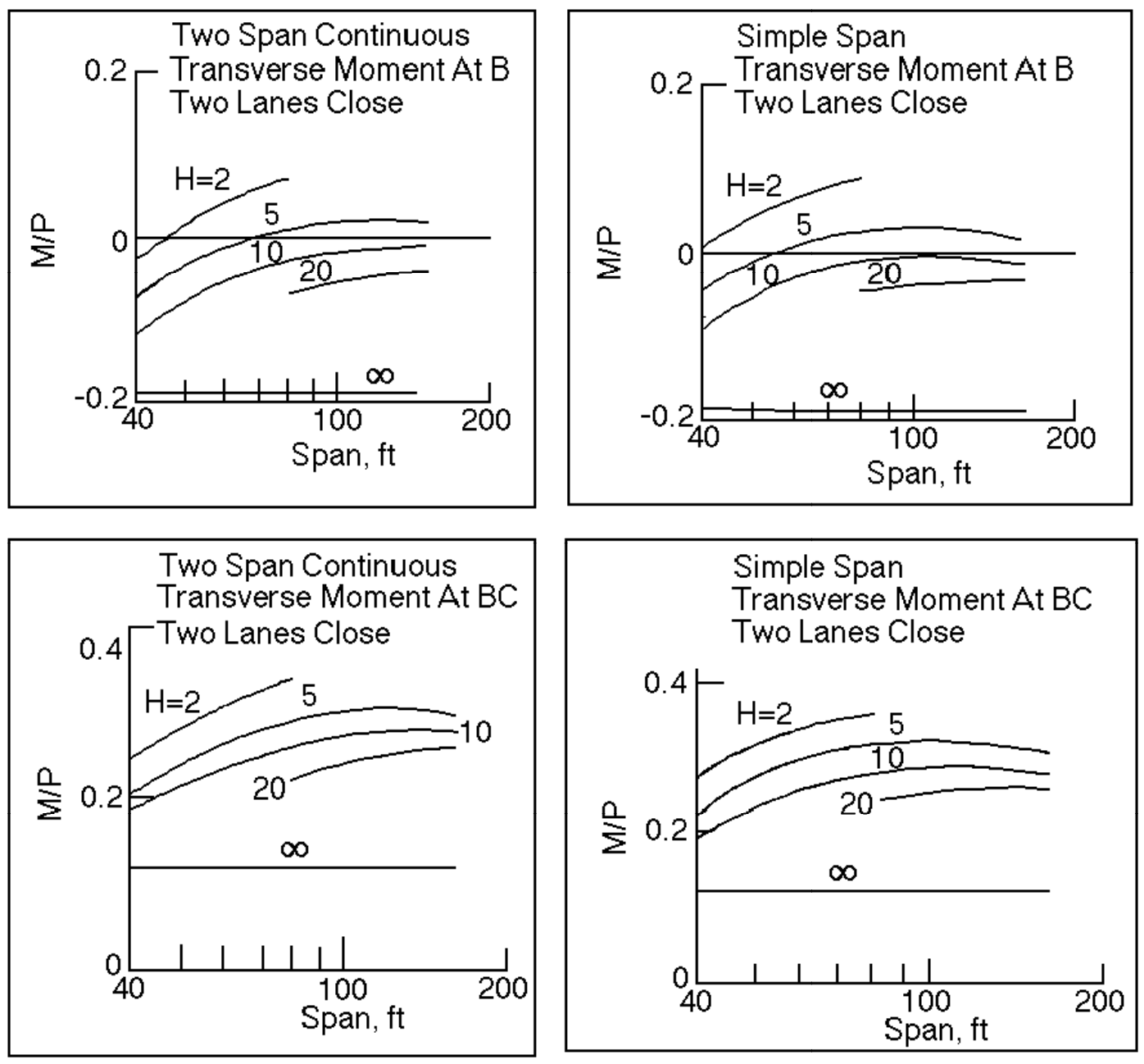

(b) Variation in Parameters

Figure 2.1. Effect of stringer flexibility on transverse moment in deck

(Wright and Walker, 1971) 


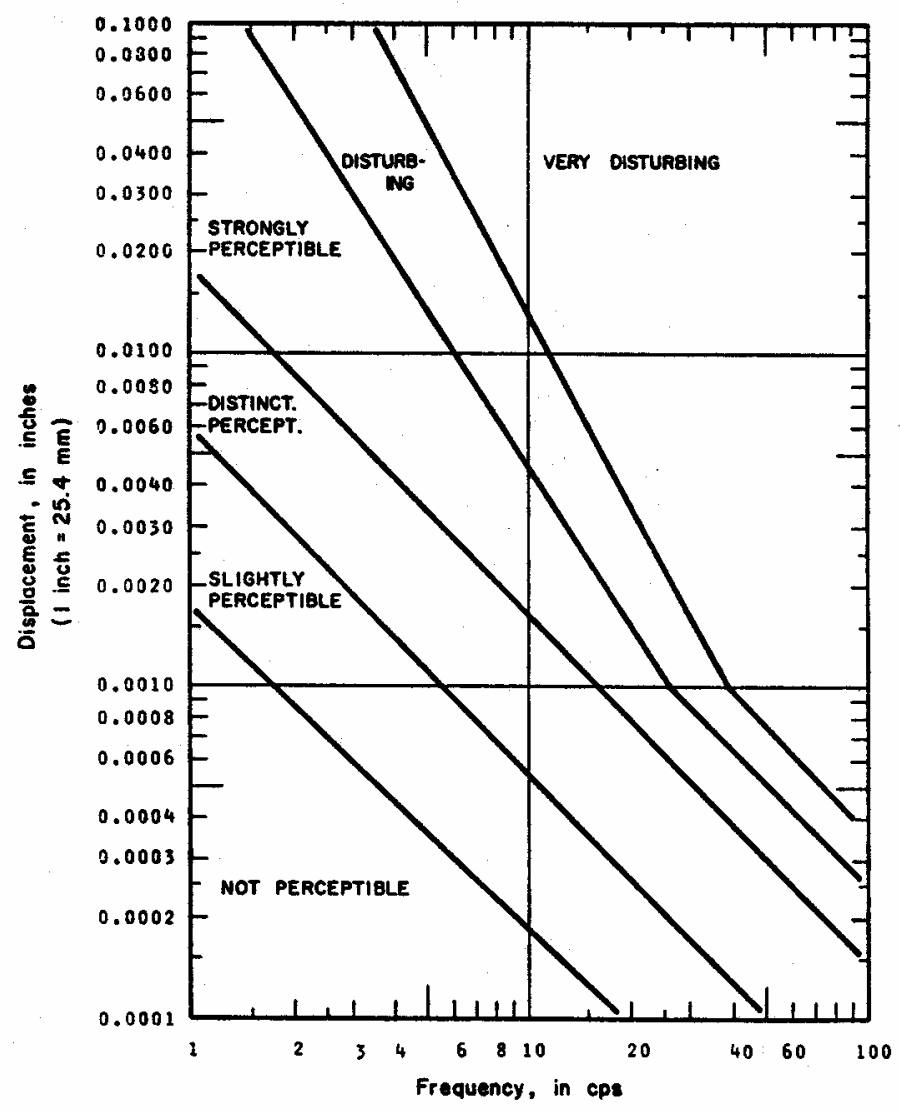

Figure 2.2. Six human tolerance levels for vertical vibration (Reiher and Meister, 1931) 


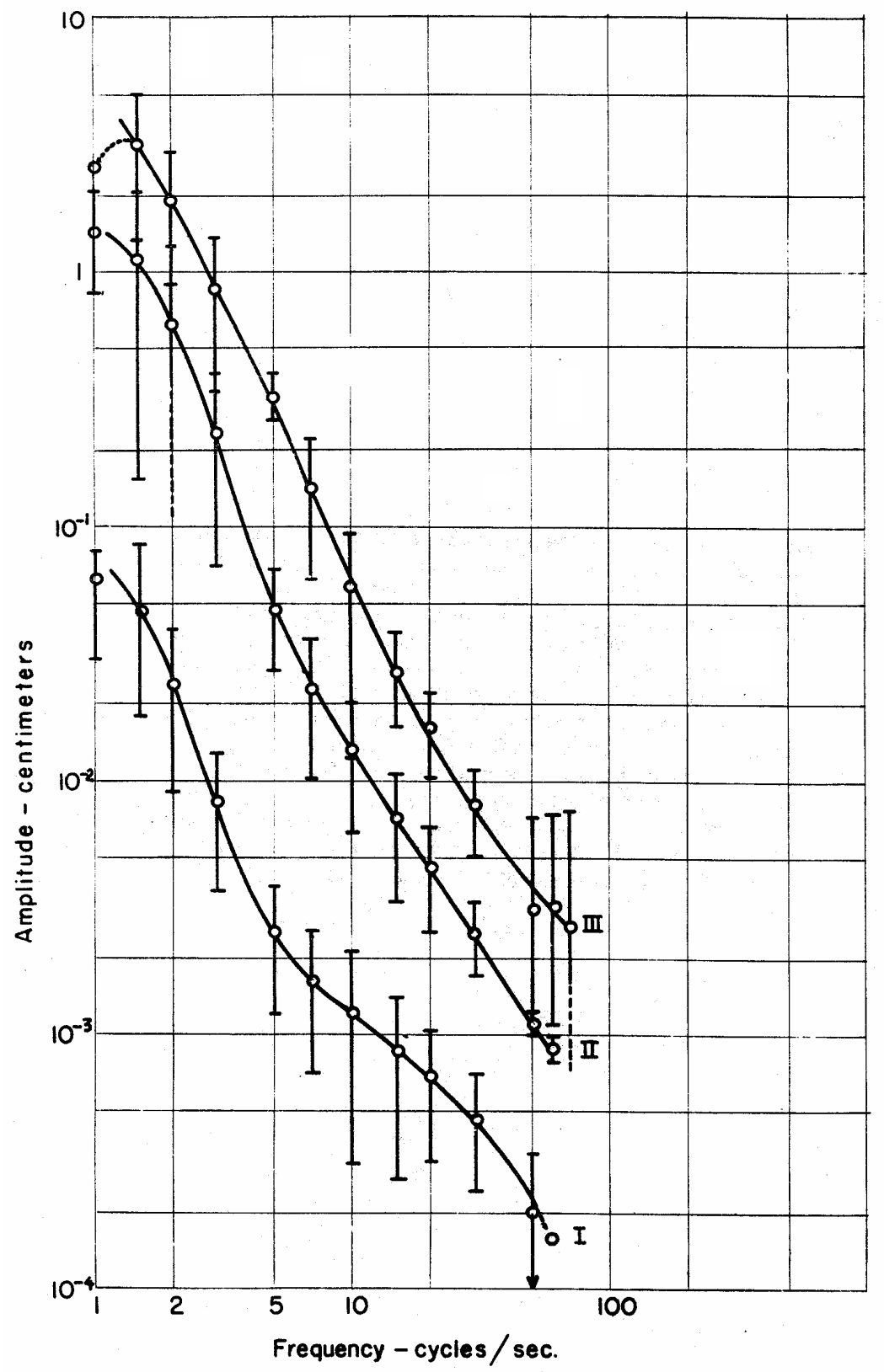

Figure 2.3. Average amplitude of vibration at various frequencies (Goldman, 1948) 


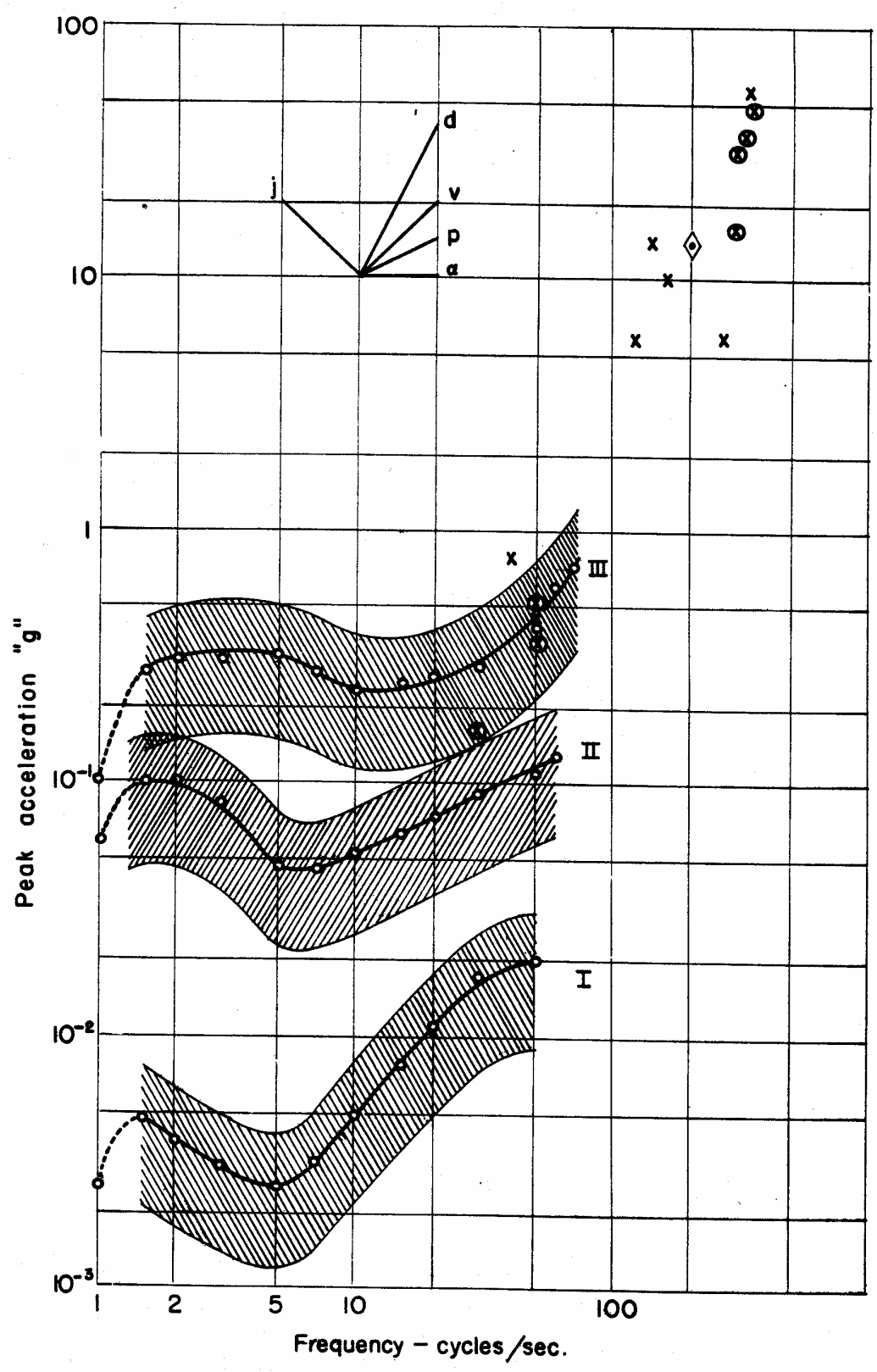

Figure 2.4. Average peak accelerations at various frequencies (Goldman, 1948) 


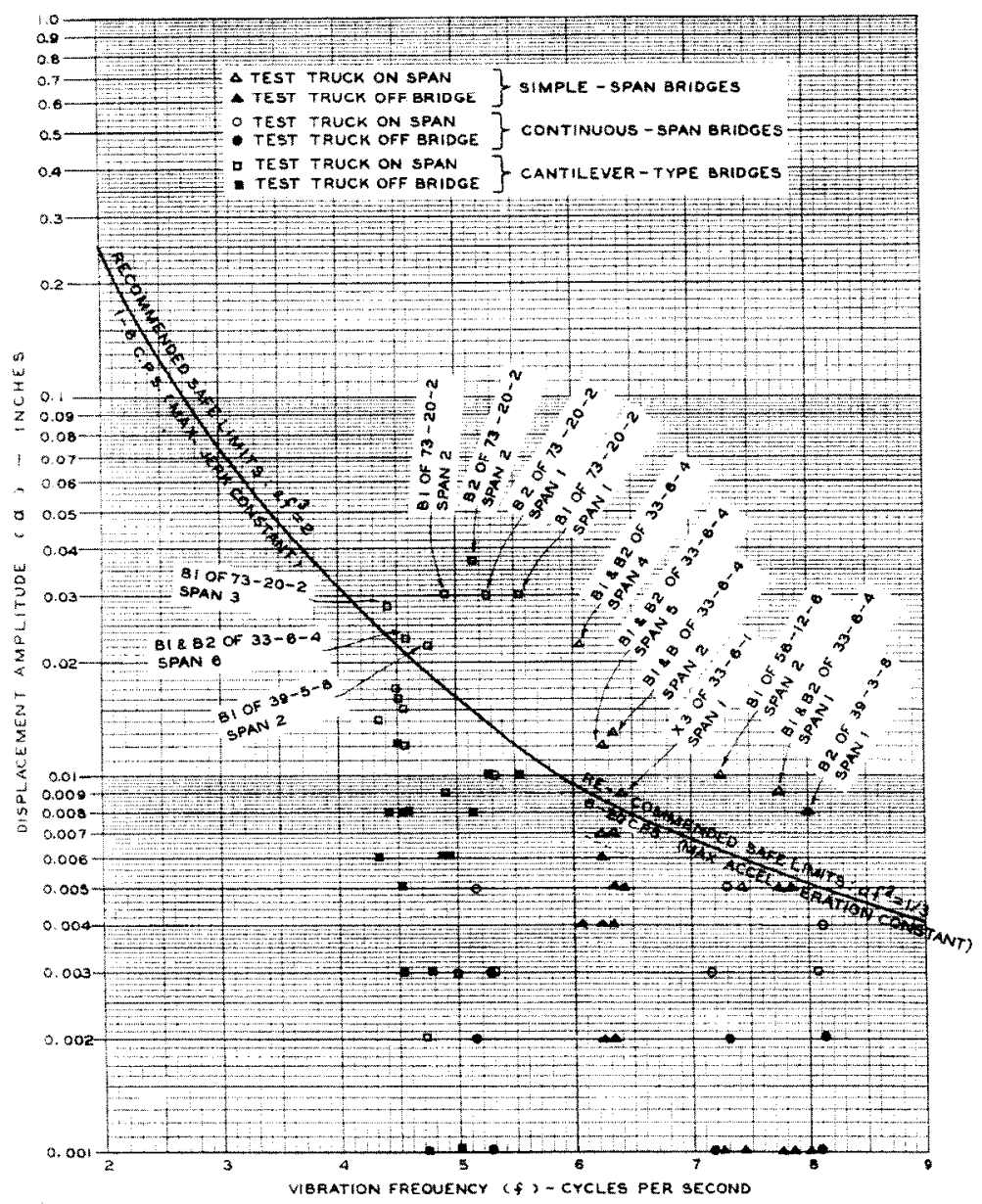

Figure 2.5. Observed amplitude and frequency of bridge vibrations compared with recommended safe limits by Janeway (Oehler, 1957) 


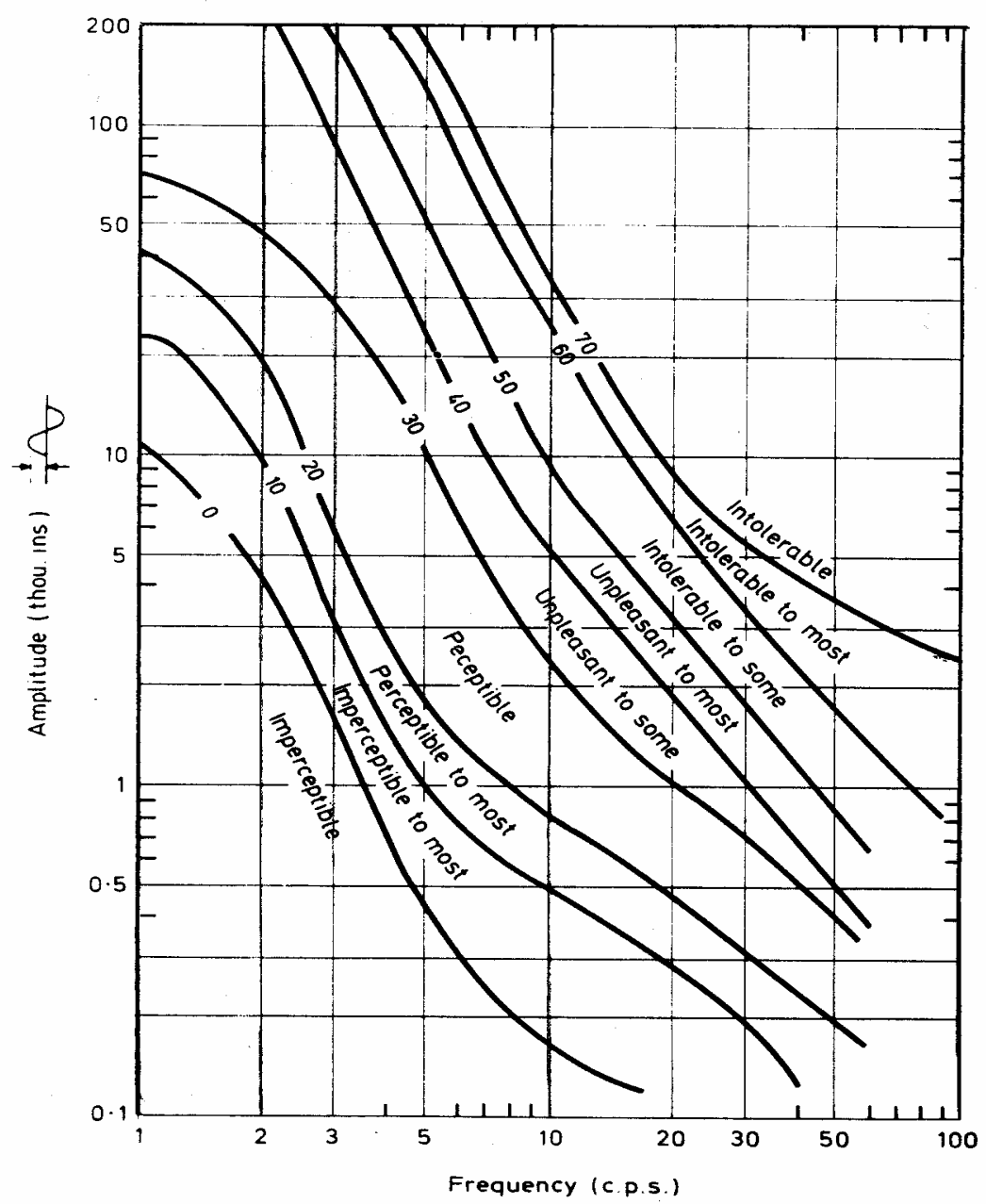

Figure 2.6. Contours of equal sensitivity to vibration - "isosensors" (Wright and Green, 1964) 


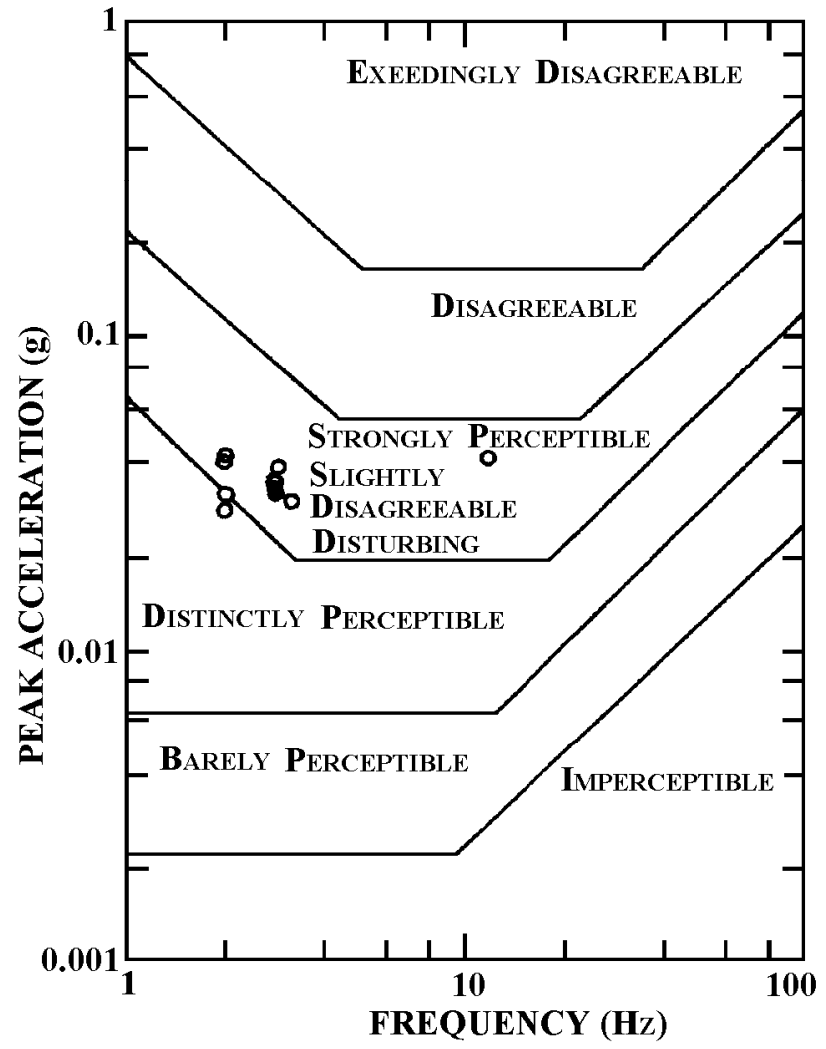

Figure 2.7. Measured acceleration compared to human tolerance limits by Bolt, Baranek and Newman (Dewolf et al., 1986) 


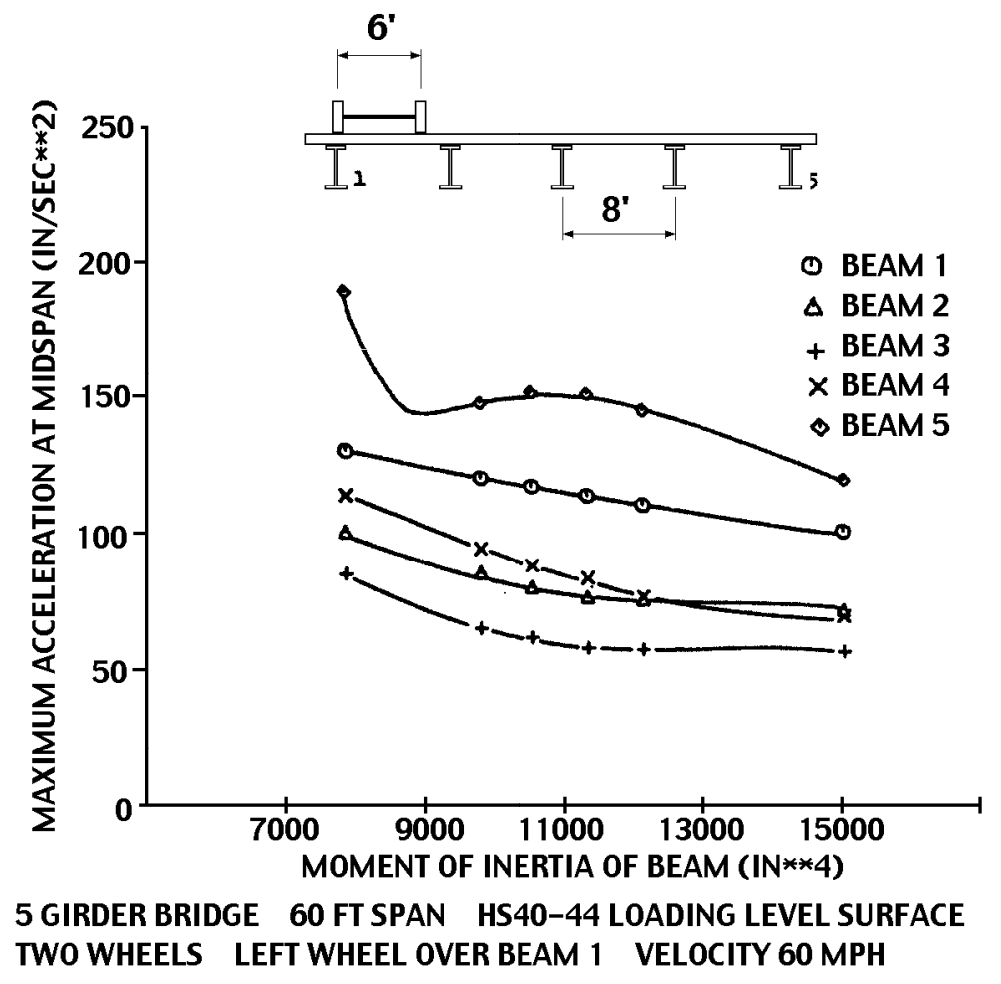

Figure 2.8. Effect of flexibility on acceleration (Aramraks, 1975) 


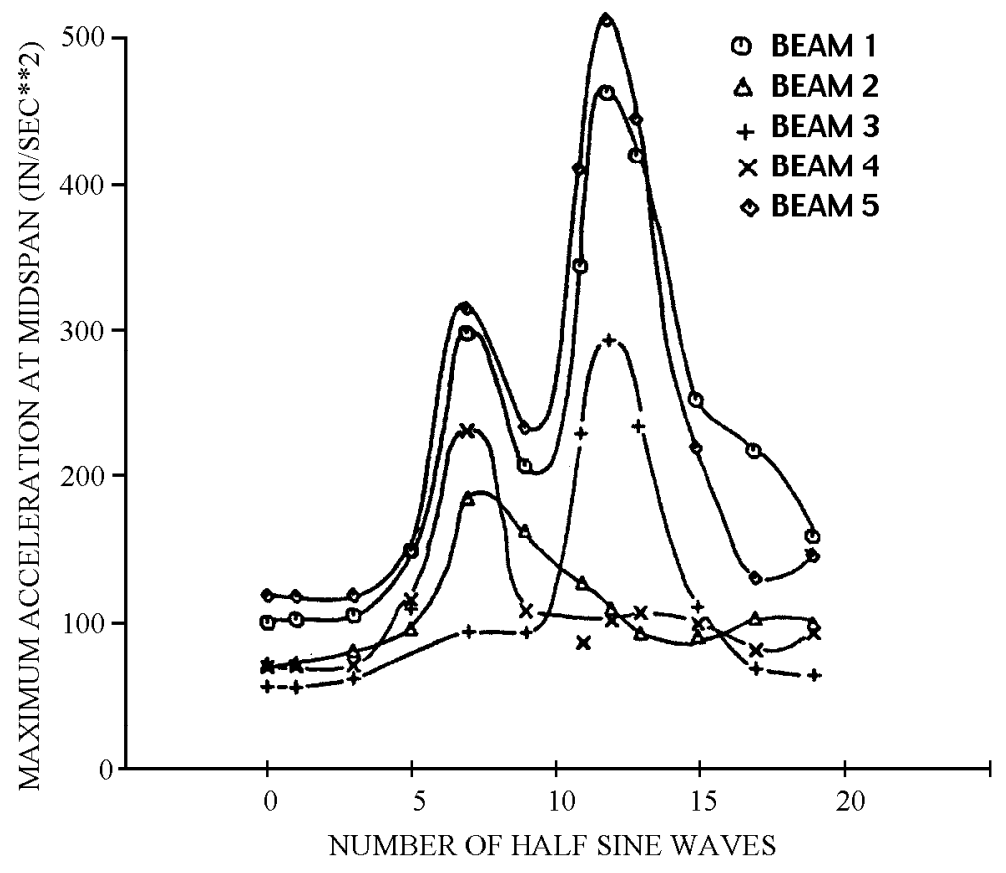

Figure 2.9. Effect of surface roughness on acceleration (Aramraks, 1975) 


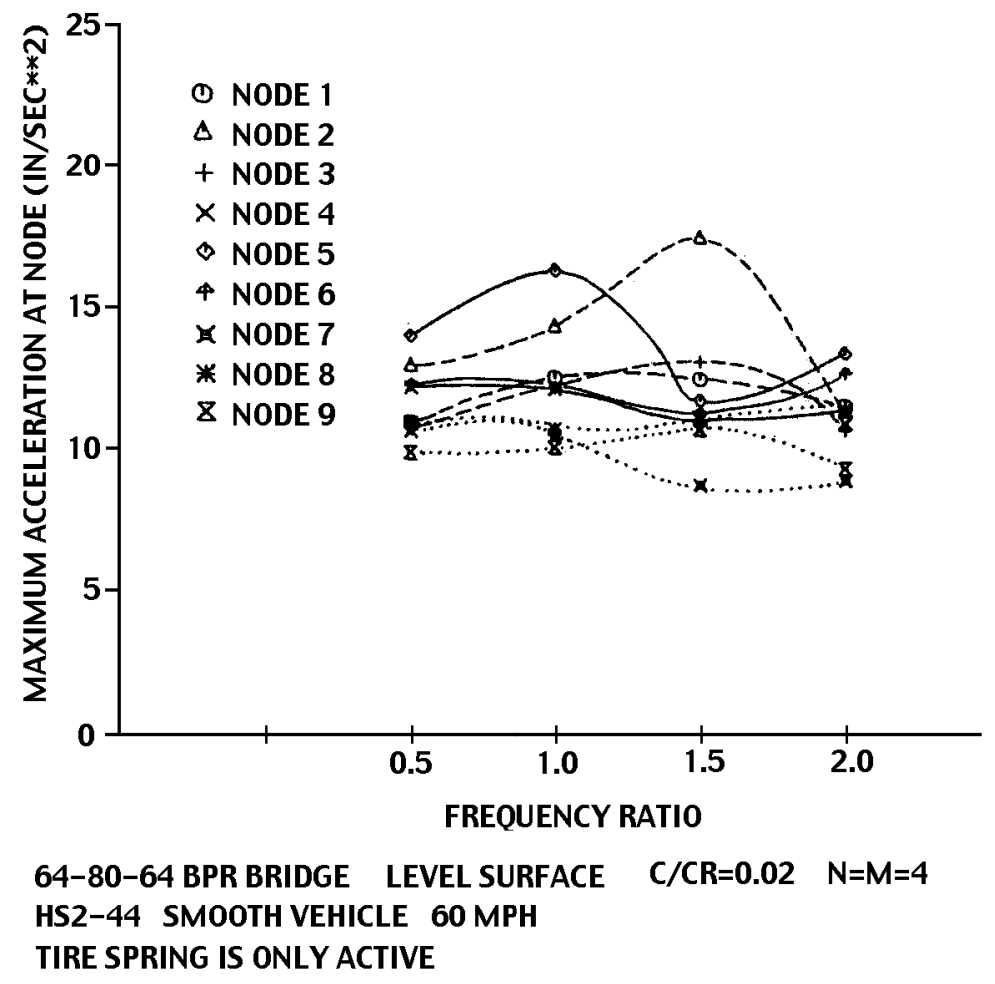

Figure 2.10. Effect of frequency ratio on acceleration (Aramraks, 1975) 


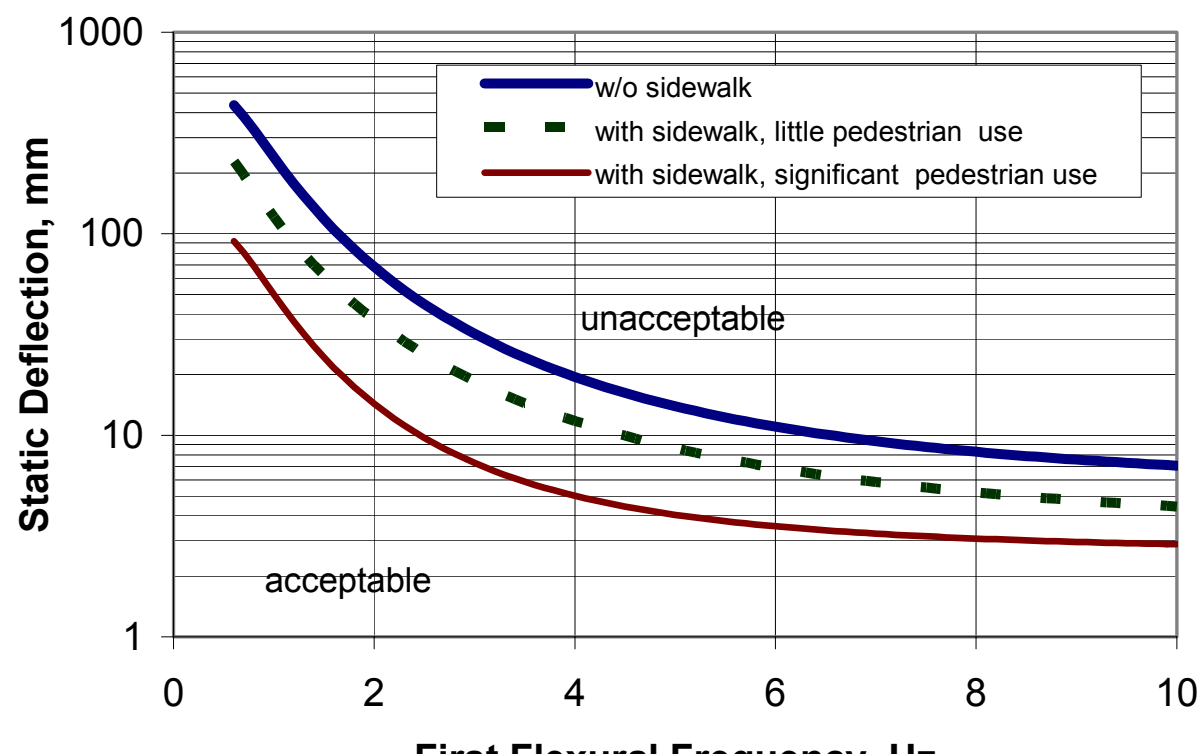

Figure 2.11. Deflection limitations

(Ministry of Transportation, 1991; CSA International, 2000) 


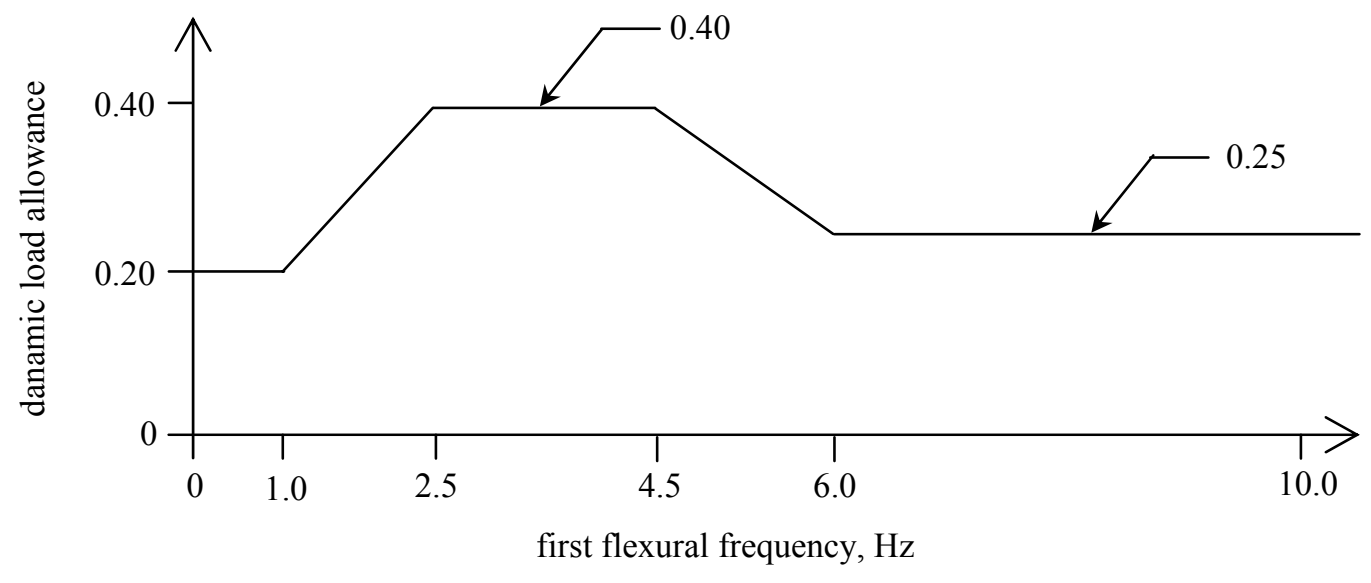

Figure 2.12. Dynamic load allowance (Ministry of Transportation, 1991 and CSA International, 2000) 


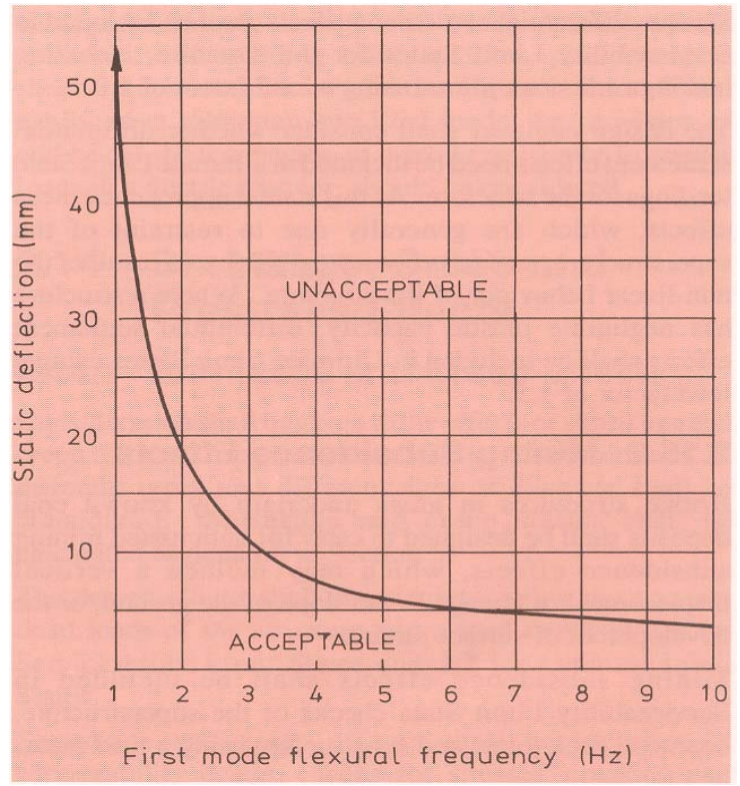

Figure 2.13. Deflection limits for vibration controls of Australian Codes (AUSTROADS, 1992; AUSTRALIAN, 1996) 


\section{CHAPTER 3}

\section{ON THE ESTIMATION OF NATURAL FREQUENCIES IN CONTIUNOUS SPANS: A LITERATURE REVIEW}

\subsection{Introduction}

It has been shown that the current AASHTO static-deflection based live-load deflection limits are not a suitable means to control live-load serviceability vibrations as originally intended, nor the deformations that cause structural damage. However, bridge engineers oppose elimination of the existing deflection limits until rationally developed, improved guidelines are available. Therefore, the need for more effective serviceability design specifications for user comfort and structural damage is obvious. It is the goal of this research to address this issue by developing recommended design specifications, that more accurately represent the functional criteria of this limit state.

Some foreign countries use the first natural frequency to assess superstructure live-load serviceability and control dynamic vibrations as shown in Figs. 2.11, 2.12 and 2.13 for the Canadian (Ministry of Transportation, 1991 and CSA International, 2000) and Australian Codes (AUSTROADS, 1992; AUSTRALIAN, 1996). However, no specific equations are provided regarding the calculation of the first flexural natural frequency in the OHBDC. Normally, for simple span bridges, Canada (Lam, 2002) and Australian Codes uses the simple beam equation (Eqn. 2.2); for more complicated structures with expected high dynamic characteristics, a more refined analysis may be needed.

Because the natural frequency is one of the major factors affecting the dynamic characteristics of highway bridges, careful consideration should be given to this topic. 
Results of field and analytical studies that focus on the natural frequencies of highway bridges are reviewed in this chapter.

\subsection{Dynamic Load Testing of Highway Bridges}

This section reviews field testing conducted to study the dynamic characteristics of composite steel stringer bridges. Details describing the bridges tested, load vehicles incorporated in the testing, instrumentation, and research results are given to the extent provided in the literature. Comparisons between field results and other empirical/ analytical methods are also provided where applicable.

\section{Foster and Oehler (1954)}

This study monitored the dynamic response of two bridges (Jackson Bridge and Fennville Bridge) under normal commercial traffic, a controlled two-axle truck, and a special three-axle truck. The Jackson Bridge was an eight-span plate girder bridge consisting of five simple spans and three spans of continuous beam designs. The Fennville Bridge consisted of six simple spans of rolled beam construction of which only one span exhibits composite action. Measured deflections were compared to theoretical predictions, and the effects of vehicle weight, vehicle type, axle arrangement, speed, and surface roughness on vibration characteristics were studied. Deck surface irregularities were simulated by boards placed on the bridge deck in the path of the test vehicle, which was found to cause increased amplitude of bridge vibration.

Results of these tests showed that computed deflections were consistently larger than the measured deflections, while computed frequencies were in good agreement with 
recorded data. Specifically, the frequency comparisons for 11 simple spans (58 ft. -5 in. to $84 \mathrm{ft}$. -3 in.) using the simple beam equation was found to be accurate within $0.2-4.3 \%$, but the frequency comparison for a continuous span had a $6.9 \%$ discrepancy. Furthermore, it was observed that increasing span flexibility increases the observed amplitude and duration of vibration. Vibrations increased when the natural period of vibration of the span nearly coincided with the time interval between axles passing a reference point on the span.

\section{Oehler (1957)}

Deflection and vibration measurements were recorded on 34 spans of fifteen bridges of 3 types (with and without composite action): simple-span, continuous-span and cantilever-type bridges. The vehicle used in this testing was a three-axle truck with axle weights of 5.6, 18.1, and 15.5 kips. Similar to the above study, comparisons between computed and measured frequencies of 11 simple spans with wide flange beams (span length of $44.8 \mathrm{ft}$. to $64.92 \mathrm{ft}$.) showed that the simple span frequency equations were quite accurate $(0.5-2.8 \%$ error). From the comparisons with the test data from 7 spans (from $39.33 \mathrm{ft}$. to $80.58 \mathrm{ft}$.) of 4 continuous-span bridges ( 2 non-composite steel bridges with uniform cross section and 2 reinforced concrete bridges), the numerical method suggested by Veletsos et al. (1957) was also shown to be accurate $(0.2-2.8 \%$ error) (see section 3.4 for a more detailed presentation of Veletsos's analytical procedure). 


\section{Linger and Hulsbos (1962)}

A correlation was presented between forced vibration theory and dynamic impact tests for a 4-span continuous bridge $(52.5+67.5+67.5+52.5 \mathrm{ft}$. $)$. The bridge has a 7.25 in. reinforced concrete (RC) slab supported by 4 wide flange steel stringers spaced at 4.5 ft. on center. Two load vehicles were used; vehicle A is an international L-190 van-type truck and vehicle B is a tandem axle, international VF-190 truck pulling a 36-ft. Monnon flat bed trailer. To experimentally determine the dynamic effect, static tests were first performed by moving the vehicle across the bridge at a very slow speed with the motor idling. The dynamic tests were conducted at vehicle speeds beginning at approximately $10 \mathrm{mph}$ and increasing by increments up to the maximum attainable speed. The amount of impact was a function of the ratio of the frequency of axle repetition to the loaded natural frequency of the bridge. The experimental frequency was $4.57 \mathrm{~Hz}$ and the theoretical method predicted $4.34 \mathrm{~Hz}$, including the effect of sidewalk curbs. The reduction in natural frequency due to the addition of vehicle mass was analyzed using an energy method.

\section{Wright and Green (1964); Green (1977)}

A group of 57 typical highway bridges in Ontario were selected for dynamic performance testing (Wright and Green, 1964). For each structure, one of two dominant frequencies of vibration was generally observed during the free vibration. In all cases the actual stiffness of the bridge was larger than conventional values of calculated stiffness, since the stiffening effect of parapet walls in beam and slab systems and the effects of the deck in truss systems were not included in frequencies calculated using the simple beam 
equation. As a consequence, the measured natural frequencies, $\mathrm{f}_{\mathrm{obs}}$, tended to be larger than calculated frequencies, $\mathrm{f}_{\text {cal }}$, (computed using Eqn. 2.2) as shown in Fig. 3.1. The following equation was suggested to correct this discrepancy, which was validated for structures with $\mathrm{f}_{\text {cal }}$ in the range of 2 to $7 \mathrm{~Hz}$,

$f_{\text {obs }}=0.95 f_{\text {cal }}+0.72$

(Eqn. 3.1)

where the frequency values are in Hz. For the calculated frequencies in the typical range of 2 to $5 \mathrm{~Hz}$, the differences between measured and computed values ranged from $9.4 \%$ to $32.5 \%$.

\section{Varney (1973)}

The first instance in the U.S. of dynamic testing of horizontally-curved bridges was tested in 1973 by using two identical harmonic force generators on a simple-span bridge and a 2-span continuous bridge. The simple span bridge had a span length of $95 \mathrm{ft}$. on a $163 \mathrm{ft}$. radius and a $7.5 \mathrm{in}$. RC slab supported by 4 steel girders spaced at $8 \mathrm{ft}$. The 2 span continuous bridge had equal span length of $200.25 \mathrm{ft}$. on a $265.5 \mathrm{ft}$. radius and a 7.5 in. RC slab supported by 5 steel girders spaced at $7.75 \mathrm{ft}$. Both bridges were designed for HS20-44 loading and were A36 welded steel girder structures. One vibration generator was located in each traffic lane and they were operated either in-phase or out-of-phase as necessary to develop the normal and torsional natural models of the bridges. The response during excitation was monitored by accelerometers, strain gages and deflection gages at various locations on the bridges. The first two observed natural frequencies of the simple span bridge were 4.0 and $6.3 \mathrm{~Hz}$; these values were compared to the first frequency of $4.9 \mathrm{~Hz}$ obtained from the computer program BOUNCE. The first three 
observed natural frequencies of the two-span bridge were 3.2, 4.8 and $6.3 \mathrm{~Hz}$, respectively, while BOUNCE gave the first frequency to be $3.8 \mathrm{~Hz}$.

\section{Kropp (1977)}

Dynamic responses of 40 steel, $19 \mathrm{RC}$ and 3 pre-stressed concrete bridges with span lengths from $27 \mathrm{ft}$. to $129 \mathrm{ft}$. were measured under normal traffic and loaded with a 21 kip (6.760 kips - front axle and 14.240 - rear axle) test vehicle with $23 \mathrm{ft}$. wheel base (Kropp, 1977). Bridges were instrumented with accelerometers mounted on the curbs of the deck near the middle of each span. Deflection responses were also measured at a single location for each bridge. The deflection gage was installed adjacent to an accelerometer so that corresponding acceleration and deflection record could be generated for the same point. More than 13,000 deflection and acceleration records corresponding to over 2200 vehicle crossing were recorded. Due to the time constraints, only 900 vehicle crossing records were selected for analysis, of these approximately 65 percent were for normal trucks, 30 percent were for the test vehicle and 5 percent were for various light vehicles. Steel bridges exhibited generally higher responses (acceleration levels were about twice as large) than those of reinforced or prestressed concrete. Both non-composite and composite bending natural frequencies were calculated by the developed program for dynamic analysis of the bridges. Measured frequencies compared moderately with analytical predictions and were used to determine the degree of composite action. There were only 5 instances in the entire testing program where a single vehicle crossing produced an acceleration larger than $100 \mathrm{in} / \mathrm{sec}^{2}$, the 
comfort limit proposed by Wright and Walker (Wright and Walker, 1971) (see section 2.4.4).

\section{Conn (1994)}

Vibration monitoring was conducted under ambient traffic by using 16 accelerometers, two cluster boxes (each controlling 8 accelerometers) and a sentry unit with a computer to process data from the accelerometers for a three-lane, two-span continuous bridge ( $96+96 \mathrm{ft}$.). This bridge consisted of a 7 in. RC slab supported by 7 welded steel plate girders with intermediate girder spacing of $6.75 \mathrm{ft}$., two side girder spacing of $6 \mathrm{ft} .-4$ in and $2 \mathrm{ft}$. overhangs. Natural frequencies, mode shapes, and the effect of temperature on the bridge's behavior and vibration response were measured. Two different experiments (Smart meter and Vibra-Metrics) both gave the $1^{\text {st }}$ bending, $1^{\text {st }}$ torsional and $2^{\text {nd }}$ bending modes of the bridge of 3.6, 4.2 and $5.2 \mathrm{~Hz}$, respectively. These results were compared to the fundamental frequencies from two analytical methods: solving a beam vibration equation and FE beam analyses. The beam vibration equation method gave $1^{\text {st }}$ bending in the range of 3.2 to $4.2 \mathrm{~Hz}$ and $2^{\text {nd }}$ bending in the range of 5.0 to $6.6 \mathrm{~Hz}$. The FE beam analysis gave $3.8 \mathrm{~Hz}$ and $6.2 \mathrm{~Hz}$ for the $1^{\text {st }}$ bending and $2^{\text {nd }}$ bending frequencies, respectively. Results of this work illustrated the apparent effect of temperature on natural frequency (adding axial force in the members) and the temperature only changed the frequencies for values between 0 to 60 degrees in Fahrenheit. Analytically, a temperature drop of 60 degrees produced up to a $5 \%$ increase in the natural frequencies, but a $10 \%$ to $13 \%$ change was obtained experimentally. 


\section{Paultre, Prouix and Talbot (1995)}

Field testing was conducted for a $233 \mathrm{ft}$. skewed bridge, consisting of a concrete slab supported by four steel girders, to evaluate the dynamic amplification factor and the natural frequencies. Both ambient and controlled traffic were used to provide excitation to the bridge. Ten-wheel trucks (54 kips) and trailers (29.2 kips - 40.5 kips) were used for controlled traffic. A total of 30 - 40 vehicle runs were carried out at various speeds and positions on the deck. Accelerometer locations were selected to obtain as many mode shapes as possible. The first four experimental frequencies were found to be $2.34,2.48$, 5.01 and $5.30 \mathrm{~Hz}$, compared to 3D FEA results giving 2.34, 2.45, 5.26 and $5.30 \mathrm{~Hz}$, respectively.

\section{Wolek, Barton, Baber and Mckeel (1996)}

Dynamic field testing was conducted under normal traffic loads for a simple span bridge that had substantial cracking in the parapets and minor cracking in the deck, indicating possible deterioration of the structure, possibly due to excessive vibration. The bridge had a span length of $106.5 \mathrm{ft}$. with a 8.5 in. RC concrete deck on 4 steel girders spaced at $8 \mathrm{ft}$. Ten accelerometers and six strain gages were positioned on the deck with accelerometers placed at the $0.25 \mathrm{~L}, 0.375 \mathrm{~L}, 0.5 \mathrm{~L}, 0.625 \mathrm{~L}$ and $0.75 \mathrm{~L}$ points and strain gages placed at the $0.25 \mathrm{~L}$ and $0.5 \mathrm{~L}$ points of the span (where $\mathrm{L}$ is the span length). Natural frequencies, mode shapes and damping characteristics were determined. All of the dominant natural frequencies were within the frequency range of 2 to $5 \mathrm{~Hz}$. The first measured bending natural frequency was $2.73 \mathrm{~Hz}$, which had 5 times greater contribution to the total response than that of the next largest mode. Structural damping for this bridge 
was very low, approximately 0.5 percent, which may be attributed to the frozen bearings this bridge exhibited. The importance of separating out the load-structure interaction frequencies from the natural frequencies of the bridge before attempting to identify the mode shapes is noted. Static design methods neglect the reversal stresses from the dynamic loading, which places the concrete deck in a state of tension after the initial compressive response. However, during the transient response, that first tensile stress may reach levels close to the initial compressive stress, which may lead to deterioration and cracking in the deck and parapets.

\subsection{Formulation of Natural Frequency Equations for Highway Bridges Based on Field Testing}

This section reviews field testing conducted to develop the empirical expressions for the first bending natural frequency of composite steel stringer bridges. Scope of these works and the limits of these expressions are discussed.

\section{Wood and Shepherd (1977)}

Vertical fundamental frequencies were measured on 8 slab-on-steel-stringer bridges with varying span lengths, number of spans, and continuity conditions. Six of these 8 bridges had frequencies in the 2 to $5 \mathrm{~Hz}$ range. Based on a linear best fit, Wood and Shepherd developed the following expression as a function of span length (L)

$f=-0.21 L+10.3$

This expression provides an inadequate representation of frequency compared to the testing data shown in Fig. 3.2. 


\section{Billing (1980); Billing and Green (1984)}

Dynamic testing was conducted for 27 structures (12 steel spans of 65.6 to 400.3

$\mathrm{ft}$, 10 concrete spans of 52.5 to $134.5 \mathrm{ft}$., and 3 timber spans of about $16.4 \mathrm{ft}$.) by using both test vehicles and normal traffic crossing the spans at a variety of speeds. Each test vehicle made a run driving at $10 \mathrm{mph}$ in each traffic lane and closely beside the righthand barrier wall or curb. Six Bruel and Kjaer 8160 seismic accelerometers were placed on the curb or beside the barrier walls of a bridge. The acceleration values recorded on the frequency modulation (FM) tapes were used to determine frequency, mode and damping ratio. Linear regression was used to develop the frequency equation

$f=\frac{110}{L_{\max }} \quad$ where $L_{\max }=$ maximum span length (in meters)

Although there is a clear relationship between first flexural frequency and longest span length, with little data for various bridge types it is unreasonable to suggest a simple relationship between frequency and span that could be codified. However, a simple relationship such as that in Eqn. 3.3 may be useful for preliminary estimation of frequency during design.

The Reiher and Meister descriptions (1931) were used to evaluate the human response by the subjects standing on the bridge. All subjects were accustomed to vibration of bridges. Subjects proved well able to distinguish significantly different vibration levels of consecutive trucks, but were not consistent in assigning an absolute rating to a particular acceleration level. 


\section{Cantieni (1983); Cantieni (1984)}

Dynamic testing of 226 bridges was conducted through passage of a single, fully loaded two-axle truck. Two hundred five (90.7\%) bridges were prestressed concrete bridges, 109 of these were straight and without skew, 97 bridges were skewed or curved and 20 bridges were both skewed and curved. $71.7 \%$ bridges were continuous beams, $48.2 \%$ were three spans, $41.6 \%$ bridges were box girders. Maximum span ranges were from $33 \mathrm{ft}$. to $356.4 \mathrm{ft}$. The test vehicle was driven at constant speed (18.75 mph to 25 mph) whenever possible. $29 \%$ of the testing bridges have the natural frequencies of about $3 \mathrm{~Hz}$ and the mean natural frequency is $3.6 \mathrm{~Hz}$. From nonlinear regression analyses of the experimental data using the program NLWOOD, Cantieni developed the expression

$f=95.4 \times L_{\max }^{-0.933}$

as shown in Fig. 3.3. The scatter of the measurement values around the regression curve (standard deviation $\sigma_{f}= \pm 0.81 \mathrm{~Hz}$ ) is considerable because of large variation in geometry and stiffness of the bridges. Alternatively, the following expression (Cantieni 1984) was proposed,

$f=\frac{100}{L[m]}+0.6=\frac{328}{L[f t]}+0.6$

which also has $\sigma_{f}= \pm 0.81 \mathrm{~Hz}$. In order to reduce the standard deviation, results from 100 of the above bridges with more similar geometry were considered after eliminating: structures that included cantilever constructions, data not measured from the maximum span, and bridges with horizontal radius of curvature less than $2953 \mathrm{ft}$. As a result, the following equation was proposed, which has $\sigma_{f}= \pm 0.61 \mathrm{~Hz}$

$$
f=90.6 \times L_{\max }{ }^{-0.933}
$$


The authors also state that the following formula is attractive, but yields fundamental frequencies that are too low

$f=100 / L_{\max }$

\section{Tilly (1986)}

Measurements of the fundamental flexural frequencies were conducted for 871 highway bridges, 16 bridges in Brussels, 630 bridges from Liege and 225 bridges from Switzerland. Most of these were concrete highway bridges. The bridges had span lengths from 65 to $525 \mathrm{ft}$., but only about 16 bridges had span lengths greater than $262.5 \mathrm{ft}$. From a nonlinear regression analysis, the following expression was developed (see Fig. 3.4), having a correlation coefficient of 0.83 ,

$f=82 \times L_{\max }{ }^{-0.9}$

where

$$
L_{\max }=\text { maximum span length in meters }
$$

\section{Dusseau (1996); Dusseau (1998)}

Field ambient analyses were conducted for 25 typical spans from 12 different highway bridges located in southern Missouri, which included 17 spans from 8 steel girder bridges with lengths ranging from 203 to $242.8 \mathrm{ft}$. Ambient vibration measurements were taken by using 8 seismometers installed on only one of the bridge sidewalks or shoulders. The signal output was amplified and recorded on an FM tape recorder. A spectrum analysis and a FFT were also performed. Dusseau proposed the 
following empirical formula for estimating the vertical frequencies based on the results of the 17 steel girder spans.

$$
f=588.118 D_{s}^{-0.4} L^{-1.45}
$$

where

$$
\begin{aligned}
& D_{s}=\text { steel girder depth } \\
& L=\text { span length }
\end{aligned}
$$

This formula was only moderately accurate (within 6.3\%) compared to field-measured frequency values for 4 of 17 spans; 8 of 17 spans were within 12.5\%, and all 17 spans with $48.0 \%$. Only 3 spans were more than $30 \%$ different.

\subsection{Formulation of Natural Frequency Equations for Highway Bridges Based on Analytical Efforts}

This section reviews analytical efforts (including Rauleigh-Ritz method, other rigorous approximated method as well as finite element analysis) conducted to develop the formulation for the natural frequencies of continuous span beams and continuous span bridges. Scope of these works and the limits of these formulations are discussed.

\section{Saibel (1940)}

A method was developed for finding the natural frequencies of vibration of a continuous beam from a knowledge of the natural frequencies and natural modes of a ordinary beam supported at the inner points of support in the same manner as the continuous beam but not subjected to any of the constraints between the ends, and the applied end conditions. An example illustrating this method to calculate the natural frequencies for a 2-span continuous beam was provided. 


\section{Looney (1954)}

A procedure was described to determine the modes of free vibration using the reciprocal theorem and Muller-Breslau's principle as applied to a steady state forced vibration. Free vibrations of continuous structures occurred with periodic moments at the ends of the members. The general requirements were that the periodic end moments and the end slopes be equal at all times. The relative values of the end moments and the frequencies were found by equations similar to slope deflection equations. This procedure was reviewed by Biggs (Biggs, 1964) as a complicated analytical work.

\section{Hayes and Sbarounis (1956)}

The following natural frequency equation was developed for 3-span continuous beams, based on a procedure similar to the Rayleigh-Ritz method suggested by Darnley (Darnley, 1921) to solve the periods of the transverse vibrations of continuous beams

$$
f=\frac{C}{L_{1}^{2}} \sqrt{\frac{I}{w}}
$$

where

$L_{1}=$ length of the end span in feet

$C=$ a coefficient depending upon the ratio $L_{2} / L_{1}$

$I=$ moment of inertia in in ${ }^{4}$

$w=$ weight of the beam in pounds per foot

A plot was also provided that gives the coefficient $\mathrm{C}$ vs. the side and middle span ratio $L 2$ / $L 1$. Dynamic field testing was also conducted to study vibration characteristics for a three-span continuous I-beam highway bridge $(65.5+75+65.5 \mathrm{ft}$. $)$ with a width of $30 \mathrm{ft}$. The bridge was designed as a non-composite bridge and had a 7 in. concrete slab on six 33WF130 stringers. The effects of percentage of composite action on natural frequency 
were studied both with and without consideration of the mass of the test truck. The following recommendations for considering the vibration problem were proposed.

- Determine the natural frequency of the bridge by considering the effect of the live load,

$$
f=\frac{C}{L_{1}^{2}} \sqrt{\frac{I}{w+\frac{2 w_{L}}{L}}}
$$

where

$w_{L}=$ Total weight of truck loading on the bridge in pounds

$L=$ Total length of the bridge in feet

- Choose the critical axle spacing and vehicle velocity for the site of the bridge and determine the frequency due to the application of this axle loading to points in the bridge. Increase the frequency of the application of axle loadings for a suitable safety margin with respect to resonance. A division factor of 0.8 should give an adequate safety margin, and

- If the bridge frequency is greater than the corrected frequency due to the application of axle loading, the vibration will not be serious. Otherwise, the stiffness of the bridge may have to be increased.

\section{Veletsos and Newmark (1957)}

A numerical method was proposed for determining the undamped natural frequencies of straight continuous beams on rigid supports. Numerical values for the various physical constants which were necessary in the analysis were tabulated. The members composing the structures were considered to be uniform in cross section and mass per unit length, but they may vary from one span to the next. The effect of shear deformation and torsional inertia were considered negligible. This procedure involved considerable computation, but was proven to be very accurate in frequency comparisons 
between analysis and field testing for three 3-span slab-on-steel-girder bridges (Oehler 1957).

\section{Yamada and Veletsos (1958)}

Two different methods of solution were proposed to obtain numerical solutions for the natural frequencies and modes of vibration of a number of simple-span, right, Ibeam bridges; Poisson's ratio for the slab was assumed equal to zero in both methods. In the first method the structure was analyzed as a plate continuous over a series of flexible beams using the Rayleigh-Ritz energy procedure. Equations to calculate the natural frequencies were presented. It was assumed that there is no horizontal shearing force or friction force between the slab and the beams. The effect of composite action could be considered in an approximate manner by modifying the stiffness of the supporting beams. In the second method, the structure was idealized as an orthotropic plate and a numerical solution was obtained from an exact solution of the governing differential equation. There was assumed to be no transfer of horizontal shear between the plate and the stiffening beams, the mass of the beams was assumed to be negligible in comparison to the slab. The authors state that the frequencies determined by the orthotropic plate theory may be sufficiently close to those of actual structures.

\section{Lee and Windover (1966)}

The investigation was particularly focused on the natural frequency of isotropic, elastic plates, with two parallel edges free, for simple span and two-span continuous plates, simulating highway slab bridges. From this study an approximate design method 
was developed for calculating the fundamental frequency of this and other types of continuous span highway bridges. The following procedure was proposed to predict the natural frequency and the factors $r, r^{\prime}, r_{2}$ and $r_{3}$ can be obtained from provided figures. $r$ is a function of the ratio of width/span, $r$ ' is a function of the ratio of width/longer span, an $\mathrm{d} r_{2}$ and $r_{3}$ are a function of the ratio of span ratio.

- The simple beam frequency $f_{s b}$ from Eqn. 2.2 is modified by the factor $r$ to allow for the effect of width,

$$
f_{s s}=r f_{s b}
$$

- For a 2-span continuous beam the frequency may be calculated from step 1 by multiplying by a factor $r^{\prime}$, and

$$
f_{2 c s}=f_{s s} r^{\prime}
$$

- For a three span continuous structure with equal end spans the frequency may be obtained by multiplying by factors $r_{3}$ and $r_{2}$.

$$
f_{3 c s}=f_{2 c s}\left(\frac{r_{3}}{r_{2}}\right)^{2}
$$

Two examples (Oehler, 1957) were shown to calculate the natural frequency for a simple span bridge and a 3 -span continuous bridge.

\section{Biggs (1964)}

A three-moment equation was developed to obtain the natural frequencies of normal modes for continuous beams with uniform mass distribution and stiffness, based on the characteristic shape of the nth mode for one of the spans and the boundary conditions. One equation was written for each support moment and the result was a set of simultaneous equations. In order for any vibration to be possible, the determinant of the 
coefficients of the support moments must be zero. Expanding this determinant led to the frequency equation. Examples were provided for 2-span, 3-span and 4-span continuous beams.

\section{Csagoly, Campbell and Agarwal (1972)}

Dynamic behavior of post-tensioned, concrete slab, continuous bridges was investigated by using lumped mass models in the STRUDL II computer program. The accuracy of the program has been tested against known theoretical solution (Biggs, 1964) to calculate the natural frequency coefficients and mode shapes of particular structural configuration, which is a symmetric 5 -span continuous beam with 0.5 for $L_{2} / L_{3}$ and 0.25 for $L_{1} / L_{3}$ ( $L_{3}$ middle span, $L_{2}$ intermediate span and $L_{1}$ end span). In addition the computer predictions have been compared with results from field tests on three posttensioned concrete slab bridges.

The span ratio of the adjacent spans was determined to be the dominant parameter effecting natural frequencies of continuous bridges in this work. A change of moment inertia over short length in the region of the supports has only a small influence on the natural frequencies of a continuous beam. Good agreements for the frequencies were observed between the field testing and beam idealization prediction for the three existing concrete slab bridges. Live-load deflections do not appear as significant parameters as far as dynamic response of highway bridges are concerned. First mode natural frequency is suggested to be greater than 5 cycles per second for the vibration control, which was not the most economic design as far as the static behavior was concerned. A limitation was put on the range of the natural frequency $f$, which can be shown to be equivalent to 
limiting the dead load deflection. However, this suggestion won't be practical for steel bridges, which may have much lower natural frequencies than concrete bridges.

$f=2 \frac{e_{1}^{2}}{\pi \times L^{2}} \sqrt{\frac{E I g}{w}} \geq 5$

where

$e_{1}=$ the first mode eigenvalue

The above equation can also be written in the form

$\eta=\left(\frac{100 \pi^{2}}{g e_{1}^{4}}\right)\left(\frac{w L^{4}}{E I}\right) \leq 1.0$

where

$\eta=$ the coefficient of vibration

\section{Gorman (1975)}

By solving the differential equation governing the free vibration of uniform beams that expresses equilibrium between inertia forces and elastic restoring forces, Gorman proposed a procedure to calculate the natural frequencies of the beams subjected to prescribed boundary conditions: both classical boundary conditions such as simply supported and nonclassical boundary conditions such as rotational spring support et al. Eigenvalue tables are provided to calculate the natural frequency. This procedure will be reviewed in detail in section 6.2.3.

\section{Billing (1979)}

A parametric study was conducted using the computer program BEAMOD, which utilizes a lumped mass method, to develop normalized tables and plots of natural 
frequency factors of symmetric, multi-span continuous and simply-supported, uniform beams having 2 to 6 spans with varied span ratios. A procedure for estimation of the natural frequencies of bridges was presented by multiplying the base frequency calculated from the simple beam equation, $f_{s b}$, (Eqn. 2.2) with frequency factors $\phi_{k}$ from these tables.

$f_{k}=f_{s b} \phi_{k}$ for $\mathrm{k}=1,2,3, \ldots \ldots$

Four continuous span bridges were used as examples to illustrate this procedure. These were a 3-span bridge with pre-stressed concrete (PC) deck on 4 steel plate girders, a 3span cast-in-place, segmental PC construction bridge, a 5-span post-tensioned concrete voided slab and a 5-span concrete deck on 2 steel box girders.

\section{Memory, Thambiratnam and Brameld (1995)}

Comparisons of natural frequencies obtained from field observations and theoretical idealizations by applying the Rayleigh method to a grillage model were conducted. The effects of using the static and dynamic modulus of elasticity of concrete in estimating the natural frequency is also evaluated. Additionally, the significance of certain types of support stiffness on the estimation of the fundamental frequency is debated.

Results of this work suggest that for straight, non-skewed bridges of approximately uniform mass and stiffness, a simple beam idealization (Eqn 2.2) will usually underestimate the natural frequency on the order of $5 \%$. For straight, continuous bridges which are longitudinally symmetric, a single beam idealization, in conjunction with adjustment factors (Billing, 1979), will yield estimates within 10\%. For 
longitudinally asymmetric or skewed, continuous bridges the only recommended method was an eigenvalue analysis of a finite beam element grillage. For simply supported structures where supports were fixed, various grillage analyses demonstrated that the frequencies significantly increased with the increase in skew. The application of the Rayleigh procedure to half of one of the central girders was theoretically accurate, regardless of transverse support conditions.

\section{Finite Element Analysis for the Natural Frequencies}

Various researchers (Deger et al., 1995; Ventura et al., 1996; Wolek et al., 1996, Barefoot et al., 1997; Issa et al., 2000; Martin et al., 2000; and Buckler et al., 2000) have investigated the use of FEA to study the natural frequencies and dynamic response of highway bridges using various commercial packages. These efforts will be reviewed in more detail in the subsequent chapter, together with the proposed FEA modeling tools that will be used in the natural frequency parametric study.

\subsection{Summary of Previous Works}

Previous and present research show that the existing AASHTO live-load deflection limits are not a rational method to guarantee live-load serviceability. Resonances of bridges are very possible when the ratio of the vehicle frequency to the bridge frequency approach unity. Foreign bridge specifications contain improved liveload serviceability criteria that are based on the relationship between the maximum static deflection, including the live-load dynamic allowance, and the first natural frequency to 
control dynamic vibrations. However, no guidelines are provided in these specifications for calculation of the first natural frequency.

While several previous investigators have conducted studies to develop empirical expressions to better predict the natural frequency for typical highway bridges, these have been limited in scope, often focused on a narrow range of parameters, and none of the resulting expressions are suitable for design specifications. Also, various analytical models are available to predict the natural frequencies of continuous span beams or continuous span bridges. While most of these are valuable for specific cases, they are of little use for design or too complicated to be applied by practical engineers. No studies discussing dynamic characteristics of HPS bridges are available from the literature.

The results of several studies have shown that frequency is closely related to span length. However, empirical expressions (Billing, 1979; Billing, 1984; and Wood, 1977) including only one parameter (span length) and based on limited field testing data are not accurate enough to reliably predict the natural frequency. The expressions developed by Cantieni $(1983,1984)$ and Tilly (1986) are based on a large sample of dynamic testing data of predominantly concrete bridges; therefore, these equations are not suitable to predict the natural frequency of slab on steel stringer bridges. Only one frequency expression (Dusseau, 1996; Dusseau, 1998) considered more than one parameter: span length and steel girder depth. However, this equation was based on a limited scope of data and was found to have only moderate accuracy. The effects of length ratio on the natural frequencies have been shown for 3-span continuous beams (Csagoly et al., 1972) and for various span configurations (Billing, 1979). However, some of these span ratios are not economically practical for typical bridge designs. The effect of sidewalks and 
parapets should also be considered (Green, 1977; Ventura, 1996; and Barefoot, 1997) to accurately predict the first natural frequency.

Finite element analysis is now widely recognized as a powerful and versatile analytical tool and it has been shown to very efficiently predict bridge vibration characteristics (Ventura et al., 1996; Barefoot et al., 1997; Issa et al., 2000; Martin et al., 2000, and Buckler et al., 2000). Meanwhile, the effects of a range of variables on natural frequencies can be very conveniently investigated in FEA models, such as effects of steel strength, parapets, girder spacing, number of girders, and the bridge width, which are practically impossible to investigate by conducting large scope field testing. Thus, there is a practical need to conduct a broad, FEA parametric study to develop more rational natural frequency expressions which can be suitable used in design specifications. FEA modeling tools developed for this purpose are described in the following chapter. 


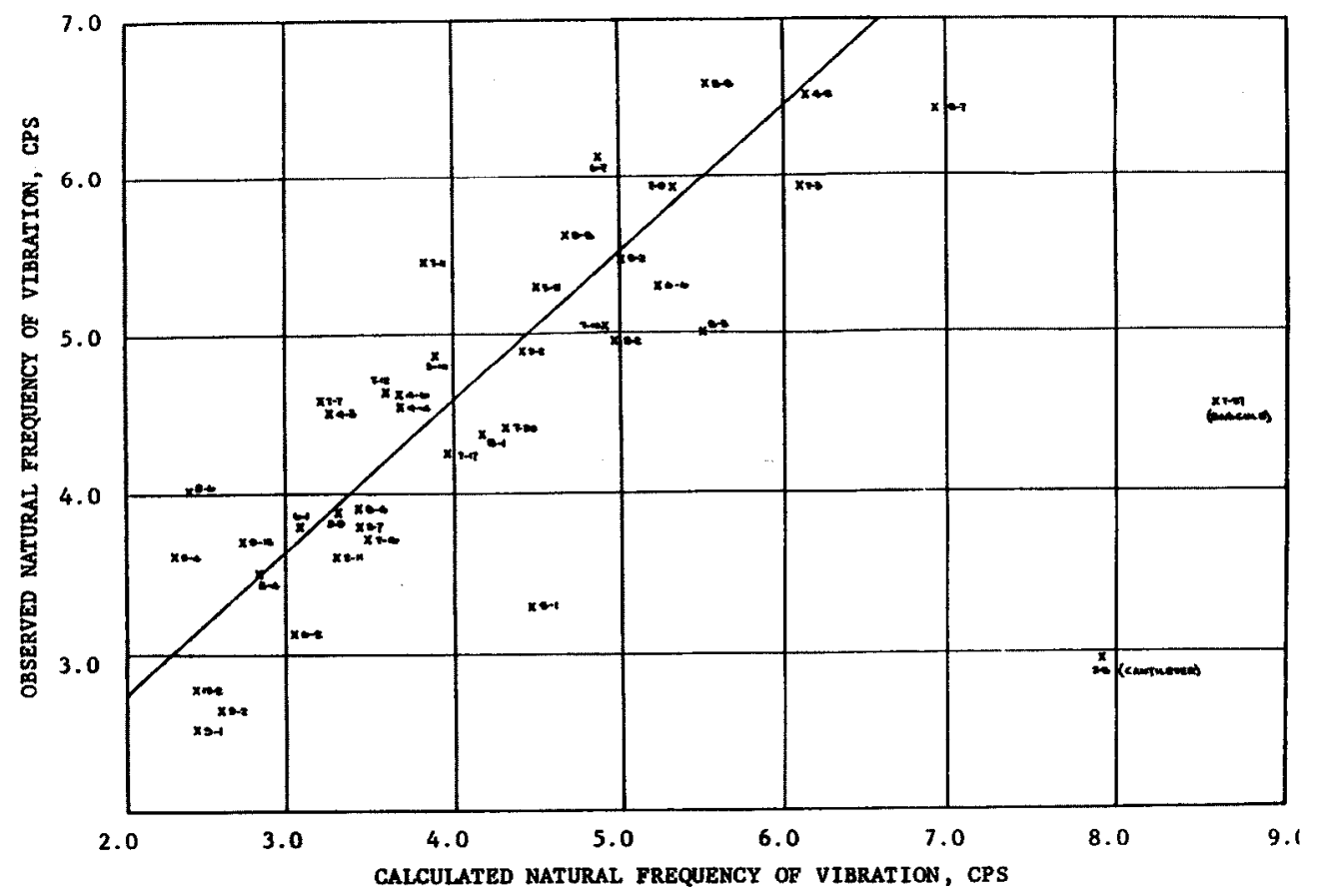

Figure 3.1. Measured bridge natural frequency versus calculated natural frequency (Wright and Green, 1959) 


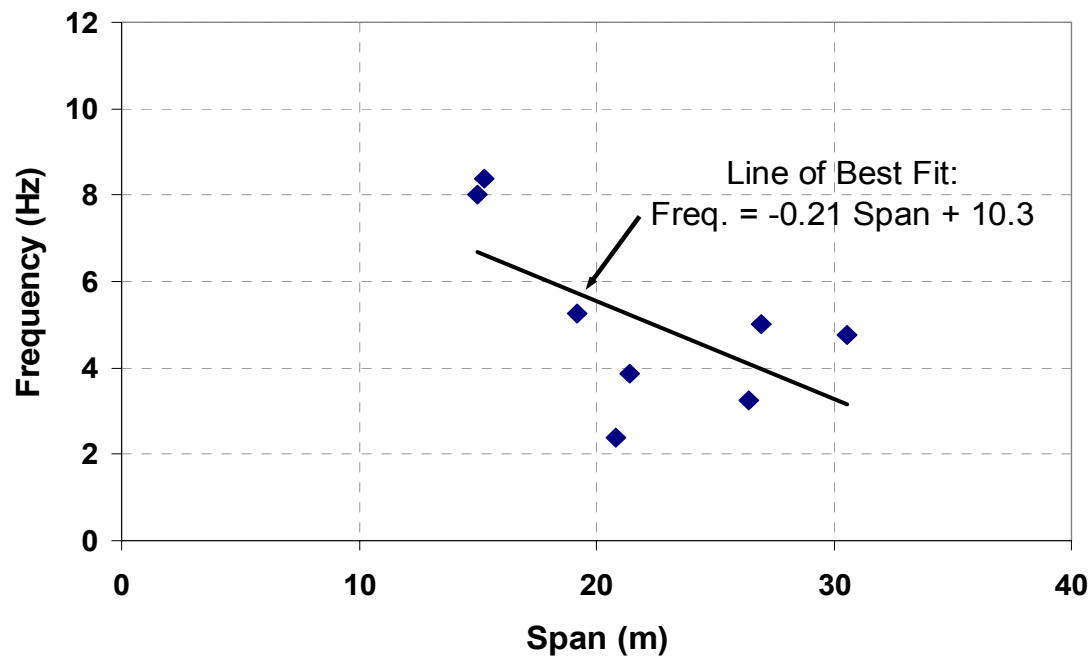

Figure 3.2. Frequency expression (Wood and Shepherd, 1977) 


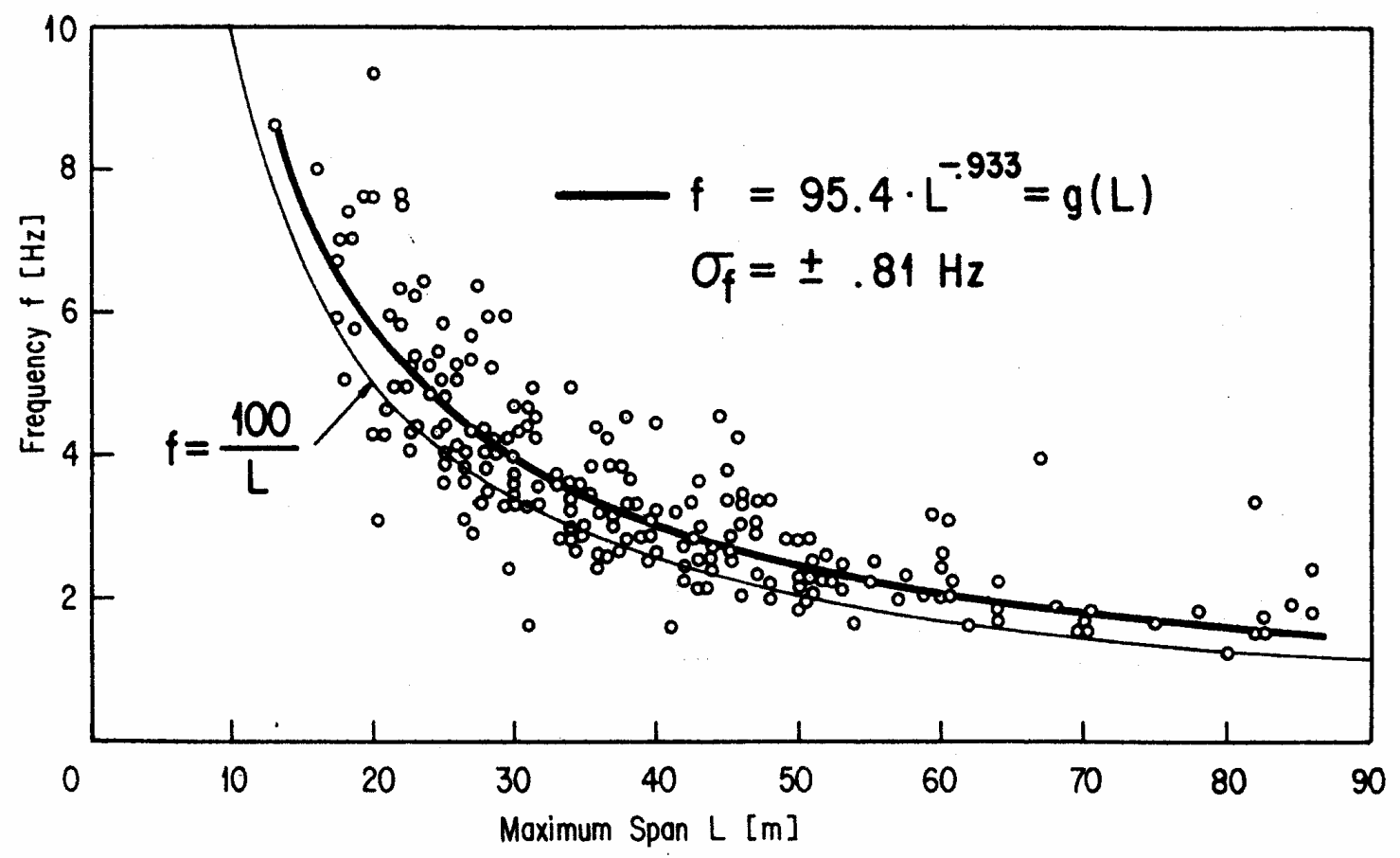

Figure 3.3. Fundamental frequencies as a function of maximum span length (Cantieni, 1983) 


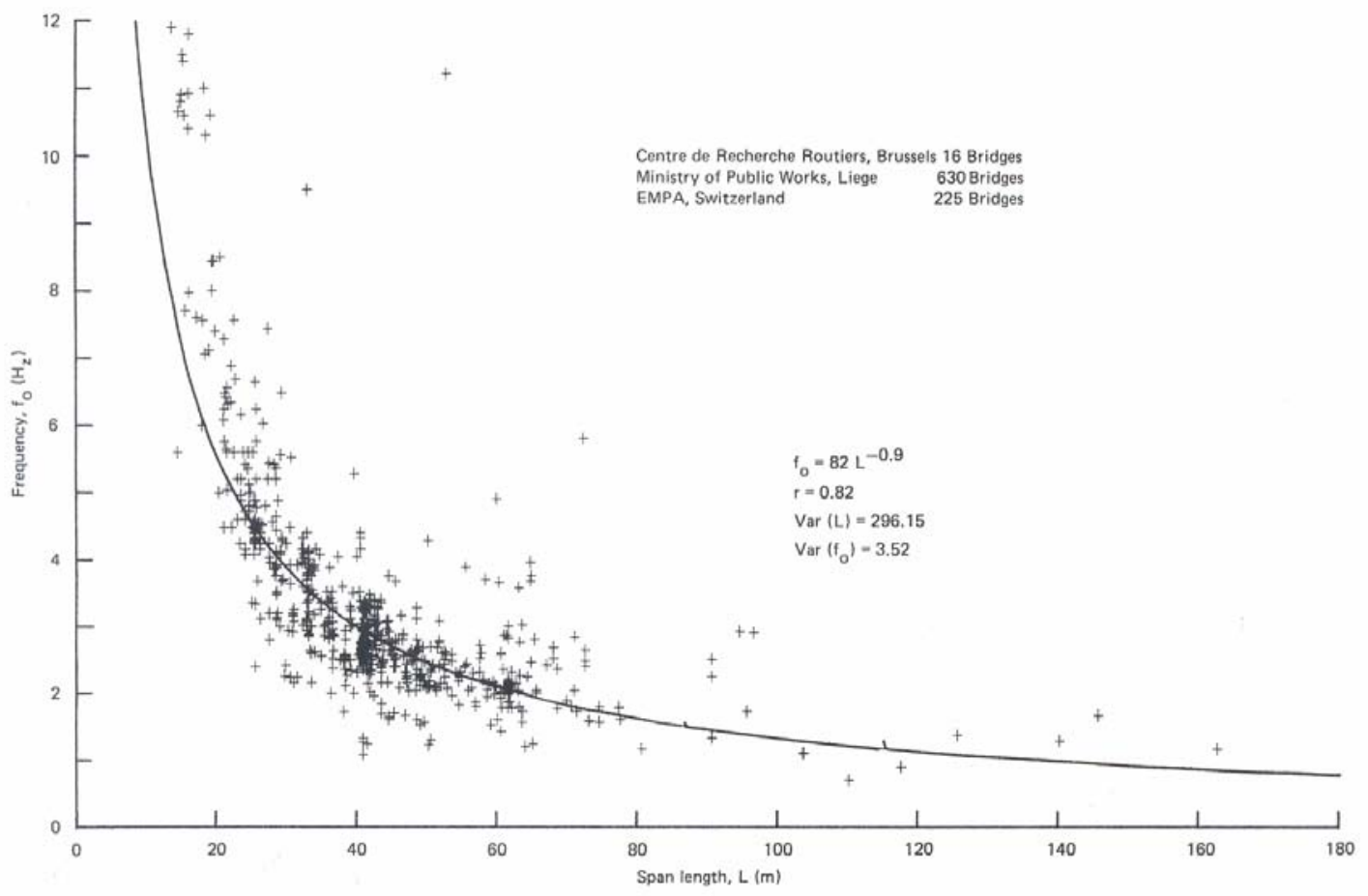

Figure 3.4. First bending frequencies for 871 highway bridges

(Tilly, 1986) 


\section{CHAPTER 4}

\section{ON THE ACCURATE FINITE ELEMENT MODELING OF LIVE-LOAD EFFECTS IN COMPOSITE STEEL BRIDGES}

\subsection{Acceptable Refined Methods}

AASHTO Specifications (1998) allow the designer make use of several available methods of analysis for bridge superstructure response due to truck loading. These methods can be categorized into two levels of increasing complexity and reliability. Both methods have varying ranges of applicability.

Level I methods, referred to as approximate analysis methods, are the simplest and most routine type of analysis. The level I methods utilize the familiar concept of wheel load distribution factors, which are determined from relatively simple empirical formulas that usually contain several bridge geometry and stiffness parameters (such as girder spacing, span length, girder stiffness, etc.). Furthermore, the distribution factor generally differs for interior and exterior girders, as well as for shear, moment, and deflection. The applicability of the formulas can be extended for skewed bridges by applying reduction/correction factors. The advantage of this level of analysis is the simplicity offered by reducing a 3D problem to a one-dimensional problem. However, when the value of one of these parameters is beyond the range of these formulas, the accuracy of the level I methods cannot be guaranteed and a refined analysis is recommended. This level of analysis is routinely used in design and in the parametric design studies in the following chapter. 
Alternatively, the level II methods are refined methods of analysis, using more detailed two-dimensional (2D) and 3D analyses. Therefore, the need for wheel load distribution factors, which approximate the structure's response to live load, is eliminated. The effects of continuous railing, parapets and median have traditionally been neglected in these analyses, but the potential exists that the influence from these members may be included. The most popular of the refined methods are the grillage analogy method, orthotropic plate analysis, finite difference method, yield line method and FEA, although any of the following methods may be used (AASHTO, 1998):

- Classical force and displacement methods,

- Finite difference method,

- Finite element method,

- Folded plate method,

- Finite strip method,

- Grillage analogy method,

- Series or other harmonic methods, and

- Yield line method.

In such analyses consideration shall be given to the aspect ratio of elements $(\leq 5)$, positioning and number of nodes, and other features of topology that may affect the analytical solution (AASHTO, 1998). The aspect ratio of elements should be less than 5:1, and preferably be close to unity (Jategaonkar et al., 1985).

There are no longer any recommendations given in the Australian Bridge Design Code for refined bridge analysis. Bridge designers are expected to be aware of all the analysis techniques. 
Six permitted refined methods of analysis (Ministry of Transportation, 1991; CSA International, 2000) are as follows:

- Grillage analogy,

- Orthotropic plate theory,

- Finite element,

- Finite strip,

- $\quad$ Folded plate, and

- Semi-continuum.

Five of the above, excluding finite strip methods, were summarized by Eamon (2000).

In the literature, many 3D FEA studies have been conducted on the behavior of composite steel bridges. These range from linear-elastic analyses to analyses incorporating large geometric deformations and material nonlinearity. The majority of these studies have been focused on live-load distribution factors, dynamic load amplification and dynamic response, and nonlinear behavior. Very limited research has been performed on live-load deflection and vibration characteristics. Furthermore, these studies generally do not consider the effects of secondary elements (such as parapets, sidewalks, etc.), which also have typically not been included in the traditional grillage and orthotropic plate analyses. In this chapter three dimensional FEA modeling techniques, using the commercial finite element software ABAQUS (version 6.2, 2001), are proposed to study the live-load deflection response and vibration characteristics of composite steel bridges. The accuracy of the FEA models will be verified by comparing experimental results of four bridges from the literature to current analytical data. 


\subsection{Background}

Finite element analysis is now widely recognized as a powerful and versatile analytical tool (Jategaonkar et al., 1985), and is effective in the analysis of structures which have complex geometry, material properties, and support conditions, and which are subjected to a variety of loading conditions. In terms of accuracy, the finite element method is ideal for any bridge superstructure, and it is especially suited for complex problems. However, accuracy and convergence to the exact solution depend not only on the number of elements but also on the type of elements.

It is during the process of idealizing a real structure into a set of elements that significant differences in modeling approaches are used by various analysts (Tarhini and Frederick, 1992). Modeling techniques differ in the types of elements used, the material constitutive models, the solution strategies used, and accuracy of geometrically representation. Also there is not general agreement on how the slab/girder interaction or bridge support conditions should be idealized (Razaqpur and Nofal, 1990). Even a detailed FEA model of a superstructure can produce incorrect results if the modeling is not done appropriately, and the results not carefully interpreted. While there are many possible FEA representations of a structure, some common idealizations, with increasing order of complexity, include:

- Using plate elements for the slab and beam elements for the girders, with the centerline of the girders coinciding with the centerline of the slab,

- Using the elements above, but imposing rigid links between the slab and beams to account for the eccentricity of the slab and girders,

- Modeling the slab by plate elements, the girder flanges as space frame members, and the girder web as plate elements, and

- Modeling the entire structure as solid and/or plate elements. 
Plane shell elements and three dimensional elements are usually more accurate, but even these elements must be chosen with care, and the use of a finer mesh does not always result in better convergence to an accurate result.

Hendrik et al. (1986) conducted a FEA parametric study by performing elastic analyses of 108 single-span, skewed, slab-and-girder bridges with span lengths ranging from 40 to $80 \mathrm{ft}$. Each structure had 5 girders and the girder stiffness was representative of bridges with pretensioned I-girders or steel I-girders. A nine-node Lagrangian-type isoparametric thin shell element, which allowed for shear deformation, was used to model the slab. An eccentric isoparametric beam element based on Timoshenko beam theory was used to model girders; this element also allowed for shear deformation, but the effects of warping and torsion were not captured. Rigid links were used to model composite action. The wheel load fraction $(\mathrm{b} / \mathrm{X})$ and the skew reduction faction $(\mathrm{Y})$ were used to calculate the girder midspan deflection $(\Delta)$ by modifying the deflection computed for a right bridge subjected to static loads $\left(\Delta_{\text {static }}\right), \Delta=\Delta_{\text {static }}(\mathrm{b} / \mathrm{X}) \mathrm{Y}$, where $\mathrm{b}$ is girder spacing in feet and $\mathrm{X}$ is distribution factor in feet for girder midspan deflection. $\mathrm{X}$ is a function of $\mathrm{H} /(\mathrm{b} / \mathrm{a})^{3}$ and $\mathrm{Y}$ is a function of $\mathrm{b} /(\mathrm{aH})$, where $\mathrm{a}$ is span of the bridge in feet and $\mathrm{H}$ is dimensionless stiffness parameters which is a relative ratio between bending stiffness of an interior composite girder and that of the slab.

Finite element analysis using ADINA (Bishara et al., 1990) was conducted to compute internal forces in intermediate and end cross frames having 3 different crosssectional areas for four $137 \mathrm{ft}$. simply supported composite steel bridges with $0,20,40$ and 60 degrees skew. The bridges were subjected to HS20-44 live load, in addition to a pedestrian live load. The slab was modeled by triangular plate elements. The stringers 
were divided into top and bottom halves and each half is modeled as beam elements joined to the other half by steel link elements. The top halves of the girders were connected to the slab plate elements by constraint equations (rigid link elements). The cross frame members were also modeled as beam elements. Web stiffeners were not included. In addition to the internal forces in the cross frames and end diaphragms, differential vertical displacements between adjacent stringers were investigated. Results indicated that the vertical deflections of steel girders were not affected by the crosssectional area of the intermediate cross-frame members.

Reactions, moments, displacements and rotations due to axle loading in a twospan continuous, composite steel girder test bridge were determined and compared with those calculated by 3D FEA using ANSYS (Tiedeman et al., 1993). The deck was modeled with 4-node shell elements, the girders with 3-node thin-walled beam elements, and the diaphragms with 2-node truss elements. The degrees of freedom of a beam node were coupled to those of a deck shell node lying on the same vertical line to simulate composite action. The FEA gave reactions and stresses that correlated very well with those from the experiment. The FEA over predicted the reaction forces by $5 \%$ to $11 \%$ and under predicted bottom flange stresses by $0 \%$ to $7 \%$.

Based on the results of 3D FEA using ANSYS 5.6 for six hypothetical, simply supported bridges, the effects of diaphragms, barriers, and sidewalks on the mid-span deflection distributions were presented (Eamon, 2000). Three dimensional linear beam elements were used to represent the steel girders and diaphragms, while 8-node brick elements were used to represent the deck, sidewalk, and parapets. A complete connection between the beam and the deck with no slip was assumed (no shear connectors modeled). 
Effects of the reinforcing steel on deck stiffness were found to be insignificant and therefore not included in the elastic analysis.

Field and FEA studies for a 3-span continuous bridge $(203.4+278.9+203.4 \mathrm{ft}$. $)$ with a prestressed concrete slab on two one-cell square box steel girders were conducted to investigate the vibration characteristics for this bridge (Deger et al., 1995). The bridge is at a maximum height of $459.3 \mathrm{ft}$. above the river bed and the intermediate inclined steel support legs have a cross section similar to that of the main girders. Two methods were used to conduct the field testing, which are a servohydraulic vibration generator used to excite the bridge randomly and rocker engines. The bridge response was measured at selected points in three directions, points on the bridge center line, the main girder's axes and at both lateral extremities of the cross section. A measurement unit consisted of three accelerometers, mounted orthogonally to each other on a supporting steel plate. The bridge was simulated by means of two separated models using the FE programs MARC and MSC/NASTRAN. Plate elements and beam elements were used. The calculations are based on the assumption of linear-elastic material behavior. The FEA predictions of the first three bending frequencies are $0.92,1.29$ and $1.55 \mathrm{~Hz}$, respectively, which are different from the experimental data $0.90,1.28$ and $1.77 \mathrm{~Hz}$ by only $2.2,0.78$ and $12.4 \%$ respectively.

Frequency comparisons (Ventura et al., 1996) were presented between ambient and pullback vibration (from abandoned railway bridge piers in the proximity) measurements and FEA using SAP90 for a five-span bridge over Colquitz River in Canada, which is $271.3 \mathrm{ft}$. long and $39 \mathrm{ft}$. wide and has six continuous W33X141 steel girders supporting a 6.9 in. thick concrete deck. Two FEA models were proposed, which 
are a base model and a refined model. Poor frequency comparisons were obtained from the base model. In the refined model, shell elements were used for the deck and the 3D beam elements were used for girders and diaphragms, with the increased stiffness due to composite action accounted for by using an effective moment of inertia for the girder elements. The mass of the parapets and sidewalks was added as a lumped mass in the model, and the increase in stiffness due to the parapets and sidewalks was added to exterior girders. Though good frequency compassions between the results of the refined model and experimental testing were achieved, the validity of the FEA techniques is questioned.

Comparisons of the natural frequency obtained from field testing and 3D FEA using ANSYS were presented for a simple span composite steel bridge with a span length of $106.5 \mathrm{ft}$. (Wolek et al., 1996). The slab, girder and diaphragm components were represented by 3D shell elements. The model of the concrete deck was comprised of an interior and exterior region, in which the exterior region was assigned increased density to account for the dead load of the barrier. The girder webs were connected directly to the slab and no representation of the upper flanges were used to reduce the size of the model. A slightly larger modulus of elasticity was used for the concrete to account for the presence of the upper flange and the reinforcement in the deck. Intermediate and end diaphragms were modeled using plate elements of the same thickness as the web stiffener plates. Deleting the diaphragms from the model had a significant effect on the torsional frequencies, and although good comparisons were observed for the first 5 natural frequencies, the FEA techniques used are questioned. 
Natural frequency comparisons (Barefoot et al., 1997) between the results of field tests and FEA using the ADPL language coupled with ANSYS 5.0 code were presented for two slab-on-steel-stringer bridges in Virginia: the Dan River Bridge and Route 220 Bridge. The Dan River Bridge consists of two four-span continuous bridges with each of the 8 spans having a length of $120 \mathrm{ft}$. and the Route 220 Bridge has 7 spans with the center portion consisting of a 3 -span continuous segment $(180+270+180 \mathrm{ft}$.). Plate elements were used for the slab and beam elements were used for girders. Diaphragms are not a factor in symmetric response such as longitudinal bending modes but may have a significant influence on transverse bending and torsional modes, so they were included in the model. Parapets with $25 \%$ reduced moment of inertia were used to account for longitudinal discontinuity. Rigid beam elements were used for shear studs, where the stiffness of these elements could be changed to model non-composite behavior. The method used to connect the slab and parapets was not discussed. Favorable comparisons were reported for the first 6 mode frequencies, with a maximum difference of $3.4 \%$ for the Dan River Bridge and 6.3\% for the Route 220 Bridge.

Three-dimensional FEA time history and dynamic analysis (Issa et al., 2000) was performed under construction loads and vibrations for a non-symmetric slab-on-steelgirder bridge over the Illinois River using SAP90. The bridge has three spans of 234.7, 297.5, and $234.7 \mathrm{ft}$. and a width of $39.4 \mathrm{ft}$. Shell elements were used to model the slab and the web of the plate girders, while frame elements were used to model the top and bottom flanges. The static modulus of elasticity of concrete was used because the modal frequencies were too low to justify the use of a large dynamic elastic modulus. The first 
three flexural bending frequencies were $1.21,1.41$ and $1.86 \mathrm{~Hz}$, respectively. No results of field testing were available.

A FEA procedure (Martin et al., 2000) was developed to evaluate the relative effects of various parameters on the dynamic response for moving loads on a reference bridge model with dimensions corresponding to the Meherrin River Bridge by using ANSYS and its Parametric Design language (APDL). The bridge has a length of $100 \mathrm{ft}$., $8.5 \mathrm{in}$. slab and a girder spacing of $8 \mathrm{ft}$. The majority of the parameter evaluations were performed using a line girder model rather than the model of the entire bridge. The line girder models consist of beam elements for the girder and shell elements for the slab. The composite action was modeled by implementing rigid beam elements. Results of the FEA gave a fundamental frequency of $2.83 \mathrm{~Hz}$, which was very close to the measured value (not provided) of Meherrin River Bridge.

Comparisons (Buckler et al., 2000) were presented for the girder deflection distributions between 3D FEA results using ABAQUS and field test results for three static load cases on the Willis River Bridge, a 3-span all simply supported bridge with a skew angle of 15 degrees. Each span has a length of $40 \mathrm{ft}$. and a width of $28 \mathrm{ft}$. The bridge consists of a RC slab supported by 4 girders spaced at $7.4 \mathrm{ft}$. The concrete deck was modeled by shell elements, the girders and parapets were represented by beam elements, and truss elements were used to represent the diaphragms. A truck was placed on the composite deck by using the "load path" method and contact elements. A "load patch" was created that consisted of six shell elements to represent dump truck or HS20 truck. The load patch was attached to the deck by means of contact elements. From the analytical model, the fundamental natural frequency of this bridge was $11.8 \mathrm{~Hz}$, which 
was very close to the value obtained from the field testing of $11.6 \mathrm{~Hz}$. FEA conducted for three hypothetical bridges clearly showed the effect of girder spacing on the stresses, stains and deflections of bridge decks.

\subsection{Proposed Finite Element Analysis Model}

A 3D FEA model has been developed in this research to investigate the elastic live-load deflection and vibration characteristics of composite steel bridges using ABAQUS (Version 6.2, 2001). Details of these efforts are presented herein.

In ABAQUS, solid elements may be used for linear analysis and for complex nonlinear analyses involving plasticity and large deformations. Twenty-node, quadratic brick elements (C3D20R) with three translation degrees of freedom per node and reduced integration are used to model the concrete slab. Second-order solid elements such as these provide higher accuracy than first-order elements for "smooth" problems that do not involve complex contact conditions, impact, or severe element distortions. Furthermore, second-order solid elements are very effective in bending dominated problems. Reduced integration uses one lower order of integration to form element stiffness matrices and reduces running time, especially in three dimensional problems. Second-order reduced-integration elements generally yield more accurate results than the corresponding full integration elements.

General-purpose shell elements (S4R) with reduced integration are used for the steel girders and stiffeners. These elements allow transverse shear deformation. They use thick shell theory as the shell thickness increases and become discrete Kirchhoff thin 
shell elements as the thickness decreases. The transverse shear deformation becomes very small as the shell thickness decreases.

Three dimensional two-node line beam elements (B31) with six degrees of freedom per node are used for diaphragms/cross frame bracings. The main advantage of beam elements is that they are geometrically simple and have few degrees of freedom. These elements allow for transverse shear deformation and can be used for thick as well as slender beams. Also, B31 elements can be subjected to large axial strains, while the axial strains due to torsion are assumed to be small.

AASHTO specifications require that full composite action should be maintained under service-level loads. Multiple-point constraint (MPC) beam elements are used to model shear studs having full composite action between the slab and steel girders. MPC elements act as a rigid beam between two nodes by constraining the displacement and rotation at a node on the slab to the displacement and rotation at a corresponding node on the girder.

The element mesh is generated in order to accommodate the truck loadings and achieve an element aspect ratio close to unity. Furthermore, the mesh of slab is generated to have nodes on the same vertical line as the centerline of the girders for generating MPC elements. Nodes are generated at the locations where lateral bracing connects to the steel girder, otherwise MPC quadratic elements or MPC bilinear elements should be used to overcome incompatibility problems between bracing nodes and steel girder nodes. Figure 4.1 shows a typical mesh for an elastic model of a composite steel bridge.

The boundary conditions for the simple span bridges include a hinge constraint with the three translation displacements constrained for all nodes along one end of the bottom 
flanges and roller constraints preventing vertical displacement for all nodes along the other end of the bottom flange. Similar boundary conditions are imposed for the continuous span bridges analyzed by adding additional roller constraints along the bottom flanges at the pier location(s). Point loads are used to represent the truck loadings, where only static effects are considered. The effect of dynamic live loads (impact factors) is beyond the scope of this research.

The densities of steel and normal weight concrete are assumed to be $490 \mathrm{lb} / \mathrm{ft}^{3}$ and $150 \mathrm{lb} / \mathrm{ft}^{3}$ in FEA respectively.

Tests have suggested that, in the elastic range of structural behavior, concrete cracking has little effect on the global behavior of bridge structures and can be safely neglected by modeling the concrete as uncracked (AASHTO, 1998). Therefore, the concrete slab is assumed uncracked. Reinforcing steel is not included in the elastic FEA modeling because it needs the definition of nonlinear properties of concrete and interaction between concrete and reinforcing steel. Because live-load deflections are a serviceability issue, the load-deflection and vibration characteristics behaviors may be assumed to be elastic. Therefore, a static, linear elastic analysis procedure is used.

\subsection{Experimental Verification}

Experimental live-load deflection results obtained from laboratory testing for two simply supported bridges (Newmark et al., 1946; Kathol et al., 1995) and natural frequency results obtained from field tests of two continuous span bridges (Ventura et al., 1996; Varney, 1971) were used to verify the proposed elastic model. 


\section{$\underline{\text { University of Illinois quarter scale model bridge } \mathrm{C} 15}$}

Laboratory testing of a quarter-scale model of a simple-span right bridge with a span of $60 \mathrm{ft}$. and a roadway width of $24 \mathrm{ft}$. was conducted at the University of Illinois (Newmark et al., 1946). The model bridge (referred to as C15) has a span length of $15 \mathrm{ft}$. and five reduced-scale beams, which have a spacing of $1.5 \mathrm{ft}$. and support a $1.75 \mathrm{in}$. thick, $6 \mathrm{ft}$ - 2.281 in. wide slab. The I-beams have the following dimensions: flange thickness of 0.188 in., flange width of 2.281 in., web thickness of 0.135 in., and a total height of 8 in. Channels with dimensions of $1 \times 3 / 8 \times 1 / 8$ in. and a spacing of 6.25 in. were used as shear connectors. Two end diaphragms consisting of 4 in., $5.4 \mathrm{lb}$. per foot channels bore directly against the bottom of the slab. Intermediate diaphragms spaced at one-third the span length consisted of $3 \times 2 \times 3 / 16$ in. angles, which were welded to the webs of the Ibeams about $1 / 2$ in. below the top of beam. Longitudinal and transverse cross sections of the scale bridge are shown in Fig. 4.2.

The FEA modeling of this bridge is performed using the procedure discussed above and the complete bridge is considered in the analysis. The elastic modulus of girder steel, $E_{S}$, was assumed as $30000 \mathrm{ksi}$ and the yield strength and ultimate strength of steel were $41 \mathrm{ksi}$ and $64.9 \mathrm{ksi}$, respectively. The elastic modulus of slab concrete, $E_{C}$, was $4000 \mathrm{ksi}$ and the averaged compressive strength of the concrete was $2.72 \mathrm{ksi}$.

The midspan deflections of all the beams subjected to 4 concentrated loads at the midspan and symmetric about the longitudinal axis of the bridge are chosen for comparison with the FEA results, which are shown in Fig. 4.3. The each applied load, P, is equal to 5 kips, which is within the linear-elastic region. 
As shown in Fig. 4.3, the experimental and FEA results compare fairly well, but the FEA results are slightly larger than experimental results. Specifically, the FEA deflection results are $2.5 \%, 5.8 \%$ and $4.1 \%$ higher for the center girder, intermediate girders, and exterior girder respectively. The average discrepancy is within 5\%. Part of this discrepancy can be attributed to the fact that the actual loads were not concentrated, but rather distributed over a disk of size $3 \frac{3}{4}$ in. diameter. This phenomenon was also observed by Wegmuller (1976) in his comparison for this bridge between FEA and the testing results subjected to a different load case, which is the two pairs of asymmetric load case. Also, inside fillets of the steel beam were not included in FEA model, which may be considerable in this size of beam; inclusion of these fillets will decrease the discrepancy further. From the above comparison, it is believed that the proposed FEA scheme is sufficient to capture the elastic behavior of the simple span composite steel bridge.

\section{Nebraska's full-scale bridge laboratory testing}

Laboratory testing was conducted (Kathol et al., 1995) of a single-span, straight, composite bridge to study the elastic and ultimate behavior. This bridge had a span length of $70 \mathrm{ft}$. As shown in Fig. 4.4, three welded composite steel beams were used to support a 7-1/2 in. deep and $26 \mathrm{ft}$. wide slab, with $10 \mathrm{ft}$. center-to-center spacing between the beams. The plates making up the girders consist of a $9 \times 3 / 4$ in. top flange, a $54 \times 3 / 8$ in. web, a $14 \times 1-1 / 4$ in. center bottom flange, and $14-3 / 4$ in. end bottom flanges. Intermediate stiffeners consisting of 5/16 $\times 4$ in. plates are spaced: 2 at 39.5 in., 10 at 67.2 in., and 2 at 39.5 in. Shear studs $7 / 8$ in. in diameter and 5 in. tall are symmetrically spaced 18 at 7 in., 
14 at 9 in., and 16 at 10-3/16 in. from left to right. WT4 $\times 9$ members were used for top and bottom chords of the end cross frames, and $\mathrm{L} 3 \times 3 \times 3 / 8$ members were used for diagonals members of the end cross frames. During the ultimate load testing, only end cross frames were used (intermediate cross frames were removed). The concrete barrier structure is a typical Nebraska Department of Roads open concrete bridge rail, with $11 \times 11$ in. posts spaced $8 \mathrm{ft}$. on center. Figure 4.4 also shows the loading configuration, which simulates two side-by-side HS20-44 vehicles.

FEA modeling of this bridge is performed using the procedure discussed above. The averaged yield and ultimate strengths of steel were 41.73 and $65.56 \mathrm{ksi}$, respectively. The elastic modulus of girder steel, $E_{s}$, was assumed equal to 29000 ksi. The average 28day compressive strength of the concrete, $f_{c}^{\prime}$, was $5.576 \mathrm{ksi}$ and the elastic modulus of slab concrete, $E_{c}$, was assumed as $4527 \mathrm{ksi}$, which is based on American Concrete Institute (ACI) empirical equation of elastic modulus in pounds for normal concrete

$$
E_{c}=33 w_{c}^{3 / 2} \sqrt{f_{c}^{\prime}}
$$

where

$$
\begin{aligned}
& w_{c}=\text { density of normal concrete in } \mathrm{lb} / \mathrm{ft}^{3} \\
& f_{c}^{\prime}=28 \text {-day concrete compressive strength in } \mathrm{lbsi}
\end{aligned}
$$

The entire bridge was modeled both with and without open concrete bridge rail. The comparisons between the testing and FEA results are presented in Fig. 4.5 for the midspan deflection of each girder. The test data was taken from the ultimate loaddeflection curves for the three girders when there were 2 HS20 trucks on the bridge. For the model with open concrete bridge rails, all of the FEA results were within $5 \%$ of the test data $(4.1 \%,-1.2 \%$ and $4.9 \%$ for girders 1,2 , and 3 respectively). For this bridge, the 
open concrete bridge rails have a considerable effect on the midspan deflections, about $30 \%$ for the two exterior girders and $11.6 \%$ for the center girder.

From the above comparisons, it is observed that the proposed elastic FEA model efficiently simulates the live-load behavior of a simply supported composite steel bridge with rails or parapets. For this bridge configuration with few steel girders, the concrete bridge rails can have considerable effects on the live-load deflection, especially for exterior girders. In such instances, and if live-load deflection controls the design, obvious cost savings may be realized by considering the effects of secondary elements of the bridges such as the open concrete rails for this bridge.

\section{Colquitz River Bridge in Canada}

Field tests of ambient vibration due to traffic and induced vibration by using pullback test measurements (Ventura et al., 1996) were conducted for a five-span continuous composite steel bridge. The total length of this bridge is approximately $270 \mathrm{ft}$. $(46+59+60+59+46 \mathrm{ft}$. $)$ with a width of $39 \mathrm{ft}$. and has six continuous steel girders W33X141 supporting a 6.9 in. thick concrete deck, which is shown in Fig. 4.6. The girders rest on the abutments and four concrete bents. There were 3 intermediate diaphragms in each span as well as end diaphragms over all abutments and piers. Diaphragm members composed of MC18X42.7 also included in the model, spaced at 11 ft. -6 in. for the two end spans, $14 \mathrm{ft}$. -9 in. for the two intermediate spans and $15 \mathrm{ft}$. for the midspan.

For the ambient test, the Hybrid Bridge Evaluation System (HBES) consisted of 6 force-balanced accelerometers (FBA) that were used to collect and process acceleration 
data. Records of longitudinal, transverse and vertical motions were obtained at different times during the day and under varying traffic conditions, including no traffic at all. Pullback tests were conducted by loading the bridge at a selected location with a force of $20.2 \mathrm{kips}$, and then quickly releasing this load to induce free vibrations in the longitudinal and transverse directions. The proximity of abandoned railway bridge piers provided an ideal anchor point for the pullback testing.

A value of $29000 \mathrm{ksi}$ was used for the elastic modulus of the steel. The 28-day compressive strength of concrete was assumed to be $4 \mathrm{ksi}$ and the elastic modulus of the concrete slab was assumed to be $3834.3 \mathrm{ksi}$ from the Eqn. 4.1 in the FEA.

The bridge was also modeled both with and without parapets by using the above FEA procedure. The comparison of natural frequencies obtained from the field tests and the proposed elastic FEA are shown in Table 4.1. The averaged difference between the field data and the FEA predictions with parapets for the first three vertical modes are within 5\%. Comparing the results of the two FEA models, the effects of the parapets are $4.6 \%, 2.5 \%$ and $1.3 \%$ for the first three natural frequencies, respectively. Thus, the proposed elastic model accurately predicts the vibration characteristics of continuous span composite steel bridges.

\section{Tennessee Rt. 130 Elk River Bridge}

A field study of the bridge resonant excitation (Varney, 1971) was conducted for a 4 -span continuous bridge $(70+90+90+70 \mathrm{ft}$.), attempting to identify as many of the resonant frequencies as possible, together with their mode shapes and logarithmic decrements of damping. Also recorded were maximum cyclic variations of strain and 
displacement. As shown in Fig. 4.7, the bridge has a 7 in. RC slab resting on 4 coverplated W36X170 steel beams spaced at $8 \mathrm{ft}$. -4 in. The bridge was designed composite in positive moment regions for an HS-20 loading and constructed in 1963.

Vibration generators were installed in each traffic lane, $3 \mathrm{ft}$. from midspan of one of the $90 \mathrm{ft}$. interior spans. The bridge was first excited over the slowly-varied frequency range of the vibration generators to identify the various resonances. For this investigation, accelerometers were located at calculated antinodal points on the bridge deck. The vibration generators were then carefully set at each of the bridge resonant frequencies. A heavy 3-axle truck simulating HS20-44 loading was driven on the bridge to provide a static live load surcharge during resonant vibration. Ambient vibrations in the absence of any forced excitation were also observed. The dynamic interaction of the truck and bridge was measured with the truck parked on the bridge during vibration at the common resonant frequency. The torsional and normal responses occurred at the same frequencies, depending only on the phasing of the vibration generators. The vibration amplitudes were generally about the same in each of the two end spans and in each of the interior spans. Strain ranges decreased slightly when the span being excited was loaded with the HS2044 vehicle, and increased slightly when the adjacent span was loaded.

In the FEA, the entire bridge was modeled using the procedures discussed above. While in reality the curbs are not at the same level as the deck slab, these are assumed to be at the same level in the FEA. This is done in order to simplify the analysis and will not have any appreciable influence on the behavior of the bridge. The actual length of cover plates is not available; consequently, the cover plates were ignored in the analysis, which 
may have some effect on the FEA results. Furthermore, a 2 in. concrete haunch was assumed.

The material properties used in this analysis are given by Burdette et al. (1971), where applicable; in the absence of experimental data, standard values are assumed for some material properties. The yield strength, the ultimate strength and the elastic modulus of girder steel are 40, 60 and $30750 \mathrm{ksi}$, respectively. The compressive stress of concrete is $6.87 \mathrm{ksi}$ and $4776 \mathrm{ksi}$ is used for the elastic modulus of concrete in FEA. The diaphragms were assumed to be comprised of L4X4X1/2 standard angles, spaced at 23'4" and 22'-6" for the two side spans and the two inner spans, respectively.

Comparisons between the natural frequencies obtained from the field testing and the proposed elastic FEA are shown in Table 4.2. The predicted natural frequencies for the $1^{\text {st }}, 2^{\text {nd }}$ and $4^{\text {th }}$ modes are $3.2,4.3$ and $6.2 \mathrm{~Hz}$ and the corresponding experimental natural frequencies are $3.1,4.3$ and $6.0 \mathrm{~Hz}$ (experimental natural frequency for the $3^{\text {rd }}$ mode is not available). As shown in Table 4.2, the percent difference is less than $3.5 \%$ for the $1^{\text {st }}, 2^{\text {nd }}$ and $4^{\text {th }}$ vertical modes, again suggesting that the proposed elastic model accurately predicts the vibration characteristics of continuous span composite steel bridges.

\subsection{Conclusions}

This chapter has presented a state-of-the-art review of elastic finite element analysis for composite steel bridges. Three dimensional FEA modeling techniques using ABAQUS have been proposed to analyze the live-load deflection, vibration characteristics, and the effects of parapets on the deflection and natural frequencies for 
composite steel bridges. The FEA model has been proven to be efficient and accurate in capturing the elastic behavior of composite steel bridges through comparisons between FEA results and experimental test results for four cases.

Based on the bridges studied, it has been observed that there will be a greater difference between the deflections of interior and exterior girders, the greater the lateral distance between applied loads and the fewer girders the bridge has. For example, the interior girder of the Nebraska full-scale bridge, which has twelve axle loads (laterally distributed across nearly the entire bridge width) and 3 steel girders, deflects $33.6 \%$ more than the exterior girders. Conversely, the experimental girder deflections in the University of Illinois model bridge, which has four concentrated loads arranged as shown in Fig. 4.2 and 5 steel girders, vary $19.2 \%$ between the center girder and the exterior girder.

When investigating the live-load deflection serviceability limit state for composite steel bridges, it is recommended that the effects of secondary elements, such as bridge rails or parapets, be included. As shown in Fig. 4.5 for the Nebraska bridge, including the effects of rails reduces the deflection by $30 \%$ for side girders and $12 \%$ for the center girder. Comparisons of the natural frequencies obtained from the FEA of the 5-span continuous Colquitz River Bridge with and without parapets show that the effects of the parapets is within $5 \%$. However, the effect of parapets can possibly be more significant for some configurations of composite steel bridges. Therefore, this issue will be investigated in the FEA parametric study on the natural frequencies of composite steel bridges. 
The main problem encountered during frequency calibration was that there are several frequencies and eigenmodes that are calculated but not measured. There is no unique solution to this problem, since the number of physical parameters in the FEA model typically exceeds the number of experimentally measured characteristics. This problem was also observed by Deger et. al. (1995). However, it is possible to considerably narrow the discrepancy if special care is taken during the FE modeling phase, such as the secondary elements (rails or parapets) and sensitivity of the boundary conditions, which is the analyst's responsibility to create a potential best model to properly reflect the significant details of the bridges concerning the mass, stiffness and boundary conditions et al..

In the following chapter, the verified elastic 3D FEA model will be used to conduct a FEA parametric study on the natural frequencies of composite steel bridges. 
Table 4.1. Comparisons of natural frequencies for Colquitz Rive Bridge

\begin{tabular}{|c|c|c|c|c|c|}
\hline Mode & $\begin{array}{c}\text { Field test } \\
(\mathbf{H z})\end{array}$ & $\begin{array}{c}\text { FEA } \\
\text { w/ parapets } \\
(\mathbf{H z})\end{array}$ & $\begin{array}{c}\text { \% } \\
\text { Difference }\end{array}$ & $\begin{array}{c}\text { FEA } \\
\text { w/o } \\
\text { parapets } \\
(\mathbf{H z})\end{array}$ & $\begin{array}{c}\% \\
\text { Difference }\end{array}$ \\
\hline $1^{\text {st }}$ Vertical & 5.95 & 6.273 & 5.4 & 5.983 & 0.6 \\
\hline $2^{\text {nd }}$ Vertical & 7.14 & 7.397 & 3.6 & 7.213 & 0.1 \\
\hline $3^{\text {rd }}$ Vertical & 8.70 & 8.456 & -2.8 & 8.348 & 4.0 \\
\hline
\end{tabular}


Table 4.2. Comparisons of natural frequencies for Tennessee Rt. 13 Elk River Bridge

\begin{tabular}{|c|c|c|c|}
\hline Mode & $\begin{array}{c}\text { Field test } \\
(\mathbf{H z})\end{array}$ & $\begin{array}{c}\text { FEA } \\
(\mathbf{H z})\end{array}$ & \% Difference \\
\hline $1^{\text {st }}$ Vertical & 3.1 & 3.2 & 3.2 \\
\hline $2^{\text {nd }}$ Vertical & 4.3 & 4.3 & 0 \\
\hline $4^{\text {th }}$ Vertical & 6.0 & 6.2 & 3.3 \\
\hline
\end{tabular}




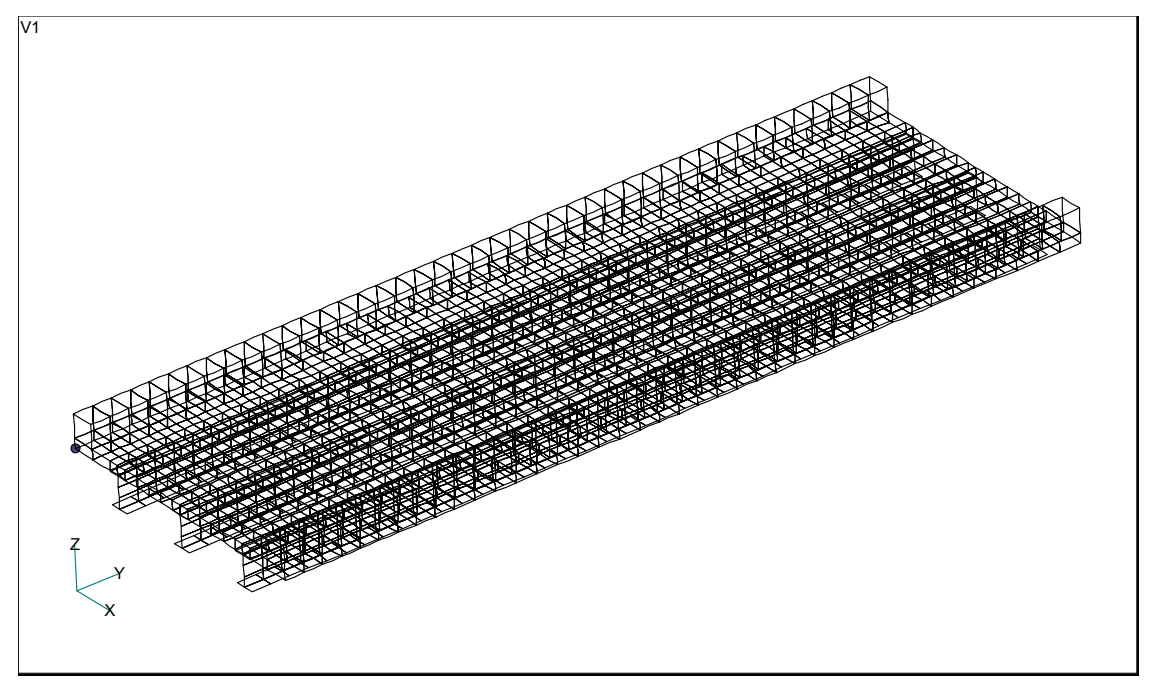

Figure 4.1. Typical FEA mesh of elastic modeling for bridge evaluation 


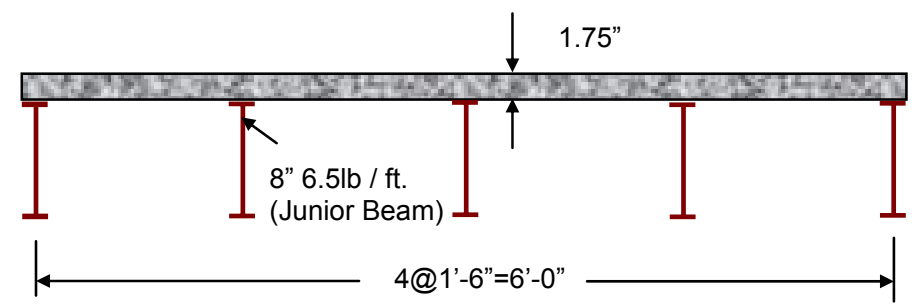

$\underline{\text { Transverse section }}$

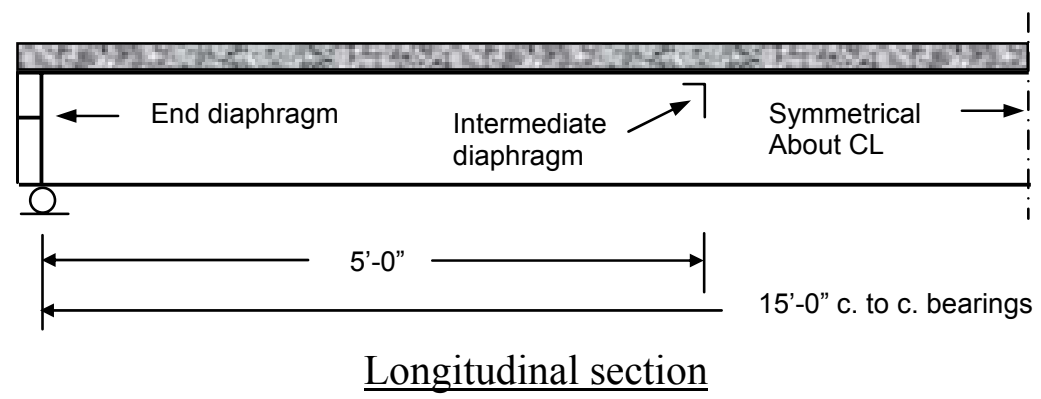

Figure 4.2. Sections of University of Illinois Model Bridge C15 

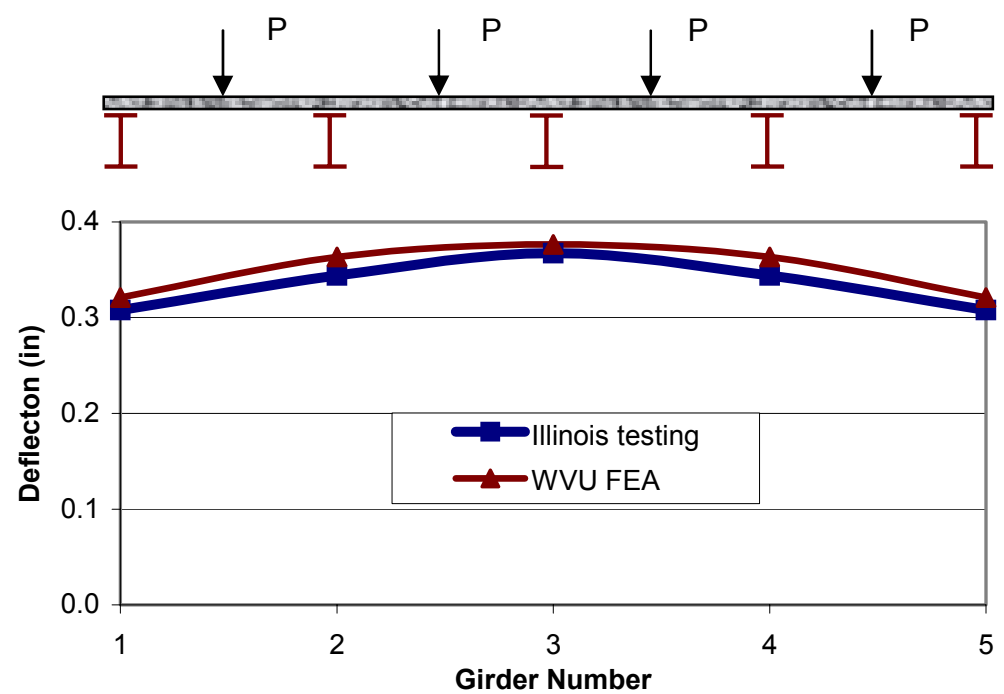

Figure 4.3. Deflection distribution at mid-span cross section 


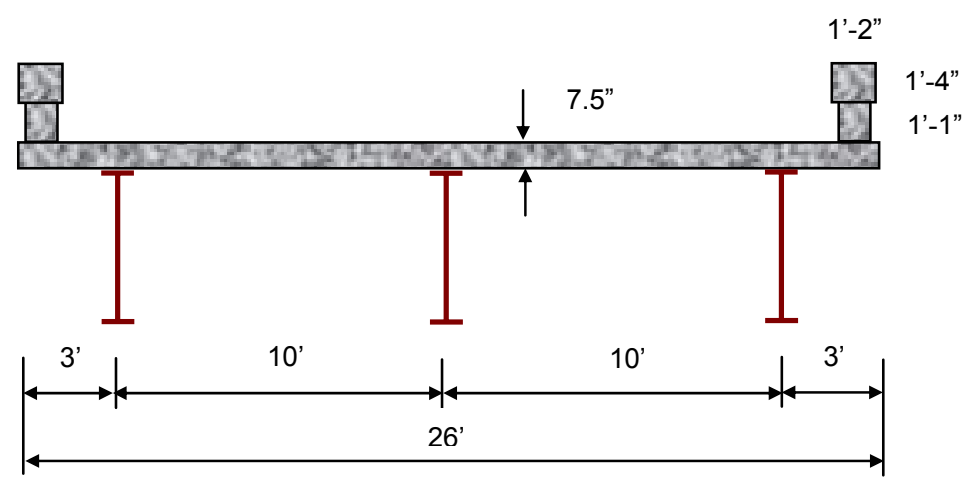

$\underline{\text { Transverse cross section }}$

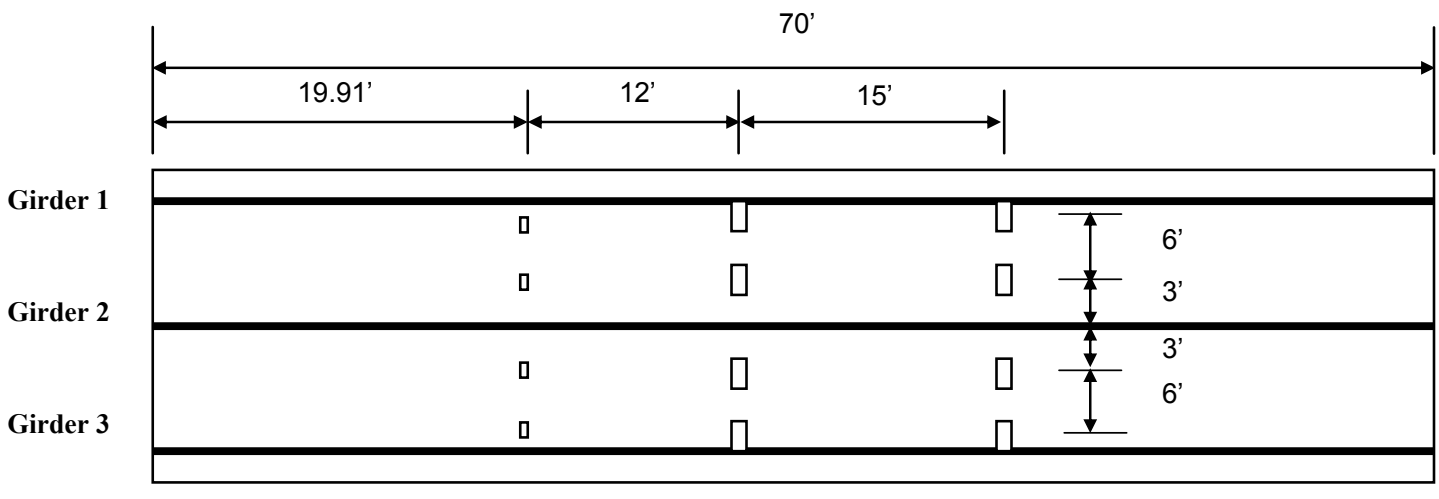

$\underline{\text { Plan view and two side-by-side HS20 trucks }}$

Figure 4.4. Cross section and layout of wheel load positions for University of Nebraska Bridge 


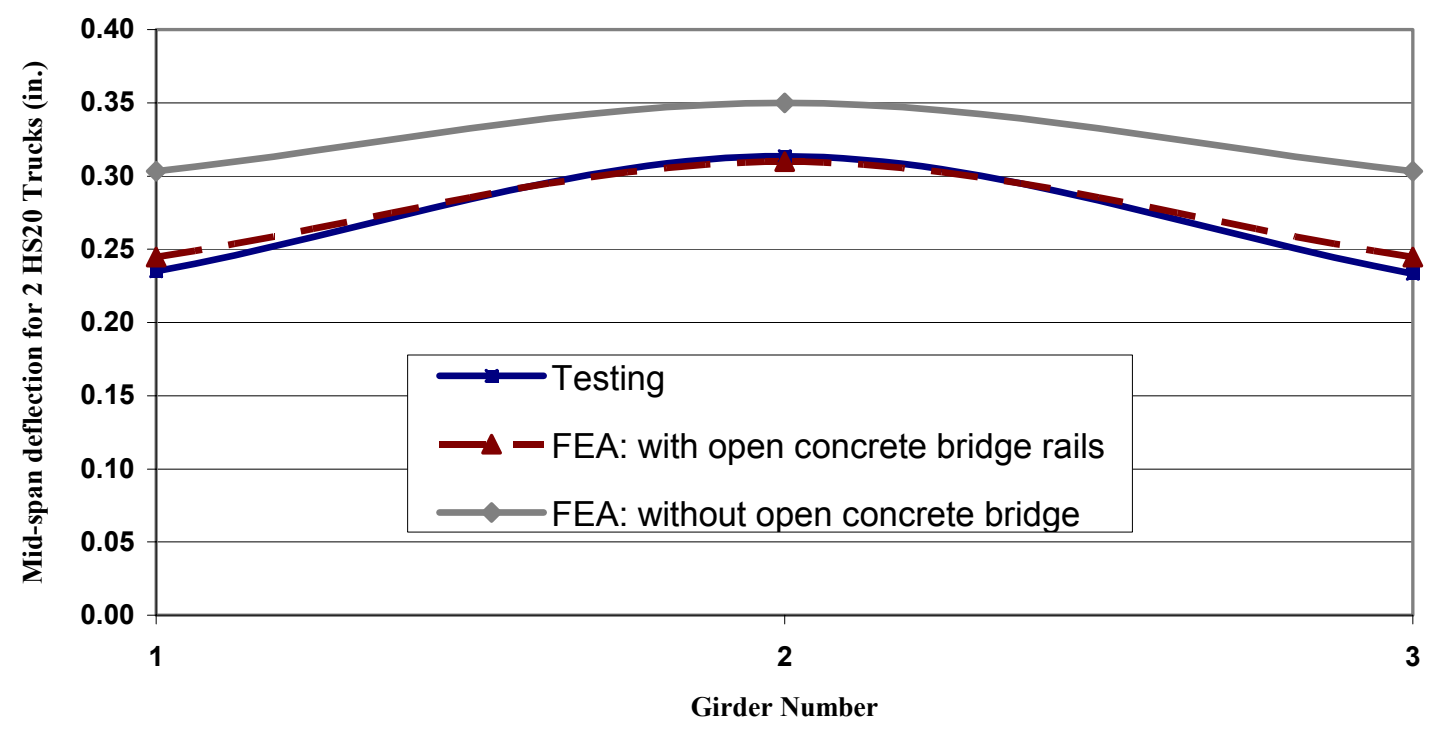

Figure 4.5. Deflection distributions at mid-span cross section for 2 HS20 trucks 


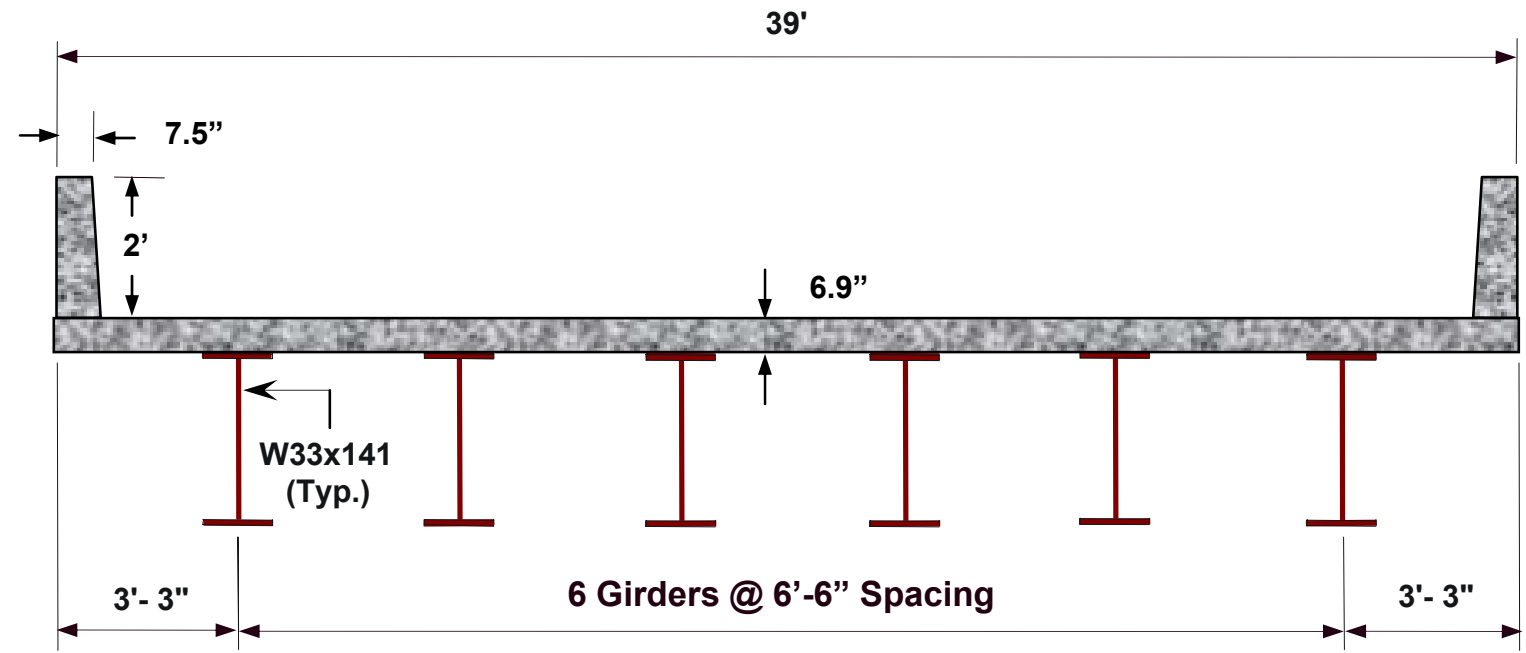

Figure 4.6. Cross section of Colquitz River Bridge in Canada 


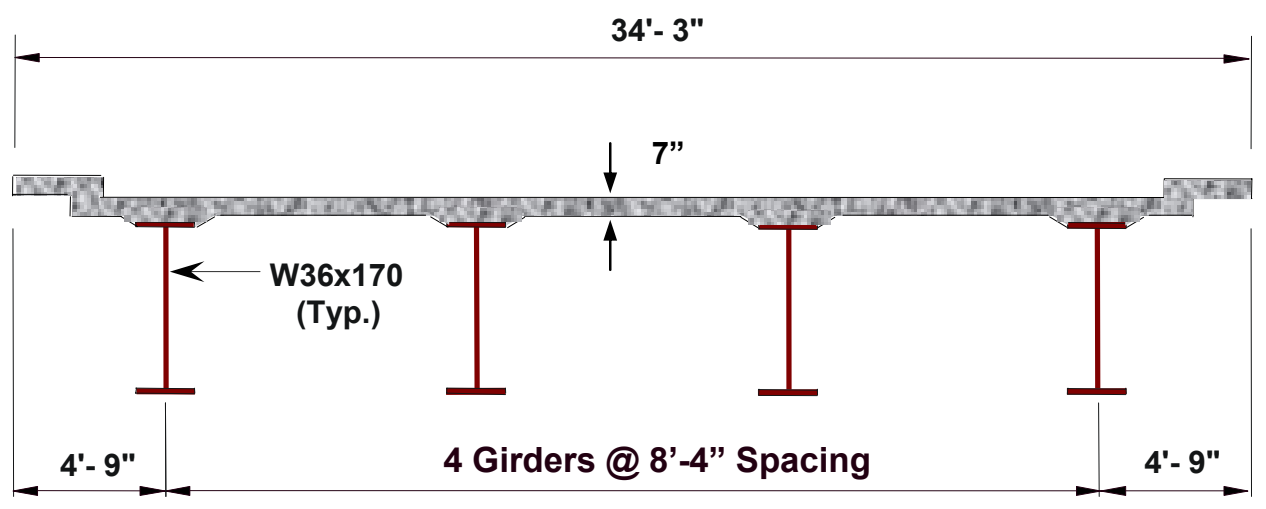

Figure 4.7. Cross section of Tennessee 4-Span Continuous Bridge (Sections over piers had the similar beams W36 $\times 160$ with $10 \frac{1 / 2}{2} \times 1$ " cover plates) 


\section{CHAPTER 5}

\section{EVALUATION OF AASHTO DEFLECTION LIMITS ON PARAMETRIC DESIGN STUDY BRIDGES AND EXISTING PLATE GIRGER BRIDGES}

\subsection{Parametric Design Study}

\subsubsection{Introduction}

One of the major impedances to the economical implementation of HPS in highway bridges is the current AASHTO live-load deflection limit. Conventional steel bridges (Grade 50W) usually have live-load deflections that are slightly smaller than that associated with the AASHTO deflection criteria; however HPS bridges require less steel due to their larger yield stress, and consequently the live-load deflections of these bridges commonly exceed the existing AASHTO deflection limits. Thus the economical benefits of HPS are not fully realized because of the current AASHTO deflection limitations. This section presents the results of a comprehensive design optimization study focused on evaluating the effects of the AASHTO deflection limit on the performance and economy of typical I shaped steel plate girder bridges.

A series of key design variables (including features such as span length, girder spacing, cross-section geometry, and girder material configurations) is selected to develop a matrix of bridges representing a wide range of steel bridge designs. Bridges are then designed for combinations of these variables based on a least weight approach using various commercial bridge design software programs. Initial designs are conducted by disregarding the AASHTO deflection criteria (i.e. $\delta \leq L / 800$ ). That is, a given girder 
is designed to meet all other relevant AASHTO strength and serviceability criteria other than live-load deflections. Girders found to initially fail the deflection criteria are then redesigned such that the live-load deflection, $\delta$, is less than $L / 800$.

One of the primary goals of this study is to develop insight into what combinations of design variables may generate girders that would not meet current deflection limits. For these girders not initially meeting the deflection limits, a comparison is made between the initial girder weight and that of the redesigned girder to determine additional steel requirements needed for girders to meet the AASHTO limits. It is recognized that least weight girders are not always the optimum designs for a given situation.

Additionally, girder designs generated in this parametric study are compared to two alternative serviceability criteria: Wright and Walker recommendations (Wright and Walker, 1971) and specifications in the Ontario Highway Bridge Design Code (Ministry of Transportation, 1991). Note that the fundamental principles of these criteria are presented in Chapter 2.

\subsubsection{Methodolgy}

A set of geometric and material parameters has been selected that have an effect on the superstructure live-load deflection characteristics. Girder designs are conducted for various combinations of these parameters.

The majority of the studies focused on girder optimizations using the AASHTO Load Factor Design (LFD) Specifications. However, a subset of comparison was also made using the AASHTO Load and Resistance Factor Design (LRFD) Specifications. 
Those girders failing to meet the L/800 limit were redesigned by modifying the crosssection geometry to meet or slightly exceed the deflection limit in both LFD and LRFD. The LFD bridge designs were completed using a steel bridge design optimization program, SIMON (SIMON SYSTEMS, 1996) and LRFD designs were performed using MDX (MDX, 2000). Both of these are commercially available bridge design packages that perform complete analysis and design for given input parameters. Extensive hand calculations were performed to verify program output including shear and moment envelopes as well as respective strength and serviceability limit state calculations. It was typical that several iterations were conducted for a given set of design variables for the initial designs generated by the software in order to develop a more practical design. For example, sometimes it was necessary to reduce the number of plate thickness transitions or to make minor changes to plate widths to produce cleaner designs.

\section{Procedures}

To begin a design, a preliminary superstructure depth based on the targeted length to depth $(L / D)$ ratio was calculated, where $L$ is the total span length or the distance between points of contraflexures, and $D$ is the total depth of the bridges. Once the preliminary superstructure depth, $D$, was calculated, the structural depth of the deck, the haunch, and the bottom flange was subtracted to achieve the web depth. From this web depth, an initial flange width was selected such that $D_{w} / b_{f}$ fell in the range of 3.00 to 4.5 where $D_{w}$ is the web depth and $\mathrm{b}_{\mathrm{f}}$ is the flange width. These target $D_{w} / b_{f}$ ratios resulted from previous research by Barth, White and Bobb (2000). It was not possible to remain within this range for all the designs, and the maximum permitted variation was between 2 
and 5. After a preliminary girder was chosen, the appropriate noncomposite and composite dead loads were calculated. This preliminary information was input into the respective design package (i.e., SIMON for LFD designs and MDX for LRFD designs) to obtain an optimized section.

For the simple span designs, a flange thickness transition was included $25 \%$ away from each abutment if a weight savings of $900 \mathrm{lbs}$ or more was achieved. In the negative moment region of the two-span continuous bridges, a flange thickness transition was included $25 \%$ away from the pier if a weight savings of more than $900 \mathrm{lbs}$ was achieved. In the negative moment region of the three-span continuous bridges, a flange thickness transition was included 25\% away from the pier for mid span and $20 \%$ away from the pier for two side spans if a weight savings of more than $900 \mathrm{lbs}$ was achieved. The 900 lbs was selected to economically justify a flange transition, material saving versus the additional fabrication cost of this transition.

The web thickness was selected by incorporating a partially stiffened approach. That is, for a given girder a web thickness, $t_{w}$, that would require no transverse stiffeners was determined. This thickness was then reduced by 1/16-in. to 1/8-in., depending upon weight savings and the resulting stiffener layout required for lateral bracing only or where additional stiffeners also added. This web thickness was held constant for a given girder.

The haunch (which includes the top flange thickness) was assumed to be 2 in. unless section requirements mandated that the top flange thickness be greater than 2 in. In these cases, the haunch was increased to the thickness of the top flange. 


\subsubsection{Design Parameters}

Table 5.1 shows a matrix of design variables that were selected for four representative bridge cross sections. Fig. 5.1 shows each of the four cross sections, these cross sections were selected to investigate the influence of both the number of lanes and the number of girders.

\section{Constant Parameters}

Parameters that were held constant throughout the studies include:

- HS25 live loading for LFD or HL93 live loading for LRFD,

- $\quad$ Stay in place metal forms $=15 \mathrm{psf}$,

- $\quad$ Future wearing surface $=25 \mathrm{psf}$,

- $\quad$ Parapet weight $=505 \mathrm{lb} / \mathrm{ft}$,

- $\quad$ Cross frame spacing $=25 \mathrm{ft}$.,

- $5 \%$ increase in dead weight for miscellaneous steel,

- Interior girder design,

- Class I roadway, and

- Constant top flange and bottom flange widths and web thickness.

\section{Varied Parameters}

Two groups of parameters are varied: parameters that describe the cross-section of the member (i.e. geometric parameters) and material parameters. 


\section{- Geometric Parameters}

The study considered 3 span arrangements, simple, two-span continuous and three-span continuous for cross sections 1, 2, and 4, and 2 span arrangements, simple and two-span continuous for cross sections 3, with spans lengths ranging from $100 \mathrm{ft}$. to 300 ft. Four span-to-depth $(L / D)$ ratios are incorporated: 15, 20, 25, and 30 (note that in cross sections 1,2 , and $4, L$ is defined as the total span length and $D$ is defined as the to superstructure depth, conc. slab plus steel girder, for cross section $3 \mathrm{~L}$ is the length between dead load contraflexure points and $D$ is the total superstructure depth). Also as shown in Fig. 5.1, the bridges have 4 or 5 steel girders, girder spacing ranging from $8 \mathrm{ft}$. -6 in. to $11 \mathrm{ft}$. -6 in., and roadway width ranging from $28 \mathrm{ft}$. to $40 \mathrm{ft}$.

The ratio of the web depth to flange width $\left(D_{w} / b_{f}\right)$ varied between 2 and 5 . This was a limit set to find a feasible design. Some of the girders with high span-to-depth ratios, $L / D$, could not be designed with $D_{w} / b_{f}$ ratio in the "practical" range. Therefore, girders with these geometries were eliminated from the results presented in this section.

\section{- Material Parameters}

Two material configurations were used for each combination of the above geometric variables, girder comprised of conventional Grade 50W (G345W) steel and girders comprised of HPS 70W.

\subsubsection{Results}

The combinations of material and geometric parameters described above and summarized in Table 5.1 and Fig. 5.1 yield an initial set of 280 LFD girder designs, 64 LRFD girder designs for cross section \#3, as well as 35 LFD and 6 LRFD girder 
redesigns for bridges initially failing to meet the $L / 800$ deflection limit. These bridges span a broad range of span lengths, material configurations, cross section geometries and continuity conditions. Fig. 5.2 shows the girder elevations for simple, 2-span continuous and 3-span continuous bridges used in this study. Detailed girder elevation dimensions are provided in Tables B5.1 through B5.4 in Appendix B for cross sections 1, 2, 3, and 4 bridges, respectively. Parametric design summaries are given in Tables C5.1 through C5.4 in Appendix C for cross sections 1, 2, 3, and 4 bridges respectively, where the bridges failing L/800 deflection limit are highlighted. In table $\mathrm{C} 5.1$ through $\mathrm{C} 5.4$, a parameter, performance ratios, is computed for each of the AASHTO design criteria and is defined as: performance ratio $=$ calculated value $/$ allowable value. A performance ratio greater than a user-input maximum acceptable ratio (default $=1.0)$ indicates that the current design is invalid. Designs indicated with NA are not feasible designs violating the ratio of the web depth to flange width in the range of 2 to 5 .

Table D5.1 in Appendix D gives the girder elevation dimensions of the redesigned girders for those original bridge designs failing $L / 800$ deflection limits, which are 6 bridges for cross section 1, 3 for cross section 2, 23 LFD bridges and 6 LRFD bridges for cross section 3, and 3 for cross section 4. Table D5.2 in Appendix D shows the design summary for the redesigned bridges, with the exception of 6 LFD twospan bridges of cross section 3, which failed the $\mathrm{L} / 800$ deflection limit and with $0.8 \mathrm{~L} / \mathrm{D}$ equal to 30 , which were not redesigned due to the unrealistically low of $D_{w} / b_{f}$ ratios necessary to achieve a satisfactory design.

The results of natural frequency calculated using Eqn. 2.2 for simple and two span bridges and Eqn. 2.2 with Billing's correction factor 1.266 for 3-span bridges with 
$L_{2} / L_{1}$ equal to 0.8 and bridge vibration characteristics investigated by using the Wright and Walker Procedure and OHBDC (see Chapter 2 for details) are shown in Tables E5.1 through E5.4 in Appendix E for cross sections 1, 2, 3 and 4, respectively.

\section{General Results Summary}

Tables 5.2 through 5.5 present comparisons of design summary information between initial girder designs that failed to meet the AASHTO deflection limits and the corresponding girder redesign (shown in italics) performed to meet the deflection limits. These tables also present the Walker and Wright classification for both the initial designs as well as the girder redesigns.

Figures 5.3, 5.4, 5.5, and 5.6 show the influences of various design variables on the normalized live-load deflection. The $y$-axis of these plots, $L / \delta / 800$, gives a relative picture of how the designs perform with respect to the deflection limits. A value less than 1 indicates that the girder failed to meet the criteria. The dashed line drawn at 1.25 represents a deflection of $\mathrm{L} / 1000$, the AASHTO limit for bridges in urban areas.

Figure 5.7 shows the comparison with OHBDC limits for the initial bridge designs. Figures 5.8 and 5.9 show a subset of this data by plotting each of the initial bridge designs that fail to meet the AASHTO deflection criteria relative to the OHBDC requirements for simple-span bridges and two-span bridges, respectively.

\section{Effect of Variations in Geometric and Material Properties}

As shown in Fig. 5.3, no bridges having an $L / D$ of either 15 or 20 exceeded the $\mathrm{L} / 800$ deflection limit. However, as the $L / D$ ratio is increased to 25 and 30 , more 
structures fail to meet the AASHTO limits. Also for bridges with higher $L / D$ ratios (25 or 30) the deflection range for a given $L / D$ is much narrower that that of the bridges with lower $L / D$ ratio (15 or 20 ). In the four sets of cross sections studied, cross section 3 is the most susceptible to failing the present deflection limits, which has 23 LFD bridges failing the present deflection limit and this number is greater than the total failing bridges of the other three cross sections. It is relevant to note that plots of girder weight versus $L / D$ ratio would show the optimum weight to be around $L / D=25$, this is also the recommended value of $L / D$ specified in AASHTO. Further, site restrictions may exist, such as hydraulic openings that may necessitate reduced depth structures. These are indeed the group of structures that are most severely affected by the deflection limits.

Figure 5.4 also shows a clear trend that structures with shorter span lengths are more likely to encroach upon the $L / 800$ limit. A separate study by the authors has also indicated that bridges in the 75 to $125 \mathrm{ft}$. span range may be the most susceptible to failing the present deflection limits.

Continuous span bridges are less likely to fail the AASHTO deflection limit. No 3 -span bridges failed the deflection limit. If the 62 -span bridges of cross section 3 with $0.8 L / D$ equal 30 (actual $L / D$ equal 37.5 ) are excluded, only 82 -span bridges failed the deflection limit, however there were 27 simple-span bridges failing the deflection limit.

As seen in Fig. 5.5, the HPS $70 \mathrm{~W}$ designs have more bridges failing the AASHTO deflection limits, but a clear trend cannot be found between the Gr. 50W and HPS 70W designs. However, it is noted that the HPS70W designs did tend to produce "cleaner" designs specifically for the higher $L / D$ ratios: this included thinner required 
top flanges as well as narrower required flange widths. Often times in the shorter span designs, the $D_{w} / b_{f}$ ratios for the Gr. 50W bridges were quite low, producing in a number of cases with structures having "infeasible" girder geometries. That is, girders with $D_{w} / b_{f}$ ratios in a range not typically seen in highway girder designs. One may also point out though that for a given superstructure configuration having a specific set of flexure and fatigue requirements, optimum solutions for Gr. 50W and HPS 70W girders may produce different $L / D$ ratios. In fact, often times one is able to meet given demands with a shallower HPS 70W girder resulting in various project economies.

\section{Comparison of Re-Designs}

As noted earlier, those structures that had deflections exceeding the $L / 800$ limit were redesigned to meet the deflection limit. Doing so naturally decreased the overall performance ratio of the girder, the ratio of the required capacity, or demand, to the available capacity (i.e. moment capacity) for a given limit state, with respect to other design criteria such as maximum load and overload limits as well as fatigue. In no case with the initial designs did the performance ratio fall below 0.965 and the majority of the initial designs have the performance ratios over 0.980 . However, these ratios fell as low as 0.645 for the redesigns. Three of the more important comparisons to make with the redesigned girders are: how was the weight influenced, how was the natural frequency influenced (as it was indicated earlier, this parameter is intricately related to the vibration perceptibility of the structure), and lastly how do these compare with the alternate serviceability criteria. 
Figure 5.10 shows a plot of the deflections for $150 \mathrm{ft}$. simple span bridges for cross section 3 for a range of $L / D$ ratios for both 50 and $70 \mathrm{ksi}$ designs. This figure shows values for the LFD designs. Again, in this figure it may be seen that no initial girder design with $L / D$ of 15 or 20 fails the AASHTO deflection criteria. However, at $L / D=25$, the $70 \mathrm{ksi}$ design fails the limit and at $L / D=30$ both the 50 and $70 \mathrm{ksi}$ design fails to meet the limits. Fig. 5.11 shows a plot of the weight of a single girder for both the initial and redesigns for the same example designs. While the increase in require steel weight at $L / D=25$ was negligible, at $L / D=30$ a substantial increase in steel weight was required for a given girder to meet the deflection limit.

Again, Tables 5.2 through 5.5 show design summary values for both the original design failing to meet the AASHTO criteria as well as the associated redesigns. On average, $36 \%$ more steel was required to meet the given deflection limits. This increase was the highest for the continuous span structures and lowest for the longer span simplespan bridges. Naturally, these numbers may vary based on design input, but it is clear that substantial cost savings may be possible with the incorporation of alternate serviceability criteria. The average change in natural frequencies of the redesigned girders of cross sections 1,2 and 4 is below $4 \%$, but in some cases may increase $7 \%$. However, the average change for the redesigned girders of cross section 3 is $5 \%$ and $8 \%$ for LFD and LRFD designs, respectively, and some redesigns have frequencies up to $15 \%$ higher. Furthermore, the redesigned girders have the same Wright and Walker classifications as the original girders for cross sections 1,2 and 4, and majority cases of cross section 3. However, some redesigns of cross section 3 change the classifications 
from unpleasant to few to perceptible (3 out of 23 bridges) or from perceptible to perceptible to most (4 out of 23 bridges).

\section{Comparison with Alternate Criteria}

As noted earlier, a number of foreign specifications place limits on superstructure vibration characteristics rather than live-load deflection. Also, the Wright and Walker Procedure cited earlier is referenced as a footnote in the LRFD specifications. None of the bridges from the initial set of studies was found to exceed the limits developed by Wright and Walker (see Tables E5.1 through E5.4 in Appendix E). About 49.5\% of the total of 329 girders would be classified as perceptible with the highest $63.8 \%$ of cross section 3 LFD girders classified as perceptible. About 34\% girders among the total of 329 girders had the classification of perceptible to most with highest $48 \%$ of cross section 3 LRFD with the same classification. Only $9.7 \%$ of girders of the total girders had the classification of perceptible to some with highest $17 \%$ of cross section 2 girders having the same classification. In fact, in only few designs (5.5\%) were the structures classified as unpleasant to few (6 girders for cross section 1, 4 girders for cross section 3 LFD and 8 girders for cross section 4). And only $1.5 \%$ girder designs were classified as imperceptible ( 2 girders from cross section 2 and 3 girders from cross section 2). It is obvious that girders of cross section 3 had higher level vibration classifications based on Wright and Walker Procedure.

Figure 5.7 and Tables E5.1 through E5.4 in Appendix E show the OHBDC results for all the initial bridge designs. The OHBDC was reported to limit the combined static deflection with the first flexural frequency as a function of intended use. While the 
majority of bridges $(85.7 \%)$ were found to fall within the limits for having "sidewalks and little pedestrian use" and $40.5 \%$ bridges were found to fall within the limit for "having sidewalks-significant pedestrian use", all designs were found to fall within the acceptable range for bridges "with no sidewalks" limit. Based on the distribution of bridges of all cross sections within the 3 limits of OHBDC shown in Fig. 5.7, it could not be clearly found which cross section is most susceptive to fail these limits. Figures 5.8 and 5.9 show the plots for the Ontario specifications with data points plotted for those girders initially failing to meet the $\mathrm{L} / 800$ limit for simple and two span continuous bridges respectively. These plots clearly show the effect of span configuration, with the 2-span bridges failing AASHTO deflection limits concentrated on the "having sidewalksignificant pedestrian use" limit, and the simple-span bridges failing AASHTO deflection limits having a wide range of distribution between "with no sidewalk" and "with sidewalk-little pedestrian use" limits. Also for these plots, the effect of cross section configuration could not be clearly found.

\section{Comparison of LFD with LRFD}

Figure 5.6 shows a comparison of the normalized deflections for the LFD and LRFD designs. For cross section 3, there are 23 bridges designed with LFD that exceed the deflection limit, including those designs with $0.8 L / D=30$. However, only 6 of the LRFD designs exceeded $L / 800$. This is in part due to the design vehicle used in the respective codes for evaluation of the limits. In LFD, it is specified that the vehicle used to evaluate strength must also be used to evaluate serviceability; hence, the HS25 loading is used. In LRFD, it is specified that the deflection criteria are to be evaluated using the 
design truck only, which is the HS20-44. Also, differences in resistance equations, distribution factors, and design loadings produce different geometries for LFD and LRFD. Both methods incorporate the same live-load deflection distribution factor, which is determined by assuming that any load placed on the structure after deck placement may be assumed to be carried equally by all girders.

\section{Final Remarks of Parametric Design Study}

While it is clear that the present AASHTO deflection limits may have a significant influence on girder economy for some ranges of bridge superstructure geometries, it should be noted that other superstructure geometries may not be as dramatically influenced by the existing criteria.

Those bridge designs failing AASHTO deflection limits do not necessarily fail the limits of the alternative serviceability criteria: Wright and Walker Procedure and OHBDC.

\subsection{Evaluation of Existing Plate Girder Bridges}

\subsubsection{Introduction}

From the survey in Appendix A and from meetings with state bridge engineers affiliated with the AASHTO T-14 Steel Bridge Committee, the plans of 13 typical plate girder bridges have been obtained. These plans represent bridges obtained from 6 different state transportation departments and were constructed roughly over the last 10 years. The set of plans includes bridges that are both simply supported and continuous 
spans and structures fabricated from both Grade 50 and from HPS 70W steels. Hence, they are a representative cross-section of I shaped steel plate girder bridge designs typically employed by U.S. State DOTs. Additional bridges having haunched girder configurations, box-girder cross sections, and very wide deck widths were obtained, but these are not considered in the present section.

The primary objective of this study is to evaluate the live-load deflection performance of representative I-shaped steel bridges against current AASHTO Specifications as well as two alternative serviceability criteria: Wright and Walker recommendations (Wright and Walker, 1971) and the Ontario Highway Bridge Design Codes (Ministry of Transportation, 1991).

\subsubsection{Analysis Methods}

Two sets of analyses are conducted for each bridge: a line girder analysis incorporating the effective width, load distribution factors, and loadings as implied by the AASHTO Standard Specifications (AASHTO LFD, 1996) and a similar analysis based on the requirements specified in the OHBDC. The commercial design package SIMON (SIMON SYSTEMS, 1996) was used for the LFD analyses and CONSYS (CONSYS, 2000) was used to conduct the live-load envelopes and deflection analyses based on the Ontario specifications for each of the bridge. For each analysis, both dead loads and section properties were calculated based on cross section information provided in the plans. Analyses were conducted assuming composite action throughout. The analyses accounted for all flange thickness transitions. Non-composite dead loads were applied to the bare steel section, moving loads were applied to the short term composite section (i.e, 
based on $b_{\text {effective }} / n$; where $n=E_{s} / E_{c}$ ) and permanent loads were applied to the long term composite section (i.e, based on $3 n$ ). The maximum deflection for a given span from the software output was then recorded and compared to respective limits. The natural frequency for both the Walker and Wright recommendations and the Ontario Highway Bridge Design Code are computed using the simple beam equation Eqn. 2.2 for simple and two span bridges and Eqn. 2.2 with Billing's correction factors for three-span bridge.

\subsubsection{Description of Bridges}

Design drawings, inspection reports and other detailed information for these candidate bridges were obtained. The following is a brief description of each of these existing bridges. Table 5.6 provides summary information for each of the bridges described below. Only two of the thirteen bridges failed the AASHTO $L / 800$ deflection limit with $L / \delta$ of 481 and 456 .

\section{Illinois - Route I 27 over Cedar Creek in Jackson County}

The Route I 27 Bridge is a simple-span composite steel plate girder bridge with a span length of $103 \mathrm{ft} .-103 / 4$ in. and has integral abutments. It consists of a $7.5 \mathrm{in}$. reinforced concrete deck supported by 5 girders spaced at $7 \mathrm{ft}$. -5 in. on center. The girders are fabricated from conventional Grade 50 (G345) steel. It was designed using the 1992 AASHTO $15^{\text {th }}$ Edition LFD Design Specifications and the design vehicle is HS20-44. This bridge was selected for evaluation because it is a representative typical steel bridge. 


\section{Illinois - Route 860 over Old Mississippi River Channel in Randolph County}

The Route 860 Bridge is a four-span continuous steel plate girder with equal exterior span lengths of $82 \mathrm{ft} .-3$ in. and equal interior span lengths of $129 \mathrm{ft} .-6 \mathrm{in}$.. It consists of a 7.5 in. reinforced concrete deck supported by 5 girders spaced at $5 \mathrm{ft}$. -2 in. on center. The girders are fabricated from conventional Grade 50 (G345W) steel. It was designed using the 1996 AASHTO LFD $16^{\text {th }}$ Edition Design Specifications with the 1997 Interim and the design vehicle is HS20-44. This bridge was selected for evaluation because it is a representative typical steel bridge.

Nebraska - Dodge Street over I - 480 in Douglas County

The Dodge Street Bridge is a two-span continuous steel plate girder bridge with equal spans of $236 \mathrm{ft}$. -6 in.. It consists of an 8.5 in. reinforced concrete deck supported by 8 girders spaced at $9 \mathrm{ft}$. -6 in. on center. The hybrid girders are fabricated from high performance steel HPS70W (485W) in the flanges of the negative bending region and conventional Grade 50W (G345W) steel is used in the web of the negative bending region and both the web and flanges in the positive bending region. It was designed using the 1997 AASHTO LRFD Design Specifications and the design vehicle is HL93. This bridge was selected for evaluation, as it is a representative bridge designed and constructed using HPS.

\section{Nebraska - Highway No. N-79 Snyder South}

The Snyder South Bridge is a simple-span composite steel plate girder bridge with a span length of $151 \mathrm{ft}$. It consists of a $7.5 \mathrm{in}$. reinforced concrete deck supported by 5 
girders spaced at $8 \mathrm{ft}$. on center. The girders are fabricated from high performance steel HPS 70W (485W). It was designed using the 1994 AASHTO LFD Design Specifications and the design vehicle is HS25 (MS22.5). This bridge was selected for evaluation, as it is a representative bridge designed and constructed using HPS.

\section{New York - Interstate 502-2-2 Ushers Road}

The Interstate 502-2-2 Bridge is a two-span continuous steel plate girder bridge with equal spans of $183 \mathrm{ft}$. It consists of a $9.5 \mathrm{in}$. reinforced concrete deck supported by 6 girders spaced at $9 \mathrm{ft}$. -4 in. on center. For live-load deflections the design vehicle is HS25 and the design load was applied according to AASHTO $16^{\text {th }}$ Edition Act. 10.6.4. This bridge was selected for evaluation, as it is a representative steel bridge.

\section{NY State Thruway - Bridge No. TAS 98-8B Seneca 5 Bridges}

The New York State Thruway authority used one typical plan set for the replacement of 5 bridges. The Seneca 5 Bridges are two-span continuous composite steel plate girder bridges with equal spans of $100 \mathrm{ft}$. It consists of an $8 \mathrm{in}$. reinforced concrete deck with a 1.5 in. wearing course supported by 5 girders spaced at $7 \mathrm{ft}$. $-4 \frac{1}{2}$ in. on center. The girders are fabricated from high performance steel HPS 70W (485W). It was designed using the 1996 AASHTO ASD Specifications and the design vehicle is HS25 (MS22.5). This bridge was selected for evaluation, as it is a representative bridge designed and constructed using HPS. 


\section{NY State DOT - US Route 20 over Route 11 A in Onondaga County}

The Route 20 Bridge is a simple-span composite steel plate girder bridge with a span length of $133 \mathrm{ft}$. It consists of a 9.5 in. reinforced concrete deck supported by 6 girders spaced at $9 \mathrm{ft}$. -6 in. on center. The girders are fabricated from conventional Grade $50(\mathrm{G} 345 \mathrm{~W})$ steel. It was designed using the AASHTO $16^{\text {th }}$ Edition and the design vehicle is HS25 (MS22.5). The bridge was selected for evaluation, as it is a representative steel bridge.

\section{$\underline{\text { Pennsylvania Department of Transportation - Berks County }}$}

The Berks County Bridge is a single-span composite steel plate girder bridge with a span length of $211 \mathrm{ft}$. It consists of an $8 \frac{1}{2}$ in. reinforced concrete deck supported by 4 girders spaced at $10 \mathrm{ft}$. -11 in. on center. The girders are fabricated from conventional Grade $50(\mathrm{G} 345 \mathrm{~W})$ steel. It was designed using the 1992 AASHTO $15^{\text {th }}$ Edition LFD Design Specification with the 1993 and 1994 interim and a HS25 design vehicle, 125 percent of the alternative military loading, or the P-82 permit load.

\section{Pennsylvania Department of Transportation - Northampton County}

The Northampton County Bridge is a single-span composite steel plate girder bridge with a span length of $123 \mathrm{ft}$. It consists of an 8.5 in. reinforced concrete deck supported by 5 girders spaced at $9 \mathrm{ft}$. -0 in. on center. The girders are fabricated from conventional Grade $50(\mathrm{G} 345 \mathrm{~W})$ steel. It was designed using the 1992 AASHTO $15^{\text {th }}$ Edition LFD Design Specification with the 1993 and the 1994 interim and a HS25 design vehicle, 125 percent of the alternative military loading, or the P-82 permit load. 
Tennessee - Bridge No. 25SR0520009 State Route 52 over Clear Fork River in Morgan

$\underline{\text { County }}$

The Clear Fork River Bridge is a four-span continuous composite steel plate girder bridge with span lengths of 145, 220, 350, and $280 \mathrm{ft}$. It consists of a $9.25 \mathrm{in}$. reinforced concrete deck supported by 4 girders spaced at $12 \mathrm{ft}$. -0 in. on center. The hybrid girders are fabricated from high performance steel HPS $70 \mathrm{~W}(485 \mathrm{~W})$ in the negative moment regions and in the tension flange in spans 3 and 4 conventional Grade 50W steel is used in all other locations. It was designed using the 1996 AASHTO LFD Design Specifications and the design vehicle is HS20-44 plus alternate military loading. This bridge was selected for evaluation, as it is a representative bridge designed and constructed using HPS.

\section{Tennessee - Bridge No. 44SR0530001 State Route 53 over Martin Creek}

The Martin Creek Bridge is a two-span continuous composite steel plate girder bridge with equal spans of $235 \mathrm{ft}$. -6 in.. It consists of a 9 in. reinforced concrete deck (slab + wearing course) and is supported by 3 girders spaced at $12 \mathrm{ft}$. on center. The girders are fabricated from high performance steel HPS 70W (485W). It was designed using the 1994 AASHTO LRFD Design Specifications and the design vehicle is the HL93 model. This bridge was selected for evaluation as live-load deflection limits were not imposed in the design however, to date, there have been no reported structural or serviceability related problems. 


\section{Utah Department of Transportation - Asay Creek Bridge in Garfield County}

The Asay Creek Bridge is a simple span composite steel plate girder bridge with a span length of $76 \mathrm{ft} .-1 \frac{1}{2}$ in.. It consists of a 8 in. reinforced concrete deck and is supported by 6 girders spaced at $7 \mathrm{ft}$ - $10 \frac{1}{2}$ in. on center. The girders are fabricated from A36 steel (Grade 250). It was designed using the 1996 AASHTO LFD Design Specifications and Interim and a HS20 (MS-18) design vehicle or alternative loading.

\section{Minnesota Department of Transportation - Truck Highway No. 169}

The Bloomington Township overpass is a two-span continuous composite steel plate girder bridge with spans of $86 \mathrm{ft}$ - $11 / 16$ in. and $95 \mathrm{ft}$. -6 1/8 in.. It consists of a 9 in. $\mathrm{RC}$ deck (slab + wearing course) supported by 13 girders spaced at $8 \mathrm{ft}$. -6 in. on center. The cross section has a gradient of $0.044 \mathrm{ft} . / \mathrm{ft}$. The girders are fabricated from conventional Grade 50 steel. It was designed using the 1976 AASHTO LFD Design Specification and the design vehicle is HS20-44 with military alternative loading. This bridge meets AASHTO deflection criteria but has been reported to vibrate objectively.

\subsubsection{Analysis Results}

\section{Comparisons with AASHTO Standard Specifications}

Table 5.7 presents a summary of the maximum live-load deflections as well as the computed $L / \delta$ ratio for each of the 13 bridges. Additionally, this table shows the calculated $L / D$ ratio for each bridge along with the maximum allowable deflection, $L / 800$. Note that the calculated $L / D$ ratios shown in Table 5.7 are based on the full span length of the span in which the maximum deflection was calculated divided by the 
total superstructure depth (i.e. bottom flange + web + haunch + deck thickness, note in cases where a haunch dimension was not provided on structural drawings the haunch was assumed to be 2 inches). It may be seen in Table 5.7 that only two of the bridges in this study (both the Tennessee structures) were found to fail the AASHTO deflection limits with $L / \delta$ values of 481 and 456 . It should be noted that these structure also had the highest $L / D$ values of all the bridges in the study, 38.1 and 33.1 respectively. Fig. 5.13 shows the dependence of $L / \delta$ on the $L / D$ ratio selected by the designer for the 13 bridges considered. It is clear that when larger $L / D$ ratios are selected, the girders will be subjected to larger normalized live-load deflections.

This is an important factor to take into account when reconsidering the methodology used to evaluate live-load deflection and vibration serviceability, as studies (Clingenpeel, 2001; Horton et al., 2000) have shown HPS 70W girders may be very economical for both cases where depth restrictions are mandated due to site restrictions or where it may be advantageous to use reduced superstructure depths to increase vertical clearances or reduce substructure requirements. Should girders designed for these situations be required to meet $L / 800$ deflection criteria, HPS $70 \mathrm{~W}$ steel may not be used to its full potential.

\section{Comparison to Wright and Walker Recommendations}

Again, the Wright and Walker recommendations (Wright and Walker, 1971) determine an allowable effective peak acceleration based on the fundamental natural frequency along with a speed parameter and an impact factor. The value of this peak acceleration is then compared against tabulated limits that suggest the potential level of 
user comfort that may be expected. If the peak acceleration exceeds $100 \mathrm{in} . / \mathrm{sec}^{2}$ the member is to be redesigned such that this limit is not exceeded. This procedure is detailed in Chapter 2.

Table 5.8 shows a comparison of the computed peak accelerations for each of the thirteen bridges studied. In no case was any girder found to be unacceptable. As shown in Fig. 5.14, a comparison between the predicted accelerations and the $L / \delta$ values for each of the bridge indicates that there is not a trend between predicted $L / \delta$ values and vibration performance as computed by the Walker and Wright procedures. In fact, in many cases there were inverse relationships. For example, the New York Usher's road bridge has an $L / \delta$ of 1760 but is found to be categorized as "Perceptable to Most" based on Wright and Walker's procedures. Further, the Tennessee Clear Fork Bridge with an $L / \delta$ of 481 (far below the allowable AASHTO limit) is found to be categorized as "Perceptible". Further discrepancies may also be found; for example the Nebraska Dodge Street Bridge with and $L / \delta$ of 873 is categorized as "Unpleasant to Few" as is the Illinois Jackson Street Bridge with an $L / \delta$ of 1430 (considerably above the require AASHTO limit). While it is not suggested that the Wright and Walker criteria is the most valid measure of superstructure vibration acceptability, these trends do indicate that there is not a direct relationship between superstructure deflections and vibration serviceability.

\section{Comparison with the Ontario Highway Bridge Design Code}

Table 5.9 presents the deflections calculated using the procedures specified in the Ontario Highway Bridge Design Code along with the natural frequency calculated using Eqn. 2.2 for simple and continuous span bridges with equal span lengths and Eqn. 2.2 
with Billing's corrector factor for continuous span bridges with unequal span lengths. This table also shows the performance criteria classification of each of the respective structures based on the Ontario specifications. Figure 5.12 provides a graphical presentation of the data from Table 5.9.

It is interesting to note that the two bridges closest to failing the OHBDC procedures, Illinois Jackson Co. (\#1) and Utah's Asay Creek (\#12) had lower $L / D$ ratios (21.6 and 19.6 respectively) than many of the typical bridges in this study. The reader should recall that it has been suggested that there is a relationship between $L / D$ ratios and $L / \delta$ ratios and hence it would follow that lower $L / D$ ratios would lead to improved deflection serviceability.

It may also be noted that both of the Tennessee bridges, which were specifically designed with disregard for the deflection limit (i.e., in both cases the lane load deflections exceeded $L / 800$, however, all other strength and serviceability criteria were met), were found to almost meet the highest level of bridge vibration criteria.

Figure 5.12 suggests that there is not a clear relationship between the $L / \delta$ and implied user comfort ratings. For example, the two structures with the largest $L / \delta$, New York's US Rt. 20 (\#6) and Ushers Road (\#7) (with $L / \delta=1757$ and 1760 respectively) are not the structures with the "best" performance as suggested by the Ontario recommendations. There is no dependent trend seen in this figure between $L / \delta$ and performance ratings. 


\subsubsection{Concluding Remarks}

While only two of the thirteen structures in this section failed to meet AASHTO deflection criteria, it should be noted that these structure were designed to meet these respective live-load limitations. The two structures that did fail to meet the criteria (the Tennessee bridges) were designed disregarding the criteria. These bridges were reported to save approximately $10 \%$ of the cost of conventional I girder bridges.

The above remarks regarding the apparent discrepancies between live-load deflections and vibration performance are an indicator that, as has been reported by others, the AASHTO deflection limits or $L / D$ ratios, as they were proposed, are not a practical design limit to control superstructure performance.

Both the Wright and Walker and OHBDC depend on the accuracy of the prediction of the fundamental natural frequency. In both cases, they use the standard equation for the natural frequency of a simply supported beam. However, this expression is not specifically applicable for continuous spans, especially for cases where a continuous span has either unequal spans or greater than two spans. Closed form solutions are not readily available for typical design configurations. While there are empirical expressions (see Chapter 3) based on analytical and experimental work that better predict the natural frequency for typical highway bridges, these tend to be limited in scope, often focused on a narrow range of parameters, and none of these equations can be coded. For example, normalized tables exist for the calculation of natural frequencies in continuous spans (Billing, 1979), but little documentation is available to relate this to the actual vibration periods of typical bridge superstructures. Current research efforts are aimed towards developing such expressions. 
In neither of the Tennessee bridges (the only bridges in this study found to exceed the AASHTO requirements) has there been any report of rider discomfort nor reports of excessive deck cracking or other forms of structural damage. Results of this study suggest that there is little relationship between a direct limit state check on live-load deflection and the suitability of a given structure to either resist structural damage or provide acceptable levels of user comfort. While it is acknowledged that bridges have been found to sustain structural damage due to excessive deflections, the nature of reported structural damage is such that it is predominantly due to local force effects which are in no way controlled by global live-load deflection checks.

Also, refined 3D finite element modeling of composite steel bridges has indicated that actual live-load deflections, which account more accurately for load sharing among structural components, may be considerably smaller than those computed using line girder type analyses. Additionally, accounting for the beneficial effects of other stiffening elements such as parapets, sidewalks, and such components lead to a further reduction in computed live-load deflections. 
Table 5.1. Matrix of initial parameters

\begin{tabular}{|c|l|l|l|l|l|}
\hline $\begin{array}{c}\text { Cross } \\
\text { Section }\end{array}$ & $\begin{array}{c}\text { Span Length, } \\
\mathbf{L} \\
(\mathbf{f t} .)\end{array}$ & $\begin{array}{c}\text { Steel } \\
\text { Strength, } \\
\text { Fy (ksi.) }\end{array}$ & \multicolumn{1}{|c|}{ L/D Ratio } & $\begin{array}{c}\text { Girder } \\
\text { Spacing, } \\
\text { S }\end{array}$ & \multicolumn{1}{|c|}{$\begin{array}{c}\text { Span } \\
\text { Configuration }\end{array}$} \\
\hline 1 & $100,200,300$ & 50,70 & $15,20,25,30$ & $9^{\prime}-0^{\prime \prime}$ & $\begin{array}{l}\text { Simple, 2-span, } \\
\text { 3-span }\end{array}$ \\
\hline 2 & $100,200,300$ & 50,70 & $15,20,25,30$ & $11^{\prime}-6 ”$ & $\begin{array}{l}\text { Simple, 2-span, } \\
\text { 3-span }\end{array}$ \\
\hline 3 & $\begin{array}{l}100,150,200, \\
250\end{array}$ & 50,70 & $15^{1}, 20^{1}, 25^{1}, 30^{1}$ & $10^{\prime}-4^{\prime \prime}$ & Simple, 2-span \\
\hline 4 & $100,200,300$ & 50,70 & $15,20,25,30$ & $8^{\prime}-6^{\prime \prime}$ & $\begin{array}{l}\text { Simple, 2-span, } \\
\text { 3-span }\end{array}$ \\
\hline
\end{tabular}

Note:

${ }^{1} \mathrm{~L} / \mathrm{D}$ ratio for cross section \# 3 two-span bridges uses $\mathrm{L}=0.80 \mathrm{~L}$, the length between dead load contraflexure points. 
Table 5.2. Comparison of initial girder designs with girders not meeting the deflection criteria for cross section 1

\begin{tabular}{|c|c|c|c|c|c|c|c|}
\hline $\begin{array}{c}\text { Span } \\
\text { (ft.) }\end{array}$ & $\begin{array}{c}\text { Fy } \\
\text { (ksi) }\end{array}$ & L/D & L/ $\delta$ & $\begin{array}{c}\text { Weight }{ }^{1} \\
\text { (tons) }\end{array}$ & $\begin{array}{l}\mathbf{f}_{\mathrm{b}}{ }^{2} \\
(\mathrm{~Hz})\end{array}$ & $\begin{array}{c}a^{3} \\
\text { in/sec }\end{array}$ & Classification $^{3}$ \\
\hline \multicolumn{8}{|c|}{ simple span } \\
\hline 100 & 70 & 30.1 & 615 & 11.0 & 2.22 & 63.116 & Unpleasant to Few \\
\hline 100 & 70 & 25.1 & 806 & 19.7 & 2.39 & 53.542 & Unpleasant to Few \\
\hline 200 & 70 & 30.1 & 671 & 38.0 & 1.27 & 37.229 & Perceptible \\
\hline 200 & 70 & 25.0 & 802 & 48.9 & 1.34 & 33.711 & Perceptible \\
\hline 300 & 70 & 29.9 & 716 & 102.0 & 0.92 & 27.143 & Perceptible \\
\hline 300 & 70 & 25.6 & 815 & 130.6 & 0.93 & 56.838 & Perceptible \\
\hline 100 & 50 & 30.3 & 657 & 12.0 & 2.28 & 61.337 & Unpleasant to Few \\
\hline 100 & 50 & 30.1 & 821 & 19.5 & 2.41 & 53.210 & Unpleasant to Few \\
\hline 200 & 50 & 30.0 & 768 & 44.0 & 1.33 & 34.821 & Perceptible \\
\hline 200 & 50 & 30.0 & 802 & 46.2 & 1.35 & 34.072 & Perceptible \\
\hline \multicolumn{8}{|c|}{2 span continuous } \\
\hline 300 & 70 & 29.6 & 774 & 184.6 & 0.67 & 15.863 & Perceptible to Most \\
\hline 300 & 70 & 29.7 & 801 & 188.6 & 0.68 & 15.658 & Perceptible to Most \\
\hline
\end{tabular}

Notes:

1 weight is for one steel girder

2 natural frequency computed using Eqn. 2.2

3 classification based on Wright and Walker (1971) 
Table 5.3. Comparison of initial girder designs with girders not meeting the deflection criteria for cross section 2

\begin{tabular}{|c|c|c|c|c|c|c|c|}
\hline $\begin{array}{c}\text { Span } \\
\text { (ft.) }\end{array}$ & $\begin{array}{c}\text { Fy } \\
(\mathbf{k s i})\end{array}$ & L/D & $\mathrm{L} / \delta$ & $\begin{array}{l}\text { Weight } \\
\text { (tons) }\end{array}$ & $\begin{array}{c}f_{\mathrm{b}}{ }^{2} \\
(\mathrm{~Hz})\end{array}$ & $\begin{array}{c}a^{3} \\
\left(\mathrm{in} / \mathrm{sec}^{2}\right) \\
\end{array}$ & Classification $^{3}$ \\
\hline \multicolumn{8}{|c|}{ simple spans } \\
\hline 100 & 70 & 30.4 & 629 & 15.0 & 2.07 & 44.680 & Perceptible \\
\hline 100 & 70 & 30.0 & 815 & 26.5 & 2.22 & 38.076 & Perceptible \\
\hline 200 & 70 & 30.1 & 711 & 50.0 & 1.22 & 26.502 & Perceptible \\
\hline 200 & 70 & 30.0 & 808 & 58.9 & 1.27 & 24.714 & Perceptible \\
\hline 300 & 70 & 29.6 & 774 & 126.0 & 0.91 & 19.764 & Perceptible to Most \\
\hline 300 & 70 & 25.3 & 806 & 144.7 & 0.90 & 18.658 & Perceptible to Most \\
\hline
\end{tabular}

Notes:

1 weight is for one steel girder

2 natural frequency computed using Eqn. 2.2

3 parametric based on Wright and Walker (Wright and Walker, 1971) 
Table 5.4. Comparison of initial girder designs with girders not meeting the deflection criteria for cross section 3

\begin{tabular}{|c|c|c|c|c|c|c|c|c|}
\hline $\begin{array}{l}\text { Span } \\
\text { (ft.) }\end{array}$ & $\begin{array}{c}\text { Fy } \\
\text { (ksi) }\end{array}$ & $\begin{array}{l}\text { Design } \\
\text { method }\end{array}$ & L/D & $\mathrm{L} / \delta$ & \begin{tabular}{|c|} 
Weight \\
(tons)
\end{tabular} & $\begin{array}{l}f_{b}{ }^{2} \\
(H z)\end{array}$ & $\begin{array}{c}a^{3} \\
\text { in/sec2 }\end{array}$ & Classification $^{3}$ \\
\hline \multicolumn{9}{|c|}{ Simple Spans } \\
\hline 100 & 50 & LFD & 25.3 & 726 & 11.42 & 2.54 & 51.991 & Unpleasant to Few \\
\hline 100 & 50 & $L F D$ & 25.1 & 811 & 14.06 & 2.64 & 49.237 & Perceptible \\
\hline 100 & 50 & LFD & 30.0 & 628 & 14.93 & 2.27 & 51.036 & Unpleasant to Few \\
\hline 100 & 50 & $L F D$ & 29.7 & 808 & 26.25 & 2.44 & 44.051 & Perceptible \\
\hline 100 & 50 & LRFD & 30.5 & 638 & 11.90 & 2.10 & 44.954 & Perceptible \\
\hline 100 & 50 & $L R F D$ & 30.0 & 802 & 15.40 & 2.28 & 40.206 & Perceptible \\
\hline 100 & 70 & LFD & 25.1 & 734 & 10.86 & 2.57 & 52.254 & Unpleasant to Few \\
\hline 100 & 70 & $L F D$ & 25.1 & 800 & 12.19 & 2.66 & 50.460 & Unpleasant to Few \\
\hline 100 & 70 & LRFD & 25.3 & 752 & 8.00 & 2.36 & 45.052 & Perceptible \\
\hline 100 & 70 & $\angle R F D$ & 25.1 & 864 & 9.00 & 2.51 & 42.909 & Perceptible \\
\hline 100 & 70 & LFD & 30.0 & 548 & 12.72 & 2.19 & 55.584 & Unpleasant to Few \\
\hline 100 & 70 & $L F D$ & 29.7 & 806 & 25.45 & 2.45 & 44.374 & Perceptible \\
\hline 100 & 70 & LRFD & 30.5 & 582 & 9.50 & 2.05 & 47.629 & Perceptible \\
\hline 100 & 70 & LRFD & 30.0 & 824 & 15.0 & 2.35 & 40.902 & Perceptible \\
\hline 150 & 50 & LFD & 30.2 & 711 & 26.27 & 1.72 & 37.430 & Perceptible \\
\hline 150 & 50 & $L F D$ & 29.5 & 817 & 37.52 & 1.73 & 32.830 & Perceptible \\
\hline 150 & 70 & LFD & 24.9 & 723 & 20.17 & 1.77 & 38.410 & Perceptible \\
\hline 150 & 70 & $L F D$ & 24.9 & 810 & 23.83 & 1.82 & 35.687 & Perceptible \\
\hline 150 & 70 & LFD & 29.8 & 567 & 21.10 & 1.57 & 41.068 & Perceptible \\
\hline 150 & 70 & $L F D$ & 29.8 & 840 & 41.14 & 1.70 & 32.333 & Perceptible \\
\hline 150 & 70 & LRFD & 29.7 & 731 & 16.9 & 1.55 & 31.307 & Perceptible \\
\hline 150 & 70 & LRFD & 29.5 & 819 & 19.2 & 1.65 & 30.563 & Perceptible \\
\hline 200 & 50 & LFD & 29.9 & 716 & 48.95 & 1.38 & 31.519 & Perceptible \\
\hline 200 & 50 & $L F D$ & 29.9 & 801 & 65.66 & 1.36 & 27.585 & Perceptible \\
\hline 200 & 70 & LFD & 25.0 & 729 & 36.82 & 1.43 & 32.669 & Perceptible \\
\hline 200 & 70 & $L F D$ & 25.0 & 803 & 44.51 & 1.44 & 30.064 & Perceptible \\
\hline 200 & 70 & LFD & 30.0 & 571 & 37.48 & 1.27 & 35.003 & Perceptible \\
\hline 200 & 70 & $L F D$ & 29.9 & 801 & 65.66 & 1.36 & 26.783 & Perceptible \\
\hline 250 & 70 & LFD & 24.9 & 777 & 69.24 & 1.21 & 27.164 & Perceptible \\
\hline 250 & 70 & $L F D$ & 25.1 & 804 & 74.59 & 1.19 & 28.831 & Perceptible \\
\hline 250 & 70 & LFD & 30.0 & 578 & 63.34 & 1.07 & 30.371 & Perceptible \\
\hline 250 & 70 & $L F D$ & 29.9 & 802 & 101.85 & 1.13 & 26.752 & Perceptible \\
\hline \multicolumn{9}{|c|}{2 span continuous (L/D = 0.8L/D) } \\
\hline 150 & 50 & LFD & 24.9 & 765 & 56.88 & 1.27 & 22.539 & Perceptible \\
\hline 150 & 50 & $L F D$ & 24.9 & 900 & 75.39 & 1.29 & 19.580 & Perceptible to Most \\
\hline 150 & 50 & LFD & 30.0 & 623 & 76.88 & 1.07 & 21.870 & Perceptible \\
\hline 150 & 50 & $L F D$ & 30.0 & 845 & 111.65 & 1.15 & 17.788 & Perceptible to Most \\
\hline 150 & 50 & LRFD & 30.1 & 710 & 62.3 & 1.01 & 17.755 & Perceptible to Most \\
\hline 150 & 50 & LRFD & 30.0 & 818 & 67.4 & 1.07 & 16.662 & Perceptible to Most \\
\hline
\end{tabular}


Table 5.4. Continued

\begin{tabular}{|c|c|c|c|c|c|c|c|c|}
\hline $\begin{array}{c}\text { Span } \\
\text { (ft.) }\end{array}$ & $\begin{array}{c}\text { Fy } \\
\text { (ksi) }\end{array}$ & $\begin{array}{l}\text { Design } \\
\text { method }\end{array}$ & L/D & $\mathrm{L} / \delta$ & \begin{tabular}{|c|} 
Weight \\
(tons)
\end{tabular} & $\begin{array}{l}\mathrm{f}_{\mathrm{b}}{ }^{2} \\
(\mathrm{~Hz})\end{array}$ & $\begin{array}{c}a^{3} \\
\text { in/sec2 }\end{array}$ & Classification $^{3}$ \\
\hline \multicolumn{9}{|c|}{2 spans Continuous (Cont') } \\
\hline 150 & 70 & LFD & 24.8 & 739 & 43.78 & 1.34 & 25.155 & Perceptible \\
\hline 150 & 70 & $\angle F D$ & 24.9 & 812 & 54.38 & 1.35 & 23.144 & Perceptible \\
\hline 150 & 70 & LFD & 30.0 & 575 & 55.68 & 1.12 & 25.235 & Perceptible \\
\hline 150 & 70 & $L F D$ & 30.0 & 845 & 111.65 & 1.16 & 18.820 & Perceptible to Most \\
\hline 150 & 70 & LRFD & 30.0 & 781 & 53.6 & 1.09 & 17.893 & Perceptible to Most \\
\hline 150 & 70 & $\angle R F D$ & 30.0 & 816 & 55.4 & 1.15 & 18.423 & Perceptible to Most \\
\hline 200 & 50 & $\overline{L F D}$ & 24.9 & 728 & 100.27 & 0.96 & 18.395 & Perceptible to Most \\
\hline 200 & 50 & $L F D$ & 24.9 & 805 & 109.20 & 0.99 & 17.376 & Perceptible to Most \\
\hline 200 & 50 & LFD & 29.5 & 669 & 132.12 & 0.86 & 17.185 & Perceptible to Most \\
\hline 200 & 50 & $\angle F D$ & 29.5 & 905 & 179.77 & 0.92 & 13.946 & Perceptible to Most \\
\hline 200 & 70 & LFD & 25.0 & 647 & 75.97 & 0.97 & 21.013 & Perceptible \\
\hline 200 & 50 & $L F D$ & 25.7 & 822 & 107.72 & 1.02 & 17.738 & Perceptible to Most \\
\hline 200 & 70 & LFD & 29.7 & 522 & 90.45 & 0.84 & 21.337 & Perceptible \\
\hline 200 & 70 & $\angle F D$ & 29.5 & 816 & 157.38 & 0.92 & 15.466 & Perceptible to Most \\
\hline 250 & 50 & LFD & 30.0 & 720 & 224.77 & 0.71 & 19.641 & Perceptible to Most \\
\hline 250 & 50 & LFD & 30.0 & 804 & 165.60 & 0.75 & 12.029 & Perceptible to Most \\
\hline 250 & 70 & LFD & 25.1 & 630 & 126.35 & 0.78 & 17.699 & Perceptible to Most \\
\hline 250 & 70 & $L F D$ & 25.5 & 827 & 178.75 & 0.83 & 14.701 & Perceptible to Most \\
\hline 250 & 70 & LFD & 30.0 & 498 & 148.23 & 0.66 & 17.773 & Perceptible to Most \\
\hline 250 & 70 & $L F D$ & 30.0 & 804 & 239.59 & 0.75 & 13.127 & Perceptible to Most \\
\hline
\end{tabular}

Notes:

1 weight is for one steel girder

2 natural frequency computed using Eqn. 2.2

3 parametric based on Wright and Walker (Wright and Walker, 1971) 
Table 5.5. Comparison of initial girder designs with girders not meeting the deflection criteria for cross section 4

\begin{tabular}{|c|c|c|c|c|c|c|c|}
\hline $\begin{array}{c}\text { Span } \\
\text { (ft.) }\end{array}$ & $\begin{array}{c}\text { Fy } \\
\text { (ksi) }\end{array}$ & L/D & L/ $\delta$ & $\begin{array}{c}\text { Weight } \\
\text { (tons) }\end{array}$ & $\begin{array}{c}f_{b}{ }^{2} \\
(\mathrm{~Hz}) \\
\end{array}$ & $\begin{array}{c}\mathrm{a}^{3} \\
\left(\mathrm{in} / \mathrm{sec}^{2}\right) \\
\end{array}$ & Classification $^{3}$ \\
\hline \multicolumn{8}{|c|}{ simple spans } \\
\hline 100 & 70 & 29.2 & 743 & 12.3 & 2.37 & 68.844 & Unpleasant to Few \\
\hline 100 & 70 & 29.1 & 802 & 14.6 & 2.42 & 65.773 & Unpleasant to Few \\
\hline 200 & 70 & 29.5 & 732 & 35.5 & 1.33 & 43.803 & Perceptible \\
\hline 200 & 70 & 29.4 & 801 & 38.9 & 1.38 & 42.268 & Perceptible \\
\hline 300 & 70 & 29.3 & 781 & 105.1 & 0.95 & 31.306 & Perceptible \\
\hline 300 & 70 & 29.8 & 812 & 107.8 & 0.96 & 30.620 & Perceptible \\
\hline
\end{tabular}

Notes:

${ }^{1}$ weight is for one steel girder

2 natural frequency computed using Eqn. 2.2

3 parametric based on Wright and Walker (Wright and Walker, 1971) 
Table 5.6. Summary of typical plate girder bridges analyzed in this study

\begin{tabular}{|c|c|c|c|c|}
\hline & Bridge & State & $\begin{array}{c}\text { Standard } \\
\text { Evaluation }\end{array}$ & Comments \\
\hline 1 & Jackson County & Illinois & Pass & $\begin{array}{c}\text { Simple span composite. } 103^{\prime}-103 / 4 " \text { span. } 75^{\circ} \text { skew. } 5 \text { girders at } 7 \text { ' } \\
\text { 5" spacing. Staggered diaphragms. }\end{array}$ \\
\hline 2 & Randolph County & Illinois & Pass & $\begin{array}{l}\text { 4-span continuous. } 81^{\prime}-0^{\prime \prime}, 129^{\prime}-6 ”, 129^{\prime}-6 ”, 81^{\prime}-0 " \text { spans. Right } \\
\text { bridge. } 5 \text { girders at 5' }-2 \text { " spacing. Non-staggered diaphragms. }\end{array}$ \\
\hline 3 & Dodge Street & Nebraska & Pass & $\begin{array}{c}\text { 2-span continuous. } 236 \text { ' } 6 \text { " spans. Right bridge. } 8 \text { girders at 9' }-6 " \\
\text { spacing. Non-staggered diaphragms. }\end{array}$ \\
\hline 4 & Snyder South & Nebraska & Pass & $\begin{array}{c}\text { Simple span composite. } 151^{\prime}-0 " \text { span. Right bridge. } 5 \text { girders at } 8^{\prime}- \\
0 " \text { spacing. Non-staggered diaphragms. }\end{array}$ \\
\hline 5 & Seneca & New York & Pass & $\begin{array}{c}\text { 2-span continuous. } 100^{\prime}-0 \text { " spans. Right bridge. } 5 \text { girders at } 7>-4^{1} /{ }^{\prime \prime} \\
\text { spacing. Non-staggered diaphragms. }\end{array}$ \\
\hline 6 & US Route 20 & New York & Pass & $\begin{array}{c}\text { Simple span composite. } 133^{\prime}-0 " \text { span. } 120^{\circ} \text { skew. } 6 \text { girders at } 9^{\prime}-6^{\prime \prime} \\
\text { spacing. Non-staggered. }\end{array}$ \\
\hline 7 & $\begin{array}{l}\text { Interstate } 502-2-2 \\
\text { Ushers Road }\end{array}$ & New York & Pass & $\begin{array}{c}\text { 2-span continuous. } 183^{\prime}-0 \text { " spans. Right bridge. } 6 \text { girders at 9' }-4 \text { " } \\
\text { spacing. Non-staggered diaphragms. }\end{array}$ \\
\hline 8 & Berks County & Pennsylvania & Pass & $\begin{array}{l}\text { Simple span composite. } 211^{\prime}-0 " \text { span. } 45^{\circ} \text { skew. } 4 \text { girders at } 10^{\prime}- \\
11 ” \text { spacing. Non-staggered diaphragms. }\end{array}$ \\
\hline 9 & $\begin{array}{l}\text { Northampton } \\
\text { County }\end{array}$ & Pennsylvania & Pass & $\begin{array}{c}\text { Simple span composite. } 123^{\prime}-0 \text { " span. Right bridge. } 5 \text { girders at 9' }- \\
0 \text { " spacing. Non-staggered diaphragms. }\end{array}$ \\
\hline 10 & Clear Fork & Tennessee & $\begin{array}{l}\text { Doesn't } \\
\text { Pass }\end{array}$ & $\begin{array}{l}\text { 4-span continuous. } 145^{\prime}-0 ”, 220^{\prime}-0 ”, 350 '-0 ”, 280 \text { ' }-0 " \text { spans. } \\
\text { Right bridge. } 4 \text { girders at } 12 \text { ' }-0 \text { "spacing. Non-staggered diaphragms. }\end{array}$ \\
\hline
\end{tabular}


Table 5.6. continued

\begin{tabular}{|c|c|c|c|c|}
\hline & Bridge & State & $\begin{array}{c}\text { Standard } \\
\text { Evaluation }\end{array}$ & Comments \\
\hline 11 & Martin Creek & Tennessee & $\begin{array}{l}\text { Doesn't } \\
\text { Pass }\end{array}$ & $\begin{array}{c}\text { 2-span continuous. } 235^{\prime}-6 \text { " spans. Right bridge. } 3 \text { girders at } 10^{\prime}-6 \text { " } \\
\text { spacing. Non-staggered diaphragms. }\end{array}$ \\
\hline 12 & Asay Creek & Utah & Pass & $\begin{array}{c}\text { Simple span composite. } 76^{\prime}-1 \frac{1}{2}{ }^{\prime \prime} \text { span. Right bridge. } 6 \text { girders at } 8^{\prime}- \\
\text { 0" spacing. Non-staggered diaphragms. }\end{array}$ \\
\hline 13 & $\begin{array}{l}\text { Trunk Highway } \\
\text { No. } 169\end{array}$ & Minnesota & Pass & $\begin{array}{c}\text { 2-span continuous. 86'-1 1/16", 95'-6 1/8” spans. w/ 0.044'/Ft. gradient. } \\
13 \text { girders at 8'-6" spacing. Non-staggered diaphragms }\end{array}$ \\
\hline
\end{tabular}


Table 5.7. Comparisons with AASHTO Standard Specifications

\begin{tabular}{|c|c|c|c|c|c|}
\hline & Bridge Name & Actual L/D & $\delta$ max (in.) & L/d max & L/800 \\
\hline & & & & & \\
1 & Illinois Jackson Co. & 21.6 & 0.872 & 1430 & 1.559 \\
\hline 2 & Illinois Randolph Co. & 26.7 & 1.436 & 1082 & 1.943 \\
\hline 3 & Nebraska Dodge Street & 32.6 & 3.232 & 873 & 3.525 \\
\hline 4 & Nebraska Snyder St. & 27.1 & 1.640 & 1101 & 2.258 \\
\hline 5 & New York Seneca & 29.5 & 1.190 & 1008 & 1.500 \\
\hline 6 & New York US Rt. 20 & 21.7 & 0.915 & 1757 & 2.010 \\
\hline 7 & New York Ushers Road & 28.6 & 1.248 & 1760 & 2.745 \\
\hline 8 & Pennsylvania Berks Co. & 23.9 & 1.806 & 1402 & 3.165 \\
\hline 9 & Pennsylvania Northampton Co. & 18.5 & 0.886 & 1666 & 1.845 \\
\hline 10 & Tennessee Clear Fork & 38.1 & 8.729 & 481 & 5.250 \\
\hline 11 & Tennessee Martin Creek & 33.1 & 6.180 & 456 & 3.525 \\
\hline 12 & Utah Asay Creek & 19.6 & 0.465 & 1961 & 1.140 \\
\hline 13 & Minnesota Trunk Highway No. 169 & 25.4 & 0.708 & 1619 & 1.433 \\
\hline
\end{tabular}


Table 5.8. Comparisons with Wright and Walker alternative serviceability criteria

\begin{tabular}{|c|c|c|c|c|c|c|}
\hline & Bridge Name & $\delta \mathbf{m a x}$ (in.) & $\mathbf{f}(\mathbf{H z} .)^{\mathbf{1}}$ & $\mathbf{L} / \delta \mathbf{m a x}$ & $\mathbf{a ~ i n / s e c ~}^{\mathbf{2}}$ & $\begin{array}{c}\text { Wright and Walker } \\
\text { Human Response }\end{array}$ \\
\hline & Illinois Jackson Co. & 0.872 & 3.12 & 1430 & 68.774 & Unpleasant to few \\
\hline 2 & Illinois Randolph Co. & 1.436 & 2.10 & 1082 & 57.007 & Unpleasant to few \\
\hline 3 & Nebraska Dodge Street & 3.232 & 1.11 & 873 & 30.793 & Perceptible \\
\hline 4 & Nebraska Snyder St. & 1.640 & 1.91 & 1101 & 35.293 & Perceptible \\
\hline 5 & New York Seneca & 1.190 & 2.07 & 1008 & 52.250 & Unpleasant to few \\
\hline 6 & New York US Rt. 20 & 0.915 & 2.39 & 1757 & 26.175 & Perceptible \\
\hline 7 & New York Ushers Road & 1.248 & 1.66 & 1760 & 18.080 & Perceptible to most \\
\hline 8 & Pennsylvania Berks Co. & 1.806 & 1.53 & 1402 & 29.115 & Perceptible \\
\hline 9 & $\begin{array}{c}\text { Pennsylvania Northampton } \\
\text { Co. }\end{array}$ & 0.886 & 2.93 & 1666 & 39.664 & Perceptible \\
\hline 10 & Tennessee Clear Fork & 8.729 & 0.65 & 481 & 21.111 & Perceptible \\
\hline 11 & Tennessee Martin Creek & 6.180 & 0.69 & 456 & 22.535 & Perceptible \\
\hline 12 & Utah Asay Creek & 0.465 & 4.75 & 1961 & 63.090 & Unpleasant to few \\
\hline 13 & MinnesotaTrunk Highway & & & & & \\
& No. 169 & 0.708 & 2.54 & 1619 & 31.665 & Perceptible \\
\hline
\end{tabular}

notes:

${ }^{1}$ natural frequency computed using Eqn. 2.2 for simple or continuous span bridges with equal span lengths and Eqn. 2.2 with Billing's correction factor for continuous span bridges with unequal span lengths 
Table 5.9. Comparisons with Ontario Highway Bridge Design Code

\begin{tabular}{|c|c|c|c|c|c|}
\hline & Bridge Name & $\delta \max (\text { in. })^{1}$ & $f(\mathbf{H z} .)^{2}$ & L/S max & Meets Criterion \\
\hline 1 & Illinois Jackson Co. & 1.169 & 3.12 & 1430 & Without Sidewalks \\
\hline 2 & Illinois Randolph Co. & 2.091 & 2.10 & 1082 & Without Sidewalks \\
\hline 3 & Nebraska Dodge Street & 2.909 & 1.11 & 873 & With Sidewalks,Little Ped. Use \\
\hline 4 & Nebraska Snyder St. & 2.085 & 1.91 & 1101 & Without Sidewalks \\
\hline 5 & New York Seneca & 1.691 & 2.07 & 1008 & Without Sidewalks \\
\hline 6 & New York US Rt. 20 & 0.959 & 2.39 & 1757 & With Sidewalks,Little Ped. Use \\
\hline 7 & New York Ushers Road & 1.198 & 1.66 & 1760 & With Sidewalks,Little Ped. Use \\
\hline 8 & Pennsylvania Berks Co. & 0.837 & 1.53 & 1402 & With Sidewalks,Sig. Ped. Use \\
\hline 9 & $\begin{array}{c}\text { Pennsylvania Northampton } \\
\text { Co. }\end{array}$ & 0.913 & 2.93 & 1666 & Without Sidewalks \\
\hline 10 & Tennessee Clear Fork & 3.396 & 0.65 & 481 & With Sidewalks,Sig. Ped. Use \\
\hline 11 & Tennessee Martin Creek & 4.169 & 0.69 & 456 & With Sidewalks,Little Ped. Use \\
\hline 12 & Utah Asay Creek & 0.576 & 4.75 & 1961 & Without Sidewalks \\
\hline 13 & $\begin{array}{c}\text { Minnesota Trunk Highway } \\
\text { No. } 169\end{array}$ & 1.174 & 2.54 & 1691 & Without Sidewalks \\
\hline
\end{tabular}

notes:

${ }^{1}$ Deflection computed for Ontario Highway Bridge Design Code

${ }^{2}$ natural frequency computed using Eqn. 2.2 for simple or continuous span bridges with equal span

lengths and Eqn. 2.2 with Billing's correction factor for continuous span bridges with unequal span

lengths 


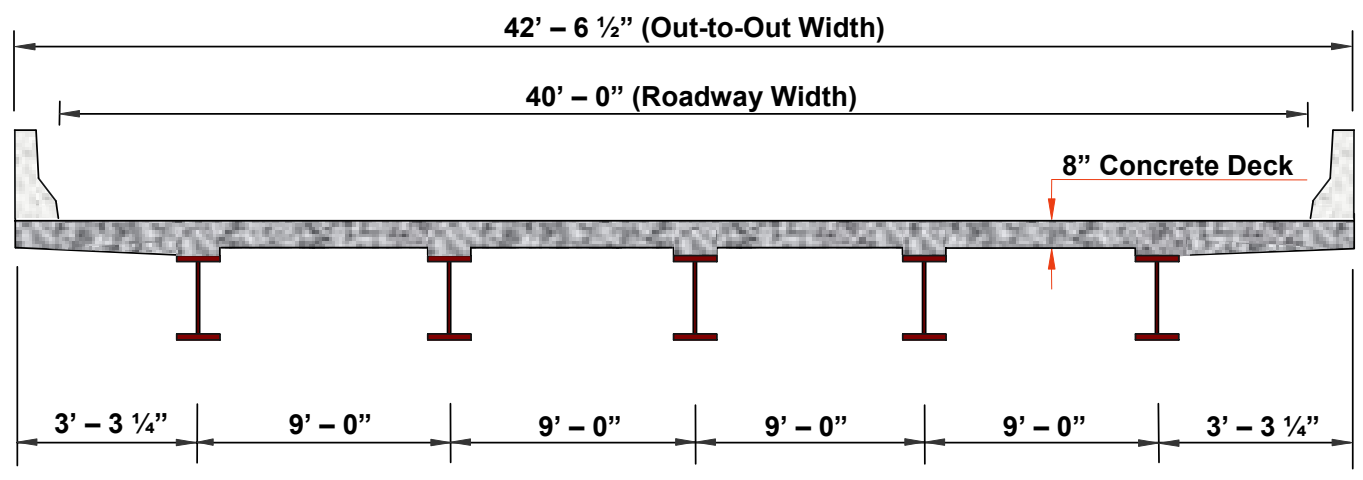

\section{a. Cross-Section \# 1}

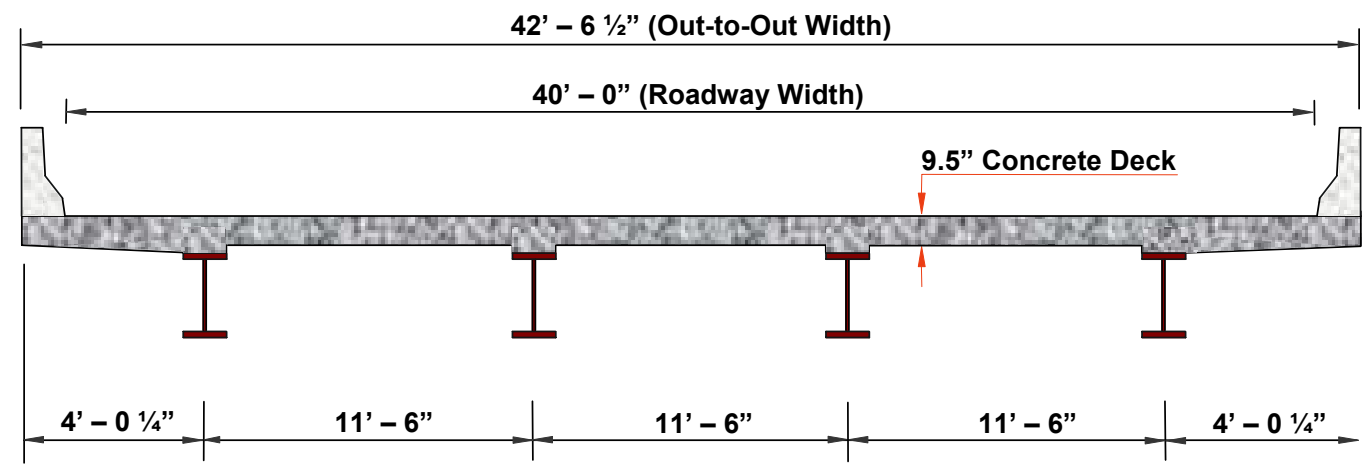

\section{b. Cross-Section \# 2}

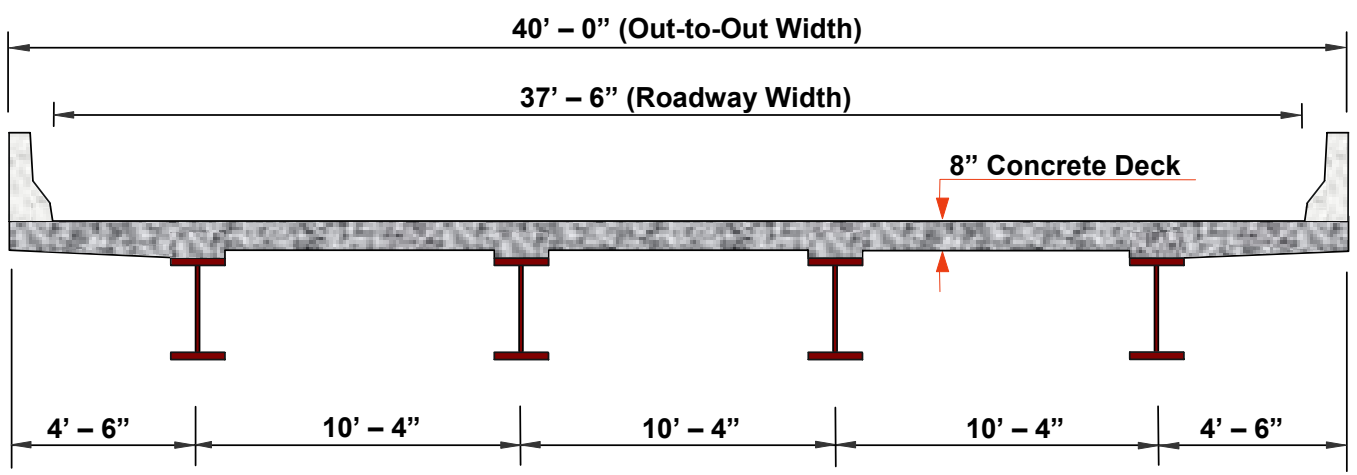

\section{c. Cross-Section \# 3}

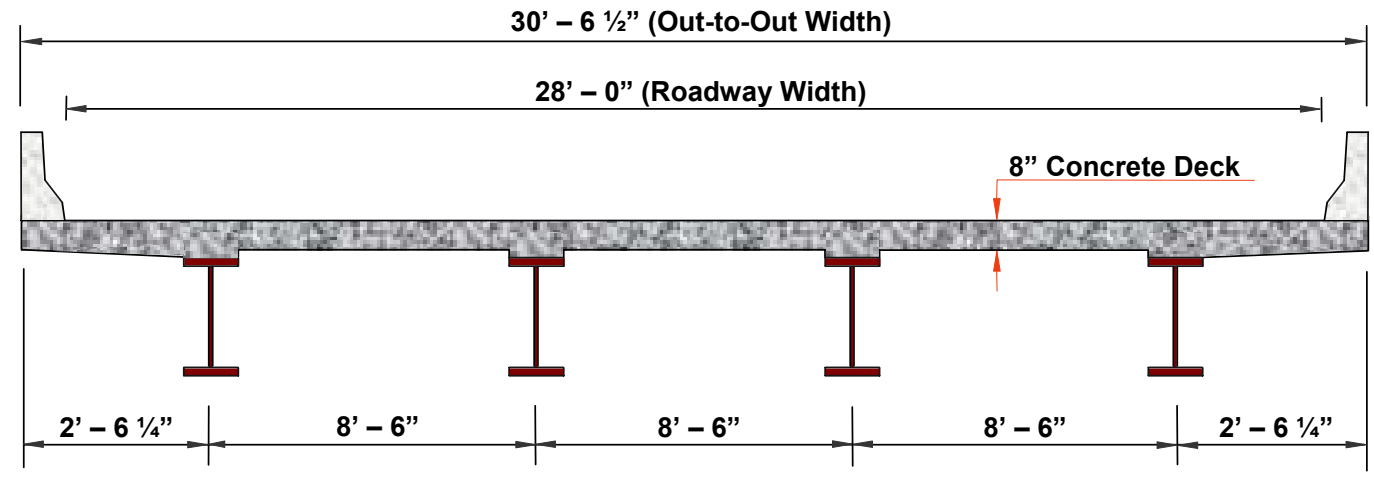

\section{d. Cross-Section \# 4}

Figure 5.1. Cross-sectional geometry for 4 bridge arrangements 


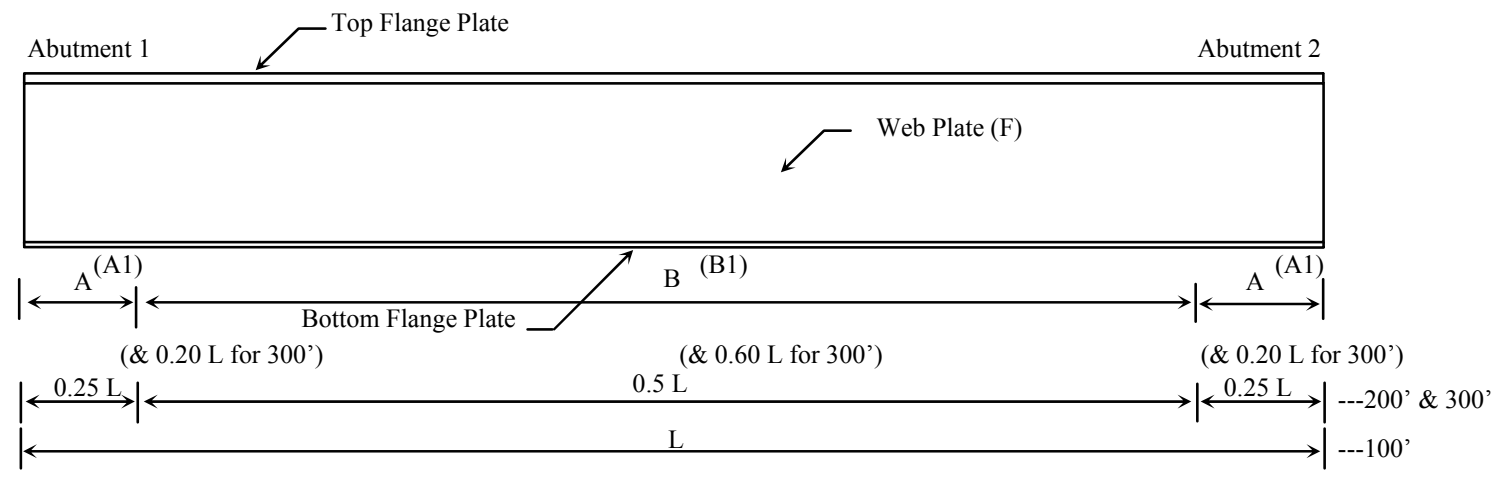

\section{Simple Span Composite Bridge}

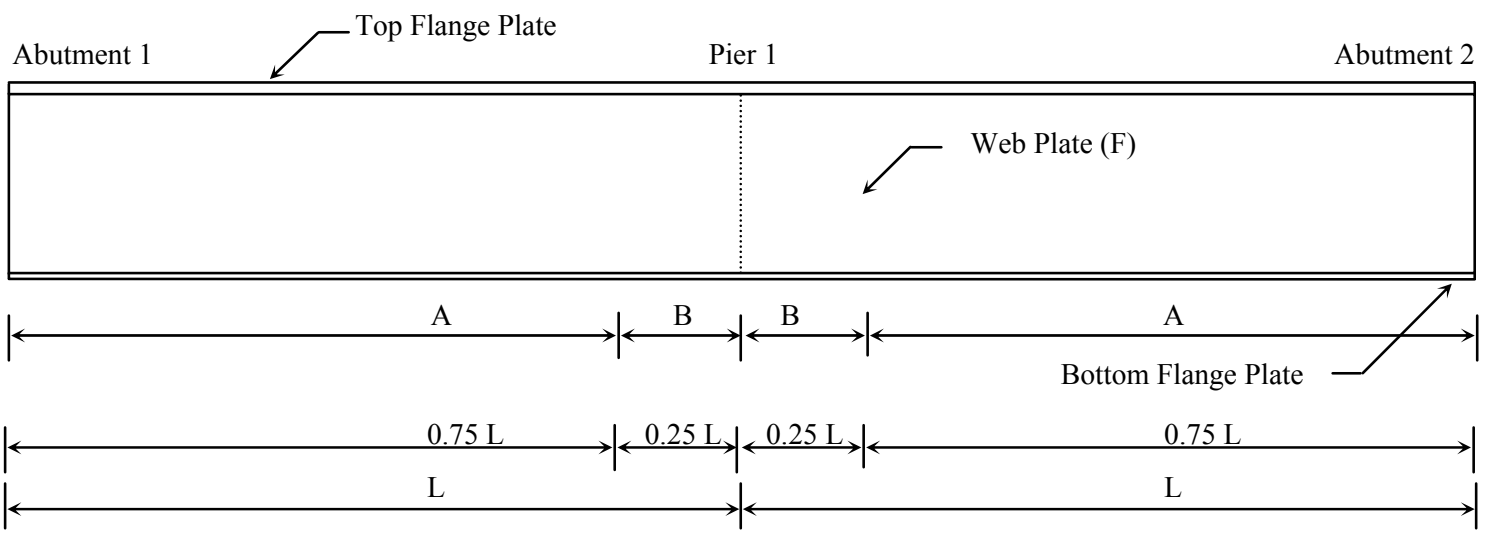

\section{Two span (L) Continuous Composite Bridge}

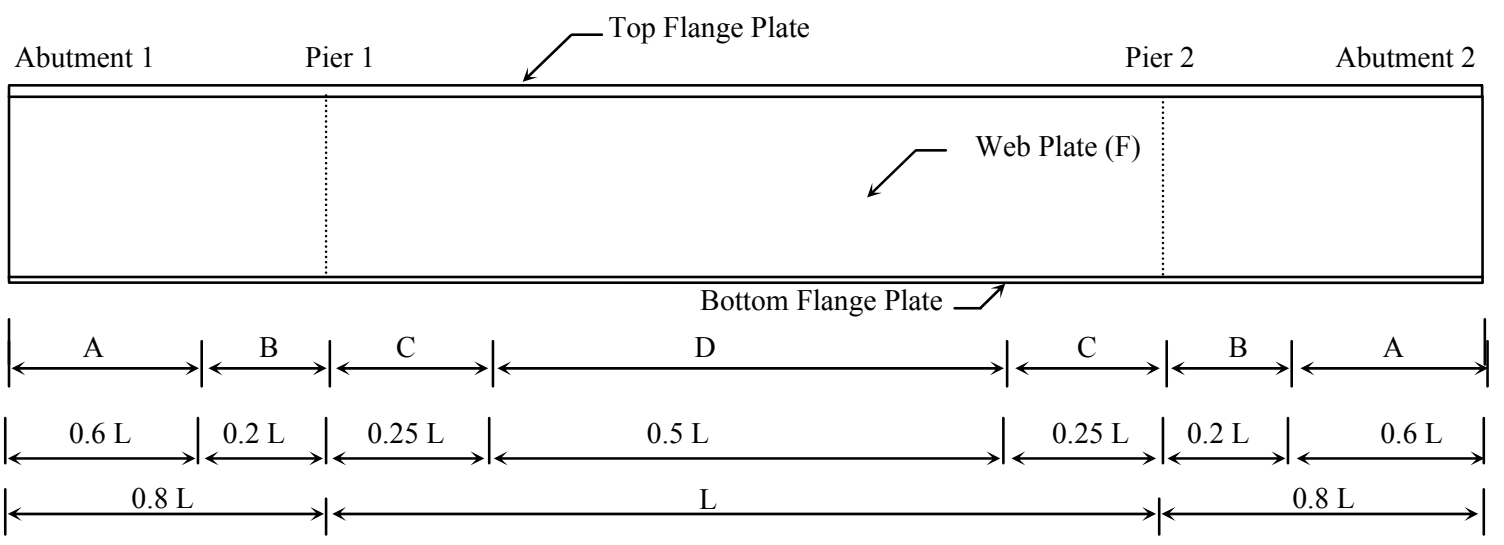

\section{Three-span (L) Continuous Composite Bridge}

Figure 6.2. Girder elevations of parametric design study bridges 


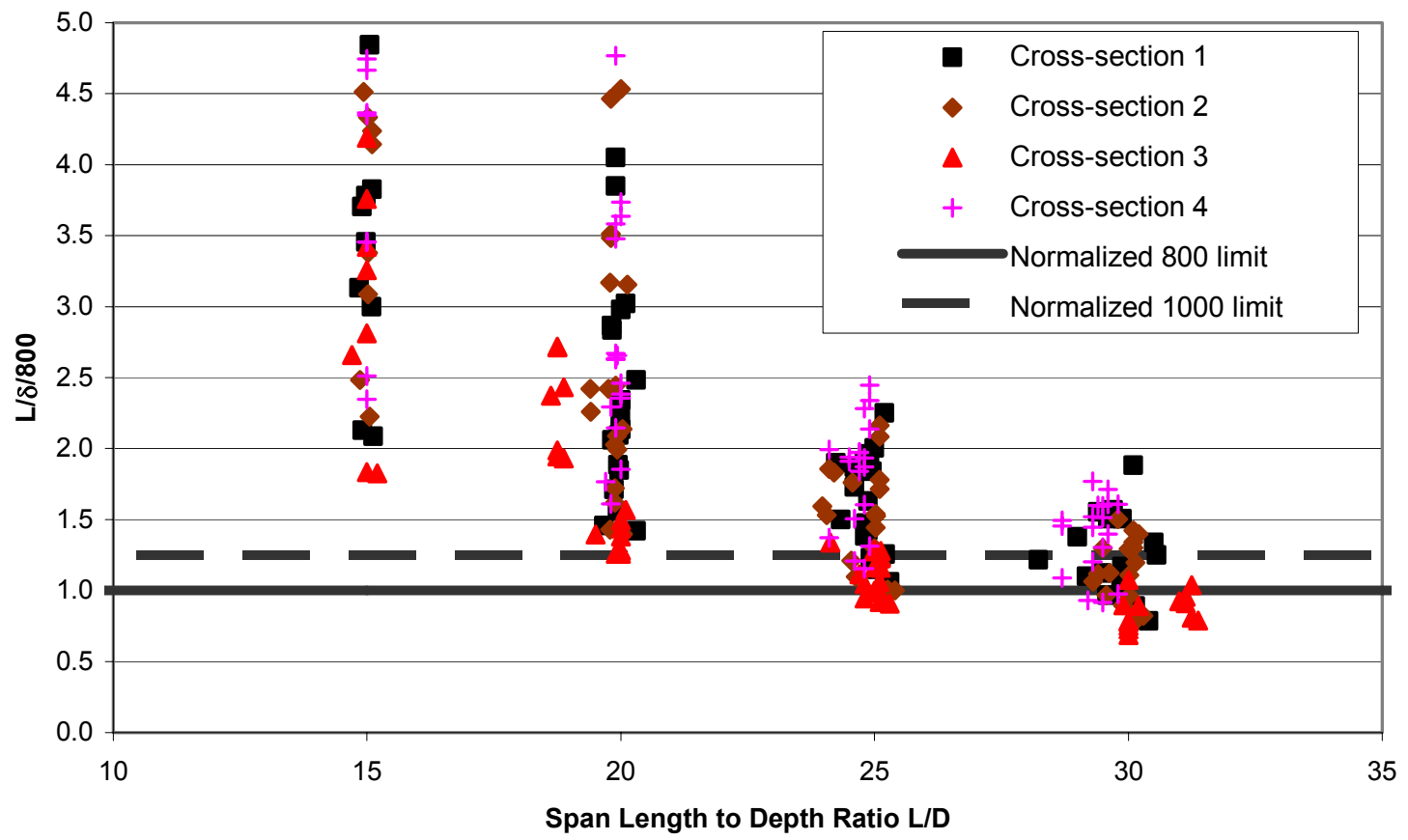

Figure 5.3. The influence of $\mathrm{L} / \mathrm{D}$ on live-load deflection 


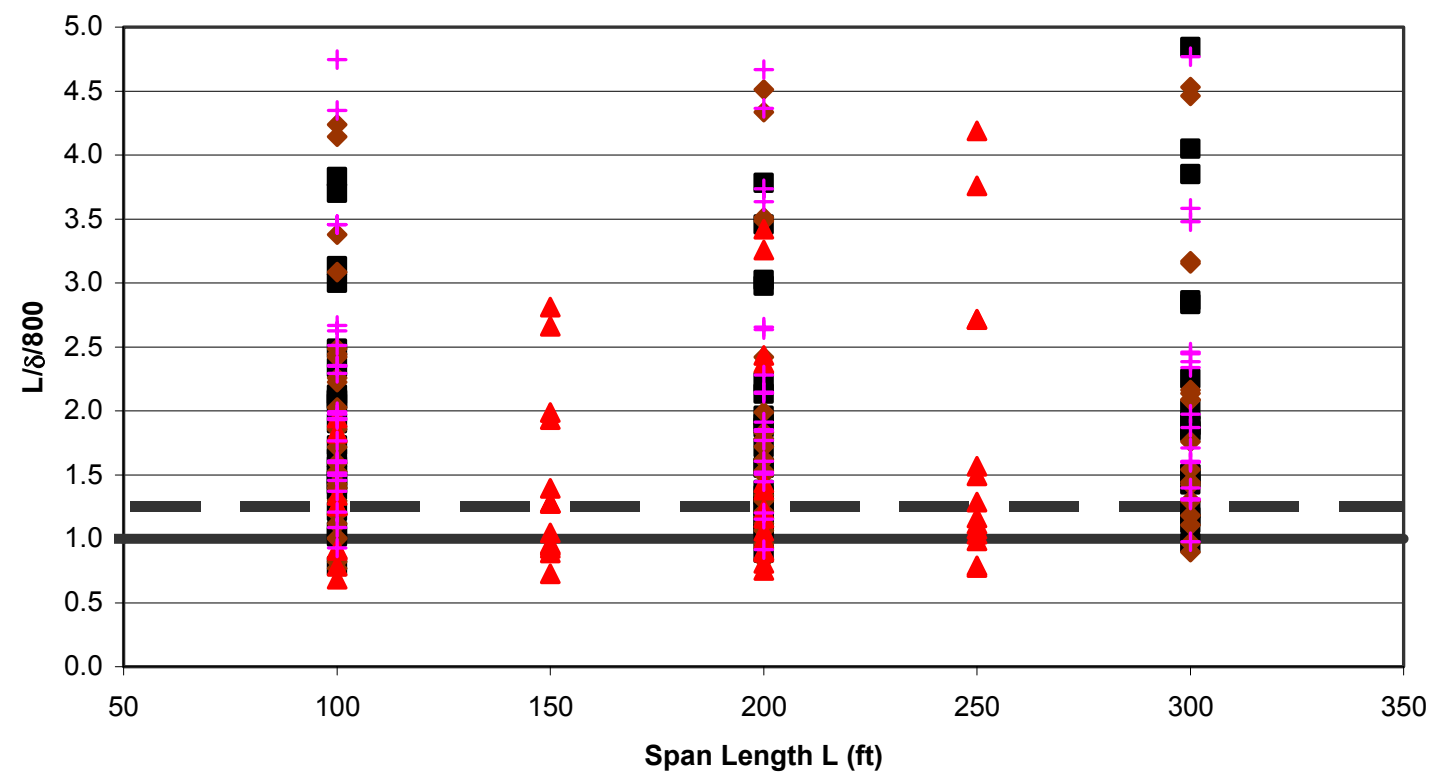

Figure 5.4. The influence of span length on live-load deflection 


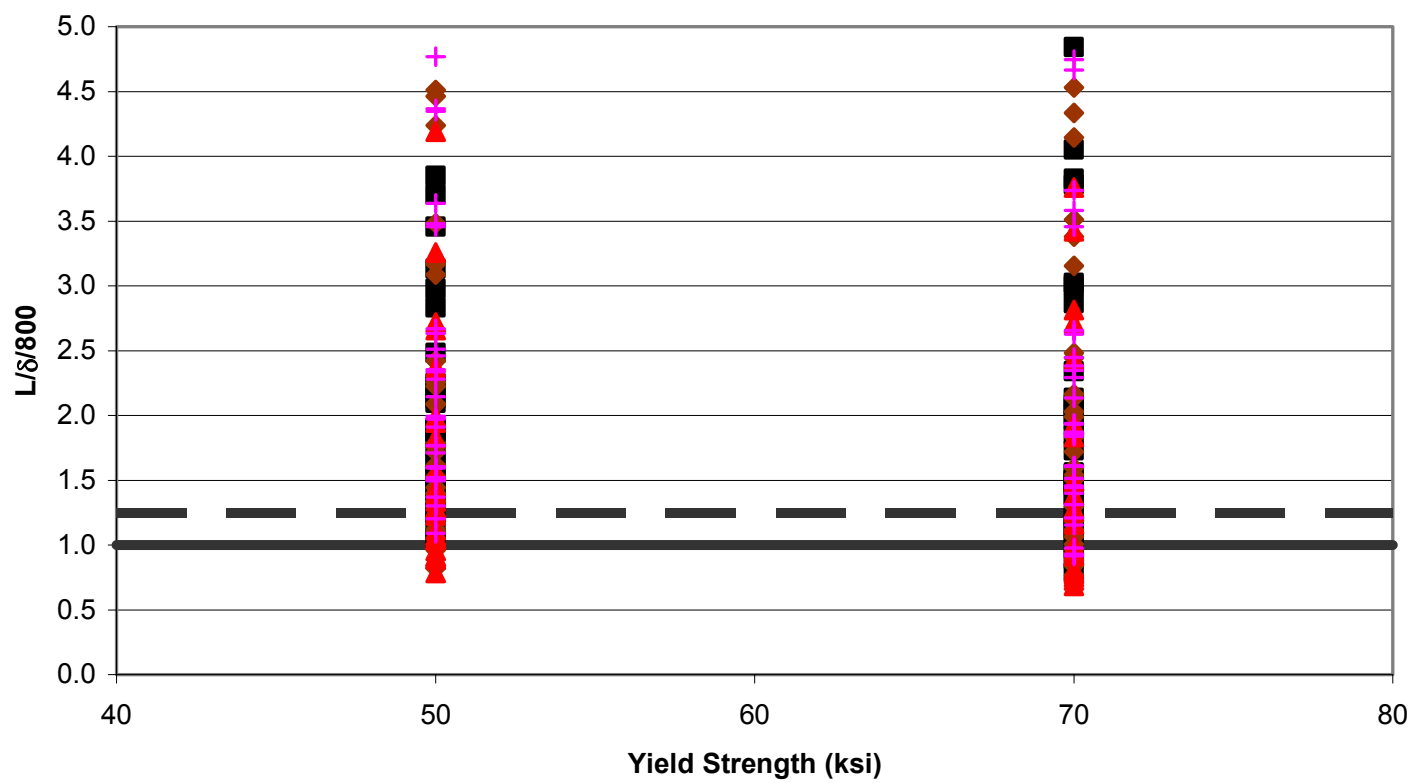

Figure 5.5. The influence of steel strength on live-load deflections 


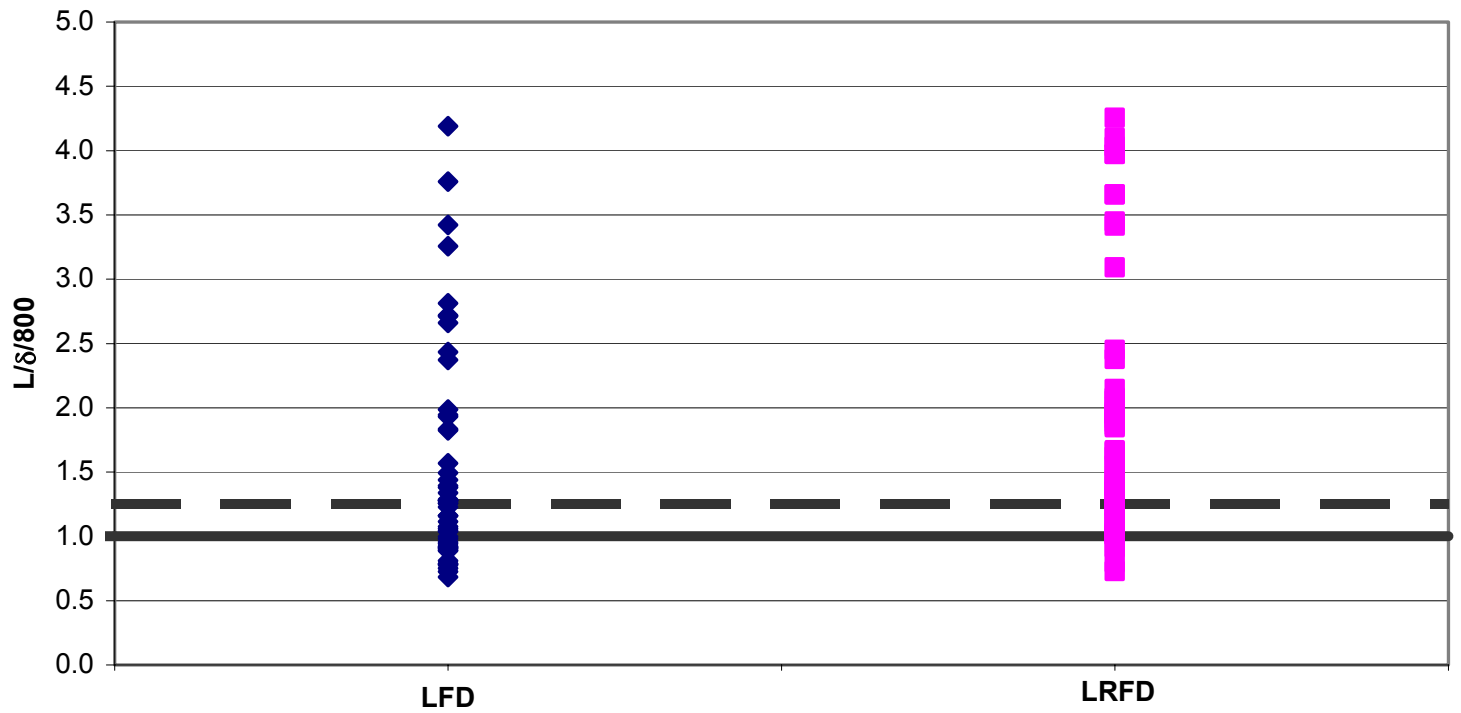

Figure 5.6. Comparison of LFD with LRFD on live-load deflection for cross-section\#3 


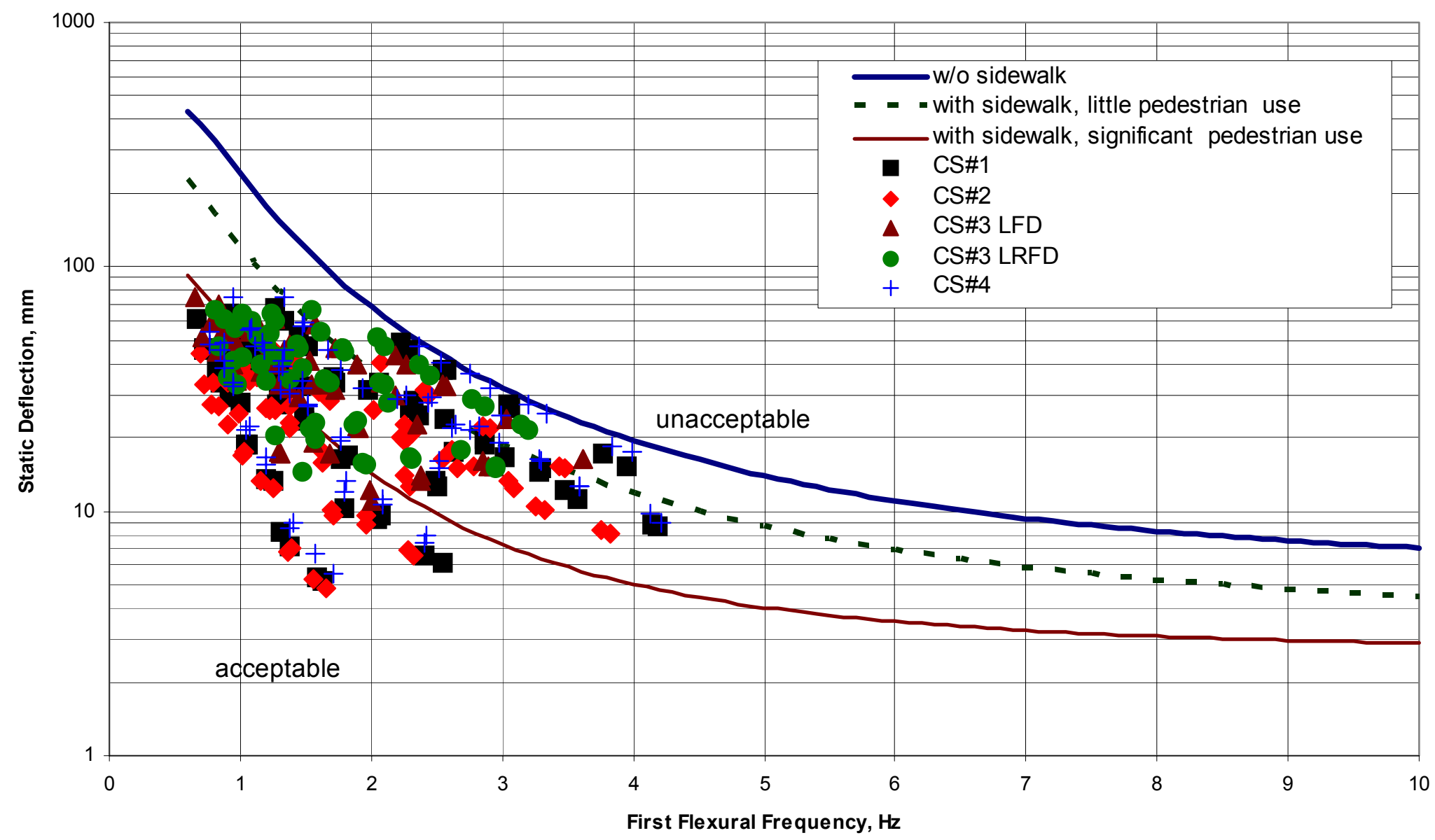

Figure 5.7. Comparison with OHBDC for the initial bridge designs 


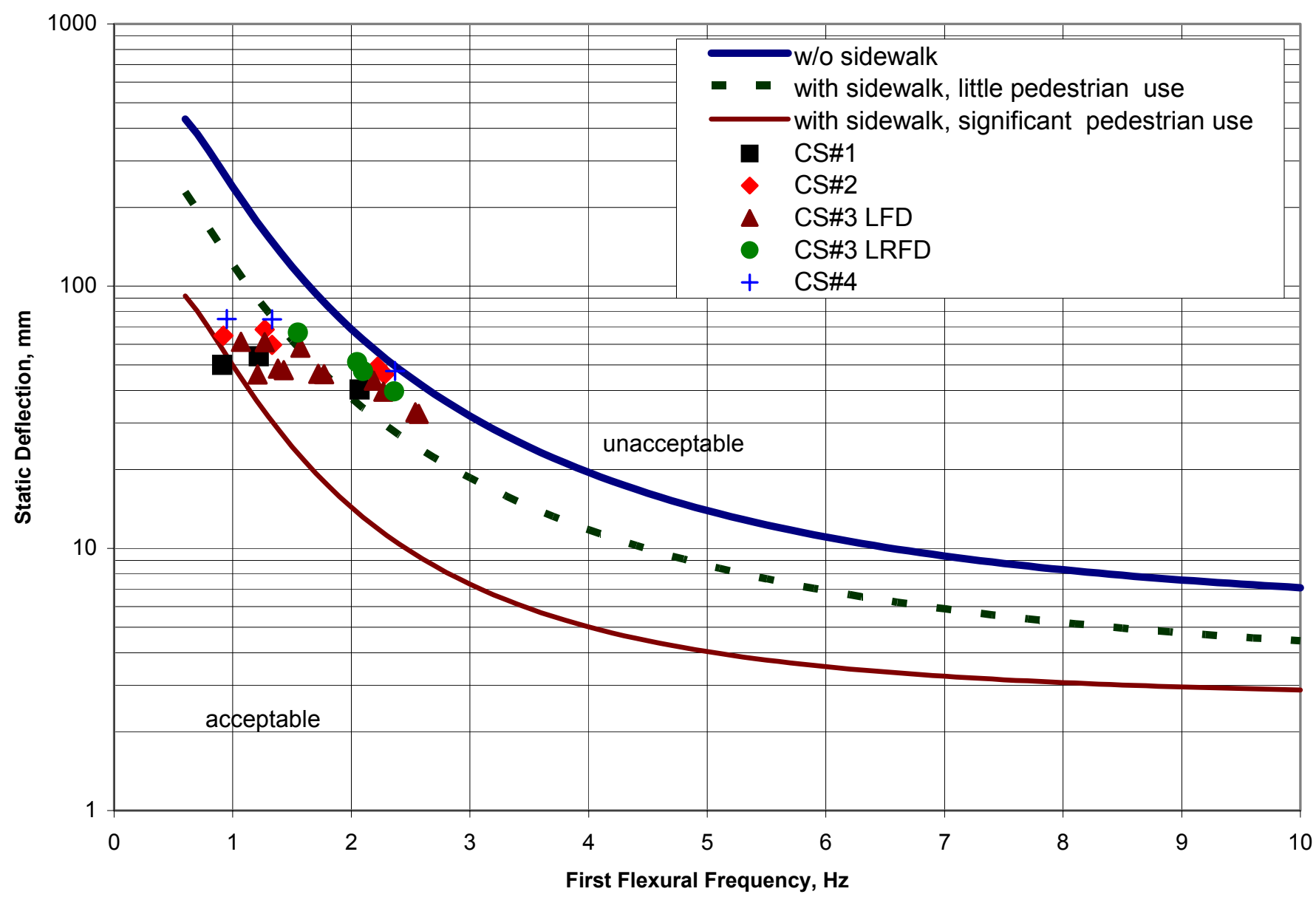

Figure 5.8. Comparison with OHBDC for simple span girders failing the AASHTO L/800 Deflection Limit 


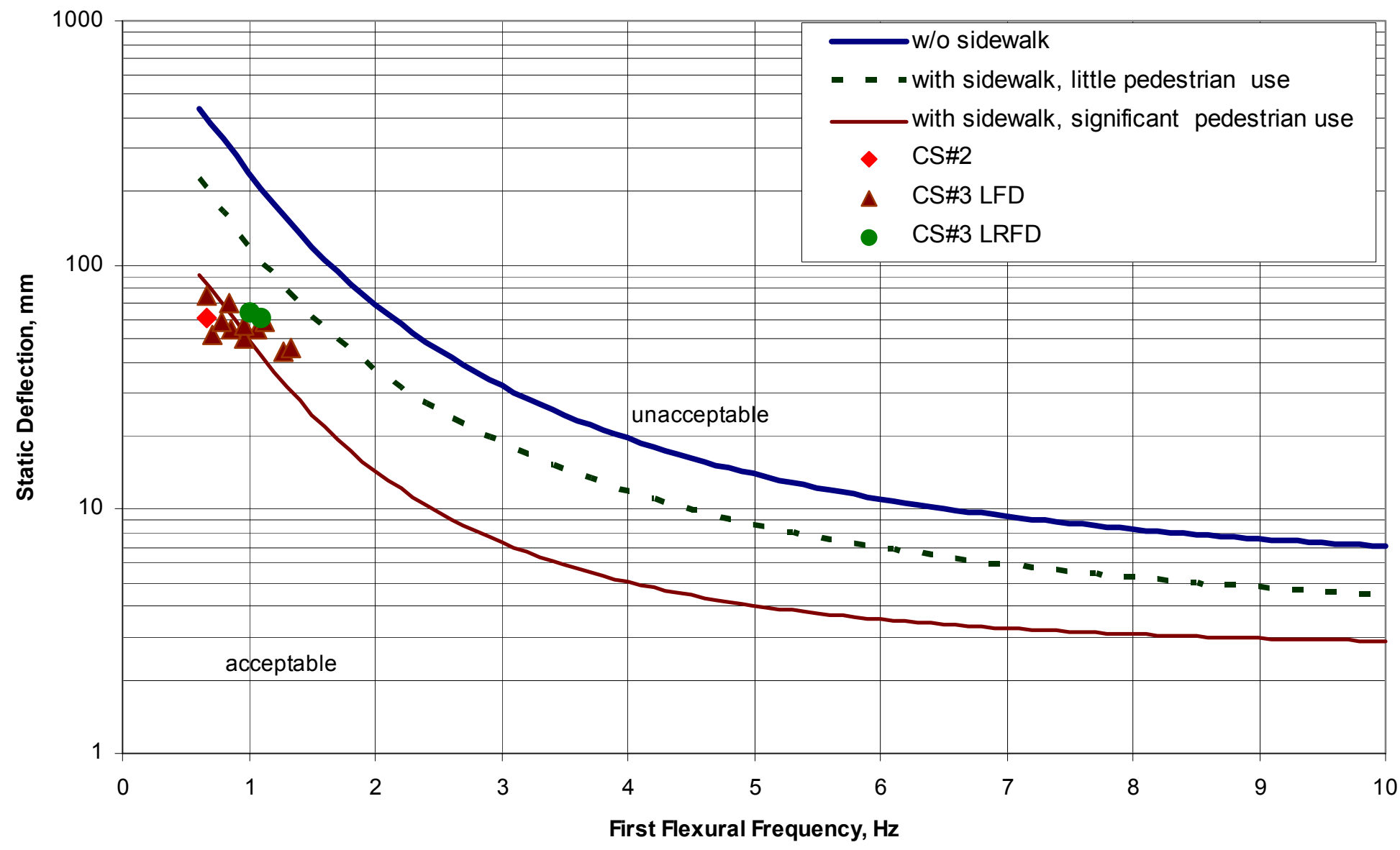

Figure 5.9. Comparison with OHBDC for 2-Span continuous girders failing the AASHTO L/800 deflection limit 


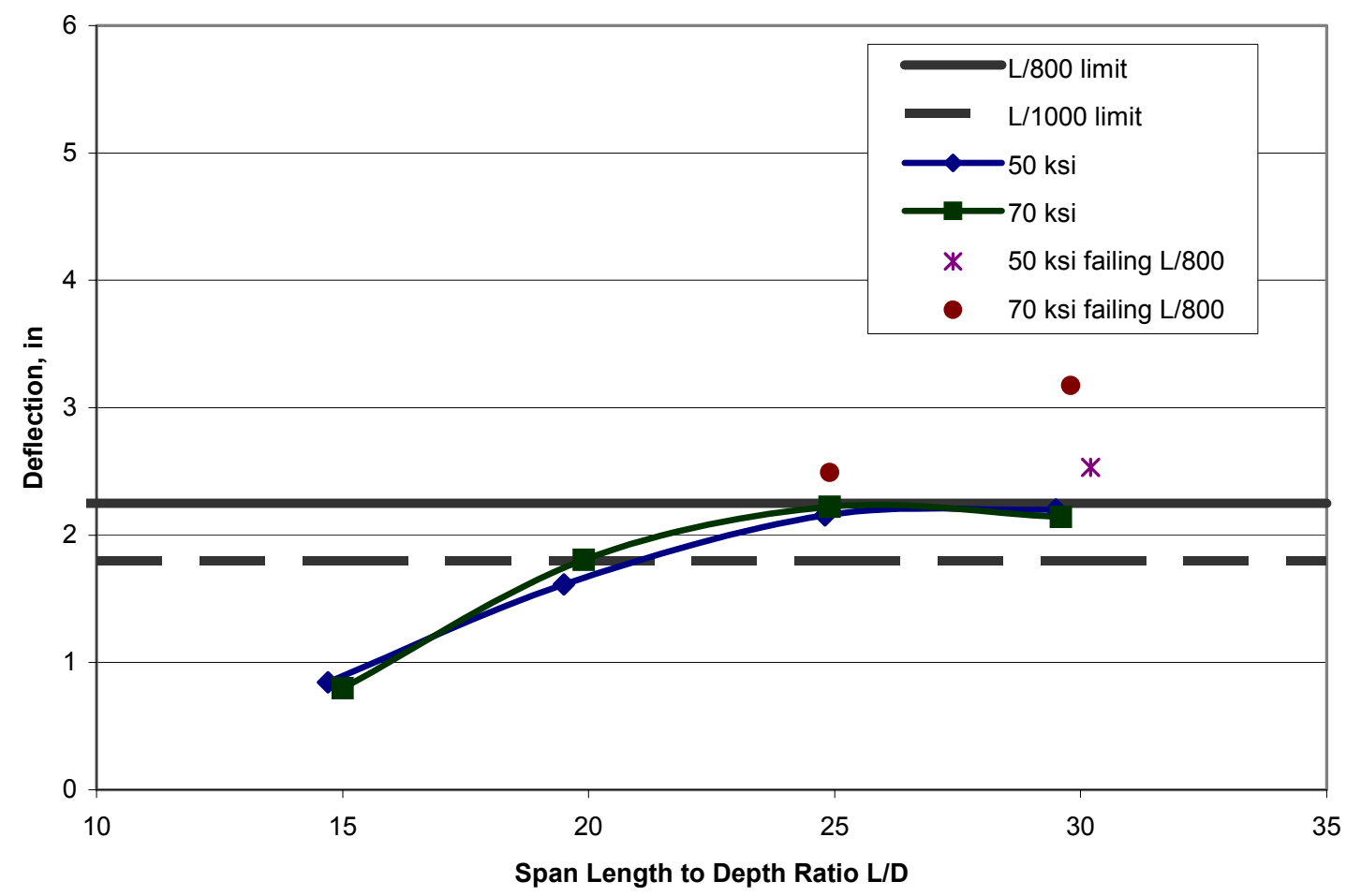

Figure 5.10. Deflection versus L/D for $150 \mathrm{ft}$. simple span bridge, cross section 3 


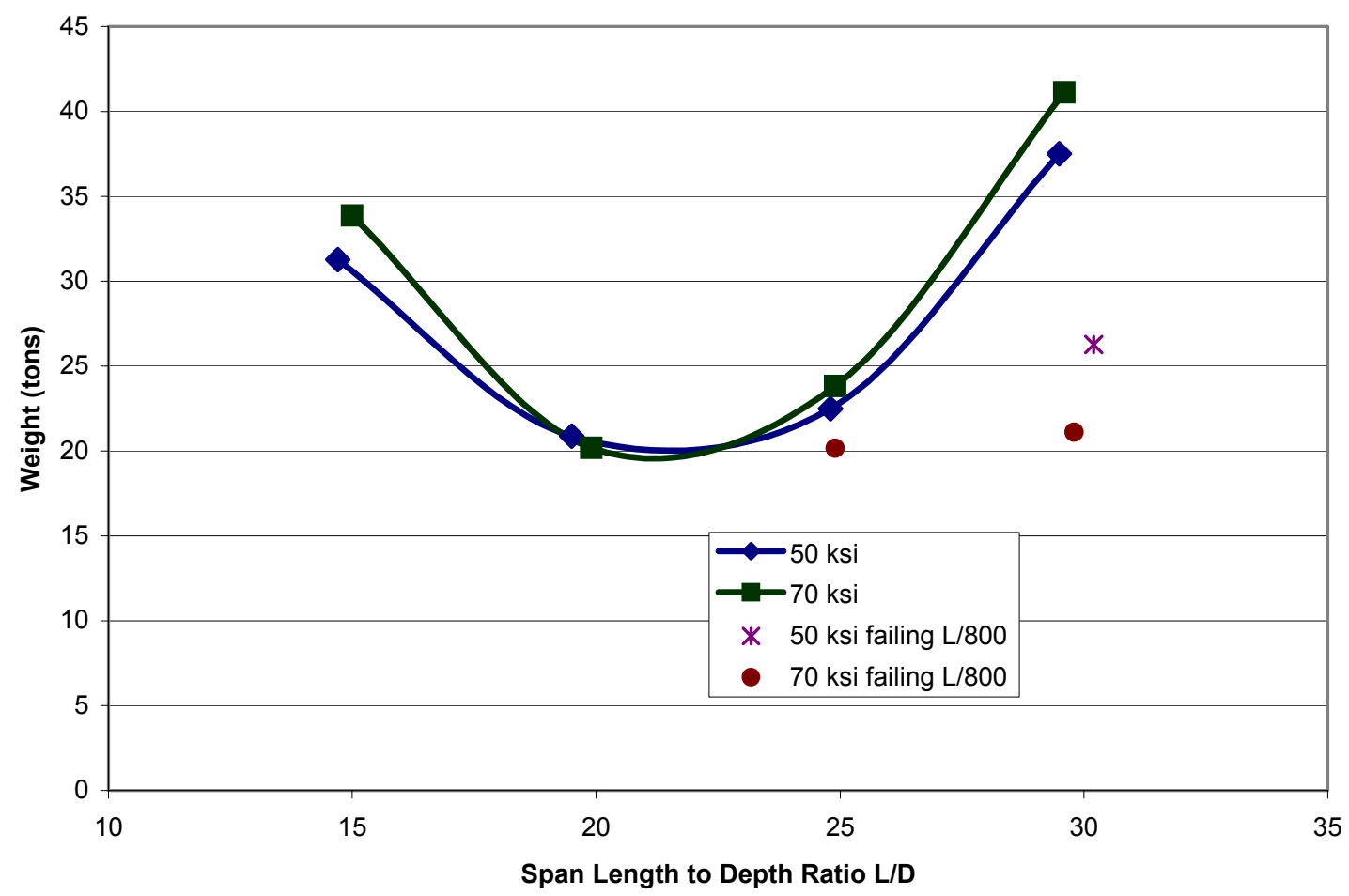

Fig. 5.11. Weight versus L/D for $150 \mathrm{ft}$. simple span bridge, cross section 3 


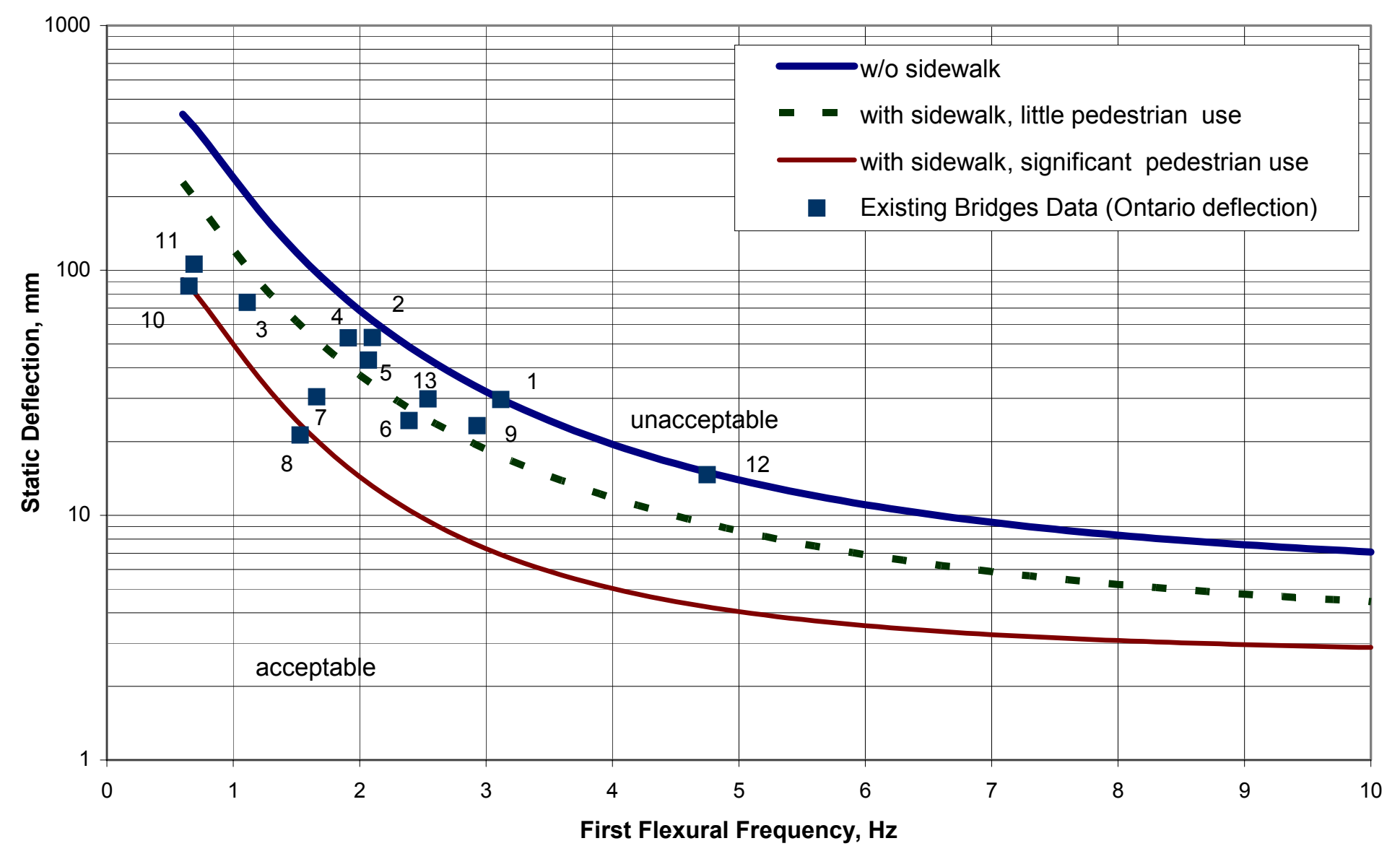

Figure 5.12. Deflection limits of bridges comparing to OHBDC 


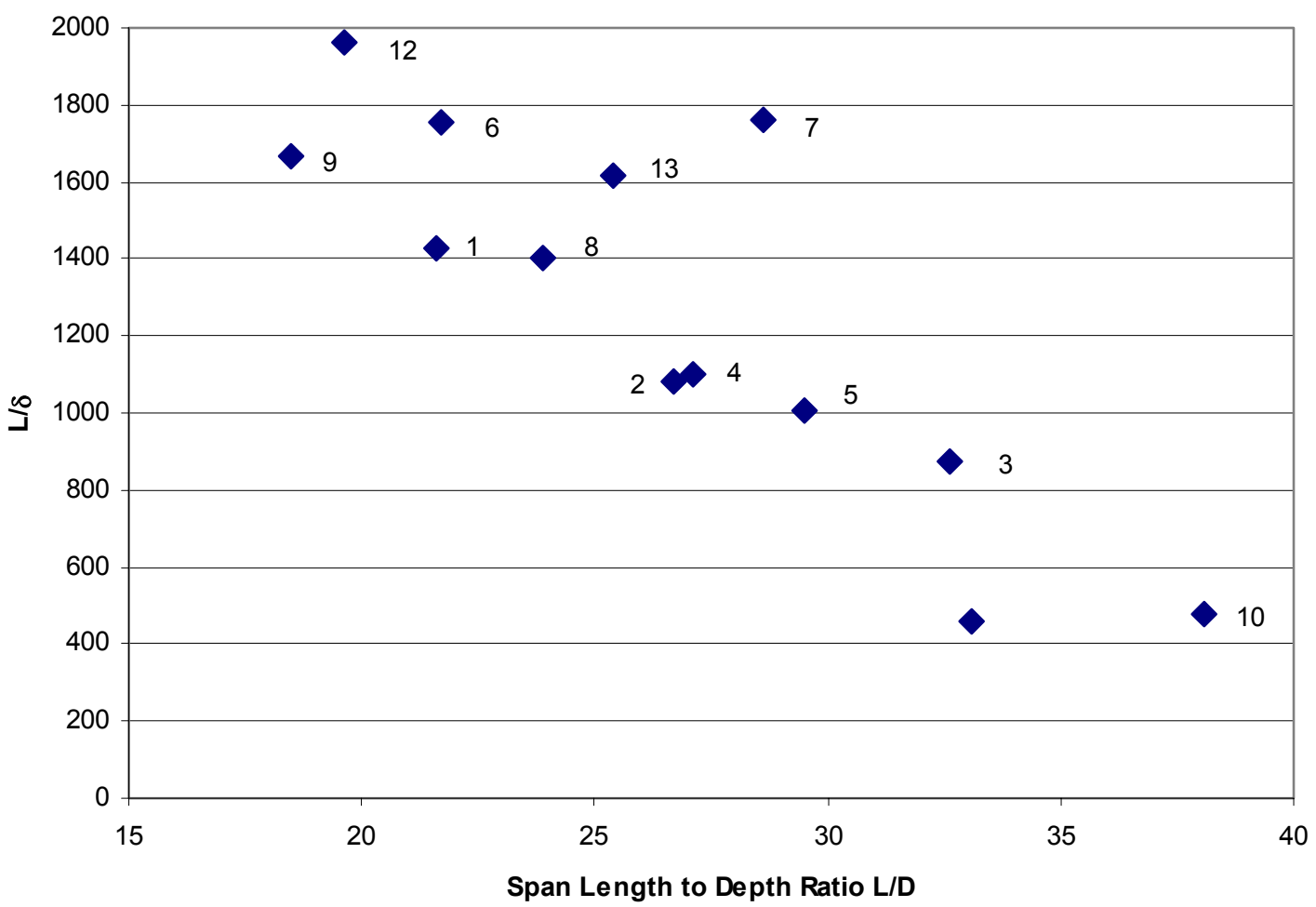

Figure 5.13. L/ $\delta$ versus $\mathrm{L} / \mathrm{D}$ for typical highway bridges 


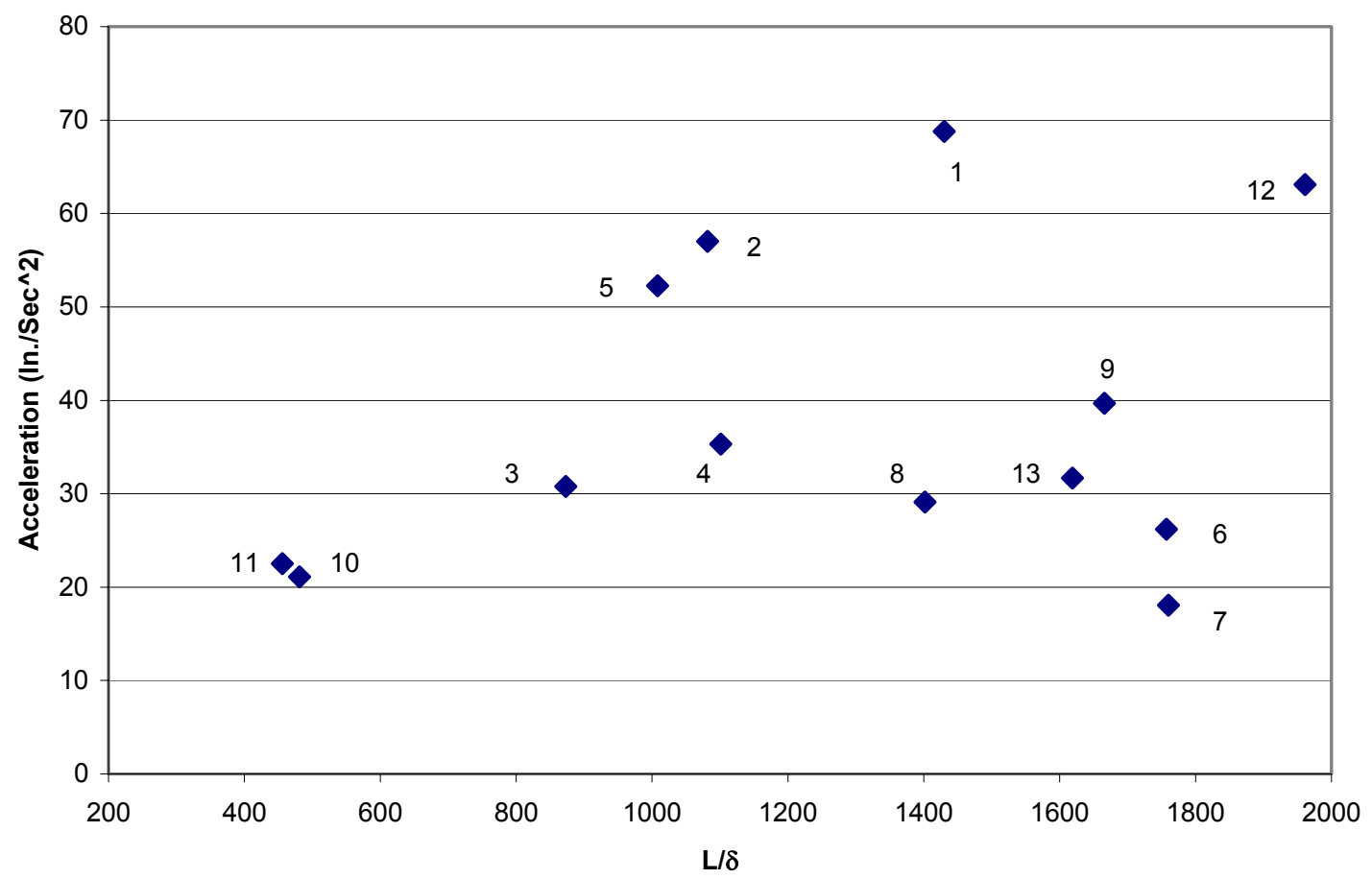

Figure 5.14. Comparisons to Wright and Walker recommendation for typical highway bridges 


\section{CHAPTER 6}

\section{DEVELOPMENT OF NATURAL FREQUENCY EQUATIONS FOR COMPOSITE STEEL I-GIRDER BRIDGES}

\subsection{Introduction}

The efforts presented in previous chapters have indicated that; (1) current AASHTO deflection criteria may have a negative economic impact on HPS bridges and (2) currently available expressions for the natural frequencies of continuous span bridges lack the simplicity or accuracy required for the use with existing frequency based serviceability limits. More accurate natural frequency expressions coupled with the use of more rational live-load serviceability criteria may significantly impact the design of composite steel bridges using HPS by leading to more economical designs. The previously calibrated elastic 3D FEA model, which has been shown to efficiently capture the vibration characteristics of composite steel bridges, is utilized in this chapter to conduct a FEA parametric study for the purpose of developing more accurate natural frequency expressions.

In order to propose more practical natural frequency equations, the FEA parametric study covers a wide range of variables that may affect the natural frequencies of typical composite steel bridges. Variables considered in the parametric study include span length, span length to depth ratio, girder bending stiffness, and presence of parapets. Through this parametric study, other parameters contributing to the natural frequency are identified and included in the suggested natural frequency equations. Based on the natural frequencies resulting from the parametric study, a set of more rational and practical 
equations to predict the first bending natural frequency of composite steel bridges (including continuous span composite steel bridges) are obtained by using the multiple variable nonlinear regression method.

The parametric study results are compared with existing frequency expressions such as the standard expression for the natural frequency of a simple span beam (Eqn. 2.2) (Biggs, 1964), a procedure developed by Billing (1979) where the $1^{\text {st }}$ bending frequency is obtained simply by multiplication of a correction factor obtained from the provided tables and a base frequency from Eqn. 2.2 and a procedure developed by Gorman (1975) where the natural frequency is obtained by solving the governing differential equation of free vibration of uniform beams. Furthermore, the accuracy of the suggested equations is verified by comparing the natural frequencies predicted by the proposed equations to the natural frequencies reported in experimental dynamic tests available in the literature.

\subsection{Parametric Study}

This section presents the FEA natural frequency study on the bridges in the design parametric study by using the previously proposed FEA modeling procedure. Effects of various parameters (such as span length, span length to depth ratio, material strength, span configuration, and the parapets) on the natural frequencies are investigated. The FEA natural frequency results are compared with the existing prediction methods and are used to develop natural frequency equations subsequently in section 6.3. 


\subsubsection{Variables}

The parametric natural frequency study is performed using the bridges originally designed in the parametric design study presented in section 5.1, except that bridges with a span length to depth ratio, $L / D$, equal to 15 are omitted since this $L / D$ ratio is significantly less than the ratio $(L / D=25)$ suggested by AASHTO. These bridges cover a wide range of design variables. Specifically, this study considers three span arrangements (simple span, two-span continuous and three-span continuous), span lengths ranging from 100 to $300 \mathrm{ft}$, and three $L / D$ ratios $(20,25$ and 30$)$. Two material configurations (Grade 50 and HPS 70W) are used for each combination of the above geometric variables. In total there are 202 bridges analyzed, including 77 simple-span, 71 two-span, and 54 three-span bridges.

To evaluate the effects of edge stiffening by parapets, simple span models were conducted both with and without a typical parapet. The AISI parapet with the dimensions shown in Fig. 6.1 represents a typical parapet used in practical applications and is used for the parapet modeled in these studies. Because of the increasing natural frequencies and decreasing stiffness ratios between the parapets and the bridge for continuous span bridges, the effect of parapets is expected to be low for these bridges, and is therefore neglected.

\subsubsection{Results}

Figures 6.2 through 6.5 summarize the results of the FEA natural frequency studies as a function of cross-section configuration (CS1, CS2, CS3, or CS4; the reader is referred to Fig. 5.1) and steel yield strength for the simple span, 2-span continuous, 3- 
span continuous and all bridges, respectively. The natural frequency for all bridges ranges between 0.85 and $3.9 \mathrm{~Hz}$, which includes the frequency range of approximately 2 to $5 \mathrm{~Hz}$ noted for the body bounce and pitch frequencies of modern commercial vehicles (Cantieni, 1983).

The effect of parapets on the natural frequency data for the simple span bridges is shown in Fig. 6.6 with frequency ratio (natural frequency with parapets divided by natural frequency without parapets) versus span length.

\section{Effect of Span Length}

As shown in Figs. 6.2 through 6.5, span length is one of the most significant variables influencing the natural frequency. With increasing span length (and all other variables constant), there is a clear trend showing decreasing natural frequencies. Further, the changes in natural frequency ratio with increasing span length are only slightly different for the bridges with varying $L / D$ ratios.

\section{Effect of L/D Ratio}

With an increase in the $L / D$ ratio from 20 to 30 (while keeping all other variables constant), there is a decrease in the natural frequency, as shown in Figs. 6.2 through 6.5. However, this trend is more obvious for bridges with shorter span lengths, especially for bridges with span lengths of $100 \mathrm{ft}$. For simple span bridges, the changes of frequency ratios are in the range of 1.12 to 1.23 when the $L / D$ ratio changes from 25 to 20 (while keeping all other variables constant), and the changes of frequency ratios are in the range of 1.08 to 1.18 when the $L / D$ changes from 30 to 25 . 
The superstructure depth is closely related to the bending stiffness of the bridge, and it should have considerable effect on the natural frequency of the bridge, as shown in Eqn. 2.2. Therefore, the superstructure depth or bending stiffness should be included in the suggested natural frequency equations.

\section{Effect of Material Strengths}

As shown in Figs. 6.2 through 6.5, the steel yield strength only slightly changes the natural frequency of a bridge. Typically, for a given set of parameters, a HPS 70W bridge has a lower natural frequency compared with that of a Gr. 50W bridge. However, for a given superstructure configuration having a specific set of flexure and fatigue requirements, optimum solutions for Gr. $50 \mathrm{~W}$ and HPS $70 \mathrm{~W}$ bridges may produce different $L / D$ ratios. Bridge designed with HPS 70W will generally produce shallower girders with higher $L / D$ ratios, which may lower the natural frequencies of the bridge.

\section{Effect of Span Configuration}

As shown in Fig. 6.5, the continuous span bridges typically have higher natural frequencies than the simple-span bridges when all other variables are the same. This is especially true for 3-span continuous bridges compared to simple span bridges, which was also been observed by Billing (1979). Obviously, for 3-span bridges or bridges with more than three spans, the end restraints from the side spans on the span with the maximum span length help to increase the natural frequency of the bridge. The effect of the end restraints on the natural frequency of continuous span beams and the amount of end restraint provided by the side spans of 2- and 3-span bridges is subsequently further 
discussed in section 6.2.3. However, with span lengths increasing from 100 to $300 \mathrm{ft}$., the effect of span configuration on the natural frequencies decreases. This is illustrated in Fig. 6.5, as the magnitudes of the natural frequencies for bridges with different span configurations vary less with increasing span length.

Furthermore, span configuration is influential in that the 2-span continuous bridges with equal span lengths in this study may not necessarily have the same natural frequencies suggested by simple beam equation shown in Eqn. 2.2, Billing's method, or Gorman's method for 2-span continuous beams with equal span lengths. This indicates that the existing methods from beam idealization for 2-span bridges can not accurately represent the natural frequencies of the bridges as 3D systems.

\section{Effect of Parapets}

Figure 6.6 shows the effect of parapets vs. span length for the simple span bridges, where it is shown that the FEA predicts natural frequencies up to $10 \%$ higher when parapets are included. The effect of the parapets is most significant for bridges with span lengths of $100 \mathrm{ft}$., where the presence of parapets increases the natural frequency between $2.9 \%$ and $10 \%$. For $100 \mathrm{ft}$. and $150 \mathrm{ft}$. span length bridges, the effect of parapets is slightly larger for the $70 \mathrm{ksi}$ bridges than for the $50 \mathrm{ksi}$ bridges. For bridges with span lengths of $150 \mathrm{ft}$. and greater, the effect of parapets is less than $3 \%$, which is considered negligible. However, it is expected that the effects of parapets on the natural frequency will be more significant for bridges with span lengths less than $100 \mathrm{ft}$., since the relative stiffness ratio between the parapets and the cross section increases, and it is 
recommended to include the effect of the parapets on the natural frequencies of these bridges.

\section{Suggested Equation for the Effect of Parapets on the Natural Frequency}

Considering these results, it is recommended that the effect of parapets be included for bridges with shorter span lengths and higher $L / D$ ratios. To develop this expression commercial software (DATAFIT, 2002) was used to conduct multiple nonlinear regression analyses of the FEA natural frequency data obtained from the simple-span bridges with and without parapets, and the following equation is suggested to represent the influence of parapets on natural frequency

$f_{n \_ \text {w/ parapets }}=\zeta \times f_{n \_ \text {w/o parapets }}$

where

$\zeta=\frac{1.34}{L^{-0.0054} I^{0.024}}$, from the regression analysis

$L=$ span length in $\mathrm{ft}$. , and

$I=$ bending stiffness of composite steel girder in in ${ }^{4}$

The difference in natural frequencies obtained using Eqn. 6.1 and the actual FEA natural frequencies for the simple-span bridges with parapets are within 3.2\%. This margin of error represents a significant improvement in accuracy compared to Eqn. 3.1, because Eqn. 3.1 over predicts the natural frequencies in the range of $15 \%$ to $70 \%$, when compared to the actual FEA natural frequencies for the simple-span bridges with parapets. Also the errors of the predictions from Eqn. 3.1 increase with the increasing of span lengths, where the bridges have lower natural frequencies. 


\subsubsection{Comparisons with Existing Methods}

This section compares the natural frequencies obtained in the FEA parametric study with the simple beam equation, Billing's method, Gorman's method, and the beam equations with nonclassical boundary conditions.

\section{Comparisons with Beam Equations, Billing's Method and Gorman's Method}

\section{Simple-Span Bridges}

For simple-span bridges, Billing's method (Billing, 1979) and Gorman's method (Gorman, 1975) both use the simple beam equation shown in Eqn. 2.2 to calculate the natural frequencies. Figure 6.7 compares the natural frequency from the FEA results and the simple beam equation for simple span bridges. It can be seen that the simple beam equation is accurate in predicting the natural frequencies of these bridges within $5 \%$ for all of the simple-span bridges analyzed in this study. Furthermore, for $87 \%$ of these bridges, the simple beam equation predicted a lower natural frequency than the value obtained in the FEA.

However, it is noted that the simple beam equation may not be accurate for some simple-span bridges having irregular geometry, such as variable girder spacing or large skew, which were beyond the scope of this study. For these types of bridges, the assumption made in the simple beam equation that the beam is uniform becomes invalid. 


\section{$\underline{\text { Two-Span Bridges }}$}

For two span bridges with equal span lengths, Billing's method uses a natural frequency correction factor of 1 , resulting in the same natural frequency as obtained using the simple beam equation. Gorman's method (see section 3.4) also gives the same results as the simple beam equation for 2 -span continuous beams with equal span lengths. Figure 6.8 compares the FEA natural frequency results and the values obtained using the simple beam equation for 2 -span continuous bridges. As shown, the simple beam equation predicts lower natural frequencies for all of the 2 -span bridges. The simple beam equation gives natural frequencies: within 5\% of the FEA results for 5 bridges, between 5 and $10 \%$ lower than the FEA results for 26 bridges, and more than $10 \%$ lower than the FEA data for the majority of the bridges. The highest discrepancy between the equation and FEA data is $22 \%$. In summary, for $93 \%$ of the 2 -span bridges, the natural frequencies obtained from the simple beam equation, Billing's method, and Gorman's method are more than 5\% lower than the FEA results.

For a 2-span bridge, the natural frequency should be bounded by the simple beam equation given by Eqn. 2.2 and the equation for a pinned-clamped beam (Biggs, 1964) equal to

$$
f_{n s c}=\lambda^{2} f_{s b}
$$

where

$\lambda=\mathrm{n}+1 / 4$ and $\mathrm{n}$ is the mode number $\left(\lambda=1.25\right.$ for the $1^{\text {st }}$ mode $)$

$f_{s b}=$ frequency obtained from simple beam equation in Eqn. 2.2

This is confirmed by evaluating the data shown in Fig. 6.8 comparing FEA frequencies and the simple beam equation predictions as well as the comparisons shown in Fig. 6.9 between FEA frequencies and the pinned-clamped beam predictions. The highest ratio in 
Fig. 6.8 is 1.216 and the lowest ratio in Fig. 6.9 is 0.645 . Therefore, the actual natural frequencies for 2-span bridges must lie between these values.

\section{Three-Span Bridges}

Figure 6.10 compares the natural frequency obtained from the FEA results and the simple beam equation for 3-span bridges. For all the 3-span bridges, the simple beam equation predicts considerably lower natural frequencies (from $42 \%$ to $91 \%$ lower). For the majority of the 3 -span bridges ( 39 bridges), the simple beam equation is from $42 \%$ to $50 \%$ lower than the analytical result; the simple beam equation is $50 \%$ to $91 \%$ lower than the FEA data for the remaining 15 . This suggests that the simple beam equation cannot be used to predict the natural frequencies for 3-span continuous bridges.

For 3-span continuous bridges with side span to middle span ratios of 0.8 (as used in this study), Billing's correction factor is 1.266. Using Gorman's method, interpolation from the eigenvalue tables provided for 3-span continuous beams gives an equivalent natural frequency coefficient $\left(\lambda^{2}\right)$ equal to 1.2575 .

Figure 6.11 compares the natural frequency from the FEA results and Billing's method for 3-span bridges. Compared to the simple beam equation, Billing's method results in more favorable comparisons, however, Billing's method still predicts considerably lower natural frequencies than FEA results. The discrepancy between Billing's method and the FEA frequencies ranges between $10.5 \%$ and $50.8 \%$. Given the above evaluation, it is suggested that Billing's method cannot be used to predict the natural frequencies of 3-span continuous bridges. Compared to Billing's method, Gorman's method is expected to give slightly less favorable comparisons with the FEA 
data because Gorman's frequency coefficient is slightly smaller than Billing's correction factor. Therefore, Gorman's method also cannot be used for 3-span bridges.

For a 3-span bridge, the natural frequency should be bounded by the simple beam equation shown in Eqn. 2.2 and that of a clamped-clamped beam equation (Biggs, 1964) equal to

$f_{n c c}=\lambda^{2} f_{s b}$

where

$$
\lambda=\mathrm{n}+1 / 2 \text { and } \mathrm{n} \text { is the mode }\left(\lambda=1.5 \text { for the } 1^{\text {st }} \text { mode }\right)
$$

This is confirmed by evaluating the data shown in Fig. 6.10 comparing FEA frequencies and the simple beam equation predictions as well as the comparisons shown in Fig. 6.12 between FEA frequencies and the clamped-clamped beam predictions. The highest ratio in Fig. 6.10 is 1.909 and the lowest ratio in Fig. 6.12 is 0.629 . Therefore, the actual natural frequencies for 3-span bridges must lie between these values.

The above comparisons of FEA natural frequencies to various existing methods (simple beam equation, Billing's method, Gorman's method, pinned-clamped beam equation, clamped-clamped beam equation) suggest that the simple beam equation can be used to predict the natural frequencies of simple span bridges with sufficient accuracy. However, none of the existing methods can predict the natural frequencies of typical 2span continuous and 3-span continuous bridges with acceptable accuracy.

\section{Comparisons with Beam Equations with Nonclassical Boundary Conditions}

The above evaluation has shown that the pinned-clamped and clamped-clamped beam equations are too stiff to predict the natural frequencies for typical 2-span and 3- 
span continuous bridges, respectively. Consequently, this section investigates the relationship between natural frequency (or frequency coefficient $\lambda^{2}$ ) and the stiffness of the end restraint(s).

With shear and the rotational effects neglected, the differential equation governing the free vibration of uniform beams can be found in many structural dynamics books (Biggs, 1964), which is expressed as

$E I \frac{\partial^{4} y}{\partial x^{4}}+m \ddot{y}=0$

And in any normal model, by definition

$y_{n}(t, n)=f_{n}(t) \phi_{n}(x)$

where

$$
\begin{aligned}
& f_{n}(t)=\text { a time function } \\
& \phi_{n}(x)=\text { the characteristics shape }
\end{aligned}
$$

By substituting Eqn. 6.5 into Eqn. 6.4 and rearranging the equation, we have

$\frac{E I}{m \phi_{n}(x)} \frac{d^{4}}{d x^{4}} \phi_{n}(x)=-\frac{\ddot{f}_{n}(t)}{f_{n}(t)}$

Since the left side of Eqn. 6.6 varies only with $x$ and the right side varies with only with $t$, each side must be equal to a constant, which is defined as $\omega_{n}{ }^{2}$. Equation 6.6 can then be rewritten in two equations

$\ddot{f}_{n}(t)+\omega_{n}^{2} f_{n}(t)=0$

and

$\frac{d^{4}}{d x^{4}} \phi_{n}(x)-\frac{m \omega_{n}{ }^{2}}{E I} \phi_{n}(x)=0$

The solution for the first of these is 
$f_{n}(t)=C_{1} \sin \omega_{n} t+C_{2} \cos \omega_{n} t$

which indicts that the time function is harmonic with natural frequency $\omega_{n}$.

The general solution of Eqn, $6.7 \mathrm{~b}$ is

$\phi_{n}(x)=A_{n} \sin a_{n} x+B_{n} \cos a_{n} x+C_{n} \sinh a_{n} x+D_{n} \cosh a_{n} x$

where

$$
\begin{aligned}
& A_{n}, B_{n}, C_{n} \text { and } D_{n}=\text { constants obtained for particular boundary conditions } \\
& a_{n}=\sqrt[4]{\frac{m \omega_{n}^{2}}{E I}}
\end{aligned}
$$

The natural frequency may then be expressed as

$$
f_{n}=\frac{\omega_{n}}{2 \pi}=\frac{a_{n}{ }^{2}}{2 \pi} \sqrt{\frac{E I}{m}}=\lambda^{2} f_{s b}
$$

where

$$
\lambda=\frac{a_{n} L}{\pi}
$$

Equation 6.10 is general in that it may be applied to spans with any type of end restraints because the effects of the restraints are accounted for in the constants $A_{n}, B_{n}, C_{n}$ and $D_{n}$.

\section{Two-Span Bridges}

To study the effect of restraint from another span on the natural frequency, a 2span bridge can be simplified as a beam with a pinned support at the left end and a pinned rotational spring with rotational stiffness $K$ at the right end. For the left end with pinned 
supports, the boundary conditions are $y=0$ and $M=0\left(\frac{\partial^{2} y}{\partial x^{2}}=0\right)$. Since $f_{n}(t)$ cannot be zero at all times, these two boundary conditions are expressed as

$\left.\phi_{n}(x)\right|_{x=0}=0$ and $\left.\frac{d^{2} \phi_{n}(x)}{d x^{2}}\right|_{x=0}=0$

We can then determine that $B_{n}$ and $D_{n}$ are zero, and

$\phi_{n}(x)=A_{n} \sin a_{n} x+C_{n} \sinh a_{n} x$

For right end with pinned rotation spring, the two nonclassical boundary conditions (Gorman, 1975) are

$\left.\phi_{n}(x)\right|_{x=L}=0$ and $\left.\frac{d^{2} \phi_{n}(x)}{d x^{2}}\right|_{x=L}=\left.\frac{-K}{E I} \frac{d \phi_{n}(x)}{d x}\right|_{x=L}$

which gives

$A_{n} \sin a_{n} L+C_{n} \sinh a_{n} L=0$

(Eqn. 6.14)

$A_{n}\left(-a_{n} \sin a_{n} L+\frac{K}{E I} \cos a_{n} L\right)+C_{n}\left(a_{n} \sinh a_{n} L+\frac{K}{E I} \cosh a_{n} L\right)=0$

For $A_{n}$ and/or $C_{n}$ to be nonzero, which is the necessary conditions for vibration, the determinant of the coefficients in Eqns. 6.14 and 6.15 must be zero, which gives the normalized rotational stiffness

$$
K^{*}=\frac{K L}{E I}=\frac{2 a_{n} L \sin a_{n} L \sinh a_{n} L}{\cos a_{n} L \sinh a_{n} L-\sin a_{n} L \cosh a_{n} L}
$$

Substituting $a_{n} L=\lambda \pi$ into Eqn. 6.16, we can obtain

$$
K^{*}=\frac{K L}{E I}=\frac{2 \lambda \pi \sin \lambda \pi \sinh \lambda \pi}{\cos \lambda \pi \sinh \lambda \pi-\sin \lambda \pi \cosh \lambda \pi}
$$


Figure 6.13 shows the FEA analytical frequency data for 2-span bridges using Eqn. 6.17, with $\lambda=\sqrt{f_{n_{-a n a l y s i s}} / f_{s b}}$. The 2-span bridges in this study, which are thought to represent practical bridge designs, have relatively low $K^{*}$ values, ranging between 0 and 3.50. Furthermore, $\lambda$ ranges between 0 and 1.10. Therefore, the relationship between $\lambda$ and $K^{*}$ for higher $K^{*}$ values has only theoretical significance; higher $K^{*}$ probably cannot be provided by the end restraint due to the side span for practical 2-span bridges.

\section{Three-Span Bridges}

A center span of a 3-span bridge can be simplified as a beam with two pinned rotational supports, with rotational stiffness $K_{1}$ at the left end and rotational stiffness $K_{2}$ at the right end, in order to study the effects of the restraint from side spans on the natural frequency.

The two boundary conditions for the left support are

$$
\begin{aligned}
& \left.\phi_{n}(x)\right|_{x=0}=0 \Rightarrow B_{n}+D_{n}=0 \\
& \left.\frac{d^{2} \phi_{n}(x)}{d x^{2}}\right|_{x=0}=\left.\frac{K_{1}}{E I} \frac{d \phi_{n}(x)}{d x}\right|_{x=0} \Rightarrow \frac{K_{1}}{E I}\left(A_{n}+C_{n}\right)+a_{n}\left(B_{n}+D_{n}\right)=0
\end{aligned}
$$

The two boundary conditions for the right support are

$$
\begin{aligned}
& \left.\phi_{n}(x)\right|_{x=L}=0 \Rightarrow A_{n} \sin a_{n} L+B_{n} \cos a_{n} L+C_{n} \sinh a_{n} L+D_{n} \cosh a_{n} L=0 \\
& \left.\frac{d^{2} \phi_{n}(x)}{d x^{2}}\right|_{x=L}=\left.\frac{-K_{2}}{E I} \frac{d \phi_{n}(x)}{d x}\right|_{x=L} \Rightarrow
\end{aligned}
$$


$\left(\frac{K_{2}}{E I} \cos a_{n} L-a_{n} \sin a_{n} L\right) A_{n}-\left(a_{n} \cos a_{n} L-\frac{K_{2}}{E I} \sin a_{n} L\right) B_{n}+\left(a_{n} \sinh a_{n} L+\frac{K_{2}}{E I} \cosh a_{n} L\right) C_{n}+$ $\left(a_{n} \cosh a_{n} L+\frac{K_{2}}{E I} \sinh a_{n} L\right) D_{n}=0$

Again for $A_{n}, B_{n}, C_{n}$ and/or $D_{n}$ to be nonzero, which is the necessary condition for vibration, the determinant of the coefficients in Eqns. 6.18 through 6.21 must be zero, which gives the implicit relationship (Gorman, 1975) between spring rotation stiffness and $\lambda$ as

$$
K_{1}^{* 2}+K_{1}^{*} \frac{\beta(1+\alpha)(\sin \beta \cosh \beta-\cos \beta \sinh \beta)}{\alpha(1-\cos \beta \cosh \beta)}+\frac{2 \beta^{2} \sin \beta \sinh \beta}{\alpha(1-\cos \beta \cosh \beta)}=0
$$

where

$$
\begin{gathered}
K_{1}^{*}=\frac{K_{1} L}{E I} \\
K_{2}^{*}=\frac{K_{2} L}{E I} \\
\alpha=\frac{K_{2}^{*}}{K_{1}^{*}}=\frac{K_{2}}{K_{1}} \\
\beta=a_{n} L=\lambda \pi
\end{gathered}
$$

For the 3 -span bridges with two symmetric side spans, $\alpha$ is equal to 1 and Eqn. 6.22 can be rewritten as

$$
K_{1}^{* 2}+K_{1}^{*} \frac{2 \lambda \pi(\sin \lambda \pi \cosh \lambda \pi-\cos \lambda \pi \sinh \lambda \pi)}{1-\cos \lambda \pi \cosh \lambda \pi}+\frac{2(\lambda \pi)^{2} \sin \lambda \pi \sinh \lambda \pi}{1-\cos \lambda \pi \cosh \lambda \pi}=0
$$

Figure 6.14 shows the FEA analytical frequency data for 3-span bridges using Eqn. 6.23, with $\lambda=\sqrt{f_{n_{-} \text {analysis }} / f_{s b}}$. It is expected that the 3-span bridges should have a higher end restraint than that of the 2 -span bridges. As anticipated, $K_{1}^{*}$ is in the range of 3.23 to 17.7, which is much higher than $K^{*}$ for the 2 -span bridges ( 0 to 3.50). Additionally, $\lambda$ ranges between 1.12 and 1.38 , which is also higher than that of 2 -span bridges ( 0 to 
1.10). Again, the relationship between $\lambda$ and $K_{1}{ }^{*}$ for relatively high $K_{1}{ }^{*}$ has only theoretical significance, and probably cannot be provided by the end restraints from the two side spans for 3-span bridges.

The beam equations for nonclassical boundary conditions shown in Eqns. 6.17 and 6.23 cannot be used to predict the natural frequencies for the 2-span and 3-span continuous bridges because these equations only determine the relationship between end restraints (the rotation spring stiffness) and the natural frequency coefficient $\lambda$; the rotational spring stiffness from the other $\operatorname{span}(\mathrm{s})$ for practical continuous span bridges cannot be determined. These discussions only show how many effects of the end restraints (the rotational spring stiffness) on the natural frequencies can be provided by the side spans of typical continuous span steel bridges, if beam equations for nonclassical boundary conditions are used.

\subsection{Suggested Equations}

Through the comparisons of natural frequency data in the above section, it has been shown that none of the existing methods can be used to predict the natural frequencies for continuous span bridges with acceptable accuracy. Therefore, there is a need to develop new equations to better predict natural frequencies for continuous span composite steel bridges.

Based on the FEA natural frequency data, nonlinear multiple variable regression analysis is conducted (DATAFIT, 2002) to develop a set of more rational natural frequency equations. Regression trials were performed to determine the most important factors influencing the natural frequencies of these bridges. It was desired that the 
proposed equations should be simple enough to be used in practical situations, as well as predicting the natural frequencies with acceptable accuracy. As a result, the following equation is suggested to predict the first bending natural frequencies, $f$, of continuous span bridges.

$f=\lambda^{2} f_{s b}$

where

$\lambda^{2}=a \frac{I^{c}}{L_{\max }{ }^{b}}$ (the natural frequency coefficient)

$f_{s b}=$ the natural frequency from simple beam equation (Eqn. 2.2), $\mathrm{Hz}$

$L_{\max }=$ maximum span length, $\mathrm{ft}$.

$I=$ average moment of inertia of the composite girder section, in $^{4}$

$a, b$ and $\mathrm{c}=$ coefficients in Table 6.1

Table 6.1 provides the coefficients $a, b$ and c obtained from the regression analysis for 2 -span bridges and 3 or more- span bridges.

Figure 6.15 compares the natural frequencies obtained from the proposed equation to the FEA natural frequency results for 2-span bridges. As shown, the equation predicts natural frequencies that are within $10 \%$ of the FEA frequencies for all of the 71 2 -span bridges. Furthermore, the equation predicts frequencies within $5 \%$ of the FEA data for $61(86 \%)$ of these bridges. When compared to the difference between the FEA data and the existing methods (simple beam equation, Billing's method and Gorman's method), the proposed equation for 2-span continuous bridges represents a significant improvement in accuracy. The histogram shown in Fig. 6.16 again indicates that all the bridges have the difference between the proposed equation and FEA results within $10 \%$ and the deviation for the majority of 2 -span bridges is within $5 \%$. The proposed equation is very promising for use in predicting the natural frequencies of 2-span continuous 
bridges because it is as simple as the simple beam equation shown in Eqn. 2.2, but also has acceptable accuracy without doing a time consuming FEA or field study to determine vibration characteristics.

Figure 6.17 compares natural frequencies obtained using the proposed equation for the 3-span bridges to the FEA results. The difference between the two methods is within $5 \%$ for $40(74 \%)$ of the three-span bridges. The natural frequencies for twelve (22\%) of the bridges have a difference in the range of $5 \%$ to $10 \%$, and frequencies for 2 (4\%) of the bridges have a difference between the proposed equation and the FEA result greater than 10\%. As shown in Fig. 6.18, the histogram between the proposed equation and FEA results shows that the majority of the 3-span bridges (96\%) have the difference within 10\%. When compared with the difference between FEA frequencies and the frequencies predicted by existing methods (simple beam equation, Billing's method and Gorman's method), the proposed equation provides much more accurate predictions of natural frequencies for 3 -span continuous bridges. It is promising that the natural frequencies can be predicted within $10 \%$ for most cases $(96 \%)$ without performing time consuming 3D FEA or dynamic field testing studies.

\subsection{Extended Application of the Suggested Equation}

Because the proposed equations are based on FEA results of bridges with various geometric and material parameters, such as cross section, span length, $L / D$ ratio, and yield strength, it is suggested that the proposed equations should be able to predict the natural frequency for continuous span bridges outside the scope of the parameters in this study with acceptable accuracy. One influential parameter that was not significantly 
varied in this study was the span length ratio, which has been shown a considerable effect on the natural frequencies (Billing, 1979). And, it should therefore be noted that these suggested equations should not be extended to bridges with span ratios significantly different than those incorporated in this study.

All two-span bridges in this study were designed with equal span lengths. From the plans of typical composite, steel plate girder, highway bridges previously obtained from the State DOTs, it is observed that the majority of these 2-span bridges are designed with two equal or approximately equal spans. Therefore, it is recommended that the proposed equation for two-span continuous beams can be used for the majority of these types of bridges.

Typically, the most economic design for 3-span continuous bridge will have side spans that are not significantly shorter than the span length of the center span (span length ratio from 0.7 to 1 ), as was the case for the bridges designed in this study. Consequently, the proposed equation for three-span continuous bridges can be used with sufficient accuracy for the majority of three-span continuous bridges.

The proposed 3-span equation can be also used for bridges with more than 3 spans, since the natural frequency is most affected by the end restraints from the two intermediate spans closest to the span with maximum span length. The greater the distance between the side spans and the span with maximum span length, the smaller are the effects of these spans on the natural frequency. This is shown by comparing the natural frequencies predicted by the proposed equation for 3-span bridges with the experimental natural frequencies and FEA frequencies for the 5-span continuous Colquitz River Bridge $(46+59+60+59+60 \mathrm{ft}$. $)$ in Canada and the 4-span continuous Tennessee 
Rt. 130 Elk River Bridge $(70+90+90+70 \mathrm{ft}$.), both discussed in detail in Chapter 4 . For comparison, the frequency of these bridges is also determined using the available existing prediction methods.

As shown in Table 6.2, for the Colquitz River Bridge, the simple beam equation gave a first bending natural frequency of $4.42 \mathrm{~Hz}$, which is $25.7 \%$ lower than the frequency obtained during field testing of $5.95 \mathrm{~Hz}$. Billing's method gave a frequency of $4.98 \mathrm{~Hz}(16.3 \%$ lower than field data) using a correction factor of 1.127 obtained from double interpolation for $L_{2} / L_{1}$ ratio (intermediate span length / middle span length) of 0.986 and $L_{3} / L_{1}$ (side span length / middle span length) of 0.770 . The theoretical procedure required for Gorman's method is given for multispan beams with arbitrary intermediate support spacing, however only eigenvalue tables for multiple span beams with uniform support spacing are provided; thus, the natural frequency was not investigated using Gorman's method for this 5-span bridge. The proposed equation for 3span bridges gave a frequency coefficient ( $\left.\lambda^{2}\right)$ equal to 1.396 and a natural frequency of $6.17 \mathrm{~Hz}$, which is $3.7 \%$ higher than the field data. The proposed equation frequency $(6.17 \mathrm{~Hz})$ for this bridge is only $1.6 \%$ different from the FEA frequency $(6.27 \mathrm{~Hz})$, which shows proposed equation prediction can be as accurate as the 3D FEA result.

Again shown in Table 6.2 for the Tennessee Rt. 130 Bridge, the simple beam equation gave a frequency of $2.24 \mathrm{~Hz}$, which is $27.7 \%$ lower than the experimental frequency of $3.10 \mathrm{~Hz}$. Use of Billing's method resulted in a frequency of $2.61 \mathrm{~Hz}(15.8 \%$ lower that the testing frequency) using a correction factor of 1.168 for $L_{2} / L_{1}$ ratio (side span length / maximum span length) of 0.778 . Through 7 interpolations of the values provided in the eigenvalue tables for 4-span continuous beams, Gorman's method gives a 
frequency of $3.98 \mathrm{~Hz}(28.4 \%$ higher than the field test value) with an equivalent frequency coefficient $\left(\lambda^{2}\right)$ equal to 1.779 . The proposed equation for 3 -span bridges gave a frequency coefficient equal to 1.430 and a natural frequency of $3.20 \mathrm{~Hz}$, which is $3.2 \%$ higher than the field test results. The proposed equation frequency $(3.18 \mathrm{~Hz})$ for this bridge is only $0.3 \%$ different from the FEA frequency $(3.19 \mathrm{~Hz})$, which shows proposed equation prediction is as reliable as the 3D FEA result.

These two examples show that the proposed equation for 3-span bridges can be used without modification to predict natural frequencies with acceptable accuracy for continuous span steel bridges having more than three spans. The proposed equation for 2-span bridges will also be verified by experimental results for a 2-span continuous HPS bridge in the subsequent chapter.

\subsection{Conclusions}

The previously verified FEA model has been used to carry out FEA natural frequency studies for 202 bridges, representing a practical range of influential parameters. The FEA results show that the span length and bending stiffness of the composite girder are the two primary variables affecting the natural frequency of composite steel bridges. Furthermore, a continuous span bridge, especially a 3-span bridge, has a larger natural frequency than the corresponding simple span bridge.

Several other parameters were also included in the parametric study, but were not found greatly influence the natural frequency in most cases. The effect of $L / D$ on the natural frequencies was found to be most significant for bridges with shorter span length. The effect of material strength on natural frequencies was determined to be negligible, 
however the HPS $70 \mathrm{~W}$ bridge design may result in a smaller $L / D$, which means a smaller bending moment of inertial for a given span length, than the corresponding Grade 50 bridge design, which may affect the natural frequency. Results of this study also indicate that cross section configuration affects natural frequency, particularly for bridges with shorter span lengths.

Comparisons between the natural frequency obtained from the FEA of the simplespan bridges and the frequency predicted by the simple beam equation (or Billing's method and Gorman' method) show that these methods predict the first bending natural frequencies for simple-span bridges with acceptable accuracy.

The 77 simple-span bridges were analyzed with and without parapets to study this influence on natural frequency. The effect of parapets is greatest for the bridges having a span length of $100 \mathrm{ft}$., which was the shortest span length investigated in this study; the presence of parapets increased the natural frequency $2.9 \%$ to $10 \%$ for these bridges. Not only is the effect of parapets higher for bridges with shorter span lengths, but also for bridges having higher $L / D$ ratios. An equation, which is a function of span length and bending stiffness of the composite girder and based on nonlinear regression, is suggested to account for the effects of parapets on natural frequency. Comparisons between the natural frequencies predicted by this equation and the FEA analysis of 77 simple span bridges show that the proposed equation more accurately considers the effect of parapets than other methods.

For the 2-span bridges with equal span lengths, Billing's method and Gorman's method are the same as the simple beam equation. All of these methods predict natural frequencies considerably lower than the FEA results. Consequently, these methods are 
not recommended to predict the natural frequencies of 2-span bridges. Additionally, the pinned-clamped beam equation predicts natural frequencies considerably higher than the FEA data for 2-span bridges. The effect of end restraint from another span on the natural frequencies is studied, which suggests that $K^{*}$ has a practical meaning within only a certain range. By comparing the natural frequencies resulting from the proposed equation and the FEA data for the 71 2-span bridges, the proposed natural frequency equation for the 2-span bridges is shown to have improved and acceptable accuracy.

For the 3-span bridges, with side span to middle span ratios of 0.8 , the simple beam equation predicts natural frequencies considerably lower than the FEA results. Use of Billing's method or Gorman's method results in improved accuracy compared to the simple beam equation. However, these methods are still not sufficiently accurate in predicting the first bending natural frequencies. None of these three methods are recommended to predict the natural frequencies of 3-span bridges. Additionally, the clamped-clamped beam equation predicts natural frequencies that are considerably higher than the FEA results for 3-span bridges. The effect of end restraints from 2 side spans on the natural frequencies is studied, which suggests that $K_{1}{ }^{*}$ has a practical meaning in only a certain range. Also the effect of end restraint is expected to be more significant for 3 -span bridges than that of corresponding 2-span bridges.

By comparing the natural frequencies obtained from the proposed equation and the FEA data for the 543 -span bridges, the proposed natural frequency equation for the 3-span bridges is shown to have acceptable accuracy. Additionally, frequency predictions obtained from the proposed equation for 3-span bridges and the natural frequencies measured in field tests of a 5-span and 4-span continuous composite steel bridge compare 
very favorably, which suggests that this proposed equation can be used to predict the first bending natural frequency for continuous span bridges with more than three spans.

In summary, the simple equation shown in Eqn. 2.2 is suggested to predict the natural frequencies of simple-span bridges. The proposed equation shown in Eqn. 6.24 along with the coefficients given in Table 6.1 is suggested to predict the natural frequencies of continuous bridges. The effect of parapets on natural frequency can be investigated by using Eqn. 6.1. 
Table 6.1. Coefficients $a, b$ and $\mathrm{c}$ for use in multi-variable regression equation 6.24

\begin{tabular}{|c|c|c|c|}
\hline Spans & $\mathbf{a}$ & $\mathbf{b}$ & $\mathbf{c}$ \\
\hline 2 & 0.9539 & 0.04586 & 0.03176 \\
\hline 3 or more & 0.8785 & -0.03311 & 0.03348 \\
\hline
\end{tabular}


Table 6.2. Comparisons of the proposed equations, FEA, testing and existing methods

\begin{tabular}{|c|c|c|c|c|c|c|}
\hline & \multicolumn{6}{|c|}{$\mathbf{1}^{\text {st }}$ bending natural frequency (Hz) } \\
\cline { 2 - 7 } & Testing & $\begin{array}{c}\text { WVU } \\
\text { FEA }\end{array}$ & $\begin{array}{c}\text { Proposed } \\
\text { Equations }\end{array}$ & $\begin{array}{c}\text { Simple } \\
\text { Beam }\end{array}$ & $\begin{array}{c}\text { Billing } \\
\text { Method }\end{array}$ & $\begin{array}{c}\text { Gorman } \\
\text { Method }\end{array}$ \\
\hline $\begin{array}{c}\text { Colquitz } \\
\text { River Bridge }\end{array}$ & 5.95 & 6.27 & 6.17 & 4.42 & 4.98 & $\begin{array}{c}\text { Not } \\
\text { Available }\end{array}$ \\
\hline $\begin{array}{c}\text { Tennessee Rt. } \\
\text { 130 Elk River } \\
\text { Bridge }\end{array}$ & 3.10 & 3.19 & 3.20 & 2.24 & 2.62 & 3.98 \\
\hline
\end{tabular}




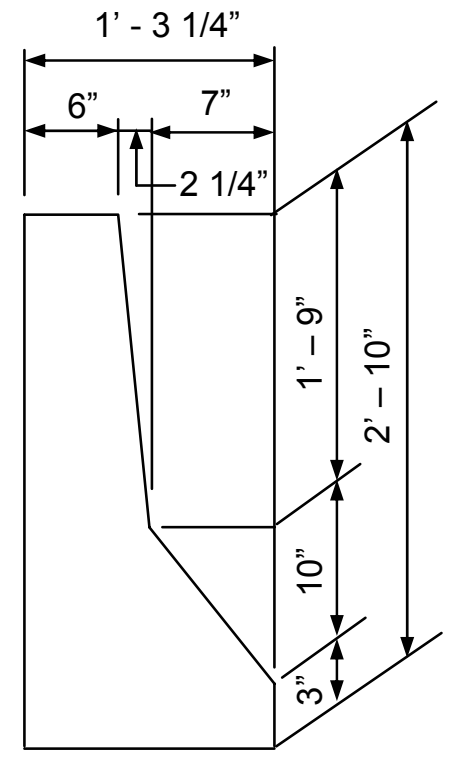

Figure 6.1. AISI parapet 


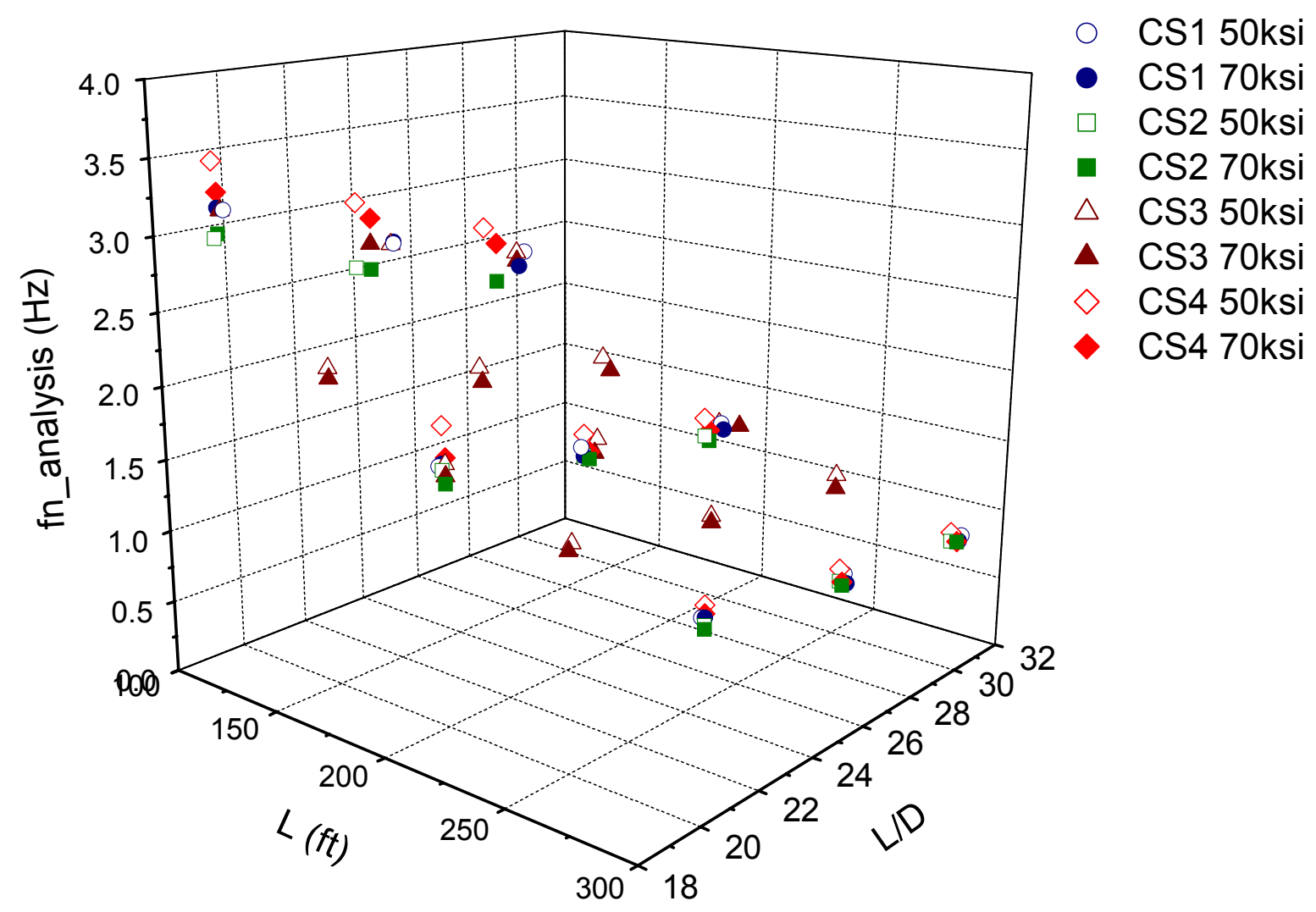

Figure 6.2. Natural frequency of simple span bridges 


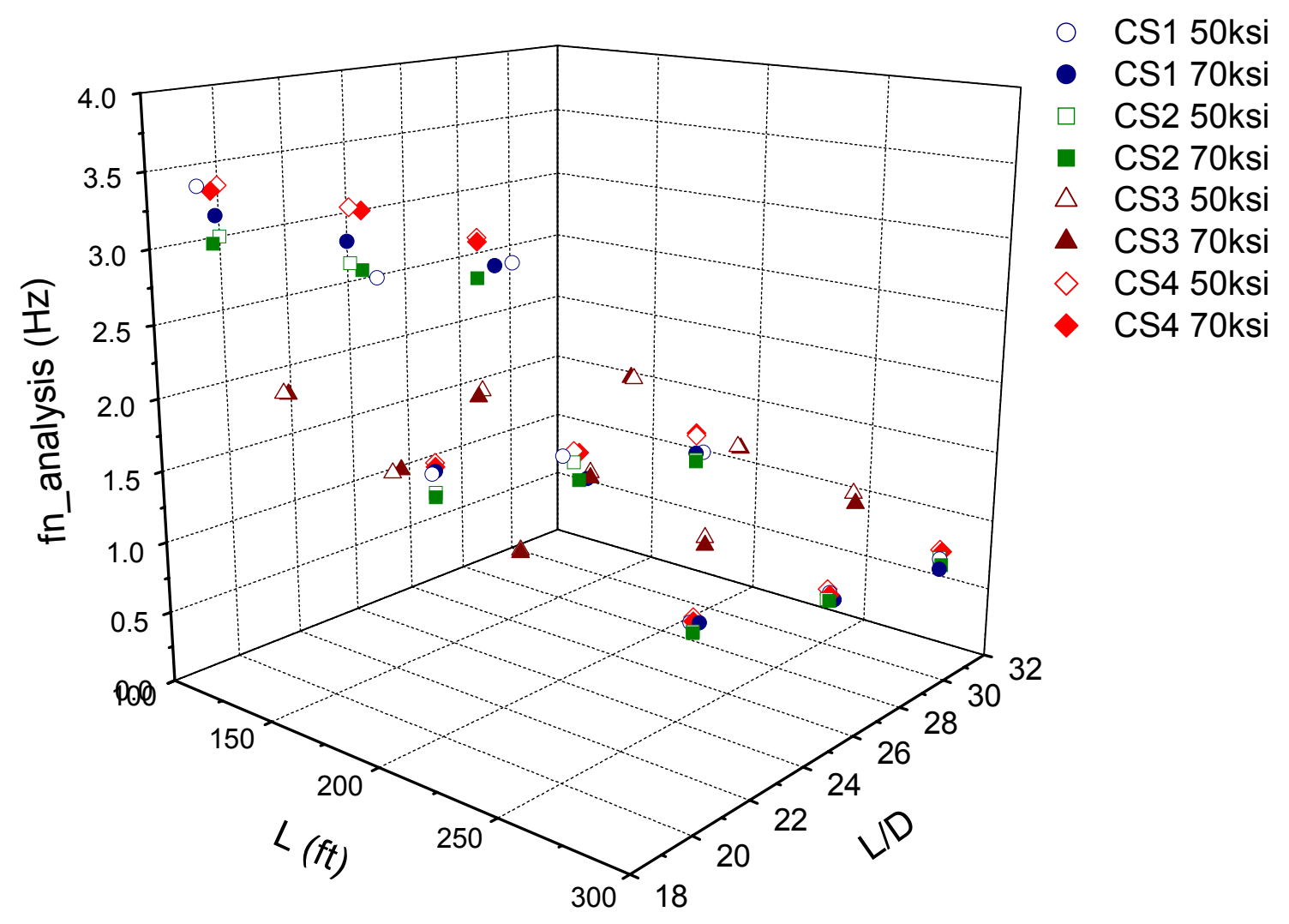

Figure 6.3. Natural frequencies of 2-span bridges 


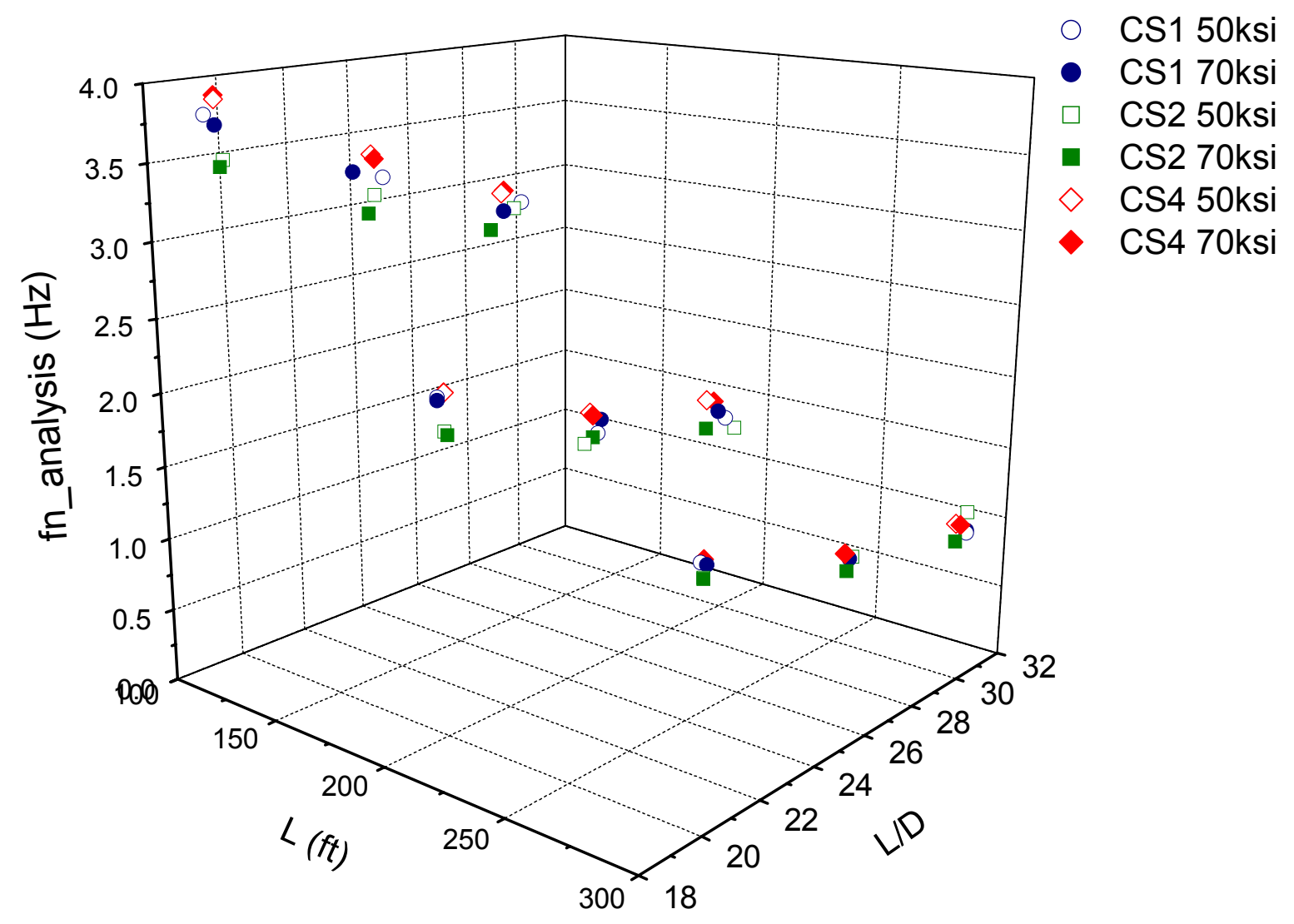

Figure 6.4. Natural frequencies of 3-span bridges 


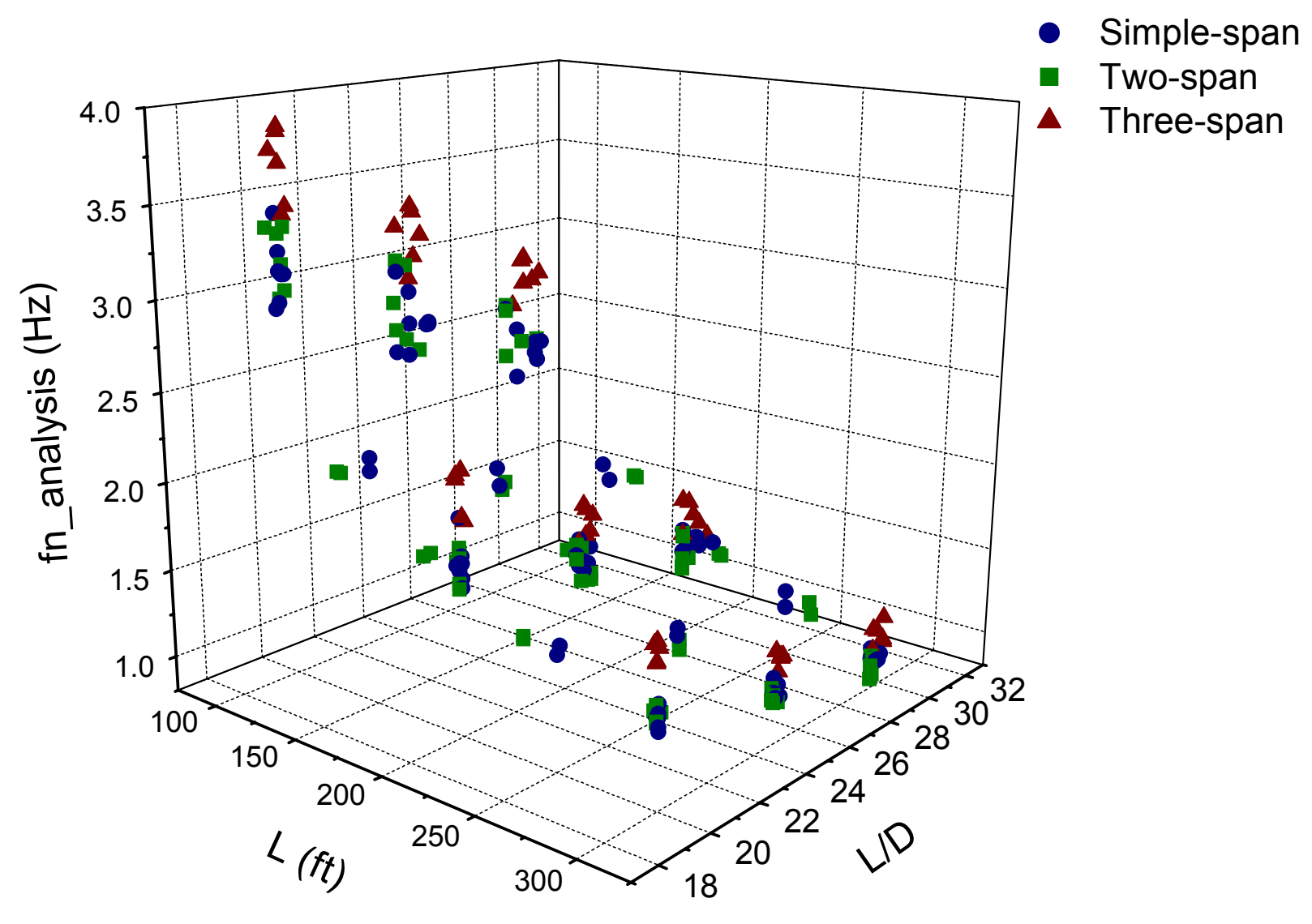

Figure 6.5. Natural frequencies for all bridges included in the parametric study 


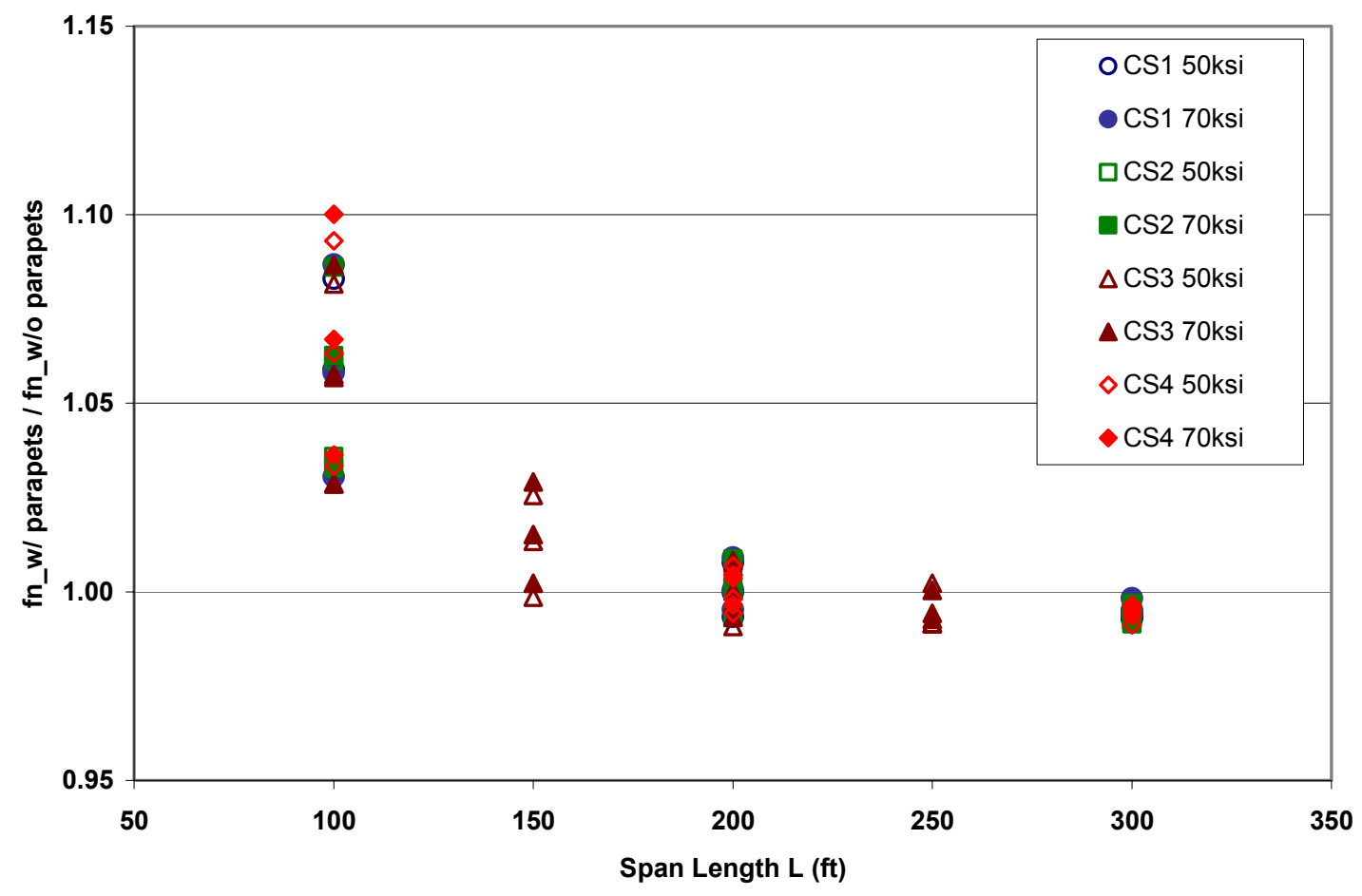

Figure 6.6. Effect of parapets versus span length for simple span bridges 


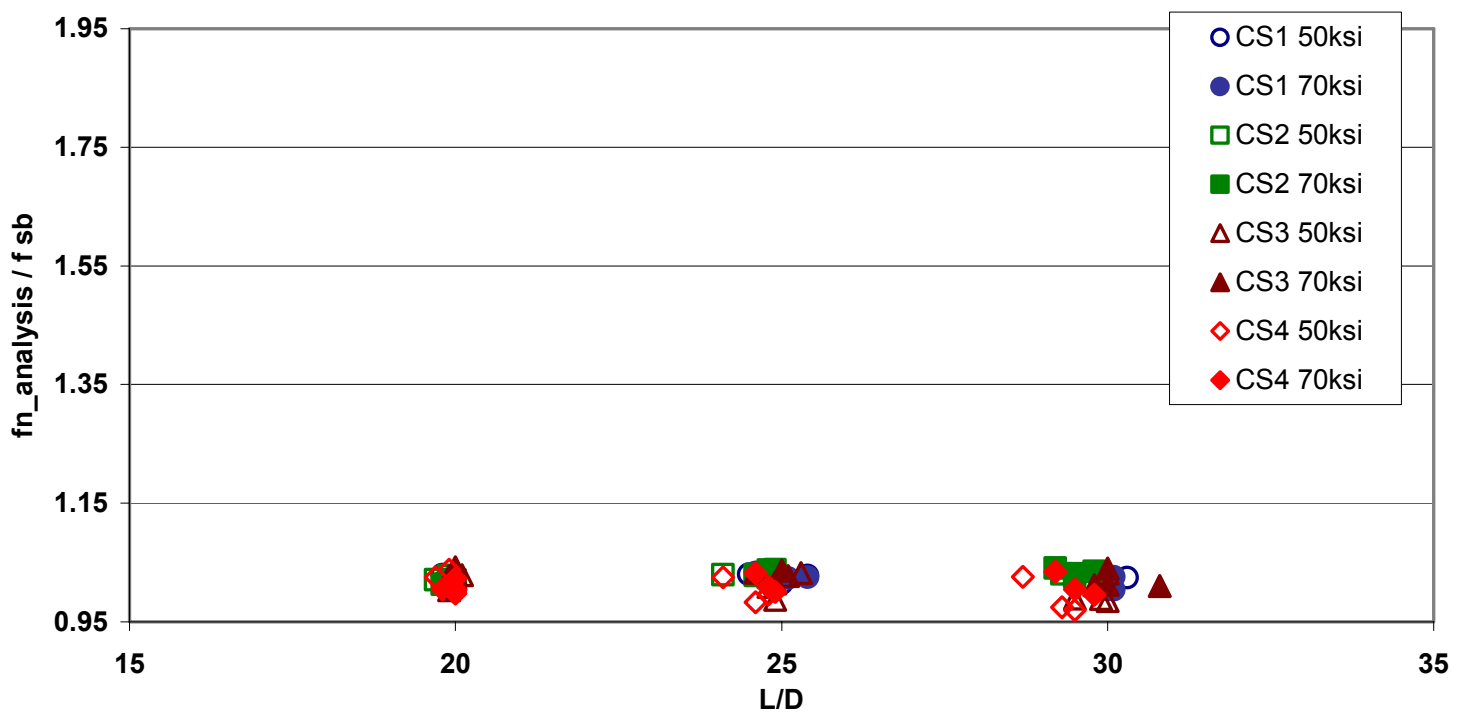

Figure 6.7. Comparisons between FEA and simple beam equation for simple span bridges 


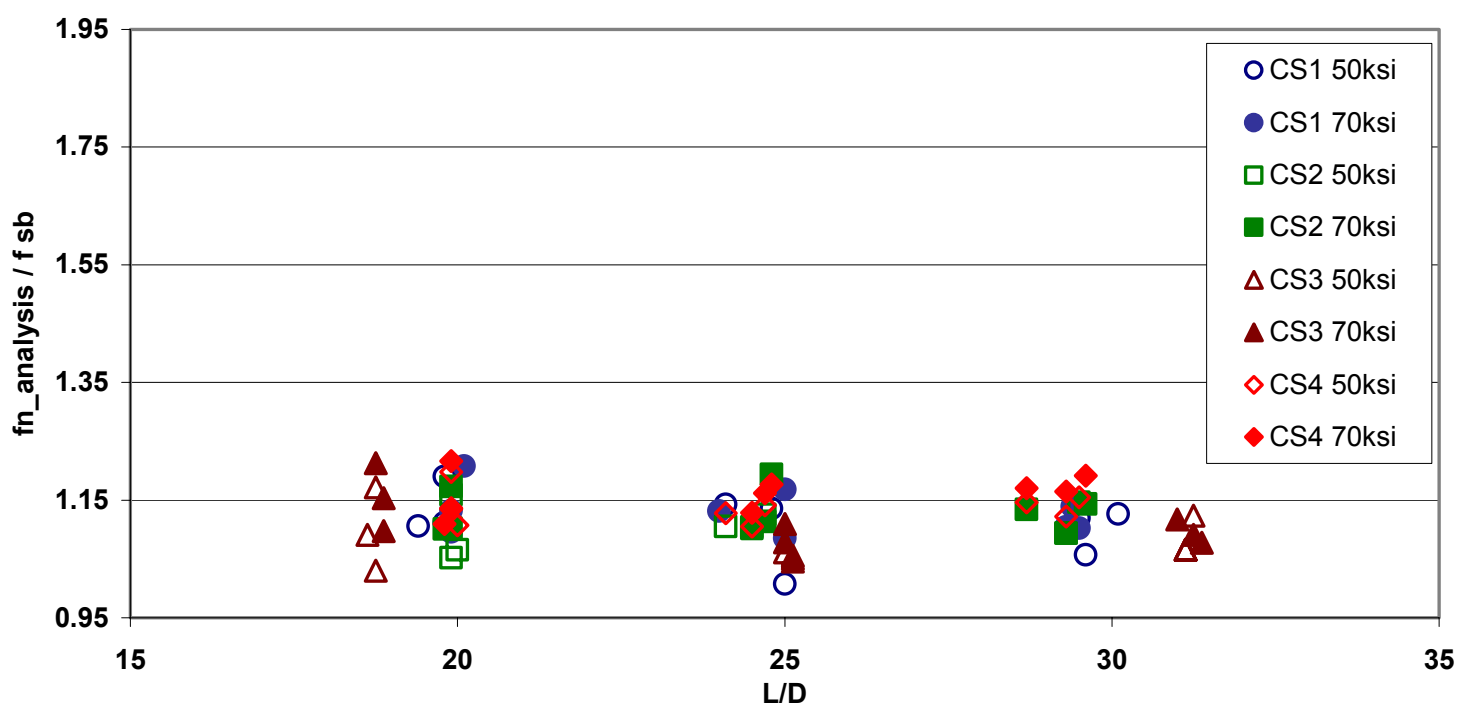

Figure 6.8. Comparisons between FEA and simple beam equation (or Billing's method and Gorman's method) for 2-span bridges 


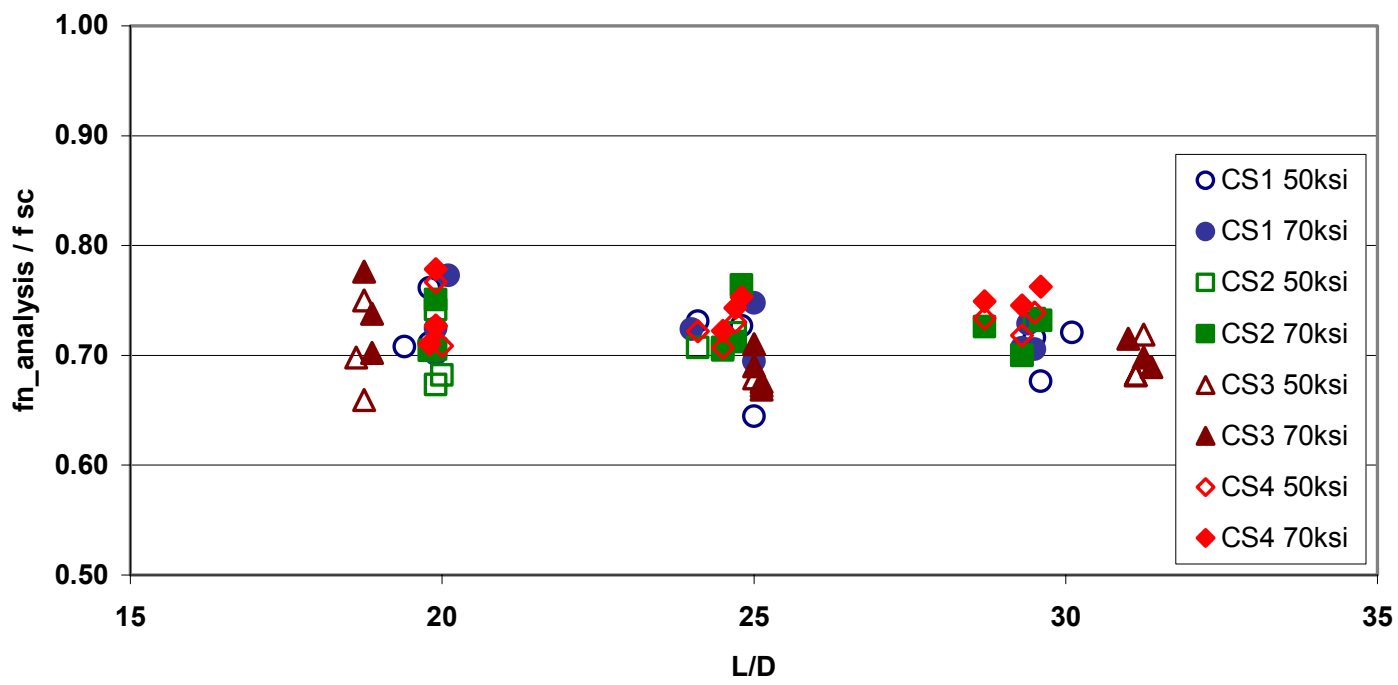

Figure 6.9. Comparisons between FEA and pinned-clamped beam equation for 2-span bridges 


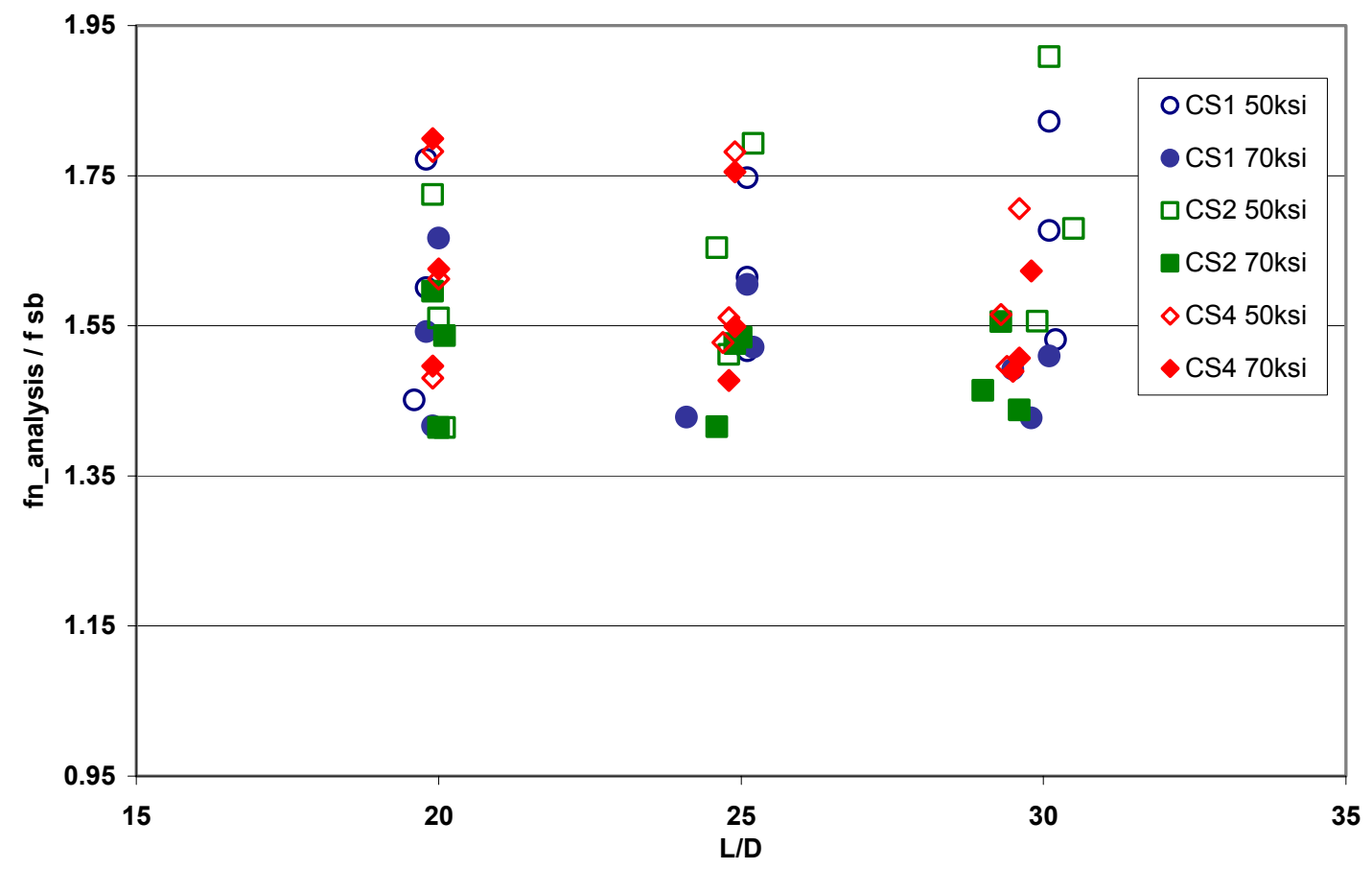

Figure 6.10. Comparisons between FEA and simple beam equation for 3-span bridges 


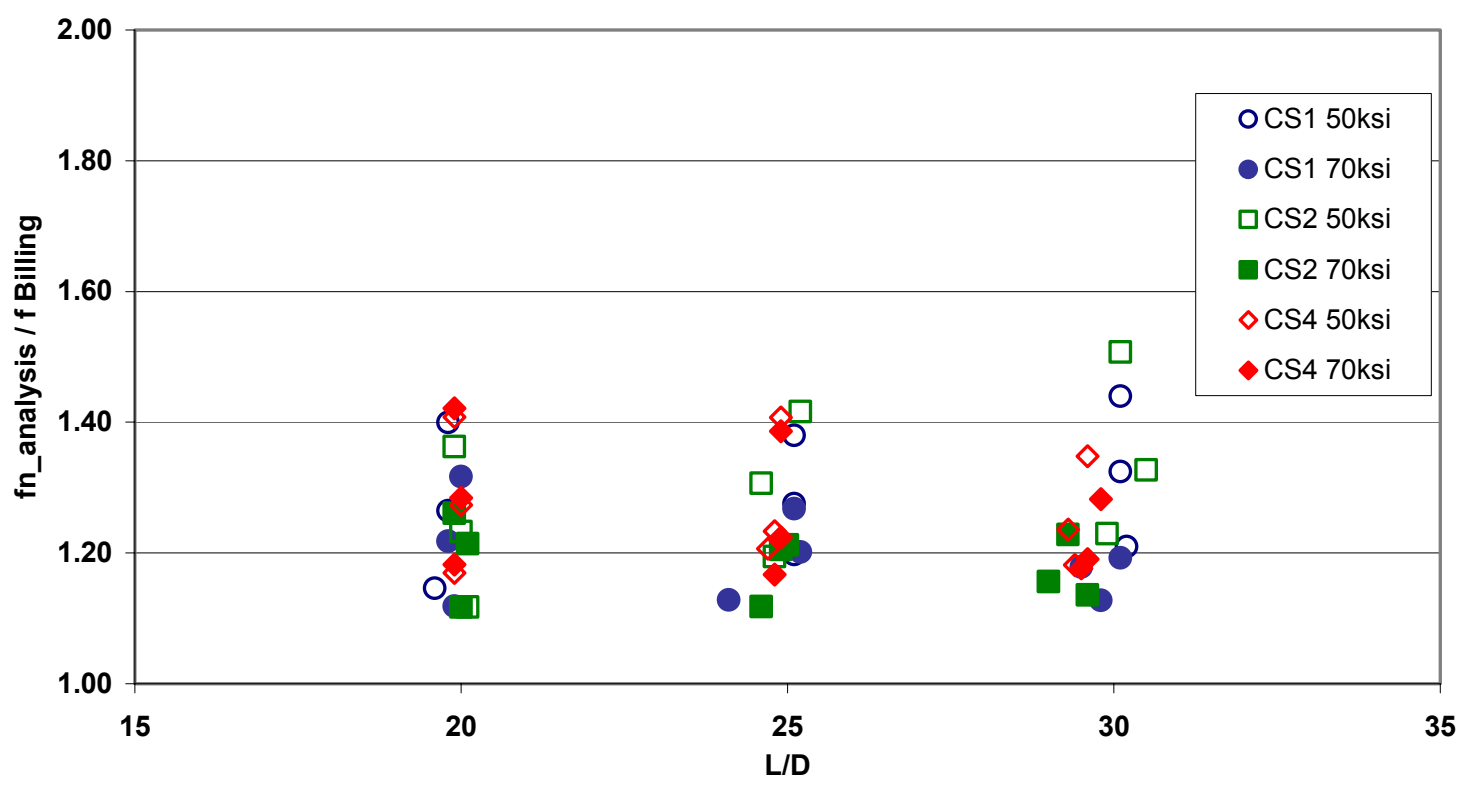

Figure 6.11. Comparisons between FEA and Billing's method for 3-span bridges 


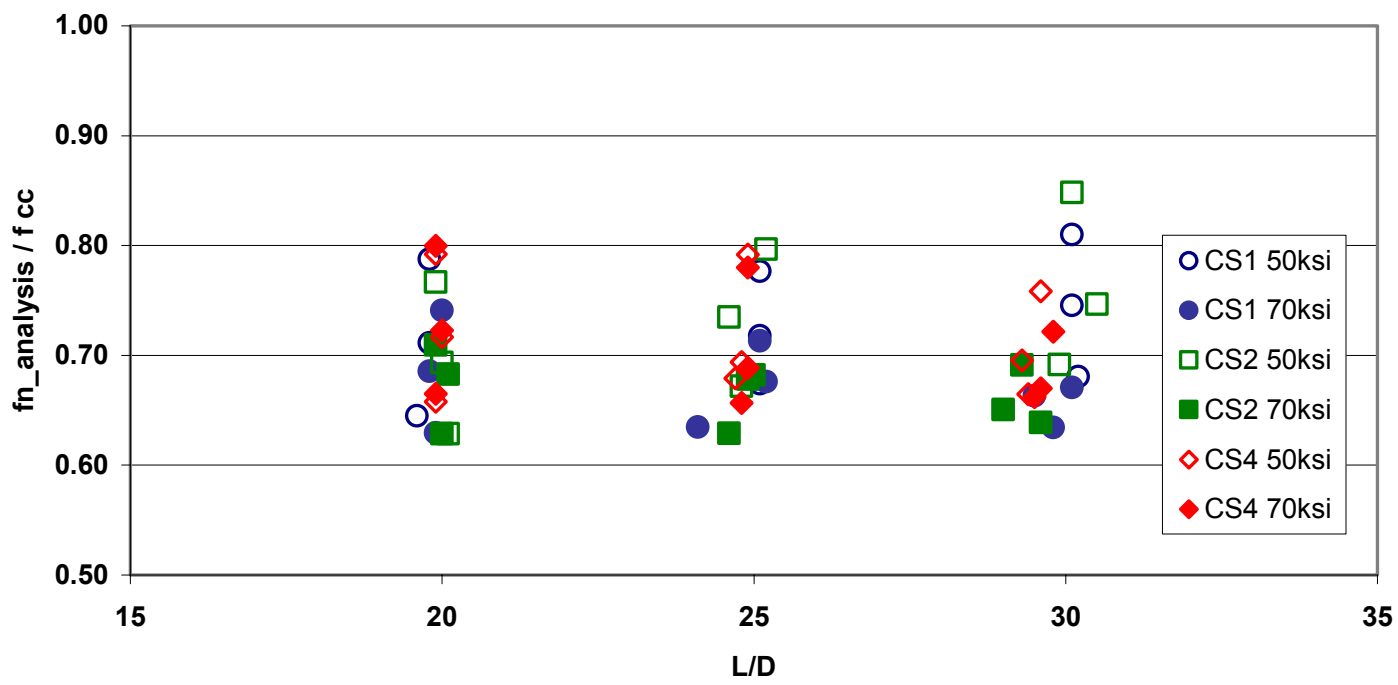

Figure 6.12. Comparisons between FEA and clamped-clamped beam equation for 3-span bridges 


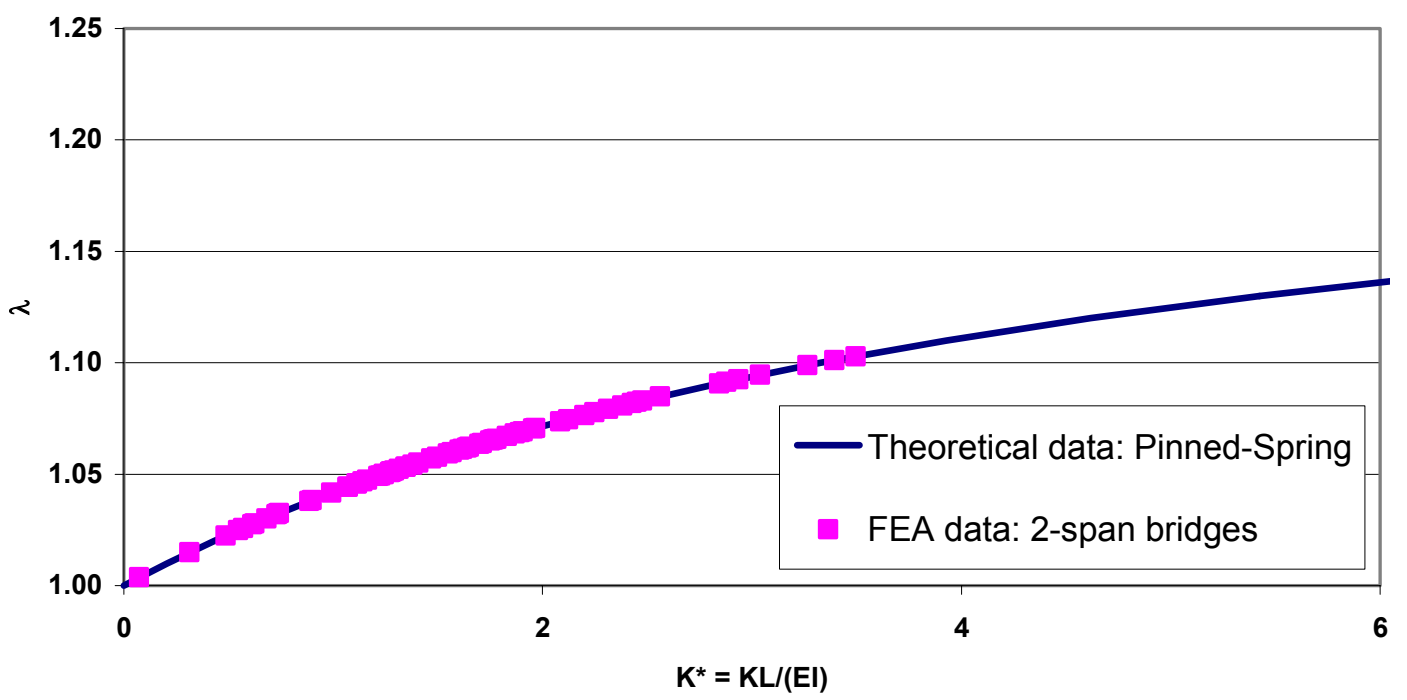

Figure 6.13. Effect of end restraint on the nature frequencies for 2-span bridges 


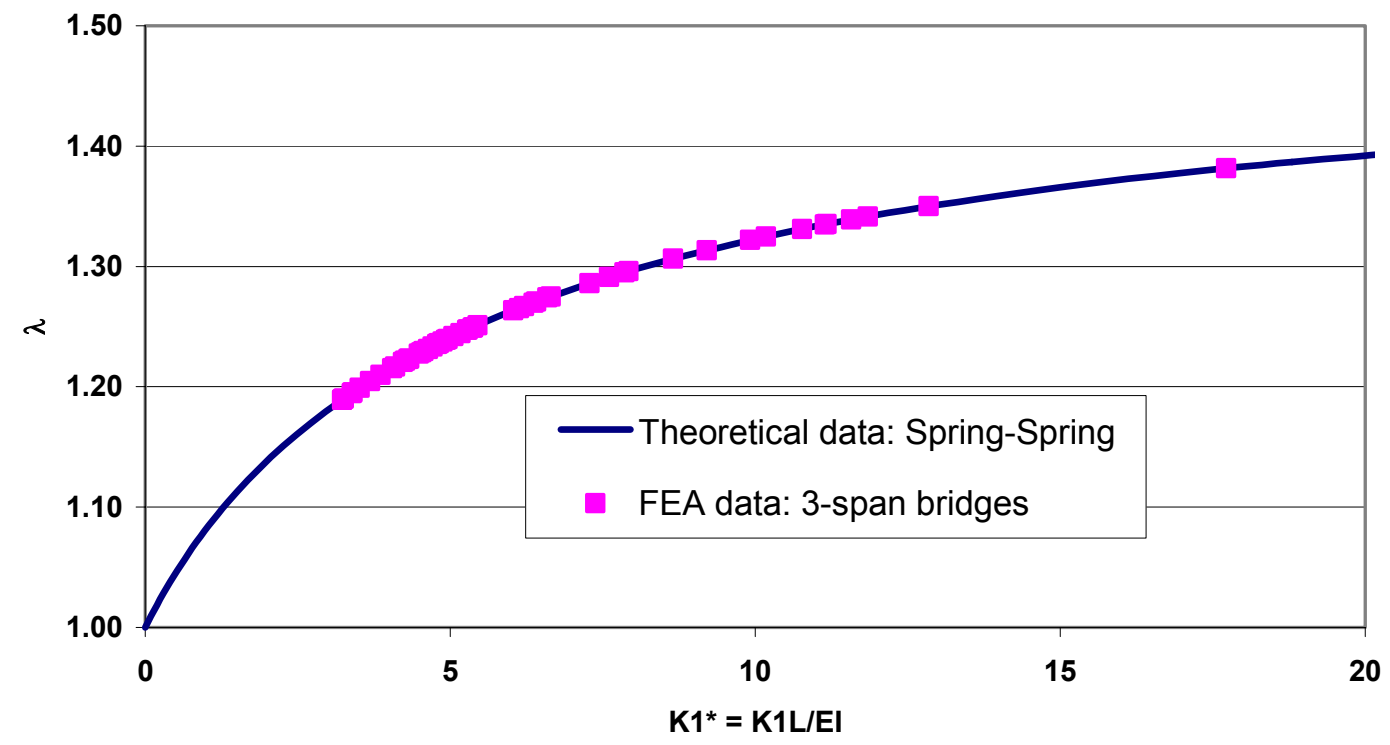

Figure 6.14. Effect of end restraints on the nature frequencies for 3-span bridges 


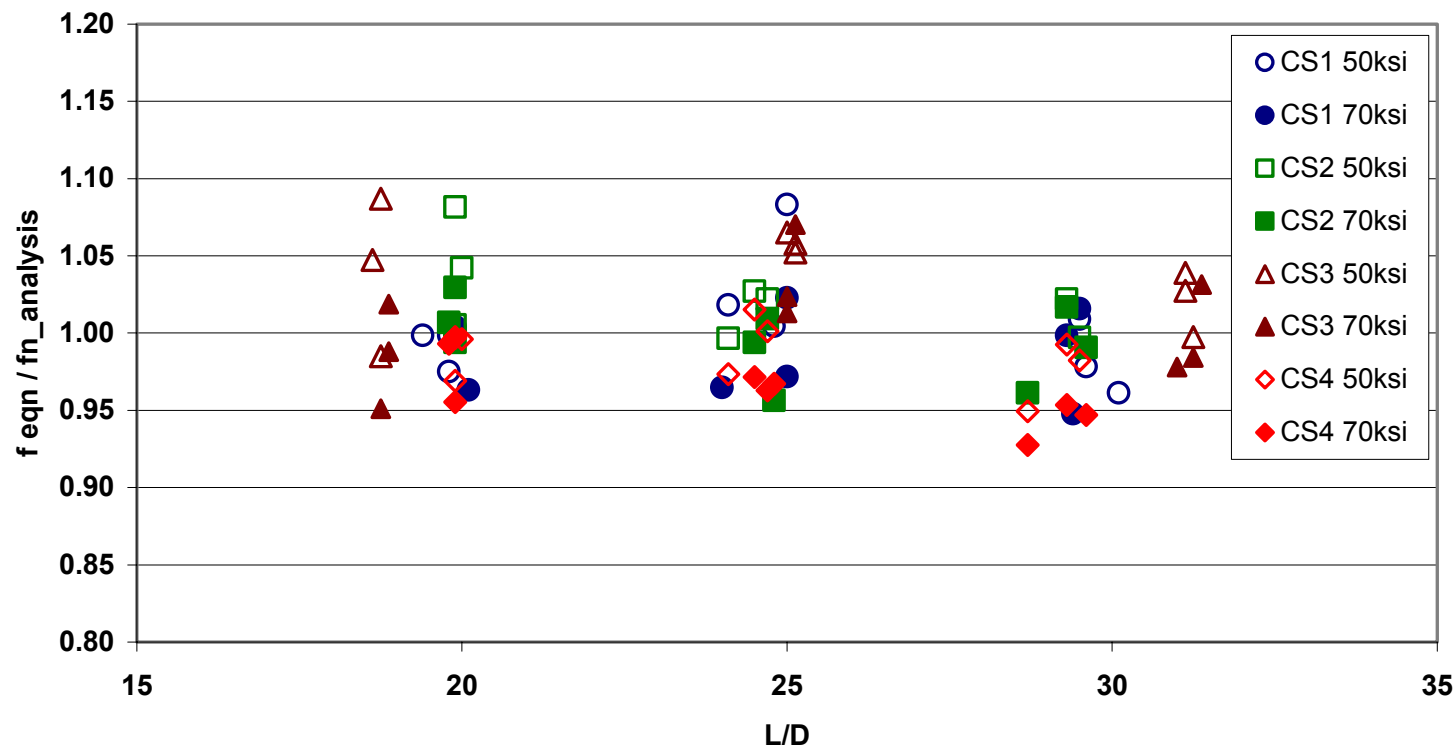

Figure 6.15. Comparisons between proposed equation and FEA results for 2-span bridge 


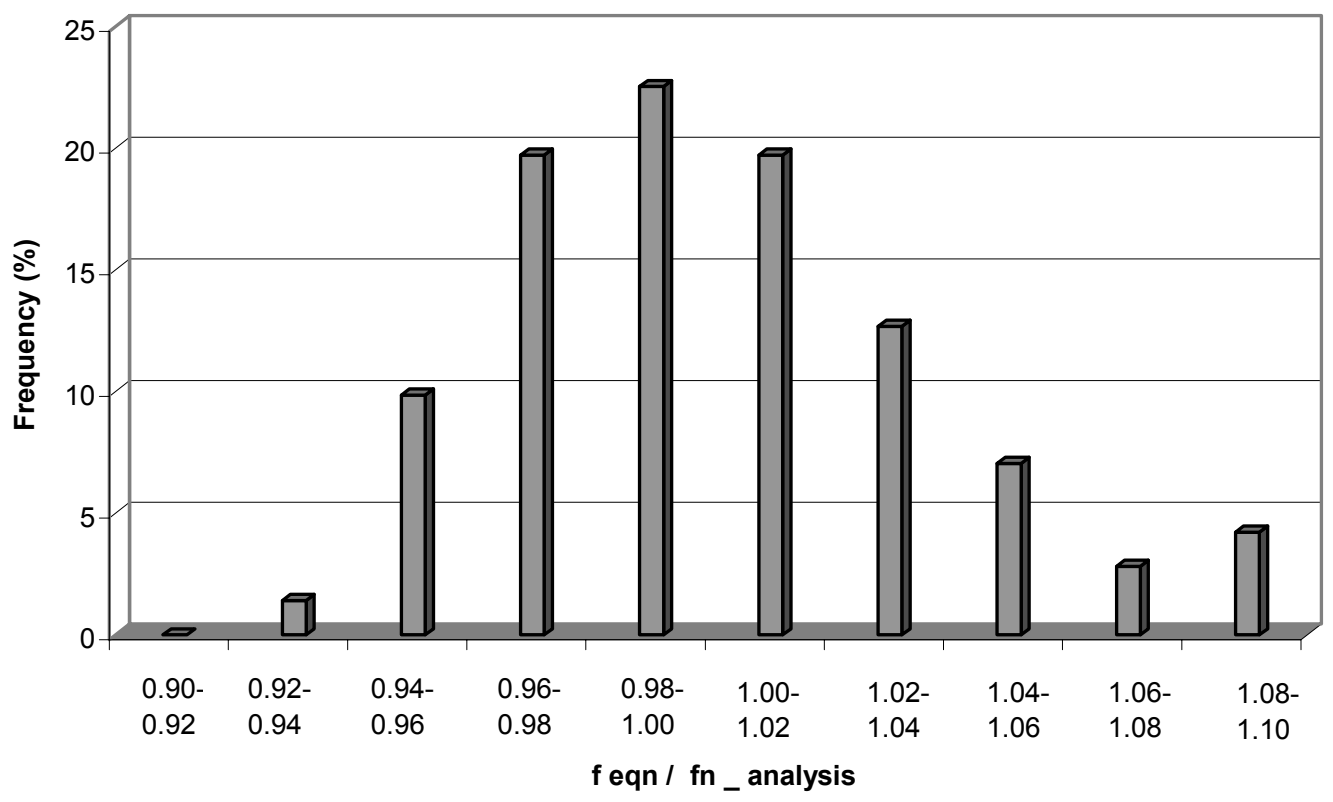

Figure 6.16. Histogram between proposed equation and FEA results for 2-span bridges 


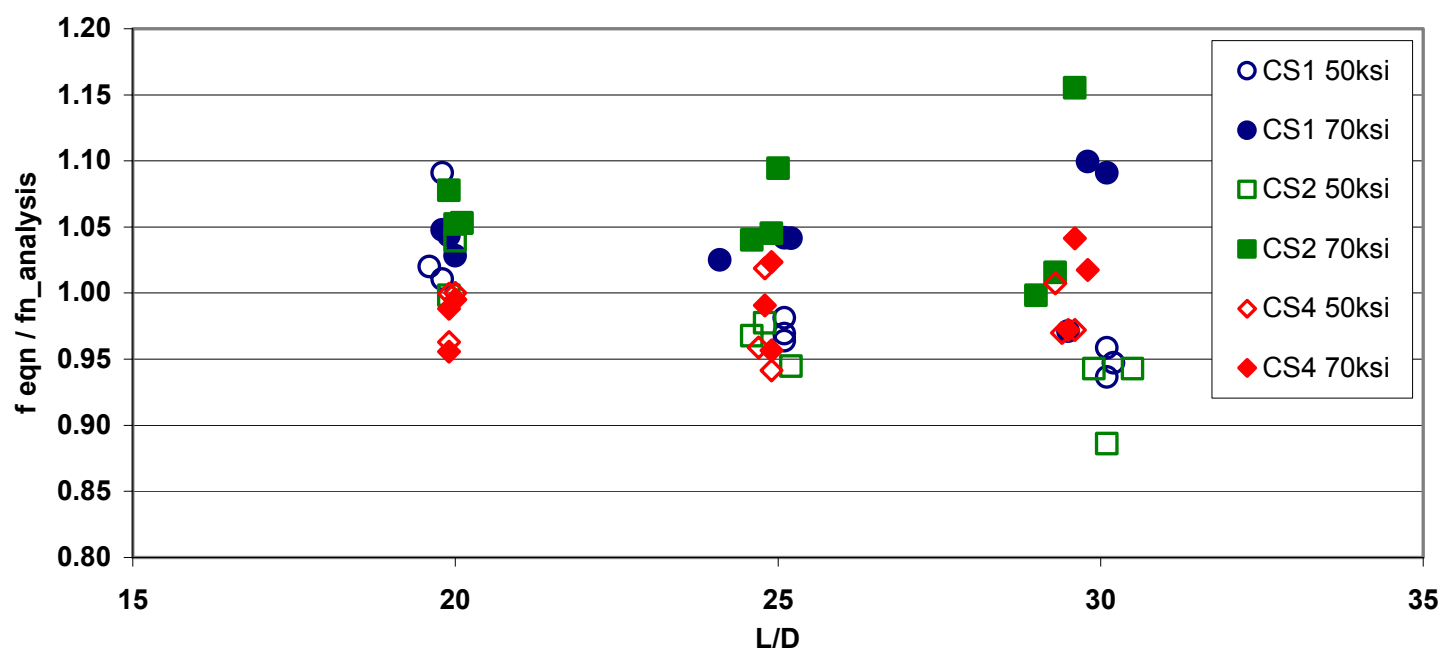

Figure 6.17. Comparisons between proposed equation and FEA results for 3-span bridge 


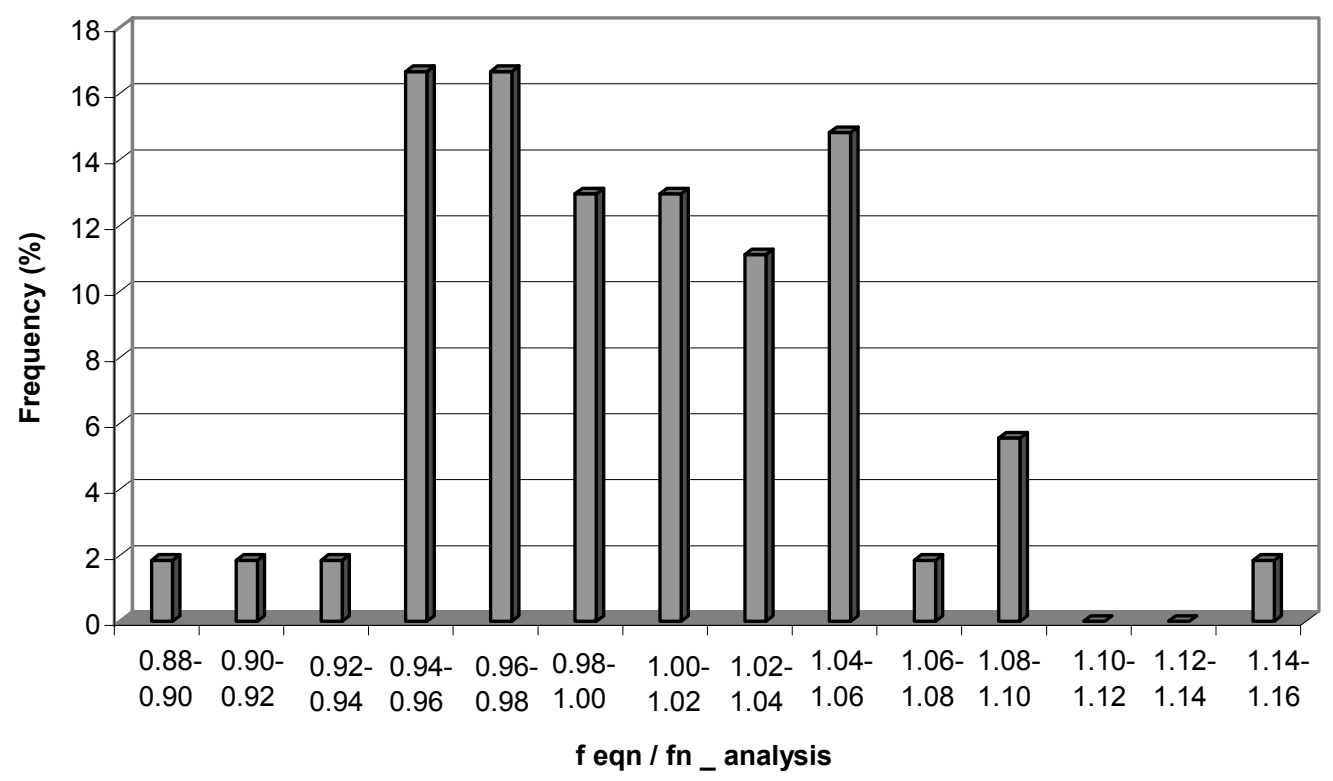

Figure 6.18. Histogram between proposed equation and FEA results for 3-span bridges 


\section{CHAPTER 7}

\section{FIELD PERFORMANCE EVALUATION OF A CONTINUOUS SPAN HPS STEEL I-GIRDER BRIDGE}

\subsection{Introduction}

Field testing of a new 2-span continuous HPS bridge was conducted by the University of Missouri - Columbia in co-operation with the Missouri Department of Transportation (MoDOT) in August, 2002. Because HPS was first introduced to the bridge market only 7 years ago and no field tests of this type of bridge has been reported in the literature, this field performance evaluation is believed to be the first to investigate the live-load deflections and vibration characteristics of HPS bridges in the United States. Finite element analytical work related to this field evaluation was conducted to evaluate the live-load deflections, stresses and vibration characteristics as part of the present study.

This chapter presents a thorough description of the field testing, including details of the testing system, instrumentation, and loading, along with the results obtained from this testing, aimed at evaluation of the live-load deflection and vibration characteristics of this HPS bridge. Comparisons between the FEA and field testing are also presented for live-load deflection, stresses, and natural frequencies. Further, this bridge serves as additional experimental verification for the FEA model previously proposed in Chapter 4 and the experimental natural frequency of this bridge is used as an example to verify the natural frequency equation proposed for 2-span continuous composite steel bridges in Chapter 6. Live-load deflections of this HPS bridge are compared with the AASHTO L/800 limit and two alternative criteria, Wright and Walker's procedure and OHBDC. 


\subsection{Description of the Bridge}

The subject of the field testing described in this chapter is the first HPS bridge (Missouri Bridge A6101) built in Missouri, constructed by MoDOT in 2002 as part of the FHWA's Innovative Bridge Research and Construction Program. The bridge is located on Route 224 over the relocated Route 13 in Lafayette County, Missouri. As shown in the photograph in Fig. 7.1, the bridge is a two-span continuous bridge, having two equal spans (138 ft. $+138 \mathrm{ft}$.) with a total width of $42 \mathrm{ft}$. (Roadway width $39.37 \mathrm{ft}$.) and a skew angle of 17.08 degrees. From the photograph shown in Fig. 7.2, the five steel girders, staggered cross frames, and one abutment may be seen. The girders are approximately 61 in. deep and have thickness and width flange transitions in both the top and bottom flanges at the two flexural transition locations, located approximately $30 \%$ of the span length from the center pier. These girders utilize HPS 70W in the top and bottom flanges in the negative bending region, are spaced at $9 \mathrm{ft}$., and support an $8.75 \mathrm{in}$. thick concrete slab.

The girders were designed to act compositely with the concrete deck in the positive bending regions only, using shear connectors. However composite action exists in the negative bending regions due to the top flanges partially embedded in the concrete haunch. The slab haunch between the bottom surface of concrete slab and the bottom of the steel girder top flange is 2.56 in. Stud connectors, 0.75 in. in diameter by 5 in. tall, are placed in sets of three across the width of the top flanges in positive bending regions. The typical spacing of shear connectors is approximately 14.17 in. Field splice locations are also located at approximately $30 \%$ of the span length from the center pier. A typical field splice is shown in Fig. 7.3. 
As shown in Fig. 7.2, each span of the bridge has five staggered intermediate diaphragms spaced at 275.60 in.. The top and bottom members of these diaphragms are $4 \times 4 \times 5 / 16$ angles. For the end diaphragms, the top members are $\mathrm{C} 15 \times 50$ sections and the bottom members are $5 \times 5 \times 5 / 16$ angles, while in the cross frames over the pier, both the top and bottom members are $5 \times 5 \times 5 / 16$ angles. The diagonal members of all diaphragms are comprised of $3 \times 3 \times 5 / 16$ angles.

\subsection{Description of Testing Program}

The section provides detailed information on the testing system, instrumentation (strain gages, string potentiometers, laser deflection devices and accelerometer) and two types of loading used during the field testing of this bridge. Field testing was conducted before the bridge was opened to traffic, thus there was no need for traffic control.

\subsubsection{Testing System}

The University of Missouri at Columbia has developed a versatile and mobile bridge field testing system. Key features of this testing system are summarized herein and the reader is referred to Barker et al. (1999) for additional information. The command center of the testing system is the data acquisition vehicle, which is shown in Fig. 7.4. The vehicle has been refurbished to effectively provide transportation and living quarters for testing personnel as well as providing protection from the elements and airconditioned housing for the data acquisition computers and hardware. The rear workspace houses a data acquisition rack for 95 low level (strain) channels, 25 high level (deflection) channels, the data acquisition CPU, the communications receiver, and an 
oscilloscope. Other equipment in the vehicle includes a monitor for the data acquisition $\mathrm{CPU}$, a data reduction computer, a printer, and two uninterruptible power supplies (UPS).

A $4 \mathrm{KW}$ onboard power generator can be used to power the data acquisition system for small testing and a $12 \mathrm{KW}$ external generator can be used to power the full capacity of the data acquisition system for large scale field testing, as performed in this study. The electrical system is automatically configured by the use of a mechanical relay. Two cables are required when using the external generator, one of which powers the data acquisition hardware while the other powers the appliances.

Because the field testing process is a team effort, a Telex wireless intercom system was installed in the data acquisition rack to insure good communication of duties and responsibilities during the testing. This system consists of BTR-200 Base Station Transceivers, Base Station Speakers, a Base Station Microphone and four TR-200 BeltPack Receivers with headsets.

The Hewlett Packard 54602B $150 \mathrm{MHz}$ oscilloscope is located on the data acquisition rack to allow easy access for signal monitoring of any of the 120 channels of the data acquisition system. The HP 54602B provides automatic setup of the front panel and cursor measurement of frequency, time, voltage, wavefrom storage and peak detect.

A computer with a data acquisition card is used for data acquisition and another computer serves as the data reduction and general use computer for the testing system. Floppy, CD-ROM, and Zip drives are available for easy backup and storage of the test data. The data acquisition computer is mounted on anti-vibration feet to decrease the chance of damaging the computer during transit. 
The signal is carried to the data acquisition vehicle over 26 pairs of individually shielded cables. Located at the other end of these cables are the data acquisition boxes, one of which is shown in Fig. 7.5 mounted to a cross frames during testing. The data acquisition box is powered by connecting it to the $\mathrm{AC}$ connectors on the data acquisition connector panel located on the side of the data acquisition vehicle, which is shown in Fig. 7.6. Each box has been equipped with sufficient screw terminals for making all signal connections.

Commercial data acquisition software using a graphical programming language is used to inform the hardware what data to collect and how to collect it. The user interfaces with the program through the control panel, where the user provides input to the program and receives output in the form of graphs, numbers, dials, switches, etc. The data acquisition system requires the program to continuously collect voltage output from up to 125 channels while conducting a field test. The data must be acquired in a time step manner, where a signal from each channel is stored and associated with that time step. This output is saved to a data file along with the associated time.

\subsubsection{Instrumentation}

The bridge was instrumented with CEA06-W250A-350 weldable strain gages placed at three varying depths for each of the five girders at both the maximum positive section ( $0.4 \mathrm{~L}$ point) and maximum negative section (the pier section) of the second span, which results in a total of 30 strain gages. Specifically, one gage was placed on the bottom flange, one was placed on the web at $25 \%$ of its depth, and the third was placed approximately at the mid-depth of the web. A Manlift was used to access the steel girders 
from underneath of the bridge and weld the strain gages, which is shown in Fig. 7.7 along with a typical strain gage layout for one exterior girder shown in Fig. 7.8. The data from the strain gages can be used to determine maximum strains, maximum stresses, and lateral distribution factors, which can be compared with current AASHTO code predictions and to check if the cross sections are behaving in a linear elastic fashion. The strain data from the maximum negative sections can also be used to determine the bearing restraint forces and the degree of composite action provided by the partially embedded top flanges.

Due to the height of the girder from the ground, conventional LVDTs could not be used to obtain deflection measurements; instead, deflections were recorded using string potentiometers by placing a string potentiometer at the $0.4 \mathrm{~L}$ point of each girder. A view of the five string potentiometers is shown in Fig. 7.9. Fishing line was used to connect each potentiometer and the corresponding steel girder by using a steel clamp on the edge of the bottom flange, as shown in Fig. 7.8. Alternatively, as shown in Fig. 7.10 the live-load deflection of girder 2 (G2) was measured using a set of laser devices with a helium neon laser installed on a tripod (see Fig. 7.10a) and a deflection device installed on G2 of the second span (see Fig. 7.10b). The deflection data can be used to evaluate the deflection characteristics of this 2-span continuous HPS bridge, which is one of the major concerns of this research. The deflection data can also be compared with AASHTO deflection limits.

An accelerometer was placed at the $0.4 \mathrm{~L}$ point of $\mathrm{G} 2$ to measure acceleration of the bridge. The free vibration part of the acceleration record after the construction test 
vehicle (described in the subsequent section) left the bridge was used to perform a Fast Fourier Transform (FFT) to obtain the natural frequencies of this bridge.

The data acquisition boxes serviced all of the above instrumentation including the strain gages, potentiometers, and accelerometer. The boxes were carefully arranged to minimize lead wire lengths.

\subsubsection{Loading}

Two types of loading were used in this testing program. The first was a pseudo static load applied for the purposes of determining the maximum deflections and stresses in all girders of the bridge. The second was a dynamic loading conducted to determine the vibration characteristics of the bridge.

The pseudo static load tests were performed by driving an AASHTO H20 type load vehicle across the bridge at crawling speed. The axle spacing, magnitude of the wheel loads, and photograph of this test vehicle are shown in Fig. 7.11. The vehicle is a 1984 Freightliner truck equipped with an M-21-8 Jiffy Lift Classic-Lift Eagle boom. The steel blocks on the truck, each weighing an average of $1500 \mathrm{lb}$, were used to adjust the axle loads of the truck. The boom and steel blocks provide an efficient method of changing the wheel loads during the testing if needed. The wheel loads were measured by four weight pads, shown in Fig. 7.12.

All data was collected with the test vehicle moving in the same direction, towards the west direction. Tests were conducted with the truck traveling across the bridge in 12 different transverse positions across the width of the bridge. These load positions were defined such that maximum distribution factors, or load response, for each girder could 
be obtained, based on AASHTO spacing. Figures 7.13 through 7.17 show the bridge cross section along with the 12 vehicle load positions used to maximize the response of girders 1, 2, 3, 4, and 5. For example, load case 1 (shown in Fig. 7.13) was selected in order to obtain the maximum moment response for girder G1; similarly load case 12 (shown in Fig. 7.17) maximizes the moment response of girder G5. Figure 7.14 shows the load cases that maximize the response of girder G2, load cases 1 and 4 or load cases 2 and 6. Load cases 3 and 8 are shown with load cases 5 and 10 in Fig. 7.15, where one of these combinations gives the maximum moment response of girder G3. Lastly, Fig. 7.16 shows the load cases that will result in the maximum force effect for girder G4, load cases 7 and 11 or load cases 9 and 12 .

The dynamic testing was conducted by driving a construction vehicle (backhoe) across the bridge at rate of approximately $25 \mathrm{mph}$, which is shown in Fig 7.18. Wheel loads were again determined using the weight pads shown in Fig. 7.12. This testing was also performed with the vehicle traveling in the same direction as the pseudo static tests were performed. Data was collected while the construction vehicle was driven over the bridge several times to verify that reliable, repeatable data was acquired.

\subsection{Testing Results and Comparisons}

This section presents the test data resulting from these field tests, which was interpreted and provided by researchers at the University of Missouri at Columbia. The methods used to reduce the experimental voltage readings to engineering parameters, such as deflections, stresses and accelerations, are briefly described, while the reader is referred to Barker et al. (1999) for additional information on this topic. The resulting 
deflections, stresses, and natural frequencies are presented and are compared with the FEA results obtained using the proposed modeling procedure discussed in chapter 4 . The deflection results are also used to check AASHTO deflection calculation assumptions.

\subsubsection{Data Reduction Process}

The results from each test were stored in a tab delimited text file that could be easily imported to a Microsoft Excel spreadsheet (Excel, 2002). A template was created in Excel that would automatically zero the readings from each channel and apply corresponding approximate factors such as strain gage factor to convert the voltage readings into meaningful engineering units, such as deflections, stresses and accelerations.

\subsubsection{Deflection Results and Comparisons}

Reliable data was not obtained from the string potentiometers due to problems related to the calibration of the potentiometers. Therefore, only data obtained from the laser deflection device will be discussed. Furthermore, the laser was not functional during load cases 9 through 12, so actual deflection results were not available for these 4 load cases. For the remaining 8 load cases, the deflection of girder G2 measured by the laser is compared with the corresponding deflection predicted by the FEA in Fig. 7.19. The deflection predicted by the FEA for load cases 9 through 12 is also presented in the figure for completeness. As expected, larger deflections are obtained when the applied loading is near G2 (load case 1, for example), and reduced deflections are obtained as the truck position increases in distance from G2 (such as load case 12). The average deviation between deflections obtained from the fielding testing and FEA is 5.5\%, which 
shows that the previously proposed FEA model can capture the deflection characteristics of this 2-span continuous HPS bridge with acceptable accuracy.

AASHTO assumes that the deflections are the same for interior and exterior girders. However, the deflection profiles obtained from the FEA for each load case, shown in Figs. 7.20 (load cases 1 through 6) and 7.21 (load cases 7 through 12), suggest that this is not accurate. The deflections predicted for the two exterior girders subjected to the load case causing the maximum response give nearly equal results, 0.5033 in. for G1 subjected to load case 1 and 0.5016 in. for G5 subjected to load case 12. However, the interior girders have significantly different maximum deflections: 0.6364 in. for G2 subjected to load cases 1 and 4, 0.5204 in. for G3 subjected to load cases 3 and 8, and 0.6615 in. for G4 subjected to load cases 9 and 12. The largest discrepancy between maximum deflections is between G4 and G5, where the deflection of G4 is $32 \%$ higher than that of G5, illustrating that the AASHTO assumption is not valid. It is valuable to notice this because previous research (Roeder et al., 2002) shows plate girders with damaged webs at diaphragm connections were due to the out-of-pane deformation and connection rotation caused by differential girder deflections.

\subsubsection{Stress Results and Comparisons}

For each strain gage in the positive moment region, maximum stresses and concurrent stresses are recorded, while for each strain gage located at the pier, minimum stresses and concurrent stresses are recorded. To present this significant volume of data in its entirety is beyond the scope of this work. Instead, only the maximum stresses in the bottom flange of each girder (due to the load case maximizing the response) are presented 
for the positive moment regions, in addition to the minimum stresses measured in the bottom flange at the pier section of each girder.

Figure 7.22 compares the positive bending stresses in the bottom flange, resulting from the combination of load cases producing the maximum stress, from the field data and FEA. Specifically, load case 1 maximums the stress for G1; the combination of load cases 1 and 4 results in the maximum stress for G2; the maximum stress in G3 is produced by the combination of load cases 5 and 10; the combination of load cases 9 and 12 gives the maximum stress response in G4; and load case 5 produces the maximum stress in G5. The discrepancy between the analytical and field data ranges between $2.8 \%$ (G5) and 10\% (G2). Figure 7.23 shows a similar comparison between negative bending stresses at the pier section. The FEA results differ from the field data by 2 to $9.5 \%$, excluding G4, which varies from the field result by $21.3 \%$. Considering that the FEA consistently predicts stresses of acceptable accuracy for the majoring of load cases and strain gage locations, excluding negative bending stress of G4, it is suggested that the field data obtained from the strain gage at the pier section of G4 may have been erroneous.

\subsubsection{Natural Frequencies and Comparisons}

A typical vertical acceleration record for G2 is shown in Fig. 7.24, where the dark line represents the time when the test vehicle left the bridge. The acceleration information after this time represents the free vibration response of the bridge and was used to perform a FFT and determine the natural frequencies of this bridge. 
The FFT was performed by using commercial data processing and graphic software (ORIGIN, 2003). Figure 7.25 shows the power spectral density versus frequency obtained from this software. This gave experimental values of $1.86 \mathrm{~Hz}$ and $2.87 \mathrm{~Hz}$ for the first and second vertical bending natural frequencies, respectively. Additionally, the first and second vertical bending natural frequencies obtained from the FEA prediction are $1.83 \mathrm{~Hz}$ and $2.88 \mathrm{~Hz}$, which differ from the field test results by $1.6 \%$ and $0.34 \%$, respectively. This suggests that the proposed FEA modeling procedure efficiently captures the vibration characteristics of this continuous span composite steel bridge.

For this bridge with two equal span lengths, the simple beam equation (or Billing' method and Gorman's method) predicts $1.73 \mathrm{~Hz}$ for the first bending natural frequency which is $7 \%$ lower than the testing frequency of $1.86 \mathrm{~Hz}$. The proposed equation for 2span bridges gave $1.89 \mathrm{~Hz}$, which differs from the field data by $1.6 \%$, with the frequency

coefficient $\lambda^{2}$ equal to 1.09 . This example again shows that the proposed natural frequency equation can be used to predict the first bending natural frequency for 2-span continuous bridge with improved and acceptable accuracy.

\subsection{Evaluations of AASHTO L/800 Limit and Alternative Criteria}

The maximum live-load deflection resulting from the FEA analysis is the deflection of G4 subjected to load cases 9 and 12, equal to $0.6615 \mathrm{in}$. This amount of deflection is acceptable according to the AASHTO $L / 800$ limit, which permits a maximum deflection of 2.07 in.

As shown in Fig. 7.26, evaluation of the vibration of this bridge using the OHBDC (Ministry of Transportation, 1991) classifies the bridge as acceptable "with 
sidewalk, significant pedestrian use". Based on the Wright and Walker procedure (Wright and Walker, 1971), the bridge has an acceleration of $14.124 \mathrm{in} / \mathrm{s}^{2}$, which classifies the vibration of the bridge as "perceptible to most".

AASHTO live-load $L / 800$ deflection and the two alternative criteria suggest that there should be no intolerable vibrations due to the live-load deflection limits.

\subsection{Conclusions}

The field performance evaluation for a 2-span skewed continuous HPS bridge is presented in this chapter. The field testing system (Barker et al., 1999) is introduced, which includes the data acquisition vehicle, power generators, oscilloscope, computers, data acquisition software, etc. Strain gages, string potentiometers, laser deflection devices, an accelerometer, and data acquisition boxes were used to measure the live-load deflection, stresses, and natural frequencies. The bridge was evaluated under two types of loading, pseudo static testing conducted by very slowly driving a HS20 type vehicle across the bridge at various transverse locations and a dynamic test performed by using a construction vehicle to excite the bridge.

The live-load deflections, stresses, and natural frequencies resulting from the field tests are presented and compared with results obtained from the FEA. The average difference between the deflections obtained from the FEA and field tests of G2 is 5.5\%. FEA results are also included showing the deflection of G2 under all load cases and deflection profiles of all girders under their maximum loads. From the deflection profiles it is observed that the deflection of an interior girder can be up to $32 \%$ higher than that of 
and exterior girder, contradicting the assumption used in AASHTO live-load deflection calculations.

Maximum stresses recorded at the maximum positive bending location and minimum stresses measured at the pier are compared to FEA results for each girder. Considering the many uncertain factors present during field testing, these comparisons are acceptable with one exception. This occurred at the pier section of G4 where the FEA results differed from the measured values by $21.3 \%$. Because the majority of the stresses compare favorably, the high percent error at this location may be caused by inaccurate field data.

The first two vertical natural frequencies obtained from the field testing differ from those obtained in the FEA by $1.6 \%$ and $0.34 \%$, respectively. Given the favorable comparisons between live-load deflections, stresses, and natural frequencies obtained from the field testing and the proposed FEA modeling procedure, the accuracy of the proposed FEA is again verified.

The live-load deflection and vibration characteristics of this bridge are also evaluated using the AASHTO L/800 limit and two alternative criteria, Wright and Walker procedure and OHBDC. These efforts suggest that the live-load deflection and the vibration limits are not the design limits for this 2-span continuous HPS bridge. 


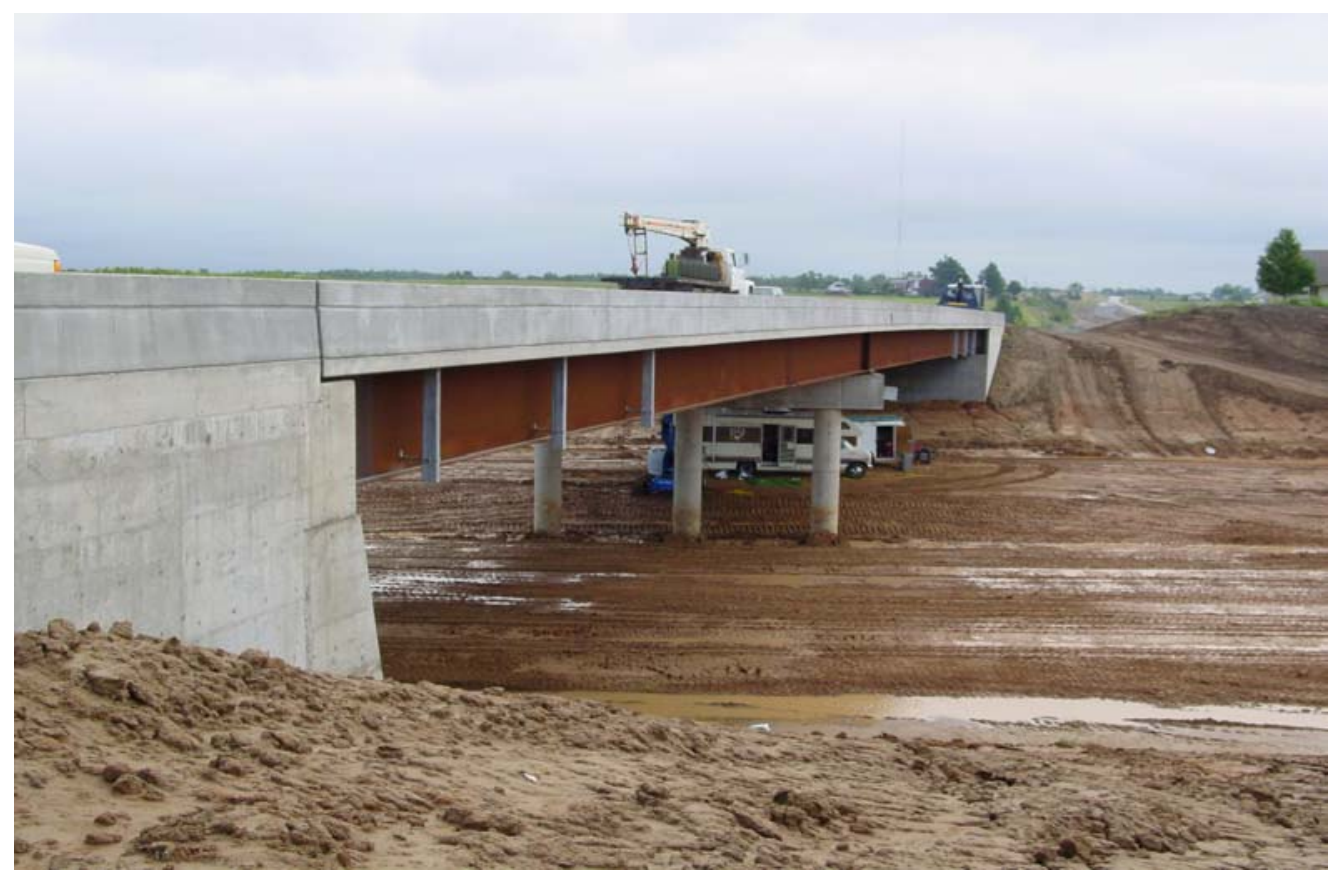

Figure 7.1. Elevation of field-tested/Missouri Bridge A6101 


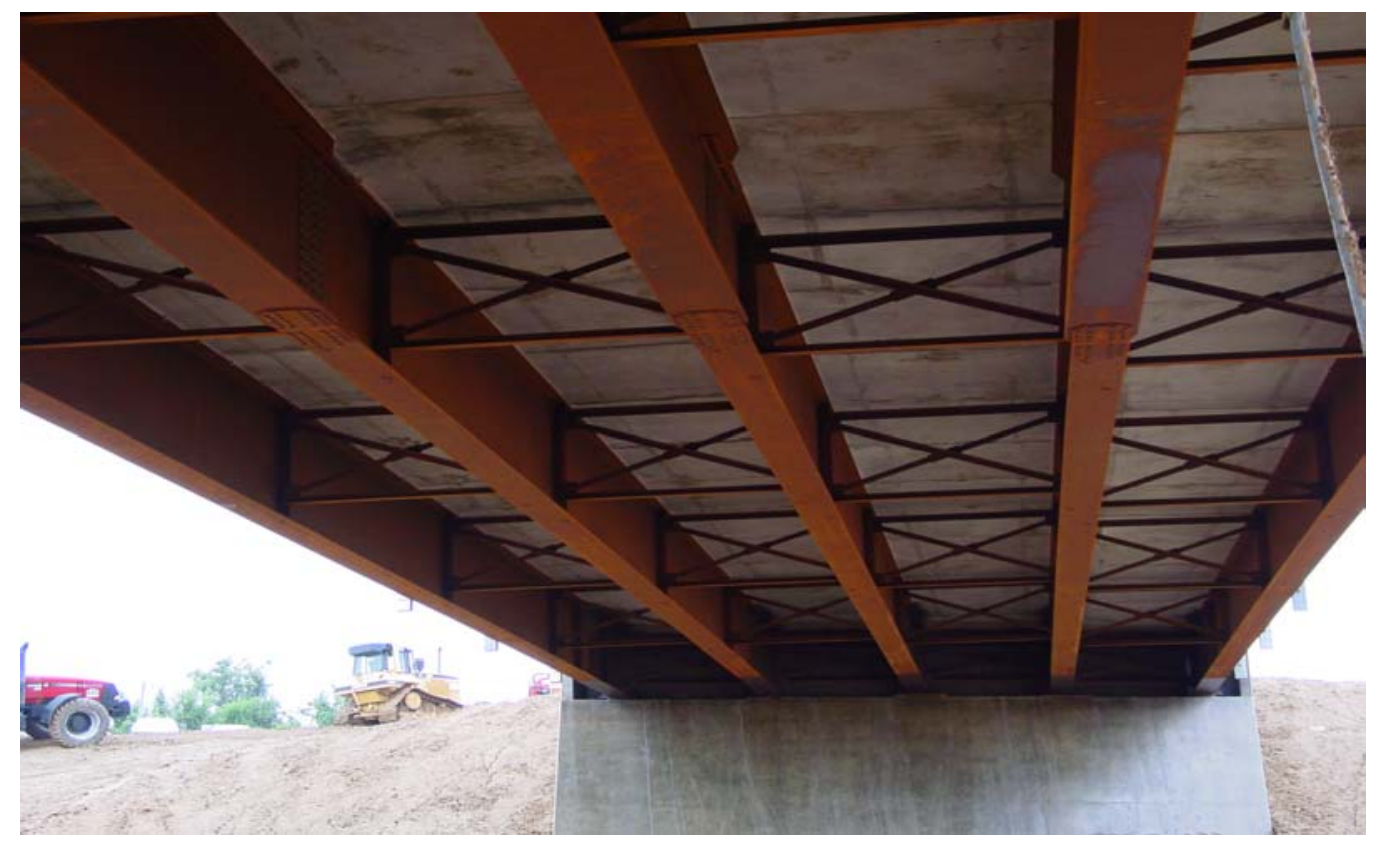

Figure 7.2. Underside of Missouri Bridge A6101 


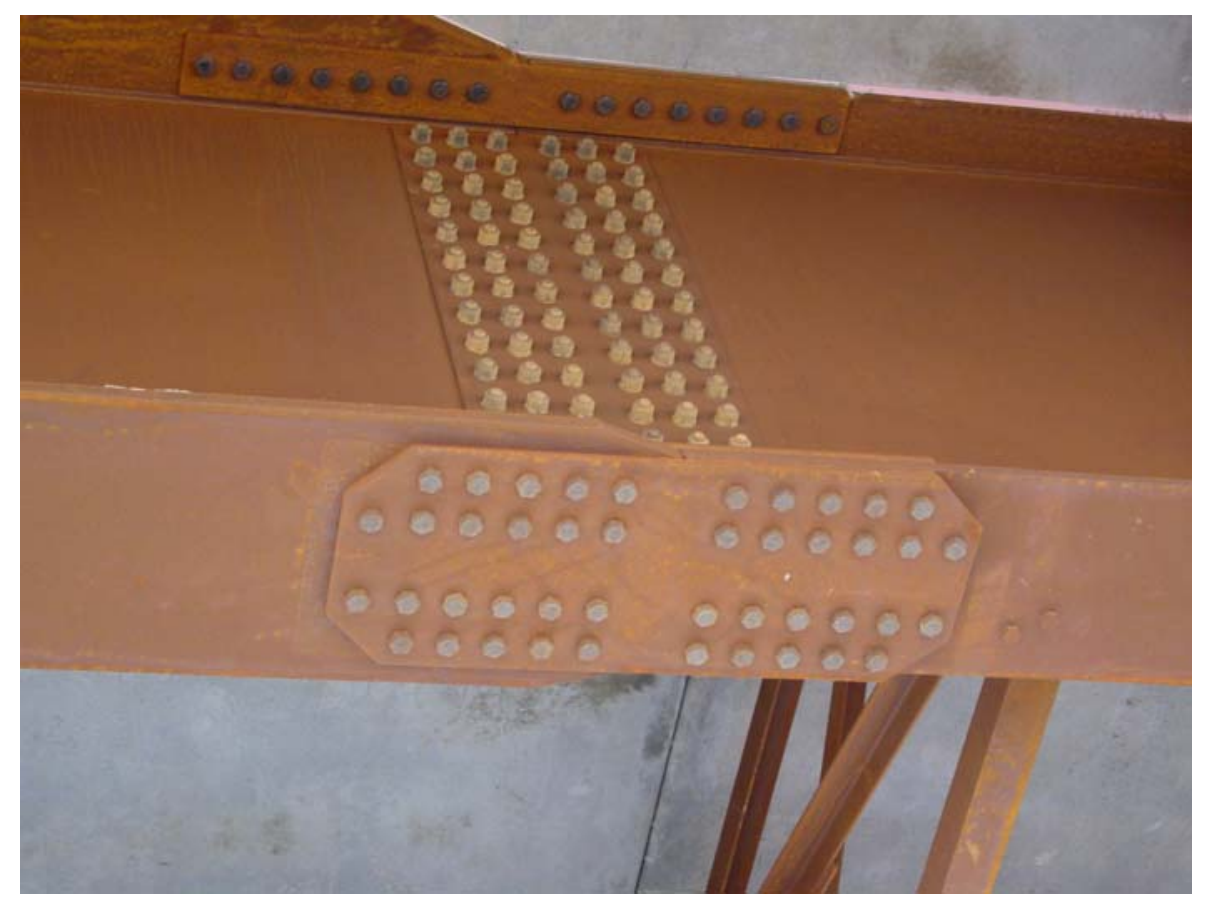

Figure 7.3. Typical field splice 


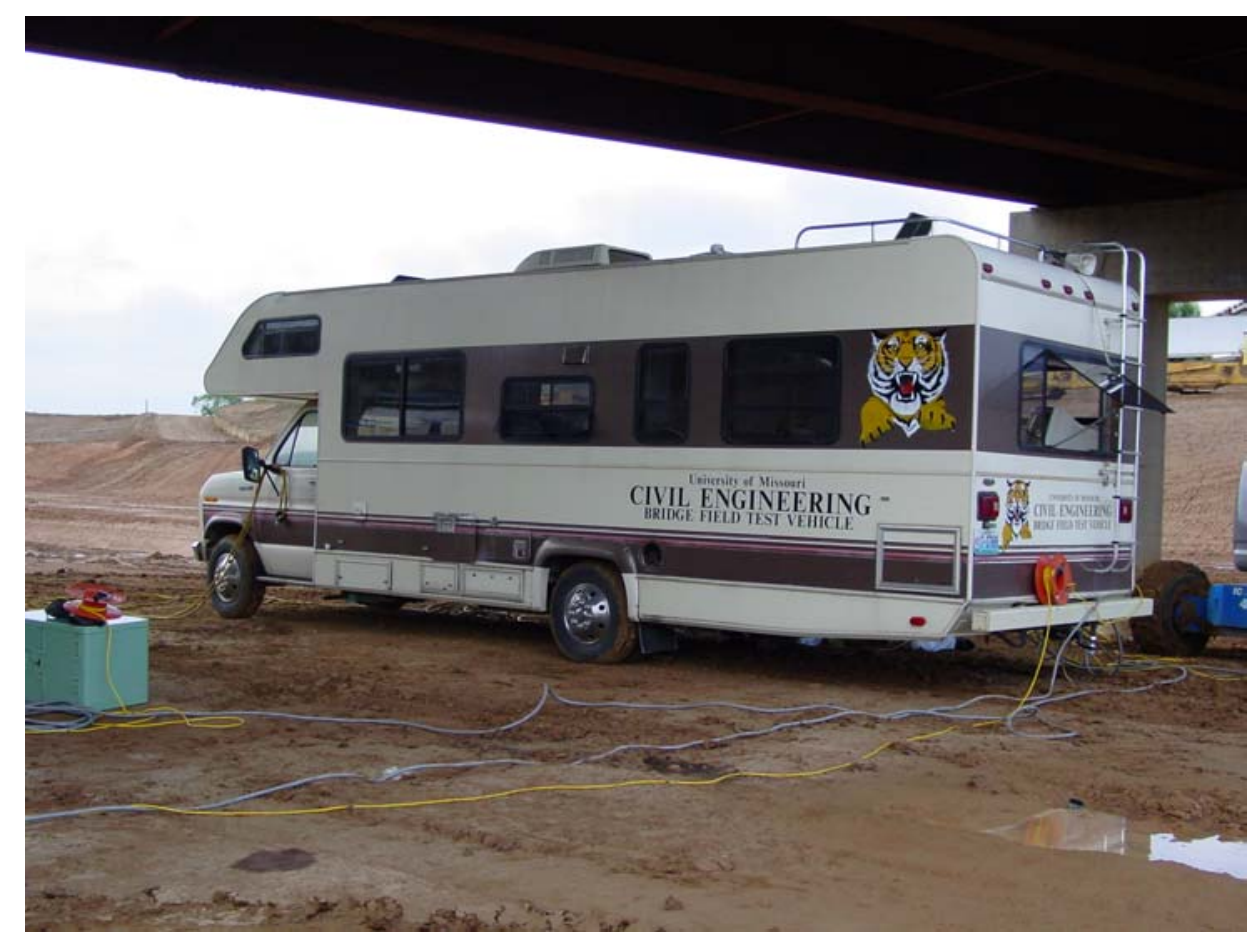

Figure 7.4. Data acquisition vehicle 


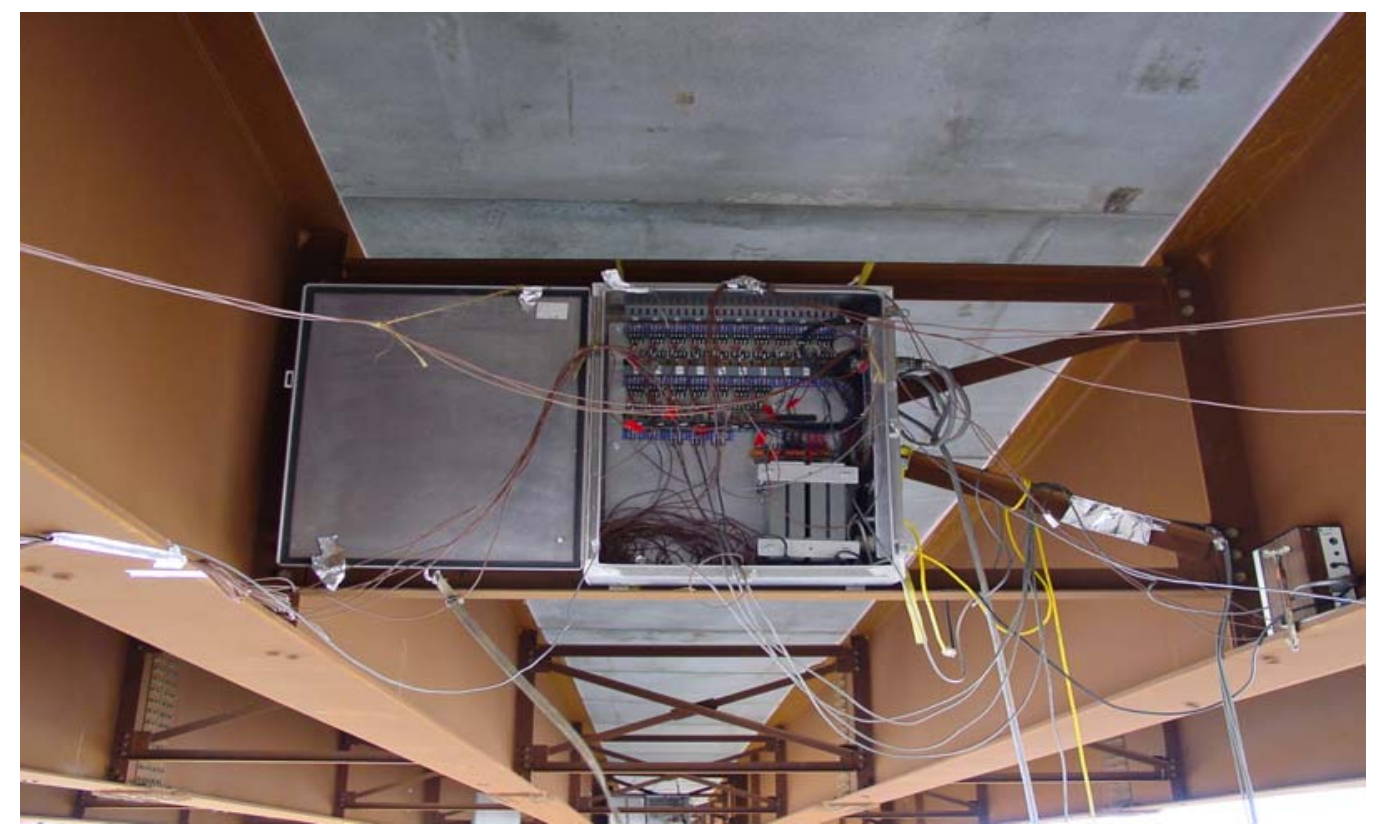

Figure 7.5. Data acquisition box 


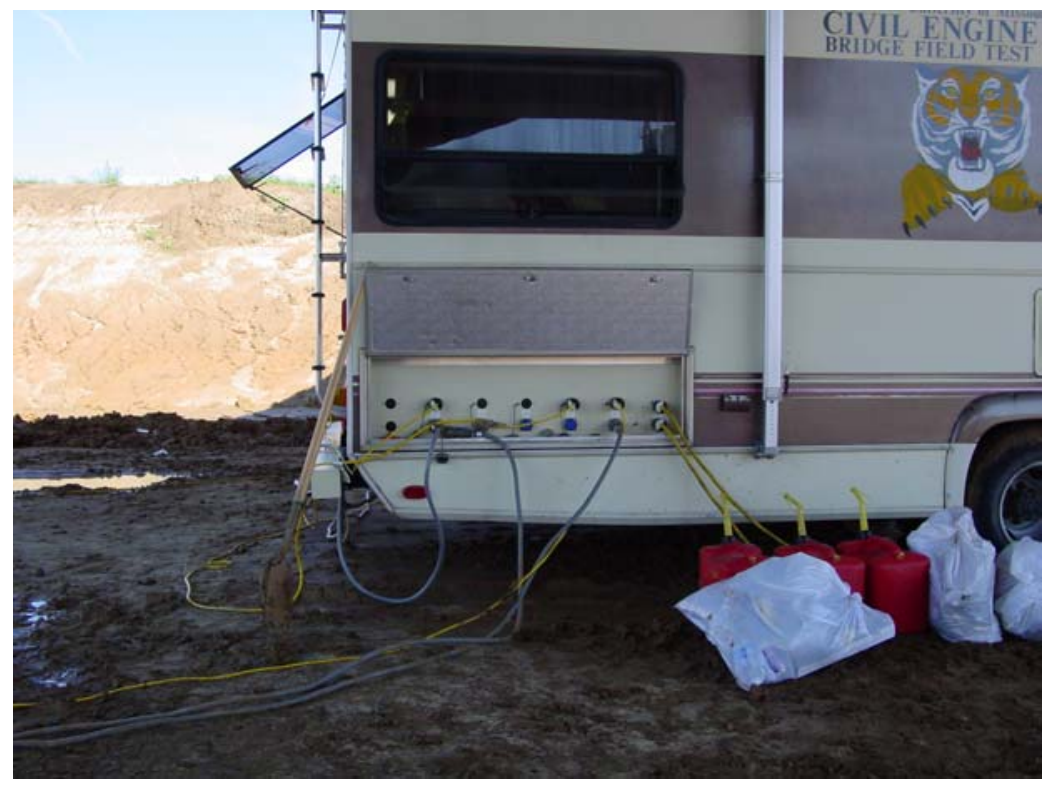

Figure 7.6. Data acquisition connector panel 


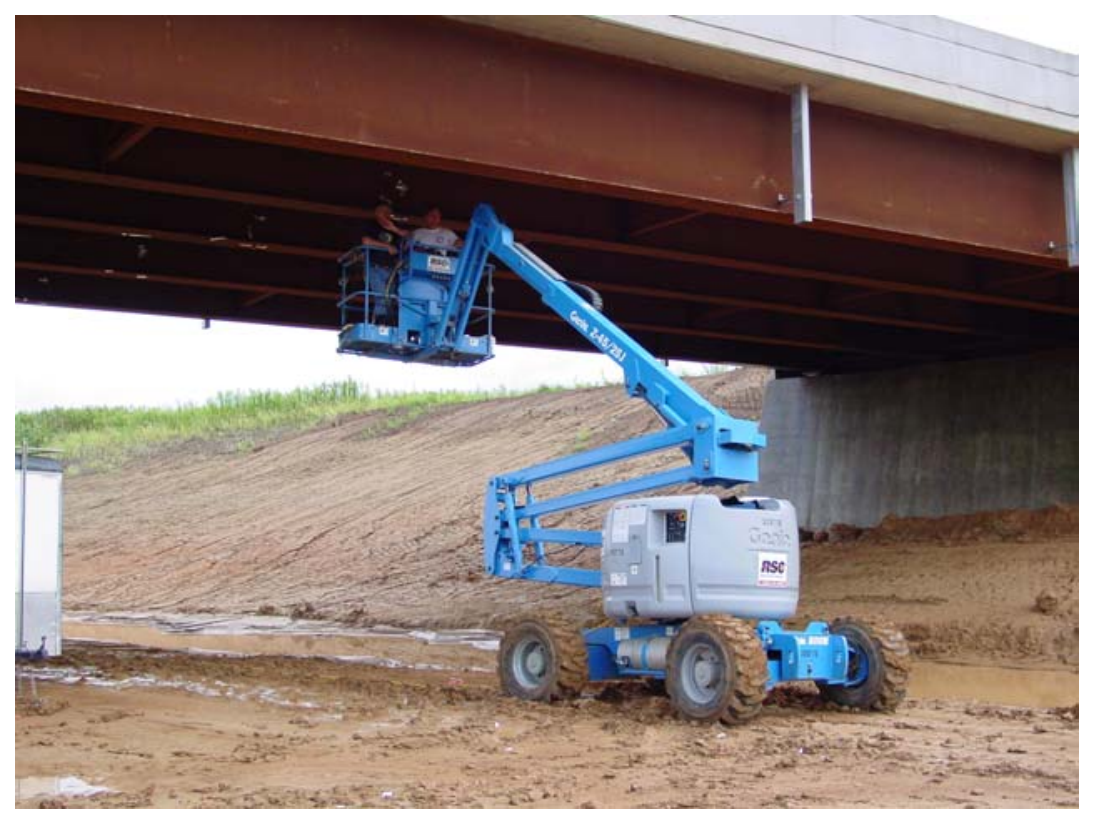

Figure 7.7. Manlift 


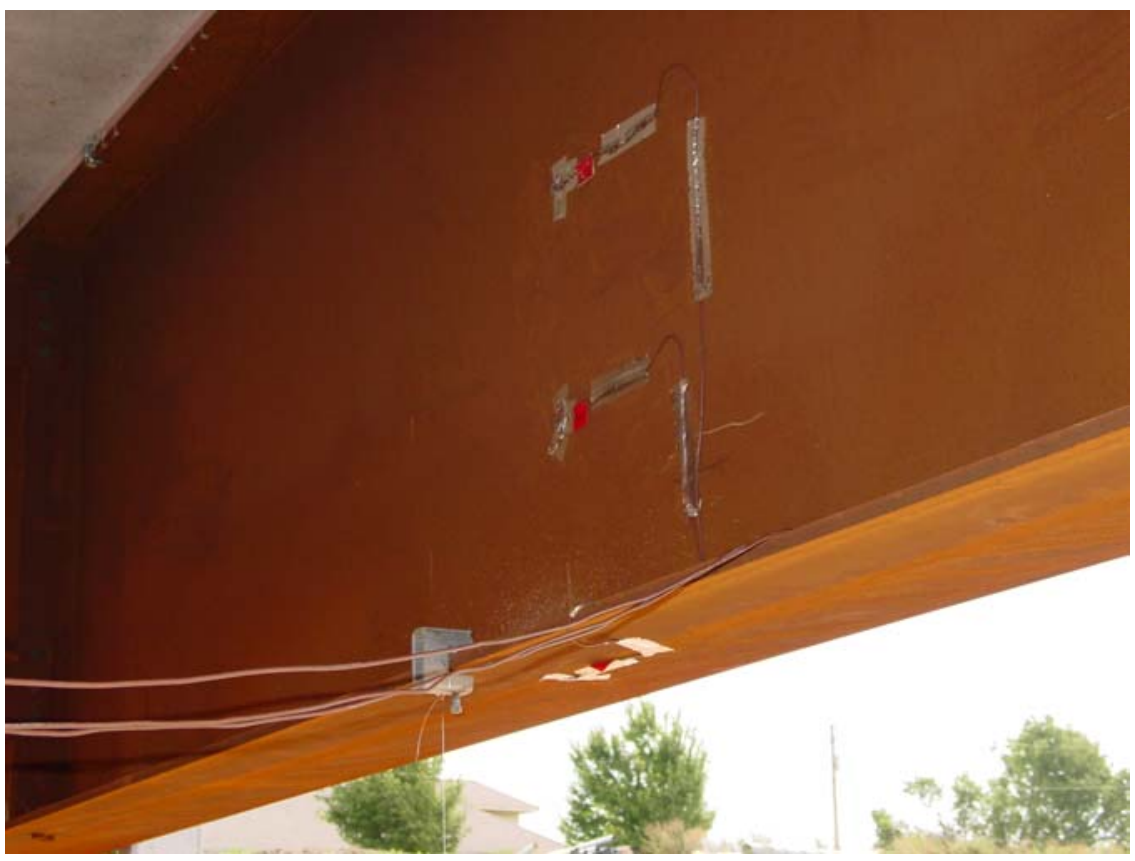

Figure 7.8. Strain gages for one exterior girder 


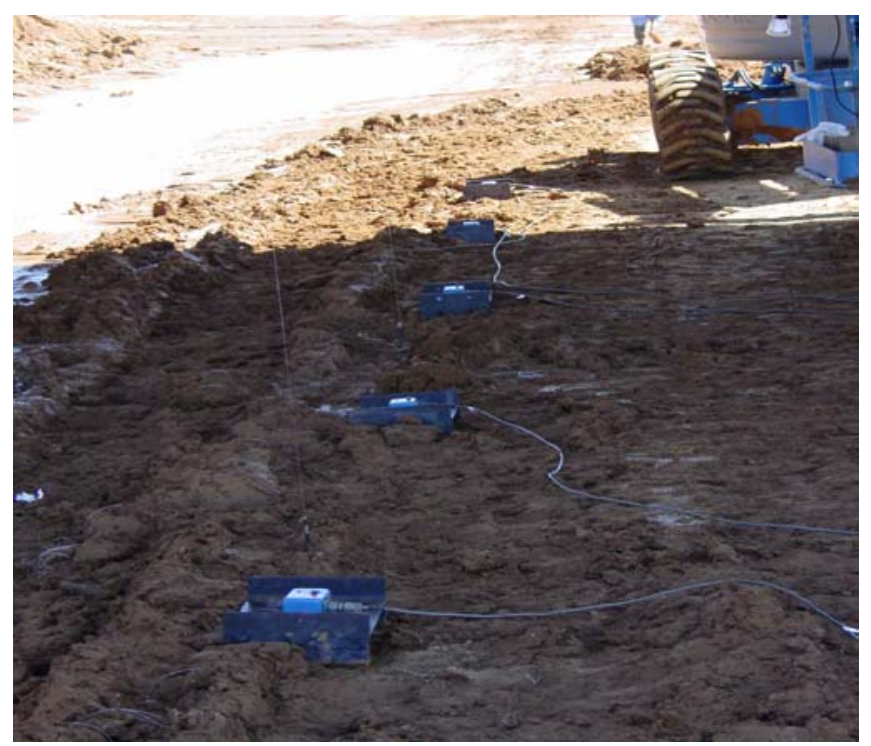

Figure 7.9. String potentiometers 

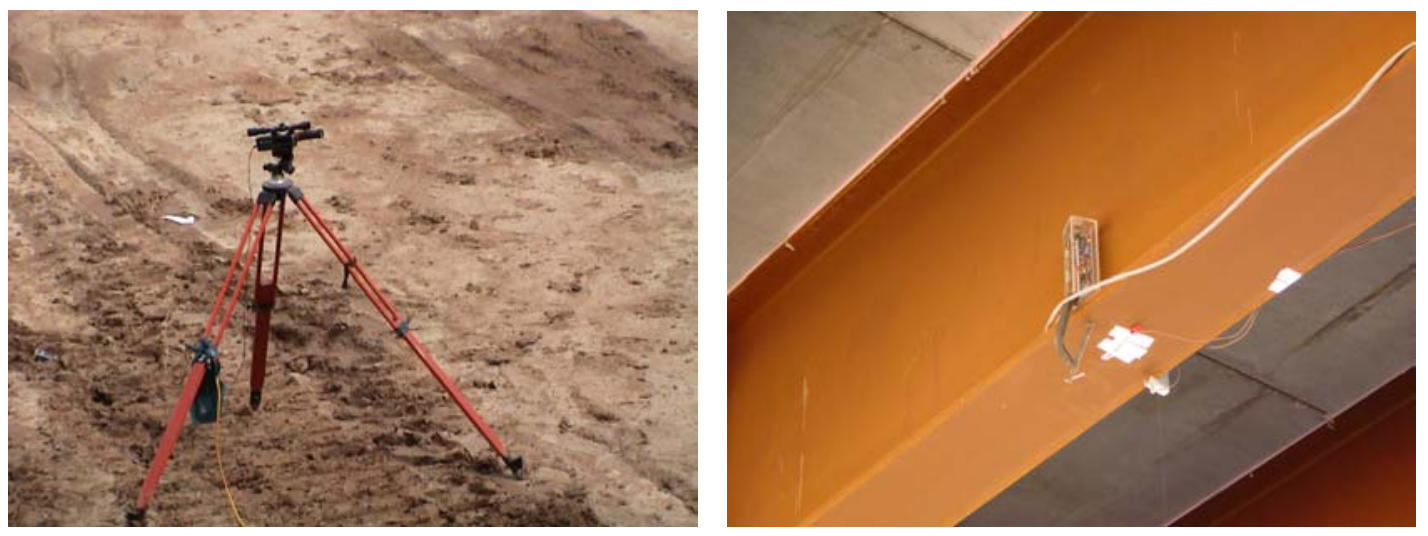

Figure 7.10. Laser deflection devices 

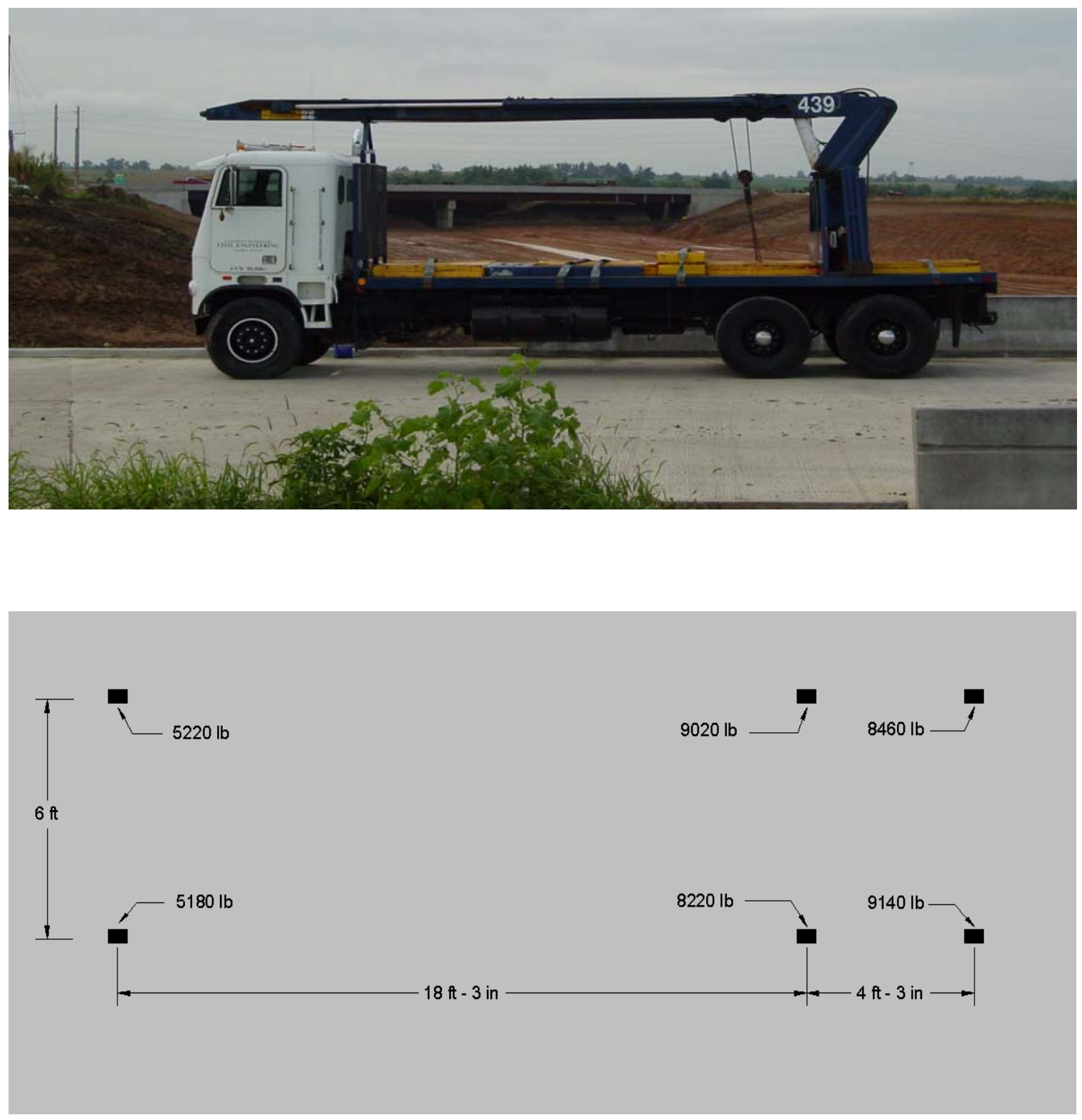

Figure 7.11. Missouri test vehicle and weight distribution 


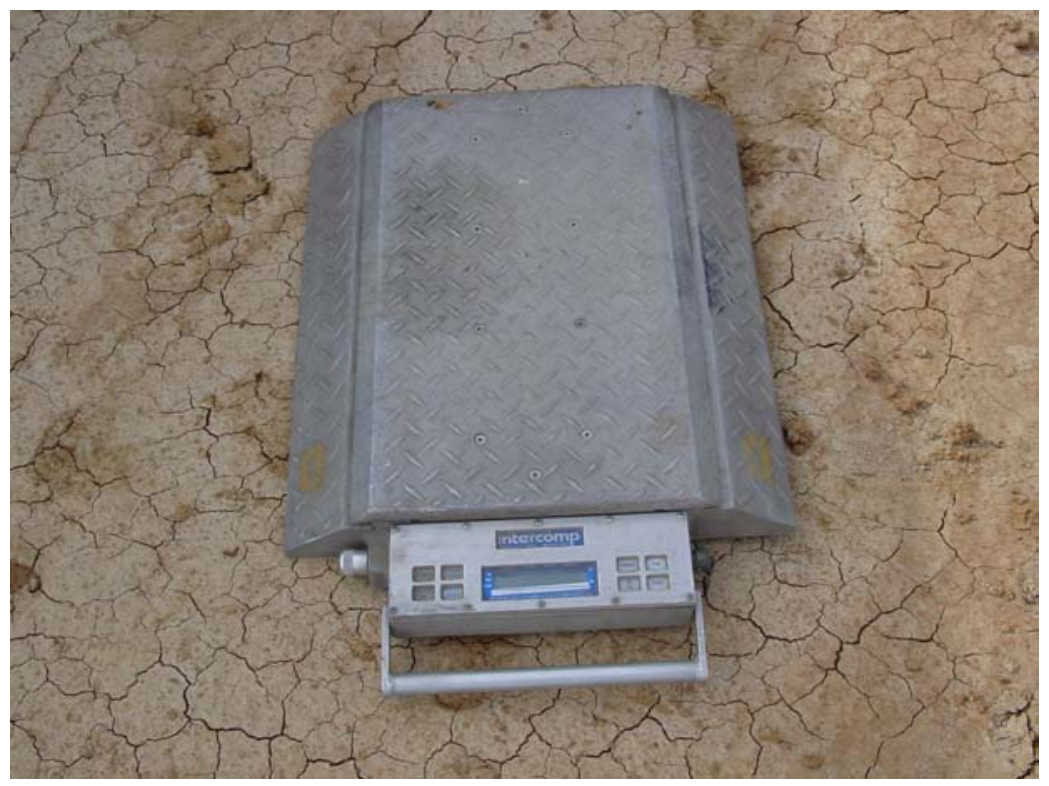

Figure 7.12. Weight pad 


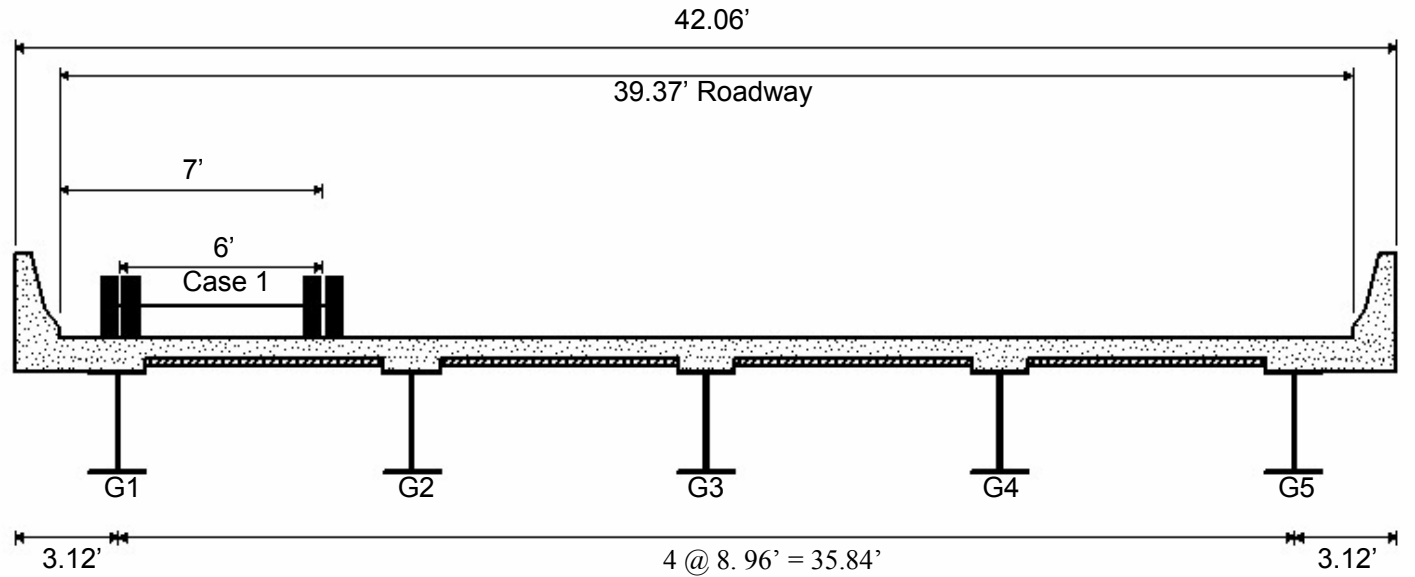

Figure 7.13. Maximum load positions for girder 1 (load case 1) 


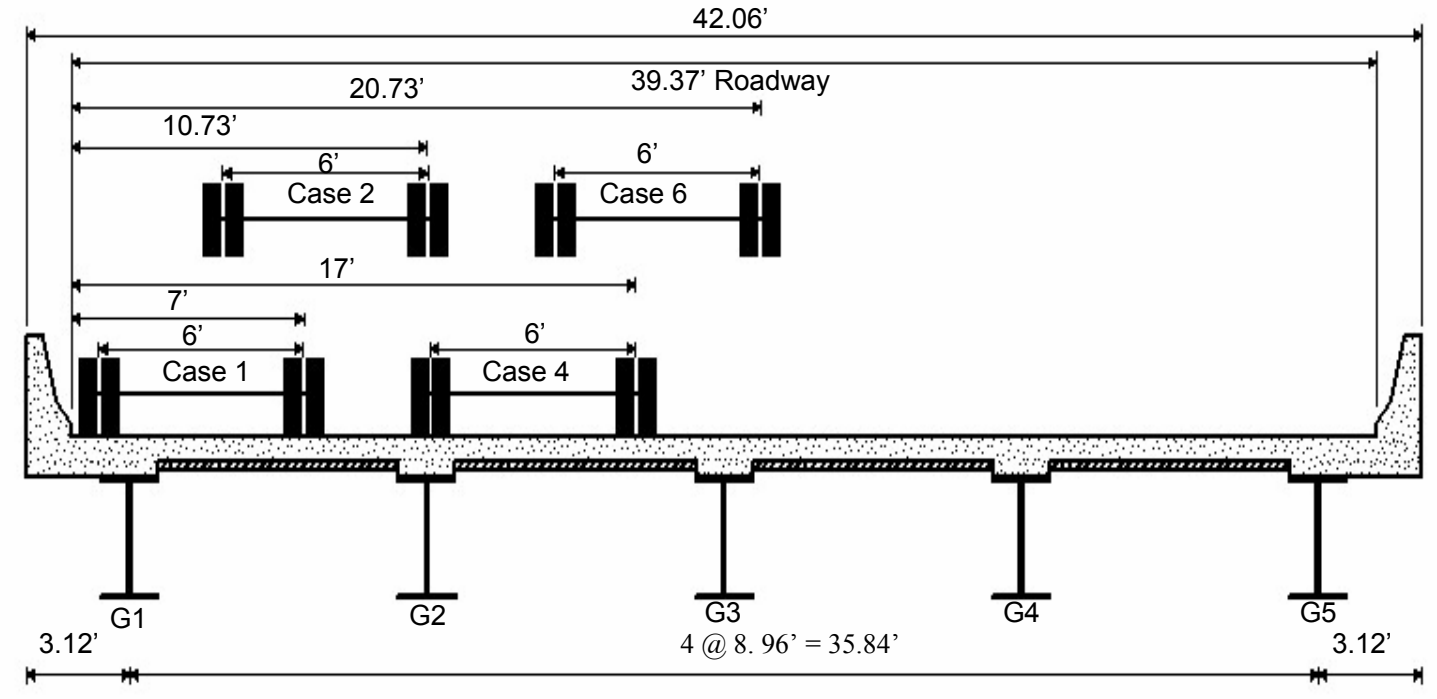

Figure 7.14. Maximum load positions for girder 2

(load cases $1 \& 4$ and load cases $2 \& 6$ ) 


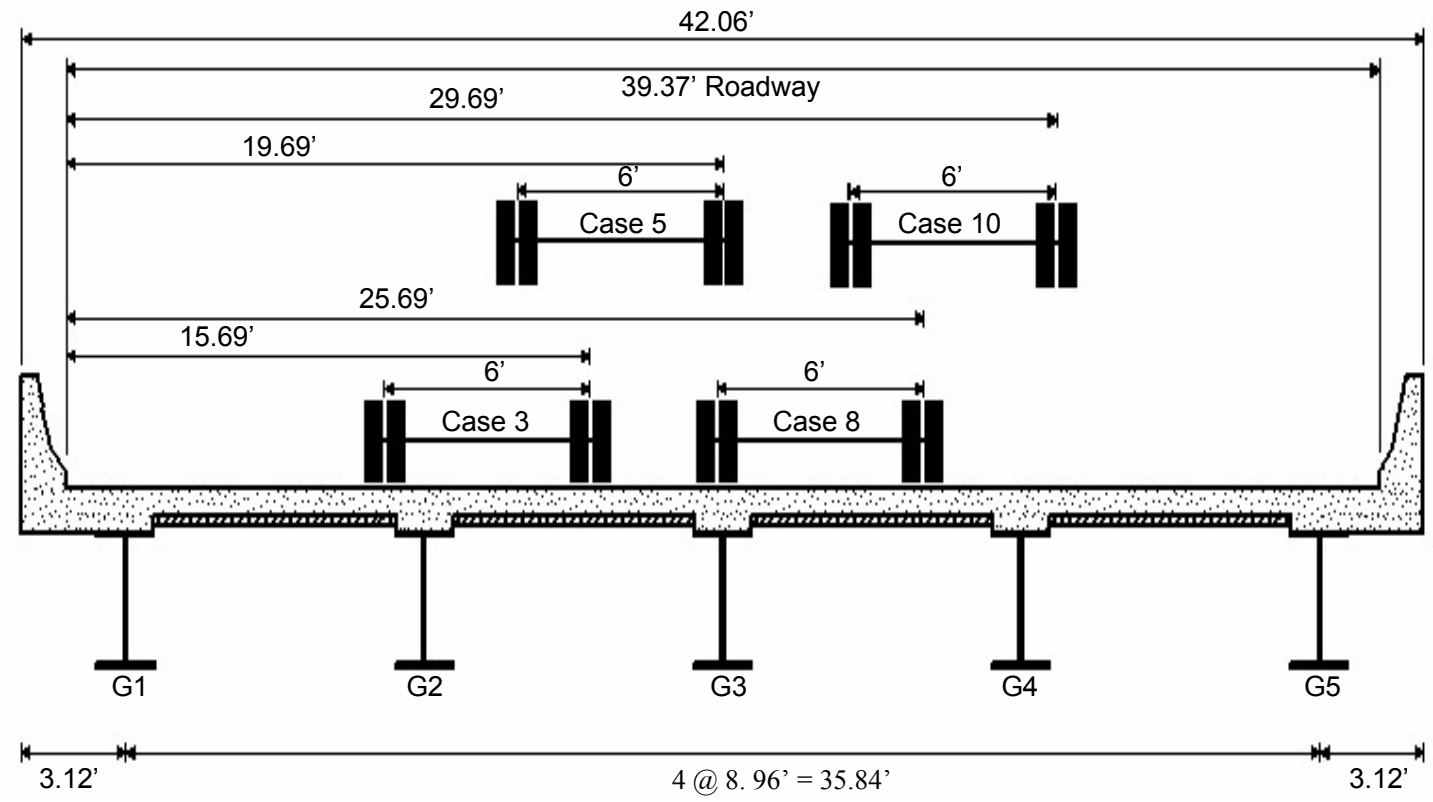

Figure 7.15. Maximum load positions for girder 3

(load cases $3 \& 8$ and load cases 5 \& 10) 


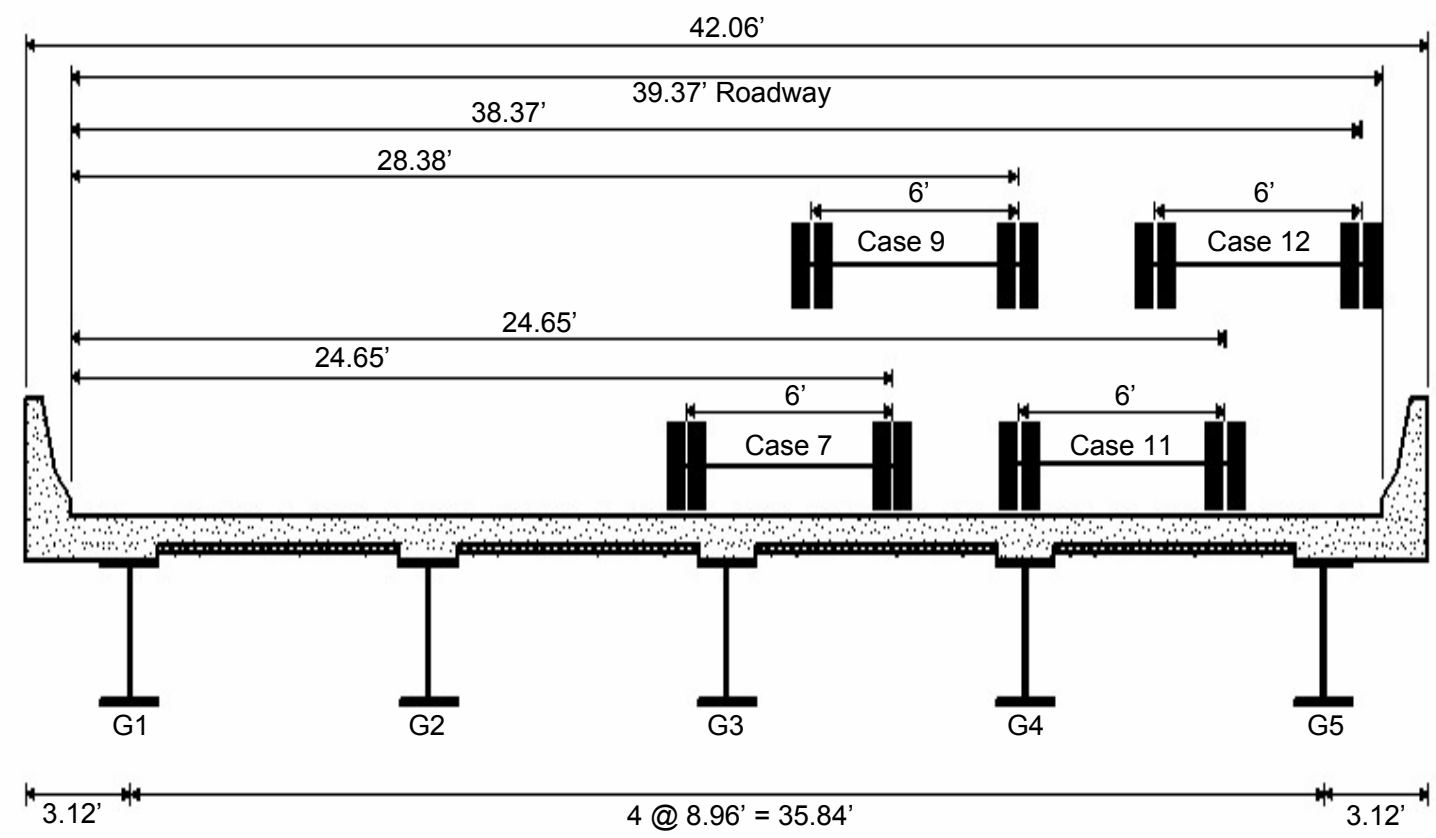

Figure 7.16. Maximum load positions for girder 4 (load cases $7 \& 11$ and load cases $9 \& 12$ ) 


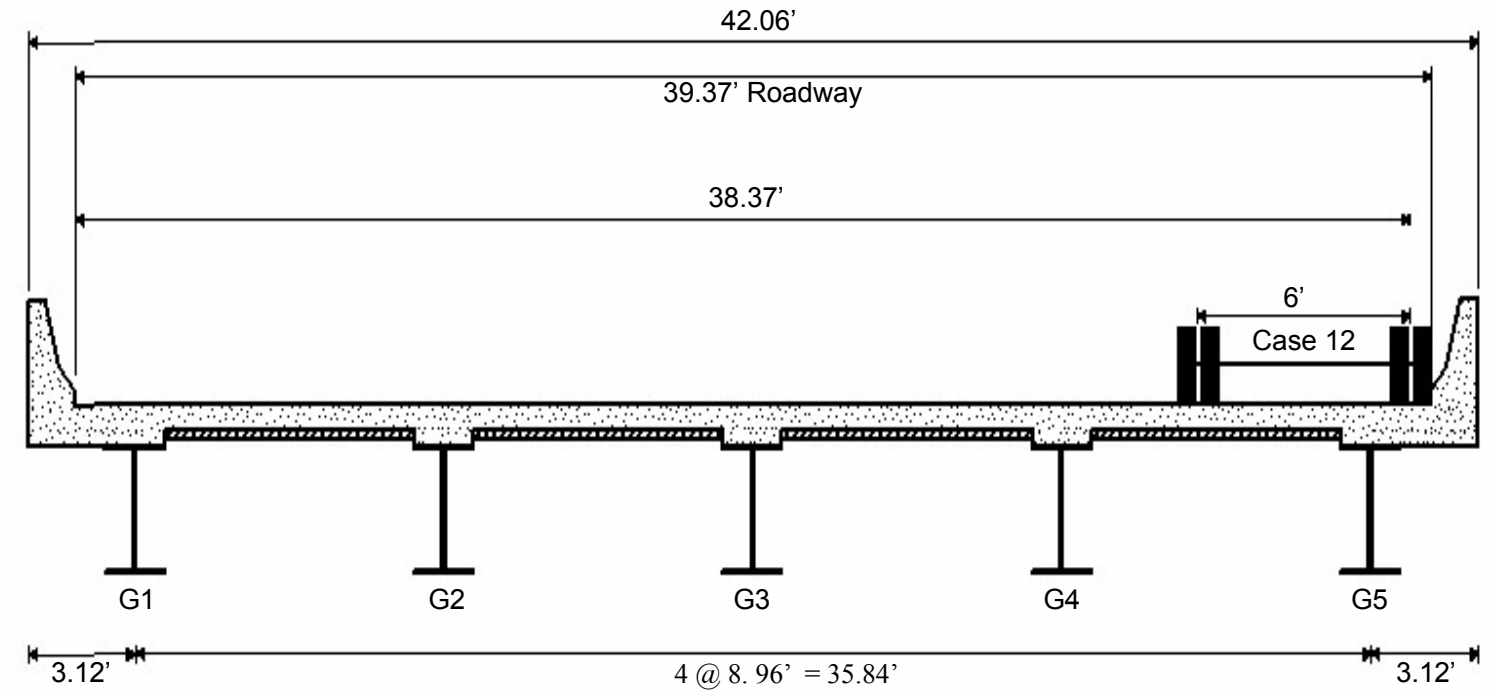

Figure 7.17. Maximum load position for girder 5 (load case 12) 


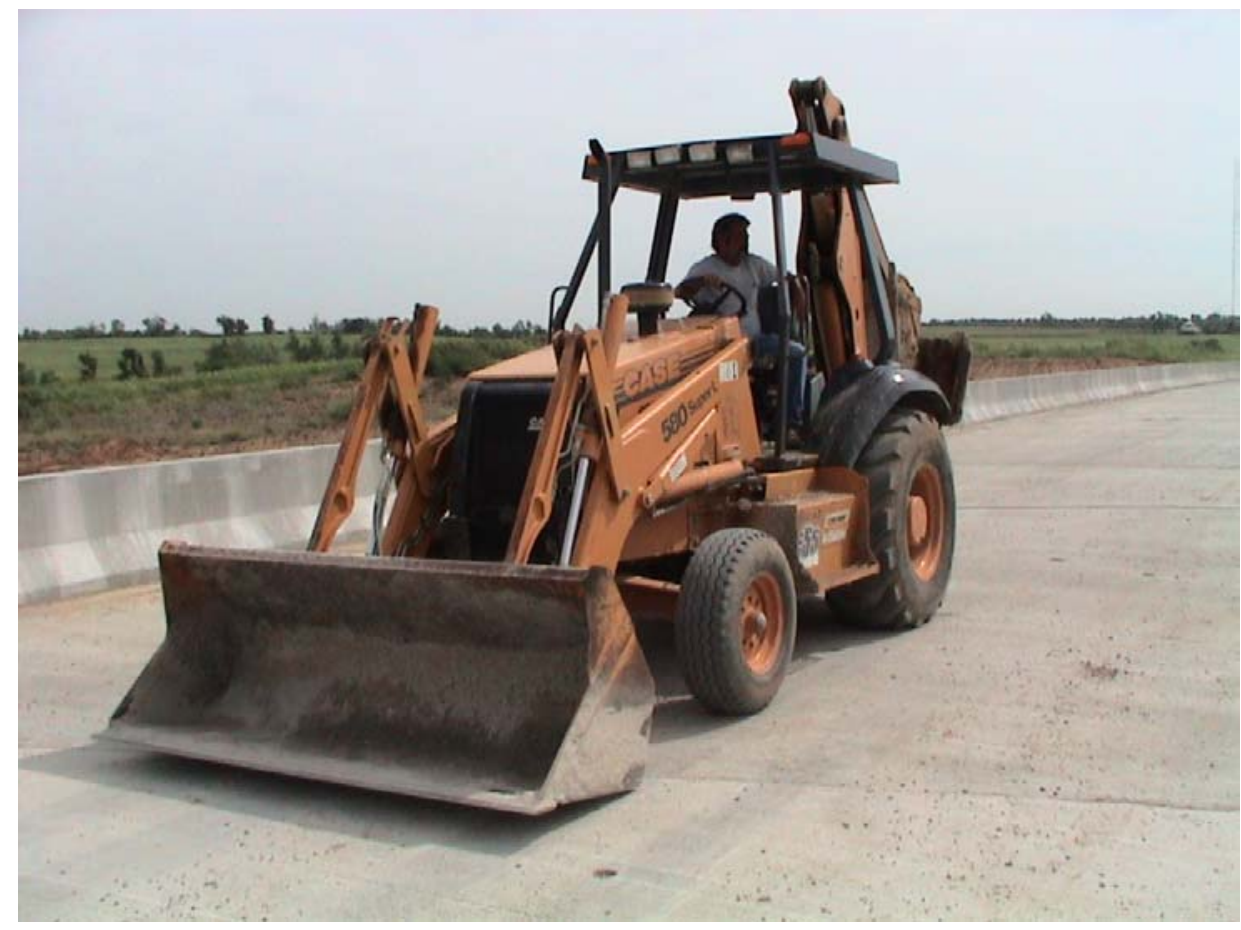

Figure 7.18. Construction vehicle used for dynamic testing 


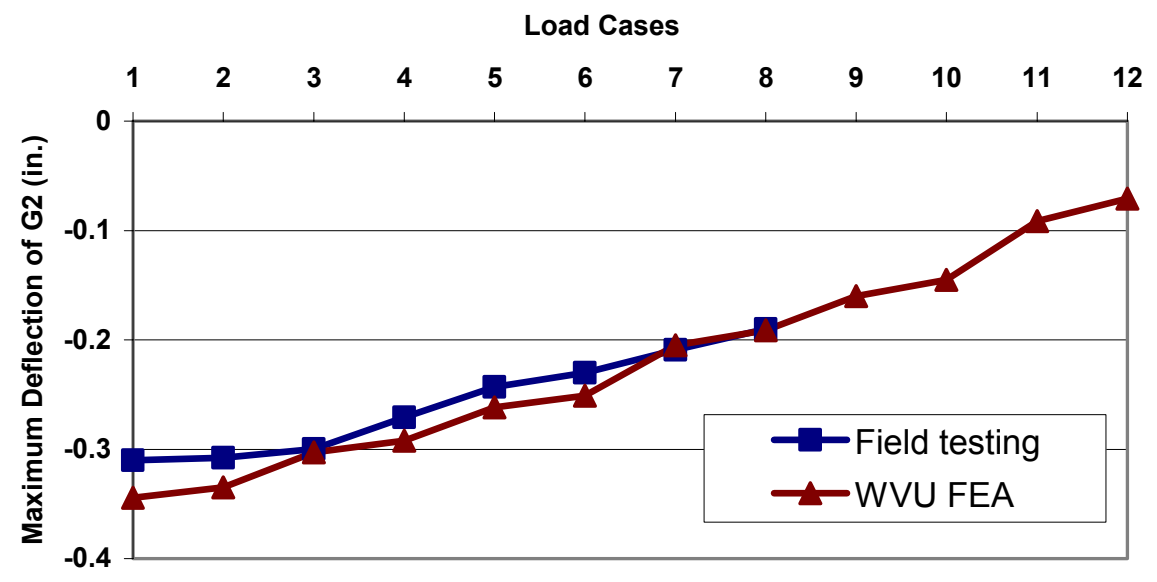

Figure 7.19. Comparison of maximum deflections for G2 
Girder Number

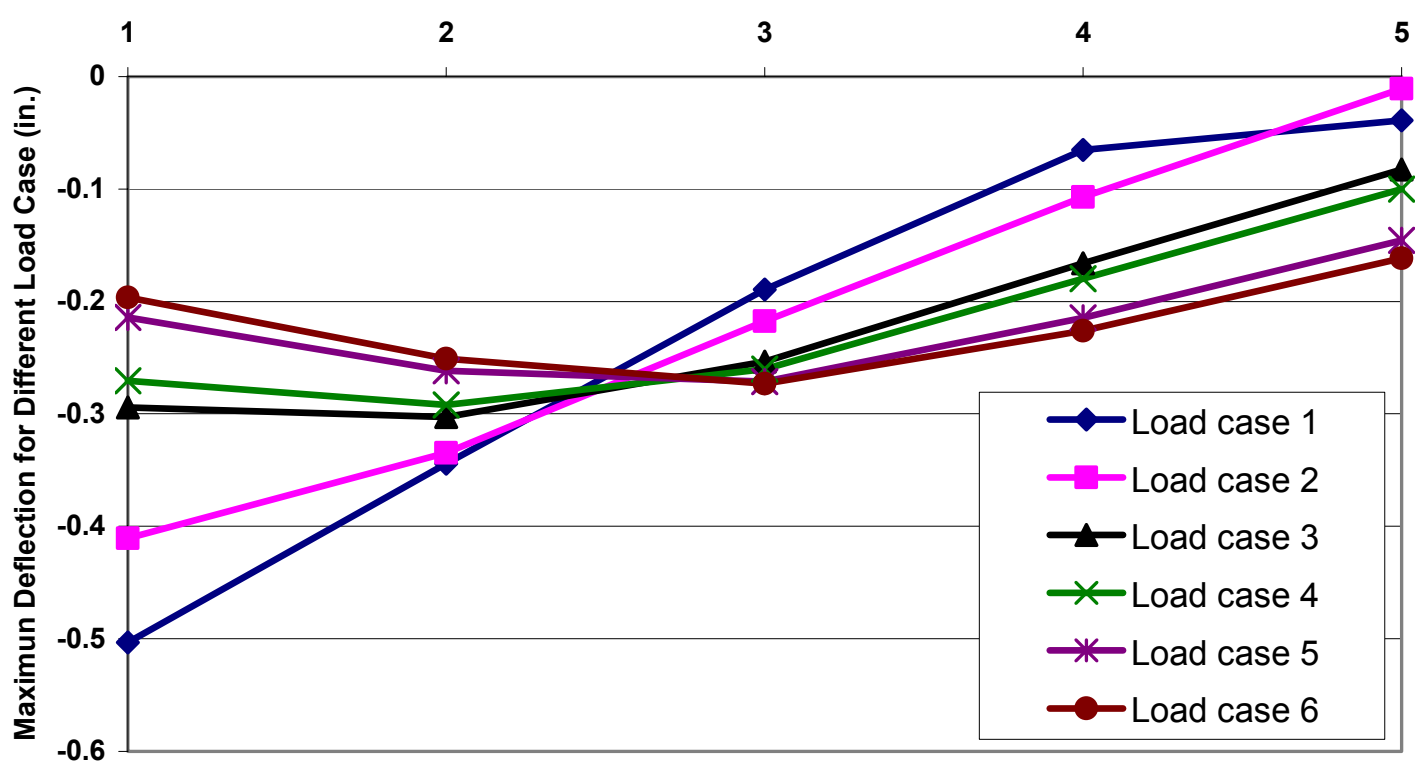

Figure 7.20. FEA maximum deflections - load cases 1 through 6 


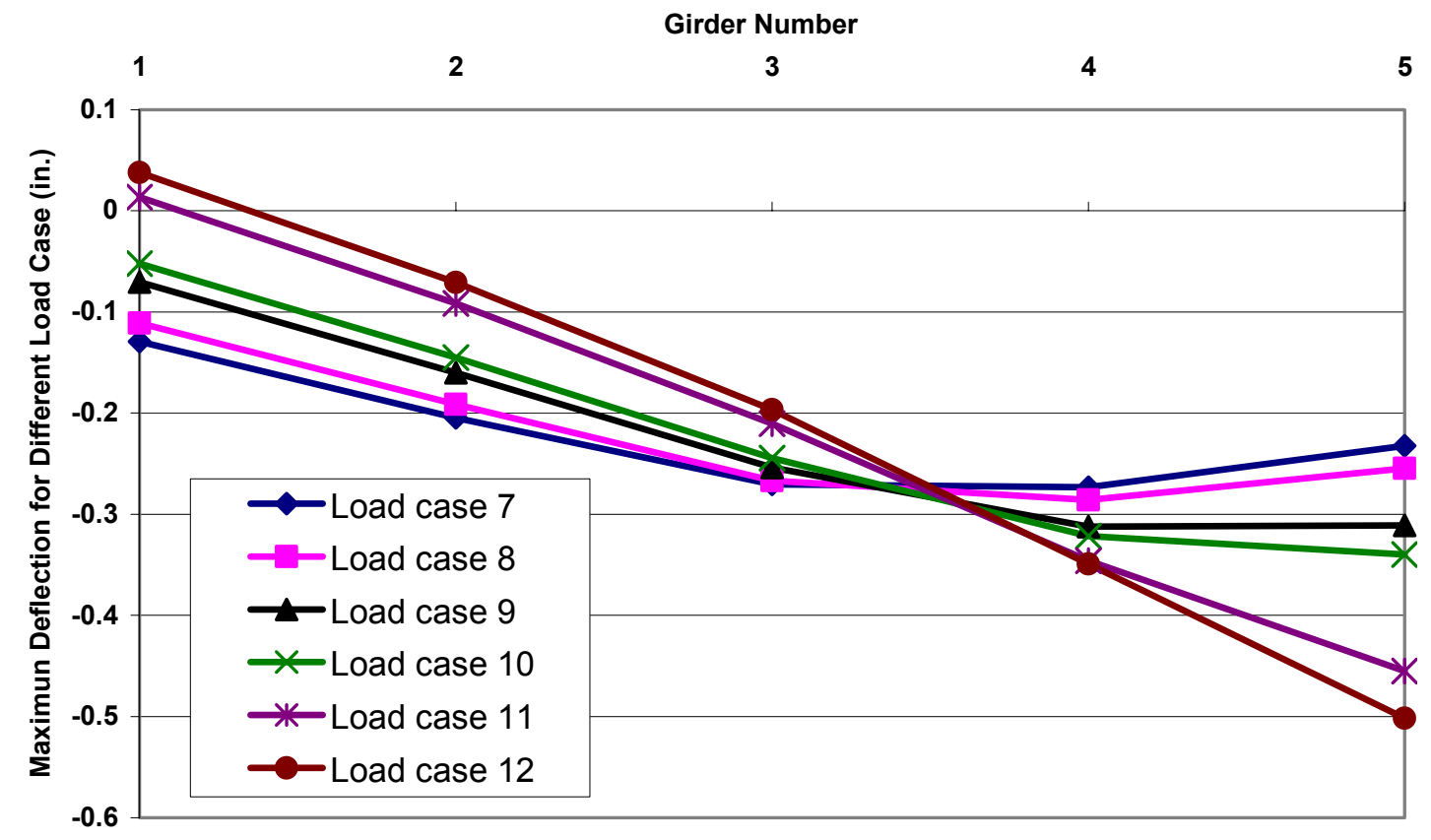

Figure 7.21. FEA maximum deflection - load cases 7 through 12 


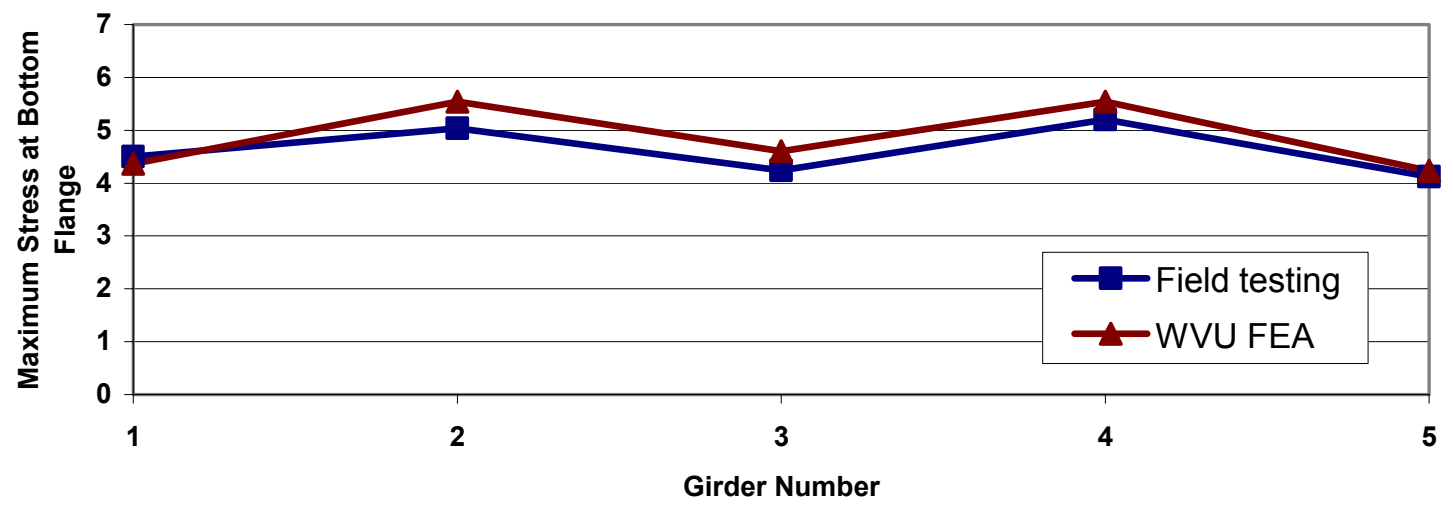

Figure 7.22. Maximum stress in bottom flange at $0.4 \mathrm{~L}$ section 


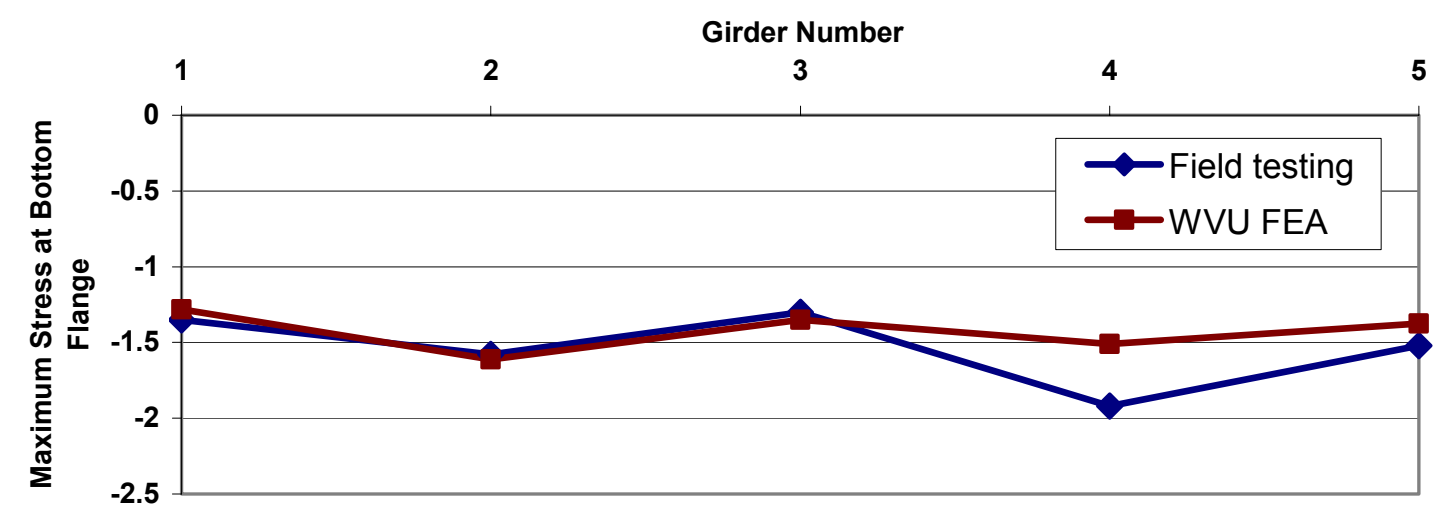

Figure 7.23. Maximum stress in bottom flange of pier section 


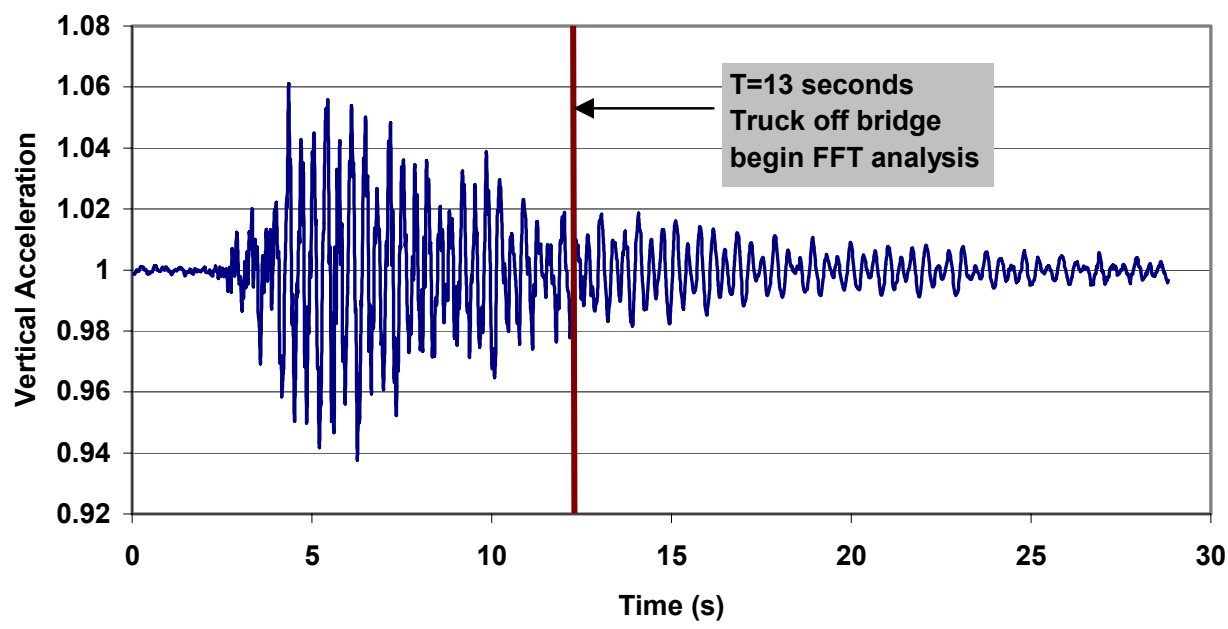

Figure 7.24. Typical acceleration record of G2 


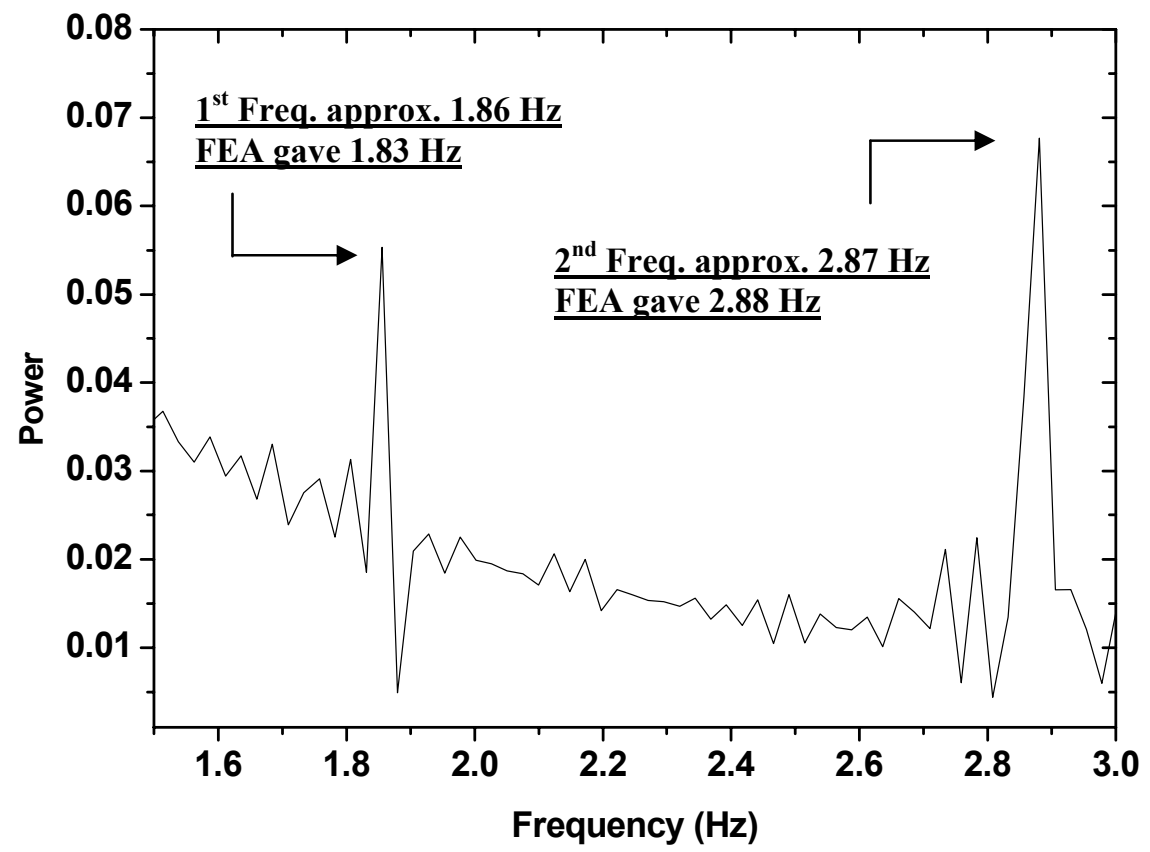

Figure 7.25. Natural frequency results 


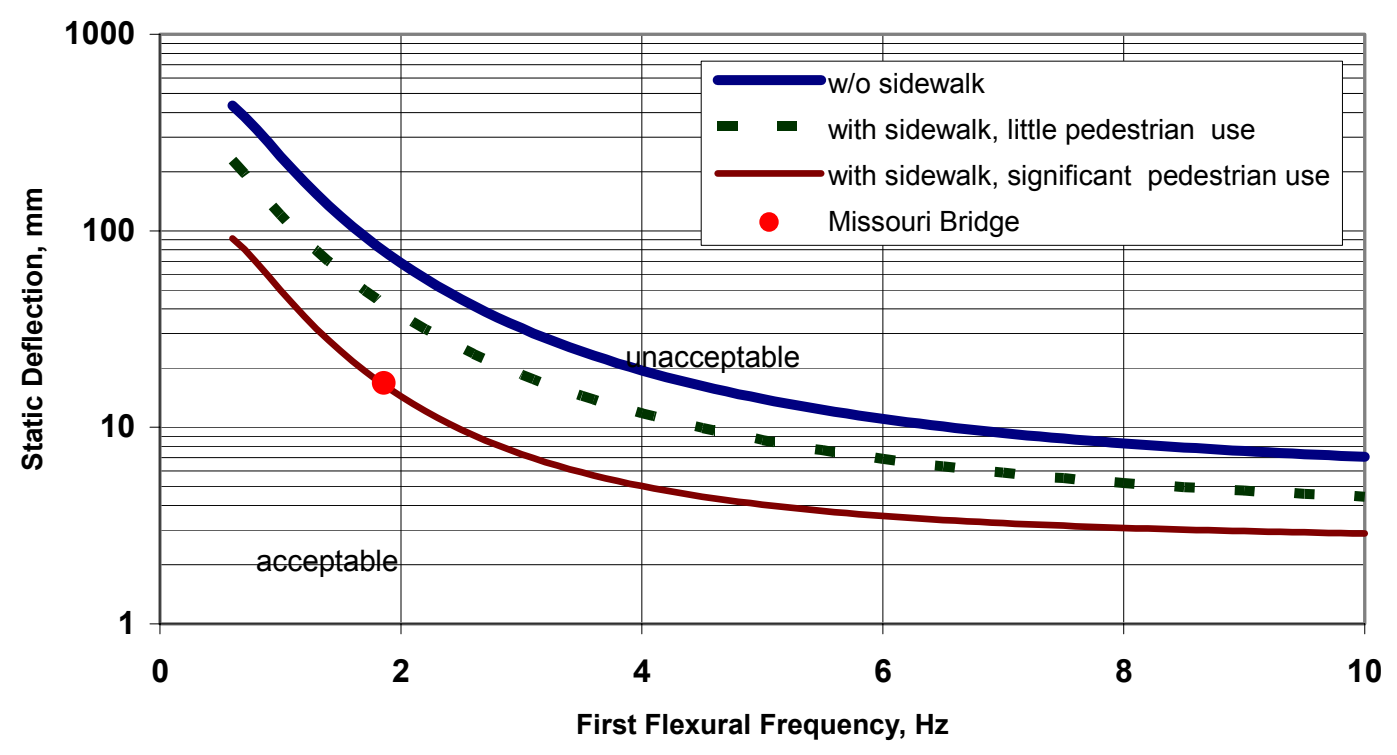

Figure 7.26. OHBDC evaluation of Missouri Bridge

(Ministry of Transportation, 1991) 


\section{CHAPTER 8}

\section{CONCLUSIONS AND RECOMMENDATIONS}

\subsection{Summary}

This research has studied the effects of the AASHTO live-load deflection limits on the economy and performance of composite steel I-girder bridges, especially focusing on these effects for HPS bridges. As discussed, this issue is of great importance to fully realize the benefits offered by the use HPS. The results of this research should contribute to improved guidelines and specification provisions for live-load deflection limits that: better control bridge vibrations, provide adequate user comfort, result in more economical designs, and lead to more consistent performance of HPS and other steel bridges.

An overview and the historic background of the current AASHTO live-load deflection limits were presented in Chapter 2. This review showed that the justification of these limits is not clearly defined, but suggested that they were initiated to control the undesired vibration of bridge superstructures. Research has shown that increased bridge stiffness and reduced bridge deflections will reduce bridge vibrations; however, this is clearly not the best way to control bridge vibration. Furthermore, the bridge design specifications of other countries do not commonly employ live-load deflection limits. Instead vibration control is often achieved through a relationship between bridge natural frequency, acceleration, and live-load deflection.

A survey was conducted of bridge engineers in 48 states to gain insight into professional practice regarding the bridge deflection limit. The survey sought specific 
information about deflection limits, $L / D$ ratio, and the applied live-loads used in the application of deflection limits for steel bridges in that state. This survey found that the combined variability of the deflection limit, the methods of calculating deflections, and the loads used to calculate deflection shows that the variability of the practical deflection limits used in the different states is huge. On the surface, it appears that variations of at least $200 \%$ to $300 \%$ are possible.

A literature review of field and theoretical studies investigating the natural frequencies of highway bridges was presented in Chapter 3. This discussion has illustrated that rigorous theoretical studies are not suitable for typical design applications. Furthermore, several existing empirical equations to predict first bending natural frequencies of highway bridges are described. However, these equations are generally limited in scope and often focused on a narrow range of parameters. Consequently, none of these existing equations are appropriate for incorporation into AASHTO specifications.

As FEA is used extensively in this research to investigate the serviceability behavior of composite steel bridges (live-load deflections and vibration characteristics), a state-of-the-art review of FEA conducted on this subject is presented in Chapter 4. This review specifically focuses on methods available for the analysis of bridge superstructure response to truck loading. Also, 3D FEA modeling using the commercial FEA package ABAQUS is proposed to study the live-load deflection, stresses and vibration characteristics of these types of bridges. The FEA results from four field-tested bridges available in the literature verify the accuracy of the proposed FEA modeling.

A comprehensive parametric design optimization study was described in Chapter 5 , focused on evaluating the effects of the AASHTO live-load deflection limit on the 
performance and economy of typical I shaped steel plate girder bridges. A series of key design variables (including features such as span length, girder spacing, cross-section geometry, and girder material configurations) is selected to develop a matrix of bridges representing a wide range of typical steel bridge designs. Bridges are then designed for combinations of these variables based on a least weight approach using various commercial bridge design software. The AASHTO live-load deflection limit is also evaluated using a set of 13 typical plate girder bridge plans obtained from 6 different state transportation departments. Both the parametric design bridges and the 13 typical bridges are also evaluated using two alternative serviceability procedures, Wright and Walker's procedure (Wright and Walker, 1971) and OHBDC (Ministry of Transportation, 1991). It is clear that the present AASHTO live-load deflection limits may have a significant influence on girder economy for some ranges of bridge superstructure geometries. Those bridge designs failing AASHTO live-load deflection limits do not necessarily fail the limits of the alternative serviceability criteria: Wright and Walker Procedure and OHBDC. These studies corroborate previous findings that current AASHTO deflection limits are not a suitable means of assuring acceptable serviceability performance.

Chapter 6 presents an FEA parametric study used to assess bridge natural frequencies. The FEA natural frequency results from this parametric study are compared with some existing frequency expressions that include the simple beam equation (Biggs, 1964), Billing's procedure (Billing, 1979), and Gorman's method (Gorman, 1975). Based on the resulting FEA natural frequencies, a simple more accurate equation is obtained using multiple variable nonlinear regression methods; this equation is suggested to 
predict the first bending natural frequency of 2-span continuous and 3-span continuous composite steel bridges. Also, an equation is proposed to account for the effect of parapets on natural frequencies for simple span structures. Furthermore, the extended application of the suggested equation for 3-span continuous bridges to bridges with more than three spans is shown by comparing the natural frequency results using the proposed equation and the natural frequencies resulting from experimental dynamic testing of a 5span and a 4-span continuous span bridge available in the literature.

Chapter 7 described field testing conducted to evaluate the live-load deflections, stresses, and vibration characteristics of a new 2-span continuous HPS skewed bridge. Information regarding the testing system, instrumentation, and loading were presented. Comparisons between the FEA and the field testing were also presented for the live-load deflection, stresses, and natural frequencies, which again show the accuracy of the previously proposed FEA model. The experimental natural frequency of this bridge was also used as an example to verify the proposed natural frequency equation for 2-span continuous composite steel bridges. Live-load deflections of this HPS bridge were evaluated using the AASHTO $L / 800$ live-load deflection limit and two alternative criteria, Wright and Walker procedure and OHBDC, which suggest that the bridge has acceptable deflection and vibration characteristics.

\subsection{Conclusions}

The following conclusions regarding the evaluation of the AASHTO live-load deflection limit and the evaluation of the two alternative methods for controlling vibrations of composite steel bridges are drawn from this research. 
1. The current AASHTO live-load deflection limit should not be used for highway steel bridges to control bridge vibrations. Research has shown that existing deflection limits do not have a rational background and do not prevent damage or reduced service life of bridges. The survey of practicing engineers revealed that there is wide variation in the way these limits are applied and that the loads used to compute the deflections have even greater variability. With elimination of this live-load deflection limit, the benefits of utilizing HPS can be obtained, as shown by the design studies discussed in Chapter 5 .

2. The FEA method is an effective analysis method once the procedure is verified by existing experimental data. The proposed FEA modeling procedure efficiently and accurately captures the live-load deflection, stresses, and vibration characteristics for the serviceability behavior of composite steel bridges. The proposed FEA model can readily be used by practicing engineers to conduct rating, design, and parametric study evaluations of composite steel bridges.

3. It is recommended that the relationship between bridge first natural frequency and live-load deflection used in the OHBDC be used to control bridge vibrations. However, the OHBDC does not specify how the first natural frequency should be calculated. Furthermore, existing methods to calculate the first bending natural frequency are not accurate for continuous span composite steel bridges. Instead, the proposed natural frequency equations given in Eqn. 6.24, coupled with the coefficients listed in Table 6.1, are suggested to calculate the first bending natural frequencies. Compared to all the existing methods (the simple beam equation, Billing's method, and Gorman's method), the proposed equations have been 
shown to have improved and acceptable accuracy in predicting the natural frequencies for continuous span bridges.

4. The simple beam equation shown in Eqn. 2.2 can be use to predict the natural frequencies of simple span composite steel bridges with acceptable accuracy. Equation 6.1 is suggested to account for the effect of parapets on the first bending natural frequencies of composite steel bridges.

5. The field performance of a 2-span continuous HPS bridge again shows the accuracy of the proposed FEA modeling procedure and the proposed natural frequency equation for the 2-span continuous bridges.

\subsection{Recommendations for Future Work}

Several subjects that were beyond the scope of this research, but would be beneficial to this study, are discussed below as topics for future work.

1. Additional Experimental Verification of the Extended Application of the Suggested 3-Span Frequency Equation: The experimental natural frequency results of a 5-span continuous and a 4-span continuous composite steel bridge have compared very favorably with the frequencies predicted by the suggested natural frequency equation for the 3-span bridges. However, because very limited natural frequency data is available in the literature, natural frequency data from additional multi-span bridges (with more than three spans) is desired to further validate use of this equation in these applications.

2. Analysis of Bridges outside the Scope of this Research: The bridges considered in the parametric studies conducted in this research were comprised of straight, 
nonskewed, slab on steel I girder bridges, of various cross sections, span lengths, $L / D$ ratios, and material strengths. For bridges outside this scope, a refined analysis using the previously proposed FEA procedure is recommended to investigate the dynamic characteristics. These bridges include bridges with varying span ratios, significant skew angle, or curvature.

3. Additional Analytical and Field Evaluation of Composite Steel Bridges: Previous efforts (Roeder et al., 2002) have identified a strong database of existing typical highway composite steel bridges for further analysis. These candidate bridges follow one of 4 basic categories: bridges failing the current AASHTO deflection limits but still provide good performance, bridges constructed of HPS steel, bridges experiencing structural damage associated with excessive deflection, and bridges having passenger or pedestrian discomfort due to vibration. A matrix of bridges will be: (1) critically analyzed and compared for deflection, vibration characteristics and differential deformations, (2) selected bridges from this database will be visually inspected to provide a consistent measure of their long term performance and a correlation of this performance to existing and proposed serviceability criteria, and (3) field measurement of a selected group of these bridges to establish actual bridge performance and to correlate this performance to the analytical study and observed performance. The selected bridges should cover various girder spacing, span lengths and span configurations, and represent the wide diversity of steel bridge construction and truck loading patterns noted throughout the United States. 
The previously proposed FEA procedure can be used for performing the first task. This is shown through the favorable comparisons achieved between the deflections, stresses and natural frequencies obtained from the FEA and the field testing results of the 2-span continuous HPS bridge presented in Chapter 7. The detailed FEA modeling can be performed to more closely investigate local deformations and differential deformations between members as well as rotation and strain levels in an effort to investigate member and system behavior. The FEA modeling will be used to calibrate and correlate damage results from the second task. Also the experimental results from the third task will be used to generate the necessary base of physical information to more accurately calibrate existing tools as well as analytically evaluate the performance response of the bridges tested in task 3 .

Task 2 will evaluate the in-situ field condition of candidate bridges, and it will compare and evaluate this observed performance to existing and proposed serviceability design criteria. Task 1 analyses and past state inspection data will be used as an aid for the inspection of the subject bridges. The past inspection data will be obtained from the contact with the bridge and maintenance engineers established in a previous research study (Roeder et al., 2002).

Field testing will then be conducted for a selected group of bridges. The results of the task 1 analyses and the task 2 field inspections will be used in the selection process. Each selected bridge will be studied for known truck loading and normal traffic. Barker (2001) has developed standardized bridge field test procedures for composite steel bridges. The emphasis of the field tests will be 
measured deflection, differential deformations, vibration characteristics and elastic response of the bridge subjected to a calibrated truck. Differential deformations will be studied, since they are expected to provide a stronger indictor of the structural damage that may be caused by deformations in the bridge. Local measurements will be used to determine the extent of composite action, restraint of secondary elements, distribution of load due to diaphragms and wind bracing, and other related effects. These results are to be used directly to establish actual bridge performance and in the comparisons to current practice and the proposed serviceability criteria. 


\section{List of References}

'92 AUSTROADS BRIDGE Design Code (1992). SECTION TWO-CODE Design Loads and its COMMENTARY, AUSTROADS, HAYMARKET, NSW, AUSTRALIA.

'96 AUSTRALIAN BRIDGE Design Code (1996). SECTION SIX-CODE Steel and Composite Construction, AUSTROADS, HAYMARKET, NSW, AUSTRALIA.

AASHTO (1996). Load Factor Design, Bridge Design Specifications. (16 ${ }^{\text {th }}$ edition). America Association of State Highway and Transportation Official, Washington, D.C.

AASHTO (1998). Load Resistance and Factor Design, Bridge Design Specifications. ( $2^{\text {nd }}$ edition). America Association of State Highway and Transportation Official, Washington, D.C..

ABAQUS/Standard User's Manual, Version 6.2 (2001). Hibbitt, Karlsson \& Sorensen, Inc.

American Society of Civil Engineering. (1958, May). Deflection Limitation of a Bridge. Journal of the Structural Division, 84, (Rep. No. ST3).

Aramraks, T. (1975, February). Highway Bridge Vibration Studies. Joint Highway Research Project (Report No. JHRP -75-2). Purdue University \& Indiana State Highway Commission.

Bakht, B. and Pinjarkar, S. G. (1989). Dynamic Testing of Highway Bridges - A Review. Transportation Research Record 1223, Washington, D. C., p93-100.

Barefoot, J. B., Barton, F. W., Baber, T. T., and Mckeel, W. T. (1997, October). Development of Finite Element Models to Predict Dynamic Bridge Response. Final report VTRC 98-R8, Virginia Transportation.

Barker, M. G., Imhoff, C. M., McDaniel, W. T., and Frederick, T. L. (1999, May). Field Testing and Load Rating Procedures for Steel Girder Bridges. University of Missouri at Columbia, Columbia, Missouri.

Barker, M. G. and Schrage, S. D. (2000, June). High Performance Steel: Design and Cost Comparisons. Model Steel Construction, 16, 35-41.

Barth, K. E., White, D. W., and Bobb, B. (2000). Negative Bending Resistance of HPS70W Girders. Journal of Construction Steel Research, Elsevier Science,53,1-31.

Biggs, J.M., Suer, H.S., and Louw, J.M., (1959). Vibration of Simple Span Highway Bridges, Transactions, ASCE, Vol. 124, New York. 
Biggs, J. M. (1964, June). Introduction to Structural Dynamics. McGraw-Hill Book Company. Ch4, P150.

Billing, J. R. (1979). Estimation of the Natural Frequencies of Continuous Multi-Span Bridges. Research Report 219, Ontario Ministry of Transportation and Communications, Research and Development Division, Ontario, Canada.

Billing, J. R. (1980). Dynamic Loading and Testing of Bridges in Ontario, 1980. International Conference on Short and Medium Span Bridges, Section 2. Toronto 1982.

Billing, J. R. and Green, R. (1984). Design Provisions for Dynamic Loading of Highway Bridges. Transportation Research Record 950, Washington D. C., p94-103.

Bishara, A. G. and Elmir, W. F. (1990, May). Interaction between Cross Frames and Girders. Journal of Structural Engineering, Vol. 116, No. 5, P1319-1333.

Bolt, Beranek, and Newman, Inc. (1966). Passenger Noise and Vibration Criteria. The MBTA South Shore Project, BBN Rep. No. 1428.

Buckler, J. G., Barton, F. W., Gomez, J. P., Massarelli, P. J., and Mckeel, W. T. Jr. (2000, December). Effect of Girder Spacing on Bridge Deck Response. Final Report, VTRC 01-R6, Charlottesville, Virginia.

Burdette, E. G. and Goodpasture, D. W. (1971, December). Final Report in Full-Scale Bridge Testing an Evaluation of Bridge Design Criteria. Department of Civil Engineering, The University of Tennessee.

Cantieni, R. (1983). Dynamic Load Tests on Highway Bridges in Switzerland, 60 years of Experience of EMPA, report N. 211. EMPA, Switzerland.

Cantieni, R. (1984). Dynamic Load Testing of Highway Bridges. Transportation Research Record 950, Washington D. C., p141-148.

Chatterkee, P. K., Datta, T. K., and Surana, C. S. (1994). Vibration of Continuous Bridges under Moving Vehicles. Journal of sound and vibration, Vol. 169, No.5, p619-632.

Clingenpeel, B. F. (2001, December). The Economical Use of High Performance Steel in Slab-on-Steel Stringer Bridge Design. Master Thesis, Department of Civil and Environmental Engineering, West Virginia University, Morgantown, WV.

CONSYS 2000, USER'S MANUAL (1997). LEAP Software, Inc., Tampa, Florida.

Conn, P. E. (1994). Monitoring the Vibrations of a Continuous Bridge. Master Thesis, the University of Connecticut. 
CSA International (2000, May). CAN/CSA- S6- 00 and Commentary. Canadian Highway Bridge Design Code. Canadian Standards Association, Toronto, Ontario, Canada.

Csagoly, P. F., Campbell, T. I., and Agarwal, A. C. (1972, September). Bridge Vibration Study. M.T.C. Report No. RR181, Ministry of Transportation and Communications.

Darnley, R. R. (1921). the Transverse Vibrations of Beams and the Whirling of Shafts Supported at Intermediate Points. Philosophical Magazine, Vol. 41, p81-97.

DATAFIT for Windows Version 8.0, User's Manual. Oakdale Engineering, Oakdale, Pennsylvania.

Deger, Y., Cantieni, R., and Pietrzko, S. (1995). Modal Analysis of a Highway Bridge: Experiment, Finite Element Analysis and Link. Proceedings of the $13^{\text {th }}$ international model analysis conference. Nashville, Tennessee.

Demitz, J. R., Mertz, D. R., and Gillespie, J. W. (2003, March). Deflection Requirements for Bridges Constructed with Advanced Composite Materials. Journal of Bridge Engineering, 8(2), 73-83.

Dewolf, J. T., Kou, J-W., and Rose, A. T. (1986). Field Study of Vibrations in a Continuous Bridge, Proceeding of the $3^{\text {rd }}$ International Bridge Conference in Pittsburgh, PA, 103-109.

Dewolf, J. T. and Kou, J-W. (1987, April). Monitor bridge vibrations. JHP 87-171, Department of Transportation, University of Connecticut.

Dorka, Ewe (2001, February). Personal Communication with Charles Roeder. University of Rostock, Wismar, Germany.

Dunker, K. F. and Rabbat, B.G., (1990). Performance of Highway Bridges, Concrete International: Design and Construction, Vol. 12, No. 8.

Dunker, K.F. and Rabbat, B.G., (1995). Assessing Infrastructure Deficiencies: The Case of Highway Bridges, ASCE, Journal of Infrastructure Systems, Vol. 1, No. 2.

Dusseau, R. A. (1996). Natural Frequencies of Highway Bridges in the New Madrid Region (Final Report). Civil Engineering Department, Wayne State University.

Dusseau, R. A. (1998). Profiles of Design Dimensions and Fundamental Natural Frequencies for Steel Interstate Highway Bridges in Southeastern Missouri. Transportation Research Record, Transportation Research Board, 1624, 82-92.

Eamon, C. D. (2000) Reliability-Based Resistance Model for Bridge Structural Systems, Ph.D. Dissertation, the University of Michigan. 
Eberhardt, A. C. (1972). A Finite Element Approach to the Dynamic Analysis of Continuous Highway Bridges. Doctoral Thesis, University of Illinois at Urbana, 1972.

Eom, Junsik and Nowak, A. S. (2001). Live Load Distribution for Steel Girder Bridges. Journal of Bridge Engineering, 6(6), P489-497.

Excel (2002). Microsoft Corporation. Redmond, WA.

Federal Highway Administration (2002, April). A High-Performance Steel Scoreboard. FHWA Website, (http://www.tfhrc.gov/focus/apr02/steel.htm).

Foster, G. M. and Oehler, L. T. (1954). Vibration and Deflection of Rolled Beam and Plate Girder Type Bridges (Progress Report No. 219). Michigan State Highway Department.

Fountain, R. S. and Thunman, C. E. (1987). Deflection Criteria for Steel Highway Bridges. Proceeding of the AISC National Engineering Conference, New Orleans, 20$1-20-12$.

French, C., Eppers, L. J., Le, Q. T., and Hajjar, J. F. (1999). Transverse Cracking in Bridge Decks. University of Minnesota Department of Civil Engineering.

Goldman, D. E. (1948). A Review of Subjective Responses to Vibratory Motion of the Human Body in the Frequency Range 1 to 70 Cycle per Second. Naval medical research institute, National naval medical center, Bethesda, MD.

Gooddpasture, D. W. and Goodwin, W. A. (1971). Final Report on the Evaluation of Bridge Vibration as Related to Bridge Deck Performance. The university of Tennessee and Tennessee Department of Transportation.

Gorman, D. R. (1975). Free Vibration Analysis of Beams and Shafts. John Wiley \& Sons.

Green, R. (1977). Dynamic Response of Bridge Superstructures-Ontario Observation. TRRL Suppleemental Report SR 275, Crawthorne, England, 40-55.

Haslebacher, C. A. and GangaRao H.V.S. (1981, February). Vibration Analysis of highway bridges. Shock and Vibration Digest, 13(2), 3-8.

Hayes, J. M. and Sbarounis, J. A. (1956). Vibration Study of Three-Span Continuous Beam Bridges. Highway Research Board, Bulletin 124, p47-78.

Hendrik, J. Marx, Khachaturian, N., and Gamble, W. L. (1986, January). Development of Design Criteria for Simply Supported Skew Slab-on-Girder Bridges. UILU-ENG-862001 SRS 522, Department of Civil Engineering, UIUC, Urbana, IL. 
Horton, R., Power E., Van Ooyen, and K., Azizinamini, A. (2000). High Performance Steel Cost Comparison Study. Steel bridge design and construction for the new millennium with emphasis on high performance steel, Conference proceeding, 120137.

Huang, Tseng and Veletsos, A. S. (1960, December). Dynamic Response of Three-Span Continuous Highway Bridges. The engineering experiment of station, University of Illinois.

Issa, Mahmoud, A., Yousif, A. A., and Issa, M. A. (2000, August). Effect of Construction Loads and Vibration on New Concrete Bridge Decks. Journal of Bridge Engineering, 5(3), 249-258.

Issa, Mohsen, A. (1999, May). Investigation of Cracking in Concrete Bridge Decks at Early Ages. Journal of Bridge Engineering, 4(2), 116-124.

Janeway, R. N. (1950). Vehicle Vibration Limits for Passenger Comfort. From Ride and Vibration Data, Special Publications Department (SP-6), Society of Automotive Engineers, Inc., p. 23.

Jategaonkar, R., Jaeger, L. G., and Cheung, M. S. (1985). Bridge Analysis Using Finite Elements. Canadian Society for Civil Engineering.

Kathol, S., Azizinamini, A., and Luedke, J. (1995, February). Strength Capacity of Steel Girder Bridges. Final Report, NDOR research project number RES1(0099) P469, Department of Civil Engineering, University of Nebraska-Lincoln.

Kawatani, M.,Nishiyama, S., and Yamada, Y. (1993, April). Dynamic Response Analysis of Highway Girder Bridges under Moving Vehicle. Technology Reports of the Osaka University, 43 (2137), 109-118.

Kou, Jine-Wen and Dewolf, J. T. (1997). Vibrational Behavior of Continuous Span Highway Bridge - Influence Variables. Journal of Structural Engineering, 123(3), $333-344$.

Krauss, P. D. and Rogalla, E. A. (1996). Transverse Cracking in Newly Constructed Bridge Decks (National Cooperative Highway Research Program Report No. 380). Washington, DC: Transportation Research Board, National Research Council.

Kropp, P. K. (1977, March). Experimental Study of Dynamic Response of Highway Bridges. Joint Highway Research Project (Report No. JHRP-77-5). Purdue University \& Indiana State Highway Commission.

Lam, Clifford. (2002, July). Personal Communication with Haiyong Wu. Head of Bridge Research, Ministry of Transportation, Ontario, Canada. 
Lee, J. A. N. and Windover, L. (1966, February). Highway Bridge Vibration IV the Vibration of Continuous Bridges. Department of Civil Engineering, Queen's University, Kingston, Ontario.

Linger, D. A. and Hulsbos, C. L. (1962). Forced Vibration of Continuous Highway Bridges. Highway Research Board, Bulletin 339, p1-22.

Looney, C. T. G. (1954). Behavior of Structures Subjected to a Forced Vibration. Proceedings of ASCE, June 14-19, Vol. 80, Separate No. 451.

Martin, T. M., Barton, F. W., Mckeel, W. T. Jr., Gomez, J. P., and Massarelli, P. J. (2000, June). Effect of Design Parameters on the Dynamic Response of Bridges. Final Report, VTRC 00-R23, Charlottesville, Virginia.

MDX Software ${ }^{\circledR},(2000$, March) Curved \& Straight Steel Bridge Design \& Rating for Windows 95/98/NT. (C) 2000 MDX Software, Inc.

Memory, T. J.,Thambiratnam, D. P., and Brameld, G. H. (1995). Free Vibration Analysis of Bridges. Engineering Structures, 17(10), 705-713.

Mertz, D. R. (1999). High-Performance Steel Bridge Design Issues. Structural Engineering of the $21^{\text {st }}$ Century: Proceedings of 1999 Structures Congress, April 1821, 749-752.

Ministry of Transportation, Quality and Standards Division (1991) Ontario Highway Bridge Design Code/Commentary, ( $3^{\text {rd }}$ edition). Toronto, Ontario, Canada.

Nassif, H. H., Liu, M., and Ertekin, O. (2003, March). Model Validation for BridgeRoad-Vehicle Dynamic Interaction System. Journal of bridge engineering, Vol. 8, No. 2, p112-120.

Nevels, J. B. and Hixon, D. C. (1973). A Study to Determine the Causes of Bridge Deck Deterioration. Research and Development Division. (Final Report). State of Oklahoma Department of Highways. Oklahoma City, Oklahoma.

Newmark, N. W., Siess, C. P., and Penman R. R. (1946). Studies of Slab and Beam Highway Bridges Part I Tests of Simple-Span Right I-Beam Bridges. Bulletin series No. 363, the Engineering Experimental Station, the University of Illinois, Urbana, Ill.

Nowak, A. S. and Grouni, H. N. (1988). Serviceability Considerations for Guideways and Bridges. Canadian Journal of Civil Engineering, 15(4), 534-537.

Oehler, L. T. (1957). Vibration Susceptibilities of Various Highway Bridge Types. Michigan State Highway Department (Project 55 F-40 No. 272). 
Oehler, L. T. (1970, February). Bridge Vibration - Summary of Questionnaire to State Highway Departments. Highway Research Circular. Highway Research Board (No. 107).

Oran, Cenap and Veletos, A. S. (1961, July). Analysis of Static and Dynamic Response of Simple-Span, Multigirder Highway Bridges. Eleven Progress Report of the Highway Bridge Impact Investigation, University of Illinois, Urbana, Illinois.

ORIGIN (2003). Version 7 (Demo). OriginLab Corporation, Northampton, MA.

Paultre, P., Chaallal, O., and Proulx, J. (1992). Bridge Dynamic and Dynamic Application Factors-a Review of Analysis and Experimental Findings. Canadian Journal of Civil Engineering, Vol. 19, P206-278.

Paultre, P., Prouix, J., and Talbot, M. (1995). Dynamic Testing Procedures for Highway Bridges Using Traffic Loads. Journal of structural engineering, Vol. 121, No. 2, p362-376.

PCA (1970). Durability of Concrete Bridge Decks: A Cooperative Study, Final Report, Portland Cement Association (PCA), Skokie, IL.

Poppe, J. B. (1981). Factors Affecting the Durability of Concrete Bridge Decks (Final Report SD-81/2). Sacramento, CA: California Department of Transportation; Division of Transportation Facilities Design.

Reiher, H. and Meister, F. J. (1931). the Effect of Vibration on People. (in German(, Forschung auf dem Gebeite des Ingenieurwesens, Vol. 2, No. II, P381. Translation: Report No. F-TS-616-RE, Headquarters Air Material Command, Wright Field, Ohio, 1946.

Roeder, C. W., Barth, K. B., and Bergman, A. (2002, May). Improved Live Load Deflection Criteria for Steel Bridges. Final Report NCHRP 20-07/133, University of Washington, Seattle, WA.

Saibel, E. (1940). Vibration Frequencies of Continuous Beams. Journal of the Aeronautical Sciences, p88-90.

Senthilvasan, J., Thambiratnam, D. P., and Brameld, G. H. (2002). Dynamic Response of a Curved Bridge under Moving Truck Load. Engineering Structures, 24, P1283-1293, Elsevier Science.

Sergeev, S. N. and Pressley, J. S. (1999). Towards Rational Serviceability Criteria in the Australian Bridge Design Code. International Conference on Current and Future Trends in Bridge Design Construction and Maintenance, London, UK. Thomas Telford, p167-178. 
Shahabadi, A. (1977, September). Bridge Vibration Studies. Joint Highway Research Project (Report No. JHRP -77-17). Purdue University \& Indiana State Highway Commission.

SIMON SYSTEMS USER MANUAL, Version 8.1 (Rev. July 15, 1996). The National Steel Bridge Alliance, a division of AISC, Chicago, Illinois.

State Highway Commission of Kansas. (1965). Durability of Concrete Bridge Decks (Final Report SD-81/2). Bureau of Public Loads, Portland Cement Association.

Tarhini, K. M. and Frederick, G. R. (1992). Wheel Load Distribution in I-Girder Highway Bridges. Journal of Structural Engineering, Vol. 118, No. 5, P1285-1294.

Tiedeman, J. L., Albrecht, P., and Cayes, L. R. (1993). Behavior of Two-Span Continuous Bridge under Truck Axle Loading. Journal of Structural Engineering, Vol. 119, No. 4, P1234-1250.

Tilly, G. P. (1986). Dynamic Behavior of Concrete Structures. Report of the RILEM 65 MDB committee.

Varney, R. F. (1971, September). Bridge Resonant Excitation with Portable Vibration Generators. FHWA-RD-71-5, Federal Highway Administration, U.S. Department of Transportation, Washington, D. C..

Varney, R. F. (1973, September). Resonant Vibration Responses of two Horizontally Curved Steel Girder Bridges. FHWA-RD-73-79, Federal Highway Administration, U.S. Department of Transportation, Washington, D. C..

Veletsos, A. S. and Newmark, N. M. (1957). Natural Frequencies of Continuous Flexural Members. Transactions of the American Society of Civil Engineers, 112, 249-278.

Ventura, C. E., Felber, A. J., and Stiemer, S. F. (1996). Determination of the Dynamic Characteristics of the Colquitz River Bridge by Full-Scale Testing. Canadian Journal of Civil Engineering, 23: 536-548.

Walpole, W. (2001, March). Personal Communication with Charles Roeder. University of Canterbury, New Zealand.

Wang, T. L., Huang, D. Z., and Shahawy, M. (1993). Vibration and Impact in Multigirder Steel Bridges. Transportation research record, No. 1393, p96-103.

Wang, T. L., Huang, D. Z., Shahawy, M., and Huang, K. (1996). Dynamic Response of Highway Girder Bridges. Computers \& Structures, Vol. 60, No. 6, p1021-1027. 
Wegmuller, A. W. (1976). Post Elastic Behavior of Composite Steel-Concrete Bridges. International Conference on Finite Element Methods in Engineering $2^{\text {nd }}, 1976$, University of Adelaid.

Wolek, A. L., Barton, F. W., Baber, T. T., and Mckeel, W. T. Jr. (1996). Dynamic Field Testing of the Route 58 Meherrin River Bridge. Virginia Transportation Research Council, Charlottesville, Virginia.

Wood, J. H. and Shepherd, R. (1977). Vehicle Induced Vibrations. Ministry of Works and Development and the University of Auckland, Bulletin 44.

Wright, D. T. and Green, R. (1959, February). Human Sensitive to Vibration (Report No. 7). Ontario Department of Highway and Queen's University, Kingston, Ontario.

Wright, D. T. and Green, R. (1964, May). Highway Bridge Vibration. Part II: Report No. 5 Ontario Test Programme. Ontario Department of Highways and Queen's University. Kingston, Ontario.

Wright, R. N. and Walker, W. H. (1971, November). Criteria for the Deflection of Steel Bridges. Bulletin for the America Iron and Steel Institute, No. 19.

Yamada, Y. and Veletsos, A. S. (1958). Free Vibration of Simple Span I-Beam Bridges. Eight Progress Report, Highway Bridge Impact Investigation, UIUC. 


\section{APPENDIX A - Survey of Professional Practice}




\section{A.1. Introduction}

This work was completed at the University of Washington under the supervision of Dr. Charles Roeder under a collaborative NCHRP project (Roeder, Barth and Bergman, 2002) between the University of Washington and West Virginia University and is included in this dissertation for completeness.

\section{A.2. Description of the Survey}

A survey was completed to better understand the professional practice with regard to the AASHTO live-load deflection limit. The survey was completed by bridge engineers from 48 states and sought specific information about the application of deflection limits for steel bridges in that state.

The survey consisted of 10 general questions, which depending upon the interviewee's response potentially led to prepared follow-up questions that were needed to fully define the response. The information requested from the survey included:

- deflection limits that are applied to steel bridges in that state and the circumstances under which they are used,

- the loads used to compute these deflections for steel-stringer bridges and other bridge types,

- the calculation methods and the stiffness considered in the deflection calculation, and

- the role of the span-to-depth $(L / D)$ ratio limits in that state (deflection limits and $L / D$ ratio limits appear to accomplish similar objectives in deflection control).

The survey also aimed to identify candidate bridges for more detailed study that was to be completed in later stages of the research. This included: 
- information on HPS applications due the adverse effect of the existing deflection limit on the economy of HPS bridges,

- identification of bridges with structural damage that engineers attributed to excessive bridge deflections,

- information regarding deflection serviceability resulting from live-load induced vibrations, and

- identification of bridges that fail to satisfy the existing deflection limit but still provide good bridge performance, as these bridges are strong candidates for further study because they provide a basis for modifying present serviceability limits.

Lastly, the survey sought comments on the use and suitability of present live-load deflection limits and research reports or other information that was relevant to the study. Field measurements and research reports related to this study were requested.

\section{A.3. Results of Survey}

Table A.1 attempts to provide a state by state summary of key issues noted from the survey. It must be recognized that this table is not a precise indicator of the answers provided by the interviewee, but the evaluation of the total response. For example, question 4 was to determine:

- whether deflections were computed by using a line girder approach or by analyzing the total bridge system,

- whether stiffness in the deflection calculations included composite action of the girders, or

- whether the stiffness of curbs, railings and sidewalks were included in the calculation.

Individual answers to these individual questions varied widely, but the total effects of the different state responses were often quite similar. This occurred because different states compensated for the various issues at different steps in their evaluation process. The last 
column of Table A.1 summarizes the consensus of the final effect regarding this issue rather than the individual answers to specific questions. 
Table A.1. Summary of general survey results

\begin{tabular}{|c|c|c|c|c|c|c|}
\hline \multirow[t]{2}{*}{ State } & \multicolumn{2}{|c|}{ Deflection limits } & \multirow[t]{2}{*}{ Span / Depth Ratios } & \multicolumn{2}{|c|}{ Load Magnitude } & \multirow[t]{2}{*}{ Lane Application } \\
\hline & Ped. & Non-Ped. & & Load Used & Factored & \\
\hline Alabama & $\mathrm{L} / 1000$ & $\mathrm{~L} / 800$ & Loose AASHTO & HS 2044 Truck & No & $\begin{array}{c}\text { Evaluated with AASHTO } \\
\text { lane distribution factor } \\
\text { but analyzed as a system } \\
\text { If too large }\end{array}$ \\
\hline Alaska & $\mathrm{L} / 1000$ & $\mathrm{~L} / 800$ & Loose AASHTO & HS 20 Truck + I & No & Evaluated as a system \\
\hline Arizona & $\mathrm{L} / 1000$ & $\mathrm{~L} / 800$ & AASHTO & $\begin{array}{c}\text { HS } 20 \text { Truck + I } \\
\text { or Lane; } \\
\text { whichever governs }\end{array}$ & No & $\begin{array}{l}\text { Evaluated as single girder } \\
\text { with lane distribution } \\
\text { factors }\end{array}$ \\
\hline Arkansas & $\mathrm{L} / 1000$ & $\mathrm{~L} / 800$ & AASHTO & Truck + Lane + I & Yes & $\begin{array}{l}\text { Evaluated as system with } \\
\text { lane distribution factors }\end{array}$ \\
\hline California & $\mathrm{L} / 800$ & $\mathrm{~L} / 800$ & $\begin{array}{l}\text { Non-composite beams } \\
\text { or girders are } \mathrm{D} / \mathrm{S}> \\
0.04 \text { and composite } \\
\text { girders are } \mathrm{D} / \mathrm{S}>0.045 \\
\text { for simple and } 0.04 \text { for } \\
\text { continuous }\end{array}$ & Truck + Lane + I & No & $\begin{array}{l}\text { Evaluated as single girder } \\
\text { with lane distribution } \\
\text { factors }\end{array}$ \\
\hline Colorado & $\mathrm{L} / 1000$ & $\mathrm{~L} / 800$ & Strict AASHTO & Truck + Lane + I & No & $\begin{array}{l}\text { Evaluated as single girder } \\
\text { with lane distribution } \\
\text { factors }\end{array}$ \\
\hline Connecticut & $\mathrm{L} / 1000$ & $\mathrm{~L} / 800$ & No & Truck + Lane + I & No & $\begin{array}{l}\text { Evaluated as single girder } \\
\text { with lane distribution } \\
\text { factors }\end{array}$ \\
\hline Delaware & $\mathrm{L} / 1000$ & $\mathrm{~L} / 800$ & AASHTO & $\begin{array}{l}\text { HS } 25 \text { Truck }+ \text { I } \\
\text { Before, now HL } 93 \\
\text { Truck }+ \text { I }\end{array}$ & No & $\begin{array}{c}\text { Evaluated with AASHTO } \\
\text { lane distribution factor } \\
\text { but analyzed as a system } \\
\text { If too large }\end{array}$ \\
\hline
\end{tabular}




\begin{tabular}{|c|c|c|c|c|c|c|}
\hline Florida & $\mathrm{L} / 1000$ & $\mathrm{~L} / 800$ & $\begin{array}{l}\text { AASHTO but may } \\
\text { occasionally ignore }\end{array}$ & Truck + I & No & $\begin{array}{l}\text { Effectively system } \\
\text { analysis with equal } \\
\text { distribution }\end{array}$ \\
\hline Georgia & $\mathrm{L} / 1000$ & $\mathrm{~L} / 800$ & AASHTO & $\begin{array}{c}\text { Lane }+ \text { I or Truck } \\
+ \text { I or military } \\
\text { Load + I; } \\
\text { whichever governs }\end{array}$ & No & $\begin{array}{l}\text { Effectively system } \\
\text { analysis with equal } \\
\text { distribution }\end{array}$ \\
\hline Hawaii & \multicolumn{3}{|c|}{ Have not designed a steel bridge in $30+$ years } & & & \\
\hline Idaho & $\mathrm{L} / 800$ & $\mathrm{~L} / 800$ & $\begin{array}{l}\text { recommend } \\
\text { AASHTO }\end{array}$ & Truck + I & No & $\begin{array}{l}\text { Equal distribution with } \\
\text { system analysis }\end{array}$ \\
\hline Illinois & $\mathrm{L} / 1000$ & $\mathrm{~L} / 800$ & No & $\begin{array}{c}\text { Lane }+ \text { I or Truck } \\
+ \text { I; whichever } \\
\text { governs }\end{array}$ & No & $\begin{array}{l}\text { Effectively system } \\
\text { analysis with equal } \\
\text { distribution }\end{array}$ \\
\hline Indiana & & & & & No & \\
\hline Iowa & $\mathrm{L} / 1000$ & $\mathrm{~L} / 800$ & No & Truck + Lane + I & No & $\begin{array}{l}\text { Evaluated as a single } \\
\text { girder with lane load } \\
\text { distribution }\end{array}$ \\
\hline Kansas & $\mathrm{L} / 1000$ & $\mathrm{~L} / 800$ & No & Truck + I & No & $\begin{array}{l}\text { Effectively system } \\
\text { analysis with equal } \\
\text { distribution }\end{array}$ \\
\hline Kentucky & $\mathrm{L} / 1000$ & $\mathrm{~L} / 800$ & AASHTO & $\begin{array}{l}\text { HS } 20 \text { Truck + } \\
\text { Lane }+ \text { I }\end{array}$ & No & $\begin{array}{l}\text { Start with girder analysis } \\
\text { but move to system } \\
\text { analysis but use lane load } \\
\text { distribution }\end{array}$ \\
\hline Louisiana & $\mathrm{L} / 1000$ & $\mathrm{~L} / 800$ & Strict AASHTO & Truck + Lane + I & No & $\begin{array}{c}\text { Evaluated as a single } \\
\text { girder with lane load } \\
\text { distribution }\end{array}$ \\
\hline Maine & $\mathrm{L} / 1000$ & $\mathrm{~L} / 800$ & Strict AASHTO & $\begin{array}{l}\text { HS } 20 \text { Truck + } \\
\text { Lane + I }\end{array}$ & No & $\begin{array}{c}\text { Evaluated as a single } \\
\text { girder with lane load } \\
\text { distribution }\end{array}$ \\
\hline
\end{tabular}




\begin{tabular}{|c|c|c|c|c|c|c|}
\hline Maryland & $\mathrm{L} / 1000$ & $\mathrm{~L} / 800$ & AASHTO & $\begin{array}{l}\text { HS } 25 \text { Truck or lane; } \\
\text { whichever governs } \\
\text { (respondent did not } \\
\text { know if impact was } \\
\text { included) }\end{array}$ & No & $\begin{array}{c}\text { Evaluated as a single } \\
\text { girder with lane load } \\
\text { distribution }\end{array}$ \\
\hline Massachusetts & $\mathrm{L} / 1000$ & $\begin{array}{l}\mathrm{L} / 800 \text { as an } \\
\text { upper limit } \\
\text { but L / } 1000 \text { is } \\
\text { preferred }\end{array}$ & Strict AASHTO & Truck + Lane + I & No & $\begin{array}{c}\text { Evaluated as a single } \\
\text { girder with lane load } \\
\text { distribution }\end{array}$ \\
\hline Michigan & $\mathrm{L} / 1000$ & $\mathrm{~L} / 800$ & $\begin{array}{c}\text { Loose AASHTO used } \\
\text { for preliminary } \\
\text { design }\end{array}$ & HS 25 Truck + I & No & $\begin{array}{l}\text { Evaluated as single girder } \\
\text { with } \mathrm{S} / 14 \text { lane load } \\
\text { distribution - effectively } \\
\text { system analysis with } \\
\text { uniform distribution } \\
\end{array}$ \\
\hline Minnesota & $\mathrm{L} / 1200$ & $\mathrm{~L} / 1000$ & $\begin{array}{l}\text { AASHTO as } \\
\text { preliminary }\end{array}$ & Truck + I & No & $\begin{array}{l}\text { Effectively system } \\
\text { analysis with equal } \\
\text { distribution }\end{array}$ \\
\hline Mississippi & $\mathrm{L} / 1000$ & $\mathrm{~L} / 800$ & AASHTO & $\begin{array}{l}\text { Truck }+ \text { I or Lane } \\
+ \text { I or military }+ \text { I; } \\
\text { whichever } \\
\text { governs }\end{array}$ & $\begin{array}{c}\text { No } \\
\text { Response }\end{array}$ & $\begin{array}{c}\text { Start with single girder and } \\
\text { advance to system analysis } \\
\text { if needed but with lane load } \\
\text { distribution }\end{array}$ \\
\hline Missouri & $\mathrm{L} / 1000$ & $\mathrm{~L} / 800$ & AASHTO & Truck + Lane + I & No & $\begin{array}{l}\text { Evaluated as a single } \\
\text { girder with lane load } \\
\text { distribution }\end{array}$ \\
\hline Montana & $\mathrm{L} / 1000$ & $\mathrm{~L} / 1000$ & Loose AASHTO & Truck + Lane & Yes & $\begin{array}{c}\text { Evaluated as system } \\
\text { with lane distribution factors }\end{array}$ \\
\hline Nebraska & $\mathrm{L} / 1000$ & $\mathrm{~L} / 800$ & AASHTO & $\begin{array}{c}\text { Truck + I or HS } 25 \\
\text { Truck + I; whichever } \\
\text { governs }\end{array}$ & No & $\begin{array}{c}\text { Effectively system } \\
\text { analysis with equal } \\
\text { distribution }\end{array}$ \\
\hline
\end{tabular}




\begin{tabular}{|c|c|c|c|c|c|c|}
\hline Nevada & $\mathrm{L} / 1000$ & $\mathrm{~L} / 800$ & AASHTO & $\begin{array}{c}\text { HS } 20 \text { Truck }+ \text { I for } \\
\text { non-NHS roads and } \\
\text { HS } 25 \text { Truck + I for } \\
\text { NHS roads }\end{array}$ & No & $\begin{array}{l}\text { Evaluated as a single } \\
\text { girder with lane load } \\
\text { distribution }\end{array}$ \\
\hline \multicolumn{7}{|l|}{$\begin{array}{c}\text { New } \\
\text { Hampshire }\end{array}$} \\
\hline New Jersey & $\mathrm{L} / 1000$ & $\mathrm{~L} / 1000$ & No & $\begin{array}{c}\text { HL } 93 \text { Truck + I } \\
\text { and a permit } \\
\text { vehicle }\end{array}$ & No & $\begin{array}{c}\text { Evaluated as system } \\
\text { with lane distribution } \\
\text { factors }\end{array}$ \\
\hline New Mexico & $\mathrm{L} / 1000$ & $\mathrm{~L} / 800$ & AASHTO & $\begin{array}{l}\text { No set policy, up to } \\
\text { design engineer }\end{array}$ & $\begin{array}{l}\text { No set } \\
\text { policy, up to } \\
\text { design } \\
\text { engineer }\end{array}$ & $\begin{array}{l}\text { Evaluated as a single } \\
\text { girder with lane load } \\
\text { distribution }\end{array}$ \\
\hline New York & $\begin{array}{c}\text { L / } 1000 \\
\text { Recommended }\end{array}$ & $\begin{array}{c}\text { L / } 800 \\
\text { Recommended }\end{array}$ & $\begin{array}{l}\text { AASHTO as a } \\
\text { guideline }\end{array}$ & $\begin{array}{c}\text { Truck + I or Lane + } \\
\text { I; whichever } \\
\text { governs }\end{array}$ & No & $\begin{array}{c}\text { Effectively system } \\
\text { analysis with equal } \\
\text { distribution }\end{array}$ \\
\hline North Carolina & $\mathrm{L} / 1000$ & $\mathrm{~L} / 800$ & $\begin{array}{c}\text { AASHTO } \\
\text { recommended }\end{array}$ & Truck + Lane + I & No & \\
\hline North Dakota & $\mathrm{L} / 1000$ & $\mathrm{~L} / 800$ & AASHTO & Truck + Lane + I & No & $\begin{array}{c}\text { Evaluated as system } \\
\text { with lane distribution } \\
\text { factors }\end{array}$ \\
\hline Ohio & $\mathrm{L} / 800$ & $\mathrm{~L} / 800$ & $\begin{array}{c}\text { Ratio of } 10 \text { to } \\
20\end{array}$ & Lane + I & No response & $\begin{array}{c}\text { Evaluated as a single } \\
\text { girder with lane load } \\
\text { distribution }\end{array}$ \\
\hline Oklahoma & $\mathrm{L} / 1000$ & $\mathrm{~L} / 800$ & AASHTO & Truck + Lane + I & Yes & $\begin{array}{c}\text { Evaluated as a single } \\
\text { girder with lane load } \\
\text { distribution }\end{array}$ \\
\hline Oregon & $\mathrm{L} / 800$ & $\mathrm{~L} / 800$ & AASHTO & Truck + I & no & $\begin{array}{l}\text { Evaluated as a single } \\
\text { girder with lane load } \\
\text { distribution }\end{array}$ \\
\hline
\end{tabular}




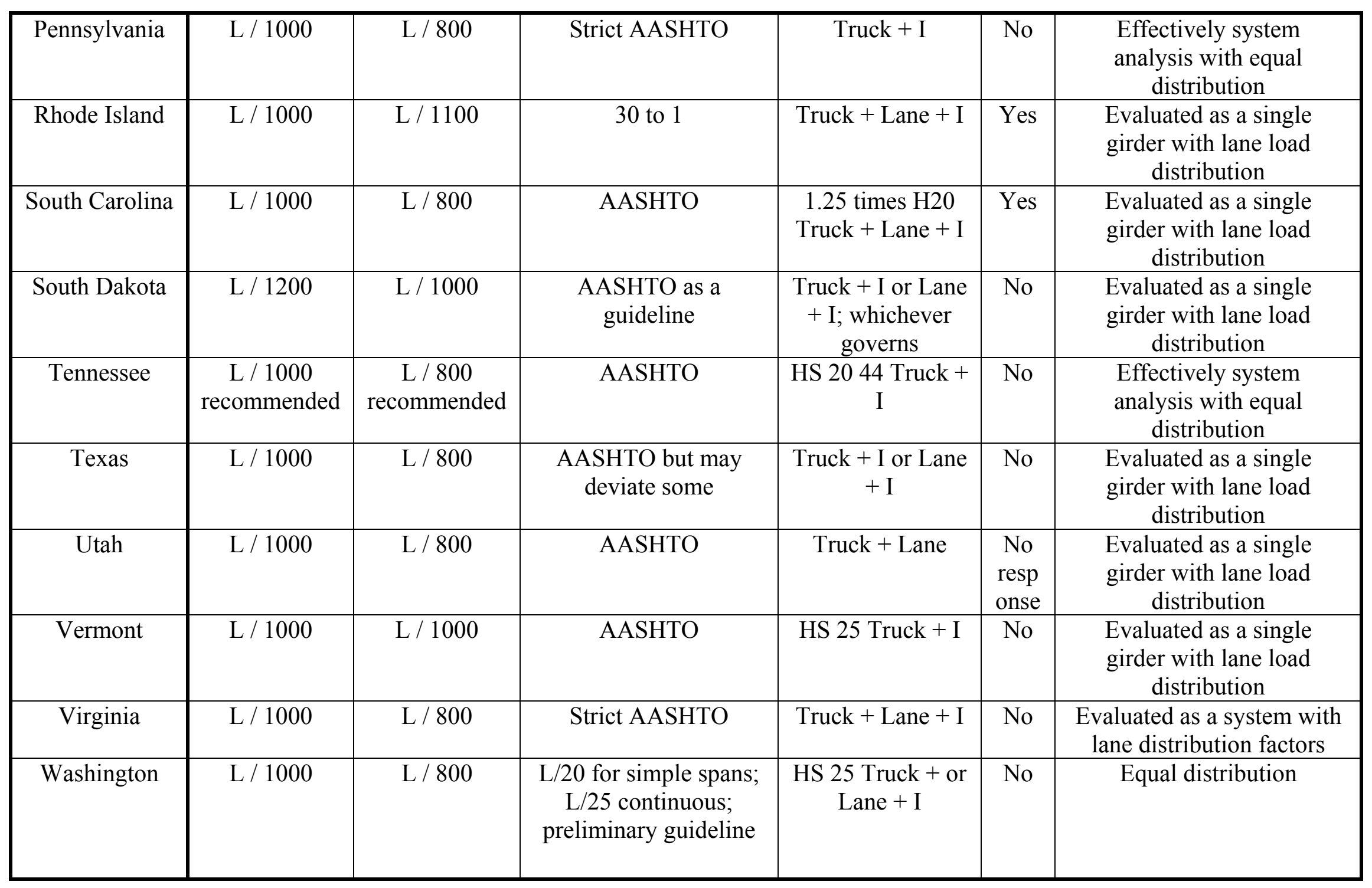




\begin{tabular}{|c|c|c|c|c|c|c|}
\hline West Virginia & L /1000 & L / 800 & No limit & $\begin{array}{c}\text { HS 25 Truck + or } \\
\text { Lane + I }\end{array}$ & $\begin{array}{c}\text { No } \\
\text { Equal distribution including } \\
\text { all stiffness contributing } \\
\text { elements such as curbs and } \\
\text { railings }\end{array}$ \\
\hline Wisconsin & L / 1600 & L / 1600 & $\begin{array}{c}\text { No but with L / 1600 } \\
\text { deflection will usually } \\
\text { control anyway }\end{array}$ & HS 25 Truck + I & No & $\begin{array}{c}\text { Evaluated as system with } \\
\text { lane distribution factors }\end{array}$ \\
\hline Wyoming & L / 1000 & L / 800 & No & Truck + Lane + I & Yes & $\begin{array}{c}\text { Start with single girder and } \\
\text { advance to system analysis } \\
\text { if needed but with lane load } \\
\text { distribution }\end{array}$ \\
\hline
\end{tabular}


The AASHTO Standard Specification limits the maximum live-load deflection to $L / 800$ for steel bridges, which do not carry pedestrians, but the survey shows that there is wide variation in the deflection limit employed by the various states. Of 47 states reporting deflection limits for bridges without pedestrian access:

- 1 state employs a $L / 1600$ limit,

- 1 state uses a $L / 1100$ limit,

- 5 states employ a $L / 1000$ limit,

- 1 state expresses a preference for $L / 1000$ but requires $L / 800$ limit, and

- 39 states employ a $L / 800$ limit.

Of the states reporting deflection limits for bridges with pedestrian access:

- 1 state employs a $L / 1600$ limit,

- 2 states use a $L / 1200$ limit,

- 1 state employs a $L / 1100$ limit,

- 39 states use a $L / 1000$ limit, and

- 3 states employ a $L / 800$ limit.

There is very wide variation in these deflection limits, since the largest deflection limit is twice as large as the smallest deflection limit. Two of the 47 states treat the deflection limit as a recommendation rather than a design requirement.

The AASHTO Specification indicates that deflections due to live-load plus impact are to be limited by the deflection limit. Within this context, there is ambiguity in the loads and load combinations that should be used for the deflection calculations, because design live-loads are expressed as both individual truck loads and uniform lane loads. 
The survey showed that the loads used to compute these deflections have even greater variability than observed in the deflection limits.

- 1 state employs the HS (or in some cases LRFD HL) truck load only,

- 16 states use the truck load plus impact,

- 1 state uses distributed lane load plus impact,

- 1 state uses truck load plus distributed lane load without impact,

- 7 states use the larger deflection caused by either truck load plus impact or the distributed lane load with impact,

- 17 states use truck load plus distributed lane load plus impact, and

- 4 states consider deflections due to some form of military or special permit vehicle.

The combination of the variability of the load and the variability of the deflection limit results in considerable difficulty in directly comparing the various state deflection limits. For example, Wisconsin uses the smallest deflection limit, but it also employs smaller loads than most other states. However, the relative importance of the lane load and design truck load are likely to be different for long and short span bridges, and so the $L / 1600$ limit used in Wisconsin may be more restrictive for short span bridges. Conversely, the Wisconsin limit may be a generous deflection limit for very long span bridges, because the truck load becomes relatively smaller with longer bridge spans despite the small deflection limit.

The actual methods used to calculate deflections are not defined in the AASHTO Specification. In typical engineering practice, deflection limits are based upon deflections caused by service loads under actual service conditions. Load factors or other factors used to arbitrarily increase design loads are not normally used in these deflection 
calculations, and the actual expected stiffness of the full structure is used. The survey shows that this is a further source of variability in the application of the deflection limits. Load factors and lane load distribution factors are employed in some states while they are neglected in others. Lane load distribution factors can significantly affect the magnitude of the loads used to compute the deflections. The survey shows that 26 states use lane load distribution factors from the AASHTO Standard Specifications in calculating these deflections. Three states report that they use the LRFD lane load distribution factors. Thirteen states indicate that they effectively apply the loads uniformly to the traffic lanes by the AASHTO multiple presence lane load rules. They then compute the deflections of the bridge as a system without any increase for load factors, girder spacing or lane load distribution. These states effectively use an equal distribution of deflection principle. One state uses its own lane load distribution factor that is comparable to system deflection calculations. Several states indicate some flexibility in the calculation method, and a few states indicate a reluctance to permit the bridge deflection limit to control the design. The effect of the lane load distribution factor can be quite significant. Depending upon the spacing of bridge girders, the load used for bridge deflection calculations can be $40 \%$ to $100 \%$ larger than the load used for states where deflections are computed for the bridge as a system or where the loads are uniformly distributed to girders.

Load factors may also be an issue of concern. Five states report that they apply load factors to the load used for the deflection calculation. These load factors also increase the loads used to compute bridge deflections, and they increase the variability in the application of the deflection limit between different states. 
Span-to-depth, $L / D$, ratio limits were also examined because they also have interrelation with deflection limits. Seven states indicate that they employ no $L / D$ limits, while 34 indicate that they use the AASHTO design limits. Of these 34 states, 6 indicate that they strictly employ the limit, but 8 indicate that they employ it only as a guideline. The impact of this observation is not immediately clear, because some states that have no limit or a loose $L / D$ limit have relatively tight deflection limits. Some states that strictly apply the AASHTO $L / D$ ratio limits have relatively less restrictive deflection limits.

The combined variability of the deflection limit, the methods of calculating deflections, and the loads used to calculate deflection indicates that the resulting variability of the practical deflection limits used in the different states are huge. On the surface, it appears that variations of at least $200 \%$ to $300 \%$ are possible. However, the comparison is neither simple nor precise.

\section{A.4. Bridges for Further Study}

The survey identified a number of bridges that serve as candidate bridges for further analysis. These candidate bridges fall into one of 4 basic categories including:

- Bridges experiencing structural damage associated with large deflections,

- Bridges having passenger or pedestrian discomfort due to vibration,

- Bridges constructed of HPS steel, and

- Bridges failing existing deflection limits but still providing good performance.

Very few bridges that fail existing deflection limits but still provide good structural performance were identified in this survey. A small number of bridges with 
vibration problems were also identified. A number of HPS bridges were identified and information regarding these bridges was obtained for possible further evaluation. The identification of bridges with structural damage that is caused by bridge deflection provided somewhat confusing results. A number of damaged bridges were identified, but most state bridge engineers did not believe that they had any bridges with damage due to excessive deflections. A few states were very clear that they had a significant number of bridges with structural damage that was apparently associated with large deflections. This damage was usually deck cracking and steel cracking or other damage due to differential deflection and out-of-plane bending. However, some of the damage relates to cracking of bolts or other steel elements. It must be emphasized that even states reporting damage note that the damaged bridges were a small minority of their total inventory.

Nevertheless, the fact that some engineers felt that they had a significant number of bridges with the reported damage, was a source of concern while others felt that they had absolutely none. This contradiction may mean that some states have much better bridge performance than other state, or it may indicate that bridge engineers may have widely disparate views as to what constitutes bridge damage. As a result, a limited follow-up survey was directed toward maintenance and inspection engineers to better understand and address these results. This survey was limited to 11 states. The states were selected to represent all geographical parts of the United States, to include populous and lightly populated states, and to include states with a wide range of vehicle load limits. The selected states were:
California
Florida
Illinois
Michigan 
Montana

Pennsylvania

Texas
New York

Tennessee

Washington

Wyoming

The results of this follow-up survey showed that the contradictions in reported bridge behavior are caused by differences in engineer perspective, and there are not likely to be significant differences in bridge performance from state to state. Most state bridge engineers are intimately involved in the design and construction of new highway bridges, but they have limited contact with the repair, maintenance and day to day performance of most of the bridges in their inventory. Maintenance and inspection engineers often have a different perspective of bridge performance than the design engineers for their state. They note a significant number of bridges with cracked steel and cracked concrete decks, and they are more conscience of the potential causes of this damage. As a result, a number of damaged bridges were identified from a number of different states, and the damage of these bridges is usually attributable to some form of bridge deflection. However, none of this deflection damage can be attributed to the direct deflections that are evaluated in the AASHTO deflection check. Instead the damage is caused by differential deflections or relative deflections and other forms of local deformation. As a result, a significant number of candidate bridges were located for this category, it must be clearly recognized that the damage noted in those bridges is often different than what some engineers would regard as bridge deflection damage.

Bridges that were identified as viable candidates by the above criteria were investigated in much greater detail. Design drawings, inspection reports, and photographs 
were obtained for these candidate bridges, and this information was used for the bridge analysis discussed in Chapter 5 (Section 5.2: Evaluation of Existing Plate Girder Bridges). 
Appendix B - Detailed Girder Elevation 
Table B5.1. Detailed girder elevation for cross section $1(\mathrm{~S}=9 \mathrm{ft})$

Simple Composite Plate Girder Using SIMON-LFD

\begin{tabular}{|c|c|c|c|c|c|c|c|c|c|c|c|}
\hline \multirow{2}{*}{$\begin{array}{c}\text { Span } \\
\text { Length, ft. } \\
\text { (L) }\end{array}$} & \multicolumn{2}{|c|}{$\begin{array}{c}\text { Top Flange } \\
\text { (A) }\end{array}$} & \multicolumn{2}{|c|}{$\begin{array}{c}\text { Top Flange } \\
\text { (B) }\end{array}$} & \multirow[b]{2}{*}{$\begin{array}{c}\text { Web Plate, in. } \\
\text { (F) }\end{array}$} & \multicolumn{2}{|c|}{$\begin{array}{c}\text { Bottom Flange } \\
\text { (A) }\end{array}$} & \multicolumn{2}{|c|}{$\begin{array}{c}\text { Bottom Flange } \\
\text { (B) }\end{array}$} & \multirow[b]{2}{*}{$\begin{array}{l}\text { Fy, } \\
\text { ksi }\end{array}$} & \multirow[b]{2}{*}{$\begin{array}{c}\text { L/D } \\
\text { (Actual) }\end{array}$} \\
\hline & Plate, in. & Length, ft. & Plate, in. & Length,ft. & & Plate, in. & Length, ft. & $\begin{array}{c}\text { Plate, } \\
\text { in. }\end{array}$ & Length,ft. & & \\
\hline 100 & $21 \times 3 / 4$ & 100 & & & $69 \times 7 / 16$ & $18 \times 3 / 4$ & 100 & & & 50 & 15.0 \\
\hline 100 & $12 \times 3 / 4$ & 100 & & & $48 \times 3 / 8$ & $12 \times 17 / 8$ & 100 & & & 50 & 20.0 \\
\hline 100 & $13 \times 7 / 8$ & 100 & & & $35 \times 7 / 16$ & $14 \times 21 / 4$ & 100 & & & 50 & 25.4 \\
\hline 100 & $12 \times 15 / 16$ & 100 & & & $27 \times 7 / 16$ & $17 \times 25 / 8$ & 100 & & & 50 & 30.3 \\
\hline 100 & $19 \times 3 / 4$ & 100 & & & $70 \times 9 / 16$ & $18 \times 3 / 4$ & 100 & & & 70 & 14.9 \\
\hline 100 & $14 \times 3 / 4$ & 100 & & & $49 \times 7 / 16$ & $13 \times 15 / 8$ & 100 & & & 70 & 19.8 \\
\hline 100 & $12 \times 3 / 4$ & 100 & & & $35 \times 3 / 8$ & $14 \times 25 / 16$ & 100 & & & 70 & 25.4 \\
\hline 100 & $12 \times 1 \quad 1 / 4$ & 100 & & & $27 \times 3 / 8$ & $14 \times 27 / 8$ & 100 & & & 70 & 30.1 \\
\hline 200 & $39 \times 11 / 16$ & 200 & & & $150 \times 13 / 16$ & $38 \times 3 / 4$ & 200 & & & 50 & 14.9 \\
\hline 200 & $28 \times 11 / 16$ & 200 & & & $110 \times 11 / 16$ & $28 \times 3 / 4$ & 200 & & & 50 & 19.9 \\
\hline 200 & $22 \times 11 / 16$ & 200 & & & $86 \times 9 / 16$ & $22 \times 113 / 16$ & 200 & & & 50 & 24.5 \\
\hline 200 & $18 \times 2$ & 200 & & & $67 \times 7 / 16$ & $21 \times 215 / 16$ & 200 & & & 50 & 30.0 \\
\hline 200 & $38 \times 11 / 16$ & 200 & & & $149 \times 11 / 8$ & $38 \times 3 / 4$ & 200 & & & 70 & 15.0 \\
\hline 200 & $30 \times 11 / 16$ & 200 & & & $110 \times 13 / 16$ & $28 \times 3 / 4$ & 200 & & & 70 & 19.9 \\
\hline 200 & $22 \times 11 / 16$ & 200 & & & $86 \times 5 / 8$ & $22 \times 17 / 16$ & 200 & & & 70 & 24.6 \\
\hline 200 & $18 \times 11 / 2$ & 200 & & & $67 \times 1 / 2$ & $19 \times 25 / 8$ & 200 & & & 70 & 30.1 \\
\hline 300 & NAD & NAD & & & NAD & NAD & NAD & & & 50 & NAD \\
\hline 300 & $43 \times 11 / 2$ & 300 & & & $170 \times 11 / 8$ & $43 \times 3 / 4$ & 300 & & & 50 & 19.9 \\
\hline 300 & $34 \times 2$ & 300 & & & $132 \times 7 / 8$ & $35 \times 17 / 8$ & 300 & & & 50 & 25.0 \\
\hline 300 & $32 \times 215 / 16$ & 300 & & & $106 \times 11 / 16$ & $30 \times 3$ & 300 & & & 50 & 30.0 \\
\hline 300 & $59 \times 15 / 8$ & 300 & & & $229 \times 111 / 16$ & $57 \times 3 / 4$ & 300 & & & 70 & 15.0 \\
\hline 300 & $43 \times 11 / 2$ & 300 & & & $169 \times 11 / 4$ & $42 \times 3 / 4$ & 300 & & & 70 & 20.0 \\
\hline 300 & $34 \times 17 / 16$ & 300 & & & $132 \times 1$ & $33 \times 11 / 4$ & 300 & & & 70 & 25.1 \\
\hline 300 & $27 \times 15 / 8$ & 300 & & & $108 \times 13 / 16$ & $27 \times 27 / 16$ & 300 & & & 70 & 29.9 \\
\hline
\end{tabular}


Table B5.1. Continued

Two-Span Continuous Composite Plate Girder Using SIMON-LFD

\begin{tabular}{|c|c|c|c|c|c|c|c|c|c|c|c|}
\hline \multirow{2}{*}{$\begin{array}{c}\text { Span } \\
\text { Length, ft. } \\
\text { (L) }\end{array}$} & \multicolumn{2}{|c|}{$\begin{array}{c}\text { Top Flange } \\
\text { (A) }\end{array}$} & \multicolumn{2}{|c|}{$\begin{array}{c}\text { Top Flange } \\
\text { (B) }\end{array}$} & \multirow[b]{2}{*}{$\begin{array}{l}\text { Web Plate, in. } \\
\text { (F) }\end{array}$} & \multicolumn{2}{|c|}{$\begin{array}{c}\text { Bottom Flange } \\
\text { (A) }\end{array}$} & \multicolumn{2}{|c|}{$\begin{array}{c}\text { Bottom Flange } \\
\text { (B) }\end{array}$} & \multirow[b]{2}{*}{$\begin{array}{l}\text { Fy, } \\
\text { ksi }\end{array}$} & \multirow[b]{2}{*}{$\begin{array}{c}\text { L/D } \\
\text { (Actual) }\end{array}$} \\
\hline & Plate, in. & $\begin{array}{c}\text { Length, } \\
\text { ft. }\end{array}$ & Plate, in. & Length,ft. & & Plate, in. & $\begin{array}{c}\text { Length, } \\
\text { ft. }\end{array}$ & Plate, in. & Length,ft. & & \\
\hline 100 & $16 \times 3 / 4$ & 75 & $16 \times 3 / 4$ & 25 & $69 \times 1 / 2$ & $16 \times 3 / 4$ & 75 & $16 \times 7 / 8$ & 25 & 50 & 15.0 \\
\hline 100 & $12 \times 3 / 4$ & 75 & $12 \times 15 / 8$ & 25 & $50 \times 3 / 8$ & $14 \times 113 / 16$ & 75 & $14 \times 113 / 16$ & 25 & 50 & 19.4 \\
\hline 100 & $13 \times 3 / 4$ & 75 & $13 \times 3$ & 25 & $34 \times 9 / 16$ & $14 \times 27 / 16$ & 75 & $14 \times 215 / 16$ & 25 & 50 & 25.0 \\
\hline 100 & $18 \times 3 / 4$ & 75 & $18 \times 213 / 16$ & 25 & $26 \times 3 / 4$ & $19 \times 23 / 8$ & 75 & $19 \times 3$ & 25 & 50 & 30.1 \\
\hline 100 & $18 \times 3 / 4$ & 75 & $18 \times 3 / 4$ & 25 & $69 \times 9 / 16$ & $18 \times 3 / 4$ & 75 & $18 \times 7 / 8$ & 25 & 70 & 15.0 \\
\hline 100 & $14 \times 3 / 4$ & 75 & $14 \times 13 / 16$ & 25 & $49 \times 7 / 16$ & $16 \times 13 / 8$ & 75 & $16 \times 13 / 8$ & 25 & 70 & 19.9 \\
\hline 100 & $12 \times 3 / 4$ & 75 & $12 \times 15 / 8$ & 25 & $38 \times 3 / 8$ & $16 \times 21 / 16$ & 75 & $16 \times 15 / 8$ & 25 & 70 & 24.0 \\
\hline 100 & $12 \times 3 / 4$ & 75 & $12 \times 23 / 8$ & 25 & $28 \times 1 / 2$ & $16 \times 27 / 16$ & 75 & $16 \times 27 / 16$ & 25 & 70 & 29.4 \\
\hline 200 & $38 \times 7 / 8$ & 150 & $38 \times 7 / 8$ & 50 & $150 \times 1$ & $38 \times 3 / 4$ & 150 & $38 \times 17 / 16$ & 50 & 50 & 14.9 \\
\hline 200 & $28 \times 13 / 16$ & 150 & $28 \times 11 / 4$ & 50 & $110 \times 3 / 4$ & $28 \times 3 / 4$ & 150 & $28 \times 17 / 16$ & 50 & 50 & 19.8 \\
\hline 200 & $22 \times 3 / 4$ & 150 & $22 \times 23 / 4$ & 50 & $86 \times 5 / 8$ & $22 \times 13 / 16$ & 150 & $22 \times 3$ & 50 & 50 & 24.1 \\
\hline 200 & $29 \times 1$ & 150 & $29 \times 215 / 16$ & 50 & $67 \times 9 / 16$ & $30 \times 11 / 4$ & 150 & $30 \times 3$ & 50 & 50 & 29.6 \\
\hline 200 & $38 \times 13 / 16$ & 150 & $38 \times 13 / 16$ & 50 & $149 \times 13 / 16$ & $38 \times 3 / 4$ & 150 & $38 \times 13 / 8$ & 50 & 70 & 15.0 \\
\hline 200 & $28 \times 13 / 16$ & 150 & $28 \times 13 / 16$ & 50 & $109 \times 7 / 8$ & $28 \times 3 / 4$ & 150 & $28 \times 17 / 16$ & 50 & 70 & 19.9 \\
\hline 200 & $21 \times 3 / 4$ & 150 & $21 \times 111 / 16$ & 50 & $84 \times 5 / 8$ & $21 \times 11 / 16$ & 150 & $21 \times 2$ & 50 & 70 & 25.0 \\
\hline 200 & $18 \times 3 / 4$ & 150 & $18 \times 27 / 8$ & 50 & $68 \times 9 / 16$ & $19 \times 17 / 8$ & 150 & $19 \times 3$ & 50 & 70 & 29.3 \\
\hline 300 & $58 \times 15 / 16$ & 225 & $58 \times 3 / 4$ & 75 & $230 \times 19 / 16$ & $58 \times 7 / 8$ & 225 & $58 \times 2$ & 75 & 50 & 14.9 \\
\hline 300 & $43 \times 13 / 16$ & 225 & $43 \times 1$ & 75 & $170 \times 11 / 18$ & $43 \times 15 / 16$ & 225 & $43 \times 115 / 16$ & 75 & 50 & 19.8 \\
\hline 300 & $34 \times 11 / 8$ & 225 & $24 \times 21 / 2$ & 75 & $134 \times 7 / 8$ & $34 \times 11 / 4$ & 225 & $34 \times 211 / 16$ & 75 & 50 & 24.6 \\
\hline 300 & $42 \times 13 / 8$ & 225 & $42 \times 3$ & 75 & $106 \times 11 / 16$ & $44 \times 17 / 16$ & 225 & $44 \times 3$ & 75 & 50 & 30.0 \\
\hline 300 & $57 \times 13 / 8$ & 225 & $57 \times 3 / 4$ & 75 & $227 \times 113 / 16$ & $57 \times 13 / 16$ & 225 & $57 \times 21 / 16$ & 75 & 70 & 15.1 \\
\hline 300 & $42 \times 13 / 16$ & 225 & $42 \times 3 / 4$ & 75 & $168 \times 15 / 8$ & $42 \times 7 / 8$ & 225 & $42 \times 17 / 8$ & 75 & 70 & 20.1 \\
\hline 300 & $33 \times 11 / 8$ & 225 & $33 \times 11 / 2$ & 75 & $132 \times 11 / 16$ & $33 \times 15 / 16$ & 225 & $33 \times 17 / 8$ & 75 & 70 & 25.0 \\
\hline 300 & $27 \times 11 / 16$ & 225 & $27 \times 3$ & 75 & $108 \times 7 / 8$ & $27 \times 11 / 8$ & 225 & $27 \times 3$ & 75 & 70 & 29.5 \\
\hline
\end{tabular}


Table B5.1. Continued

Three-Span Continuous Composite Plate Girder Using SIMON-LFD

\begin{tabular}{|c|c|c|c|c|c|c|c|c|c|c|c|c|c|c|c|c|c|c|c|}
\hline \multirow{2}{*}{$\begin{array}{l}\text { Span } \\
\text { Len. } \\
\text {, ft. } \\
\text { (L) }\end{array}$} & \multicolumn{2}{|c|}{$\begin{array}{l}\text { Top Flange } \\
\text { (A) }\end{array}$} & \multicolumn{2}{|c|}{$\begin{array}{l}\text { Top Flange } \\
\text { (B) }\end{array}$} & \multicolumn{2}{|c|}{$\begin{array}{l}\text { Top Flange } \\
\text { (C) }\end{array}$} & \multicolumn{2}{|c|}{$\begin{array}{l}\text { Top Flange } \\
\text { (D) }\end{array}$} & \multirow{2}{*}{$\begin{array}{c}\text { Web } \\
\text { Plate, in. } \\
\text { (F) }\end{array}$} & \multicolumn{2}{|c|}{$\begin{array}{l}\text { Bottom Flange } \\
\text { (A) }\end{array}$} & \multicolumn{2}{|c|}{$\begin{array}{c}\text { Bottom Flange } \\
\text { (B) }\end{array}$} & \multicolumn{2}{|c|}{$\begin{array}{l}\text { Bottom Flange } \\
\text { (C) }\end{array}$} & \multicolumn{2}{|c|}{$\begin{array}{l}\text { Bottom Flange } \\
\text { (D) }\end{array}$} & \multirow[b]{2}{*}{$\begin{array}{l}\text { Fy, } \\
\text { ksi }\end{array}$} & \multirow[b]{2}{*}{$\underset{\text { (Actual) }}{\mathbf{L} / \mathbf{D}}$} \\
\hline & $\begin{array}{c}\text { Plate, } \\
\text { in. }\end{array}$ & $\begin{array}{l}\text { Len., } \\
\text { ft. }\end{array}$ & $\begin{array}{c}\text { Plate, } \\
\text { in. }\end{array}$ & $\begin{array}{l}\text { Len., } \\
\text { ft. }\end{array}$ & $\begin{array}{c}\text { Plate, } \\
\text { in. }\end{array}$ & $\begin{array}{l}\text { Len., } \\
\text { ft. }\end{array}$ & $\begin{array}{c}\text { Plate, } \\
\text { in. }\end{array}$ & $\begin{array}{l}\text { Len., } \\
\text { ft. }\end{array}$ & & Plate, in. & $\begin{array}{l}\text { Len., } \\
\text { ft. }\end{array}$ & Plate, in. & $\begin{array}{l}\text { Len., } \\
\text { ft. }\end{array}$ & Plate, in. & $\begin{array}{l}\text { Len., } \\
\text { ft. }\end{array}$ & Plate, in. & $\begin{array}{l}\text { Len., } \\
\text { ft. }\end{array}$ & & \\
\hline 100 & $\begin{array}{c}15 \mathrm{x} \\
3 / 4 \\
\end{array}$ & 60 & $\begin{array}{l}15 \mathrm{x} \\
3 / 4 \\
\end{array}$ & 20 & $\begin{array}{l}15 \mathrm{x} \\
3 / 4 \\
\end{array}$ & 25 & $\begin{array}{l}15 \mathrm{x} \\
3 / 4 \\
\end{array}$ & 50 & $69 \times 1 / 2$ & $15 \times 3 / 4$ & 60 & $15 \times 3 / 4$ & 20 & $15 \times 3 / 4$ & 25 & $15 \times 3 / 4$ & 50 & 50 & 15.1 \\
\hline 100 & $\begin{array}{l}12 \mathrm{x} \\
3 / 4\end{array}$ & 60 & $\begin{array}{c}12 \times \\
7 / 8\end{array}$ & 20 & $\begin{array}{l}12 \times \\
7 / 8\end{array}$ & 25 & $\begin{array}{l}12 \times \\
3 / 4\end{array}$ & 50 & $50 \times 3 / 8$ & $14 \times 13 / 8$ & 60 & $14 \times 13 / 8$ & 20 & $14 \times 13 / 16$ & 25 & $14 \times 11 / 8$ & 50 & 50 & 19.6 \\
\hline 100 & $\begin{array}{l}12 \mathrm{x} \\
3 / 4\end{array}$ & 60 & $\begin{array}{l}12 \mathrm{x} \\
11 / 2\end{array}$ & 20 & $\begin{array}{c}12 \times 1 \\
1 / 2\end{array}$ & 25 & $\begin{array}{l}12 \mathrm{x} \\
3 / 4\end{array}$ & 50 & $36 \times 9 / 16$ & $\begin{array}{l}13 \times 1 \\
13 / 16\end{array}$ & 60 & $13 \times 17 / 8$ & 20 & $13 \times 17 / 8$ & 25 & $13 \times 15 / 8$ & 50 & 50 & 25.1 \\
\hline 100 & $\begin{array}{l}18 \mathrm{x} \\
3 / 4\end{array}$ & 60 & $\begin{array}{l}18 x \\
17 / 8 \\
\end{array}$ & 20 & $\begin{array}{c}18 \times 1 \\
7 / 8\end{array}$ & 25 & $\begin{array}{c}18 \mathrm{x} \\
3 / 4\end{array}$ & 50 & $28 \times 3 / 4$ & $\begin{array}{l}19 \times 1 \\
11 / 16\end{array}$ & 60 & $19 \times 15 / 8$ & 20 & $19 \times 15 / 8$ & 25 & $19 \times 15 / 8$ & 50 & 50 & 30.2 \\
\hline 100 & $\begin{array}{l}14 x \\
3 / 4\end{array}$ & 60 & $\begin{array}{l}14 x \\
3 / 4\end{array}$ & 20 & $\begin{array}{l}14 x \\
3 / 4\end{array}$ & 25 & $\begin{array}{l}14 \mathrm{x} \\
3 / 4\end{array}$ & 50 & $68 \times 9 / 16$ & $14 \times 3 / 4$ & 60 & $14 \times 3 / 4$ & 20 & $14 \times 3 / 4$ & 25 & $14 \times 3 / 4$ & 50 & 70 & 15.1 \\
\hline 100 & $\begin{array}{l}12 \mathrm{x} \\
3 / 4\end{array}$ & 60 & $\begin{array}{l}12 \times \\
3 / 4\end{array}$ & 20 & $\begin{array}{l}12 \times \\
3 / 4\end{array}$ & 25 & $\begin{array}{l}12 \mathrm{x} \\
3 / 4\end{array}$ & 50 & $49 \times 7 / 16$ & $\begin{array}{c}14 \times 1 \\
3 / 16\end{array}$ & 60 & $\begin{array}{c}14 \times 1 \\
3 / 16\end{array}$ & 20 & $14 \times 13 / 16$ & 25 & $14 \times 13 / 16$ & 50 & 70 & 19.9 \\
\hline 100 & $\begin{array}{c}2 \mathrm{x} \\
3 / 4 \\
\end{array}$ & 60 & $\begin{array}{c}12 x \\
7 / 8 \\
\end{array}$ & 20 & $\begin{array}{l}12 x \\
7 / 8\end{array}$ & 25 & $\begin{array}{l}12 x \\
7 / 8\end{array}$ & 50 & $38 \times 3 / 8$ & $\begin{array}{l}13 \times 1 \\
13 / 16 \\
\end{array}$ & 60 & $\begin{array}{l}13 \times 1 \\
13 / 16 \\
\end{array}$ & 20 & $13 \times 113 / 16$ & 25 & $13 \times 113 / 16$ & 50 & 70 & 24.1 \\
\hline 100 & $\begin{array}{l}12 x \\
3 / 4\end{array}$ & 60 & $\begin{array}{c}12 \mathrm{x} \\
1 \\
7 / 16 \\
\end{array}$ & 20 & $\begin{array}{r}12 \times 1 \\
7 / 16\end{array}$ & 25 & $\begin{array}{r}12 \times 1 \\
7 / 16\end{array}$ & 50 & $28 \times 7 / 16$ & $13 \times 25 / 8$ & 60 & $\begin{array}{l}13 \times 2 \\
3 / 16 \\
\end{array}$ & 20 & $13 \times 23 / 16$ & 25 & $13 \times 23 / 16$ & 50 & 70 & 29.5 \\
\hline 200 & $\begin{array}{c}36 \mathrm{x} \\
3 / 4 \\
\end{array}$ & 120 & $\begin{array}{c}36 \mathrm{x} \\
3 / 4 \\
\end{array}$ & 40 & $\begin{array}{c}36 x \\
3 / 4 \\
\end{array}$ & 50 & $\begin{array}{c}36 \mathrm{x} \\
3 / 4 \\
\end{array}$ & 100 & $150 \times 1$ & $36 \times 3 / 4$ & 120 & $\begin{array}{c}36 \times 1 \\
3 / 16 \\
\end{array}$ & 40 & $36 \times 13 / 16$ & 50 & $36 \times 3 / 4$ & 100 & 50 & 14.9 \\
\hline 200 & $\begin{array}{c}26 \mathrm{x} \\
3 / 4 \\
\end{array}$ & 120 & $\begin{array}{c}26 \mathrm{x} \\
3 / 4 \\
\end{array}$ & 40 & $\begin{array}{c}26 \mathrm{x} \\
3 / 4 \\
\end{array}$ & 50 & $\begin{array}{c}26 x \\
3 / 4 \\
\end{array}$ & 100 & $110 \times 3 / 4$ & $27 \times 3 / 4$ & 120 & $\begin{array}{c}27 \times 1 \\
3 / 16 \\
\end{array}$ & 40 & $27 \times 13 / 16$ & 50 & $27 \times 3 / 4$ & 100 & 50 & 19.8 \\
\hline 200 & $\begin{array}{r}21 \mathrm{x} \\
3 / 4 \\
\end{array}$ & 120 & $\begin{array}{l}21 \mathrm{x} \\
15 / 8 \\
\end{array}$ & 40 & $\begin{array}{c}21 \times 1 \\
5 / 8\end{array}$ & 50 & $\begin{array}{l}21 x \\
3 / 4\end{array}$ & 100 & $84 \times 5 / 8$ & $22 \times 3 / 4$ & 120 & $\begin{array}{l}22 \times 1 \\
13 / 16 \\
\end{array}$ & 40 & $22 \times 113 / 16$ & 50 & $22 \times 3 / 4$ & 100 & 50 & 25.1 \\
\hline 200 & $\begin{array}{c}29 \times \\
7 / 8 \\
\end{array}$ & 120 & $\begin{array}{c}29 x \\
1 \\
11 / 16 \\
\end{array}$ & 40 & $\begin{array}{l}29 \times 1 \\
11 / 16 \\
\end{array}$ & 50 & $\begin{array}{c}29 \times \\
13 / 16 \\
\end{array}$ & 100 & $68 \times 1 / 2$ & $29 \times 1$ & 120 & $29 \times 17 / 8$ & 40 & $29 \times 17 / 8$ & 50 & $29 \times 11 / 16$ & 100 & 50 & 30.1 \\
\hline 200 & $\begin{array}{c}35 \mathrm{x} \\
3 / 4 \\
\end{array}$ & 120 & $\begin{array}{c}35 \mathrm{x} \\
3 / 4 \\
\end{array}$ & 40 & $\begin{array}{c}35 \mathrm{x} \\
3 / 4 \\
\end{array}$ & 50 & $\begin{array}{c}35 \mathrm{x} \\
3 / 4 \\
\end{array}$ & 100 & $\begin{array}{c}149 \times 1 \\
1 / 8 \\
\end{array}$ & $35 \times 3 / 4$ & 120 & $35 \times 11 / 4$ & 40 & $35 \times 11 / 4$ & 50 & $35 \times 11 / 4$ & 100 & 70 & 15.0 \\
\hline 200 & $\begin{array}{l}22 \mathrm{x} \\
3 / 4\end{array}$ & 120 & $\begin{array}{l}22 \mathrm{x} \\
3 / 4\end{array}$ & 40 & $\begin{array}{l}22 \mathrm{x} \\
3 / 4\end{array}$ & 50 & $\begin{array}{l}22 \mathrm{x} \\
3 / 4\end{array}$ & 100 & $109 \times 7 / 8$ & $22 \times 3 / 4$ & 120 & $\begin{array}{c}22 \times 1 \\
1 / 16\end{array}$ & 40 & $22 \times 11 / 16$ & 50 & $22 \times 11 / 16$ & 100 & 70 & 19.8 \\
\hline 200 & $\begin{array}{c}18 \mathrm{x} \\
3 / 4\end{array}$ & 120 & $\begin{array}{l}18 \mathrm{x} \\
7 / 8\end{array}$ & 40 & $\begin{array}{l}18 \mathrm{x} \\
7 / 8\end{array}$ & 50 & $\begin{array}{l}18 \mathrm{x} \\
7 / 8\end{array}$ & 100 & $84 \times 11 / 16$ & $\begin{array}{c}18 \mathrm{x} \\
13 / 16\end{array}$ & 120 & $\begin{array}{c}18 \times 1 \\
5 / 16\end{array}$ & 40 & $18 \times 15 / 16$ & 50 & $18 \times 15 / 16$ & 100 & 70 & 25.2 \\
\hline 200 & $\begin{array}{l}14 \times \\
3 / 4 \\
\end{array}$ & 120 & $\begin{array}{c}14 \mathrm{x} \\
1 \\
15 / 16 \\
\end{array}$ & 40 & $\begin{array}{l}14 \times 1 \\
15 / 16 \\
\end{array}$ & 50 & $\begin{array}{l}14 \times 1 \\
15 / 16 \\
\end{array}$ & 100 & $68 \times 9 / 16$ & $\begin{array}{l}15 \times 1 \\
11 / 16 \\
\end{array}$ & 120 & $15 \times 25 / 8$ & 40 & $15 \times 25 / 8$ & 50 & $15 \times 25 / 8$ & 100 & 70 & 29.8 \\
\hline 300 & $\begin{array}{c}58 \times 1 \\
3 / 16\end{array}$ & 180 & $\begin{array}{l}58 \mathrm{x} \\
3 / 4\end{array}$ & 60 & $\begin{array}{c}58 \mathrm{x} \\
3 / 4\end{array}$ & 75 & $\begin{array}{c}58 \times 1 \\
1 / 8\end{array}$ & 150 & $\begin{array}{c}230 \times 1 \\
1 / 2\end{array}$ & $\begin{array}{c}58 \mathrm{x} \\
13 / 16\end{array}$ & 180 & $\begin{array}{l}58 \times 1 \\
13 / 16\end{array}$ & 60 & $58 \times 113 / 16$ & 75 & $58 \times 3 / 4$ & 150 & 50 & 14.9 \\
\hline 300 & $43 \times 1$ & 180 & $\begin{array}{c}43 x \\
3 / 4\end{array}$ & 60 & $\begin{array}{c}43 \times x \\
3 / 4\end{array}$ & 75 & $43 \times 1$ & 150 & $\begin{array}{c}170 \times 1 \\
1 / 8\end{array}$ & $44 \times 7 / 8$ & 180 & $\begin{array}{l}44 \times 1 \\
11 / 16\end{array}$ & 60 & $44 \times 111 / 16$ & 75 & $44 \times 3 / 4$ & 150 & 50 & 19.8 \\
\hline 300 & $34 \times 1$ & 180 & $\begin{array}{c}34 \mathrm{x} \\
1 \\
5 / 16\end{array}$ & 60 & $\begin{array}{c}34 \times 1 \\
5 / 16\end{array}$ & 75 & $\begin{array}{c}34 \mathrm{x} \\
7 / 8\end{array}$ & 150 & $132 \times 7 / 8$ & $33 \times 7 / 8$ & 180 & $33 \times 15 / 8$ & 60 & $33 \times 15 / 8$ & 75 & $33 \times 3 / 4$ & 150 & 50 & 25.1 \\
\hline 300 & $\begin{array}{c}27 x \\
15 / 16\end{array}$ & 180 & $\begin{array}{l}27 \mathrm{x} \\
27 / 8\end{array}$ & 60 & $\begin{array}{c}27 \times 2 \\
7 / 8\end{array}$ & 75 & $\begin{array}{c}27 x \\
13 / 16\end{array}$ & 150 & $\begin{array}{l}106 \mathrm{x} \\
11 / 16 \\
\end{array}$ & $28 \times 11 / 8$ & 180 & $28 \times 27 / 8$ & 60 & $28 \times 27 / 8$ & 75 & $28 \times 7 / 8$ & 150 & 50 & 30.1 \\
\hline 300 & $\begin{array}{c}46 \mathrm{x} \\
15 / 16\end{array}$ & 180 & $\begin{array}{c}46 \mathrm{x} \\
15 / 16\end{array}$ & 60 & $\begin{array}{c}46 \mathrm{x} \\
15 / 16\end{array}$ & 75 & $\begin{array}{c}46 \mathrm{x} \\
15 / 16\end{array}$ & 150 & $\begin{array}{c}229 \times 1 \\
3 / 4\end{array}$ & $46 \times 3 / 4$ & 180 & $\begin{array}{c}46 \times 1 \\
7 / 16\end{array}$ & 60 & $46 \times 17 / 16$ & 75 & $46 \times 17 / 16$ & 150 & 70 & 15.0 \\
\hline 300 & $\begin{array}{c}34 x \\
7 / 8\end{array}$ & 180 & $\begin{array}{c}34 x \\
13 / 16\end{array}$ & 60 & $\begin{array}{c}34 x \\
13 / 16\end{array}$ & 75 & $\begin{array}{c}34 x \\
13 / 16\end{array}$ & 150 & $\begin{array}{c}169 \times 1 \\
5 / 16\end{array}$ & $34 \times 3 / 4$ & 180 & $\begin{array}{c}34 \times 1 \\
7 / 16\end{array}$ & 60 & $34 \times 17 / 16$ & 75 & $34 \times 17 / 16$ & 150 & 70 & 20.0 \\
\hline 300 & $\begin{array}{c}26 x \\
13 / 16 \\
\end{array}$ & 180 & $\begin{array}{c}26 x \\
7 / 8\end{array}$ & 60 & $\begin{array}{c}26 x \\
7 / 8 \\
\end{array}$ & 75 & $\begin{array}{c}26 x \\
7 / 8 \\
\end{array}$ & 150 & $\begin{array}{c}132 \times 1 \\
1 / 16 \\
\end{array}$ & $26 \times 3 / 4$ & 180 & $26 \times 13 / 8$ & 60 & $26 \times 13 / 8$ & 75 & $26 \times 13 / 8$ & 150 & 70 & 25.1 \\
\hline 300 & $\begin{array}{c}22 \mathrm{x} \\
13 / 16\end{array}$ & 180 & $\begin{array}{l}22 \mathrm{x} \\
13 / 4\end{array}$ & 60 & $\begin{array}{c}22 \times 1 \\
3 / 4\end{array}$ & 75 & $\begin{array}{c}22 \times 1 \\
3 / 4\end{array}$ & 150 & $\begin{array}{l}108 \times \\
13 / 16\end{array}$ & $25 \times 7 / 8$ & 180 & $25 \times 13 / 4$ & 60 & $25 \times 13 / 4$ & 75 & $25 \times 13 / 4$ & 150 & 70 & 30.1 \\
\hline
\end{tabular}


Table B5.2. Detailed girder elevation for cross section 2 ( $\mathrm{S}=11$ ' -6 ')

Simple Composite Plate Girder Using SIMON-LFD

\begin{tabular}{|c|c|c|c|c|c|c|c|c|c|c|c|}
\hline \multirow[b]{2}{*}{$\begin{array}{l}\text { Span Length, } \\
\text { ft. (L) }\end{array}$} & \multicolumn{2}{|c|}{$\begin{array}{c}\text { Top Flange } \\
\text { (A) }\end{array}$} & \multicolumn{2}{|c|}{$\begin{array}{c}\text { Top Flange } \\
\text { (B) }\end{array}$} & \multirow[b]{2}{*}{$\begin{array}{l}\text { Web Plate, in. } \\
\text { (F) }\end{array}$} & \multicolumn{2}{|c|}{$\begin{array}{c}\text { Bottom Flange } \\
\text { (A) }\end{array}$} & \multicolumn{2}{|c|}{$\begin{array}{c}\text { Bottom Flange } \\
\text { (B) }\end{array}$} & \multirow[b]{2}{*}{$\begin{array}{l}\text { Fy, } \\
\text { ksi }\end{array}$} & \multirow[b]{2}{*}{$\begin{array}{c}\text { L/D } \\
\text { (Actual) }\end{array}$} \\
\hline & Plate, in. & Length, ft. & $\begin{array}{c}\text { Plate, } \\
\text { in. }\end{array}$ & $\begin{array}{c}\text { Length, } \\
\text { ft. }\end{array}$ & & Plate, in. & Length, ft. & $\begin{array}{l}\text { Plate, } \\
\text { in. }\end{array}$ & $\begin{array}{c}\text { Length, } \\
\text { ft. }\end{array}$ & & \\
\hline 100 & $17 \times 3 / 4$ & 100 & & & $68 \times 7 / 16$ & $17 \times 1$ & 100 & & & 50 & 14.9 \\
\hline 100 & $12 \times 13 / 16$ & 100 & & & $45 \times 7 / 16$ & $12 \times 25 / 8$ & 100 & & & 50 & 20.3 \\
\hline 100 & $12 \times 17 / 16$ & 100 & & & $33 \times 1 / 2$ & $15 \times 215 / 16$ & 100 & & & 50 & 25.3 \\
\hline 100 & NAD & 100 & & & NAD & NAD & 100 & & & 50 & NAD \\
\hline 100 & $17 \times 3 / 4$ & 100 & & & $67 \times 9 / 16$ & $17 \times 7 / 8$ & 100 & & & 70 & 15.1 \\
\hline 100 & $12 \times 3 / 4$ & 100 & & & $47 \times 3 / 8$ & $12 \times 21 / 2$ & 100 & & & 70 & 19.7 \\
\hline 100 & $12 \times 11 / 8$ & 100 & & & $33 \times 7 / 16$ & $14 \times 3$ & 100 & & & 70 & 25.3 \\
\hline 100 & $12 \times 111 / 16$ & 100 & & & $25 \times 9 / 16$ & $18 \times 3$ & 100 & & & 70 & 30.4 \\
\hline 200 & $38 \times 13 / 16$ & 200 & & & $148 \times 15 / 16$ & $35 \times 3 / 4$ & 200 & & & 50 & 15.0 \\
\hline 200 & $27 \times 13 / 16$ & 200 & & & $108 \times 11 / 16$ & $27 \times 15 / 16$ & 200 & & & 50 & 19.9 \\
\hline 200 & $22 \times 15 / 8$ & 200 & & & $82 \times 9 / 16$ & $22 \times 211 / 16$ & 200 & & & 50 & 25.0 \\
\hline 200 & $27 \times 27 / 8$ & 200 & & & $65 \times 5 / 8$ & $28 \times 3$ & 200 & & & 50 & 29.9 \\
\hline 200 & $39 \times 13 / 16$ & 200 & & & $148 \times 11 / 8$ & $37 \times 3 / 4$ & 200 & & & 70 & 15.0 \\
\hline 200 & $27 \times 11 / 8$ & 200 & & & $108 \times 13 / 16$ & $29 \times 7 / 8$ & 200 & & & 70 & 19.9 \\
\hline 200 & $21 \times 11 / 4$ & 200 & & & $82 \times 5 / 8$ & $22 \times 25 / 16$ & 200 & & & 70 & 25.0 \\
\hline 200 & $18 \times 23 / 8$ & 200 & & & $65 \times 1 / 2$ & $25 \times 23 / 4$ & 200 & & & 70 & 30.0 \\
\hline 300 & $57 \times 13 / 4$ & 300 & & & $228 \times 113 / 16$ & $57 \times 3 / 4$ & 300 & & & 50 & 15.0 \\
\hline 300 & $42 \times 15 / 8$ & 300 & & & $168 \times 11 / 8$ & $42 \times 15 / 16$ & 300 & & & 50 & 20.0 \\
\hline 300 & $33 \times 23 / 4$ & 300 & & & $130 \times 7 / 8$ & $33 \times 21 / 2$ & 300 & & & 50 & 24.9 \\
\hline 300 & $38 \times 3$ & 300 & & & $105 \times 11 / 16$ & $42 \times 3$ & 300 & & & 50 & 29.9 \\
\hline 300 & $59 \times 13 / 4$ & 300 & & & $227 \times 111 / 16$ & $57 \times 3 / 4$ & 300 & & & 70 & 15.0 \\
\hline 300 & $42 \times 15 / 8$ & 300 & & & $168 \times 11 / 4$ & $42 \times 3 / 4$ & 300 & & & 70 & 20.0 \\
\hline 300 & $33 \times 19 / 16$ & 300 & & & $131 \times 1$ & $33 \times 115 / 16$ & 300 & & & 70 & 24.9 \\
\hline 300 & $27 \times 23 / 8$ & 300 & & & $107 \times 13 / 16$ & $33 \times 213 / 16$ & 300 & & & 70 & 29.6 \\
\hline
\end{tabular}


Table B5.2. Continued

Two-Span Continuous Composite Plate Girder Using SIMON-LFD

\begin{tabular}{|c|c|c|c|c|c|c|c|c|c|c|c|}
\hline \multirow{2}{*}{$\begin{array}{c}\text { Span } \\
\text { Length, ft. } \\
\text { (L) }\end{array}$} & \multicolumn{2}{|c|}{$\begin{array}{c}\text { Top Flange } \\
\text { (A) }\end{array}$} & \multicolumn{2}{|c|}{$\begin{array}{l}\text { Top Flange } \\
\text { (B) }\end{array}$} & \multirow{2}{*}{$\begin{array}{l}\text { Web Plate, } \\
\text { in. } \\
\text { (F) }\end{array}$} & \multicolumn{2}{|c|}{$\begin{array}{c}\text { Bottom Flange } \\
\text { (A) }\end{array}$} & \multicolumn{2}{|c|}{$\begin{array}{c}\text { Bottom Flange } \\
\text { (B) }\end{array}$} & \multirow[b]{2}{*}{$\begin{array}{l}\text { Fy, } \\
\text { ksi } \\
\end{array}$} & \multirow[b]{2}{*}{$\begin{array}{c}\text { L/D } \\
\text { (Actual) }\end{array}$} \\
\hline & Plate, in. & $\begin{array}{c}\text { Length, } \\
\text { ft. }\end{array}$ & Plate, in. & $\begin{array}{c}\text { Length, } \\
\text { ft. }\end{array}$ & & Plate, in. & $\begin{array}{c}\begin{array}{c}\text { Length, } \\
\text { ft. }\end{array} \\
\end{array}$ & Plate, in. & Length, ft. & & \\
\hline 100 & $17 \times 3 / 4$ & 75 & $17 \times 7 / 8$ & 25 & $68 \times 1 / 2$ & $17 \times 1$ & 75 & $17 \times 15 / 16$ & 25 & 50 & 14.9 \\
\hline 100 & $12 \times 3 / 4$ & 75 & $12 \times 23 / 4$ & 25 & $45 \times 5 / 8$ & $14 \times 21 / 8$ & 75 & $14 \times 27 / 8$ & 25 & 50 & 20.0 \\
\hline 100 & $18 \times 3 / 4$ & 75 & $18 \times 27 / 8$ & 25 & $33 \times 13 / 16$ & $20 \times 21 / 4$ & 75 & $20 \times 27 / 8$ & 25 & 50 & 24.9 \\
\hline 100 & NAD & NAD & NAD & NAD & NAD & NAD & NAD & NAD & NAD & 50 & NAD \\
\hline 100 & $17 \times 3 / 4$ & 75 & $17 \times 3 / 4$ & 25 & $67 \times 9 / 16$ & $18 \times 7 / 8$ & 75 & $18 \times 1$ & 25 & 70 & 15.1 \\
\hline 100 & $12 \times 3 / 4$ & 75 & $12 \times 17 / 16$ & 25 & $47 \times 3 / 8$ & $16 \times 2$ & 75 & $16 \times 15 / 8$ & 25 & 70 & 19.8 \\
\hline 100 & $12 \times 3 / 4$ & 75 & $12 \times 23 / 8$ & 25 & $35 \times 1 / 2$ & $16 \times 27 / 16$ & 75 & $16 \times 27 / 16$ & 25 & 70 & 24.3 \\
\hline 100 & $14 \times 3 / 4$ & 75 & $14 \times 3$ & 25 & $27 \times 11 / 16$ & $16 \times 3$ & 75 & $16 \times 3$ & 25 & 70 & 28.2 \\
\hline 200 & $35 \times 15 / 16$ & 150 & $35 \times 3 / 4$ & 50 & $148 \times 1$ & $35 \times 3 / 4$ & 150 & $35 \times 19 / 16$ & 50 & 50 & 14.9 \\
\hline 200 & $27 \times 7 / 8$ & 150 & $27 \times 21 / 8$ & 50 & $107 \times 3 / 4$ & $27 \times 15 / 16$ & 150 & $27 \times 23 / 8$ & 50 & 50 & 20.0 \\
\hline 200 & $30 \times 11 / 16$ & 150 & $30 \times 23 / 4$ & 50 & $84 \times 9 / 16$ & $32 \times 13 / 4$ & 150 & $32 \times 23 / 4$ & 50 & 50 & 24.2 \\
\hline 200 & $41 \times 13 / 8$ & 150 & $41 \times 215 / 16$ & 50 & $63 \times 3 / 4$ & $43 \times 17 / 16$ & 150 & $43 \times 3$ & 50 & 50 & 30.6 \\
\hline 200 & $38 \times 15 / 16$ & 150 & $38 \times 15 / 16$ & 50 & $147 \times 13 / 16$ & $38 \times 3 / 4$ & 150 & $38 \times 19 / 16$ & 50 & 70 & 15.0 \\
\hline 200 & $26 \times 7 / 8$ & 150 & $26 \times 11 / 4$ & 50 & $107 \times 7 / 8$ & $26 \times 13 / 16$ & 150 & $26 \times 11 / 2$ & 50 & 70 & 20.0 \\
\hline 200 & $22 \times 7 / 8$ & 150 & $22 \times 21 / 2$ & 50 & $82 \times 11 / 16$ & $22 \times 11 / 2$ & 150 & $22 \times 23 / 4$ & 50 & 70 & 24.8 \\
\hline 200 & $26 \times 11 / 16$ & 150 & $26 \times 23 / 4$ & 50 & $67 \times 5 / 8$ & $26 \times 13 / 4$ & 150 & $26 \times 3$ & 50 & 70 & 29.2 \\
\hline 300 & $57 \times 13 / 8$ & 225 & $57 \times 3 / 4$ & 75 & $228 \times 19 / 16$ & $57 \times 15 / 16$ & 225 & $57 \times 21 / 8$ & 75 & 50 & 14.9 \\
\hline 300 & $42 \times 15 / 16$ & 225 & $42 \times 13 / 4$ & 75 & $168 \times 11 / 8$ & $42 \times 11 / 16$ & 225 & $42 \times 21 / 16$ & 75 & 50 & 19.8 \\
\hline 300 & $45 \times 17 / 16$ & 225 & $45 \times 3$ & 75 & $129 \times 7 / 8$ & $47 \times 17 / 16$ & 225 & $47 \times 213 / 16$ & 75 & 50 & 25.0 \\
\hline 300 & $59 \times 17 / 8$ & 225 & $59 \times 3$ & 75 & $105 \times 3 / 4$ & $58 \times 111 / 16$ & 225 & $58 \times 3$ & 75 & 50 & 29.9 \\
\hline 300 & $57 \times 13 / 8$ & 225 & $57 \times 3 / 4$ & 75 & $227 \times 113 / 16$ & $57 \times 7 / 8$ & 225 & $57 \times 21 / 8$ & 75 & 70 & 15.0 \\
\hline 300 & $42 \times 11 / 4$ & 225 & $42 \times 7 / 8$ & 75 & $168 \times 13 / 8$ & $42 \times 15 / 16$ & 225 & $42 \times 21 / 8$ & 75 & 70 & 19.8 \\
\hline 300 & $33 \times 13 / 16$ & 225 & $33 \times 21 / 8$ & 75 & $131 \times 11 / 8$ & $33 \times 11 / 16$ & 225 & $33 \times 23 / 8$ & 75 & 70 & 24.8 \\
\hline 300 & $40 \times 11 / 2$ & 225 & $40 \times 21 / 2$ & 75 & $107 \times 7 / 8$ & $40 \times 17 / 16$ & 225 & $40 \times 25 / 8$ & 75 & 70 & 29.5 \\
\hline
\end{tabular}


Table B5.2. Continued

Three-Span Continuous Composite Plate Girder Using SIMON-LFD

\begin{tabular}{|c|c|c|c|c|c|c|c|c|c|c|c|c|c|c|c|c|c|c|c|}
\hline \multirow{2}{*}{$\begin{array}{l}\text { Span } \\
\text { Len. } \\
\text {, ft. } \\
\text { (L) }\end{array}$} & \multicolumn{2}{|c|}{$\begin{array}{l}\text { Top Flange } \\
\text { (A) }\end{array}$} & \multicolumn{2}{|c|}{$\begin{array}{l}\text { Top Flange } \\
\text { (B) }\end{array}$} & \multicolumn{2}{|c|}{$\begin{array}{l}\text { Top Flange } \\
\text { (C) }\end{array}$} & \multicolumn{2}{|c|}{$\begin{array}{l}\text { Top Flange } \\
\text { (D) }\end{array}$} & \multirow[b]{2}{*}{$\begin{array}{l}\text { Web Plate, } \\
\text { in. (F) }\end{array}$} & \multicolumn{2}{|c|}{$\begin{array}{l}\text { Bottom Flange } \\
\text { (A) }\end{array}$} & \multicolumn{2}{|c|}{$\begin{array}{l}\text { Bottom Flange } \\
\text { (B) }\end{array}$} & \multicolumn{2}{|c|}{$\begin{array}{l}\text { Bottom Flange } \\
\text { (C) }\end{array}$} & \multicolumn{2}{|c|}{$\begin{array}{l}\text { Bottom Flange } \\
\text { (D) }\end{array}$} & \multirow[b]{2}{*}{$\begin{array}{l}\begin{array}{l}\text { Fy, } \\
\text { ksi }\end{array} \\
\text { (n) }\end{array}$} & \multirow[b]{2}{*}{$\begin{array}{c}\mathrm{L} / \mathrm{D} \\
\text { (Actual) }\end{array}$} \\
\hline & $\begin{array}{c}\text { Plate, } \\
\text { in. }\end{array}$ & $\begin{array}{l}\text { Len., } \\
\text { ft. }\end{array}$ & Plate, in. & $\begin{array}{l}\text { Len., } \\
\text { ft. }\end{array}$ & Plate, in. & $\begin{array}{c}\text { Len., } \\
\text { ft. }\end{array}$ & Plate, in. & $\begin{array}{c}\text { Len., } \\
\text { ft. }\end{array}$ & & Plate, in. & $\begin{array}{l}\text { Len., } \\
\text { ft. }\end{array}$ & Plate, in. & $\begin{array}{c}\text { Len., } \\
\text { ft. }\end{array}$ & Plate, in. & $\begin{array}{l}\text { Len., } \\
\text { ft. }\end{array}$ & Plate, in. & $\begin{array}{l}\text { Len., } \\
\text { ft. }\end{array}$ & & \\
\hline 100 & $\begin{array}{l}15 \mathrm{x} \\
3 / 4 \\
\end{array}$ & 60 & $15 \times 3 / 4$ & 20 & $15 \times 3 / 4$ & 25 & $15 \times 3 / 4$ & 50 & $68 \times 1 / 2$ & $15 \times 3 / 4$ & 60 & $\begin{array}{l}15 \mathrm{x} \\
15 / 16 \\
\end{array}$ & 20 & $\begin{array}{l}15 \mathrm{x} \\
15 / 16 \\
\end{array}$ & 25 & $15 \times 3 / 4$ & 50 & 50 & 14.9 \\
\hline 100 & $\begin{array}{l}12 x \\
3 / 4\end{array}$ & 60 & $\begin{array}{c}12 \times 1 \\
7 / 16\end{array}$ & 20 & $\begin{array}{l}12 \times 1 \\
7 / 16\end{array}$ & 25 & $12 \times 3 / 4$ & 50 & $46 \times 5 / 8$ & $14 \times 11 / 2$ & 60 & $\begin{array}{c}14 \times 1 \\
5 / 8\end{array}$ & 20 & $\begin{array}{c}14 \times 1 \\
5 / 8\end{array}$ & 25 & $\begin{array}{c}14 \times 1 \\
5 / 8\end{array}$ & 50 & 50 & 20.1 \\
\hline 100 & $\begin{array}{l}17 x \\
3 / 4 \\
\end{array}$ & 60 & $\begin{array}{c}17 \times 1 \\
7 / 16 \\
\end{array}$ & 20 & $\begin{array}{c}17 \times 1 \\
7 / 16 \\
\end{array}$ & 25 & $17 \times 3 / 4$ & 50 & $35 \times 13 / 16$ & $\begin{array}{c}20 \times 1 \\
9 / 16 \\
\end{array}$ & 60 & $\begin{array}{l}20 \times 1 \\
13 / 16 \\
\end{array}$ & 20 & $\begin{array}{l}20 \times 1 \\
13 / 16 \\
\end{array}$ & 25 & $\begin{array}{c}20 \times 1 \\
7 / 16 \\
\end{array}$ & 50 & 50 & 24.8 \\
\hline 100 & $\begin{array}{l}16 \mathrm{x} \\
3 / 4 \\
\end{array}$ & 60 & $\begin{array}{l}16 \times 2 \\
15 / 16 \\
\end{array}$ & 20 & $\begin{array}{l}16 \times 2 \\
15 / 16 \\
\end{array}$ & 25 & $16 \times 3 / 4$ & 50 & $25 \times 7 / 8$ & $\begin{array}{l}18 \times 2 \\
11 / 16 \\
\end{array}$ & 60 & $18 \times 23 / 4$ & 20 & $18 \times 23 / 4$ & 25 & $\begin{array}{l}18 \times 2 \\
11 / 16 \\
\end{array}$ & 50 & 50 & 29.9 \\
\hline 100 & $\begin{array}{l}13 x \\
3 / 4 \\
\end{array}$ & 60 & $13 \times 3 / 4$ & 20 & $13 \times 3 / 4$ & 25 & $13 \times 3 / 4$ & 50 & $67 \times 5 / 8$ & $15 \times 3 / 4$ & 60 & $15 \times 3 / 4$ & 20 & $15 \times 3 / 4$ & 25 & $15 \times 3 / 4$ & 50 & 70 & 15.1 \\
\hline 100 & \begin{tabular}{|l}
$12 x$ \\
$3 / 4$ \\
\end{tabular} & 60 & $12 \times 3 / 4$ & 20 & $12 \times 3 / 4$ & 25 & $12 \times 3 / 4$ & 50 & $47 \times 7 / 16$ & $\begin{array}{l}14 \times 1 \\
11 / 16 \\
\end{array}$ & 60 & $14 \times 11 / 2$ & 20 & $14 \times 11 / 2$ & 25 & $14 \times 11 / 2$ & 50 & 70 & 20.0 \\
\hline 100 & $\begin{array}{l}12 x \\
3 / 4\end{array}$ & 60 & $\begin{array}{c}12 \times 1 \\
3 / 16\end{array}$ & 20 & $\begin{array}{l}12 \times 1 \\
3 / 16\end{array}$ & 25 & $\begin{array}{l}12 \times 1 \\
3 / 16\end{array}$ & 50 & $35 \times 7 / 16$ & $\begin{array}{l}14 \times 2 \\
5 / 16\end{array}$ & 60 & $14 \times 2$ & 20 & $14 \times 2$ & 25 & $14 \times 2$ & 50 & 70 & 24.6 \\
\hline 100 & $\begin{array}{l}12 x \\
3 / 4\end{array}$ & 60 & $\begin{array}{l}12 \times 1 \\
15 / 16\end{array}$ & 20 & $\begin{array}{l}12 \times 1 \\
15 / 16\end{array}$ & 25 & $\begin{array}{l}12 \times 1 \\
15 / 16\end{array}$ & 50 & $27 \times 9 / 16$ & $\begin{array}{l}14 \times 2 \\
13 / 16\end{array}$ & 60 & $\begin{array}{l}14 \times 2 \\
11 / 16\end{array}$ & 20 & $\begin{array}{l}14 \times 2 \\
11 / 16\end{array}$ & 25 & $\begin{array}{l}14 \times 2 \\
11 / 16\end{array}$ & 50 & 70 & 29.0 \\
\hline 200 & $\begin{array}{l}35 \mathrm{x} \\
3 / 4 \\
\end{array}$ & 120 & $35 \times 3 / 4$ & 40 & $35 \times 3 / 4$ & 50 & $35 \times 3 / 4$ & 100 & $148 \times 1$ & $36 \times 3 / 4$ & 120 & $\begin{array}{l}36 \times 1 \\
5 / 16 \\
\end{array}$ & 40 & $\begin{array}{l}36 \times 1 \\
5 / 16 \\
\end{array}$ & 50 & $36 \times 3 / 4$ & 100 & 50 & 14.9 \\
\hline 200 & $\begin{array}{l}26 x \\
3 / 4\end{array}$ & 120 & $\begin{array}{c}26 \times 1 \\
1 / 16\end{array}$ & 40 & $\begin{array}{c}26 \times 1 \\
1 / 16\end{array}$ & 50 & $26 \times 3 / 4$ & 100 & $107 \times 3 / 4$ & $27 \times 3 / 4$ & 120 & $27 \times 13 / 8$ & 40 & $27 \times 13 / 8$ & 50 & $27 \times 3 / 4$ & 100 & 50 & 20.0 \\
\hline 200 & $\begin{array}{c}29 x \\
7 / 8\end{array}$ & 120 & $\begin{array}{l}29 \times 1 \\
11 / 16\end{array}$ & 40 & $\begin{array}{l}29 \times 1 \\
11 / 16\end{array}$ & 50 & $\begin{array}{l}29 x \\
13 / 16\end{array}$ & 100 & $84 \times 5 / 8$ & $\begin{array}{l}29 x \\
15 / 16\end{array}$ & 120 & $\begin{array}{l}29 \times 1 \\
15 / 16\end{array}$ & 40 & $\begin{array}{l}29 \times 1 \\
15 / 16\end{array}$ & 50 & $29 \times 3 / 4$ & 100 & 50 & 24.6 \\
\hline 200 & $30 \times 1$ & 120 & $\begin{array}{c}30 \times 2 \\
7 / 16\end{array}$ & 40 & $\begin{array}{c}30 \times 2 \\
7 / 16\end{array}$ & 50 & $30 \times 7 / 8$ & 100 & $64 \times 3 / 4$ & $30 \times 11 / 8$ & 120 & $\begin{array}{l}30 \times 2 \\
11 / 16\end{array}$ & 40 & $\begin{array}{l}30 \times 2 \\
11 / 16\end{array}$ & 50 & $30 \times 1$ & 100 & 50 & 30.5 \\
\hline 200 & $\begin{array}{l}29 x \\
3 / 4\end{array}$ & 120 & $29 \times 3 / 4$ & 40 & $29 \times 3 / 4$ & 50 & $29 \times 3 / 4$ & 100 & $147 \times 11 / 8$ & $29 \times 3 / 4$ & 120 & $29 \times 11 / 8$ & 40 & $29 \times 11 / 8$ & 50 & $29 \times 3 / 4$ & 100 & 70 & 15.0 \\
\hline 200 & $\begin{array}{l}21 \mathrm{x} \\
3 / 4 \\
\end{array}$ & 120 & $21 \times 3 / 4$ & 40 & $21 \times 3 / 4$ & 50 & $21 \times 3 / 4$ & 100 & $107 \times 7 / 8$ & $21 \times 3 / 4$ & 120 & $21 \times 11 / 8$ & 40 & $21 \times 11 / 8$ & 50 & $\begin{array}{l}21 x \\
13 / 16 \\
\end{array}$ & 100 & 70 & 20.1 \\
\hline 200 & $\begin{array}{l}16 \mathrm{x} \\
3 / 4\end{array}$ & 120 & $\begin{array}{c}16 \times 1 \\
5 / 8\end{array}$ & 40 & $16 \times 15 / 8$ & 50 & $16 \times 13 / 4$ & 100 & $83 \times 11 / 16$ & $19 \times 11 / 2$ & 120 & $\begin{array}{l}19 \times 1 \\
13 / 16\end{array}$ & 40 & $\begin{array}{l}19 \times 1 \\
13 / 16\end{array}$ & 50 & $19 \times 11 / 2$ & 100 & 70 & 24.9 \\
\hline 200 & $\begin{array}{l}14 \mathrm{x} \\
3 / 4 \\
\end{array}$ & 120 & $\begin{array}{l}14 \times 2 \\
7 / 8\end{array}$ & 40 & $14 \times 27 / 8$ & 50 & $14 \times 3 / 4$ & 100 & $67 \times 9 / 16$ & $18 \times 2$ & 120 & $18 \times 25 / 8$ & 40 & $18 \times 25 / 8$ & 50 & $\begin{array}{c}18 \times 1 \\
15 / 16 \\
\end{array}$ & 100 & 70 & 29.3 \\
\hline 300 & $\begin{array}{c}57 \times 1 \\
1 / 8 \\
\end{array}$ & 180 & $57 \times 3 / 4$ & 60 & $57 \times 3 / 4$ & 75 & $57 \times 11 / 8$ & 150 & $228 \times 11 / 2$ & $57 \times 7 / 8$ & 180 & $\begin{array}{c}57 \times 1 \\
7 / 8 \\
\end{array}$ & 60 & $\begin{array}{c}57 \times 1 \\
7 / 8 \\
\end{array}$ & 75 & $57 \times 3 / 4$ & 150 & 50 & 14.9 \\
\hline 300 & $\begin{array}{c}42 \times 1 \\
1 / 8 \\
\end{array}$ & 180 & $42 \times 3 / 4$ & 60 & $42 \times 3 / 4$ & 75 & $\begin{array}{c}42 \times 1 \\
1 / 16 \\
\end{array}$ & 150 & $168 \times 11 / 8$ & $\begin{array}{l}42 x \\
15 / 16 \\
\end{array}$ & 180 & $\begin{array}{l}42 \times 1 \\
13 / 16 \\
\end{array}$ & 60 & $\begin{array}{l}42 \times 1 \\
13 / 16 \\
\end{array}$ & 75 & $42 \times 3 / 4$ & 150 & 50 & 19.9 \\
\hline 300 & $\begin{array}{c}45 \times 1 \\
1 / 4 \\
\end{array}$ & 180 & $\begin{array}{c}45 \times 1 \\
1 / 2 \\
\end{array}$ & 60 & $45 \times 11 / 2$ & 75 & $\begin{array}{c}45 \times 1 \\
3 / 16 \\
\end{array}$ & 150 & $129 \times 7 / 8$ & $45 \times 11 / 4$ & 180 & $45 \times 21 / 8$ & 60 & $45 \times 21 / 8$ & 75 & $45 \times 7 / 8$ & 150 & 50 & 25.2 \\
\hline 300 & $\begin{array}{l}57 \times 1 \\
9 / 16\end{array}$ & 180 & $\begin{array}{l}57 \times 1 \\
11 / 16\end{array}$ & 60 & $\begin{array}{l}57 \times 1 \\
11 / 16\end{array}$ & 75 & $\begin{array}{l}57 \times 1 \\
9 / 16\end{array}$ & 150 & $105 \times 3 / 4$ & $57 \times 11 / 2$ & 180 & $57 \times 25 / 8$ & 60 & $57 \times 25 / 8$ & 75 & $57 \times 11 / 8$ & 150 & 50 & 30.1 \\
\hline 300 & $46 \times 1$ & 180 & $\begin{array}{l}46 \mathrm{x} \\
15 / 16 \\
\end{array}$ & 60 & $\begin{array}{l}46 \mathrm{x} \\
15 / 16 \\
\end{array}$ & 75 & $\begin{array}{l}46 \mathrm{x} \\
15 / 16 \\
\end{array}$ & 150 & $227 \times 13 / 4$ & $46 \times 3 / 4$ & 180 & $46 \times 13 / 4$ & 60 & $46 \times 13 / 4$ & 75 & $46 \times 13 / 4$ & 150 & 70 & 15.0 \\
\hline 300 & $\begin{array}{l}33 x \\
15 / 16 \\
\end{array}$ & 180 & $33 \times 7 / 8$ & 60 & $33 \times 7 / 8$ & 75 & $33 \times 7 / 8$ & 150 & $168 \times 15 / 16$ & $33 \times 3 / 4$ & 180 & $\begin{array}{c}33 \times 1 \\
9 / 16\end{array}$ & 60 & $\begin{array}{c}33 \times 1 \\
9 / 16\end{array}$ & 75 & $\begin{array}{l}33 \times 1 \\
9 / 16\end{array}$ & 150 & 70 & 19.9 \\
\hline 300 & $\begin{array}{c}26 x \\
7 / 8\end{array}$ & 180 & $\begin{array}{c}26 \times 1 \\
1 / 2\end{array}$ & 60 & $26 \times 11 / 2$ & 75 & $26 \times 11 / 2$ & 150 & $131 \times 11 / 16$ & $\begin{array}{l}26 x \\
13 / 16\end{array}$ & 180 & $26 \times 11 / 2$ & 60 & $26 \times 11 / 2$ & 75 & $26 \times 11 / 2$ & 150 & 70 & 25.0 \\
\hline 300 & $24 \times 1$ & 180 & $24 \times 2$ & 60 & $24 \times$ & 77 & $24 \times 23 / 8$ & 150 & $107 \times 7 / 8$ & 24,1 & 180 & $24 \times 2518$ & 6 & 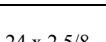 & 75 & $24 \times 25 / 8$ & 150 & 70 & 2 \\
\hline
\end{tabular}


Table B5.3. Detailed girder elevation for cross section 3 ( $\mathrm{S}=10$ '-4”)

Simple Composite Plate Girder Using SIMON-LFD

\begin{tabular}{|c|c|c|c|c|c|c|c|c|c|c|c|}
\hline \multirow[b]{2}{*}{$\begin{array}{l}\text { Span Length, ft. } \\
\text { (L) }\end{array}$} & \multicolumn{2}{|c|}{$\begin{array}{l}\text { Top Flange } \\
\text { (A) }\end{array}$} & \multicolumn{2}{|c|}{$\begin{array}{l}\text { Top Flange } \\
\text { (B) }\end{array}$} & \multirow[b]{2}{*}{$\begin{array}{l}\text { Web Plate, in. } \\
\text { (F) }\end{array}$} & \multicolumn{2}{|c|}{$\begin{array}{c}\text { Bottom Flange } \\
\text { (A) }\end{array}$} & \multicolumn{2}{|c|}{$\begin{array}{l}\text { Bottom Flange } \\
\text { (B) }\end{array}$} & \multirow[b]{2}{*}{$\begin{array}{l}\text { Fy, } \\
\text { ksi }\end{array}$} & \multirow[b]{2}{*}{$\begin{array}{c}\text { L/D } \\
\text { (Actual) }\end{array}$} \\
\hline & Plate, in. & $\begin{array}{c}\text { Length, } \\
\text { ft. }\end{array}$ & Plate, in. & Length, ft. & & Plate, in. & Length, ft. & Plate, in. & $\begin{array}{c}\text { Length, } \\
\text { ft. }\end{array}$ & & \\
\hline 100 & $16 \times 3 / 4$ & 100 & & & $68 \times 1 / 2$ & $16 \times 7 / 8$ & 100 & & & 50 & 15.2 \\
\hline 100 & $12 \times 3 / 4$ & 100 & & & $48 \times 7 / 16$ & $12 \times 23 / 16$ & 100 & & & 50 & 19.9 \\
\hline 100 & $12 \times 11 / 8$ & 100 & & & $35 \times 7 / 16$ & $16 \times 23 / 8$ & 100 & & & 50 & 25.3 \\
\hline 100 & $12 \times 113 / 16$ & 100 & & & $27 \times 7 / 16$ & $18 \times 3$ & 100 & & & 50 & 30.0 \\
\hline 100 & $16 \times 3 / 4$ & 100 & & & $68 \times 1 / 2$ & $16 \times 7 / 8$ & 100 & & & 70 & 15.2 \\
\hline 100 & $12 \times 3 / 4$ & 100 & & & $48 \times 7 / 16$ & $12 \times 23 / 16$ & 100 & & & 70 & 19.9 \\
\hline 100 & $12 \times 13 / 16$ & 100 & & & $35 \times 7 / 16$ & $14 \times 23 / 4$ & 100 & & & 70 & 24.6 \\
\hline 100 & $12 \times 15 / 16$ & 100 & & & $27 \times 7 / 16$ & $16 \times 215 / 16$ & 100 & & & 70 & 30.0 \\
\hline 150 & $12 \times 7 / 8$ & 150 & & & $109 \times 11 / 16$ & $26 \times 3 / 4$ & 150 & & & 50 & 15.0 \\
\hline 150 & $18 \times 15 / 16$ & 150 & & & $79 \times 1 / 2$ & $18 \times 7 / 8$ & 30 & $18 \times 19 / 16$ & 90 & 50 & 19.9 \\
\hline 150 & $16 \times 13 / 16$ & 30 & $16 \times 13 / 8$ & 90 & $60 \times 9 / 16$ & $16 \times 19 / 16$ & 30 & $16 \times 25 / 8$ & 90 & 50 & 24.8 \\
\hline 150 & $18 \times 1$ & 30 & $18 \times 2$ & 90 & $48 \times 1 / 2$ & $20 \times 2$ & 30 & $20 \times 3$ & 90 & 50 & 29.5 \\
\hline 150 & $26 \times 13 / 16$ & 150 & & & $109 \times 13 / 16$ & $26 \times 3 / 4$ & 150 & & & 70 & 15.0 \\
\hline 150 & $16 \times 3 / 4$ & 150 & & & $79 \times 5 / 8$ & $16 \times 3 / 4$ & 30 & $16 \times 11 / 4$ & 90 & 70 & 19.9 \\
\hline 150 & $14 \times 3 / 4$ & 30 & $14 \times 11 / 2$ & 90 & $60 \times 9 / 16$ & $14 \times 11 / 2$ & 30 & $14 \times 25 / 16$ & 90 & 70 & 24.9 \\
\hline 150 & $14 \times 1$ & 30 & $14 \times 13 / 4$ & 90 & $48 \times 1 / 2$ & $18 \times 11 / 2$ & 30 & $18 \times 21 / 2$ & 90 & 70 & 29.8 \\
\hline 200 & $38 \times 11 / 8$ & 200 & & & $149 \times 15 / 16$ & $38 \times 3 / 4$ & 200 & & & 50 & 15.0 \\
\hline 200 & $28 \times 11 / 16$ & 200 & & & $109 \times 11 / 16$ & $28 \times 3 / 4$ & 40 & $28 \times 11 / 16$ & 120 & 50 & 20.0 \\
\hline 200 & $22 \times 15 / 16$ & 40 & $22 \times 15 / 8$ & 120 & $86 \times 9 / 16$ & $22 \times 11 / 4$ & 40 & $22 \times 21 / 2$ & 120 & 50 & 25.1 \\
\hline 200 & $21 \times 13 / 8$ & 40 & $21 \times 2 \times 3 / 8$ & 120 & $67 \times 1 / 2$ & $28 \times 19 / 16$ & 40 & $28 \times 27 / 8$ & 120 & 50 & 29.9 \\
\hline 200 & $36 \times 11 / 16$ & 200 & & & $149 \times 11 / 8$ & $36 \times 3 / 4$ & 200 & & & 70 & 15.0 \\
\hline 200 & $26 \times 11 / 16$ & 200 & & & $109 \times 13 / 16$ & $26 \times 3 / 4$ & 200 & & & 70 & 20.0 \\
\hline 200 & $20 \times 11 / 16$ & 200 & & & $63 \times 5 / 8$ & $20 \times 1$ & 40 & $20 \times 21 / 8$ & 120 & 70 & 25.0 \\
\hline 200 & $14 \times 11 / 16$ & 40 & $14 \times 113 / 16$ & 120 & $67 \times 1 / 2$ & $20 \times 111 / 16$ & 40 & $20 \times 27 / 8$ & 120 & 70 & 30.8 \\
\hline
\end{tabular}


Table B5.3. Continued

Simple Composite Plate Girder Using SIMON-LFD

\begin{tabular}{|c|c|c|c|c|c|c|c|c|c|c|c|}
\hline \multirow[b]{2}{*}{$\begin{array}{l}\text { Span Length, ft. } \\
\text { (L) }\end{array}$} & \multicolumn{2}{|c|}{$\begin{array}{l}\text { Top Flange } \\
\text { (A) }\end{array}$} & \multicolumn{2}{|c|}{$\begin{array}{l}\text { Top Flange } \\
\text { (B) }\end{array}$} & \multirow[b]{2}{*}{$\begin{array}{c}\text { Web Plate, in. } \\
(\text { F) }\end{array}$} & \multicolumn{2}{|c|}{$\begin{array}{c}\text { Bottom Flange } \\
\text { (A) }\end{array}$} & \multicolumn{2}{|c|}{$\begin{array}{l}\text { Bottom Flange } \\
\text { (B) }\end{array}$} & \multirow[b]{2}{*}{$\begin{array}{l}\text { Fy, } \\
\text { ksi }\end{array}$} & \multirow[b]{2}{*}{$\begin{array}{c}\text { L/D } \\
\text { (Actual) }\end{array}$} \\
\hline & Plate, in. & Length, ft. & Plate, in. & $\begin{array}{c}\text { Length, } \\
\text { ft. }\end{array}$ & & Plate, in. & $\begin{array}{c}\begin{array}{c}\text { Length, } \\
\text { ft. }\end{array} \\
\end{array}$ & Plate, in. & Length, ft. & & \\
\hline 250 & $42 \times 11 / 4$ & 250 & & & $189 \times 13 / 4$ & $42 \times 3 / 4$ & 250 & & & 50 & 15.0 \\
\hline 250 & $32 \times 15 / 16$ & 250 & & & $138 \times 1$ & $32 \times 1$ & 250 & & & 50 & 20.1 \\
\hline 250 & $28 \times 11 / 8$ & 50 & $28 \times 21 / 8$ & 150 & $109 \times 11 / 16$ & $28 \times 11 / 16$ & 50 & $28 \times 11 / 8$ & 150 & 50 & 24.9 \\
\hline 250 & $28 \times 13 / 8$ & 50 & $28 \times 27 / 8$ & 150 & $86 \times 7 / 8$ & $40 \times 113 / 16$ & 50 & $40 \times 3$ & 150 & 50 & 30.0 \\
\hline 250 & $42 \times 11 / 4$ & 250 & & & $189 \times 13 / 8$ & $42 \times 3 / 4$ & 250 & & & 70 & 15.0 \\
\hline 250 & $30 \times 1$ & 50 & $30 \times 13 / 16$ & 150 & $139 \times 11 / 16$ & $30 \times 3 / 4$ & 250 & & & 70 & 20.0 \\
\hline 250 & $28 \times 1 / 4$ & 250 & & & $109 \times 13 / 16$ & $28 \times 13 / 16$ & 50 & $28 \times 15 / 8$ & 150 & 70 & 24.9 \\
\hline 250 & $22 \times 11 / 8$ & 50 & $22 \times 2$ & 150 & $87 \times 3 / 4$ & $24 \times 15 / 8$ & 50 & $24 \times 27 / 8$ & 150 & 70 & 30.0 \\
\hline
\end{tabular}

Two-Span Continuous Composite Plate Girder Using SIMON-LFD

\begin{tabular}{|c|c|c|c|c|c|c|c|c|c|c|c|c|c|}
\hline \multirow[b]{2}{*}{$\begin{array}{l}\text { Span Length, ft. } \\
\text { (L) }\end{array}$} & \multicolumn{2}{|c|}{$\begin{array}{c}\text { Top Flange } \\
\text { (A) }\end{array}$} & \multicolumn{2}{|c|}{$\begin{array}{c}\text { Top Flange } \\
\text { (B) }\end{array}$} & \multirow{2}{*}{$\begin{array}{c}\text { Web Plate, } \\
\text { in. } \\
\text { (F) }\end{array}$} & \multicolumn{2}{|c|}{$\begin{array}{c}\text { Bottom Flange } \\
\text { (A) }\end{array}$} & \multicolumn{2}{|c|}{$\begin{array}{l}\text { Bottom Flange } \\
\text { (B) }\end{array}$} & \multicolumn{2}{|c|}{ (D) } & \multirow[b]{2}{*}{$\begin{array}{l}\text { Fy, } \\
\text { ksi }\end{array}$} & \multirow[b]{2}{*}{$\begin{array}{c}\text { L/D } \\
\text { (Actual }\end{array}$} \\
\hline & Plate, in. & Length, ft. & Plate, in. & $\begin{array}{c}\text { Length, } \\
\text { ft. }\end{array}$ & & Plate, in. & $\begin{array}{c}\text { Length, } \\
\text { ft. }\end{array}$ & $\begin{array}{c}\text { Plate, } \\
\text { in. }\end{array}$ & $\begin{array}{c}\text { Length, } \\
\text { ft. }\end{array}$ & $\begin{array}{l}\text { Plate, } \\
\text { in. }\end{array}$ & $\begin{array}{c}\text { Length } \\
\text {,ft. }\end{array}$ & & \\
\hline 100 & \multicolumn{4}{|c|}{ No acceptable design could be found } & & & & & & & & 50 & \\
\hline 100 & & & & & & & & & & & & 50 & \\
\hline 100 & & & & & & & & & & & & 50 & \\
\hline 100 & & & & & & & & & & & & 50 & \\
\hline 100 & \multicolumn{4}{|c|}{ No acceptable design could be found } & & & & & & & & 70 & \\
\hline 100 & & & & & & & & & & & & 70 & \\
\hline 100 & & & & & & & & & & & & 70 & \\
\hline 100 & & & & & & & & & & & & 70 & \\
\hline
\end{tabular}


Table B5.3. Continued

Two-Span Continuous Composite Plate Girder Using SIMON-LFD

\begin{tabular}{|c|c|c|c|c|c|c|c|c|c|c|c|c|c|c|c|}
\hline \multirow{2}{*}{$\begin{array}{l}\text { Span } \\
\text { Leng., ft. } \\
\text { (L) }\end{array}$} & \multicolumn{2}{|c|}{$\begin{array}{c}\text { Top Flange } \\
\text { (A) }\end{array}$} & \multicolumn{2}{|c|}{$\begin{array}{c}\text { Top Flange } \\
\text { (B) }\end{array}$} & \multicolumn{2}{|c|}{$\begin{array}{c}\text { Top Flange } \\
\text { (D) }\end{array}$} & \multirow[t]{2}{*}{$\begin{array}{l}\text { Web late, in. } \\
\qquad(F)\end{array}$} & \multicolumn{2}{|c|}{ (A) } & \multicolumn{2}{|c|}{$\begin{array}{c}\text { Bottom Flange } \\
\text { (B) }\end{array}$} & \multicolumn{2}{|c|}{ Bottom Flange (D) } & \multirow[b]{2}{*}{$\begin{array}{l}\text { Fy, } \\
\text { ksi }\end{array}$} & \multirow[b]{2}{*}{$\underset{\text { (Actual) }}{\mathbf{L} / \mathbf{D}}$} \\
\hline & Plate, in. & $\begin{array}{c}\text { Leng., } \\
\text { ft. }\end{array}$ & Plate, in. & $\begin{array}{c}\text { Leng., } \\
\text { ft. }\end{array}$ & Plate, in. & $\begin{array}{c}\text { Leng., } \\
\text { ft. }\end{array}$ & & Plate, in. & $\begin{array}{c}\text { Leng., } \\
\text { ft. }\end{array}$ & Plate, in. & $\begin{array}{c}\text { Leng., } \\
\text { ft. }\end{array}$ & Plate, in. & $\begin{array}{l}\text { Leng., } \\
\text { in. }\end{array}$ & & \\
\hline 150 & $20 \times 3 / 4$ & 135 & $20 \times 19 / 16$ & 15 & & & $84 \times 5 / 8$ & $20 \times 13 / 16$ & 120 & $20 \times 1$ & 15 & $\begin{array}{l}20 \times 1 \\
15 / 16 \\
\end{array}$ & 15 & 50 & 15.0 \\
\hline 150 & $20 \times 3 / 4$ & 120 & $20 \times 13 / 8$ & 15 & $20 \times 27 / 8$ & 15 & $58 \times 9 / 16$ & $22 \times 11 / 2$ & 120 & $22 \times 17 / 16$ & 15 & $22 \times 25 / 8$ & 15 & 50 & 20.1 \\
\hline 150 & $28 \times 1$ & 120 & $28 \times 19 / 16$ & 15 & $28 \times 27 / 8$ & 15 & $44 \times 9 / 16$ & $30 \times 19 / 16$ & 120 & $30 \times 11 / 2$ & 15 & $30 \times 27 / 8$ & 15 & 50 & 24.9 \\
\hline 150 & $34 \times 11 / 4$ & 120 & $34 \times 15 / 8$ & 15 & $34 \times 3$ & 15 & $34 \times 7 / 8$ & $\begin{array}{l}36 \times 1 \\
13 / 16 \\
\end{array}$ & 120 & $36 \times 17 / 8$ & 15 & $36 \times 3$ & 15 & 50 & 30.0 \\
\hline 150 & $20 \times 3 / 4$ & 120 & $20 \times 7 / 8$ & 30 & & & $84 \times 11 / 16$ & $20 \times 3 / 4$ & 120 & $20 \times 11 / 8$ & 30 & & & 70 & 15.1 \\
\hline 150 & $16 \times 3 / 4$ & 135 & $16 \times 113 / 16$ & 15 & & & $60 \times 9 / 16$ & $\begin{array}{l}18 \times 1 \\
13 / 16 \\
\end{array}$ & 120 & $18 \times 11 / 16$ & 15 & $18 \times 2$ & 15 & 70 & 20.0 \\
\hline 150 & $16 \times 3 / 4$ & 120 & $16 \times 11 / 2$ & 15 & $16 \times 3$ & 15 & $44 \times 1 / 2$ & $18 \times 25 / 8$ & 120 & $18 \times 111 / 16$ & 15 & $18 \times 3$ & 15 & 70 & 24.8 \\
\hline 150 & $22 \times 1$ & 120 & $22 \times 19 / 16$ & 15 & $22 \times 3$ & 15 & $34 \times 9 / 16$ & $24 \times 25 / 8$ & 120 & $24 \times 13 / 4$ & 15 & $24 \times 3$ & 15 & 70 & 30.0 \\
\hline 200 & $28 \times 13 / 16$ & 160 & $28 \times 3 / 4$ & 25 & $28 \times 11 / 4$ & 15 & $117 \times 13 / 16$ & $28 \times 7 / 8$ & 160 & $28 \times 17 / 16$ & 40 & & & 50 & 14.9 \\
\hline 200 & $24 \times 7 / 8$ & 160 & $24 \times 113 / 16$ & 25 & $\begin{array}{l}24 \times 2 \\
13 / 16 \\
\end{array}$ & 15 & $82 \times 11 / 16$ & $26 \times 11 / 4$ & 160 & $26 \times 17 / 8$ & 25 & $\begin{array}{l}26 \times 2 \\
13 / 16\end{array}$ & 15 & 50 & 20.1 \\
\hline 200 & $34 \times 13 / 16$ & 160 & $34 \times 2$ & 25 & $34 \times 3$ & 15 & $63 \times 11 / 16$ & $34 \times 3 / 8$ & 160 & $34 \times 2$ & 25 & $34 \times 3$ & 15 & 50 & 24.9 \\
\hline 200 & $44 \times 17 / 16$ & 160 & $44 \times 17 / 8$ & 25 & $44 \times 3$ & 15 & $51 \times 11 / 16$ & $\begin{array}{l}46 \times 1 \\
11 / 16 \\
\end{array}$ & 160 & $46 \times 21 / 4$ & 25 & $16 \times 3$ & 15 & 50 & 29.5 \\
\hline 200 & $28 \times 13 / 16$ & 160 & $28 \times 3 / 4$ & 40 & & & $116 \times 15 / 16$ & $28 \times 7 / 8$ & 160 & $28 \times 17 / 16$ & 40 & & & 70 & 15.1 \\
\hline 200 & $24 \times 7 / 8$ & 160 & $24 \times 13 / 16$ & 25 & $24 \times 15 / 8$ & 15 & $84 \times 11 / 16$ & $26 \times 11 / 16$ & 160 & $26 \times 3 / 4$ & 40 & & & 70 & 20.1 \\
\hline 200 & $22 \times 15 / 16$ & 160 & $22 \times 17 / 8$ & 25 & $22 \times 27 / 8$ & 15 & $63 \times 5 / 8$ & $24 \times 13 / 4$ & 160 & $24 \times 2$ & 25 & $24 \times 27 / 8$ & 15 & 70 & 25.0 \\
\hline 200 & $30 \times 13 / 16$ & 160 & $30 \times 17 / 8$ & 25 & $30 \times 23 / 4$ & 15 & $51 \times 5 / 8$ & $30 \times 17 / 8$ & 160 & $30 \times 21 / 8$ & 25 & $30 \times 27 / 8$ & 15 & 70 & 29.7 \\
\hline 250 & $36 \times 1$ & 200 & $36 \times 3 / 4$ & 35 & $36 \times 11 / 16$ & 15 & $148 \times 1$ & $36 \times 1$ & 200 & $36 \times 11 / 2$ & 35 & $\begin{array}{l}36 \times 1 \\
11 / 16 \\
\end{array}$ & 15 & 50 & 15.0 \\
\hline 250 & $28 \times 1$ & 200 & $28 \times 21 / 8$ & 35 & $28 \times 3$ & 15 & $106 \times 13 / 16$ & $30 \times 11 / 4$ & 200 & $30 \times 21 / 4$ & 35 & $30 \times 3$ & 15 & 50 & 20.0 \\
\hline 250 & $40 \times 13 / 8$ & 200 & $40 \times 21 / 4$ & 35 & $\begin{array}{l}40 \times 2 \\
15 / 16\end{array}$ & 15 & $82 \times 3 / 4$ & $\begin{array}{l}40 \times 1 \\
11 / 16\end{array}$ & 200 & $40 \times 11 / 4$ & 35 & $40 \times 3$ & 15 & 50 & 25.0 \\
\hline 250 & $\begin{array}{l}52 \times 1 \\
11 / 16\end{array}$ & 200 & $52 \times 21 / 4$ & 35 & $52 \times 3$ & 15 & $66 \times 13 / 16$ & $54 \times 17 / 8$ & 200 & $54 \times 27 / 8$ & 35 & $54 \times 3$ & 15 & 50 & 30.0 \\
\hline 250 & $34 \times 1$ & 200 & $34 \times 3 / 4$ & 50 & & & $148 \times 11 / 8$ & $34 \times 15 / 16$ & 200 & $34 \times 15 / 8$ & 50 & & & 70 & 15.0 \\
\hline 250 & $26 \times 1$ & 200 & $26 \times 11 / 16$ & 35 & $26 \times 13 / 4$ & 15 & $108 \times 7 / 8$ & $26 \times 11 / 16$ & 200 & $26 \times 1 / 2$ & 35 & $26 \times 2$ & 15 & 70 & 20.0 \\
\hline 250 & $28 \times 11 / 8$ & 200 & $28 \times 2$ & 35 & $28 \times 7 / 8$ & 15 & $82 \times 3 / 4$ & $30 \times 17 / 16$ & 200 & $30 \times 17 / 8$ & 35 & $30 \times 27 / 8$ & 15 & 70 & 25.1 \\
\hline 250 & $36 \times 17 / 16$ & 200 & $36 \times 21 / 8$ & 35 & $36 \times 27 / 8$ & 15 & $66 \times 3 / 4$ & $36 \times 15 / 8$ & 200 & $3621 / 4$ & 35 & $36 \times 3$ & 15 & 70 & 30.0 \\
\hline
\end{tabular}


Table B5.3. Continued

Simple Composite Plate Girder Using MDX-LRFD

\begin{tabular}{|c|c|c|c|c|c|c|c|c|c|c|c|}
\hline \multirow[b]{2}{*}{$\begin{array}{c}\text { Span Length, ft. } \\
\text { (L) }\end{array}$} & \multicolumn{2}{|c|}{$\begin{array}{c}\text { Top Flange } \\
\text { (A) }\end{array}$} & \multicolumn{2}{|c|}{$\begin{array}{c}\text { Top Flange } \\
\text { (B) }\end{array}$} & \multirow{2}{*}{$\begin{array}{l}\text { Web Plate, } \\
\text { in. } \\
\text { (F) }\end{array}$} & \multicolumn{2}{|c|}{$\begin{array}{c}\text { Bottom Flange } \\
\text { (A) }\end{array}$} & \multicolumn{2}{|c|}{$\begin{array}{c}\text { Bottom Flange } \\
\text { (B) }\end{array}$} & \multirow[b]{2}{*}{$\begin{array}{l}\text { Fy, } \\
\text { ksi }\end{array}$} & \multirow[b]{2}{*}{$\begin{array}{c}\text { L/D } \\
\text { (Actual) }\end{array}$} \\
\hline & Plate, in. & $\begin{array}{c}\text { Length, } \\
\text { ft. }\end{array}$ & Plate, in. & $\begin{array}{c}\text { Length, } \\
\text { ft. }\end{array}$ & & Plate, in. & $\begin{array}{c}\text { Length, } \\
\text { ft. }\end{array}$ & Plate, in. & Length, ft. & & \\
\hline 100 & $14 \times 3 / 4$ & 100 & & & $68 \times 5 / 16$ & $14 \times 3 / 4$ & 100 & & & 50 & 15.2 \\
\hline 100 & $12 \times 15 / 16$ & 100 & & & $48 \times 3 / 8$ & $12 \times 113 / 16$ & 100 & & & 50 & 20.1 \\
\hline 100 & $12 \times 1$ & 100 & & & $35 \times 3 / 8$ & $16 \times 115 / 16$ & 100 & & & 50 & 25.6 \\
\hline 100 & $14 \times 13 / 4$ & 100 & & & $27 \times 5 / 16$ & $18 \times 25 / 16$ & 100 & & & 50 & 30.5 \\
\hline 100 & $12 \times 3 / 4$ & 100 & & & $69 \times 5 / 16$ & $12 \times 3 / 4$ & 100 & & & 70 & 15.0 \\
\hline 100 & $12 \times 3 / 4$ & 100 & & & $48 \times 1 / 2$ & $12 \times 11 / 2$ & 100 & & & 70 & 20.2 \\
\hline 100 & $12 \times 7 / 8$ & 100 & & & $35 \times 3 / 8$ & $12 \times 23 / 8$ & 100 & & & 70 & 25.3 \\
\hline 100 & $12 \times 11 / 4$ & 100 & & & $27 \times 3 / 8$ & $16 \times 25 / 16$ & 100 & & & 70 & 30.5 \\
\hline 150 & $24 \times 1$ & 150 & & & $109 \times 9 / 16$ & $24 \times 1$ & 150 & & & 50 & 15.0 \\
\hline 150 & $18 \times 13 / 16$ & 150 & & & $79 \times 9 / 16$ & $18 \times 13 / 16$ & 30 & $18 \times 13 / 16$ & 90 & 50 & 20.0 \\
\hline 150 & $16 \times 3 / 4$ & 30 & $16 \times 15 / 8$ & 90 & $60 \times 9 / 16$ & $16 \times 3 / 4$ & 30 & $16 \times 21 / 16$ & 90 & 50 & 24.9 \\
\hline 150 & $22 \times 13 / 16$ & 30 & $22 \times 11 / 4$ & 90 & $48 \times 7 / 16$ & $22 \times 13 / 16$ & 30 & $22 \times 21 / 4$ & 90 & 50 & 29.9 \\
\hline 150 & $24 \times 1$ & 150 & & & $109 \times 9 / 16$ & $24 \times 1$ & 150 & & & 70 & 15.0 \\
\hline 150 & $18 \times 3 / 4$ & 150 & & & $79 \times 5 / 8$ & $18 \times 11 / 16$ & 150 & & & 70 & 20.0 \\
\hline 150 & $14 \times 3 / 4$ & 30 & $14 \times 11 / 8$ & 90 & $60 \times 9 / 16$ & $14 \times 3 / 4$ & 30 & $14 \times 21 / 4$ & 90 & 70 & 24.9 \\
\hline 150 & $16 \times 3 / 4$ & 30 & $16 \times 13 / 8$ & 90 & $48 \times 5 / 16$ & $16 \times 3 / 4$ & 30 & $16 \times 211 / 16$ & 90 & 70 & 29.7 \\
\hline 200 & $30 \times 3 / 4$ & 200 & & & $149 \times 3 / 4$ & $30 \times 3 / 4$ & 200 & & & 50 & 15.0 \\
\hline 200 & $28 \times 3 / 4$ & 200 & & & $109 \times 11 / 16$ & $29 \times 13 / 16$ & 200 & & & 50 & 20.0 \\
\hline 200 & $22 \times 3 / 4$ & 40 & $22 \times 11 / 4$ & 120 & $83 \times 11 / 16$ & $22 \times 3 / 4$ & 40 & $22 \times 113 / 16$ & 120 & 50 & 25.3 \\
\hline 200 & $28 \times 3 / 4$ & 40 & $28 \times 13 / 16$ & 120 & $67 \times 7 / 16$ & $28 \times 3 / 4$ & 40 & $28 \times 21 / 16$ & 120 & 50 & 30.4 \\
\hline 200 & $30 \times 15 / 16$ & 200 & & & $149 \times 11 / 16$ & $30 \times 3 / 4$ & 200 & & & 70 & 15.0 \\
\hline 200 & $26 \times 3 / 4$ & 200 & & & $109 \times 3 / 4$ & $26 \times 3 / 4$ & 200 & & & 70 & 20.0 \\
\hline 200 & $20 \times 3 / 4$ & 40 & $20 \times 11 / 4$ & 120 & $84 \times 5 / 8$ & $20 \times 3 / 4$ & 40 & $20 \times 17 / 8$ & 120 & 70 & 25.0 \\
\hline 200 & $22 \times 3 / 4$ & 40 & $22 \times 13 / 8$ & 120 & $67 \times 7 / 16$ & $22 \times 3 / 4$ & 40 & $22 \times 23 / 8$ & 120 & 70 & 30.2 \\
\hline
\end{tabular}


Table B5.3. Continued

Simple Composite Plate Girder Using MDX-LRFD

\begin{tabular}{|c|c|c|c|c|c|c|c|c|c|c|c|}
\hline \multirow[b]{2}{*}{$\begin{array}{c}\text { Span Length, ft. } \\
\text { (L) }\end{array}$} & \multicolumn{2}{|c|}{$\begin{array}{c}\text { Top Flange } \\
\text { (A) }\end{array}$} & \multicolumn{2}{|c|}{$\begin{array}{c}\text { Top Flange } \\
\text { (B) } \\
\end{array}$} & \multirow{2}{*}{$\begin{array}{l}\text { Web Plate, } \\
\text { in. } \\
\text { (F) }\end{array}$} & \multicolumn{2}{|c|}{$\begin{array}{c}\text { Bottom Flange } \\
\text { (A) }\end{array}$} & \multicolumn{2}{|c|}{$\begin{array}{c}\text { Bottom Flange } \\
\text { (B) }\end{array}$} & \multirow[b]{2}{*}{$\begin{array}{l}\text { Fy, } \\
\text { ksi } \\
\end{array}$} & \multirow[b]{2}{*}{$\begin{array}{c}\text { L/D } \\
\text { (Actual) }\end{array}$} \\
\hline & Plate, in. & $\begin{array}{c}\text { Length, } \\
\text { ft. }\end{array}$ & Plate, in. & $\begin{array}{c}\text { Length, } \\
\text { ft. }\end{array}$ & & Plate, in. & Length, ft. & Plate, in. & Length, ft. & & \\
\hline 250 & $36 \times 13 / 16$ & 250 & & & $189 \times 13 / 16$ & $36 \times 3 / 4$ & 250 & & & 50 & 15.0 \\
\hline 250 & $26 \times 11 / 8$ & 250 & & & $138 \times 7 / 8$ & $32 \times 11 / 2$ & 250 & & & 50 & 20.1 \\
\hline 250 & $28 \times 3 / 4$ & 50 & $28 \times 17 / 16$ & 150 & $109 \times 11 / 16$ & $28 \times 3 / 4$ & 50 & $28 \times 13 / 4$ & 150 & 50 & 24.8 \\
\hline 250 & $36 \times 13 / 16$ & 50 & $36 \times 13 / 4$ & 150 & $86 \times 5 / 8$ & $40 \times 13 / 16$ & 50 & $40 \times 2$ & 150 & 50 & 30.6 \\
\hline 250 & $28 \times 3 / 4$ & 250 & & & $189 \times 1$ & $28 \times 3 / 4$ & 250 & & & 70 & 15.0 \\
\hline 250 & $30 \times 3 / 4$ & 250 & & & $137 \times 7 / 8$ & $30 \times 3 / 4$ & 250 & & & 70 & 20.0 \\
\hline 250 & $28 \times 3 / 4$ & 50 & $28 \times 11 / 4$ & 150 & $108 \times 13 / 16$ & $28 \times 3 / 4$ & 50 & $28 \times 17 / 16$ & 150 & 70 & 25.1 \\
\hline 250 & $28 \times 3 / 4$ & 50 & $28 \times 23 / 8$ & 150 & $87 \times 11 / 16$ & $28 \times 3 / 4$ & 50 & $28 \times 23 / 8$ & 150 & 70 & 30.2 \\
\hline
\end{tabular}

Two-Span Continuous Composite Plate Girder Using MDX-LRFD

\begin{tabular}{|c|c|c|c|c|c|c|c|c|c|c|c|}
\hline \multirow[b]{2}{*}{$\begin{array}{c}\text { Span Length, ft. } \\
\text { (L) }\end{array}$} & \multicolumn{2}{|c|}{$\begin{array}{c}\text { Top Flange } \\
\text { (A) }\end{array}$} & \multicolumn{2}{|c|}{$\begin{array}{l}\text { Top Flange } \\
\text { (B) }\end{array}$} & \multirow{2}{*}{$\begin{array}{l}\text { Web Plate, } \\
\text { in. } \\
\text { (F) }\end{array}$} & \multicolumn{2}{|c|}{$\begin{array}{l}\text { Bottom Flange } \\
\text { (A) }\end{array}$} & \multicolumn{2}{|c|}{$\begin{array}{l}\text { Bottom Flange } \\
\text { (B) } \\
\end{array}$} & \multirow[b]{2}{*}{$\begin{array}{l}\text { Fy, } \\
\text { ksi }\end{array}$} & \multirow[b]{2}{*}{$\begin{array}{c}\text { L/D } \\
\text { (Actual) }\end{array}$} \\
\hline & Plate, in. & $\begin{array}{c}\text { Length, } \\
\text { ft. }\end{array}$ & Plate, in. & $\begin{array}{c}\text { Length, } \\
\text { ft. }\end{array}$ & & Plate, in. & Length, ft. & Plate, in. & Length, ft. & & \\
\hline 100 & $14 \times 3 / 4$ & 80 & $14 \times 13 / 4$ & 20 & $52 \times 1 / 2$ & $14 \times 13 / 16$ & 80 & $14 \times 2$ & 20 & 50 & 18.8 \\
\hline 100 & $14 \times 3 / 4$ & 80 & $14 \times 21 / 2$ & 20 & $36 \times 5 / 16$ & $17 \times 11 / 2$ & 80 & $17 \times 29 / 16$ & 20 & 50 & 24.8 \\
\hline 100 & & & & & & & & & & 50 & \\
\hline 100 & & & & & & & & & & 50 & \\
\hline 100 & & & & & & & & & & 70 & \\
\hline 100 & & & & & & & & & & 70 & \\
\hline 100 & & & & & & & & & & 70 & \\
\hline 100 & & & & & & & & & & 70 & \\
\hline
\end{tabular}


Table B5.3. Continued

Two-Span Continuous Composite Plate Girder Using MDX-LRFD

\begin{tabular}{|c|c|c|c|c|c|c|c|c|c|c|c|}
\hline \multirow[b]{2}{*}{$\begin{array}{c}\text { Span Length, ft. } \\
\text { (L) }\end{array}$} & \multicolumn{2}{|c|}{$\begin{array}{c}\text { Top Flange } \\
\text { (A) }\end{array}$} & \multicolumn{2}{|c|}{$\begin{array}{l}\text { Top Flange } \\
\text { (B) }\end{array}$} & \multirow{2}{*}{$\begin{array}{c}\text { Web Plate, } \\
\text { in. } \\
\text { (F) }\end{array}$} & \multicolumn{2}{|c|}{$\begin{array}{l}\text { Bottom Flange } \\
\text { (A) }\end{array}$} & \multicolumn{2}{|c|}{$\begin{array}{l}\text { Bottom Flange } \\
\text { (B) }\end{array}$} & \multirow[b]{2}{*}{$\begin{array}{l}\text { Fy, } \\
\text { ksi }\end{array}$} & \multirow[b]{2}{*}{$\begin{array}{c}\text { L/D } \\
\text { (Actual) }\end{array}$} \\
\hline & Plate, in. & $\begin{array}{c}\text { Length, } \\
\text { ft. }\end{array}$ & Plate, in. & $\begin{array}{c}\text { Length, } \\
\text { ft. }\end{array}$ & & Plate, in. & $\begin{array}{c}\text { Length, } \\
\text { ft. }\end{array}$ & Plate, in. & $\begin{array}{c}\text { Length, } \\
\text { ft. }\end{array}$ & & \\
\hline 150 & $20 \times 3 / 4$ & 112.5 & $20 \times 15 / 8$ & 37.5 & $84 \times 9 / 16$ & $20 \times 3 / 4$ & 112.5 & $20 \times 13 / 4$ & 37.5 & 50 & 18.8 \\
\hline 150 & $22 \times 3 / 4$ & 112.5 & $22 \times 21 / 2$ & 37.5 & $58 \times 1 / 2$ & $22 \times 11 / 8$ & 112.5 & $22 \times 29 / 16$ & 37.5 & 50 & 25.5 \\
\hline 150 & $30 \times 11 / 8$ & 112.5 & $30 \times 21 / 8$ & 37.5 & $44 \times 1 / 2$ & $30 \times 11 / 8$ & 112.5 & $30 \times 21 / 2$ & 37.5 & 50 & 31.6 \\
\hline 150 & $34 \times 11 / 2$ & 112.5 & $34 \times 21 / 16$ & 37.5 & $34 \times 7 / 16$ & $34 \times 17 / 16$ & 112.5 & $34 \times 213 / 16$ & 37.5 & 50 & 37.6 \\
\hline 150 & $20 \times 3 / 4$ & 150 & & & $84 \times 9 / 16$ & $20 \times 3 / 4$ & 112.5 & $20 \times 13 / 16$ & 37.5 & 70 & 18.9 \\
\hline 150 & $20 \times 3 / 4$ & 112.5 & $20 \times 2$ & 37.5 & $60 \times 9 / 16$ & $20 \times 11 / 8$ & 112.5 & $20 \times 115 / 16$ & 37.5 & 70 & 24.6 \\
\hline 150 & $18 \times 11 / 8$ & 112.5 & $18 \times 25 / 8$ & 37.5 & $44 \times 7 / 16$ & $18 \times 115 / 16$ & 112.5 & $18 \times 3$ & 37.5 & 70 & 31.0 \\
\hline 150 & $24 \times 11 / 8$ & 112.5 & $24 \times 25 / 8$ & 37.5 & $34 \times 7 / 16$ & $24 \times 23 / 8$ & 112.5 & $24 \times 3$ & 37.5 & 70 & 37.5 \\
\hline 200 & $28 \times 3 / 4$ & 150 & $28 \times 11 / 8$ & 50 & $117 \times 3 / 4$ & $28 \times 13 / 16$ & 150 & $28 \times 11 / 2$ & 50 & 50 & 18.6 \\
\hline 200 & $34 \times 1$ & 150 & $34 \times 113 / 16$ & 50 & $82 \times 5 / 8$ & $34 \times 11 / 8$ & 150 & $34 \times 115 / 16$ & 50 & 50 & 25.5 \\
\hline 200 & $38 \times 13 / 8$ & 150 & $38 \times 21 / 2$ & 50 & $63 \times 9 / 16$ & $38 \times 17 / 16$ & 150 & $38 \times 21 / 2$ & 50 & 50 & 31.4 \\
\hline 200 & $46 \times 7 / 8$ & 150 & $46 \times 21 / 4$ & 50 & $51 \times 7 / 16$ & $46 \times 13 / 16$ & 150 & $46 \times 211 / 16$ & 50 & 50 & 37.4 \\
\hline 200 & $24 \times 3 / 4$ & 200 & & & $116 \times 11 / 16$ & $26 \times 3 / 4$ & 150 & $26 \times 11 / 2$ & 50 & 70 & 18.9 \\
\hline 200 & $24 \times 3 / 4$ & 150 & $24 \times 11 / 2$ & 50 & $84 \times 13 / 16$ & $26 \times 7 / 8$ & 150 & $26 \times 15 / 8$ & 50 & 70 & 25.1 \\
\hline 200 & $24 \times 11 / 4$ & 150 & $24 \times 21 / 2$ & 50 & $63 \times 5 / 8$ & $24 \times 15 / 8$ & 150 & $24 \times 21 / 2$ & 50 & 70 & 31.4 \\
\hline 200 & $30 \times 11 / 2$ & 150 & $30 \times 23 / 8$ & 50 & $51 \times 7 / 16$ & $30 \times 21 / 8$ & 150 & $30 \times 21 / 2$ & 50 & 70 & 37.3 \\
\hline 250 & $34 \times 3 / 4$ & 200 & $34 \times 13 / 16$ & 50 & $148 \times 7 / 8$ & $34 \times 13 / 16$ & 200 & $34 \times 13 / 4$ & 50 & 50 & \\
\hline 250 & $28 \times 1$ & 200 & $28 \times 3$ & 50 & $106 \times 7 / 8$ & $28 \times 11 / 2$ & 200 & $34 \times 13 / 4$ & 50 & 50 & \\
\hline 250 & $40 \times 13 / 4$ & 200 & $40 \times 3$ & 50 & $82 \times 11 / 16$ & $42 \times 21 / 8$ & 200 & $42 \times 3$ & 50 & 50 & \\
\hline 250 & NA & & & & & & & & & 50 & \\
\hline 250 & $30 \times 3 / 4$ & 250 & & & $148 \times 7 / 8$ & $30 \times 3 / 4$ & 200 & $30 \times 111 / 16$ & 50 & 70 & \\
\hline 250 & $26 \times 3 / 4$ & 250 & & & $108 \times 13 / 16$ & $26 \times 1$ & 200 & $26 \times 21 / 16$ & 50 & 70 & \\
\hline 250 & $30 \times 11 / 4$ & 200 & $30 \times 21 / 2$ & 50 & $82 \times 5 / 8$ & $30 \times 21 / 8$ & 200 & $30 \times 215 / 16$ & 50 & 70 & \\
\hline 250 & $36 \times 17 / 16$ & 200 & $36 \times 213 / 16$ & 50 & $66 \times 11 / 16$ & $36 \times 21 / 4$ & 200 & $36 \times 3$ & 50 & 70 & \\
\hline
\end{tabular}


Table B5.4. Detailed girder elevation for cross section 4 ( $\mathrm{S}=8$ '-6”)

Simple Composite Plate Girder Using SIMON-LFD

\begin{tabular}{|c|c|c|c|c|c|c|c|c|c|c|c|}
\hline \multirow{2}{*}{$\begin{array}{c}\text { Span Length, } \\
\text { ft. } \\
\text { (L) }\end{array}$} & \multicolumn{2}{|c|}{$\begin{array}{c}\text { Top Flange } \\
\text { (A) }\end{array}$} & \multicolumn{2}{|c|}{$\begin{array}{c}\text { Top Flange } \\
\text { (B) }\end{array}$} & \multirow[b]{2}{*}{$\begin{array}{l}\text { Web Plate, in. } \\
\text { (F) }\end{array}$} & \multicolumn{2}{|c|}{$\begin{array}{c}\text { Bottom Flange } \\
\text { (A) }\end{array}$} & \multicolumn{2}{|c|}{$\begin{array}{l}\text { Bottom Flange } \\
\text { (B) }\end{array}$} & \multirow[b]{2}{*}{$\begin{array}{l}\text { Fy, } \\
\text { ksi }\end{array}$} & \multirow[b]{2}{*}{$\begin{array}{c}\text { L/D } \\
\text { (Actual) }\end{array}$} \\
\hline & Plate, in. & $\begin{array}{c}\text { Length, } \\
\text { ft. } \\
\end{array}$ & Plate, in. & $\begin{array}{c}\text { Length, } \\
\text { ft. }\end{array}$ & & Plate, in. & $\begin{array}{c}\text { Length, } \\
\text { ft. }\end{array}$ & Plate, in. & $\begin{array}{c}\text { Length, } \\
\text { ft. }\end{array}$ & & \\
\hline 100 & $14 \times 3 / 4$ & 100 & & & $69 \times 7 / 16$ & $14 \times 11 / 16$ & 100 & & & 50 & 15.0 \\
\hline 100 & $14 \times 3 / 4$ & 100 & & & $49 \times 3 / 8$ & $14 \times 115 / 16$ & 100 & & & 50 & 19.7 \\
\hline 100 & $14 \times 11 / 16$ & 100 & & & $37 \times 7 / 16$ & $14 \times 23 / 4$ & 100 & & & 50 & 24.1 \\
\hline 100 & $18 \times 13 / 16$ & 100 & & & $29 \times 7 / 16$ & $18 \times 213 / 16$ & 100 & & & 50 & 28.7 \\
\hline 100 & $12 \times 3 / 4$ & 100 & & & $69 \times 7 / 16$ & $12 \times 7 / 8$ & 100 & & & 70 & 15.0 \\
\hline 100 & $14 \times 3 / 4$ & 100 & & & $49 \times 5 / 16$ & $14 \times 15 / 8$ & 100 & & & 70 & 19.8 \\
\hline 100 & $16 \times 3 / 4$ & 100 & & & $37 \times 3 / 8$ & $16 \times 21 / 16$ & 100 & & & 70 & 24.6 \\
\hline 100 & $20 \times 15 / 16$ & 100 & & & $29 \times 3 / 8$ & $20 \times 21 / 16$ & 100 & & & 70 & 29.2 \\
\hline 200 & $38 \times 7 / 8$ & 40 & $38 \times 11 / 16$ & 120 & $149 \times 15 / 16$ & $38 \times 3 / 4$ & 40 & $38 \times 3 / 4$ & 120 & 50 & 15.0 \\
\hline 200 & $28 \times 7 / 8$ & 40 & $28 \times 11 / 16$ & 120 & $109 \times 11 / 16$ & $28 \times 3 / 4$ & 40 & $28 \times 13 / 4$ & 120 & 50 & 19.9 \\
\hline 200 & $22 \times 7 / 8$ & 40 & $22 \times 11 / 2$ & 120 & $85 \times 7 / 16$ & $22 \times 15 / 16$ & 40 & $22 \times 21 / 2$ & 120 & 50 & 24.6 \\
\hline 200 & $26 \times 11 / 8$ & 40 & $26 \times 13 / 4$ & 120 & $69 \times 5 / 16$ & $26 \times 111 / 16$ & 40 & $26 \times 27 / 8$ & 120 & 50 & 29.3 \\
\hline 200 & $36 \times 7 / 8$ & 40 & $36 \times 1$ & 120 & $149 \times 13 / 16$ & $36 \times 3 / 4$ & 40 & $36 \times 3 / 4$ & 120 & 70 & 15.0 \\
\hline 200 & $28 \times 7 / 8$ & 40 & $28 \times 1$ & 120 & $109 \times 7 / 8$ & $28 \times 3 / 4$ & 40 & $28 \times 3 / 4$ & 120 & 70 & 20.0 \\
\hline 200 & $20 \times 13 / 16$ & 40 & $20 \times 15 / 16$ & 120 & $85 \times 11 / 16$ & $20 \times 7 / 8$ & 40 & $20 \times 15 / 8$ & 120 & 70 & 24.8 \\
\hline 200 & $20 \times 7 / 8$ & 40 & $20 \times 13 / 16$ & 120 & $69 \times 5 / 8$ & $20 \times 15 / 16$ & 40 & $20 \times 23 / 8$ & 120 & 70 & 29.5 \\
\hline 300 & $56 \times 15 / 16$ & 60 & $56 \times 15 / 8$ & 180 & $229 \times 17 / 16$ & $56 \times 3 / 4$ & 60 & $56 \times 3 / 4$ & 180 & 50 & 15.0 \\
\hline 300 & $44 \times 15 / 16$ & 60 & $44 \times 11 / 2$ & 180 & $169 \times 11 / 16$ & $44 \times 3 / 4$ & 60 & $44 \times 11 / 8$ & 180 & 50 & 20.0 \\
\hline 300 & $34 \times 11 / 4$ & 60 & $34 \times 19 / 16$ & 180 & $133 \times 7 / 8$ & $34 \times 11 / 4$ & 60 & $34 \times 21 / 4$ & 180 & 50 & 24.8 \\
\hline 300 & $38 \times 11 / 2$ & 60 & $38 \times 21 / 8$ & 180 & $109 \times 11 / 16$ & $38 \times 15 / 8$ & 60 & $38 \times 27 / 8$ & 180 & 50 & 29.5 \\
\hline 300 & $56 \times 15 / 16$ & 60 & $56 \times 19 / 16$ & 180 & $229 \times 113 / 16$ & $56 \times 3 / 4$ & 60 & $56 \times 3 / 4$ & 180 & 70 & 15.0 \\
\hline 300 & $44 \times 15 / 16$ & 60 & $44 \times 11 / 2$ & 180 & $169 \times 15 / 16$ & $44 \times 3 / 4$ & 60 & $44 \times 3 / 4$ & 180 & 70 & 20.0 \\
\hline 300 & $30 \times 11 / 8$ & 60 & $30 \times 13 / 8$ & 180 & $133 \times 11 / 16$ & $30 \times 3 / 4$ & 60 & $30 \times 11 / 2$ & 180 & 70 & 24.9 \\
\hline 300 & $36 \times 13 / 8$ & 60 & $36 \times 15 / 8$ & 180 & $109 \times 7 / 8$ & $36 \times 1$ & 60 & $36 \times 13 / 4$ & 180 & 70 & 29.8 \\
\hline
\end{tabular}


Table B5.4. Continued

Two-Span Continuous Composite Plate Girder Using SIMON-LFD

\begin{tabular}{|c|c|c|c|c|c|c|c|c|c|c|c|}
\hline \multirow{2}{*}{$\begin{array}{c}\text { Span Length, } \\
\text { ft. } \\
\text { (L) }\end{array}$} & \multicolumn{2}{|c|}{$\begin{array}{c}\text { Top Flange } \\
\text { (A) }\end{array}$} & \multicolumn{2}{|c|}{$\begin{array}{c}\text { Top Flange } \\
\text { (B) }\end{array}$} & \multirow{2}{*}{$\begin{array}{c}\text { Web Plate, } \\
\text { in. } \\
\text { (F) }\end{array}$} & \multicolumn{2}{|c|}{$\begin{array}{c}\text { Bottom Flange } \\
\text { (A) }\end{array}$} & \multicolumn{2}{|c|}{$\begin{array}{l}\text { Bottom Flange } \\
\text { (B) }\end{array}$} & \multirow[b]{2}{*}{$\begin{array}{l}\text { Fy, } \\
\text { ksi }\end{array}$} & \multirow[b]{2}{*}{$\begin{array}{c}\text { L/D } \\
\text { (Actual) }\end{array}$} \\
\hline & Plate, in. & $\begin{array}{c}\text { Length, } \\
\text { ft. }\end{array}$ & Plate, in. & $\begin{array}{c}\text { Length, } \\
\text { ft. }\end{array}$ & & Plate, in. & $\begin{array}{c}\text { Length, } \\
\text { ft. }\end{array}$ & Plate, in. & $\begin{array}{c}\text { Length, } \\
\text { ft. }\end{array}$ & & \\
\hline 100 & $16 \times 3 / 4$ & 75 & $16 \times 3 / 4$ & 25 & $69 \times 9 / 16$ & $16 \times 3 / 4$ & 75 & $16 \times 13 / 16$ & 25 & 50 & 15.0 \\
\hline 100 & $14 \times 3 / 4$ & 75 & $14 \times 11 / 2$ & 25 & $49 \times 7 / 16$ & $14 \times 13 / 4$ & 75 & $14 \times 113 / 16$ & 25 & 50 & 20.0 \\
\hline 100 & $16 \times 3 / 4$ & 75 & $16 \times 21 / 8$ & 25 & $37 \times 9 / 16$ & $16 \times 21 / 2$ & 75 & $16 \times 23 / 4$ & 25 & 50 & 24.1 \\
\hline 100 & $20 \times 3 / 4$ & 75 & $20 \times 23 / 8$ & 25 & $29 \times 3 / 4$ & $20 \times 23 / 8$ & 75 & $20 \times 23 / 4$ & 25 & 50 & 28.7 \\
\hline 100 & $16 \times 3 / 4$ & 75 & $16 \times 3 / 4$ & 25 & $69 \times 9 / 16$ & $16 \times 3 / 4$ & 75 & $16 \times 113 / 16$ & 25 & 70 & 15.0 \\
\hline 100 & $14 \times 3 / 4$ & 75 & $14 \times 15 / 16$ & 25 & $49 \times 7 / 16$ & $14 \times 111 / 16$ & 75 & $14 \times 111 / 16$ & 25 & 70 & 19.8 \\
\hline 100 & $16 \times 3 / 4$ & 75 & $16 \times 15 / 8$ & 25 & $37 \times 7 / 16$ & $16 \times 21 / 2$ & 75 & $16 \times 21 / 2$ & 25 & 70 & 24.5 \\
\hline 100 & $18 \times 3 / 4$ & 75 & $18 \times 115 / 16$ & 25 & $29 \times 7 / 16$ & $18 \times 23 / 4$ & 75 & $18 \times 21 / 4$ & 25 & 70 & 28.7 \\
\hline 200 & $38 \times 13 / 16$ & 150 & $38 \times 3 / 4$ & 50 & $149 \times 1$ & $38 \times 3 / 4$ & 150 & $38 \times 17 / 16$ & 50 & 50 & 15.0 \\
\hline 200 & $28 \times 13 / 16$ & 150 & $28 \times 13 / 8$ & 50 & $109 \times 3 / 4$ & $28 \times 13 / 16$ & 150 & $28 \times 11 / 2$ & 50 & 50 & 19.9 \\
\hline 200 & $24 \times 13 / 16$ & 150 & $24 \times 23 / 4$ & 50 & $85 \times 9 / 16$ & $24 \times 111 / 16$ & 150 & $24 \times 3$ & 50 & 50 & 24.5 \\
\hline 200 & $32 \times 11 / 16$ & 150 & $32 \times 23 / 4$ & 50 & $69 \times 7 / 16$ & $32 \times 111 / 16$ & 150 & $32 \times 27 / 8$ & 50 & 50 & 29.3 \\
\hline 200 & $38 \times 13 / 16$ & 150 & $38 \times 13 / 16$ & 50 & $149 \times 13 / 16$ & $38 \times 3 / 4$ & 150 & $38 \times 13 / 8$ & 50 & 70 & 15.0 \\
\hline 200 & $28 \times 13 / 16$ & 150 & $28 \times 13 / 16$ & 50 & $109 \times 7 / 8$ & $28 \times 3 / 4$ & 150 & $28 \times 17 / 16$ & 50 & 70 & 19.9 \\
\hline 200 & $22 \times 3 / 4$ & 150 & $22 \times 17 / 8$ & 50 & $85 \times 11 / 16$ & $22 \times 13 / 4$ & 150 & $22 \times 2$ & 50 & 70 & 24.7 \\
\hline 200 & $20 \times 13 / 16$ & 150 & $20 \times 3$ & 50 & $69 \times 9 / 16$ & $20 \times 23 / 4$ & 150 & $20 \times 3$ & 50 & 70 & 29.3 \\
\hline 300 & $58 \times 11 / 4$ & 225 & $58 \times 3 / 4$ & 75 & $229 \times 19 / 16$ & $58 \times 7 / 8$ & 225 & $58 \times 2$ & 75 & 50 & 14.9 \\
\hline 300 & $44 \times 13 / 16$ & 225 & $44 \times 13 / 16$ & 75 & $169 \times 11 / 8$ & $44 \times 1$ & 225 & $44 \times 115 / 16$ & 75 & 50 & 19.9 \\
\hline 300 & $34 \times 11 / 8$ & 225 & $34 \times 27 / 8$ & 75 & $133 \times 7 / 8$ & $34 \times 17 / 16$ & 225 & $34 \times 3$ & 75 & 50 & 24.7 \\
\hline 300 & $46 \times 17 / 16$ & 225 & $46 \times 213 / 16$ & 75 & $109 \times 3 / 4$ & $46 \times 19 / 16$ & 225 & $46 \times 3$ & 75 & 50 & 29.5 \\
\hline 300 & $58 \times 11 / 4$ & 225 & $58 \times 3 / 4$ & 75 & $229 \times 113 / 16$ & $58 \times 13 / 16$ & 225 & $58 \times 2$ & 75 & 70 & 14.9 \\
\hline 300 & $44 \times 13 / 16$ & 225 & $44 \times 3 / 4$ & 75 & $169 \times 13 / 8$ & $44 \times 7 / 8$ & 225 & $44 \times 115 / 16$ & 75 & 70 & 19.9 \\
\hline 300 & $34 \times 11 / 8$ & 225 & $34 \times 11 / 2$ & 75 & $133 \times 1$ & $34 \times 11 / 4$ & 225 & $34 \times 115 / 16$ & 75 & 70 & 24.8 \\
\hline 300 & $30 \times 11 / 8$ & 225 & $30 \times 21 / 2$ & 75 & $109 \times 7 / 8$ & $30 \times 21 / 8$ & 225 & $30 \times 23 / 4$ & 75 & 70 & 29.6 \\
\hline
\end{tabular}


Table B5.4. Continued

Three-Span Continuous Composite Plate Girder Using SIMON-LFD

\begin{tabular}{|c|c|c|c|c|c|c|c|c|c|c|c|c|c|c|c|c|c|c|c|}
\hline \multirow{2}{*}{$\begin{array}{l}\text { Span } \\
\text { Len. } \\
\text {,ft. } \\
\text { (L) }\end{array}$} & \multicolumn{2}{|c|}{$\begin{array}{l}\text { Top Flange } \\
\text { (A) }\end{array}$} & \multicolumn{2}{|c|}{$\begin{array}{l}\text { Top Flange } \\
\text { (B) }\end{array}$} & \multicolumn{2}{|c|}{$\begin{array}{l}\text { Top Flange } \\
\text { (C) }\end{array}$} & \multicolumn{2}{|c|}{$\begin{array}{l}\text { Top Flange } \\
\text { (D) }\end{array}$} & \multirow{2}{*}{$\begin{array}{c}\text { Web } \\
\text { Plate, in. } \\
\text { (F) }\end{array}$} & \multicolumn{2}{|c|}{$\begin{array}{c}\text { Bottom Flange } \\
\text { (A) }\end{array}$} & \multicolumn{2}{|c|}{$\begin{array}{c}\text { Bottom Flange } \\
\text { (B) }\end{array}$} & \multicolumn{2}{|c|}{$\begin{array}{c}\text { Bottom Flange } \\
\text { (C) }\end{array}$} & \multicolumn{2}{|c|}{$\begin{array}{l}\text { Bottom Flange } \\
\text { (D) }\end{array}$} & \multirow[b]{2}{*}{$\begin{array}{l}\text { Fy, } \\
\text { ksi }\end{array}$} & \multirow[b]{2}{*}{$\underset{\text { (Actual) }}{\mathbf{L} / \mathbf{D}}$} \\
\hline & Plate, in. & $\begin{array}{l}\text { Len., } \\
\text { ft. }\end{array}$ & Plate, in. & $\begin{array}{c}\text { Len.,f } \\
\text { t. }\end{array}$ & $\begin{array}{c}\text { Plate, } \\
\text { in. }\end{array}$ & $\begin{array}{c}\text { Len.,f } \\
\text { t. }\end{array}$ & Plate, in. & $\begin{array}{c}\text { Len., } \\
\text { ft. }\end{array}$ & & Plate, in. & $\begin{array}{l}\text { Len., } \\
\text { ft. }\end{array}$ & Plate, in. & $\begin{array}{l}\text { Len., } \\
\text { ft. }\end{array}$ & Plate, in. & $\begin{array}{l}\text { Len., } \\
\text { ft. }\end{array}$ & Plate, in. & $\begin{array}{c}\text { Len., } \\
\mathrm{ft}\end{array}$ & & \\
\hline 100 & $12 \times 3 / 4$ & 60 & $12 \times 3 / 4$ & 20 & $\begin{array}{l}12 \mathrm{x} \\
3 / 4 \\
\end{array}$ & 25 & $12 \times 3 / 4$ & 50 & $69 \times 1 / 2$ & $12 \times 3 / 4$ & 60 & $\begin{array}{c}2 \times 1 \\
1 / 16 \\
\end{array}$ & 20 & $\begin{array}{c}12 \times 1 \\
1 / 16 \\
\end{array}$ & 25 & $12 \times 3 / 4$ & 50 & 50 & 15.0 \\
\hline 100 & $16 \times 3 / 4$ & 60 & $16 \times 3 / 4$ & 20 & $\begin{array}{l}16 \mathrm{x} \\
3 / 4\end{array}$ & 25 & $16 \times 3 / 4$ & 50 & $49 \times 3 / 8$ & $\begin{array}{c}16 \times 1 \\
3 / 16\end{array}$ & 60 & $\begin{array}{c}16 \times 1 \\
1 / 16\end{array}$ & 20 & $\begin{array}{c}16 \times 1 \\
1 / 16\end{array}$ & 25 & $\begin{array}{c}16 \times 1 \\
3 / 16\end{array}$ & 50 & 50 & 19.9 \\
\hline 100 & $16 \times 3 / 4$ & 60 & $16 \times 11 / 4$ & 20 & $\begin{array}{c}16 \times 1 \\
1 / 4\end{array}$ & 25 & $16 \times 3 / 4$ & 50 & $37 \times 7 / 16$ & $16 \times 15 / 8$ & 60 & $\begin{array}{c}16 \times 1 \\
7 / 16\end{array}$ & 20 & $\begin{array}{c}16 \times 1 \\
7 / 16\end{array}$ & 25 & $16 \times 15 / 8$ & 50 & 50 & 24.7 \\
\hline 100 & $16 \times 3 / 4$ & 60 & $16 \times 17 / 16$ & 20 & $\begin{array}{c}16 \times 1 \\
7 / 16 \\
\end{array}$ & 25 & $16 \times 3 / 4$ & 50 & $29 \times 9 / 16$ & $\begin{array}{l}16 \times 1 \\
13 / 16 \\
\end{array}$ & 60 & $16 \times 17 / 8$ & 20 & $16 \times 17 / 8$ & 25 & $\begin{array}{l}16 \times 1 \\
13 / 16 \\
\end{array}$ & 50 & 50 & 29.4 \\
\hline 100 & $12 \times 3 / 4$ & 60 & $12 \times 3 / 4$ & 20 & $\begin{array}{l}12 \mathrm{x} \\
3 / 4\end{array}$ & 25 & $12 \times 3 / 4$ & 50 & $69 \times 5 / 8$ & $12 \times 3 / 4$ & 60 & $\begin{array}{c}12 \times 1 \\
1 / 16\end{array}$ & 20 & $\begin{array}{c}12 \times 1 \\
1 / 16\end{array}$ & 25 & $12 \times 3 / 4$ & 50 & 70 & 15.0 \\
\hline 100 & $14 \times 3 / 4$ & 60 & $14 \times 3 / 4$ & 20 & $\begin{array}{l}1 / 7 x \\
3 / 4\end{array}$ & 25 & $14 \times 3 / 4$ & 50 & $49 \times 7 / 16$ & $14 \times 11 / 4$ & 60 & $14 \times 11 / 4$ & 20 & $14 \times 11 / 4$ & 25 & $14 \times 11 / 8$ & 50 & 70 & 19.9 \\
\hline 100 & $16 \times 3 / 4$ & 60 & $16 \times 7 / 8$ & 20 & $\begin{array}{c}16 \\
\times 77 / 8 \\
\end{array}$ & 25 & $16 \times 3 / 4$ & 50 & $37 \times 3 / 8$ & $\begin{array}{l}16 \times 1 \\
11 / 16 \\
\end{array}$ & 60 & $\begin{array}{c}16 \times 1 \\
7 / 16 \\
\end{array}$ & 20 & $\begin{array}{c}16 \times 1 \\
7 / 16\end{array}$ & 25 & $16 \times 11 / 2$ & 50 & 70 & 24.8 \\
\hline 100 & $18 \times 3 / 4$ & 60 & $18 \times 11 / 16$ & 20 & $\begin{array}{c}18 \times 1 \\
1 / 16 \\
\end{array}$ & 25 & $18 \times 3 / 4$ & 50 & $29 \times 3 / 8$ & $18 \times 17 / 8$ & 60 & $18 \times 15 / 8$ & 20 & $18 \times 15 / 8$ & 25 & $18 \times 13 / 4$ & 50 & 70 & 29.5 \\
\hline 200 & $36 \times 3 / 4$ & 120 & $36 \times 3 / 4$ & 40 & $\begin{array}{l}36 x \\
3 / 4 \\
\end{array}$ & 50 & $36 \times 3 / 4$ & 100 & $149 \times 1$ & $36 \times 3 / 4$ & 120 & $\begin{array}{c}36 \times 1 \\
3 / 16 \\
\end{array}$ & 40 & $\begin{array}{c}36 \times 1 \\
3 / 16 \\
\end{array}$ & 50 & $36 \times 3 / 4$ & 100 & 50 & 15.0 \\
\hline 200 & $26 \times 3 / 4$ & 120 & $26 \times 3 / 4$ & 40 & $\begin{array}{l}26 \mathrm{x} \\
3 / 4\end{array}$ & 50 & $26 \times 3 / 4$ & 100 & $109 \times 3 / 4$ & $26 \times 3 / 4$ & 120 & $\begin{array}{c}26 \times 1 \\
3 / 16\end{array}$ & 40 & $\begin{array}{c}26 \times 1 \\
3 / 16\end{array}$ & 50 & $26 \times 3 / 4$ & 100 & 50 & 20.0 \\
\hline 200 & $22 \times 3 / 4$ & 120 & $22 \times 11 / 2$ & 40 & $\begin{array}{c}22 \times 1 \\
1 / 2\end{array}$ & 50 & $22 \times 3 / 4$ & 100 & $85 \times 5 / 8$ & $\begin{array}{c}22 \times 1 \\
1 / 16 \\
\end{array}$ & 120 & $22 \times 13 / 4$ & 40 & $22 \times 13 / 4$ & 50 & $\begin{array}{l}22 \times 1 \\
1 / 16\end{array}$ & 100 & 50 & 24.8 \\
\hline 200 & $18 \times 3 / 4$ & 120 & $18 \times 25 / 8$ & 40 & $\begin{array}{c}18 \times 2 \\
5 / 8\end{array}$ & 50 & $18 \times 3 / 4$ & 100 & $69 \times 1 / 2$ & $\begin{array}{l}18 \times 1 \\
13 / 16\end{array}$ & 120 & $18 \times 3$ & 40 & $18 \times 3$ & 50 & $18 \times 21 / 4$ & 100 & 50 & 29.3 \\
\hline 200 & $38 \times 3 / 4$ & 120 & $38 \times 3 / 4$ & 40 & $\begin{array}{l}38 \mathrm{x} \\
3 / 4 \\
\end{array}$ & 50 & $38 \times 3 / 4$ & 100 & $\begin{array}{c}149 \times 1 \\
1 / 8\end{array}$ & $38 \times 3 / 4$ & 120 & $38 \times 11 / 4$ & 40 & $38 \times 11 / 4$ & 50 & $38 \times 3 / 4$ & 100 & 70 & 15.0 \\
\hline 200 & $24 \times 3 / 4$ & 120 & $24 \times 3 / 4$ & 40 & $\begin{array}{c}24 x \\
3 / 4\end{array}$ & 50 & $24 \times 3 / 4$ & 100 & $109 \times 7 / 8$ & $24 \times 3 / 4$ & 120 & $24 \times 11 / 4$ & 40 & $24 \times 11 / 4$ & 50 & $24 \times 3 / 4$ & 100 & 70 & 20.0 \\
\hline 200 & $22 \times 3 / 4$ & 120 & $22 \times 11 / 8$ & 40 & $\begin{array}{c}22 \times 1 \\
1 / 8\end{array}$ & 50 & $22 \times 3 / 4$ & 100 & $85 \times 11 / 16$ & $22 \times 7 / 8$ & 120 & $22 \times 11 / 4$ & 40 & $22 \times 11 / 4$ & 50 & $22 \times 11 / 8$ & 100 & 70 & 24.9 \\
\hline 200 & $18 \times 3 / 4$ & 120 & $18 \times 13 / 4$ & 40 & $\begin{array}{c}18 \times 1 \\
3 / 4\end{array}$ & 50 & $18 \times 3 / 4$ & 100 & $69 \times 9 / 16$ & $18 \times 13 / 4$ & 120 & $18 \times 13 / 4$ & 40 & $18 \times 13 / 4$ & 50 & $18 \times 21 / 8$ & 100 & 70 & 29.6 \\
\hline 300 & $\begin{array}{c}58 \times 1 \\
1 / 16\end{array}$ & 180 & $58 \times 3 / 4$ & 60 & $\begin{array}{l}58 \mathrm{x} \\
3 / 4\end{array}$ & 75 & $58 \times 1$ & 150 & $\begin{array}{c}229 \times 1 \\
1 / 2\end{array}$ & $\begin{array}{c}58 \times \\
13 / 16\end{array}$ & 180 & $\begin{array}{l}58 \times 1 \\
11 / 16\end{array}$ & 60 & $58 \times 3 / 4$ & 75 & $58 \times 3 / 4$ & 150 & 50 & 15.0 \\
\hline 300 & $44 \times 1$ & 180 & $44 \times 3 / 4$ & 60 & $\begin{array}{l}44 \mathrm{x} \\
3 / 4\end{array}$ & 75 & $44 \times 1$ & 150 & $\begin{array}{c}169 \times 1 \\
1 / 8\end{array}$ & $44 \times 7 / 8$ & 180 & $\begin{array}{l}44 \times 1 \\
11 / 16\end{array}$ & 60 & $\begin{array}{l}44 \times 1 \\
11 / 16\end{array}$ & 75 & $44 \times 3 / 4$ & 150 & 50 & 19.9 \\
\hline 300 & $\begin{array}{c}34 \times \\
15 / 16\end{array}$ & 180 & $34 \times 17 / 16$ & 60 & $\begin{array}{c}34 \times 1 \\
7 / 16\end{array}$ & 75 & $34 \times 7 / 8$ & 150 & $133 \times 7 / 8$ & $\begin{array}{c}34 \times \\
15 / 16\end{array}$ & 180 & $\begin{array}{l}34 \times 1 \\
11 / 16\end{array}$ & 60 & $\begin{array}{l}34 \times 1 \\
11 / 16\end{array}$ & 75 & $34 \times 3 / 4$ & 150 & 50 & 24.9 \\
\hline 300 & $28 \times 7 / 8$ & 180 & $28 \times 21 / 2$ & 60 & $\begin{array}{c}28 \times 2 \\
1 / 2\end{array}$ & 75 & $\begin{array}{c}28 \times \\
13 / 16 \\
\end{array}$ & 150 & $109 \times 3 / 4$ & $28 \times 13 / 8$ & 180 & $28 \times 25 / 8$ & 60 & $28 \times 25 / 8$ & 75 & $\begin{array}{c}28 \times 1 \\
9 / 16\end{array}$ & 150 & 50 & 29.6 \\
\hline 300 & $58 \times 1$ & 180 & $58 \times 3 / 4$ & 60 & $58 \mathrm{x}$ & 75 & $58 \times 1-2$ & 150 & $229 \times 1$ & $58 \mathrm{x}$ & 180 & $58 \times 1$ & 60 & $58 \times 1$ & 75 & $58 \times 3 / 4$ & 150 & 70 & 0 \\
\hline 300 & $44 \times 1$ & 180 & $\begin{array}{l}58 \times 3 / 4 \\
44 \times 3 / 4\end{array}$ & 60 & $\begin{array}{l}3 / 4 \\
44 x \\
3 / 4\end{array}$ & 75 & $58 \times 1$ & $\begin{array}{l}150 \\
150\end{array}$ & $\begin{array}{c}3 / 4 \\
169 \times 1 \\
5 / 16\end{array}$ & $\frac{13 / 16}{44 \times 7 / 8}$ & $\begin{array}{l}180 \\
180\end{array}$ & $\frac{11 / 16}{44 \times 13 / 4}$ & 60 & $44 \times 13 / 4$ & 75 & $\begin{array}{l}58 \times 3 / 4 \\
44 \times 3 / 4\end{array}$ & 150 & 70 & 15.0 \\
\hline 300 & $\begin{array}{c}34 x \\
15 / 16 \\
\end{array}$ & 180 & $34 \times 3 / 4$ & 60 & $\begin{array}{l}34 \mathrm{x} \\
3 / 4 \\
\end{array}$ & 75 & $\begin{array}{c}34 \mathrm{x} \\
15 / 16 \\
\end{array}$ & 150 & $\begin{array}{c}133 \times 1 \\
1 / 16 \\
\end{array}$ & $34 \times 7 / 8$ & 180 & $\begin{array}{l}34 \times 1 \\
11 / 16 \\
\end{array}$ & 60 & $\begin{array}{l}34 \times 1 \\
11 / 16 \\
\end{array}$ & 75 & $34 \times 3 / 4$ & 150 & 70 & 24.9 \\
\hline & $28 \times 1$ & & & & $28 \times 1$ & & $28 \times 1$ & & $109 \mathrm{x}$ & $28 \times 1$ & & & & $28 \times 1$ & & $28 \times 1$ & & & \\
\hline 300 & $3 / 16$ & 180 & $28 \times 15 / 8$ & 60 & $5 / 8$ & 75 & $3 / 16$ & 150 & $13 / 16$ & $3 / 16$ & 180 & $28 \times 15 / 8$ & 60 & $13 / 16$ & 75 & $9 / 16$ & 150 & 70 & 29.8 \\
\hline
\end{tabular}




\section{Appendix C - Design Summary}


Table C5.1. Design summary for cross section $1\left(\mathrm{~S}=9^{\prime}\right)$

Simple-Span Composite Plate Girder Using SIMON-LFD

\begin{tabular}{|c|c|c|c|c|c|c|c|}
\hline $\begin{array}{c}\text { Span } \\
\text { Length } \\
\text { ft. }\end{array}$ & $\begin{array}{c}\text { Fy } \\
\text { ksi }\end{array}$ & $\begin{array}{c}\text { L/D } \\
\text { Ratio }\end{array}$ & $\begin{array}{c}\text { L/800 } \\
\text { in. }\end{array}$ & $\begin{array}{c}\text { Deflection } \\
\text { in. }\end{array}$ & L/ $\delta$ & $\begin{array}{c}\text { Total } \\
\text { Steel Wt } \\
\text { tons }\end{array}$ & $\begin{array}{c}\text { Performance } \\
\text { Ratio }\end{array}$ \\
\hline 100 & 50 & 15.1 & 1.50 & 0.674 & 1780 & 11 & 0.966 \\
\hline 100 & 50 & 20.0 & 1.50 & 1.074 & 1117 & 9 & 0.999 \\
\hline 100 & 50 & 25.4 & 1.50 & 1.498 & 801 & 10 & 0.997 \\
\hline 100 & 50 & 30.3 & 1.50 & 1.827 & 657 & 12 & 0.993 \\
\hline 100 & 70 & 14.9 & 1.50 & 0.604 & 1987 & 12 & 0.902 \\
\hline 100 & 70 & 19.8 & 1.50 & 1.051 & 1142 & 9 & 0.997 \\
\hline 100 & 70 & 25.3 & 1.50 & 1.490 & 805 & 9 & 0.988 \\
\hline 100 & 70 & 30.1 & 1.50 & 1.952 & 615 & 11 & 0.994 \\
\hline 200 & 50 & 14.9 & 3.00 & 0.665 & 3609 & 87 & 0.999 \\
\hline 200 & 50 & 19.9 & 3.00 & 1.854 & 1295 & 45 & 0.993 \\
\hline 200 & 50 & 24.5 & 3.00 & 2.478 & 969 & 39 & 0.995 \\
\hline 200 & 50 & 30.0 & 3.00 & 3.127 & 768 & 44 & 0.995 \\
\hline 200 & 70 & 15.0 & 3.00 & 0.692 & 3468 & 83 & 0.983 \\
\hline 200 & 70 & 19.9 & 3.00 & 1.743 & 1377 & 49 & 1.000 \\
\hline 200 & 70 & 24.6 & 3.00 & 2.738 & 877 & 38 & 0.997 \\
\hline 200 & 70 & 30.1 & 3.00 & 3.578 & 671 & 38 & 0.992 \\
\hline 300 & 50 & 15.0 & 4.50 & NA & NA & NA & NA \\
\hline 300 & 50 & 19.9 & 4.50 & 2.154 & 1671 & 153 & 0.998 \\
\hline 300 & 50 & 25.0 & 4.50 & 3.116 & 1155 & 131 & 0.998 \\
\hline 300 & 50 & 30.0 & 4.50 & 4.064 & 886 & 134 & 0.999 \\
\hline 300 & 70 & 15.1 & 4.50 & 0.790 & 4557 & 278 & 0.997 \\
\hline 300 & 70 & 20.0 & 4.50 & 2.107 & 1709 & 161 & 0.997 \\
\hline 300 & 70 & 25.1 & 4.50 & 3.806 & 946 & 115 & 0.990 \\
\hline 300 & 70 & 29.9 & 4.50 & 5.030 & 716 & 102 & 0.995 \\
\hline & & & & & & & \\
\hline
\end{tabular}


Table C5.1. Continued

Two-Span Continuous Composite Plate Girder Using SIMON-LFD

\begin{tabular}{|c|c|c|c|c|c|c|c|}
\hline $\begin{array}{c}\text { Span } \\
\text { Length } \\
\text { ft. }\end{array}$ & $\begin{array}{c}\text { Fy } \\
\text { ksi }\end{array}$ & $\begin{array}{c}\text { Lmax/D } \\
\text { Ratio }\end{array}$ & $\begin{array}{c}\text { L/800 } \\
\text { in. }\end{array}$ & $\begin{array}{c}\text { Deflection } \\
\text { in. }\end{array}$ & L/ 8 & $\begin{array}{c}\text { Total } \\
\text { Steel Wt } \\
\text { tons }\end{array}$ & $\begin{array}{c}\text { Performance } \\
\text { Ratio }\end{array}$ \\
\hline $100+100$ & 50 & 15.0 & 1.50 & 0.486 & 2469 & 20.5 & 0.990 \\
\hline $100+100$ & 50 & 19.4 & 1.50 & 0.664 & 1807 & 19.4 & 0.993 \\
\hline $100+100$ & 50 & 25.0 & 1.50 & 0.984 & 1220 & 24.6 & 0.996 \\
\hline $100+100$ & 50 & 30.1 & 1.50 & 1.255 & 956 & 30.9 & 0.995 \\
\hline $100+100$ & 70 & 15.0 & 1.50 & 0.444 & 2703 & 23.0 & 0.970 \\
\hline $100+100$ & 70 & 19.9 & 1.50 & 0.740 & 1622 & 18.7 & 0.989 \\
\hline $100+100$ & 70 & 24.0 & 1.50 & 0.941 & 1275 & 19.7 & 0.933 \\
\hline $100+100$ & 70 & 29.4 & 1.50 & 1.342 & 894 & 22.8 & 0.997 \\
\hline \hline $200+200$ & 50 & 14.9 & 3.00 & 0.496 & 4839 & 152.7 & 0.974 \\
\hline $200+200$ & 50 & 19.8 & 3.00 & 1.239 & 1937 & 93.0 & 0.995 \\
\hline $200+200$ & 50 & 24.1 & 3.00 & 1.961 & 1224 & 80.9 & 0.990 \\
\hline $200+200$ & 50 & 29.6 & 3.00 & 2.675 & 897 & 91.2 & 0.999 \\
\hline $200+200$ & 70 & 15.0 & 3.00 & 0.477 & 5031 & 169.0 & 1.000 \\
\hline $200+200$ & 70 & 19.9 & 3.00 & 1.507 & 1593 & 99.5 & 0.967 \\
\hline $200+200$ & 70 & 25.0 & 3.00 & 2.313 & 1038 & 69.2 & 0.999 \\
\hline $200+200$ & 70 & 29.3 & 3.00 & 2.821 & 851 & 70.3 & 0.998 \\
\hline $300+300$ & 50 & 14.9 & 4.50 & 0.556 & 6475 & 519.8 & 0.975 \\
\hline $300+300$ & 50 & 19.8 & 4.50 & 1.420 & 2535 & 307.3 & 0.987 \\
\hline $300+300$ & 50 & 24.6 & 4.50 & 2.556 & 1408 & 231.8 & 0.998 \\
\hline $300+300$ & 50 & 30.0 & 4.50 & 3.477 & 1035 & 241.4 & 0.992 \\
\hline $300+300$ & 70 & 15.1 & 4.50 & 0.546 & 6593 & 570.8 & 0.975 \\
\hline $300+300$ & 70 & 20.1 & 4.50 & 1.426 & 2523 & 325.3 & 1.000 \\
\hline $300+300$ & 70 & 25.0 & 4.50 & 2.922 & 1232 & 226.3 & 0.982 \\
\hline $300+300$ & 70 & 29.6 & 4.50 & 4.649 & 774 & 184.6 & 0.991 \\
\hline & & & & & & & \\
\hline
\end{tabular}


Table C5.1. Continued

Three-Span Continuous Composite Plate Girder Using SIMON-LFD

\begin{tabular}{|c|c|c|c|c|c|c|c|}
\hline $\begin{array}{c}\text { Span } \\
\text { Length } \\
\text { ft. }\end{array}$ & $\begin{array}{c}\text { Fy } \\
\text { ksi }\end{array}$ & $\begin{array}{c}\text { L/D } \\
\text { Ratio }\end{array}$ & $\begin{array}{c}\text { L/800 } \\
\text { in. }\end{array}$ & $\begin{array}{c}\text { Deflection } \\
\text { in. }\end{array}$ & L/ $\mathbf{c}$ & $\begin{array}{c}\text { Total } \\
\text { Steel Wt } \\
\text { tons }\end{array}$ & $\begin{array}{c}\text { Performance } \\
\text { Ratio }\end{array}$ \\
\hline $80-100-80$ & 50 & 15.1 & 1.50 & 0.354 & 3390 & 25.7 & 0.965 \\
\hline 100 & 50 & 19.4 & 1.50 & 0.620 & 1936 & 20.2 & 0.999 \\
\hline 100 & 50 & 25.1 & 1.50 & 0.874 & 1373 & 24.8 & 0.993 \\
\hline 100 & 50 & 30.2 & 1.50 & 1.073 & 1118 & 32.5 & 0.999 \\
\hline 100 & 70 & 15.1 & 1.50 & 0.362 & 3315 & 26.5 & 0.997 \\
\hline 100 & 70 & 19.9 & 1.50 & 0.614 & 1954 & 21.1 & 0.979 \\
\hline 100 & 70 & 24.1 & 1.50 & 0.808 & 1485 & 21.4 & 0.988 \\
\hline 100 & 70 & 29.5 & 1.50 & 1.155 & 1039 & 25.2 & 0.996 \\
\hline $160-200-160$ & 50 & 14.9 & 3.00 & 0.348 & 6897 & 190.2 & 0.980 \\
\hline 200 & 50 & 19.8 & 3.00 & 0.861 & 2787 & 113.5 & 1.000 \\
\hline 200 & 50 & 25.1 & 3.00 & 1.684 & 1425 & 88.9 & 1.000 \\
\hline 200 & 50 & 30.1 & 3.00 & 2.237 & 1073 & 94.7 & 0.994 \\
\hline 200 & 70 & 15.0 & 3.00 & 0.314 & 7643 & 207.8 & 0.995 \\
\hline 200 & 70 & 19.8 & 3.00 & 0.854 & 2810 & 118.1 & 0.965 \\
\hline 200 & 70 & 24.2 & 3.00 & 1.638 & 1465 & 82.0 & 0.989 \\
\hline 200 & 70 & 29.8 & 3.00 & 1.999 & 1201 & 80.8 & 0.994 \\
\hline $240-300-240$ & 50 & 14.9 & 4.50 & 0.397 & 9068 & 653.9 & 1.000 \\
\hline 300 & 50 & 19.8 & 4.50 & 1.008 & 3571 & 385.1 & 0.994 \\
\hline 300 & 50 & 25.1 & 4.50 & 2.159 & 1667 & 257.3 & 0.994 \\
\hline 300 & 50 & 30.1 & 4.50 & 3.459 & 1041 & 219.9 & 0.997 \\
\hline 300 & 70 & 15.0 & 4.50 & 0.388 & 9278 & 669.4 & 0.985 \\
\hline 300 & 70 & 20.0 & 4.50 & 0.993 & 3625 & 387.4 & 0.975 \\
\hline 300 & 70 & 25.1 & 4.50 & 2.081 & 1730 & 254.8 & 0.995 \\
\hline 300 & 70 & 30.1 & 4.50 & 3.163 & 1138 & 201.2 & 0.996 \\
\hline
\end{tabular}


Table C5.2. Design summary for cross section $2\left(\mathrm{~S}=11^{\prime}-6\right.$ ')

Simple-Span Composite Plate Girder Using SIMON-LFD

\begin{tabular}{|c|c|c|c|c|c|c|c|}
\hline $\begin{array}{c}\text { Span } \\
\text { Length } \\
\text { ft. }\end{array}$ & $\begin{array}{c}\text { Fy } \\
\text { ksi }\end{array}$ & $\begin{array}{c}\text { L/D } \\
\text { Ratio }\end{array}$ & $\begin{array}{c}\text { L/800 } \\
\text { in. }\end{array}$ & $\begin{array}{c}\text { Deflection } \\
\text { in. }\end{array}$ & L/ $\delta$ & $\begin{array}{c}\text { Total } \\
\text { Steel Wt } \\
\text { tons }\end{array}$ & $\begin{array}{c}\text { Performance } \\
\text { Ratio }\end{array}$ \\
\hline 100 & 50 & 14.9 & 1.50 & 0.705 & 1702 & 11 & 0.995 \\
\hline 100 & 50 & 20.3 & 1.50 & 1.057 & 1135 & 11 & 0.996 \\
\hline 100 & 50 & 25.3 & 1.50 & 1.416 & 847 & 13 & 0.999 \\
\hline 100 & 50 & NA & 1.50 & NA & NA & NA & NA \\
\hline 100 & 70 & 15.1 & 1.50 & 0.719 & 1669 & 11 & 0.995 \\
\hline 100 & 70 & 19.7 & 1.50 & 1.029 & 1166 & 10 & 0.994 \\
\hline 100 & 70 & 25.3 & 1.50 & 1.474 & 814 & 12 & 0.991 \\
\hline 100 & 70 & 30.4 & 1.50 & 1.908 & 629 & 15 & 0.992 \\
\hline 200 & 50 & 15.0 & 3.00 & 0.868 & 2765 & 75 & 0.992 \\
\hline 200 & 50 & 19.9 & 3.00 & 1.752 & 1370 & 50 & 0.998 \\
\hline 200 & 50 & 25.2 & 3.00 & 2.391 & 1004 & 49 & 1.000 \\
\hline 200 & 50 & 29.9 & 3.00 & 2.841 & 845 & 70 & 0.999 \\
\hline 200 & 70 & 15.0 & 3.00 & 0.793 & 3026 & 84 & 0.994 \\
\hline 200 & 70 & 19.9 & 3.00 & 1.925 & 1247 & 50 & 0.999 \\
\hline 200 & 70 & 25.1 & 3.00 & 2.610 & 919 & 44 & 0.993 \\
\hline 200 & 70 & 30.1 & 3.00 & 3.376 & 711 & 50 & 0.996 \\
\hline \hline 300 & 50 & 15.0 & 4.50 & 0.894 & 4027 & 293 & 1.000 \\
\hline 300 & 50 & 20.0 & 4.50 & 2.386 & 1509 & 155 & 0.993 \\
\hline 300 & 50 & 24.9 & 4.50 & 3.162 & 1138 & 149 & 0.996 \\
\hline 300 & 50 & 29.9 & 4.50 & 3.852 & 935 & 164 & 1.000 \\
\hline 300 & 70 & 15.1 & 4.50 & 0.929 & 3875 & 280 & 0.995 \\
\hline 300 & 70 & 20.0 & 4.50 & 2.436 & 1478 & 162 & 0.990 \\
\hline 300 & 70 & 24.9 & 4.50 & 3.653 & 985 & 128 & 0.992 \\
\hline 300 & 70 & 29.6 & 4.50 & 4.653 & 774 & 126 & 0.996 \\
\hline
\end{tabular}


Table C5.2. Continued

Two-Span Continuous Composite Plate Girder Using SIMON-LFD

\begin{tabular}{|c|c|c|c|c|c|c|c|}
\hline $\begin{array}{c}\text { Span } \\
\text { Length } \\
\text { ft. }\end{array}$ & $\begin{array}{c}\text { Fy } \\
\text { ksi }\end{array}$ & $\begin{array}{c}\text { L/D } \\
\text { Ratio }\end{array}$ & $\begin{array}{c}\text { L/800 } \\
\text { in. }\end{array}$ & $\begin{array}{c}\text { Deflection } \\
\text { in. }\end{array}$ & L/ $\delta$ & $\begin{array}{c}\text { Total } \\
\text { Steel Wt } \\
\text { tons }\end{array}$ & $\begin{array}{c}\text { Performance } \\
\text { Ratio }\end{array}$ \\
\hline $100+100$ & 50 & 14.9 & 1.50 & 0.479 & 2505 & 22.9 & 0.988 \\
\hline $100+100$ & 50 & 20.0 & 1.50 & 0.716 & 1676 & 25.8 & 0.994 \\
\hline $100+100$ & 50 & 24.9 & 1.50 & 0.921 & 1303 & 33.5 & 0.998 \\
\hline $100+100$ & 50 & 27.6 & 1.50 & NA & NA & NA & NA \\
\hline $100+100$ & 70 & 15.1 & 1.50 & 0.500 & 2400 & 23.1 & 0.989 \\
\hline $100+100$ & 70 & 19.8 & 1.50 & 0.728 & 1648 & 20.6 & 0.984 \\
\hline $100+100$ & 70 & 24.3 & 1.50 & 1.001 & 1199 & 24.1 & 0.997 \\
\hline $100+100$ & 70 & 28.2 & 1.50 & 1.233 & 973 & 29.0 & 0.996 \\
\hline $200+200$ & 50 & 14.9 & 3.00 & 0.589 & 4075 & 148.1 & 0.984 \\
\hline $200+200$ & 50 & 20.0 & 3.00 & 1.349 & 1779 & 102.1 & 0.995 \\
\hline $200+200$ & 50 & 24.2 & 3.00 & 1.580 & 1519 & 109.4 & 0.997 \\
\hline $200+200$ & 50 & 30.6 & 3.00 & 2.402 & 999 & 136.9 & 1.000 \\
\hline $200+200$ & 70 & 15.0 & 3.00 & 0.544 & 4412 & 171.8 & 0.972 \\
\hline $200+200$ & 70 & 20.0 & 3.00 & 1.406 & 1707 & 99.6 & 0.973 \\
\hline $200+200$ & 70 & 24.8 & 3.00 & 2.171 & 1106 & 85.7 & 0.991 \\
\hline $200+200$ & 70 & 29.2 & 3.00 & 2.729 & 879 & 92.5 & 0.999 \\
\hline $300+300$ & 50 & 14.9 & 4.50 & 0.644 & 5590 & 521.1 & 0.987 \\
\hline $300+300$ & 50 & 19.8 & 4.50 & 1.588 & 2267 & 316.4 & 0.990 \\
\hline $300+300$ & 50 & 25.0 & 4.50 & 2.448 & 1471 & 292.0 & 0.998 \\
\hline $300+300$ & 50 & 29.9 & 4.50 & 2.989 & 1204 & 344.4 & 0.994 \\
\hline $300+300$ & 70 & 15.0 & 4.50 & 0.621 & 5797 & 574.5 & 0.977 \\
\hline $300+300$ & 70 & 19.8 & 4.50 & 1.571 & 2292 & 344.0 & 1.000 \\
\hline $300+300$ & 70 & 24.8 & 4.50 & 3.052 & 1180 & 247.8 & 0.995 \\
\hline $300+300$ & 70 & 29.5 & 4.50 & 4.014 & 897 & 241.9 & 0.999 \\
\hline
\end{tabular}


Table C5.2. Continued

Three-Span Continuous Composite Plate Girder Using SIMON-LFD

\begin{tabular}{|c|c|c|c|c|c|c|c|}
\hline $\begin{array}{c}\text { Span } \\
\text { Length } \\
\text { ft. }\end{array}$ & $\begin{array}{c}\text { Fy } \\
\text { ksi }\end{array}$ & $\begin{array}{c}\text { L/D } \\
\text { Ratio }\end{array}$ & $\begin{array}{c}\text { L/800 } \\
\text { in. }\end{array}$ & $\begin{array}{c}\text { Deflection } \\
\text { in. }\end{array}$ & L/ $\mathbf{c}$ & $\begin{array}{c}\text { Total } \\
\text { Steel Wt } \\
\text { tons }\end{array}$ & $\begin{array}{c}\text { Performance } \\
\text { Ratio }\end{array}$ \\
\hline $80-100-80$ & 50 & 14.9 & 1.50 & 0.405 & 2963 & 26.0 & 0.997 \\
\hline 100 & 50 & 20.3 & 1.50 & 0.604 & 1987 & 27.9 & 0.997 \\
\hline 100 & 50 & 24.8 & 1.50 & 0.789 & 1521 & 34.6 & 1.000 \\
\hline 100 & 50 & 29.7 & 1.50 & 0.958 & 1253 & 42.0 & 0.997 \\
\hline 100 & 70 & 15.1 & 1.50 & 0.392 & 3061 & 28.1 & 0.967 \\
\hline 100 & 70 & 20.0 & 1.50 & 0.641 & 1872 & 23.3 & 0.988 \\
\hline 100 & 70 & 24.6 & 1.50 & 0.967 & 1384 & 25.8 & 0.993 \\
\hline 100 & 70 & 29.0 & 1.50 & 1.088 & 1103 & 31.2 & 0.974 \\
\hline $160-200-160$ & 50 & 14.9 & 3.00 & 0.399 & 6015 & 188.9 & 0.985 \\
\hline 200 & 50 & 20.0 & 3.00 & 1.007 & 2383 & 115.8 & 0.997 \\
\hline 200 & 50 & 24.6 & 3.00 & 1.605 & 1495 & 110.5 & 0.995 \\
\hline 200 & 50 & 30.5 & 3.00 & 2.241 & 1071 & 126.5 & 0.996 \\
\hline 200 & 70 & 15.0 & 3.00 & 0.396 & 6061 & 193.0 & 0.999 \\
\hline 200 & 70 & 20.1 & 3.00 & 0.993 & 2417 & 115.6 & 0.994 \\
\hline 200 & 70 & 24.9 & 3.00 & 1.530 & 1569 & 96.6 & 1.000 \\
\hline 200 & 70 & 29.4 & 3.00 & 1.932 & 1242 & 97.1 & 0.998 \\
\hline $240-300-240$ & 50 & 14.9 & 4.50 & 0.464 & 7759 & 647.9 & 0.993 \\
\hline 300 & 50 & 19.9 & 4.50 & 1.169 & 3080 & 380.5 & 0.988 \\
\hline 300 & 50 & 25.2 & 4.50 & 2.000 & 1800 & 325.7 & 0.992 \\
\hline 300 & 50 & 30.1 & 4.50 & 2.392 & 1505 & 378.8 & 0.996 \\
\hline 300 & 70 & 15.0 & 4.50 & 0.431 & 8352 & 676.7 & 0.985 \\
\hline 300 & 70 & 19.9 & 4.50 & 1.111 & 3240 & 388.6 & 0.986 \\
\hline 300 & 70 & 25.0 & 4.50 & 2.244 & 1604 & 269.4 & 1.000 \\
\hline 300 & 70 & 29.6 & 4.50 & 2.989 & 1204 & 242.5 & 0.999 \\
\hline
\end{tabular}


Table C5.3. Design summary for cross section 3 ( $\mathrm{S}=10$ '-4”)

Simple-Span Composite Plate Girder Using SIMON-LFD

\begin{tabular}{|c|c|c|c|c|c|c|c|}
\hline $\begin{array}{c}\text { Span } \\
\text { Length } \\
\text { ft. }\end{array}$ & $\begin{array}{c}\text { Fy } \\
\text { ksi }\end{array}$ & $\begin{array}{c}\text { R/D } \\
\text { Ratio }\end{array}$ & $\begin{array}{c}\text { L/800 } \\
\text { in. }\end{array}$ & $\begin{array}{c}\text { Deflection } \\
\text { in. }\end{array}$ & L/ 8 & $\begin{array}{c}\text { Total } \\
\text { Steel Wt } \\
\text { tons }\end{array}$ & $\begin{array}{c}\text { Performance } \\
\text { Ratio }\end{array}$ \\
\hline 100 & 50 & 15.2 & 1.500 & 0.822 & 1460 & 10.48 & 0.986 \\
\hline 100 & 50 & 19.9 & 1.500 & 1.192 & 1007 & 9.70 & 0.985 \\
\hline 100 & 50 & 25.3 & 1.500 & 1.654 & 726 & 11.42 & 0.985 \\
\hline 100 & 50 & 30.0 & 1.500 & 1.911 & 628 & 14.93 & 0.985 \\
\hline 100 & 70 & 15.2 & 1.500 & 0.822 & 1460 & 10.48 & 0.986 \\
\hline 100 & 70 & 19.9 & 1.500 & 1.192 & 1007 & 9.70 & 0.985 \\
\hline 100 & 70 & 24.6 & 1.500 & 1.634 & 734 & 10.86 & 0.997 \\
\hline 100 & 70 & 30.0 & 1.500 & 2.191 & 548 & 12.72 & 0.983 \\
\hline 150 & 50 & 14.7 & 2.250 & 0.846 & 2128 & 31.26 & 0.971 \\
\hline 150 & 50 & 19.5 & 2.250 & 1.613 & 1116 & 20.87 & 0.999 \\
\hline 150 & 50 & 24.8 & 2.250 & 2.154 & 836 & 22.49 & 0.992 \\
\hline 150 & 50 & 30.2 & 2.250 & 2.532 & 711 & 26.27 & 0.989 \\
\hline 150 & 70 & 15.0 & 2.250 & 0.800 & 2250 & 33.87 & 0.985 \\
\hline 150 & 70 & 19.9 & 2.250 & 1.805 & 997 & 20.18 & 0.981 \\
\hline 150 & 70 & 24.9 & 2.250 & 2.491 & 723 & 20.17 & 0.999 \\
\hline 150 & 70 & 29.8 & 2.250 & 3.173 & 567 & 21.10 & 0.990 \\
\hline 200 & 50 & 15.0 & 3.000 & 0.921 & 2606 & 75.77 & 0.974 \\
\hline 200 & 50 & 20.0 & 3.000 & 2.087 & 1150 & 46.24 & 0.999 \\
\hline 200 & 50 & 25.1 & 3.000 & 2.829 & 848 & 41.69 & 0.986 \\
\hline 200 & 50 & 29.9 & 3.000 & 3.350 & 716 & 48.95 & 0.999 \\
\hline 200 & 70 & 15.0 & 3.000 & 0.881 & 2724 & 81.68 & 0.977 \\
\hline 200 & 70 & 20.0 & 3.000 & 2.296 & 1045 & 47.05 & 0.983 \\
\hline 200 & 70 & 25.0 & 3.000 & 3.293 & 729 & 36.82 & 0.999 \\
\hline 200 & 70 & 30.8 & 3.000 & 4.205 & 571 & 37.48 & 0.998 \\
\hline 250 & 50 & 15.0 & 3.750 & 0.895 & 3352 & 180.42 & 0.978 \\
\hline 250 & 50 & 20.1 & 3.750 & 2.392 & 1254 & 91.92 & 0.989 \\
\hline 250 & 50 & 24.7 & 3.750 & 3.363 & 892 & 74.45 & 0.989 \\
\hline 250 & 50 & 30.0 & 3.750 & 3.489 & 860 & 102.84 & 0.995 \\
\hline 250 & 70 & 15.0 & 3.750 & 0.998 & 3006 & 150.62 & 0.996 \\
\hline 250 & 70 & 20.0 & 3.750 & 2.625 & 1143 & 87.63 & 0.968 \\
\hline 250 & 70 & 24.9 & 3.750 & 3.863 & 777 & 69.24 & 0.999 \\
\hline 250 & 70 & 30.0 & 3.750 & 5.189 & 578 & 63.34 & 0.998 \\
\hline
\end{tabular}


Table C5.3. Continued

Two-Span Continuous Composite Plate Girder Using SIMON-LFD

\begin{tabular}{|c|c|c|c|c|c|c|c|}
\hline $\begin{array}{c}\text { Span } \\
\text { Length } \\
\text { ft. }\end{array}$ & $\begin{array}{l}\text { Fy } \\
\text { ksi }\end{array}$ & $\begin{array}{l}0.8 \mathrm{~L} / \mathrm{D} \\
\text { Ratio }\end{array}$ & $\begin{array}{c}\text { L/800 } \\
\text { in. }\end{array}$ & $\begin{array}{c}\text { Deflection } \\
\text { in. }\end{array}$ & $\mathrm{L} / \delta$ & $\begin{array}{c}\text { Total } \\
\text { Steel Wt } \\
\text { tons } \\
\end{array}$ & $\begin{array}{c}\text { Performance } \\
\text { Ratio }\end{array}$ \\
\hline $100+100$ & 50 & 15.0 & 1.500 & 0.771 & 1556 & 21.27 & 0.994 \\
\hline $100+100$ & 50 & 19.3 & 1.500 & 1.120 & 1071 & 23.73 & 0.996 \\
\hline $100+10$ & 50 & \multirow{2}{*}{\multicolumn{6}{|c|}{ No acceptable design could be found }} \\
\hline $100+100$ & 50 & & & & & & \\
\hline $100+100$ & 70 & \multirow{4}{*}{\multicolumn{6}{|c|}{ No acceptable design could be found }} \\
\hline $100+100$ & 70 & & & & & & \\
\hline $100+100$ & 70 & & & & & & \\
\hline $100+100$ & 70 & & & & & & \\
\hline $150+150$ & 50 & 15.0 & 2.250 & 1.132 & 1590 & 45.57 & 0.991 \\
\hline $150+150$ & 50 & 20.1 & 2.250 & 1.761 & 1022 & 45.72 & 0.999 \\
\hline $150+150$ & 50 & 24.9 & 2.250 & 2.353 & 765 & 56.88 & 0.999 \\
\hline $150+150$ & 50 & 30.0 & 2.250 & 2.889 & 623 & 76.88 & 0.981 \\
\hline $150+150$ & 70 & 15.1 & 2.250 & 1.166 & 1544 & 46.43 & 0.999 \\
\hline $150+150$ & 70 & 20.0 & 2.250 & 1.763 & 1021 & 40.74 & 0.987 \\
\hline $150+150$ & 70 & 24.8 & 2.250 & 2.436 & 739 & 43.78 & 0.992 \\
\hline 150150 & 70 & 30.0 & 2.250 & 3.133 & 575 & 55.68 & 0.997 \\
\hline $200+200$ & 50 & 14.9 & 3.000 & 1.265 & 1897 & 101.32 & 0.991 \\
\hline $200+200$ & 50 & 20.1 & 3.000 & 2.443 & 982 & 83.54 & 0.990 \\
\hline $200+200$ & 50 & 24.9 & 3.000 & 3.297 & 728 & 100.27 & 0.978 \\
\hline $200+200$ & 50 & 29.5 & 3.000 & 3.586 & 669 & 132.12 & 0.978 \\
\hline $200+200$ & 70 & 15.1 & 3.000 & 1.233 & 1946 & 109.73 & 0.956 \\
\hline $200+200$ & 70 & 20.1 & 3.000 & 2.587 & 928 & 76.67 & 0.996 \\
\hline $200+200$ & 70 & 25.0 & 3.000 & 3.712 & 647 & 75.97 & 0.995 \\
\hline $200+200$ & 70 & 29.7 & 3.000 & 4.598 & 522 & 91.45 & 0.982 \\
\hline $250+250$ & 50 & 15.0 & 3.750 & 1.380 & 2174 & 193.17 & 0.988 \\
\hline $250+250$ & 50 & 20.0 & 3.750 & 2.916 & 1029 & 143.63 & 0.985 \\
\hline $250+250$ & 50 & 25.0 & 3.750 & 3.621 & 829 & 172.33 & 0.999 \\
\hline $250+250$ & 50 & 30.0 & 3.750 & 4.168 & 720 & 224.77 & 0.992 \\
\hline $250+250$ & 70 & 15.0 & 3.750 & 1.382 & 2171 & 203.42 & 0.995 \\
\hline $250+250$ & 70 & 20.0 & 3.750 & 3.228 & 929 & 131.05 & 0.996 \\
\hline $250+250$ & 70 & 25.1 & 3.750 & 4.764 & 630 & 126.35 & 1.000 \\
\hline $250+250$ & 70 & 30.0 & 3.750 & 6.024 & 498 & 148.23 & 0.973 \\
\hline
\end{tabular}


Table C5.3. Continued

Simple-Span Composite Plate Girder Using MDX-LRFD

\begin{tabular}{|c|c|c|c|c|c|c|c|}
\hline $\begin{array}{c}\text { Span } \\
\text { Length } \\
\text { ft. }\end{array}$ & $\begin{array}{c}\text { Fy } \\
\text { ksi }\end{array}$ & $\begin{array}{c}\text { L/D } \\
\text { Ratio }\end{array}$ & $\begin{array}{c}\text { L/800 } \\
\text { in. }\end{array}$ & $\begin{array}{c}\text { Deflection } \\
\text { in. }\end{array}$ & L/ 8 & $\begin{array}{c}\text { Total } \\
\text { Steel Wt } \\
\text { tons }\end{array}$ & $\begin{array}{c}\text { Performance } \\
\text { Ratio }\end{array}$ \\
\hline 100 & 50 & 15.2 & 1.50 & 0.783 & 1533 & 7.8 & 0.977 \\
\hline 100 & 50 & 20.1 & 1.50 & 1.152 & 1042 & 7.6 & 0.999 \\
\hline 100 & 50 & 25.5 & 1.50 & 1.455 & 825 & 8.9 & 0.983 \\
\hline 100 & 50 & 30.5 & 1.50 & 1.881 & 638 & 11.9 & 0.998 \\
\hline 100 & 70 & 15.0 & 1.50 & 0.812 & 1478 & 7.4 & 0.976 \\
\hline 100 & 70 & 20.2 & 1.50 & 1.176 & 1020 & 7.8 & 0.979 \\
\hline 100 & 70 & 25.3 & 1.50 & 1.595 & 752 & 8.0 & 0.988 \\
\hline 100 & 70 & 30.5 & 1.50 & 2.062 & 582 & 9.5 & 0.995 \\
\hline 150 & 50 & 15.0 & 2.25 & 0.615 & 2927 & 25.1 & 0.856 \\
\hline 150 & 50 & 20.0 & 2.25 & 1.347 & 1336 & 17.7 & 0.998 \\
\hline 150 & 50 & 24.9 & 2.25 & 1.828 & 985 & 18.9 & 0.995 \\
\hline 150 & 50 & 29.9 & 2.25 & 2.225 & 809 & 19.7 & 0.996 \\
\hline 150 & 70 & 15.0 & 2.25 & 0.615 & 2927 & 25.1 & 0.850 \\
\hline 150 & 70 & 20.0 & 2.25 & 1.375 & 1326 & 18.9 & 0.985 \\
\hline 150 & 70 & 24.9 & 2.25 & 1.905 & 945 & 16.8 & 1.000 \\
\hline 150 & 70 & 29.7 & 2.25 & 2.464 & 731 & 16.9 & 0.994 \\
\hline 200 & 50 & 15.0 & 3.00 & 0.732 & 3279 & 48.0 & 0.875 \\
\hline 200 & 50 & 20.0 & 3.00 & 1.525 & 1574 & 36.6 & 0.992 \\
\hline 200 & 50 & 25.3 & 3.00 & 2.166 & 1108 & 35.0 & 0.995 \\
\hline 200 & 50 & 30.4 & 3.00 & 2.706 & 887 & 35.3 & 0.991 \\
\hline 200 & 70 & 15.0 & 3.00 & 0.755 & 3179 & 46.9 & 0.788 \\
\hline 200 & 70 & 20.0 & 3.00 & 1.592 & 1508 & 37.0 & 0.992 \\
\hline 200 & 70 & 25.0 & 3.00 & 2.234 & 1074 & 32.3 & 0.984 \\
\hline 200 & 70 & 30.2 & 3.00 & 2.958 & 811 & 32.3 & 0.987 \\
\hline 250 & 50 & 15.0 & 3.75 & 0.881 & 3405 & 85.5 & 0.867 \\
\hline 250 & 50 & 20.1 & 3.75 & 1.553 & 1932 & 69.4 & 0.982 \\
\hline 250 & 50 & 24.8 & 3.75 & 2.537 & 1182 & 58.4 & 0.997 \\
\hline 250 & 50 & 30.6 & 3.75 & 3.096 & 969 & 65.9 & 0.995 \\
\hline 250 & 70 & 15.0 & 3.75 & 0.944 & 3178 & 86.2 & 0.884 \\
\hline 250 & 70 & 20.0 & 3.75 & 1.927 & 1557 & 63.8 & 0.994 \\
\hline 250 & 70 & 25.1 & 3.75 & 2.670 & 1124 & 59.7 & 0.992 \\
\hline 250 & 70 & 30.2 & 3.75 & 3.487 & 860 & 56.8 & 0.982 \\
\hline & & & & & & & \\
\hline
\end{tabular}


Table C5.3. Continued

Two-Span Continuous Composite Plate Girder Using MDX-LRFD

\begin{tabular}{|c|c|c|c|c|c|c|c|}
\hline $\begin{array}{c}\text { Span } \\
\text { Length } \\
\mathrm{ft.}\end{array}$ & $\begin{array}{l}\text { Fy } \\
\text { ksi }\end{array}$ & $\begin{array}{c}0.8 \mathrm{~L} / \mathrm{D} \\
\text { Ratio }\end{array}$ & $\begin{array}{l}\text { L/800 } \\
\text { in. }\end{array}$ & $\begin{array}{l}\text { Deflection } \\
\text { in. }\end{array}$ & $\mathrm{L} / \delta$ & $\begin{array}{c}\text { Total } \\
\text { Steel Wt } \\
\text { tons }\end{array}$ & $\begin{array}{c}\text { Performance } \\
\text { Ratio }\end{array}$ \\
\hline $100+100$ & 50 & 15.0 & 1.50 & 0.722 & 1662 & 18.2 & 0.995 \\
\hline $100+100$ & 50 & 19.8 & 1.50 & 1.078 & 1113 & 19.1 & 0.986 \\
\hline $100+100$ & 50 & \multirow{2}{*}{\multicolumn{6}{|c|}{ No acceptable design could be found }} \\
\hline $100+100$ & 50 & & & & & & \\
\hline $100+100$ & 70 & \multirow{4}{*}{\multicolumn{6}{|c|}{ No acceptable design could be found }} \\
\hline $100+100$ & 70 & & & & & & \\
\hline $100+100$ & 70 & & & & & & \\
\hline $100+100$ & 70 & & & & & & \\
\hline $150+150$ & $\overline{50}$ & 15.0 & 2.25 & 0.918 & 1961 & 44.3 & 0.989 \\
\hline $150+150$ & 50 & 20.4 & 2.25 & 1.449 & 1242 & 41.7 & 0.991 \\
\hline $150+150$ & 50 & 25.3 & 2.25 & 2.123 & 848 & 49.3 & 0.999 \\
\hline $150+150$ & 50 & 30.1 & 2.25 & 2.535 & 710 & 62.3 & 0.983 \\
\hline $150+150$ & 70 & 15.1 & 2.25 & 0.946 & 1903 & 36.5 & 0.994 \\
\hline $150+150$ & 70 & 19.7 & 2.25 & 1.660 & 1084 & 34.4 & 0.990 \\
\hline $150+150$ & 70 & 24.8 & 2.25 & 2.154 & 836 & 39.5 & 0.992 \\
\hline $150+150$ & 70 & 30.0 & 2.25 & 2.305 & 781 & 53.6 & 0.999 \\
\hline $200+200$ & 50 & 14.9 & 3.00 & 0.870 & 2759 & 85.2 & 0.984 \\
\hline $200+200$ & 50 & 20.4 & 3.00 & 1.494 & 1616 & 82.8 & 1.000 \\
\hline $200+200$ & 50 & 25.1 & 3.00 & 1.972 & 1217 & 98.7 & 0.992 \\
\hline $200+200$ & 50 & 29.9 & 3.00 & 2.920 & 822 & 95.1 & 0.974 \\
\hline $200+200$ & 70 & 15.1 & 3.00 & 0.971 & 2473 & 75.0 & 0.992 \\
\hline $200+200$ & 70 & 20.1 & 3.00 & 1.851 & 1297 & 66.9 & 0.998 \\
\hline $200+200$ & 70 & 25.1 & 3.00 & 2.491 & 963 & 74.2 & 0.999 \\
\hline $200+200$ & 70 & 29.8 & 3.00 & 2.785 & 862 & 76.5 & 0.996 \\
\hline $250+250$ & 50 & 15.0 & 3.75 & 0.930 & 3226 & 156.9 & 0.982 \\
\hline $250+250$ & 50 & 20.2 & 3.75 & 1.748 & 1716 & 146.0 & 1.000 \\
\hline $250+250$ & 50 & 25.0 & 3.75 & 2.011 & 1492 & 181.9 & 0.998 \\
\hline $250+250$ & 50 & & 3.75 & \multicolumn{4}{|c|}{ No acceptable design could be found } \\
\hline $250+250$ & 70 & 15.0 & 3.75 & 1.098 & 2732 & 139.1 & 1.000 \\
\hline $250+250$ & 70 & 20.0 & 3.75 & 2.012 & 1491 & 113.6 & 0.995 \\
\hline $250+250$ & 70 & 25.0 & 3.75 & 2.614 & 1148 & 128.7 & 0.997 \\
\hline $250+250$ & 70 & 30.0 & 3.75 & 3.340 & 898 & 150.2 & 0.991 \\
\hline
\end{tabular}


Table C5.4. Design summary for cross section $4\left(\mathrm{~S}=8^{\prime}-6^{\prime \prime}\right)$

Simple-Span Composite Plate Girder Using SIMON-LFD

\begin{tabular}{|c|c|c|c|c|c|c|c|}
\hline $\begin{array}{c}\text { Span } \\
\text { Length } \\
\text { ft. }\end{array}$ & $\begin{array}{c}\text { Fy } \\
\text { ksi }\end{array}$ & $\begin{array}{c}\text { L/D } \\
\text { Ratio }\end{array}$ & $\begin{array}{c}\text { L/800 } \\
\text { in. }\end{array}$ & $\begin{array}{c}\text { Deflection } \\
\text { in. }\end{array}$ & L/ 8 & $\begin{array}{c}\text { Total } \\
\text { Steel Wt } \\
\text { tons }\end{array}$ & $\begin{array}{c}\text { Performance } \\
\text { Ratio }\end{array}$ \\
\hline 100 & 50 & 15 & 15.0 & 0.597 & 2010 & 9.7 & 0.985 \\
\hline 100 & 50 & 20 & 19.7 & 0.850 & 1412 & 9.8 & 0.998 \\
\hline 100 & 50 & 25 & 24.1 & 1.094 & 1097 & 11.6 & 0.983 \\
\hline 100 & 50 & 30 & 28.7 & 1.377 & 871 & 14.5 & 0.985 \\
\hline 100 & 70 & 15 & 15.0 & 0.639 & 1878 & 10.0 & 0.999 \\
\hline 100 & 70 & 20 & 19.8 & 0.932 & 1288 & 9.5 & 0.993 \\
\hline 100 & 70 & 25 & 24.6 & 1.241 & 967 & 10.2 & 0.980 \\
\hline 100 & 70 & 30 & 29.2 & 1.615 & 743 & 29.2 & 0.995 \\
\hline 200 & 50 & 15 & 15.0 & 0.687 & 3493 & 74.0 & 0.992 \\
\hline 200 & 50 & 20 & 19.9 & 1.398 & 1717 & 47.3 & 0.987 \\
\hline 200 & 50 & 25 & 24.6 & 1.993 & 1204 & 42.0 & 0.983 \\
\hline 200 & 50 & 30 & 29.3 & 2.497 & 961 & 46.2 & 0.987 \\
\hline 200 & 70 & 15 & 15.0 & 0.643 & 3733 & 83.5 & 0.993 \\
\hline 200 & 70 & 20 & 20.0 & 1.617 & 1484 & 49.7 & 0.995 \\
\hline 200 & 70 & 25 & 24.8 & 2.600 & 923 & 35.4 & 0.989 \\
\hline 200 & 70 & 30 & 29.5 & 3.287 & 732 & 35.5 & 0.999 \\
\hline 300 & 50 & 15 & 15.0 & 0.797 & 4517 & 245.6 & 0.985 \\
\hline 300 & 50 & 20 & 20.0 & 1.829 & 1968 & 152.3 & 0.990 \\
\hline 300 & 50 & 25 & 24.8 & 2.807 & 1283 & 119.7 & 1.000 \\
\hline 300 & 50 & 30 & 29.5 & 3.456 & 1042 & 124.6 & 0.992 \\
\hline 300 & 70 & 15 & 15.0 & 0.723 & 4979 & 284.5 & 0.990 \\
\hline 300 & 70 & 20 & 20.0 & 1.888 & 1907 & 166.4 & 0.999 \\
\hline 300 & 70 & 25 & 24.9 & 3.428 & 1050 & 111.4 & 0.983 \\
\hline 300 & 70 & 30 & 29.8 & 4.609 & 781 & 105.1 & 0.994 \\
\hline & & & & & & & \\
\hline
\end{tabular}


Table C5.4. Continued

Two-Span Continuous Composite Plate Girder Using SIMON-LFD

\begin{tabular}{|c|c|c|c|c|c|c|c|}
\hline $\begin{array}{c}\text { Span } \\
\text { Length } \\
\text { ft. }\end{array}$ & $\begin{array}{c}\text { Fy } \\
\text { ksi }\end{array}$ & $\begin{array}{c}\text { L/D } \\
\text { Ratio }\end{array}$ & $\begin{array}{c}\text { L/800 } \\
\text { in. }\end{array}$ & $\begin{array}{c}\text { Deflection } \\
\text { in. }\end{array}$ & L/ $\delta$ & $\begin{array}{c}\text { Total } \\
\text { Steel Wt } \\
\text { tons }\end{array}$ & $\begin{array}{c}\text { Performance } \\
\text { Ratio }\end{array}$ \\
\hline $100+100$ & 50 & 15 & 15.0 & 0.434 & 2765 & 21.8 & 0.986 \\
\hline $100+10$ & 50 & 20 & 20.0 & 0.637 & 1884 & 20.5 & 0.983 \\
\hline $100+100$ & 50 & 25 & 24.1 & 0.753 & 1594 & 27.1 & 0.990 \\
\hline $100+100$ & 50 & 30 & 28.7 & 1.004 & 1195 & 32.3 & 0.994 \\
\hline $100+100$ & 70 & 15 & 15.0 & 0.434 & 2765 & 21.8 & 0.990 \\
\hline $100+100$ & 70 & 20 & 19.8 & 0.654 & 1835 & 19.4 & 0.981 \\
\hline $100+100$ & 70 & 25 & 24.5 & 0.773 & 1552 & 24.0 & 0.981 \\
\hline $100+100$ & 70 & 30 & 28.7 & 1.031 & 1164 & 27.1 & 0.987 \\
\hline $200+200$ & 50 & 15 & 15.0 & 0.469 & 5117 & 150.4 & 0.980 \\
\hline $200+200$ & 50 & 20 & 19.9 & 1.139 & 2107 & 94.3 & 0.973 \\
\hline $200+20$ & 50 & 25 & 24.5 & 1.570 & 1529 & 88.6 & 0.996 \\
\hline $200+200$ & 50 & 30 & 29.3 & 1.974 & 1216 & 104.7 & 0.992 \\
\hline $200+200$ & 70 & 15 & 15.0 & 0.442 & 5430 & 169.0 & 0.995 \\
\hline $200+200$ & 70 & 20 & 19.9 & 1.116 & 2125 & 99.5 & 0.967 \\
\hline $200+200$ & 70 & 25 & 24.7 & 1.630 & 1472 & 83.3 & 0.996 \\
\hline $200+200$ & 70 & 30 & 29.3 & 2.076 & 1156 & 84.2 & 0.971 \\
\hline \hline $300+300$ & 50 & 15 & 14.9 & 0.524 & 6870 & 507.8 & 0.988 \\
\hline $300+300$ & 50 & 20 & 19.9 & 1.294 & 2782 & 313.5 & 0.987 \\
\hline $300+300$ & 50 & 25 & 24.7 & 2.280 & 1579 & 241.7 & 0.988 \\
\hline $300+300$ & 50 & 30 & 29.5 & 2.822 & 1276 & 265.8 & 0.986 \\
\hline $300+300$ & 70 & 15 & 14.9 & 0.499 & 7214 & 570.9 & 0.985 \\
\hline $300+300$ & 70 & 20 & 19.9 & 1.256 & 2866 & 343.3 & 0.986 \\
\hline $300+300$ & 70 & 25 & 24.8 & 2.405 & 1497 & 230.3 & 0.982 \\
\hline $300+300$ & 70 & 30 & 29.6 & 3.219 & 1118 & 214.2 & 0.993 \\
\hline
\end{tabular}


Table C5.4. Continued

Three-Span Continuous Composite Plate Girder Using SIMON-LFD

\begin{tabular}{|c|c|c|c|c|c|c|c|}
\hline $\begin{array}{c}\text { Span } \\
\text { Length } \\
\text { ft. }\end{array}$ & $\begin{array}{c}\text { Fy } \\
\text { ksi }\end{array}$ & $\begin{array}{c}\text { L/D } \\
\text { Ratio }\end{array}$ & $\begin{array}{c}\text { L/800 } \\
\text { in. }\end{array}$ & $\begin{array}{c}\text { Deflection } \\
\text { in. }\end{array}$ & L/8 & $\begin{array}{c}\text { Total } \\
\text { Steel } \\
\text { Wt } \\
\text { tons }\end{array}$ & $\begin{array}{c}\text { Performance } \\
\text { Ratio }\end{array}$ \\
\hline $80-100-80$ & 50 & 15 & 15.0 & 0.345 & 3478 & 26.1 & 0.980 \\
\hline 100 & 50 & 20 & 19.9 & 0.562 & 2135 & 22.5 & 0.977 \\
\hline 100 & 50 & 25 & 24.7 & 0.760 & 1579 & 25.1 & 0.994 \\
\hline 100 & 50 & 30 & 29.4 & 0.939 & 1278 & 29.4 & 0.972 \\
\hline 100 & 70 & 15 & 15.0 & 0.316 & 3797 & 29.0 & 0.970 \\
\hline 100 & 70 & 20 & 19.9 & 0.571 & 2101 & 22.1 & 0.999 \\
\hline 100 & 70 & 25 & 24.8 & 0.776 & 1546 & 23.2 & 0.988 \\
\hline 100 & 70 & 30 & 29.5 & 0.991 & 1211 & 26.4 & 0.976 \\
\hline $160-200-160$ & 50 & 15 & 15.0 & 0.327 & 7339 & 189.3 & 0.982 \\
\hline 200 & 50 & 20 & 20.0 & 0.825 & 2909 & 110.7 & 0.977 \\
\hline 200 & 50 & 25 & 24.8 & 1.315 & 1825 & 92.6 & 0.980 \\
\hline 200 & 50 & 30 & 29.3 & 1.696 & 1415 & 90.8 & 0.996 \\
\hline 200 & 70 & 15 & 15.0 & 0.307 & 7818 & 210.1 & 0.995 \\
\hline 200 & 70 & 20 & 20.0 & 0.803 & 2989 & 120.5 & 0.962 \\
\hline 200 & 70 & 25 & 24.9 & 1.404 & 1709 & 90.3 & 1.000 \\
\hline 200 & 70 & 30 & 29.6 & 1.868 & 1285 & 81.6 & 0.993 \\
\hline \hline $240-300-240$ & 50 & 15 & 15.0 & 0.381 & 9449 & 635.8 & 0.995 \\
\hline 300 & 50 & 20 & 19.9 & 0.944 & 3814 & 385.4 & 0.991 \\
\hline 300 & 50 & 25 & 24.9 & 1.925 & 1870 & 263.2 & 0.985 \\
\hline 300 & 50 & 30 & 29.6 & 2.630 & 1369 & 232.6 & 0.993 \\
\hline 300 & 70 & 15 & 15.0 & 0.354 & 10169 & 709.2 & 0.990 \\
\hline 300 & 70 & 20 & 19.9 & 0.891 & 4040 & 422.9 & 0.975 \\
\hline 300 & 70 & 25 & 24.9 & 1.840 & 1957 & 281.8 & 0.975 \\
\hline 300 & 70 & 30 & 29.8 & 2.802 & 1285 & 215.4 & 0.999 \\
\hline & & & & & & & \\
\hline
\end{tabular}


Appendix D - Girder Elevations and Design Summary of Redesigned Bridges 
Table D5.1. Detailed redesign girder elevations for original design bridges failing L/800

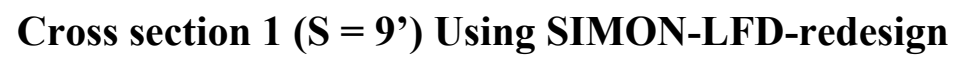

\begin{tabular}{|c|c|c|c|c|c|c|c|c|c|c|c|}
\hline \multirow[b]{2}{*}{$\begin{array}{c}\text { Span Length, ft. } \\
\text { (L) }\end{array}$} & \multicolumn{2}{|c|}{$\begin{array}{c}\text { Top Flange } \\
\text { (A) }\end{array}$} & \multicolumn{2}{|c|}{$\begin{array}{c}\text { Top Flange } \\
\text { (B) }\end{array}$} & \multirow[b]{2}{*}{$\begin{array}{l}\text { Web Plate, in. } \\
\text { (F) }\end{array}$} & \multicolumn{2}{|c|}{$\begin{array}{c}\text { Bottom Flange } \\
\text { (A) }\end{array}$} & \multicolumn{2}{|c|}{$\begin{array}{c}\text { Bottom Flange } \\
\text { (B) }\end{array}$} & \multirow[b]{2}{*}{$\begin{array}{l}\text { Fy, } \\
\text { ksi }\end{array}$} & \multirow[b]{2}{*}{$\begin{array}{c}\text { L/D } \\
\text { (Actual) }\end{array}$} \\
\hline & Plate, in. & Length, ft. & Plate, in. & $\begin{array}{c}\text { Length, } \\
\text { ft. }\end{array}$ & & Plate, in. & Length, ft. & Plate, in. & Length,ft. & & \\
\hline \multicolumn{12}{|l|}{ Simple span } \\
\hline 100 & $18 \times 115 / 16$ & 100 & & & $27 \times 3 / 4$ & $20 \times 215 / 16$ & 100 & & & 50 & 30.0 \\
\hline 100 & $17 \times 21 / 2$ & 100 & & & $27 \times 11 / 16$ & $18 \times 3$ & 100 & & & 70 & 29.6 \\
\hline 200 & $19 \times 2$ & 200 & & & $67 \times 7 / 16$ & $22 \times 3$ & 200 & & & 50 & 30.0 \\
\hline 200 & $20 \times 21 / 2$ & 200 & & & $65 \times 5 / 8$ & $27 \times 3$ & 200 & & & 70 & 30.6 \\
\hline 300 & $30 \times 2$ & 300 & & & $108 \times 11 / 8$ & $35 \times 21 / 16$ & 300 & & & 70 & 30.0 \\
\hline \multicolumn{12}{|l|}{ Two span } \\
\hline $300+300$ & $29 \times 11 / 8$ & 225 & $29 \times 21 / 2$ & 75 & $108 \times 7 / 8$ & $30 \times 11 / 8$ & 225 & $\begin{array}{c}30 \times 2 \\
3 / 4\end{array}$ & 75 & 70 & 29.7 \\
\hline
\end{tabular}

\section{Cross section 2 (S = 11'-6") Using SIMON-LFD-redesign}

\begin{tabular}{|c|c|c|c|c|c|c|c|c|c|c|c|}
\hline \multirow[b]{2}{*}{$\begin{array}{c}\text { Span Length, ft. } \\
\text { (L) }\end{array}$} & \multicolumn{2}{|c|}{$\begin{array}{c}\text { Top Flange } \\
\text { (A) }\end{array}$} & \multicolumn{2}{|c|}{$\begin{array}{l}\text { Top Flange } \\
\text { (B) }\end{array}$} & \multirow[b]{2}{*}{$\begin{array}{l}\text { Web Plate, in. } \\
\text { (F) }\end{array}$} & \multicolumn{2}{|c|}{$\begin{array}{c}\text { Bottom Flange } \\
\text { (A) }\end{array}$} & \multicolumn{2}{|c|}{$\begin{array}{l}\text { Bottom Flange } \\
\text { (B) }\end{array}$} & \multirow[b]{2}{*}{$\begin{array}{l}\text { Fy, } \\
\text { ksi }\end{array}$} & \multirow[b]{2}{*}{$\begin{array}{c}\text { L/D } \\
\text { (Actual) }\end{array}$} \\
\hline & Plate, in. & Length, ft. & Plate, in. & $\begin{array}{c}\text { Length, } \\
\text { ft. }\end{array}$ & & Plate, in. & Length, ft. & Plate, in. & Length,ft. & & \\
\hline \multicolumn{12}{|l|}{ Simple span } \\
\hline 100 & $22 \times 21 / 2$ & 100 & & & $25 \times 11 / 8$ & $24 \times 3$ & 100 & & & 70 & 30.0 \\
\hline 200 & $19 \times 2$ & 200 & & & $67 \times 5 / 8$ & $21 \times 3$ & 200 & & & 70 & 29.5 \\
\hline 300 & $34 \times 2$ & 300 & & & $107 \times 11 / 8$ & $41 \times 21 / 4$ & 300 & & & 70 & 29.8 \\
\hline
\end{tabular}


Table D5.1. Continued

Cross Section 3 (S = 10'-4") Using SIMON-LFD-redesign

\begin{tabular}{|c|c|c|c|c|c|c|c|c|c|c|c|}
\hline \multirow{2}{*}{$\begin{array}{c}\text { Span Length, } \\
\text { ft. } \\
\text { (L) }\end{array}$} & \multicolumn{2}{|c|}{$\begin{array}{c}\text { Top Flange } \\
\text { (A) }\end{array}$} & \multicolumn{2}{|c|}{$\begin{array}{c}\text { Top Flange } \\
\text { (B) }\end{array}$} & \multirow[b]{2}{*}{$\begin{array}{l}\text { Web Plate, in. } \\
\text { (F) }\end{array}$} & \multicolumn{2}{|c|}{$\begin{array}{l}\text { Bottom Flange } \\
\text { (A) }\end{array}$} & \multicolumn{2}{|c|}{$\begin{array}{c}\text { Bottom Flange } \\
\text { (B) }\end{array}$} & \multirow[b]{2}{*}{$\begin{array}{l}\text { Fy, } \\
\text { ksi }\end{array}$} & \multirow[b]{2}{*}{$\begin{array}{c}\text { L/D } \\
\text { (Actual) }\end{array}$} \\
\hline & Plate, in. & Length, ft. & $\begin{array}{l}\text { Plate, } \\
\text { in. }\end{array}$ & $\begin{array}{c}\text { Length, } \\
\text { ft. }\end{array}$ & & Plate, in. & Length, ft. & Plate, in. & $\begin{array}{c}\text { Length, } \\
\text { ft. }\end{array}$ & & \\
\hline \multicolumn{12}{|l|}{ Simple Span } \\
\hline 100 & $14 \times 15 / 8$ & 100 & & & $35 \times 7 / 16$ & $16 \times 23 / 4$ & 100 & & & 50 & 25.1 \\
\hline 100 & $24 \times 2.5$ & 100 & & & $27 \times 5 / 8$ & $26 \times 215 / 16$ & 100 & & & 50 & 29.7 \\
\hline 100 & $12 \times 1$ & 100 & & & $35 \times 7 / 16$ & $16 \times 23 / 4$ & 100 & & & 70 & 25.1 \\
\hline 100 & $24 \times 23 / 8$ & 100 & & & $27 \times 1 / 2$ & $26 \times 3$ & 100 & & & 70 & 29.7 \\
\hline 150 & $22 \times 2$ & 150 & & & $48 \times 1 / 2$ & $24 \times 3$ & 150 & & & 50 & 29.5 \\
\hline 150 & $14 \times 11 / 2$ & 150 & & & $60 \times 9 / 16$ & $16 \times 23 / 8$ & 150 & & & 70 & 24.9 \\
\hline 150 & $24 \times 23 / 8$ & 150 & & & $47 \times 9 / 16$ & $24 \times 23 / 8$ & 150 & & & 70 & 29.8 \\
\hline 200 & $26 \times 2.5$ & 200 & & & $67 \times 5 / 8$ & $28 \times 3$ & 200 & & & 50 & 29.8 \\
\hline 200 & $20 \times 11 / 16$ & 200 & & & $84 \times 3 / 4$ & $20 \times 21 / 8$ & 200 & & & 70 & 25.0 \\
\hline 200 & $26 \times 2.5$ & 200 & & & $67 \times 5 / 8$ & $28 \times 3$ & 200 & & & 70 & 29.8 \\
\hline 250 & $28 \times 15 / 16$ & 250 & & & $108 \times 13 / 16$ & $28 \times 15 / 8$ & 200 & & & 70 & 25.1 \\
\hline 250 & $32 \times 21 / 4$ & 250 & & & $87 \times 1 / 2$ & $33 \times 3$ & 200 & & & 70 & 29.9 \\
\hline
\end{tabular}


Table D5.1. Continued

Cross Section 3 (S = 10'-4") Using SIMON-LFD-redesign

\begin{tabular}{|c|c|c|c|c|c|c|c|c|c|c|c|c|c|c|c|}
\hline \multirow{2}{*}{$\begin{array}{c}\text { Span } \\
\text { Leng., } \\
\text { ft. } \\
\text { (L) }\end{array}$} & \multicolumn{2}{|c|}{$\begin{array}{l}\text { Top Flange } \\
\text { (A) }\end{array}$} & \multicolumn{2}{|c|}{$\begin{array}{c}\text { Top Flange } \\
\text { (B) }\end{array}$} & \multicolumn{2}{|c|}{$\begin{array}{c}\text { Top Flange } \\
\text { (D) } \\
\end{array}$} & \multirow[t]{2}{*}{$\begin{array}{l}\text { Web late, } \\
\text { in. (F) }\end{array}$} & \multicolumn{2}{|c|}{ (A) } & \multicolumn{2}{|c|}{$\begin{array}{c}\text { Bottom Flange } \\
\text { (B) }\end{array}$} & \multicolumn{2}{|c|}{$\begin{array}{c}\text { Bottom Flange } \\
\text { (D) }\end{array}$} & \multirow[b]{2}{*}{$\begin{array}{l}\text { Fy, } \\
\text { ksi }\end{array}$} & \multirow[b]{2}{*}{$\begin{array}{c}\text { 0.8L/D } \\
\text { (Actual) } \\
\end{array}$} \\
\hline & $\begin{array}{c}\text { Plate, } \\
\text { in. }\end{array}$ & $\begin{array}{c}\text { Leng., } \\
\text { ft. }\end{array}$ & $\begin{array}{c}\text { Plate, } \\
\text { in. }\end{array}$ & $\begin{array}{c}\text { Leng., } \\
\text { ft. }\end{array}$ & $\begin{array}{c}\text { Plate, } \\
\text { in. }\end{array}$ & $\begin{array}{c}\text { Leng., } \\
\text { ft. }\end{array}$ & & Plate, in. & $\begin{array}{c}\text { Leng., } \\
\text { ft. }\end{array}$ & $\begin{array}{c}\text { Plate } \\
\text { in. }\end{array}$ & $\begin{array}{c}\text { Leng., } \\
\text { ft. }\end{array}$ & $\begin{array}{c}\text { Plate, } \\
\text { in. }\end{array}$ & $\begin{array}{c}\text { Leng., } \\
\text { in. } \\
\end{array}$ & & \\
\hline \multicolumn{16}{|c|}{ Two Span } \\
\hline 150 & $\begin{array}{c}28 \times 1 \\
7 / 8\end{array}$ & 120 & $\begin{array}{c}28 \times 2 \\
7 / 8\end{array}$ & 30 & & & $44 \times 5 / 8$ & $30 \times 17 / 8$ & 120 & $\begin{array}{l}30 x \\
27 / 8\end{array}$ & 30 & & & 50 & 24.9 \\
\hline 150 & $\begin{array}{c}34 \times 2 \\
1 / 2 \\
\end{array}$ & 120 & $34 \times 3$ & 30 & & & $34 \times 7 / 8$ & $36 \times 23 / 4$ & 120 & $\begin{array}{c}36 \times \\
3\end{array}$ & 30 & & & 50 & 30.0 \\
\hline 150 & $\begin{array}{c}16 \times 1 \\
7 / 8 \\
\end{array}$ & 120 & $16 \times 3$ & 30 & & & $44 \times 1 / 2$ & $18 \times 27 / 8$ & 120 & $\begin{array}{c}18 \mathrm{x} \\
3 \\
\end{array}$ & 30 & & & 70 & 30.0 \\
\hline 150 & $\begin{array}{c}32 \times 2 \\
1 / 2 \\
\end{array}$ & 120 & $32 \times 3$ & 30 & & & $34 \times 5 / 8$ & $33 \times 27 / 8$ & 120 & $\begin{array}{c}33 x \\
3 \\
\end{array}$ & 30 & & & 70 & 30.0 \\
\hline 200 & $\begin{array}{c}34 \times 1 \\
1 / 2 \\
\end{array}$ & 160 & $34 \times 2$ & 25 & $34 \times 3$ & 150 & $63 \times 11 / 16$ & $34 \times 15 / 8$ & 160 & $\begin{array}{c}34 \mathrm{x} \\
2\end{array}$ & 25 & $34 \times 3$ & 150 & 50 & 24.9 \\
\hline 200 & $51 \times 2$ & 160 & $51 \times 3$ & 25 & & & $51 \times 11 / 16$ & $51 \times 23 / 8$ & 160 & $\begin{array}{c}15 x \\
3 \\
\end{array}$ & 40 & & & 50 & 29.5 \\
\hline 200 & $\begin{array}{c}24 \times 2 \\
1 / 8 \\
\end{array}$ & 160 & $24 \times 3$ & 40 & & & $63 \times 5 / 8$ & $26 \times 21 / 4$ & 160 & $\begin{array}{c}26 \mathrm{x} \\
3 \\
\end{array}$ & 40 & & & 70 & 24.9 \\
\hline 200 & $\begin{array}{c}36 \times 2 \\
3 / 8 \\
\end{array}$ & 160 & $36 \times 3$ & 40 & & & $51 \times 11 / 16$ & $38 \times 23 / 4$ & 160 & $\begin{array}{c}38 \mathrm{x} \\
3 \\
\end{array}$ & 40 & & & 70 & 29.5 \\
\hline 250 & $\begin{array}{c}52 \times 2 \\
1 / 4 \\
\end{array}$ & 200 & $52 \times 3$ & 50 & & & $66 \times 13 / 16$ & $54 \times 21 / 2$ & 200 & $\begin{array}{c}54 \mathrm{x} \\
3 \\
\end{array}$ & 50 & & & 50 & 30.0 \\
\hline 250 & $\begin{array}{c}30 \times 2 \\
1 / 2 \\
\end{array}$ & 200 & $\begin{array}{c}20 \times 2 \\
7 / 8 \\
\end{array}$ & 50 & & & $82 \times 3 / 4$ & $32 \times 2$ & 200 & $\begin{array}{l}32 x \\
27 / 8 \\
\end{array}$ & 50 & & & 70 & 25.1 \\
\hline 250 & $\begin{array}{c}42 \times 2 \\
1 / 2 \\
\end{array}$ & 200 & $42 \times 3$ & 50 & & & $66 \times 3 / 4$ & $44 \times 23 / 4$ & 200 & $\begin{array}{c}44 \mathrm{x} \\
3\end{array}$ & 50 & & & 70 & 30.0 \\
\hline
\end{tabular}


Table D5.1. Continued

Cross Section 3 (S = 10'-4") Using MDX-LRFD-redesign

\begin{tabular}{|c|c|c|c|c|c|c|c|c|c|c|c|}
\hline \multirow{2}{*}{$\begin{array}{c}\text { Span Length, } \\
\text { ft. } \\
\text { (L) }\end{array}$} & \multicolumn{2}{|c|}{$\begin{array}{c}\text { Top Flange } \\
\text { (A) }\end{array}$} & \multicolumn{2}{|c|}{$\begin{array}{c}\text { Top Flange } \\
\text { (B) }\end{array}$} & \multirow{2}{*}{$\begin{array}{l}\text { Web Plate, } \\
\text { in. } \\
\text { (F) }\end{array}$} & \multicolumn{2}{|c|}{$\begin{array}{c}\text { Bottom Flange } \\
\text { (A) }\end{array}$} & \multicolumn{2}{|c|}{$\begin{array}{l}\text { Bottom Flange } \\
\text { (B) }\end{array}$} & \multirow[b]{2}{*}{$\begin{array}{l}\text { Fy, } \\
\text { ksi }\end{array}$} & \multirow[b]{2}{*}{$\begin{array}{c}\text { L/D } \\
\text { (Actual) }\end{array}$} \\
\hline & Plate, in. & $\begin{array}{c}\text { Length, } \\
\text { ft. }\end{array}$ & Plate, in. & $\begin{array}{c}\text { Length, } \\
\text { ft. }\end{array}$ & & Plate, in. & $\begin{array}{c}\text { Length, } \\
\text { ft. }\end{array}$ & Plate, in. & $\begin{array}{c}\begin{array}{c}\text { Length, } \\
\text { ft. }\end{array} \\
\end{array}$ & & \\
\hline \multicolumn{12}{|l|}{ Simple Span } \\
\hline 100 & $18 \times 3 / 4$ & 100 & & & $27 \times 7 / 16$ & $19 \times 3$ & 100 & & & 50 & 30.0 \\
\hline 100 & $12 \times 15 / 16$ & 100 & & & $35 \times 3 / 8$ & $12 \times 27 / 8$ & 100 & & & 70 & 25.1 \\
\hline 100 & $14 \times 2$ & 100 & & & $27 \times 3 / 8$ & $20 \times 3$ & 100 & & & 70 & 30.0 \\
\hline \multicolumn{12}{|l|}{ Two Span } \\
\hline $150+150$ & $34 \times 11 / 2$ & 112.5 & $34 \times 21 / 16$ & 37.5 & $34 \times 7 / 16$ & $34 \times 113 / 16$ & 112.5 & $34 \times 3$ & 37.5 & 50 & 37.5 \\
\hline $150+150$ & $24 \times 11 / 8$ & 112.5 & $24 \times 25 / 8$ & 37.5 & $34 \times 5 / 16$ & $26 \times 25 / 8$ & 112.5 & $26 \times 3$ & 37.5 & 70 & 37.5 \\
\hline
\end{tabular}

\section{Cross Section 4 (S = 8'-5”) Using SIMON-LFD-redesign}

\begin{tabular}{|c|c|c|c|c|c|c|c|c|c|c|c|}
\hline \multirow[b]{2}{*}{$\begin{array}{c}\text { Span Length, ft. } \\
\text { (L) }\end{array}$} & \multicolumn{2}{|c|}{$\begin{array}{l}\text { Top Flange } \\
\text { (A) }\end{array}$} & \multicolumn{2}{|c|}{$\begin{array}{l}\text { Top Flange } \\
\text { (B) }\end{array}$} & \multirow{2}{*}{$\begin{array}{l}\text { Web Plate, } \\
\text { in. } \\
\text { (F) }\end{array}$} & \multicolumn{2}{|c|}{$\begin{array}{c}\text { Bottom Flange } \\
\text { (A) }\end{array}$} & \multicolumn{2}{|c|}{$\begin{array}{c}\text { Bottom Flange } \\
\text { (B) }\end{array}$} & \multirow[b]{2}{*}{$\begin{array}{l}\text { Fy, } \\
\text { ksi }\end{array}$} & \multirow[b]{2}{*}{$\begin{array}{c}\text { L/D } \\
\text { (Actual) }\end{array}$} \\
\hline & Plate, in. & $\begin{array}{c}\text { Length, } \\
\text { ft. }\end{array}$ & Plate, in. & Length, ft. & & Plate, in. & $\begin{array}{c}\text { Length, } \\
\text { ft. }\end{array}$ & Plate, in. & $\begin{array}{c}\text { Length, } \\
\text { ft. }\end{array}$ & & \\
\hline 100 & $20 \times 13 / 8$ & 100 & & & $29 \times 7 / 16$ & $20 \times 21 / 4$ & 100 & & & 70 & 29.1 \\
\hline 200 & $20 \times 15 / 16$ & 40 & $20 \times 19 / 16$ & 120 & $69 \times 5 / 8$ & $20 \times 13 / 8$ & 40 & $20 \times 23 / 4$ & 120 & 70 & 29.4 \\
\hline 300 & $36 \times 13 / 8$ & 40 & $36 \times 13 / 4$ & 120 & $109 \times 7 / 8$ & $36 \times 1$ & 40 & $36 \times 17 / 8$ & 120 & 70 & 29.8 \\
\hline
\end{tabular}


Table D5.2. Design summary for redesign bridges

\section{Cross Section $1\left(\mathrm{~S}=\right.$ 9'$\left.^{\prime}\right)$ Using SIMON-LFD-redesign}

\begin{tabular}{|c|c|c|c|c|c|c|c|}
\hline $\begin{array}{c}\text { Span } \\
\text { Length } \\
\text { ft. }\end{array}$ & $\begin{array}{c}\text { Fy } \\
\text { ksi }\end{array}$ & $\begin{array}{c}\text { L/D } \\
\text { Ratio }\end{array}$ & L/800 & $\begin{array}{c}\text { Deflection } \\
\text { in. }\end{array}$ & L/ $\delta$ & $\begin{array}{c}\text { Total } \\
\text { Steel Wt } \\
\text { tons }\end{array}$ & $\begin{array}{c}\text { Performance } \\
\text { Ratio }\end{array}$ \\
\hline Simple Span & \multicolumn{7}{|l|}{} \\
\hline 100 & 50 & 30.1 & 1.50 & 1.462 & 821 & 19.5 & 0.786 \\
\hline 100 & 70 & 29.6 & 1.50 & 1.489 & 806 & 19.7 & 0.726 \\
\hline \hline 200 & 50 & 30.0 & 3.00 & 2.993 & 802 & 46.2 & 0.973 \\
\hline 200 & 70 & 30.0 & 3.00 & 2.994 & 802 & 48.9 & 0.804 \\
\hline \hline 300 & 70 & 30.0 & 4.50 & 4.416 & 815 & 130.6 & 0.896 \\
\hline Two Span & \multicolumn{7}{|l|}{} \\
\hline $300+300$ & 70 & 29.7 & 4.50 & 4.494 & 801 & 188.6 & 0.996 \\
\hline
\end{tabular}

Cross Section 2 (S = 11'-6") Using SIMON-LFD-redesign

\begin{tabular}{|c|c|c|c|c|c|c|c|}
\hline $\begin{array}{c}\text { Span } \\
\text { Length } \\
\text { ft. }\end{array}$ & $\begin{array}{c}\text { Fy } \\
\text { ksi }\end{array}$ & $\begin{array}{c}\text { L/D } \\
\text { Ratio }\end{array}$ & L/800 & $\begin{array}{c}\text { Deflection } \\
\text { in. }\end{array}$ & L/ $\delta$ & $\begin{array}{c}\text { Total } \\
\text { Steel Wt } \\
\text { tons }\end{array}$ & $\begin{array}{c}\text { Performance } \\
\text { Ratio }\end{array}$ \\
\hline Simple Span \\
\hline 100 & 70 & 30.0 & 1.50 & 1.472 & 815 & 26.5 & 0.710 \\
\hline 200 & 70 & 30.0 & 3.00 & 2.969 & 808 & 58.9 & 0.866 \\
\hline 300 & 70 & 29.8 & 4.50 & 4.465 & 806 & 144.7 & 0.970 \\
\hline
\end{tabular}


Table D5.2. Continued

Cross Section 3 (S = 10'-4") Using SIMON-LFD-redesign

\begin{tabular}{|c|c|c|c|c|c|c|c|}
\hline $\begin{array}{c}\text { Span } \\
\text { Length } \\
\mathrm{ft.} \\
\end{array}$ & $\begin{array}{l}\text { Fy } \\
\text { ksi }\end{array}$ & $\begin{array}{l}\text { L/D } \\
\text { Ratio }\end{array}$ & $\begin{array}{c}L / 800 \\
\text { in. }\end{array}$ & $\begin{array}{l}\text { Deflection } \\
\text { in. }\end{array}$ & $\mathrm{L} / \delta$ & $\begin{array}{c}\text { Total } \\
\text { Steel Wt } \\
\text { tons }\end{array}$ & $\begin{array}{c}\text { Performance } \\
\text { Ratio } \\
\end{array}$ \\
\hline \multicolumn{8}{|c|}{ Simple Span } \\
\hline 100 & 50 & 25.1 & 1.50 & 1.480 & 811 & 14.06 & 0.887 \\
\hline 100 & 50 & 29.7 & 1.50 & 1.486 & 808 & 26.25 & 0.748 \\
\hline 100 & 70 & 25.1 & 1.50 & 1.50 & 800 & 12.19 & 0.891 \\
\hline 100 & 70 & 29.7 & 1.50 & 1.488 & 806 & 25.45 & 0.613 \\
\hline 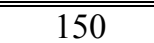 & 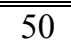 & 29.5 & 2.25 & 2.202 & 817 & 37.52 & 0.903 \\
\hline 150 & 70 & 24.9 & 2.25 & 2.221 & 810 & 23.83 & 0.894 \\
\hline 150 & 70 & 29.6 & 2.25 & 2.142 & 840 & 41.14 & 0.687 \\
\hline 200 & 50 & 29.7 & 3.00 & 2.995 & 801 & 265.66 & 0.916 \\
\hline 200 & 70 & 25.5 & 3.00 & 2.987 & 803 & 44.51 & 0.962 \\
\hline 200 & 70 & 29.8 & 3.00 & 2.995 & 801 & 65.66 & 0.777 \\
\hline 250 & $\overline{70}$ & 25.1 & 3.75 & 3.731 & 804 & 74.59 & 0.981 \\
\hline 250 & 70 & 29.9 & 3.75 & 3.739 & 802 & 101.85 & 0.841 \\
\hline \multicolumn{8}{|c|}{$\begin{array}{l}\text { Two Span } \\
\text { (6 bridges failing the } \mathrm{L} / 800 \text { with } 0.8 \mathrm{~L} / \mathrm{D}=30 \text { was taken out and were not redesigned due to the low } \\
\text { Dw/bf ratios) }\end{array}$} \\
\hline $150+150$ & 50 & No feasil & esign col & be found, the & f was & than 2.0 & \\
\hline $150+150$ & 70 & 24.8 & 2.25 & 2.218 & 812 & 54.35 & 0.977 \\
\hline $200+200$ & 50 & \multicolumn{6}{|c|}{ No feasible design could be found, the $\mathrm{D} / \mathrm{bf}$ was less than 2.0} \\
\hline $200+200$ & 70 & 25.7 & 3.00 & 2.92 & 822 & 107.72 & 0.873 \\
\hline $250+250$ & 70 & 25.5 & 3.75 & 3.626 & 827 & 178.75 & 0.888 \\
\hline
\end{tabular}

Cross Section 3 (S = 10'-4") Using MDX-LRFD-redesign

\begin{tabular}{|c|c|c|c|c|c|c|c|}
\hline $\begin{array}{c}\text { Span } \\
\text { Length } \\
\mathrm{ft} .\end{array}$ & $\begin{array}{l}\text { Fy } \\
\text { ksi }\end{array}$ & $\begin{array}{c}\text { L/D } \\
\text { Ratio }\end{array}$ & $\begin{array}{c}L / 800 \\
\text { in. }\end{array}$ & $\begin{array}{c}\text { Deflection } \\
\text { in. }\end{array}$ & $\mathrm{L} / \delta$ & $\begin{array}{c}\text { Total } \\
\text { Steel Wt } \\
\text { tons }\end{array}$ & $\begin{array}{c}\text { Performance } \\
\text { Ratio }\end{array}$ \\
\hline \multicolumn{8}{|c|}{ Simple Span } \\
\hline 100 & 50 & 30.0 & 1.50 & 1.496 & 802 & 15.4 & 0.971 \\
\hline 100 & 70 & 25.1 & 1.50 & 1.389 & 864 & 9.0 & 0.868 \\
\hline 100 & 70 & 30.0 & 1.50 & 1.457 & 824 & 15.0 & 0.645 \\
\hline 150 & 70 & 29.5 & 2.25 & 2.197 & 819 & 19.2 & 0.855 \\
\hline \multicolumn{8}{|l|}{ Two Span } \\
\hline $150+150$ & 50 & 30.0 & 2.25 & 2.201 & 818 & 67.4 & 0.953 \\
\hline $150+150$ & 70 & 30.0 & 2.25 & 2.206 & 816 & 55.4 & 0.987 \\
\hline
\end{tabular}

Cross Section 4 (S = 9') Using SIMON-LFD-redesign

\begin{tabular}{|c|c|c|c|c|c|c|c|}
\hline $\begin{array}{c}\text { Span } \\
\text { Length } \\
\text { ft. }\end{array}$ & $\begin{array}{c}\text { Fy } \\
\text { ksi }\end{array}$ & $\begin{array}{c}\text { L/D } \\
\text { Ratio }\end{array}$ & $\begin{array}{c}\text { L/800 } \\
\text { in. }\end{array}$ & $\begin{array}{c}\text { Deflection } \\
\text { in. }\end{array}$ & L/ $\delta$ & $\begin{array}{c}\text { Total } \\
\text { Steel Wt } \\
\text { tons }\end{array}$ & $\begin{array}{c}\text { Performance } \\
\text { Ratio }\end{array}$ \\
\hline \multicolumn{7}{|l|}{ Simple Span } \\
\hline 100 & 70 & 29.1 & 1.50 & 1.497 & 802 & 14.6 & 0.908 \\
\hline \hline 200 & 70 & 29.4 & 3.00 & 2.995 & 801 & 38.9 & 0.941 \\
\hline \hline 300 & 70 & 29.8 & 4.50 & 4.438 & 812 & 107.8 & 0.996 \\
\hline
\end{tabular}


Appendix E - Wright and Walker Procedure and OHBDC Results 
Table E5.1. Wright and Walker procedure and OHBDC results for cross section $1\left(\mathrm{~S}=9^{\prime}\right)$

Simple Span Bridges of Cross Section 1 Using SIMON-LFD

\begin{tabular}{|c|c|c|c|c|c|c|c|}
\hline $\begin{array}{c}\text { Span } \\
\text { Length } \\
\mathrm{ft} \\
\end{array}$ & $\begin{array}{l}\text { Fy } \\
\text { ksi } \\
\end{array}$ & $\begin{array}{c}\text { L/D Ratio } \\
\text { (Actual) }\end{array}$ & $\begin{array}{c}\text { Ontario } \\
\text { Deflection } \\
\mathbf{m m} \\
\end{array}$ & $\begin{array}{c}\text { Ontario } \\
\text { Natural Frequency } \\
\mathbf{H z} \\
\end{array}$ & Ontario Evaluation & $\begin{array}{c}\text { Wright \& Walker } \\
\text { acceleration, in/sec2 }\end{array}$ & $\begin{array}{l}\text { Wright \& Walker } \\
\text { Human Reaction } \\
\end{array}$ \\
\hline 100 & 50 & 15.1 & 17.095 & 3.770 & W/O SIDEWALKS & 48.100 & Perceptible \\
\hline 100 & 50 & 20.0 & 27.206 & 3.050 & W/O SIDEWALKS & 55.390 & Unpleasant to Few \\
\hline 100 & 50 & 25.4 & 37.854 & 2.550 & W/O SIDEWALKS & 59.198 & Unpleasant to Few \\
\hline 100 & 50 & 30.3 & 46.047 & 2.280 & W/O SIDEWALKS & 61.377 & Unpleasant to Few \\
\hline 100 & 70 & 14.9 & 15.291 & 3.950 & W/O SIDEWALKS & 46.414 & Perceptible \\
\hline 100 & 70 & 19.8 & 26.611 & 3.060 & W/O SIDEWALKS & 54.477 & Unpleasant to Few \\
\hline 100 & 70 & 25.3 & 37.643 & 2.570 & W/O SIDEWALKS & 59.561 & Unpleasant to Few \\
\hline 100 & 70 & 30.1 & 49.251 & 2.220 & W/O SIDEWALKS & 63.116 & Unpleasant to Few \\
\hline 200 & 50 & 14.9 & 12.714 & 2.510 & W/ SIDEWALKS, LITTLE PED USE & 19.872 & Perceptible to Most \\
\hline 200 & 50 & 19.9 & 35.441 & 1.710 & W/ SIDEWALKS, LITTLE PED USE & 30.151 & Perceptible \\
\hline 200 & 50 & 24.5 & 47.283 & 1.510 & W/ SIDEWALKS, LITTLE PED USE & 33.345 & Perceptible \\
\hline 200 & 50 & 30.0 & 59.679 & 1.330 & W/ SIDEWALKS, LITTLE PED USE & 34.821 & Perceptible \\
\hline 200 & 70 & 15.0 & 13.217 & 2.490 & W/ SIDEWALKS, LITTLE PED USE & 20.411 & Perceptible \\
\hline 200 & 70 & 19.9 & 33.295 & 1.730 & W/ SIDEWALKS, LITTLE PED USE & 28.858 & Perceptible \\
\hline 200 & 70 & 24.6 & 52.298 & 1.440 & W/ SIDEWALKS, LITTLE PED USE & 34.309 & Perceptible \\
\hline 200 & 70 & 30.1 & 68.266 & 1.270 & W/ SIDEWALKS, LITTLE PED USE & 37.229 & Perceptible \\
\hline 300 & 50 & 15.0 & NA & NA & NA & NA & NA \\
\hline 300 & 50 & 19.9 & 27.777 & 1.290 & ACCEPTABLE & 19.476 & Perceptible to Most \\
\hline 300 & 50 & 25.0 & 40.157 & 1.110 & ACCEPTABLE & 22.319 & Perceptible \\
\hline 300 & 50 & 30.0 & 52.433 & 0.970 & W/ SIDEWALKS, LITTLE PED USE & 23.732 & Perceptible \\
\hline 300 & 70 & 15.1 & 10.215 & 1.790 & ACCEPTABLE & 12.097 & Perceptible to Most \\
\hline 300 & 70 & 20.0 & 27.165 & 1.280 & ACCEPTABLE & 18.820 & Perceptible to Most \\
\hline 300 & 70 & 25.1 & 48.983 & 1.030 & W/ SIDEWALKS, LITTLE PED USE & 24.327 & Perceptible \\
\hline 300 & 70 & 29.9 & 64.649 & 0.920 & W/ SIDEWALKS, LITTLE PED USE & 27.143 & Perceptible \\
\hline
\end{tabular}


Table E5.1. Continued

Two Span Bridges of Cross Section 1 Using SIMON-LFD

\begin{tabular}{|c|c|c|c|c|c|c|c|}
\hline $\begin{array}{c}\text { Span } \\
\text { Length } \\
\mathrm{ft} \\
\end{array}$ & $\begin{array}{l}\text { Fy } \\
\text { ksi } \\
\end{array}$ & $\begin{array}{c}\text { L/D Ratio } \\
\text { (Actual) }\end{array}$ & $\begin{array}{c}\text { Ontario } \\
\text { Deflection } \\
\mathbf{m m} \\
\end{array}$ & $\begin{array}{c}\text { Ontario } \\
\text { Natural Frequency } \\
\mathbf{H z} \\
\end{array}$ & Ontario Evaluation & $\begin{array}{c}\text { Wright \& Walker } \\
\text { acceleration, in/sec2 }\end{array}$ & $\begin{array}{l}\text { Wright \& Walker } \\
\text { Human Reaction }\end{array}$ \\
\hline 100 & 50 & 15.0 & 12.202 & 3.480 & W/ SIDEWALKS, LITTLE PED USE & 30.656 & Perceptible \\
\hline 100 & 50 & 19.4 & 16.673 & 3.020 & W/ SIDEWALKS, LITTLE PED USE & 33.741 & Perceptible \\
\hline 100 & 50 & 25.0 & 24.558 & 2.360 & W/ SIDEWALKS, LITTLE PED USE & 34.742 & Perceptible \\
\hline 100 & 50 & 30.1 & 31.580 & 1.980 & W/ SIDEWALKS, LITTLE PED USE & 34.507 & Perceptible \\
\hline 100 & 70 & 15.0 & 11.147 & 3.570 & W/ SIDEWALKS, LITTLE PED USE & 29.134 & Perceptible \\
\hline 100 & 70 & 19.9 & 18.591 & 2.870 & W/O SIDEWALKS & 34.834 & Perceptible \\
\hline 100 & 70 & 24.0 & 23.656 & 2.560 & W/O SIDEWALKS & 39.746 & Perceptible \\
\hline 100 & 70 & 29.4 & 33.787 & 2.060 & W/ SIDEWALKS, LITTLE PED USE & 39.015 & Perceptible \\
\hline 200 & 50 & 14.9 & 9.661 & 2.070 & ACCEPTABLE & 10.871 & Perceptible to Most \\
\hline 200 & 50 & 19.8 & 24.120 & 1.490 & ACCEPTABLE & 16.341 & Perceptible to Most \\
\hline 200 & 50 & 24.1 & 38.092 & 1.200 & ACCEPTABLE & 18.789 & Perceptible to Most \\
\hline 200 & 50 & 29.6 & 52.047 & 1.000 & W/ SIDEWALKS, LITTLE PED USE & 19.754 & Perceptible to Most \\
\hline 200 & 70 & 15.0 & 9.276 & 2.050 & ACCEPTABLE & 10.295 & Perceptible to Most \\
\hline 200 & 70 & 19.9 & 23.466 & 1.490 & ACCEPTABLE & 19.876 & Perceptible to Most \\
\hline 200 & 70 & 25.0 & 45.019 & 1.160 & W/ SIDEWALKS, LITTLE PED USE & 21.099 & Perceptible \\
\hline 200 & 70 & 29.3 & 54.848 & 1.040 & W/ SIDEWALKS, LITTLE PED USE & 22.017 & Perceptible \\
\hline 300 & 50 & 14.9 & 8.184 & 1.310 & ACCEPTABLE & 5.150 & Perceptible to Some \\
\hline 300 & 50 & 19.8 & 18.697 & 1.060 & ACCEPTABLE & 9.480 & Perceptible to Some \\
\hline 300 & 50 & 24.6 & 33.601 & 0.850 & ACCEPTABLE & 12.273 & Perceptible to Most \\
\hline 300 & 50 & 30.0 & 45.757 & 0.720 & ACCEPTABLE & 13.137 & Perceptible to Most \\
\hline 300 & 70 & 15.1 & 7.213 & 1.370 & ACCEPTABLE & 5.428 & Perceptible to Some \\
\hline 300 & 70 & 20.1 & 18.772 & 1.040 & ACCEPTABLE & 9.249 & Perceptible to Some \\
\hline 300 & 70 & 25.0 & 37.678 & 0.820 & ACCEPTABLE & 13.314 & Perceptible to Most \\
\hline 300 & 70 & 29.6 & 61.050 & 0.670 & ACCEPTABLE & 15.863 & Perceptible to Most \\
\hline
\end{tabular}


Table E5.1. Continued

Three Span Bridges of Cross Section 1 Using SIMON-LFD

\begin{tabular}{|c|c|c|c|c|c|c|c|}
\hline $\begin{array}{c}\text { Span } \\
\text { Length } \\
\text { ft }\end{array}$ & $\begin{array}{l}\text { Fy } \\
\text { ksi }\end{array}$ & $\begin{array}{l}\text { L/D Ratio } \\
\text { (Actual) }\end{array}$ & $\begin{array}{c}\text { Ontario } \\
\text { Deflection } \\
\mathrm{mm} \\
\end{array}$ & $\begin{array}{c}\text { Ontario } \\
\text { Natural Frequency } \\
\mathrm{Hz} \\
\end{array}$ & Ontario Evaluation & $\begin{array}{c}\text { Wright \& Walker } \\
\text { acceleration, in/sec2 }\end{array}$ & $\begin{array}{l}\text { Wright \& Walker } \\
\text { Human Reaction }\end{array}$ \\
\hline 100 & 50 & 15.1 & 8.712 & 4.19 & W/ SIDEWALKS, LITTLE PED USE & 29.862 & Perceptible \\
\hline 100 & 50 & 19.4 & 14.427 & 3.28 & W/ SIDEWALKS, LITTLE PED USE & 35.711 & Perceptible \\
\hline 100 & 50 & 25.1 & 17.450 & 2.63 & W/ SIDEWALKS, LITTLE PED USE & 36.143 & Perceptible \\
\hline 100 & 50 & 30.2 & 26.264 & 2.29 & W/ SIDEWALKS, LITTLE PED USE & 36.274 & Perceptible \\
\hline 100 & 70 & 15.1 & 8.839 & 4.14 & W/ SIDEWALKS, LITTLE PED USE & 29.961 & Perceptible \\
\hline 100 & 70 & 19.9 & 15.088 & 3.29 & W/ SIDEWALKS, LITTLE PED USE & 35.531 & Perceptible \\
\hline 100 & 70 & 24.1 & 19.837 & 2.86 & W/ SIDEWALKS, LITTLE PED USE & 37.838 & Perceptible \\
\hline 100 & 70 & 29.5 & 28.346 & 2.32 & W/ SIDEWALKS, LITTLE PED USE & 39.785 & Perceptible \\
\hline 200 & 50 & 14.9 & 6.604 & 2.41 & ACCEPTABLE & 9.734 & Perceptible to Some \\
\hline 200 & 50 & 19.8 & 16.231 & 1.77 & ACCEPTABLE & 14.767 & Perceptible to Most \\
\hline 200 & 50 & 25.1 & 33.299 & 1.30 & ACCEPTABLE & 18.133 & Perceptible to Most \\
\hline 200 & 50 & 30.1 & 44.374 & 1.09 & ACCEPTABLE & 18.663 & Perceptible to Most \\
\hline 200 & 70 & 15.0 & 6.172 & 2.54 & ACCEPTABLE & 9.567 & Perceptible to Some \\
\hline 200 & 70 & 19.8 & 16.815 & 1.82 & ACCEPTABLE & 15.293 & Perceptible to Most \\
\hline 200 & 70 & 24.2 & 32.258 & 1.46 & W/ SIDEWALKS, LITTLE PED USE & 20.954 & Perceptible \\
\hline 200 & 70 & 29.8 & 39.294 & 1.34 & W/ SIDEWALKS, LITTLE PED USE & 22.508 & Perceptible \\
\hline 300 & 50 & 14.9 & 5.359 & 1.58 & ACCEPTABLE & 4.959 & Imperceptible \\
\hline 300 & 50 & 19.8 & 13.614 & 1.20 & ACCEPTABLE & 8.142 & Perceptible to Some \\
\hline 300 & 50 & 25.1 & 29.185 & 0.92 & ACCEPTABLE & 11.651 & Perceptible to Most \\
\hline 300 & 50 & 30.1 & 46.761 & 0.72 & ACCEPTABLE & 13.069 & Perceptible to Most \\
\hline 300 & 70 & 15.0 & 5.207 & 1.63 & ACCEPTABLE & 5.097 & Imperceptible \\
\hline 300 & 70 & 20.0 & 13.310 & 1.25 & ACCEPTABLE & 8.547 & Perceptible to Some \\
\hline 300 & 70 & 25.1 & 27.864 & 1.00 & ACCEPTABLE & 12.721 & Perceptible to Most \\
\hline 300 & 70 & 30.1 & 42.240 & 0.87 & ACCEPTABLE & 15.716 & Perceptible to Most \\
\hline
\end{tabular}


Table E5.2. Wright and Walker procedure and OHBDC results for cross section 2 ( $\mathrm{S}=11$ ' -6 ')

Simple Span Bridges of Cross Section 2 Using SIMON-LFD

\begin{tabular}{|c|c|c|c|c|c|c|c|}
\hline $\begin{array}{c}\text { Span } \\
\text { Length } \\
\text { ft } \\
\end{array}$ & $\begin{array}{l}\text { Fy } \\
\text { ksi }\end{array}$ & $\begin{array}{c}\text { L/D Ratio } \\
\text { (Actual) }\end{array}$ & $\begin{array}{c}\text { Ontario } \\
\text { Deflection } \\
\mathbf{m m} \\
\end{array}$ & $\begin{array}{c}\text { Ontario } \\
\text { Natural Frequency } \\
\mathbf{H z} \\
\end{array}$ & Ontario Evaluation & $\begin{array}{r}\text { Wright \& Walker } \\
\text { acceleration, in/sec2 }\end{array}$ & $\begin{array}{l}\text { Wright \& Walker } \\
\text { Human Reaction }\end{array}$ \\
\hline 100 & 50 & 14.9 & 14.982 & 3.480 & W/O SIDEWALKS & 35.576 & Perceptible \\
\hline 100 & 50 & 20.3 & 22.426 & 2.850 & W/O SIDEWALKS & 39.392 & Perceptible \\
\hline 100 & 50 & 25.3 & 29.980 & 2.430 & W/O SIDEWALKS & 41.726 & Perceptible \\
\hline 100 & 50 & NA & NA & NA & NA & NA & NA \\
\hline 100 & 70 & 15.1 & 15.281 & 3.430 & W/ SIDEWALKS, LITTLE PED USE & 35.483 & Perceptible \\
\hline 100 & 70 & 19.7 & 21.843 & 2.900 & W/O SIDEWALKS & 39.358 & Perceptible \\
\hline 100 & 70 & 25.3 & 31.223 & 2.400 & W/O SIDEWALKS & 42.659 & Perceptible \\
\hline 100 & 70 & 30.4 & 40.335 & 2.070 & W/O SIDEWALKS & 44.680 & Perceptible \\
\hline 200 & 50 & 15.0 & 13.896 & 2.250 & W/ SIDEWALKS, LITTLE PED USE & 17.385 & Perceptible to Most \\
\hline 200 & 50 & 19.9 & 28.054 & 1.680 & W/ SIDEWALKS, LITTLE PED USE & 22.182 & Perceptible \\
\hline 200 & 50 & 25.2 & 38.263 & 1.450 & W/ SIDEWALKS, LITTLE PED USE & 24.218 & Perceptible \\
\hline 200 & 50 & 29.9 & 44.729 & 1.270 & W/ SIDEWALKS, LITTLE PED USE & 23.649 & Perceptible \\
\hline 200 & 70 & 15.0 & 12.699 & 2.300 & W/ SIDEWALKS, LITTLE PED USE & 16.454 & Perceptible to Most \\
\hline 200 & 70 & 19.9 & 30.819 & 1.600 & W/ SIDEWALKS, LITTLE PED USE & 22.622 & Perceptible \\
\hline 200 & 70 & 25.1 & 41.730 & 1.400 & W/ SIDEWALKS, LITTLE PED USE & 25.087 & Perceptible \\
\hline 200 & 70 & 30.1 & 54.003 & 1.220 & W/ SIDEWALKS, LITTLE PED USE & 26.502 & Perceptible \\
\hline 300 & 50 & 15.0 & 9.664 & 1.710 & ACCEPTABLE & 10.160 & Perceptible to Most \\
\hline 300 & 50 & 20.0 & 25.747 & 1.220 & ACCEPTABLE & 15.819 & Perceptible to Most \\
\hline 300 & 50 & 24.9 & 34.138 & 1.070 & ACCEPTABLE & 17.131 & Perceptible to Most \\
\hline 300 & 50 & 29.9 & 41.585 & 0.950 & ACCEPTABLE & 17.443 & Perceptible to Most \\
\hline 300 & 70 & 15.1 & 10.044 & 1.700 & ACCEPTABLE & 10.457 & Perceptible to Most \\
\hline 300 & 70 & 20.0 & 26.286 & 1.200 & ACCEPTABLE & 15.741 & Perceptible to Most \\
\hline 300 & 70 & 24.9 & 39.343 & 1.020 & ACCEPTABLE & 18.406 & Perceptible to Most \\
\hline 300 & 70 & 29.6 & 50.122 & 0.910 & ACCEPTABLE & 19.764 & Perceptible to Most \\
\hline
\end{tabular}


Table E5.2. Continued

Two Span Bridges of Cross Section 2 Using SIMON-LFD

\begin{tabular}{|c|c|c|c|c|c|c|c|}
\hline $\begin{array}{c}\text { Span } \\
\text { Length } \\
\text { ft }\end{array}$ & $\begin{array}{l}\text { Fy } \\
\text { ksi }\end{array}$ & $\begin{array}{l}\text { L/D Ratio } \\
\text { (Actual) }\end{array}$ & $\begin{array}{c}\text { Ontario } \\
\text { Deflection } \\
\mathbf{m m}\end{array}$ & $\begin{array}{c}\text { Ontario } \\
\text { Natural Frequency } \\
\mathrm{Hz}\end{array}$ & Ontario Evaluation & $\begin{array}{c}\text { Wright \& Walker } \\
\text { acceleration, in/sec2 }\end{array}$ & $\begin{array}{l}\text { Wright \& Walker } \\
\text { Human Reaction }\end{array}$ \\
\hline 100 & 50 & 14.9 & 10.072 & 3.320 & W/ SIDEWALKS, LITTLE PED USE & 22.485 & Perceptible \\
\hline 100 & 50 & 20.0 & 14.998 & 2.660 & W/ SIDEWALKS, LITTLE PED USE & 24.086 & Perceptible \\
\hline 100 & 50 & 24.9 & 19.247 & 2.260 & W/ SIDEWALKS, LITTLE PED USE & 24.441 & Perceptible \\
\hline 100 & 50 & 27.6 & NAD & NAD & NAD & NA & Perceptible \\
\hline 100 & 70 & 15.1 & 10.513 & 3.260 & W/ SIDEWALKS, LITTLE PED USE & 22.825 & Perceptible \\
\hline 100 & 70 & 19.8 & 15.360 & 2.780 & W/ SIDEWALKS, LITTLE PED USE & 26.144 & Perceptible \\
\hline 100 & 70 & 24.3 & 20.915 & 2.310 & W/ SIDEWALKS, LITTLE PED USE & 27.413 & Perceptible \\
\hline 100 & 70 & 28.2 & 25.841 & 2.020 & W/ SIDEWALKS, LITTLE PED USE & 27.895 & Perceptible \\
\hline 200 & 50 & 14.9 & 9.604 & 1.960 & ACCEPTABLE & 9.474 & Perceptible to Some \\
\hline 200 & 50 & 20.0 & 21.945 & 1.380 & ACCEPTABLE & 12.692 & Perceptible to Most \\
\hline 200 & 50 & 24.2 & 25.894 & 1.270 & ACCEPTABLE & 13.152 & Perceptible to Most \\
\hline 200 & 50 & 30.6 & 39.212 & 0.960 & ACCEPTABLE & 13.402 & Perceptible to Most \\
\hline 200 & 70 & 15.0 & 8.874 & 1.960 & ACCEPTABLE & 8.751 & Perceptible to Some \\
\hline 200 & 70 & 20.0 & 22.936 & 1.380 & ACCEPTABLE & 13.229 & Perceptible to Most \\
\hline 200 & 70 & 24.8 & 35.415 & 1.130 & ACCEPTABLE & 15.257 & Perceptible to Most \\
\hline 200 & 70 & 29.2 & 44.509 & 0.990 & ACCEPTABLE & 15.896 & Perceptible to Most \\
\hline 300 & 50 & 14.9 & 7.104 & 1.390 & ACCEPTABLE & 5.241 & Perceptible to Some \\
\hline 300 & 50 & 19.8 & 17.504 & 1.030 & ACCEPTABLE & 8.120 & Perceptible to Some \\
\hline 300 & 50 & 25.0 & 26.984 & 0.830 & ACCEPTABLE & 9.082 & Perceptible to Some \\
\hline 300 & 50 & 29.9 & 33.011 & 0.730 & ACCEPTABLE & 9.214 & Perceptible to Some \\
\hline 300 & 70 & 15.0 & 6.847 & 1.360 & ACCEPTABLE & 4.882 & Imperceptible \\
\hline 300 & 70 & 19.8 & 17.038 & 1.020 & ACCEPTABLE & 7.915 & Perceptible to Some \\
\hline 300 & 70 & 24.8 & 33.562 & 0.790 & ACCEPTABLE & 10.539 & Perceptible to Most \\
\hline 300 & 70 & 29.5 & 43.973 & 0.690 & ACCEPTABLE & 11.421 & Perceptible to Most \\
\hline
\end{tabular}


Table E5.2. Continued

Three Span Bridges of Cross Section 2 Using SIMON-LFD

\begin{tabular}{|c|c|c|c|c|c|c|c|}
\hline $\begin{array}{c}\text { Span } \\
\text { Length } \\
\text { ft }\end{array}$ & $\begin{array}{l}\text { Fy } \\
\text { ksi }\end{array}$ & $\begin{array}{c}\text { L/D Ratio } \\
\text { (Actual) }\end{array}$ & $\begin{array}{c}\text { Ontario } \\
\text { Deflection } \\
\mathbf{m m} \\
\end{array}$ & $\begin{array}{c}\text { Ontario } \\
\text { Natural Frequency } \\
\mathrm{Hz} \\
\end{array}$ & Ontario Evaluation & $\begin{array}{c}\text { Wright \& Walker } \\
\text { acceleration, in/sec2 }\end{array}$ & $\begin{array}{l}\text { Wright \& Walker } \\
\text { Human Reaction }\end{array}$ \\
\hline 100 & 50 & 14.9 & 8.331 & 3.76 & W/ SIDEWALKS, LITTLE PED USE & 23.046 & Perceptible \\
\hline 100 & 50 & 20.3 & 12.421 & 3.09 & W/ SIDEWALKS, LITTLE PED USE & 25.418 & Perceptible \\
\hline 100 & 50 & 24.8 & 16.459 & 2.54 & W/ SIDEWALKS, LITTLE PED USE & 24.801 & Perceptible \\
\hline 100 & 50 & 29.7 & 20.218 & 2.23 & W/ SIDEWALKS, LITTLE PED USE & 24.941 & Perceptible \\
\hline 100 & 70 & 15.1 & 8.077 & 3.82 & W/ SIDEWALKS, LITTLE PED USE & 22.865 & Perceptible \\
\hline 100 & 70 & 20.0 & 13.208 & 3.05 & W/ SIDEWALKS, LITTLE PED USE & 26.449 & Perceptible \\
\hline 100 & 70 & 24.6 & 17.780 & 2.61 & W/ SIDEWALKS, LITTLE PED USE & 31.633 & Perceptible \\
\hline 100 & 70 & 29.0 & 22.454 & 2.25 & W/ SIDEWALKS, LITTLE PED USE & 28.690 & Perceptible \\
\hline 200 & 50 & 14.9 & 6.604 & 2.32 & ACCEPTABLE & 8.395 & Perceptible to Some \\
\hline 200 & 50 & 20.0 & 15.799 & 1.63 & ACCEPTABLE & 12.174 & Perceptible to Most \\
\hline 200 & 50 & 24.6 & 26.695 & 1.24 & ACCEPTABLE & 12.902 & Perceptible to Most \\
\hline 200 & 50 & 30.5 & 37.135 & 1.01 & ACCEPTABLE & 13.426 & Perceptible to Most \\
\hline 200 & 70 & 15.0 & 6.960 & 2.28 & ACCEPTABLE & 8.593 & Perceptible to Some \\
\hline 200 & 70 & 20.1 & 17.424 & 1.63 & ACCEPTABLE & 12.706 & Perceptible to Most \\
\hline 200 & 70 & 24.9 & 26.949 & 1.37 & ACCEPTABLE & 15.116 & Perceptible to Most \\
\hline 200 & 70 & 29.3 & 37.236 & 1.15 & ACCEPTABLE & 16.324 & Perceptible to Most \\
\hline 300 & 50 & 14.9 & 5.258 & 1.56 & ACCEPTABLE & 4.542 & Imperceptible \\
\hline 300 & 50 & 19.9 & 13.233 & 1.16 & ACCEPTABLE & 7.168 & Perceptible to Some \\
\hline 300 & 50 & 25.2 & 22.758 & 0.90 & ACCEPTABLE & 8.357 & Perceptible to Some \\
\hline 300 & 50 & 30.1 & 27.483 & 0.78 & ACCEPTABLE & 8.109 & Perceptible to Some \\
\hline 300 & 70 & 15.0 & 4.851 & 1.66 & ACCEPTABLE & 4.657 & Imperceptible \\
\hline 300 & 70 & 19.9 & 12.446 & 1.25 & ACCEPTABLE & 7.678 & Perceptible to Some \\
\hline 300 & 70 & 25.0 & 25.171 & 0.99 & ACCEPTABLE & 10.760 & Perceptible to Most \\
\hline 300 & 70 & 29.6 & 33.325 & 0.90 & ACCEPTABLE & 12.465 & Perceptible to Most \\
\hline
\end{tabular}


Table E5.3. Wright and Walker procedure and OHBDC results for cross section 3 ( $\mathrm{S}=10$ '-4")

Simple Span Bridges of Cross Section 3 Using SIMON-LFD

\begin{tabular}{|c|c|c|c|c|c|c|c|}
\hline $\begin{array}{c}\text { Span } \\
\text { Length } \\
\text { ft }\end{array}$ & $\begin{array}{l}\text { Fy } \\
\text { ksi }\end{array}$ & $\begin{array}{c}\text { L/D Ratio } \\
\text { (Actual) }\end{array}$ & $\begin{array}{c}\text { Ontario } \\
\text { Deflection } \\
\mathbf{m m}\end{array}$ & $\begin{array}{c}\text { Ontario } \\
\text { Natural Frequency } \\
\mathrm{Hz}\end{array}$ & Ontario Evaluation & $\begin{array}{c}\text { Wright \& Walker } \\
\text { acceleration, in/sec2 }\end{array}$ & $\begin{array}{l}\text { Wright \& Walker } \\
\text { Human Reaction }\end{array}$ \\
\hline 100 & 50 & 15.2 & 16.443 & 3.62 & W/O SIDEWALKS & 44.091 & Perceptible \\
\hline 100 & 50 & 19.9 & 23.800 & 3.03 & W/O SIDEWALKS & 48.698 & Perceptible \\
\hline 100 & 50 & 25.3 & 32.978 & 2.54 & W/O SIDEWALKS & 51.991 & Unpleasant to Few \\
\hline 100 & 50 & 30.0 & 39.611 & 2.27 & W/O SIDEWALKS & 51.036 & Unpleasant to Few \\
\hline 100 & 70 & 15.2 & 16.443 & 3.62 & W/O SIDEWALKS & 44.091 & Perceptible \\
\hline 100 & 70 & 19.9 & 23.800 & 3.03 & W/O SIDEWALKS & 48.698 & Perceptible \\
\hline 100 & 70 & 25.1 & 32.562 & 2.57 & W/O SIDEWALKS & 52.254 & Unpleasant to Few \\
\hline 100 & 70 & 30.0 & 43.606 & 2.19 & W/O SIDEWALKS & 55.584 & Unpleasant to Few \\
\hline 150 & 50 & 14.7 & 16.074 & 2.85 & W/ SIDEWALKS, LITTLE PED USE & 27.094 & Perceptible \\
\hline 150 & 50 & 19.5 & 29.817 & 2.19 & W/ SIDEWALKS, LITTLE PED USE & 34.243 & Perceptible \\
\hline 150 & 50 & 24.8 & 39.635 & 1.89 & W/ SIDEWALKS, LITTLE PED USE & 36.608 & Perceptible \\
\hline 150 & 50 & 30.2 & 46.268 & 1.72 & W/ SIDEWALKS, LITTLE PED USE & 37.430 & Perceptible \\
\hline 150 & 70 & 15.0 & 15.191 & 2.89 & W/ SIDEWALKS, LITTLE PED USE & 26.196 & Perceptible \\
\hline 150 & 70 & 19.9 & 33.640 & 2.07 & W/ SIDEWALKS, LITTLE PED USE & 35.050 & Perceptible \\
\hline 150 & 70 & 24.9 & 46.181 & 1.77 & W/O SIDEWALKS & 38.410 & Perceptible \\
\hline 150 & 70 & 29.8 & 58.273 & 1.57 & W/O SIDEWALKS & 41.068 & Perceptible \\
\hline 200 & 50 & 15.0 & 13.900 & 2.38 & W/ SIDEWALKS, LITTLE PED USE & 20.194 & Perceptible \\
\hline 200 & 50 & 20.0 & 31.094 & 1.72 & W/ SIDEWALKS, LITTLE PED USE & 27.397 & Perceptible \\
\hline 200 & 50 & 25.1 & 40.923 & 1.53 & W/ SIDEWALKS, LITTLE PED USE & 31.065 & Perceptible \\
\hline 200 & 50 & 29.9 & 48.411 & 1.38 & W/ SIDEWALKS, LITTLE PED USE & 31.519 & Perceptible \\
\hline 200 & 70 & 15.0 & 13.287 & 2.38 & W/ SIDEWALKS, LITTLE PED USE & 19.317 & Perceptible to Most \\
\hline 200 & 70 & 20.0 & 34.634 & 1.63 & W/ SIDEWALKS, LITTLE PED USE & 27.756 & Perceptible \\
\hline 200 & 70 & 25.0 & 47.784 & 1.43 & W/ SIDEWALKS, LITTLE PED USE & 32.669 & Perceptible \\
\hline 200 & 70 & 30.0 & 61.221 & 1.27 & W/ SIDEWALKS, LITTLE PED USE & 35.003 & Perceptible \\
\hline 250 & 50 & 15.0 & 10.981 & 2.00 & ACCEPTABLE & 13.851 & Perceptible to Most \\
\hline 250 & 50 & 20.1 & 29.344 & 1.44 & ACCEPTABLE & 21.949 & Perceptible \\
\hline 250 & 50 & 24.7 & 39.657 & 1.29 & W/ SIDEWALKS, LITTLE PED USE & 26.058 & Perceptible \\
\hline 250 & 50 & 30.0 & 40.827 & 1.20 & ACCEPTABLE & 24.229 & Perceptible \\
\hline 250 & 70 & 15.0 & 12.255 & 1.99 & ACCEPTABLE & 15.319 & Perceptible to Most \\
\hline 250 & 70 & 20.0 & 32.147 & 1.38 & W/ SIDEWALKS, LITTLE PED USE & 22.554 & Perceptible \\
\hline 250 & 70 & 24.9 & 46.073 & 1.21 & W/ SIDEWALKS, LITTLE PED USE & 27.164 & Perceptible \\
\hline 250 & 70 & 30.0 & 61.383 & 1.07 & W/ SIDEWALKS, LITTLE PED USE & 30.371 & Perceptible \\
\hline
\end{tabular}


Table E5.3. Continued

Two Span Bridges of Cross Section 3 Using SIMON-LFD

\begin{tabular}{|c|c|c|c|c|c|c|c|}
\hline $\begin{array}{c}\text { Span } \\
\text { Length } \\
\text { ft } \\
\end{array}$ & $\begin{array}{l}\text { Fy } \\
\text { ksi }\end{array}$ & $\begin{array}{c}0.8 \mathrm{~L} / \mathrm{D} \\
\text { Ratio } \\
\text { (Actual) }\end{array}$ & $\begin{array}{c}\text { Ontario } \\
\text { Deflection } \\
\mathbf{m m} \\
\end{array}$ & $\begin{array}{c}\text { Ontario } \\
\text { Natural Frequency } \\
\mathrm{Hz} \\
\end{array}$ & Ontario Evaluation & $\begin{array}{c}\text { Wright \& Walker } \\
\text { acceleration, in/sec2 }\end{array}$ & $\begin{array}{l}\text { Wright \& Walker } \\
\text { Human Reaction }\end{array}$ \\
\hline 100 & 50 & 15.0 & 15.163 & 2.94 & W/ SIDEWALKS, LITTLE PED USE & 30.102 & Perceptible \\
\hline 100 & 50 & 19.3 & 22.597 & 2.35 & W/ SIDEWALKS, LITTLE PED USE & 31.441 & Perceptible \\
\hline 100 & 50 & NA & & & & & \\
\hline 100 & 50 & NA & & & & & \\
\hline 100 & 70 & NA & & & & & \\
\hline 100 & 70 & NA & & & & & \\
\hline 100 & 70 & NA & & & & & \\
\hline 100 & 70 & NA & & & & & \\
\hline 150 & 50 & 15.0 & 21.896 & 1.90 & W/ SIDEWALKS, LITTLE PED USE & 19.391 & Perceptible to Most \\
\hline 150 & 50 & 20.1 & 33.090 & 1.54 & W/ SIDEWALKS, LITTLE PED USE & 22.167 & Perceptible \\
\hline 150 & 50 & 24.9 & 44.009 & 1.27 & W/ SIDEWALKS, LITTLE PED USE & 22.539 & Perceptible \\
\hline 150 & 50 & 30.0 & 54.320 & 1.07 & W/ SIDEWALKS, LITTLE PED USE & 21.870 & Perceptible \\
\hline 150 & 70 & 15.1 & 22.417 & 1.89 & W/ SIDEWALKS, LITTLE PED USE & 19.816 & Perceptible to Most \\
\hline 150 & 70 & 20.0 & 33.235 & 1.60 & W/ SIDEWALKS, LITTLE PED USE & 23.452 & Perceptible \\
\hline 150 & 70 & 24.8 & 45.732 & 1.34 & W/ SIDEWALKS, LITTLE PED USE & 25.155 & Perceptible \\
\hline 150 & 70 & 30.0 & 58.765 & 1.12 & W/ SIDEWALKS, LITTLE PED USE & 25.235 & Perceptible \\
\hline 200 & 50 & 14.9 & 17.262 & 1.68 & ACCEPTABLE & 16.016 & Perceptible to Most \\
\hline 200 & 50 & 20.1 & 37.002 & 1.16 & ACCEPTABLE & 17.828 & Perceptible to Most \\
\hline 200 & 50 & 24.9 & 49.908 & 0.96 & ACCEPTABLE & 18.395 & Perceptible to Most \\
\hline 200 & 50 & 29.5 & 54.401 & 0.86 & ACCEPTABLE & 17.185 & Perceptible to Most \\
\hline 200 & 70 & 15.1 & 18.937 & 1.56 & ACCEPTABLE & 13.943 & Perceptible to Most \\
\hline 200 & 70 & 20.1 & 33.068 & 1.29 & ACCEPTABLE & 22.033 & Perceptible \\
\hline 200 & 70 & 25.0 & 56.266 & 0.97 & W/ SIDEWALKS, LITTLE PED USE & 21.013 & Perceptible \\
\hline 200 & 70 & 29.7 & 69.812 & 0.84 & ACCEPTABLE & 21.337 & Perceptible \\
\hline 250 & 50 & 15.0 & 17.218 & 1.31 & ACCEPTABLE & 10.963 & Perceptible to Most \\
\hline 250 & 50 & 20.0 & 34.359 & 0.98 & ACCEPTABLE & 16.610 & Perceptible to Most \\
\hline 250 & 50 & 25.0 & 44.890 & 0.82 & ACCEPTABLE & 20.650 & Perceptible \\
\hline 250 & 50 & 30.0 & 51.898 & 0.71 & ACCEPTABLE & 19.641 & Perceptible to Most \\
\hline 250 & 70 & 15.0 & 17.449 & 1.29 & ACCEPTABLE & 10.708 & Perceptible to Most \\
\hline 250 & 70 & 20.0 & 40.081 & 0.95 & ACCEPTABLE & 15.877 & Perceptible to Most \\
\hline 250 & 70 & 25.1 & 58.765 & 0.78 & ACCEPTABLE & 17.699 & Perceptible to Most \\
\hline 250 & 70 & 30.0 & 74.646 & 0.66 & ACCEPTABLE & 17.773 & Perceptible to Most \\
\hline
\end{tabular}


Table E5.3. Continued

Simple Span Bridges of Cross Section 3 Using MDX-LRFD

\begin{tabular}{|c|c|c|c|c|c|c|c|}
\hline $\begin{array}{c}\text { Span } \\
\text { Length } \\
\text { ft }\end{array}$ & $\begin{array}{l}\text { Fy } \\
\text { ksi }\end{array}$ & $\begin{array}{c}\text { L/D Ratio } \\
\text { (Actual) }\end{array}$ & $\begin{array}{c}\text { Ontario } \\
\text { Deflection } \\
\mathbf{m m}\end{array}$ & $\begin{array}{c}\text { Ontario } \\
\text { Natural Frequency } \\
\mathrm{Hz}\end{array}$ & Ontario Evaluation & $\begin{array}{c}\text { Wright \& Walker } \\
\text { acceleration, in/sec2 }\end{array}$ & $\begin{array}{l}\text { Wright \& Walker } \\
\text { Human Reaction }\end{array}$ \\
\hline 100 & 50 & 15.2 & 21.625 & 3.20 & W/O SIDEWALKS & 34.747 & Perceptible \\
\hline 100 & 50 & 20.1 & 27.040 & 2.87 & W/O SIDEWALKS & 43.383 & Perceptible \\
\hline 100 & 50 & 25.5 & 36.217 & 2.45 & W/O SIDEWALKS & 43.390 & Perceptible \\
\hline 100 & 50 & 30.5 & 47.385 & 2.10 & W/O SIDEWALKS & 44.954 & Perceptible \\
\hline 100 & 70 & 15.0 & 22.674 & 3.14 & W/O SIDEWALKS & 35.012 & Perceptible \\
\hline 100 & 70 & 20.2 & 28.891 & 2.77 & W/O SIDEWALKS & 42.007 & Perceptible \\
\hline 100 & 70 & 25.3 & 39.702 & 2.36 & W/O SIDEWALKS & 45.052 & Perceptible \\
\hline 100 & 70 & 30.5 & 51.333 & 2.05 & W/O SIDEWALKS & 47.629 & Perceptible \\
\hline 150 & 50 & 15.0 & 15.292 & 2.95 & W/ SIDEWALKS, LITTLE PED USE & 28.966 & Perceptible \\
\hline 150 & 50 & 20.0 & 32.742 & 2.10 & W/ SIDEWALKS, LITTLE PED USE & 26.825 & Perceptible \\
\hline 150 & 50 & 24.9 & 44.617 & 1.79 & W/ SIDEWALKS, LITTLE PED USE & 28.658 & Perceptible \\
\hline 150 & 50 & 29.9 & 53.929 & 1.62 & W/ SIDEWALKS, LITTLE PED USE & 30.137 & Perceptible \\
\hline 150 & 70 & 15.0 & 15.092 & 2.95 & W/ SIDEWALKS, LITTLE PED USE & 20.811 & Perceptible \\
\hline 150 & 70 & 20.0 & 33.495 & 2.06 & W/ SIDEWALKS, LITTLE PED USE & 26.248 & Perceptible \\
\hline 150 & 70 & 24.9 & 46.297 & 1.78 & W/O SIDEWALKS & 29.619 & Perceptible \\
\hline 150 & 70 & 29.7 & 66.513 & 1.55 & W/O SIDEWALKS & 31.307 & Perceptible \\
\hline 200 & 50 & 15.0 & 16.214 & 2.31 & W/ SIDEWALKS, LITTLE PED USE & 15.295 & Perceptible to Most \\
\hline 200 & 50 & 20.0 & 33.490 & 1.68 & W/ SIDEWALKS, LITTLE PED USE & 19.308 & Perceptible to Most \\
\hline 200 & 50 & 25.3 & 46.736 & 1.44 & W/ SIDEWALKS, LITTLE PED USE & 21.713 & Perceptible \\
\hline 200 & 50 & 30.4 & 60.037 & 1.26 & W/ SIDEWALKS, LITTLE PED USE & 22.266 & Perceptible \\
\hline 200 & 70 & 15.0 & 16.595 & 2.30 & W/ SIDEWALKS, LITTLE PED USE & 15.665 & Perceptible to Most \\
\hline 200 & 70 & 20.0 & 34.974 & 1.64 & W/ SIDEWALKS, LITTLE PED USE & 19.426 & Perceptible to Most \\
\hline 200 & 70 & 25.0 & 48.152 & 1.43 & W/ SIDEWALKS, LITTLE PED USE & 22.163 & Perceptible \\
\hline 200 & 70 & 30.2 & 64.257 & 1.24 & W/ SIDEWALKS, LITTLE PED USE & 23.777 & Perceptible \\
\hline 250 & 50 & 15.0 & 15.431 & 1.96 & ACCEPTABLE & 13.193 & Perceptible to Most \\
\hline 250 & 50 & 20.1 & 23.103 & 1.57 & ACCEPTABLE & 16.310 & Perceptible to Most \\
\hline 250 & 50 & 24.8 & 43.630 & 1.25 & W/ SIDEWALKS, LITTLE PED USE & 18.739 & Perceptible to Most \\
\hline 250 & 50 & 30.6 & 52.824 & 1.12 & W/ SIDEWALKS, LITTLE PED USE & 19.390 & Perceptible to Most \\
\hline 250 & 70 & 15.0 & 15.816 & 1.93 & ACCEPTABLE & 13.787 & Perceptible to Most \\
\hline 250 & 70 & 20.0 & 34.835 & 1.37 & W/ SIDEWALKS, LITTLE PED USE & 16.372 & Perceptible to Most \\
\hline 250 & 70 & 25.1 & 47.848 & 1.19 & W/ SIDEWALKS, LITTLE PED USE & 18.310 & Perceptible to Most \\
\hline 250 & 70 & 30.2 & 58.089 & 1.08 & W/ SIDEWALKS, LITTLE PED USE & 20.692 & Perceptible \\
\hline
\end{tabular}


Table E5.3. Continued

Two Span Bridges of Cross Section 3 Using MDX-LRFD

\begin{tabular}{|c|c|c|c|c|c|c|c|}
\hline $\begin{array}{c}\text { Span } \\
\text { Length } \\
\text { ft }\end{array}$ & $\begin{array}{l}\text { Fy } \\
\text { ksi }\end{array}$ & $\begin{array}{c}0.8 \mathrm{~L} / \mathrm{D} \\
\text { Ratio } \\
\text { (Actual) }\end{array}$ & $\begin{array}{c}\text { Ontario } \\
\text { Deflection } \\
\mathbf{m m}\end{array}$ & $\begin{array}{c}\text { Ontario } \\
\text { Natural Frequency } \\
\mathrm{Hz}\end{array}$ & Ontario Evaluation & $\begin{array}{c}\text { Wright \& Walker } \\
\text { acceleration, in/sec2 }\end{array}$ & $\begin{array}{l}\text { Wright \& Walker } \\
\text { Human Reaction }\end{array}$ \\
\hline 100 & 50 & 15.0 & 17.709 & 2.69 & W/ SIDEWALKS, LITTLE PED USE & 24.694 & Perceptible \\
\hline 100 & 50 & 19.8 & 27.672 & 2.13 & W/ SIDEWALKS, LITTLE PED USE & 26.287 & Perceptible \\
\hline 100 & 50 & NA & & & & & \\
\hline 100 & 50 & NA & & & & & \\
\hline 100 & 70 & NA & & & & & \\
\hline 100 & 70 & NA & & & & & \\
\hline 100 & 70 & NA & & & & & \\
\hline 100 & 70 & NA & & & & & \\
\hline 150 & 50 & 15.0 & 22.794 & 1.86 & W/ SIDEWALKS, LITTLE PED USE & 15.234 & Perceptible to Most \\
\hline 150 & 50 & 20.4 & 42.633 & 1.33 & W/ SIDEWALKS, LITTLE PED USE & 14.806 & Perceptible to Most \\
\hline 150 & 50 & 25.3 & 51.887 & 1.17 & W/ SIDEWALKS, LITTLE PED USE & 18.154 & Perceptible to Most \\
\hline 150 & 50 & 30.1 & 64.167 & 1.01 & W/ SIDEWALKS, LITTLE PED USE & 17.755 & Perceptible to Most \\
\hline 150 & 70 & 15.1 & 23.402 & 1.89 & W/ SIDEWALKS, LITTLE PED USE & 16.078 & Perceptible to Most \\
\hline 150 & 70 & 19.7 & 38.593 & 1.47 & W/ SIDEWALKS, LITTLE PED USE & 19.546 & Perceptible to Most \\
\hline 150 & 70 & 24.8 & 53.320 & 1.22 & W/ SIDEWALKS, LITTLE PED USE & 19.513 & Perceptible to Most \\
\hline 150 & 70 & 30.0 & 60.387 & 1.09 & W/ SIDEWALKS, LITTLE PED USE & 17.893 & Perceptible to Most \\
\hline 200 & 50 & 14.9 & 19.625 & 1.57 & ACCEPTABLE & 9.934 & Perceptible to Some \\
\hline 200 & 50 & 20.4 & 33.885 & 1.20 & ACCEPTABLE & 11.452 & Perceptible to Most \\
\hline 200 & 50 & 25.1 & 42.679 & 1.02 & ACCEPTABLE & 11.979 & Perceptible to Most \\
\hline 200 & 50 & 29.9 & 66.544 & 0.80 & ACCEPTABLE & 12.681 & Perceptible to Most \\
\hline 200 & 70 & 15.1 & 21.986 & 1.53 & ACCEPTABLE & 10.662 & Perceptible to Most \\
\hline 200 & 70 & 20.1 & 39.957 & 1.16 & ACCEPTABLE & 13.508 & Perceptible to Most \\
\hline 200 & 70 & 25.1 & 56.361 & 0.96 & W/ SIDEWALKS, LITTLE PED USE & 13.898 & Perceptible to Most \\
\hline 200 & 70 & 29.8 & 61.548 & 0.88 & ACCEPTABLE & 13.774 & Perceptible to Most \\
\hline 250 & 50 & 15.0 & 14.531 & 1.48 & ACCEPTABLE & 8.905 & Perceptible to Some \\
\hline 250 & 50 & 20.0 & 32.876 & 0.97 & ACCEPTABLE & 8.861 & Perceptible to Some \\
\hline 250 & 50 & 25.0 & 35.105 & 0.90 & ACCEPTABLE & 8.754 & Perceptible to Some \\
\hline 250 & 50 & NA & & & & & \\
\hline 250 & 70 & 15.0 & 20.343 & 1.27 & ACCEPTABLE & 8.308 & Perceptible to Some \\
\hline 250 & 70 & 20.0 & 40.955 & 0.94 & ACCEPTABLE & 9.746 & Perceptible to Some \\
\hline 250 & 70 & 25.0 & 47.449 & 0.84 & ACCEPTABLE & 10.780 & Perceptible to Most \\
\hline 250 & 70 & 30 & 53.621 & 0.77 & ACCEPTABLE & 12.187 & Perceptible to Most \\
\hline
\end{tabular}


Table E5.4. Wright and Walker procedure and OHBDC results for cross section 4 ( $\mathrm{S}=8$ ' -6")

Simple Span Bridges of Cross Section 4 Using SIMON-LFD

\begin{tabular}{|c|c|c|c|c|c|c|c|}
\hline $\begin{array}{c}\text { Span } \\
\text { Length } \\
\text { ft }\end{array}$ & $\begin{array}{l}\text { Fy } \\
\text { ksi }\end{array}$ & $\begin{array}{l}\text { L/D Ratio } \\
\text { (Actual) }\end{array}$ & $\begin{array}{c}\text { Ontario } \\
\text { Deflection } \\
\mathbf{m m} \\
\end{array}$ & $\begin{array}{c}\text { Ontario } \\
\text { Natural Frequency } \\
\mathrm{Hz} \\
\end{array}$ & Ontario Evaluation & $\begin{array}{c}\text { Wright \& Walker } \\
\text { acceleration, in/sec2 }\end{array}$ & $\begin{array}{l}\text { Wright \& Walker } \\
\text { Human Reaction }\end{array}$ \\
\hline 100 & 50 & 15.0 & 17.543 & 3.99 & W/O SIDEWALKS & 55.932 & Unpleasant to Few \\
\hline 100 & 50 & 19.7 & 25.025 & 3.34 & W/O SIDEWALKS & 60.404 & Unpleasant to Few \\
\hline 100 & 50 & 24.1 & 32.137 & 2.90 & W/O SIDEWALKS & 62.767 & Unpleasant to Few \\
\hline 100 & 50 & 28.7 & 40.404 & 2.53 & W/O SIDEWALKS & 64.552 & Unpleasant to Few \\
\hline 100 & 70 & 15.0 & 18.410 & 3.84 & W/O SIDEWALKS & 56.368 & Unpleasant to Few \\
\hline 100 & 70 & 19.8 & 27.437 & 3.20 & W/O SIDEWALKS & 62.039 & Unpleasant to Few \\
\hline 100 & 70 & 24.6 & 36.487 & 2.75 & W/O SIDEWALKS & 65.782 & Unpleasant to Few \\
\hline 100 & 70 & 29.2 & 47.433 & 2.37 & W/O SIDEWALKS & 68.844 & Unpleasant to Few \\
\hline 200 & 50 & 15.0 & 16.164 & 2.52 & W/SIDEWALKS LITTLE P. USE & 24.795 & Perceptible \\
\hline 200 & 50 & 20.0 & 32.097 & 1.94 & W/SIDEWALKS LITTLE P. USE & 33.192 & Perceptible \\
\hline 200 & 50 & 24.8 & 45.426 & 1.67 & W/SIDEWALKS LITTLE P. USE & 37.505 & Perceptible \\
\hline 200 & 50 & 29.5 & 56.710 & 1.48 & W/SIDEWALKS LITTLE P. USE & 39.121 & Perceptible \\
\hline 200 & 70 & 15.0 & 15.123 & 2.52 & W/SIDEWALKS LITTLE P. USE & 23.207 & Perceptible \\
\hline 200 & 70 & 19.9 & 38.058 & 1.76 & W/SIDEWALKS LITTLE P. USE & 32.990 & Perceptible \\
\hline 200 & 70 & 24.6 & 59.604 & 1.49 & W/SIDEWALKS LITTLE P. USE & 41.149 & Perceptible \\
\hline 200 & 70 & 29.5 & 74.611 & 1.33 & W/SIDEWALKS LITTLE P. USE & 43.803 & Perceptible \\
\hline 300 & 50 & 15.0 & 13.294 & 1.81 & ACCEPTABLE & 14.916 & Perceptible to Most \\
\hline 300 & 50 & 20.0 & 30.114 & 1.37 & ACCEPTABLE & 21.819 & Perceptible \\
\hline 300 & 50 & 24.9 & 45.488 & 1.18 & ACCEPTABLE & 26.508 & Perceptible \\
\hline 300 & 50 & 29.8 & 55.562 & 1.07 & W/SIDEWALKS LITTLE P. USE & 28.086 & Perceptible \\
\hline 300 & 70 & 15.0 & 12.046 & 1.80 & ACCEPTABLE & 13.408 & Perceptible to Most \\
\hline 300 & 70 & 20.0 & 31.471 & 1.31 & ACCEPTABLE & 20.986 & Perceptible \\
\hline 300 & 70 & 24.8 & 55.797 & 1.08 & W/SIDEWALKS LITTLE P. USE & 28.256 & Perceptible \\
\hline 300 & 70 & 29.8 & 74.842 & 0.95 & W/SIDEWALKS LITTLE P. USE & 31.306 & Perceptible \\
\hline
\end{tabular}


Table E5.4. Continued

Two Span Bridges of Cross Section 4 Using SIMON-LFD

\begin{tabular}{|c|c|c|c|c|c|c|c|}
\hline $\begin{array}{c}\text { Span } \\
\text { Length } \\
\text { ft }\end{array}$ & $\begin{array}{l}\text { Fy } \\
\text { ksi }\end{array}$ & $\begin{array}{c}\text { L/D Ratio } \\
\text { (Actual) }\end{array}$ & $\begin{array}{c}\text { Ontario } \\
\text { Deflection } \\
\mathbf{m m}\end{array}$ & $\begin{array}{c}\text { Ontario } \\
\text { Natural Frequency } \\
\mathrm{Hz}\end{array}$ & Ontario Evaluation & $\begin{array}{c}\text { Wright \& Walker } \\
\text { acceleration, in/sec2 }\end{array}$ & $\begin{array}{l}\text { Wright \& Walker } \\
\text { Human Reaction }\end{array}$ \\
\hline 100 & 50 & 15.0 & 12.678 & 3.59 & W/SIDEWALKS LITTLE P. USE & 34.471 & Perceptible \\
\hline 100 & 50 & 20.0 & 24.675 & 2.99 & W/O SIDEWALKS & 38.263 & Perceptible \\
\hline 100 & 50 & 24.1 & 21.810 & 2.62 & W/SIDEWALKS LITTLE P. USE & 37.158 & Perceptible \\
\hline 100 & 50 & 28.7 & 28.633 & 2.20 & W/SIDEWALKS LITTLE P. USE & 38.455 & Perceptible \\
\hline 100 & 70 & 15.0 & 12.678 & 3.59 & W/SIDEWALKS LITTLE P. USE & 34.471 & Perceptible \\
\hline 100 & 70 & 19.8 & 19.109 & 2.98 & W/O SIDEWALKS & 39.086 & Perceptible \\
\hline 100 & 70 & 24.5 & 22.531 & 2.64 & W/SIDEWALKS LITTLE P. USE & 38.574 & Perceptible \\
\hline 100 & 70 & 28.7 & 29.973 & 2.27 & W/SIDEWALKS LITTLE P. USE & 41.301 & Perceptible \\
\hline 200 & 50 & 15.0 & 11.303 & 2.08 & ACCEPTABLE & 12.430 & Perceptible to Most \\
\hline 200 & 50 & 19.8 & 27.506 & 1.51 & W/SIDEWALKS LITTLE P. USE & 18.392 & Perceptible to Most \\
\hline 200 & 50 & 24.5 & 37.440 & 1.30 & ACCEPTABLE & 20.286 & Perceptible \\
\hline 200 & 50 & 28.7 & 47.027 & 1.11 & W/SIDEWALKS LITTLE P. USE & 20.283 & Perceptible \\
\hline 200 & 70 & 15.0 & 10.648 & 2.09 & ACCEPTABLE & 11.804 & Perceptible to Most \\
\hline 200 & 70 & 19.9 & 26.928 & 1.51 & W/SIDEWALKS LITTLE P. USE & 18.040 & Perceptible to Most \\
\hline 200 & 70 & 24.5 & 39.196 & 1.32 & W/SIDEWALKS LITTLE P. USE & 21.540 & Perceptible \\
\hline 200 & 70 & 29.3 & 48.782 & 1.17 & W/SIDEWALKS LITTLE P. USE & 21.331 & Perceptible \\
\hline 300 & 50 & 14.9 & 8.971 & 1.41 & ACCEPTABLE & 6.543 & Perceptible to Some \\
\hline 300 & 50 & 19.9 & 22.156 & 1.07 & ACCEPTABLE & 10.516 & Perceptible to Most \\
\hline 300 & 50 & 24.7 & 38.796 & 0.87 & ACCEPTABLE & 13.594 & Perceptible to Most \\
\hline 300 & 50 & 29.5 & 48.146 & 0.76 & ACCEPTABLE & 13.823 & Perceptible to Most \\
\hline 300 & 70 & 14.9 & 8.555 & 1.38 & ACCEPTABLE & 6.231 & Perceptible to Some \\
\hline 300 & 70 & 19.9 & 21.487 & 1.05 & ACCEPTABLE & 10.207 & Perceptible to Most \\
\hline 300 & 70 & 24.8 & 41.111 & 0.87 & ACCEPTABLE & 14.339 & Perceptible to Most \\
\hline 300 & 70 & 29.6 & 54.639 & 0.77 & ACCEPTABLE & 15.768 & Perceptible to Most \\
\hline
\end{tabular}


Table E5.4. Continued

Three Span Bridges of Cross Section 4 Using SIMON-LFD

\begin{tabular}{|c|c|c|c|c|c|c|c|}
\hline $\begin{array}{c}\text { Span } \\
\text { Length } \\
\text { ft }\end{array}$ & $\begin{array}{l}\text { Fy } \\
\text { ksi }\end{array}$ & $\begin{array}{l}\text { L/D Ratio } \\
\text { (Actual) }\end{array}$ & $\begin{array}{c}\text { Ontario } \\
\text { Deflection } \\
\mathbf{m m} \\
\end{array}$ & $\begin{array}{c}\text { Ontario } \\
\text { Natural Frequency } \\
\mathrm{Hz} \\
\end{array}$ & Ontario Evaluation & $\begin{array}{c}\text { Wright \& Walker } \\
\text { acceleration, in/sec2 }\end{array}$ & $\begin{array}{l}\text { Wright \& Walker } \\
\text { Human Reaction }\end{array}$ \\
\hline 100 & 50 & 15.0 & 9.830 & 4.13 & W/ SIDEWALKS LITTLE PDE USE & 34.133 & Perceptible \\
\hline 100 & 50 & 19.9 & 16.053 & 3.29 & W/ SIDEWALKS LITTLE PDE USE & 39.026 & Perceptible \\
\hline 100 & 50 & 24.7 & 21.666 & 2.76 & W/ SIDEWALKS LITTLE PDE USE & 40.503 & Perceptible \\
\hline 100 & 50 & 29.4 & 27.635 & 2.43 & W/ SIDEWALKS LITTLE PDE USE & 41.505 & Perceptible \\
\hline 100 & 70 & 15.0 & 8.992 & 4.22 & W/ SIDEWALKS LITTLE PDE USE & 32.352 & Perceptible \\
\hline 100 & 70 & 19.9 & 16.307 & 3.28 & W/ SIDEWALKS LITTLE PDE USE & 39.467 & Perceptible \\
\hline 100 & 70 & 24.8 & 22.200 & 2.82 & W/O SIDEWALKS & 42.700 & Perceptible \\
\hline 100 & 70 & 29.5 & 29.312 & 2.46 & W/ SIDEWALKS LITTLE PDE USE & 44.593 & Perceptible \\
\hline 200 & 50 & 15.0 & 8.001 & 2.42 & ACCEPTABLE & 11.049 & Perceptible to Most \\
\hline 200 & 50 & 20.0 & 20.168 & 1.77 & W/ SIDEWALKS LITTLE PDE USE & 16.980 & Perceptible to Most \\
\hline 200 & 50 & 24.8 & 32.080 & 1.48 & W/ SIDEWALKS LITTLE PDE USE & 20.602 & Perceptible \\
\hline 200 & 50 & 29.3 & 41.300 & 1.32 & W/ SIDEWALKS LITTLE PDE USE & 22.412 & Perceptible \\
\hline 200 & 70 & 15.0 & 7.493 & 2.41 & ACCEPTABLE & 10.304 & Perceptible to Most \\
\hline 200 & 70 & 20.0 & 19.507 & 1.76 & W/ SIDEWALKS LITTLE PDE USE & 16.383 & Perceptible to Most \\
\hline 200 & 70 & 24.9 & 34.239 & 1.47 & W/ SIDEWALKS LITTLE PDE USE & 21.774 & Perceptible \\
\hline 200 & 70 & 29.6 & 45.517 & 1.34 & W/ SIDEWALKS LITTLE PDE USE & 25.239 & Perceptible \\
\hline 300 & 50 & 15.0 & 6.680 & 1.57 & ACCEPTABLE & 5.652 & Perceptible to Some \\
\hline 300 & 50 & 19.9 & 16.510 & 1.20 & ACCEPTABLE & 9.150 & Perceptible to Some \\
\hline 300 & 50 & 24.9 & 33.706 & 0.94 & ACCEPTABLE & 12.871 & Perceptible to Most \\
\hline 300 & 50 & 29.6 & 45.822 & 0.85 & ACCEPTABLE & 15.155 & Perceptible to Most \\
\hline 300 & 70 & 15.0 & 5.588 & 1.71 & ACCEPTABLE & 6.034 & Perceptible to Some \\
\hline 300 & 70 & 19.9 & 15.596 & 1.19 & ACCEPTABLE & 8.525 & Perceptible to Some \\
\hline 300 & 70 & 24.9 & 32.182 & 0.95 & ACCEPTABLE & 12.498 & Perceptible to Most \\
\hline 300 & 70 & 29.8 & 48.895 & 0.87 & ACCEPTABLE & 16.706 & Perceptible to Most \\
\hline
\end{tabular}

